Jens Warburg

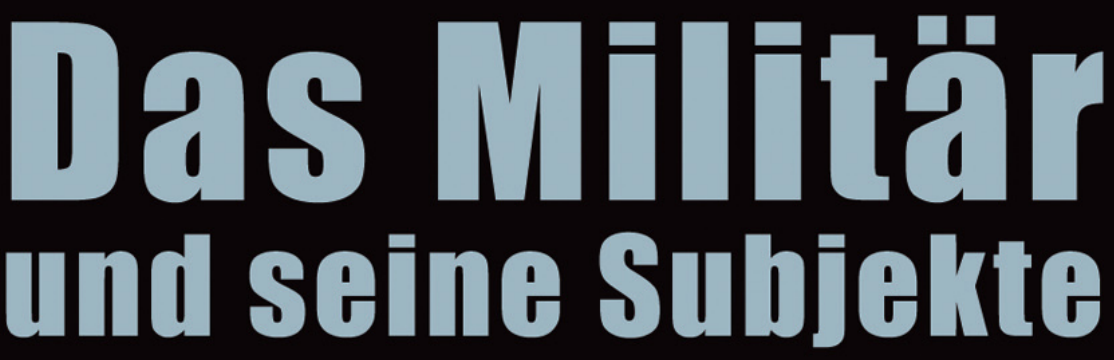

Zur Soziologie des Krieges

[transcript] sozialtheorie 
Jens Warburg

Das Militär und seine Subjekte 
Jens Warburg (Dr. rer. soc.) promovierte an der Justus-Liebig-Universität Gießen im Fachbereich Sozial- und Kulturwissenschaften. Bereits erschienen: Kampf der Zivilisten, Bielefeld 2004, transcript (zusammen mit Volker Heins). 
JENS WARBURG

\section{Das Militär und seine Subjekte}

Zur Soziologie des Krieges

[transcript] 


\section{(9) $(1) \Theta \Theta$}

Dieses Werk ist lizenziert unter der Creative Commons AttributionNonCommercial-NoDerivs 4.0 Lizenz (BY-NC-ND). Diese Lizenz erlaubt die private Nutzung, gestattet aber keine Bearbeitung und keine kommerzielle Nutzung. Weitere Informationen finden Sie unter https://creativecommons.org/licenses/by-nc-nd/4.o/deed.de/. Um Genehmigungen für Adaptionen, Übersetzungen, Derivate oder Wiederverwendung zu kommerziellen Zwecken einzuholen, wenden Sie sich bitte an rights@transcript-verlag.de

\section{(C) 2008 transcript Verlag, Bielefeld}

zugl. Dissertation, Justus-Liebig-Universität Gießen, Fachbereich Sozial- und Kulturwissenschaften.

Die Verwertung der Texte und Bilder ist ohne Zustimmung des Verlages urheberrechtswidrig und strafbar. Das gilt auch für Vervielfältigungen, Übersetzungen, Mikroverfilmungen und für die Verarbeitung mit elektronischen Systemen.

\section{Bibliografische Information der Deutschen Nationalbibliothek}

Die Deutsche Nationalbibliothek verzeichnet diese Publikation in der Deutschen Nationalbibliografie; detaillierte bibliografische Daten sind im Internet über http://dnb.d-nb.de abrufbar.

Umschlaggestaltung: Kordula Röckenhaus, Bielefeld Druck: Majuskel Medienproduktion $\mathrm{GmbH}$, Wetzlar Print-ISBN 978-3-89942-852-0 PDF-ISBN 978-3-8394-0852-0

Gedruckt auf alterungsbeständigem Papier mit chlorfrei gebleichtem Zellstoff.

Besuchen Sie uns im Internet: http://www.transcript-verlag.de Bitte fordern Sie unser Gesamtverzeichnis und andere Broschüren an unter: info@transcript-verlag.de 


\section{Inhalt}

1. Der Krieg und die soldatischen Subjekte 7

1.1. Vorbemerkungen 7

1.2. Der Krieg ist ein soziales Phänomen 8

1.2.1. Die Variabilität des Krieges 10

1.2.2. Das Militär als soziale Macht 17

1.3. Soldatische Subjektivität - zum Aufbau der Untersuchung 20

2. Bemerkungen zum Verhältnis Soziologie und Krieg 24

2.1. Ein Überblick 24

2.2. Die westdeutsche Soziologie und der Krieg 29

2.3. Soziologie des Krieges 35

3. Soldatische Subjekte - eine Begriffsbestimmung 41

3.1. Können Soldaten Subjekte sein? 41

3.2. Der Subjektbegriff in der Philosophie und Soziologie 42

3.3. Soldaten als Handelnde 65

4. Zur Geschichte des modernen Soldaten 84

4.1. Das Militär und seine historischen Vorläufer 84

4.1.1. Die Ritter 86

4.1.2. Das Söldnerwesen 92

4.1.3. Der Gewalthaufen 98

4.2. Vom Söldner zum Soldaten 104

4.3. Der Soldat in den >stehengebliebenen Heeren

4.4. Exkurs zum Seekrieg, insbesondere im 18. Jahrhundert 123

5. Maschine und Leib 128

5.1. Vorbemerkungen 128

5.2. Die Staatsmaschine 131

5.3. Das Heer als Maschine 139 
5.3.1. Wechselwirkungen von Staats- und Kriegsmaschine 143

5.4. Der maschinelle Körper und der Leib 150

5.4.1. Der Körper als Maschine 153

5.4.2. Der Leib 156

6. Soldatische Subjektivität zwischen Kontrolle

und Eigensinn 169

6.1. Subjektivität als Innovationsressource 169

6.2. Die leichten Truppen und der kleine Krieg 176

6.3. Transformationen und Kontinuitäten 184

7. Entstehung und Folgen des modernen Gefechtsfeldes 203

7.1. Die Entstehung des modernen Gefechtfeldes und die Auftragstaktik 203

7.2. Der industrialisierte Krieg 218

7.3. Folgen des industrialisierten Krieges 225

7.3.1. Das industrialisierte Kriegsgeschehen 226

7.3.2. Persönlichkeitsveränderungen und psychosomatische Reaktionen auf das Kriegsgeschehen 235

7.3.3. Taktische Angriffskonzeptionen im 1. Weltkrieg 252

8. Soldatische Subjektivität in avancierten

Militärorganisationen

8.1. Wie die Sozialwissenschaften zur Optimierung soldatischer Subjekte verwendet werden 264

8.2. Technisierung des Kriegsgeschehens 284

8.2.1. Cyborgs 292

8.2.2. Von Robotern, unbemannten Vehikeln und Agenten 296

8.2.3. Zur Transformation der Streitkräfte und der Bedeutung der Network Centric Warfare 306

8.3. Paradoxien gegenwärtiger Einsatzszenarios 320

8.3.1. Tableau der Einsatzszenarios 320

8.3.2. Zu den Auswirkungen von Auslandseinsätzen auf das Verhältnis von nichtmilitärischer Gesellschaft und Militär $\quad 326$

9. Soldatische Subjekte im modernen Krieg 339

$\begin{array}{ll}\text { 10. Literatur } & 347\end{array}$

$\begin{array}{ll}\text { Dank } & 374\end{array}$ 


\section{Der Krieg und die soldatischen Subjekte}

\subsection{Vorbemerkungen}

In der vorliegenden Untersuchung werden Soldaten als Subjekte betrachtet. Soldatisches Handeln, so die grundlegende These, ist nicht nur Ergebnis fremdbestimmter Anweisungen, also von Befehlen. Selbst dann, wenn Soldaten wie gehorsame Befehlsempfänger handeln, verkennt eine Perspektive, die in ihnen nur willfährige Objekte in den Händen ihrer Vorgesetzten sieht, einen kaum zu unterschätzenden Aspekt ihres Handelns als Subjekte.

Untersucht wird diese These anhand eines eingegrenzten und gleichzeitig zentralen Feldes soldatischen Handelns, dem Kriegseinsatz. Im Mittelpunkt der Untersuchung steht die Frage, wie die Soldaten im Gefecht eingesetzt werden bzw. sich einsetzen lassen. Das Gefecht ist, wie der Krieg insgesamt, ein variables Phänomen. Es hat auch in der Vergangenheit höchst unterschiedliche Formen angenommen. Unter einem Gefecht wird im Rahmen dieser Arbeit ein Geschehen verstanden in dessen Verlauf mindestens 2 Akteure gewaltsam aufeinander einwirken. Vor allem für den Zeitraum vor dem 20. Jahrhundert wird immer wieder auch von Schlachten und von Schlachtfeldern gesprochen werden. Damit sind gewalttätige Konfrontationen zwischen zwei Heeren gemeint, die sich auf einer bestimmten Fläche über einen bestimmten Zeitraum vollziehen. "Schlachten haben Anfang und Ende, und nach dem Ende der Schlacht ist das Feld kein Schlachtfeld mehr, sondern übernimmt erneut seine kurzfristig unterbrochene Funktion.« (Hüppauf 2003: 209) Das Wort Schlacht geht auf das althochdeutsche slatha zurück, dass wiederum das Erschlagen von Tieren und Menschen bezeichnete, so wie heute insbesondere bei der Tötung von Tieren vom >schlachten `Kampf zwischen Heeren`, wird es erst seit dem 16. Jahrhundert verwendet. Seit dem Ende des 19. Jahrhunderts, genauer gesagt mit dem 1. 
Weltkrieg, ging mit der zu beobachtenden Permanenz der Kämpfe zuerst die zeitliche Begrenzung des Kampfgeschehens und später auch die räumliche Begrenzung verloren. Eine Schlacht zerfiel in eine Vielzahl von Gefechten. Für die Abgrenzung einer Schlacht vom übrigen Kriegsgeschehen können militärische und politische Planungs- sowie Entscheidungskriterien herangezogen werden, die es erlauben, für einen bestimmten Zeitraum eine bestimmte Menge der Gefechte einer Schlacht zuzuordnen. Aus Sicht der soldatischen Subjekte wird aber eine solche Konstruktion meist, wenn überhaupt, erst im Nachhinein möglich sein. Aufgrund der Vielzahl der Gefechte, der Permanenz der Kampfhandlungen und der Schwierigkeit, das Geschehen auf einem bestimmten Zeitraum festzulegen, wird für das 20. Jahrhundert nur in Ausnahmefällen von einer Schlacht gesprochen. Eine Schlacht meint dann ein besonders intensives Kampfgeschehen innerhalb eines bestimmten Zeitraums, das von einem identifizierbaren militärischen Kalkül gekennzeichnet ist, beispielsweise dem Versuch, in die gegnerischen Stellungen einzudringen und in dem die Wahrscheinlichkeit für die Soldaten höher als sonst ist, verletzt oder getötet zu werden.

Als Soldaten werden in dieser Arbeit ausschließlich Angehörige militärischer Organisationen bezeichnet, die im Zuge des europäischen Staatenbildungsprozesses entstanden sind. Abgesehen vom Abschnitt 8.3.2. wird in dieser Arbeit die Bezeichnung Soldat oder Soldaten, also die männliche Form verwendet. Dies geschieht nicht nur der sprachlichen $>$ Einfachheit halber $\triangleleft$ Ebenso wenig ist dieser Sprachgebrauch allein dem historischen Umstand geschuldet, dass die Militärangehörigen, die für den Kampfeinsatz vorgesehen waren, fast immer biologisch männlich waren. Vielmehr ist Männlichkeit ein konstitutives Merkmal soldatischer Subjekte, selbst wenn sie biologisch weiblich sind.

\subsection{Der Krieg ist ein soziales Phänomen}

Der Krieg ist eine spezifische Form des sozialen Konflikts. Vom Krieg ist heute im Allgemeinen dann die Rede, wenn mindestens zwei Gruppen versuchen, den zwischen ihnen bestehenden Konflikt durch den Einsatz von Waffen zu entscheiden. Mit ihrer Bewaffnung verfolgen die Akteure das Ziel, ihre Aktionsmacht zu erhöhen, das heißt »die Macht, anderen in einer gegen sie gerichteten Aktion Schaden zuzufügen, - anderen >etwas anzutun`." (Popitz 1992: 43) Jemandem setwas anzutun`, ist das Ziel bewaffneter Aktionen im Krieg. Bei direkten Konfrontationen der Akteure, dem Gefecht, zielen die Handlungen letztlich immer auf den Körper des Anderen, auf seine Verletzbarkeit, und damit auf die Voraussetzung seiner Handlungsfähigkeit. Aber auch jenseits der unmittelbaren Konfrontation der Kontrahenten sollen kriegerische Aktionen die Handlungsfähigkeit des Gegners untergraben, beispielsweise, indem sie seine Infrastruktur zerstö- 
ren. Die im Krieg eingesetzte Waffengewalt zielt auf materielle Zerstörungen und physische Schädigungen. Von der Gewalt der Waffen gehen zwar auch psychische Effekte aus, die von den Kontrahenten geschätzt werden, wenn sie den Gegner zur Aufgabe seines Widerstandes bewegen, weshalb sie mitunter ins Kalkül operativer Überlegungen eingehen, aber die psychischen Effekte kriegerischer Gewalt stellen sich aufgrund von Verwüstungen, Verletzungen und Getöteten ein. Gewalt bezeichnet deshalb in dieser Untersuchung, neben den Bedeutungsgehalten der potentia, also als von den Waffen ausgehende Destruktionskraft, und potestas, im Sinne einer Amtsgewalt, vor allem eine auf die Physis ausgerichtete Gewalttätigkeit.

Menschen bewaffnen sich, um anderen leichter etwas wegnehmen, sie zu verletzen oder zu töten oder um all dies zumindest glaubhaft androhen zu können. Von der Reaktion des oder der Angegriffenen hängt der Verlauf des weiteren Geschehens ab. Ihre Reaktion entscheidet, ob eine bewaffnete Aktion das Ende des Konflikts, oder den Beginn einer länger währenden Auseinandersetzung, markiert. Entfällt jede Reaktion des Angegriffenen, beispielsweise weil dieser bereits mit der ersten Attacke überwältigt wird, findet zwischen den Konfliktparteien kein Kampf statt. Erst mit der Reaktion, der Verteidigung, entwickelt sich der Kampf, weil, wie schon Clausewitz wusste, "Abwehren und Kämpfen offenbar eins ist« (Clausewitz 1832: 644). Ein Krieg ist deshalb auch als eine Abfolge von aufeinander bezogenen gewalttätigen Handlungen zu bezeichnen, also von Handlungen, denen ein asymmetrisches Verhältnis zwischen Handlungsmacht und Erleiden eingeschrieben ist. Um einen Kampf handelt es sich dann, wenn der Angegriffene oder die Angegriffenen über Mittel und den Willen verfügen, sich bewusst zur Wehr zu setzen. Ob sie in der Lage sind, auf den Angriff symmetrisch zu reagieren und das Kräfteverhältnis zwischen Angreifer und Angegriffenen ausgewogen ist, spielt dabei zunächst keine Rolle. Allerdings gehört es zur Vorstellung des Kampfes, dass die Reaktionen der Verteidiger zumindest potenziell in der Lage sein müssen, die Handlungen der Angreifer zu konterkarieren. Die Reaktionen der Verteidiger müssen für die Angreifer eine Gefahr darstellen, die sie ihrerseits zur Abwehr motiviert. Andernfalls haben wir es nicht mit einem Kampf, sondern mit einer bloßen Misshandlung oder einer Vernichtungsaktion zu tun. Aus Raub und Mord kann, muss sich aber kein Krieg entwickeln. ${ }^{1}$

Der Krieg ist ein soziales und von der Sozialität abhängiges Phänomen. Diese Aussage wird auch nicht durch die Feststellung abgeschwächt, dass er an einigen anthropologische Eigenschaften des menschlichen Individuums anknüpft. Ohne die Fähigkeit zu aggressivem Handeln, ohne die »Bereitschaft zur Gruppenverteidigung, sein Dominanzstreben, seine territoriale Neigung oder auch seine kollektiv gegenseitig induzierte Begeisterung« (Mentzos 1993: 38) gibt es keinen Krieg. Sicher ist aber auch,

1 Ausführlich zu einer Phänomenologie bewaffneter Konflikte: siehe Heins/ Warburg 2004: 19f. 
dass zahlreiche gesellschaftliche Faktoren darüber entscheiden, wer mit welchen Motiven wie Krieg führt. Sie entscheiden darüber, wie viele Personen am Kampf beteiligt sind, mit welchen Waffen sie kämpfen und welche Vorstellungen darüber existieren, wie ein Krieg zu führen ist.

\subsubsection{Die Variabilität des Krieges}

Bewaffnet ausgetragene Konflikte gehören nicht zu den Phänomenen, die nur einem bestimmten Gesellschaftstypus zugeordnet werden können. Einzelne Sozialwissenschaftler, wie etwa Eibl-Eibesfeldt, vertreten deshalb die Auffassung, dass der Krieg allenthalben in der Geschichte und in jeder Kultur zu finden sei, weil Menschengruppen überall um Land und Naturgüter konkurrierten. Der Krieg sei eine »spezifisch menschliche Form der Zwischengruppen-Aggression« (1997a: 223). Dort wo man den Krieg nicht beobachten kann - wie bei den Polar-Eskimos - sei hierfür die extrem dünne Besiedlung des Gebietes verantwortlich, ist dies also auf einen bloßen Mangel an Gelegenheit zurückzuführen (1997b: 459). Diese Auffassung wird wiederum von anderen Autoren bestritten, die darauf verweisen, dass es Gesellschaften gab, in denen sich auch um knappe Ressourcen kein Konkurrenzkampf entzündete (siehe Fromm 1977: 191f.). Differenzen gibt es auch über die Bewertung der von Eibl-Eibesfeldt diagnostizierten Zwischengruppen-Aggression. Anders als Eibl-Eibesfeldt, wertet Mentzos die Kriege der Vergangenheit wie der Gegenwart als Ergebnis einer seit Jahrtausenden unbefriedigend verlaufenden Sozialisation der Individuen. Für Mentzos ist deshalb zu jedem Zeitpunkt die Überwindung des Krieges denkbar. Im Rahmen Eibl-Eibesfeldts Annahmen sicherte dagegen die Institution des Krieges das Überleben von Gruppen und erfüllte damit zumindest in der Vergangenheit eine sinnvolle Funktion.

Unbestritten ist, dass der Krieg ein äußerst vielgestaltiges Phänomen ist. Vor allem interkulturelle Vergleiche zeigen, wie unterschiedlich bewaffnet ausgetragene Konflikte von den jeweiligen Gesellschaften ausgestaltet werden. Diese Unterschiede lassen sich nur zum Teil auf andersartige Waffen zurückführen, da das Phänomen des Krieges auch zwischen den Kulturen variiert, die über ähnliche Waffen verfügen. Sowohl die Motive mit denen die Akteure in den Krieg ziehen, wie sie sich gegenseitig bekämpfen, als auch wie sie die Kampfhandlungen beendeten, weisen auf die jeweils gültige spezifische Kultur des Krieges hin. ${ }^{2}$ Dieses große Spektrum der Variationen dessen, was als Krieg bezeichnet wird, hat entscheidend $\mathrm{zu}$ einer kaum überschaubaren Zahl von Definitionen des Krieges beigetragen.

Auch wenn man ausschließlich die Geschichte des Krieges in Europa betrachtet, kann man feststellen, dass zahlreiche gewalttätig ausgetragene

2 Siehe hierzu Keegans Ausführungen zur Kriegführung der Yanomani und anderer Ethien (1995: 149f.). 
Konflikte nur für bestimmte Epochen als zum Kriegsgeschehen gehörig aufgefasst werden. So spricht Münkler mit Bezug auf das antike Griechenland davon, dass der Krieg der Normalzustand gewesen sei. „Sippen und Gefolgschaften lagen in ständigem Streit, Rinder- und Frauenraub waren an der Tagesordnung.« (1992: 22) Was damals ein Krieg war, wurde mit der Ausbildung der Staatlichkeit von Gesellschaften und des neuzeitlichen staatlichen Anspruchs, die innergesellschaftlichen Verhältnisse zu pazifizieren, zum kriminellen Bandengeschehen.

Bis vor wenigen Jahren war in den Politikwissenschaften das Phänomen des Krieges ein Synonym für bewaffnete Auseinandersetzungen zwischen Staaten. Diese Auffassung orientierte sich am europäischen Prozess neuzeitlicher Staatenbildung, beanspruchte aber mit der global durchgesetzten politischen Rahmung und zumindest formal gleichzeitigen Konstituierung aller Sozialitäten als Staaten umfassende Gültigkeit. Wenn es sich auch nicht bei jeder Kampfhandlung zwischen den Staaten gleich um einen Krieg handeln muss, - abhängig von der Intensität der Kampfhandlungen kann auch ein lokaler Grenzkonflikt vorliegen - war immer dann von einem Krieg zu sprechen, wenn ein Staat sein Exekutivorgan des staatlichen Gewaltmonopols, das Militär, umfassend mobilisierte. Ab einer gewissen Intensität der Kampfhandlungen, die zumeist anhand der Zahl getöteter Soldaten gemessen wurde, galt diese Definition des Krieges bis vor einigen Jahren als weitgehend unumstritten. Darüber blieb lange Zeit unbemerkt und unberücksichtigt, dass nach 1945 immer weniger zwischenstaatliche Kriege geführt wurden, obwohl es mit der Entkolonisierung ab den 50er Jahren so viele (oft nur formell) souveräne Staaten gab wie niemals zuvor. Selbst wenn man die Dekolonisierungskriege abzieht, muss man feststellen, dass die allermeisten bewaffneten Konflikte innerhalb und nicht zwischen den Staaten tobten. ${ }^{3}$ Den Krieg ausschließlich als ein intensives militärisches Kampfgeschehen zwischen Staaten aufzufassen, gilt spätestens seit dieser Feststellung als eine zu enge Definition des Phänomens. Stellte sich beim Staatenkrieg vor allem die Frage, welche Intensität und Kontinuität die Kampfhandlungen haben müssen, um das Geschehen als einen Krieg zu bezeichnen, stellt sich bei bewaffneten Konflikten innerhalb von Staaten zusätzlich die Frage, welche Akteure am Geschehen beteiligt sein müssen, damit man von einem Krieg sprechen kann.

Mit Blick auf verschiedene Kriegsdefinitionen kann man festhalten, dass der Krieg im Allgemeinen als höchste Steigerungsform bewaffneter Konfliktaustragung eingestuft wird. Um den Krieg von anderen Formen bewaffneter Auseinandersetzungen zu unterscheiden, wird als quantitatives Kriterium für die Intensität der Kampfhandlungen meist die Zahl der in

3 Seit Anfang der 80er Jahre hat in der Bundesrepublik vor allem die Arbeitsgemeinschaft Kriegsursachenforschung (AKUF) darauf aufmerksam gemacht. Zahlen zum Kriegsgeschehen seit 1945 siehe Schreiber (2004: 14f.). 
ihrem Verlauf Getöteten herangezogen. Um die Tatsache zu berücksichtigen, dass in den meisten Kriegen nicht nur Staaten und ihre Armeen gegeneinander kämpfen, sondern auch substaatliche Akteure, werden vor allem für bewaffnete Konflikte, die innerhalb eines staatlichen Territorium stattfinden, auch heute die Zahl der getöteten Zivilisten berücksichtigt. In den meisten Statistiken zum Kriegsgeschehen werden deshalb heute alle bewaffnete Auseinandersetzungen als ein Krieg berücksichtigt, wenn im Jahr mehr als 1.000 Menschen ihr Leben unmittelbar aufgrund der Kämpfe verlieren, gleichgültig ob sie als Zivilist oder Soldat gelten. ${ }^{4}$

Die Intensität der Kampfhandlungen hängt auf das engste von der organisatorischen Fähigkeit der Akteure ab, ihre Ziele kontinuierlich zu verfolgen. Viele Kriegsdefinitionen setzen daher ein Mindestmaß an organisatorischen Ressourcen voraus, über das die Akteure verfügen müssen, um bewaffnete Operationen gegen den Gegner zu planen und durchzuführen. Die Kontrahenten müssen in der Lage sein, den Kampf mit einer gewissen Kontinuität zu betreiben und die eigenen Streitkräfte zu lenken. Dieses Kriterium muss von mindestens zwei der Konfliktparteien erfüllt sein, damit die Kämpfe mehr als die Summe zufälliger Zusammenstößen bilden. Viele Forscher wie die Arbeitsgemeinschaft Kriegsursachenforschung (AKUF) sprechen ferner nur dann von Krieg, wenn mindestens einer der Kontrahenten ein Staat ist, der sich mit regulären Streitkräften an der Auseinandersetzung beteiligt. Sofern die bewaffneten Konflikte diese Kriterien nur ungenügend erfüllen, weil es zwischen den Konfliktparteien nur sporadisch, eher zufällig und nicht aufgrund strategischer Planung zu Zusammenstößen kommt, werden die Geschehnisse der jeweils niedrigeren Stufe gewalttätiger Konfliktaustragung zugeordnet. Beispielsweise gehen dann das AKUF von »bewaffneten Konflikten« und das Heidelberger Konfliktbarometer von einer »Ernsten Krise« aus. ${ }^{5}$

Kriege, die zwischen Staaten und die innerhalb desselben geführt werden, unterscheiden sich aber nicht nur im Bezug auf die Akteure, sie nehmen meist auch eine ganz andere Gestalt an. Im Krieg zwischen Staaten treten vorwiegend deren Streitkräfte gegeneinander an. Das Militär ist ein Produkt des europäischen Staatenbildungsprozesses, der sich als mas-

4 Um im Falle eines Staatenkrieges, weiterhin Grenzscharmützel von einem Krieg unterscheiden zu können, plädiert aber zum Beispiel Chojnacki dafür, dass es sich bei den 1.000 Getöteten um Soldaten handeln muss (siehe Chojnacki 2007: 493).

5 Wie folgenreich die jeweils gewählte Typologie ist, zeigt ein Vergleich zwischen der AKUF und dem Heidelberger Konfliktbarometer. Die AKUF, deren Kriegsdefinition voraussetzt, dass mindestens auf einer Seite reguläre, d.h. staatliche Truppen, eingesetzt werden, zählte im Jahr 200628 Kriege. Das Heidelberger Institut, das sich mehr an der Intensität und Kontinuität der Kampfhandlungen orientiert, zählt dagegen für den gleichen Zeitraum nur 6 Kriege, beobachtete aber zusätzlich 29 »ernste Krisen« (siehe http://tinyurl.com /23s2yt und http://tinyurl.com/2wcyuk; Zugriffe: 4.10.07). 
siver militärischer Konkurrenzkampf vollzog. Da Staaten territorial gebundene wie begrenzte Machtgefüge sind, kämpfen im Krieg zwischen Staaten die gegnerischen Truppen um die Kontrolle von Territorien. Die Struktur, die Organisation sowie die Bewaffnung der Truppen ist deshalb auf Gefechte mit Gegnern ausrichtet, die ebenso wie sie versuchen, innerhalb eines umkämpften Raumes die Herrschaft zu erringen. Das Militär ist auf anhaltende, intensive Kämpfe ausgerichtet. Hier, im >großen Krieg`, entfaltet es seine ganze Stärke. Der Preis für diese Spezialisierung zeigt sich jenseits der großen Gefechte.

Oppositionelle wie separatistische Bewegungen innerhalb eines Staates haben selten eine Chance, im Gefecht mit staatlichen Truppen zu bestehen. Mit dem 20. Jahrhundert hat sich deshalb die Kampfweise des Kleinkrieges gerade bei innerstaatlich ausgetragenen bewaffneten Konflikten etabliert, mit denen die unterschiedlichsten Bewegungen, die den Herrschaftsanspruch eines Regimes oder eines Staates ablehnen, versuchen, die Überlegenheit des Militärs zu unterlaufen. Sie vermeiden das dauerhafte und intensive Gefecht mit dem Militär und versuchen es nur dann zu attackieren, wenn sie glauben, aus einer Position der Stärke heraus zu handeln.

Die Bezeichnung `kleiner Krieg`, >Kleinkrieg` oder auch Guerilla ist irreführend, wenn man hiermit weniger Gewalttätigkeit als im >großen Krieg` assoziiert. ${ }^{6}$ Tatsächlich steht sie für ein Kriegsgeschehen, das keine Frontlinien kennt, keine klare Unterscheidung zwischen Kombattanten und Nicht-Kombattanten und damit der Gefahr Vorschub leistet, die Gewalttätigkeit zu entgrenzen. Im Zentrum dieses Kriegsgeschehens stehen keine großen Gefechte, also Kämpfe, in denen sich große Truppenverbände gegenüberstehen und beispielsweise versuchen, die gegnerische Linien $\mathrm{zu}$ durchbrechen, sondern das Scharmützel, der Überfall und das Attentat. Mit ihnen lässt sich zwar keine reguläre Armee besiegen, aber durch diese Art andauernder Nadelstiche kann sehr wohl der gegnerische Wille den Kampf fortzusetzen, gebrochen werden. Der Kleinkrieg soll den Gegner schwächen, nicht ihn militärisch besiegen. Wer die Regeln der Kleinkriegstaktik anwendet, versucht sogar eine militärische Entscheidung solange hinauszuschieben, bis er davon überzeugt ist, dass der Gegner seine Überlegenheit verloren hat. Um dieses Ziel zu erreichen, setzt die Kleinkriegführung auf Zeit, versucht, unberechenbar zu bleiben und zwingt das Militär, alle denkbaren Angriffspunkte zu verteidigen.

Einer entgrenzten Gewalttätigkeit leisten die Guerilleros Vorschub, weil sie sich weigern, eindeutig und jederzeit für den Gegner als Kombattant kenntlich zu sein. Sie verstoßen damit gegen grundlegende Regularien des Kriegs- und Völkerrechts, die kodifiziert wurden, um das Kriegsge-

6 Der Kleinkrieg, von dem hier gesprochen wird, ist, trotz zahlreicher Gemeinsamkeiten, nicht identisch mit dem Kleinkrieg des 18. Jahrhunderts (siehe Abschnitt 6.2.). 
schehen einzuhegen. Während für sie der feindliche Soldat in Uniform leicht zu erkennen ist und »das eigentliche Schussziel« (Schmitt 1963: 21) bildet, können die regulären Soldaten umgekehrt die Guerilleros nur schwer von Zivilisten unterscheiden, zumal sie ihre Waffen nach Möglichkeit verdeckt mit sich führen. Dabei ist nicht das Problem, dass sie versuchen, sich vor den Augen des Gegners zu verbergen - das tun auch Soldaten -, sondern dass sie versuchen zu verbergen, dass sie überhaupt Kombattanten sind. Die irreguläre Kampfweise liefert den attackierten regulären Truppen häufig den Vorwand, als Antwort, ihrerseits mit einer Entgrenzung und Entnormierung des Kampfverhaltens zu reagieren.

Gilt bereits für den zwischenstaatlichen Krieg, in dem sich reguläre Truppen gegenüberstehen, dass er wie ein unbefahrenes Meer voller Klippen ist, in dem plötzlich »das scheinbar Leichte schwer« werden kann (Clausewitz 1832: 263f.), so erfährt diese Unvorhersehbarkeit durch die bewusst praktizierte Regellosigkeit einer unkonventionellen Kampfweise eine weitere Steigerung und verstärkt die Tendenz zur Verselbstständigung des Kriegsgeschehens, in dem sich die Nebenfolgen der jeweils eigenen Handlungen nur schwer berechnen und höchst unvollständig kontrollieren lassen. Nebenfolgen, also Handlungsfolgen, die in den ursprünglichen Intentionen der Akteure nicht vorgesehen waren, sind höchst wahrscheinlich und erschweren den instrumentellen Einsatz des Krieges erheblich. Das Ergebnis sind langanhaltende Kriege, in deren Verlauf es immer wieder zu Gewaltexzessen gegenüber Nicht-Kombattanten kommt.

Die meisten Kriege nach 1945 tob(t)en, wie oben festgestellt wurde, innerhalb von Staaten. Mit dem Ende des Kalten Krieges ist der zwischenstaatliche gegenüber dem innerstaatlichen Krieg sogar zur Ausnahmeerscheinung geworden. Diese Fakten haben in den 90er Jahren einige Sozialwissenschaftler dazu motiviert, angeregt insbesondere von den Überlegungen Kaldors und van Crevelds (1998), die Frage zu stellen, ob der zwischenstaatliche Krieg nicht als Phänomen der Vergangenheit zu werten sei. Tatsächlich müssen zu Beginn des 21. Jahrhunderts nur wenige Staaten fürchten, dass sie von einem oder mehreren Staaten mit einem Krieg überzogen werden. Allerdings ist deshalb der zwischenstaatliche Krieg noch lange nicht aus der Welt. Er wird nicht zum historischen Auslaufmodell, wie Münkler meint (2002: 240), weil er vor allem als Verkehrsform zwischen den europäischen Staaten, den USA und anderen Industriestaaten zurzeit undenkbar geworden ist. Zwischen zahlreichen Staaten in Asien und Afrika bestehen Konflikte, die sich zu Kriegen entwickeln können. Beispielhaft sei hier auf den Konflikt zwischen Eritrea und Äthiopien sowie auf die gespannte Situation zwischen der Volksrepublik China und Taiwan hingewiesen. Derzeit ist es zwar unwahrscheinlich, dass sich die westlichen Atommächte und Russland gegenseitig einen Krieg androhen, aber eine solche Aussage lässt sich für die Atommächte Indien und Pakistan nicht mit der gleichen wünschenswerten Sicherheit formulieren. Und 
die USA wiederum schließen einen militärischen Konfliktes mit China nicht aus, wenn es zwischen China und Taiwan zu Kampfhandlungen kommen sollte. Dass militärische Macht weiterhin eine gültige und hochaktuelle Währung in den internationalen Beziehungen zwischen Staaten ist, zeigen nicht zuletzt auch die Kriege gegen Afghanistan (2002), den Irak (2003) und die wiederholten US-amerikanischen Drohungen gegenüber dem Iran. Die Kriege gegen Afghanistan und dem Irak zeigen auch an, dass der mit dem Ende des Kalten Krieges verbundene Bedeutungsverlust komplexer Waffensysteme, von dem van Creveld ausgeht, zu relativieren ist. Ein entscheidender Grund für die Überlegenheit der alliierten Truppen gegenüber ihren Kontrahenten beruht auf der unbestrittenen Luftherrschaft, die wiederum auf den Einsatz komplexer Aufklärungs-, Informationsverarbeitungs- und Raketensysteme zurückzuführen ist. Allerdings zeigen diese Kriege auch, dass nach der Zerschlagung des jeweils herrschenden Regimes und der Eroberung des Territoriums das Land nicht zum Frieden finden muss und es nicht ausreicht, über High-Tech-Waffen zu verfügen, wenn es gilt, Aufständische, Anhänger des geschlagenen Regimes etc. zu bekämpfen. Und sicher fällt es Truppen schwer, die auf einen regulär kämpfenden Gegner hin ausgerichtet sind, adäquate Taktiken zu entwickeln, um einen Gegner zu besiegen, der in einem unübersichtlichen, unzugänglichen Gelände - das kann sowohl ein urban bebautes Gebiet sein wie ein Dschungel - zumindest Elemente der Guerillakampfweise anwendet. $^{7}$

Neben den innergesellschaftlichen Kriegen, in denen eine reguläre Armee gegen eine oder mehrere Guerilla-Bewegungen kämpft, fanden in den 90er Jahren auch einige Kriege statt, die für einen neuen Typus des Krieges stehen könnten. Im Verlauf dieser Kriege wurden nicht nur viele Menschen getötet, verletzt und vertrieben und wurde im Kriegsgebiet die zivile Infrastruktur nachhaltig zerstört, obendrein bildeten sich ökonomische Strukturen aus, die es ermöglichten, dass sich die Kontrahenten anhaltend im Kriegszustand befinden konnten. Selbst wenn diese Kriege formell zwischen Widerstands- und Regierungstruppen ausgefochten werden, unterscheiden sich die verfeindeten Akteure faktisch hinsichtlich ihrer Struktur, Bewaffnung oder Ideologie kaum voneinander. ${ }^{8}$ Von einer

7 Dass der Einsatz des Militärs, auch wenn er polizeilichen Charakter haben sollte, in vielen Fällen erst dann greift, wenn flankierende politische und ökonomische Maßnahme getroffen werden, die auf die Gründe für die bewaffneten Aktivitäten eingehen, sei hier am Rande vermerkt.

8 Mitunter wird für diese Kriege der unscharfe Begriff des »low-intensity conflict« verwendet. Unscharf ist er, weil er beansprucht das Spektrum von kriminellen Bandenaktivitäten, separatistischen Aufständen bis hin zum Terrorismus zu erfassen (vgl. van Creveld 1998: 288). In seiner heutigen Form geht er auf Strategiedebatten in den USA zurück, die sich um die Frage drehten, wie die US-Streitkräfte angemessen mit unterschiedlichen Kriegsszenarios umgehen sollen. Die Kategorisierung der Kriegs- bzw. Konfliktarten in low, 
asymmetrischen Konstellation, in der eine übermächtige reguläre Armee in einen Kleinkrieg verwickelt wird, kann hier keine Rede sein, solange nicht fremde Mächte, etwa UN-mandatierte Interventionstruppen, von außen eingreifen. In Somalia, Liberia, Sierra Leone und DR Kongo kam bzw. kommt es immer zu Gefechten, in denen sich alle Akteure hauptsächlich mit leichten Waffen gegenübertreten (automatische Gewehre, Panzerfäuste, Hieb- und Stichwaffen sowie Minen). Im Unterschied zu Großwaffen wie Flugzeuge und Panzer werden für den Einsatz solcher Waffen keine komplexen bürokratischen Strukturen, kein anspruchsvolles technisches Wissen und kein umfangreich ausgebildetes Personal benötigt. Dadurch wird eine Entdisziplinierung und Entprofessionalisierung der Waffenträger begünstigt, die sich gegen geringe Transferleistungen anwerben lassen. Münkler weist darauf hin, dass zum ersten Mal seit der Verstaatlichung des Krieges mit diesen Waffen und diesen Rekrutierungsmöglichkeiten die Vorbereitung und Führung von Kriegen wieder billiger und nicht wie zuvor immer teurer geworden ist (Münkler 2002: 131f.). Auffallend an der Kriegführung der Kontrahenten ist ihr geringes Interesse, sich die Sympathie der von ihnen beherrschten Zivilisten und erst recht die eines weit entfernten Medienpublikums zu sichern. Stattdessen konzentriert sich ihr Interesse auf gewaltsame Extraktionen, also auf Raub, auf die Aneignung aller verfügbaren Ressourcen, die soweit möglich auf dem Weltmarkt verkauft werden, um sich selber zu bereichern und das eigene Kriegswesen zu unterhalten. ${ }^{9}$ Bodenschätze werden ebenso wie die im Einflussgebiet lebende Bevölkerung als Beute der Bewaffneten aufgefasst, und Gewalt gegen Zivilisten und ausländische Hilfsorganisationen ist die soziale Verkehrsform, über die die Bewaffneten ihr Verhältnis zu ihrer sozialen Umwelt regeln. Dazu gehört auch, dass Zivilisten zur Arbeit für die Bewaffneten gezwungen und als beliebig ausbeutbares Rekrutierungsreservoir angesehen werden. An die Stelle von Kämpfen um die politische, sprich staatliche Macht, sind hier Kämpfe um Bodenschätze oder Anbaugebiete von Drogen getreten. Eine Differenz zwischen kriegerischer Gewalt und organisierter Kriminalität ist in diesen Kriegsgebieten kaum auszumachen (vgl. Münkler 2002: 11). Kein Wunder, dass die Kriegsparteien häufig von Personen geführt werden, die mehr Berufskriminellen als Politikern gleichen. $\mathrm{Ob}$ sie als politische Unternehmer gedeutet werden können, ihnen die Transformation vom warlord hin zum statesman gelingen wird, gilt zumindest als offen (vgl. Knöbl 2004: 191).

Mit Blick auf das Kriegsgeschehen der vergangenen Jahre ist Münklers Einschätzung (2002) fraglich, dass es sich bei diesen `Neuen Kriegen` um ein immer mehr um sich greifendes und nicht um ein auf bestimmte Re-

middle und high bezogen sich nicht auf die Zahl der Opfer in den Kriegen, sondern auf das Ausmaß militärischer Gewalt, das die US-Streitkräfte einsetzen müssen, um erfolgreich zu sein. Siehe hierzu auch Daase (1999: 136).

9 Einen Überblick zu Kriegsökonomien der 90er Jahre gibt Jean/Rufin. 
gionen konzentriertes und besonders häufig in Afrika anzutreffendes Phänomen handelt. ${ }^{10}$ Umstritten ist auch, in welchem Umfang in den betroffenen Ländern von einem Staatszerfall gesprochen werden kann. So wendet Gantzel ein, dass nur das zerfallen kann, was vorher schon da war. In den meisten Fällen habe es in den betroffenen Kriegsgebieten noch gar keinen Staat gegeben, der sich als eine funktionsfähige Zentralgewalt etabliert hatte (vgl. Gantzel 2002: 10). Tatsache ist, dass in den betroffenen Regionen selbst die Akteure, die für sich beanspruchen, den Staat zu repräsentieren, sich wie ihre substaatlichen Gegner, kaum um mehr als die Abschöpfung von Ressourcen, wie Bodenschätze, kümmern, die zu einem guten Teil ins Ausland transportiert werden, die Versorgung eines kleinen Klientels sowie den Unterhalt der eigenen Truppen. Bislang ist nicht absehbar, ob am Ende der >Neuen Kriege` sich Staaten formieren werden, die den politischen Gebilden ähneln, die im Verlauf der europäischen Geschichte entstanden. ${ }^{11}$

\subsubsection{Das Militär als soziale Macht}

Dass das Phänomen Krieg an keine bestimmte soziale Form und auch nicht an eine bestimmte politische Verfassung eines Gemeinwesens geknüpft ist, zeigt an, dass die sich hier manifestierende militärische Macht eine eigenständige Quelle sozialer Macht darstellt. Militärische Macht kann sich auch dort entfalten, wo sie nicht oder nicht mehr im Dienst eines Staates steht. Die Gestalt des heutigen Militärs ist zwar nicht loszulösen vom politischen Gebilde des Staates, aber offenkundig auch heute nicht die einzige Organisationsform militärischer Macht.

Militärische Macht als eine gegenüber dem Staat eigenständige soziale Machtquelle einzustufen, knüpft an Michael Manns Überlegungen zur Geschichte der Macht an. Dieser geht davon aus, dass Menschen aufeinander angewiesen, also soziale Wesen sind. Dabei verstricken sie sich unvermeidlich in soziale Machtbeziehungen, die ihre Fähigkeit, Handlungsbedingungen zu verändern, um in die Verhältnisse der sie umgeben-

10 So wendet sich Chojanicki gegen die Vorstellung, dass der Staatenkrieg ein Auslaufmodell sei. Seine Untersuchungen zeigen, dass die Mehrzahl der Kriege weiterhin konventionell und staatszentriert geführt werden. Selbst dort wo das Gewaltmonopol zur Disposition stehe oder nie voll entwickelt worden sei, bleibe der Staatsapparat ein wichtiges Macht- und Steuerungsinstrument (Chojnacki 2007: 501; zur Kritik am Theorem der >Neuen Kriege «, siehe auch Kahl/Teusch 2004).

11 Es wäre beispielsweise anhand der Entwicklung in Angola zu untersuchen, ob nach dem Ende des 27 Jahre dauernden Krieges (2002) zwischen der Regierung und der Rebellenorganisation der Unita - die militärisch besiegt wurde - die Regierung Interesse am Aufbau eines Staates und ziviler Infrastrukturen zeigt oder sie sich weiterhin insbesondere die Einnahmen aus dem Rohstoffexporten privat aneignet und den Rest zum Unterhalt der Streitkräfte verwendet. 
den Welt einzugreifen, prägen. Soziale Macht meint hier nicht nur »jene Chance, innerhalb einer sozialen Beziehung den eigenen Willen auch gegen Widerstreben durchzusetzen« (Weber 1922: 28), also den distributiven Aspekt von Macht, sondern schließt auch den kollektiven Aspekt von Macht ein, die entsteht, wenn die Individuen miteinander kooperieren, um gemeinsam die Macht über Dritte oder die Natur auszuweiten. Gleichwohl, auch die Verfolgung kollektiver Ziele führt zu sozialen Organisationen, zur Arbeitsteilung, die »infolge der Momente von Überwachung und Koordination eine inhärente Tendenz zu distributiver Macht in sich« tragen (Mann 1990: 22). Soziale Macht ist folglich ein konstitutives Element menschlicher Interaktionen. Die aus den Interaktionen, aus den Zusammenschlüssen von Menschen resultierenden sozialräumlichen Machtgeflechte konstituieren nach Auffassung Manns keine sozialen Totalitäten, Gesamtheiten mit einer Grenze nach Außen und einer Struktur nach Innen, sondern vielfältige, sich überlagernde und überschneidende sozialräumliche Machtgeflechte mit jeweils unterschiedlichen Grenzen (vgl. Mann 1990: 14). Menschen leben deshalb grundsätzlich in Gesellschaften. Die Vorstellung, sie lebten in einer einheitlichen Gesellschaft mit einer fixierten Außengrenze ist erst mit den Nationalstaaten aufgekommen. Neben den ideologischen und ökonomischen Hauptquellen sozialer Macht differenziert Mann auch deshalb zwischen militärischen und politischen Machtgefechten, weil sich die militärische Macht historisch häufig unabhängig von politischen Zentren manifestiert hat, und es dem Staat, den er als die Organisationsform politischer Macht bestimmt, erst spät gelungen ist, die legitimierte physische Gewaltausübung zu monopolisieren.

Aber auch schon bevor das Militär zum Exekutivorgan des staatlichen Gewaltmonopols wurde, gab es militärische Organisationen, das heißt Organisationen konzentrierter Zwangsgewalt. "Sie mobilisieren Gewalt, jenes konzentrierteste und zugleich gröbste Instrument menschlicher Macht, dessen Wirksamkeit in Kriegszeiten am deutlichsten sichtbar wird.« (Mann 1990: 52) Diese Organisationen können mannigfaltige Formen annehmen. Anders als beim heutigen Militär, in dem die Fähigkeit zur Ausübung von Gewalt eingeübt, entwickelt und unter Befehl gestellt wird, können sie beispielsweise aus dem Zusammenschluss von Waffenträgern entstehen, die an unterschiedlichen Orten mit ihren Waffen trainiert haben und die sich lediglich für einen begrenzten Zeitraum zu einem Verband zusammenschließen.

Das heutige Militär weist im Hinblick auf seine Organisation und Struktur Merkmale der Moderne auf. Das gilt auch für seine Angehörigen, lässt sich doch die Entstehung der Sozialfigur des Soldaten als ein Prozess der Neuverknüpfung sozialer Funktionen und ihrer Ausdifferenzierung, den Schlüsselwörtern vieler Modernisierungstheorien, beschreiben. Die Bezeichnung Soldat meint hier nicht jeden beliebigen Waffenträger, sondern nur denjenigen, der dem Militär angehört. Soldaten unterscheiden sich 
von anderen Trägern organisierter Gewaltausübung, etwa Rittern, durch ihre Beschränkung auf die Rolle, die ihnen innerhalb einer militärischen Organisation zugewiesen wird. Ein adeliger Ritter vereinigte dagegen noch weitere soziale Rollen auf sich, etwa die des Grundbesitzers. Die Sozialfigur des Soldaten hat sich aus der des Söldners heraus entwickelt, der wiederum einen der ältesten Lohnberufe ausübt(e). Die Entlohnung für geleistete Kriegsdienste ist ein signifikantes Unterscheidungskriterium gegenüber anderen Kämpfenden und wird deshalb nicht zufällig im Berufsnamen selbst betont. ${ }^{12}$ Wie eng der Zusammenhang Militär und Soldat ist, lässt sich daran ablesen, dass die Adjektive soldatisch und militärisch häufig als Synonyme verwendet werden.

Da sich die im Verband kämpfenden Soldaten zwischen dem 15. und 19. Jahrhundert gegenüber allen anderen bewaffneten Formationen in zunehmende Maße als überlegen erwiesen, entschlossen sich spätestens im Laufe des 19. Jahrhunderts die nicht kolonisierten außereuropäischen politischen Machtgebilde, militärische Organisationen nach europäischen Vorbild aufzubauen. Um Armeen nach europäischem Vorbild aufzustellen, importierten sie nicht nur die Waffen und versuchten möglichst, eine eigene Rüstungsindustrie zu entwickeln, sondern orientierten sich auch bei der Rekrutierung der Soldaten, deren Ausbildung, sowie der Gliederung der Verbände nach den Mustern, die ihnen aus Europa bekannt waren. Im 20. Jahrhundert hat sich dann das Militär als beherrschende, auf den Krieg hin optimierte Gewaltorganisation weltweit durchgesetzt, sei es als koloniale Hinterlassenschaft, sei es um eine Kolonisierung zu verhindern. ${ }^{13}$

Der Einsatz überlegener Feuerwaffen, die sich gerade im 19. Jahrhundert rasant weiterentwickelten, ist ein Grund für die damalige Überlegenheit des Militärs gegenüber anderen bewaffneten Organisationen. So war beispielsweise der Einsatz des Maschinengewehrs im letzten Drittel des 19. Jahrhunderts mit verantwortlich für die Überlegenheit der Kolonialtruppen, die obendrein von den Innovationen in der Transport- und Kommunikationstechnologie profitierten. Der erfolgreiche Einsatz all dieser Technologien setzte mehr voraus als ihre bloße Verfügbarkeit, wie ein

12 Die Lohnzahlungen von Söldner und Soldaten werden als Sold bezeichnet. Der Begriff geht wiederum auf eine römische Goldmünze der Spätantike zurück, die als besonders stabil, solide, galt und mit denen die römischen Legionäre bezahlt wurden. Dass die Lohnarbeit in der Armee früher als in der übrigen Gesellschaft ausgebildet war, fiel bereits Marx auf (1858: 43).

13 Selbstverständlich gab es auch weiterhin stets andere bewaffnete Formationen. Die Guerilla ist aber als asymmetrische Antwort auf das Militär zu verstehen, die von einer irregulären zur konventionellen Kampfweise übergehen kann. Aus Guerilleros können also Soldaten werden. Den Kämpfern der Warlord-Verbände scheint diese Transformation schwerer zu fallen. Sie vermögen wohl auch gegenüber konventionellen militärischen Formationen nur eine geringe Kampfkraft zu entwickeln (siehe Heins/Warburg 2004: 32f.). Das bedeutet aber nicht, dass man sie als atavistische Phänomene einstufen kann (siehe Warburg 2001: 207). 
Blick auf die Bemühungen der außereuropäischen Mächte im 19. und 20. Jahrhundert zeigt, die durch Waffenimporte ihre militärische Macht erhöhen wollten, um keine europäische Kolonie zu werden. Die aus der Technologie resultierende Überlegenheit ließ sich nur nutzen, wenn auch administrative Voraussetzungen geschaffen wurden, die den Aufbau eines ständig unter Waffen zu haltenden Verbandes ermöglichten. Es musste entschieden werden, wer als Soldat rekrutiert wurde, und die Waffenträger mussten den Umgang mit der Waffe und ihrer Verwendung im Verband üben. Es galt, Handlungsregeln für die Soldaten und ihre Vorgesetzten zu erlassen, und es galt, die Verbände nach taktisch-operativen Überlegungen zu strukturieren, die die Potentiale der Waffen zu nutzen verstanden. Als einzigen außereuropäischen Macht gelang es nur Japan, europäische Rüstungsgüter erst zu importieren, anschließend selber zu produzieren und die traditionelle militärische Machtorganisation derart erfolgreich zu transformieren, dass es um die Jahrhundertwende zum 20. Jahrhundert ein ernsthafter und sogar überlegener Konkurrent der europäischen Kolonialmächte wurde. Dies gilt vor allem in Bezug auf Russland.

\subsection{Soldatische Subjektivität - zum Aufbau der Untersuchung}

Mit dem Militär als soziale Macht sowie dem Krieg als Phänomen mit nachhaltigen Folgen für jede Sozialität setzte sich die bundesrepublikanische Soziologie nur wenig auseinander. Dabei hat es an Kritik an ihrem Umgang mit diesen Themen nicht gemangelt. Weshalb diese Kritik weitgehend folgenlos geblieben ist und weshalb es für die Soziologie trotzdem wichtig ist, sich den Themen Militär und Krieg anzunehmen, diese Fragen werden im nächsten Kapitel beleuchtet. Das Kapitel endet mit einem Plädoyer für eine Soziologie des Krieges.

Jede militärische Organisation setzt sich aus Individuen zusammen. Die militärische Macht einer solchen Organisation hängt nicht zuletzt davon ab, in welchem Ausmaß es ihr gelingt, die individuellen Fähigkeiten ihrer Angehörigen für die Zwecke der Organisation zu mobilisieren. Gerade im Hinblick auf einen Kriegseinsatz stellt sich die Frage, wie und welche Potentiale der Waffenträger zu einer Machtsteigerung der Organisation genutzt und welche ausgegrenzt werden. Anders gefragt, welchen Stellenwert und welche Bedeutung kommt der Subjektivität der unmittelbaren Gewaltakteure, also insbesondere der Soldaten, im modernen Kriegsgeschehen zu?

Soldaten, die die erteilten Befehle befolgen, werden eher wie Objekte mit förderlichen und hinderlichen Eigenschaften wahrgenommen. Sie als Subjekte zu betrachten, also als Individuen, die ihr Geschick eigensinnig und eigenmächtig beeinflussen können, steht im Kontrast zur vorherr- 
schenden Betrachtungsweise von Soldaten. Zur Begründung der These, dass Soldaten als Subjekte aufgefasst werden können, wird in Kapitel 3 auf allgemeine philosophische und soziologische Theorien zurückgegriffen. Dabei wird der engere Gegenstandsbereich dieser Arbeit überschritten, denn diese Theorien äußern sich meist nicht oder allenfalls am Rande zum sozialen Phänomen des Krieges und zu Soldaten. Die Argumentation wird auch an einer weiteren Stelle, im Abschnitt 5.4. „Der maschinelle Körper und der Leib«, auf eine umfassende theoretische Grundlage gestellt.

Soldaten, aber auch die Angehörigen vorheriger Organisationen der Gewaltausübung, sind nicht in immer gleicher Weise Subjekte ihrer Geschichte. Im Laufe der Jahrhunderte veränderten sich die Anforderungen an die Kämpfenden und die Akteure bildeten neue Selbstdefinitionen aus, die ihr Handeln prägten und ihrerseits zu einem Wandel der Formen organisierter Gewaltausübung beitrugen. Zur Historizität der soldatischen Subjektivität gehört auch ihre Genese aus vorherigen Formen der organisierten Gewaltausübung, die in Kapitel 4 beleuchtet werden soll.

Das Handeln soldatischer Subjekte wird vor allem im Hinblick auf seine Beziehung zum Krieg, genauer zum Gefecht, betrachtet. Die Untersuchung konzentriert sich dabei auf die europäische Landkriegführung und setzt sich bevorzugt mit dem Kampf von zu Fuß kämpfenden Soldaten auseinander. Für die Gefechte der Infanterie im Besonderen wie für das Kriegsgeschehen allgemein gilt das Diktum von Clausewitz: »Die Waffenentscheidung ist für alle großen und kleinen Operationen des Krieges, was die bare Zahlung für den Wechselhandel ist« (1832: 226). Auch wenn nicht alle militärischen Operationen im Krieg Kämpfe mit dem Gegner darstellen, ganz fehlen sie niemals. Wenn auch nicht der Ausgang jedes einzelnen Gefechts über Sieg oder Niederlage im Krieg entscheidet, so zeigt doch der Ausgang der Kämpfe in toto, ob die getroffenen Vorbereitungen auf den Krieg den gestellten Aufgaben für die militärische Organisation entsprachen. Anhand verschiedener historischer Konfigurationen, in denen unterschiedlich auf die Subjektivität der Soldaten zurückgegriffen wurde, um sie für den Kampf nutzbar zu machen, werden sowohl die Schwierigkeiten als auch die machtsteigernden Effekte dieses Zugriffs untersucht. Die Art, wie die individuelle Kampfkraft formiert und als Teil des Gesamtverbandes organisiert wurde, drückt - so die hier untersuchte These - jeweils ein spezifisches Verhältnis zur Subjektivität der Soldaten aus. Um die Tragweite dieses konzeptionellen Verhältnisses zur Subjektivität zu beleuchten, werden im 5. Kapitel die verschiedenen Bedeutungshorizonte der Metapher Maschine vor allem im Hinblick auf den Körper der Soldaten untersucht. Darüber hinaus wird der Gedankengang, dass der menschliche Körper wie eine Maschine funktioniere, dem das Denken als Refugium des Subjekts äußerlich ist, mit Überlegungen zur Leibgebundenheit des Subjekts kontrastiert, die sich vor allem auf die 
Überlegungen Plessners zur exzentrischen Positionalität des Menschen beziehen.

Das Kapitel 6 ist der veränderten Stellung des soldatischen Subjekts in den Einsatzkonzeptionen gewidmet, die die Lineartaktik des 18. Jahrhunderts ablösten. Diese Veränderungen vollzogen sich nach der Französischen Revolution bei allen europäischen Landstreitkräften. Soldaten sollten in den in den neuen Führungskonzepten ausdrücklich mehr als nur Objekte in den Händen der Feld- und Kriegsherren sein. Sich als Subjekte in das Kriegsgeschehen einzubringen, wird seitdem von den Soldaten, wenn auch in unterschiedlichem Maß, verlangt. In diesem Zusammenhang wird die These vertreten, dass seither die positive Einbeziehung der soldatischen Subjektivität ein Dreh- und Angelpunkt operativer Einsatzkonzepte ist. Befehlskonform sich entfaltende soldatische Subjektivität ist eine Innovationsressource der Kriegführung. Vor diesem Hintergrund wird in einem weiteren Schritt auf Einsatzkonzeptionen einzugehen sein, die die Subjektivität der Soldaten aktiv nutzen wollten und den Soldaten deshalb einen größeren Handlungsspielraum zubilligten. Trotz zahlreicher administrativer, politischer sowie sozialer Veränderungen, die diese Bemühungen begleiteten, damit die Soldaten bereit waren, sich auf dem Schlachtfeld zu engagieren, wird auch auf die Gründe einzugehen sein, die weiterhin dafür sprachen, dass die Entfaltung soldatischer Subjektivität stark reglementiert blieb.

Bildete bis zu Beginn des 20. Jahrhunderts das Gefecht eine Ausnahmesituation innerhalb des Kriegsgeschehens, änderte sich dies im Zuge der Industrialisierung des Krieges entscheidend. Denn im Laufe des 19. Jahrhunderts wurde nicht nur ständig die Wirkung und Leistungsfähigkeit der Distanzwaffen erhöht, das heißt sie entwickelten auf immer größer werdende Entfernungen ihre letale Wirkung und konnten in immer kürzer werdenden Zeitabständen abgefeuert werden, sondern durch verbesserte Kommunikations- und Transporttechnik wurde es prinzipiell möglich, die Truppen permanent mit industriell gefertigten Gütern zu versorgen. Nur der permanente Nachschub an Lebensmitteln, Munition und auch Personal ermöglichte die Ausbildung eines sozialen Raumes, in dem der Kampf auf Dauer gestellt ist, der Front bzw. dem Gefechtsfeld. Voll zum Tragen kamen diese Veränderungen in Europa erstmals im Zuge des 1. Weltkrieges. Welche Folgen die Industrialisierung und die Permanenz des Kampfgeschehens auf die soldatischen Subjekte hatten, wird im 7. Kapitel untersucht werden.

Im 8. Kapitel wird der Frage nachgegangen, welche Stellung soldatische Subjektivität gegenwärtig in avancierten Militärorganisationen einnimmt. Untersucht wird dabei die Bedeutung der Sozialwissenschaften bei der Formierung soldatischer Subjektivität. Auch wird auf die Folgen der Technisierung des Kriegsgeschehens eingegangen. Eine wichtige Rolle spielt dabei die Feststellung, dass die Entwicklung der Kriegstechnologie 
danach strebt, Kompetenzen, die bislang unverzichtbar mit dem Individuum verbunden waren, durch Artifizielle zu ersetzen, die als vollständig beherrschbar und deren Potential als unendlich leistungsfähiger gedacht wird. Neben den Folgen gegenwärtiger (Um-)Rüstungsvorhaben auf die Militärorganisationen wird in den abschließenden Abschnitten dieser Arbeit gefragt, wie sich die so genannte Transformation der Streitkräfte und die gegenwärtig diskutierten Auslandseinsätze möglicherweise auf die soldatischen Subjekte auswirken. 


\section{Bemerkungen zum Verhältnis Soziologie und Krieg}

\subsection{Ein Überblick}

Das Phänomen des Krieges kausal allein auf die physische und psychische Natur des Menschen zurückzuführen, das heißt auf seine Fähigkeit zu aggressivem Handeln, und es damit bewenden zu lassen, wird heute allgemein als eine unbefriedigende wissenschaftliche Erklärung eingestuft. Wenn in anthropologischen, ethnologischen, psychologischen oder psychoanalytischen Schriften Fragen erörtert werden, wie Aggression entsteht und wie sie sich äußert, dann mag die von jeglicher Sozialität >unbearbeiteter Konstitution des Menschen noch keine große Rolle spielen. Aber spätestens, wenn es um die Frage geht, wie durch die Ausbildung von Regeln, Werten und sozialen Institutionen zwischenmenschliche Aggressivität begrenzt werden kann, damit sich die jeweiligen Sozialitäten nicht (selber) durch gewaltsam ausgetragene Begegnungen vernichten, werden die sozialen Verhältnisse unverzichtbarer Bestandteil der Analyse.

Wie sich Gewalt im Verkehr zwischen Individuen und Gruppen begrenzen lässt, ist ein Thema der Politikwissenschaften. In den Politikwissenschaften geht es weniger um die Aggressivität des Einzelnen und ihre Wirkung auf die Sozialität, sondern um die Bedeutung, die Gewalttätigkeiten für das politische Handeln haben bzw. haben sollen. Gewaltakte Einzelner sind für sie nur in Ausnahmefällen interessant und auch dann nur, wenn von diesen Akten ein weit reichender Effekt auf die betrachtete Sozialität ausgeht, wie dies beispielsweise der Fall ist, wenn eine Person des politischen Lebens einem Attentat zum Opfer fällt. Erst als kumulierte Ereignisse oder wenn eine Gruppe durch ihre Fähigkeit Gewalt anzuwenden ihre Gestaltungskraft auf die betrachtete Sozialität erhöht - häufig wird dann von Macht gesprochen - wird Gewalt zum Gegenstand der Politikwissenschaften. Gewalt tritt hier zumeist als quasi-natürliche Ressource 
des politischen Handelns auf, die es, bei der Umsetzung politischer Ziele rational einzusetzen gilt. Die Auseinandersetzung mit dem Phänomen Krieg gehört damit zu ihren zentralen Themen. Nicht zufällig setzt die politische Geschichtsschreibung, auf der unter anderem die modernen Politikwissenschaften beruhen, mit einem Werk ein, in dessen Zentrum ein Krieg steht. Gleichsam zum Lehrbuch wurde die »Geschichte des Peloponnesischen Krieges«, weil der Autor Thukydides (460 bis 400 v.u.Z.) den Verlust der Vormachtstellung Athens und die Zerrüttung aller griechischen Stadtstaaten in der Folge des Krieges als das Ergebnis von Entscheidungen Einzelner und der in den Städten herrschenden Fraktionen zeigte. Bei Thukydides sind es nicht Götter, die über den Krieg und seinen Verlauf entscheiden, sondern menschliche Akteure, deren Entscheidungsund Handlungsspielräume freilich durch strukturelle Momente eingeschränkt werden. So hielt er den Krieg zwar aufgrund der Konkurrenzsituation zwischen den Stadtstaaten Athen und Sparta für unvermeidlich, aber er hätte auch anders verlaufen können (vgl. Münkler 1992: 80f.). In Anknüpfung an Thukydides lässt sich als das Credo der Politikwissenschaften die Auffassung bezeichnen, dass nicht allein die Moralität der Handelnden darüber entscheidet, ob sie die Politik betreiben, die sie anstreben, sondern erst die Analyse der strukturellen Bedingungen, unter denen sie handeln.

Auch in den Werken von Machiavelli und Hobbes, mit denen die neuzeitlichen Politikwissenschaften einsetzen, fällt der Auseinandersetzung mit dem Phänomen Krieg eine entscheidende Bedeutung zu. Beide Autoren konstatieren bei den Menschen eine Neigung zum Krieg, die sie auf ihre anthropologischen Eigenschaften zurückführen. Beispielsweise lässt Machiavelli seinen Fürsten wissen, dass »die Menschen [...] undankbar, unbeständig, heuchlerisch, furchtsam und eigensinnig« sind (1513: 94). Und führt an anderer Stelle aus, dass »die menschlichen Wünsche unersättlich sind, weil uns die Natur alles zu begehren erlaubt und antreibt, das Schicksal aber nur wenig zu erreichen gestattet, so entsteht eine immerwährende Unzufriedenheit im menschlichen Gemüte und Überdruss an all den Dingen, die man besitzt.« (1513/1519: 214) Um der Schlechtigkeit aller Menschen zu begegnen, tue der Fürst deshalb gut daran, »alle seine Gedanken, allen seinen Fleiß auf das Studium der Kriegskunst, der einzigen, deren Beherrschung man von ihm erwartet, (zu) verwenden; denn durch sie allein erhalten sich Fürsten von Geburt auf ihrem Throne, und durch sie gelangen öfters Privatpersonen darauf. Dagegen zeigt es sich, dass Regenten, welche mehr an ein üppiges Leben dachten als an die Waffen, ihr Reich verloren haben.«(89) Machiavellis bereits zu seiner Zeit anstößig wirkenden Ratschläge an den Fürsten legitimieren allerdings, entgegen bis heute weit verbreiteten Ansichten, keinen wahllosen und entgrenzten Einsatz von Gewalt. Er rät dem Fürsten vielmehr dazu, Gewalt zum Erhalt und Ausbau seiner Herrschaft rational einzusetzen. Wenn er 
z.B. Grausamkeiten begehen müsse, gelte es möglichst »alle Grausamkeiten auf einmal auszuüben, damit er (es) nicht nötig habe, alle Tage damit von vorne anzufangen « (75). Er empfiehlt ihm also maßvollen und bedachten Einsatz von Gewalt, sei es nach innen oder nach außen. Gleiches empfiehlt er auch seinem politischen Ideal einer »Gemeinschaft tendenziell egalitärer Bürger, wie er sie aus den Texten der antiken Autoren [...] herauslas« (Münkler 1990: 21). Und wie Münkler ausführt, ist demnach der Staat bei Machiavelli »dazu da, der menschlichen Destruktivität, [...], Grenzen zu setzen, und er ist zugleich durch die Destruktivität der Menschen, ihre Unfähigkeit zur Selbstkontrolle, in seiner Existenz als Zwangsanstalt gerechtfertigt.« (1990: 39)

Das Thema Krieg ist geradezu konstitutiv für das Werk von Hobbes. Er geht in seiner politischen Theorie von der Überlegung aus, dass »sich die Menschen [...] im Zustand des Krieges eines jeden gegen jeden befinden« (1651: 99). Als Individuen, die sich in ihren Fähigkeiten und damit in ihren Hoffnungen gleichen, konkurrierten sie um Mittel zu ihrem Selbsterhalt und Lustgewinn. »Und wenn daher zwei Menschen nach demselben Gegenstand streben, den sie jedoch nicht zusammen genießen können, so werden sie Feinde und sind in Verfolgung ihrer Absicht [...] bestrebt, sich gegenseitig zu vernichten oder zu unterwerfen.« (ebd.: 95) Ihre Konkurrenz, ihr hieraus resultierendes Misstrauen und als drittes die Ruhmsucht der Menschen ${ }^{1}$ macht er als die Konfliktursachen zwischen den Menschen aus. Das Bild vom permanenten Kampf zwischen den Individuen hat bei Hobbes einen heuristischen Wert. Er geht davon aus, dass »es niemals eine Zeit gegeben hat, in der sich einzelne Menschen im Zustand des gegenseitigen Krieges befanden« (ebd.: 97). Es sind vielmehr zu allen Zeiten »Könige und souveräne Machthaber«, die sich ständig verhalten »wie Gladiatoren« (ebd.). Während innerhalb einer sozialen Ordnung die Individuen auf eine umfassende Durchsetzung ihrer Interessen verzichtet hätten, weil die Leidenschaften der Todesfurcht und »das Verlangen nach Dingen, die zu einem angenehmen Leben notwendig sind und die Hoffnung, sie durch Fleiß erlangen zu können« (ebd.: 98) sie friedfertig stimmen würden, herrsche zwischen den Staaten noch der Naturzustand. Eine machtvolle, ja ängstigende staatliche Ordnung nach innen wie nach außen ist für Hobbes der Garant für die Abwehr eines Bürgerkrieges wie eines Angriffes durch einen anderen Staat.

In den Sozialwissenschaften beschäftigen sich heute vor allem politikwissenschaftliche Arbeiten mit dem Phänomen Krieg. Gerade sie sind es auch, die von der gängigen Vorstellung, jeden in der Geschichte vorzufin-

1 Die Menschen würden »am Zusammenleben kein Vergnügen (empfinden), sondern im Gegenteil großen Verdruss, wenn es keine Macht gibt die dazu in der Lage ist, sie alle einzuschüchtern.« (Hobbes 1651: 95) Deshalb wären sie darauf aus, ihre »Verächter« zu schädigen und von anderen Menschen mit möglichst großer Wertschätzung behandelt zu werden. 
denden Kampf zwischen verschiedenen Gruppen als Krieg zu bezeichnen, abgerückt sind. Denn bei genauer Betrachtung der Form und Intensität, in denen sich die Gewalttätigkeiten vollziehen, sowie der Zwecke, die mit ihnen verfolgt wurden, zeigt sich, dass vom Krieg als historisch invariantem Phänomen nicht gesprochen werden kann. Dies geht so weit, dass die Abgrenzung von Verhältnissen für die heute die Begriffe >Krieg` und >Frieden` verwendet werden, nicht gelingt, wenn man den Krieg ahistorisch z.B. als »mit Waffengewalt ausgetragene Auseinandersetzung zwischen größeren Gruppen, in der Regel sind es Staaten oder Völker« (Brockhaus-Definition) definiert.

Für das heutige Verständnis dessen, was Krieg meint, kommt dem Staat eine zentrale Bedeutung zu. Mit Blick auf die Verhältnisse im antiken Griechenland streicht beispielsweise Münkler (1992) die konstitutive Rolle heraus, die dem Staat bei der Differenzierung der politischen $\mathrm{Zu}$ stände Krieg und Frieden zukommt. Im Unterschied zu Hobbes betont er nicht die Konkurrenz zwischen den Individuen, sondern die Alltäglichkeit von Kämpfen zwischen Sippen und Gefolgschaften, die es erschweren, für vorstaatliche Verhältnisse die Begriffe Frieden und Krieg anzuwenden. Von einem Frieden zu dieser Zeit könne nicht gesprochen werden, weil die Sozialverbände ständig untereinander in Streitigkeiten verwickelt waren und der Raub von Rindern und Frauen an der Tagesordnung war (22). Es gab »vor der Ausbildung der Staatlichkeit weder Krieg noch Frieden im strikten Sinne [...], sondern nur eine permanente Belligerenz, die jedoch erheblich unterhalb der Schwelle lag, was seit der Entstehung der Staatlichkeit Krieg heißt. Frieden wurde mit der Bildung von Staaten zum Normalzustand. Der Pazifizierungsfunktion der Staatlichkeit entspricht die bellizistische Intensivierung der Konfliktaustragung.«(Ebd.)

Krippendorff sieht darüber hinaus in der Entstehung neuzeitlicher Staatlichkeit spätestens ab dem 16. Jahrhundert einen grundlegenden Bruch in der Funktion von Rüstung und Krieg. Blieben bis dahin die landwirtschaftlich reproduzierenden Gesellschaften vom Kriegsgeschehen strukturell unverändert- was nicht ausschloss, dass sie durch Verwüstungen und Brandschatzungen in Mitleidenschaft gezogen wurden - und hätten sich die dynastischen Besitzstandsverhältnisse verändert, wären nun durch die Einbeziehung großer Teile der Reproduktion »immer größere Sektoren [der Gesellschaft, d.A.] an Krieg und vor allem an Rüstung indirekt und direkt interessiert« (1986: 163) gewesen. Damit habe sich die Beziehung, die die Gesellschaften zum Krieg unterhalten, strukturell verändert. Blieben bis dahin die Vorbereitungen auf einen Krieg den Gesellschaften relativ äußerlich, wurden sie nun allmählich zu prägenden Faktoren für die gesamte Produktion und Reproduktion der Gesellschaften. Deshalb weist er dem Krieg für das Verständnis neuzeitlicher Staatlichkeit und Sozialitäten eine Schlüsselstellung zu. 
Dass der Krieg keineswegs ein historisch invariantes Phänomen ist, das durch die Natur des Menschen hinreichend begründet werden kann, zeigen auch anthropologische und ethnologische Studien. Bis in die 2. Hälfte des 20. Jahrhunderts unterschieden sich gewaltsame und bewaffnete Konflikte zwischen verschiedenen Stämmen und Ethnien, die noch nicht von Modernisierungsprozessen durchdrungen waren, signifikant von den Formen der Gewaltaustragung, die von Europa ausgingen. Diese Unterschiede beziehen sich nicht nur auf die Art der Bewaffnung und Organisation, sondern betreffen auch das Kombattantenverhalten, dass mitunter stark ritualisiert war, womit die Gefahr unkontrollierbarer Eskalation der Gewalttätigkeit eingedämmt wurde. ${ }^{2}$

Der Krieg ist also als ein Phänomen zu begreifen, das seiner Form und seinem Inhalt nach von der sie vorbereitenden und führenden Sozialität abhängt. Neben anderen Kennzeichen, die soziologische Modernisierungstheorien je nach ihren Zuschnitt betonen - die industriell-kapitalistische Entwicklung, die wissenschaftlich-technische Weltbemächtigung, die Bedeutung einer rational-disziplinierten Lebensführung und der Herausbildung von Massenkommunikation und Massengesellschaft, um nur einige zu nennen - hängt die Gestalt des Krieges wesentlich von der Herausbildung eines Herrschaftsverbandes ab, der erfolgreich alle konkurrierenden »Verwaltungs- und Kriegsbetriebsmitteln, Finanzbetriebsmitteln und politisch verwendbaren Güter aller Art« enteignete (Weber 1922: 824) und als ausdifferenzierter Verband das Monopol legitim ausgeübten Gewalt beansprucht: dem modernen Staat, der aus der Differenzierung von Politik und Ökonomie entstand, was zugleich eine Differenzierung zwischen Staat und Gesellschaft bedeutete.

Der Krieg ist als ein historisch und an die sozialen Verhältnisse gebundenes Phänomen zu begreifen. ${ }^{3}$ Für die Klassifikation des Krieges als soziales Phänomen spricht auch, dass er keinesfalls ein bloßes Instrument darstellt, das den Krieg führenden Staaten, den Sozialitäten äußerlich bliebe. Reemtsma weist darauf hin, dass der Krieg die Gesellschaften nicht nur von seinem Ausgang her transformiert. Ob Sieg oder Niederlage am Ende stehen, der Krieg selber transformiere die Sozialitäten. »Wer Krieg verstehen will, muss die Vorstellung vom Krieg als einem Instrument, das man gleichsam aufnehmen und nach Gebrauch wieder weglegen kann, aufgeben. Der Krieg ist selber ein Gesellschaftszustand, und eine Gesellschaft, die Krieg führt, tritt in einen anderen Zustand ein.« (Reemtsma 1996: 353)

2 Beispiele für derartige Ritualisierungen lassen sich z.B. in dem Aufsatzband »Der Krieg«, herausgegeben von Fried und Murphy, finden. Mehr aus militärhistorischer Perspektive zeigt Keegan (1995), wie abhängig von der Kultur der sich jeweils im Krieg befindlichen Gesellschaften die Ziele, die Mittel und die Dynamiken von kriegerischen Aktivitäten sind.

3 Zum Verhältnis der Geschichtswissenschaften zum Militär und Krieg: siehe Krumeich und Pröve (2000). 
Das gilt auch für Gesellschaften, in denen ein spezifischer Sozialverband, das Militär, als ein Instrument zur Kriegführung erachtet wird. Man mag zwar das Militär als ein Machtinstrument der Politik begreifen, doch zur Ausübung von Gewalt haben die Angehörigen des Militärs, die Soldaten, nicht nur ein instrumentelles Verhältnis. Sie müssen, vor allem wenn ihr Einsatz verlangt, dass sie unmittelbar gewalttätig handeln, ihr Leben an ein »Milieu des Tötens« (ebd.) anpassen. Zu denken ist dabei zum Beispiel an die zahlreichen Formen der Entwertung des Gegners, die die Vorstellung zurücktreten lassen, dass es sich auch bei den Gegnern um Menschen handelt. Ihre zweite Adaptionsleistung besteht darin, dass sie sich an ein Leben in Todesgefahr gewöhnen müssen (354). Weder könnten die Soldaten die Adaptionen von einen auf den nächsten Tag leisten, noch könnten sie diese von einem Tag auf den anderen wieder ablegen. Der instrumentelle Einsatz des Krieges scheitere letztlich an dem Umstand, dass er von Menschen geführt wird, die sich nicht einfach wie eine Maschine wieder abstellen lassen.

\subsection{Die westdeutsche Soziologie und der Krieg}

Wer annimmt, dass die Soziologie sich in einem ähnlichen Umfang wie die Politikwissenschaften mit dem Krieg befasst, wird enttäuscht sein. Die Zahl soziologischer Arbeiten zum Thema Krieg und Militär verharrt auf einem niedrigen Niveau. ${ }^{4}$ Die Erwartung, dass das zeitgeschichtliche Geschehen der vergangenen Jahre hieran etwas geändert hätte, wird ebenfalls enttäuscht. Stärker als die militärische Gewalt ist es die unorganisierte und anomische Gewalt, etwa von Jugendlichen in verwahrlosten Vorstädten, die Neugierde weckt. Beiträge zur sozialwissenschaftlichen Militärforschung lassen sich dagegen vor allem an den Rändern der Disziplin finden, von wo aus sie auf Nachbardisziplinen übergreifen. Insgesamt hat deshalb der Satz des Soziologen Trutz von Trotha nichts an Gültigkeit verloren, dass Krieg und Militär ein von den Sozialwissenschaften »schändlich vernachlässigtes Gebiet« (Trotha 1997: 36) sind. Eine Literaturrecherche in der Deutschen Bibliothek in Frankfurt am Main ergab, dass 24.666 Treffer der Sachgruppe Militär angehören. Davon werden 5.386 Erwähnungen der Politik und lediglich 1.047 der Soziologie zugeschlagen. ${ }^{5}$

4 Die geringe Zahl soziologischer Arbeiten zum Krieg bedeutet allerdings nicht, dass diese unbedeutend seien. Militärsoziologische Publikationen gibt in der Bundesrepublik insbesondere das Sozialwissenschaftliche Institut der Bundeswehr (SOWI) heraus. Mitarbeiter des Instituts haben beispielsweise eine informative Gesamtschau der internationalen Forschungslage (Kümmel/Prüfert 2000) und auch ein Handbuch zur Militärsoziologie verfasst (Leonhard/Werkner 2005).

5 Bei diesen Zahlen bleiben Mehrfachnennungen z.B. durch eine erneute Auflage des Buches unberücksichtigt. Die 1.047 Titel verteilen sich auf den 
Die meisten soziologischen Theorien gehen von der Annahme aus, dass sich die Industriegesellschaft - ihr bevorzugtes Erkenntnisobjekt durch ihr friedliches Wesen gegenüber anderen Gesellschaftsformen auszeichnet. Diese Annahme, die keineswegs immer expliziert wird, rechtfertigt, dass man das Militär und den Krieg systematisch nicht beachtet. Sie werden als Relikte eingestuft, wenn auch als überaus zähe Relikte, die aber, so die Hoffnung, durch das weitere Voranschreiten der Industriegesellschaft in allen Teilen der Erde unbedeutender werden würden. ${ }^{6}$

Mit Blick auf die in der Bundesrepublik dominanten Modernisierungstheorien stellt dagegen Joas fest, dass »Krieg und Gewalt [...] Teil der Moderne und nicht nur ihrer Vorgeschichte« (2000: 67) sind. Er plädiert dafür, »die selbstzufriedene Identifikation von Modernisierung und abnehmender Wahrscheinlichkeit des Krieges aufzusprengen« und »die Suche nach den Bedingungen des Friedens mit einer illusionslosen Analyse auch spezifisch moderner Tendenzen zum Krieg zu verbinden.« (84) Auch Knöbl und Schmidt stellen fest, dass »die innere Widersprüchlichkeit, die Janusköpfigkeit der Neuzeit [...] in weiten Teilen der gegenwärtigen Gesellschaftstheorie keinen angemessenen Niederschlag gefunden« habe (2000: 7). Wie in den 80er Jahren, als in großen gesellschaftstheoretischen Entwürfen von Habermas und Luhmann eine eingehende Auseinandersetzung zum Krieg fehle, stünden nicht wenige Sozialwissenschaftler »nach wie vor in der friedlich-utopischen Stimmung der europäischen Aufklärung, träumen immer noch den liberalen >Traum von der gewaltfreien Moderne - eine Perspektive, aus der sich Krieg leicht als extreme Ausnahme, als vorübergehende Störung des zivilisatorischen Gleichgewichts abtun, mithin ad acta legen lässt.« (7f.)

Selbst in der Militärsoziologie spielt der Krieg eine eher untergeordnete Rolle. Da sie sich ihm weitgehend über institutionelle und organisatorische Probleme des Militärs nähert, trat er in den vergangenen Jahrzehnten zeitweise sogar völlig in den Hintergrund. Dies gilt nicht zuletzt für die bundesdeutsche Militärsoziologie, die fast ihre ganze Aufmerksamkeit den Problemen innerhalb der bundesdeutschen Militärorganisation und deren

Zeitraum zwischen 1982 bis 2003 und schwanken in den vergangenen zehn Jahren zwischen 78 (1994) und 27 (2003). Unberücksichtigt bleibt auch, aber erwähnenswert ist, dass einige Bücher, die in dieser Arbeit als soziologische Werke eingeschätzt werden, nicht in der Sachgruppe Soziologie rubriziert sind. Die Zahlen geben also nur eine ungefähre Gewichtung wieder. 2003 wurde die Systematik der Sachgruppen geändert. Seitdem wird zwischen den Sachgruppen Militär und Sozialwissenschaften unterschieden. Diesen beiden Sachgruppen wurden 2005 kein einziger Titel und 2006 lediglich zwei Titel zugeordnet.

6 Wie systematisch der Krieg über Jahrzehnte hinweg außerhalb des Blickfeldes der Soziologie blieb, zeigt das Register des von René König herausgegebenen Lexikons Soziologie (1974) an. Es wurde allein zwischen 1958 und 1974 in einer Auflage von 367.000 Exemplaren verlegt. Der einzige Eintrag zum Stichwort Krieg weist auf einen Nebensatz in einem Artikel hin. 
Soldaten schenkte. Der Atomkrieg, der für Europa bis Mitte der 80er Jahre als das wahrscheinlichste Kriegsszenario galt, bot der Militärsoziologie wenig Anreiz, sich mit dem Krieg eingehender zu beschäftigen. Sofern der konventionelle Kriegseinsatz behandelt wurde, dann galt die Aufmerksamkeit überwiegend den Streitkräften der USA. Mit den Auslandseinsätzen der Bundeswehr und der Beteiligung ihrer Soldaten an Kampfhandlungen ist freilich der Krieg zu einem stärker gewichteten Thema der bundesdeutschen Militärsoziologie geworden.

Wie bereits René König 1968 bemerkte, wird die Militärsoziologie »als eine Art angewandte Betriebssoziologie« verstanden (1968: 9). Über sie hängt bis heute das Verdikt von Wachtler, dass sie eine Soziologie für den Dienstgebrauch sei (1983: 12). Auch Warnungen, wie von Friedeburg und Brandt, dass damit eine »Perpetuierung des esoterischen Charakters von Militärpolitik« fortgeschrieben werde, »womit ein Stück Arkanpraxis« der vorbürgerlichen Epoche bis in die Gegenwart reiche, verhallten über Jahrzehnte weitgehend ungehört (1966: 11). Entscheidend für die Ausrichtung der Militärsoziologie, wie sie beispielsweise vom Sozialwissenschaftlichen Institut der Bundeswehr (SOWI) betrieben wird, ist das Erkenntnisinteresse des »Bedarfsträgers«, des Bundesministeriums für Verteidigung. Dieser Bedarfsträger hat, wie der damalige Direktor des SOWI, Geppert, betont, kein Interesse an einer Wissenschaft, die das Erkenntnisobjekt selber in Frage stellt. Das Selbstverständnis, der am Institut arbeitenden Sozialwissenschaftler müsse allerdings nicht mit dieser Einschränkung identisch sein und sie können sich das Recht auf »Nachdenklichkeit« (1998: 19) vorbehalten. Kritische Beiträge seien auch in gewissem Umfang im Interesse der Behörde, weil sie als >Frühwarnsystem` wirken können (ebd.: 21). Grundsätzlich richtet sich aber das Erkenntnisinteresse an den Problemstellungen aus, die innerhalb des Militärs, z.B. durch veränderte Einsatzziele, entstehen und die von Außen an das Militär, häufig als Akzeptanzprobleme formuliert, herangetragen werden.

Für diese Ausrichtung der Militärsoziologie ist freilich nicht allein das Interesse des >Bedarfsträger`verantwortlich zu machen. Unberücksichtigt blieben bei einer solchen Sicht die spezifisch deutschen Gründe, die dafür sorgten, dass die Militärsoziologie eine äußerst marginale Rolle in der Soziologie spielt.

Man kann wohl behaupten, dass nach dem 2. Weltkrieg in der Bundesrepublik eine intensive Auseinandersetzung mit den Themen Krieg und Militär auf die wenigsten Sozialwissenschaftler attraktiv wirkte. Während in den USA später führende Soziologen, wie z.B. Edward A. Shils und Morris Janowitz, ihre empirischen Studien, die sie im Laufe des Krieges für die US-Streitkräfte erhoben hatten, abschlossen, fand in der Bundesrepublik keine entsprechende Forschung statt. Nicht der Krieg und das Militär, sondern seine Folgen für die Familie und die Jugend gehörten, wie die Integration von Flüchtlingen und Kriegsheimkehrern, zu den Studien- 
objekten der deutschen Soziologie. Darüber hinaus standen betriebssoziologische Untersuchungen, die versuchten, die umfassenden Veränderungen in der Arbeitswelt zu erfassen, im Mittelpunkt des Interesses. Das Desinteresse an den Themen Militär und Krieg hielt auch an, nachdem in den 50er Jahren die Wiederaufrüstung beschlossen wurde. Sofern militärsoziologische Arbeiten erstellt wurden, ging es in diesen unter Anknüpfung an die Arbeiten aus dem angloamerikanischen Raum, neben der Sozialpsychologie von Soldaten, vor allem um die Frage, wie die Akzeptanz des Militärs in der >Industriegesellschaft` erhöht werde kann. Für »weiterreichende Informationen über gesellschaftliche Entstehungs- und Wirkungszusammenhänge von Streitkräften« (Wachtler 1983: 10) waren diese Arbeiten ungeeignet. Möglicherweise lässt sich diese anhaltende Abstinenz gegenüber dem Krieg und dem Militär mit Schivelbusch (2001) als eine spezifische Reaktion auf die Niederlage im 2. Weltkrieg werten, als eine spezifische Ausprägung einer >Kultur der Niederlage $\prec$. Der Abbruch der eigenen Traditionslinien wie der historischen Soziologie und das gleichzeitige Zurücktreten philosophischer Reflexionen für die Theoriebildung $^{7}$ bedeuteten demnach nicht nur, eine große Distanz zum Nationalsozialismus und dem verlorenen Krieg zu halten. Er bedeutete gleichzeitig auch, dass es nun galt, vom `Sieger zu lernen`, dessen Vorstellungen, Praxis und Theorie das Modell zur geistig-kulturellen Revitalisierung und Regeneration abgeben sollte (siehe hierzu Schivelbusch 2001: 46f.). Folgenreich ist in diesem Zusammenhang die weit verbreitete Vermutung, es gebe eine Affinität zwischen Forschenden und Forschungsgegenstand. Sie minderte die Neigung sich mit den Themen Militär und Krieg zu beschäftigen. (Wachtler 1983: 9). ${ }^{8}$

Wie oben bereits angedeutet, ist das Desinteresse an Krieg und Militär kein alleiniges Spezifikum der deutschen Soziologie. Man kann höchstens sagen, dass es bei ihr seit dem 2. Weltkrieg besonders ausgeprägt ist. Um das allgemeine Desinteresse zu verstehen, ist es sinnvoll, auf ein Erbe aus der Aufklärung und der Sozialphilosophie hinzuweisen. Aufklärung und

7 Die »sinnfälligste Tendenz in der deutschen Soziologie nach dem Krieg«, so Adorno 1959, sei »die Zuwendung zu den Methoden« der Empirical Social Research »und das Zurücktreten der Theorie, die vor der Katastrophe für Deutschland charakteristisch war« (1959: 501). In ihrem Bemühen »ihre Methoden soweit wie möglich dem quantifizierenden und klassifizierenden Verfahren der Naturwissenschaften« anzugleichen (ebd.: 502), drücke sich auch ein »gewisses Bedürfnis« aus, »die Amerikaner womöglich zu überamerikanisieren, während umgekehrt diese selber heute bereits zur kritisch-philosophischen Reflexion der Soziologie tendieren.« (Ebd.: 503)

8 Wer sich trotzdem der Erforschung des Militärs zuwendet, riskiert, so Wachtler, seine Berufschancen zu verschlechtern (ebd.). Es ist obendrein nicht sonderlich attraktiv in einem Bereich zu arbeiten, in dem der Auftraggeber womöglich plötzlich ein Publikationsverbot für empirische Ergebnisse erlässt, weil er befürchtet, der Gegner könnte aus ihnen einen Nutzen ziehen (siehe auch König 1968: 9). 
späterhin der Fortschritt und die Moderne $^{9}$ teilen miteinander eine Entdeckung: Die Verhältnisse, in denen Menschen leben, sind nicht natürlich, sondern durch menschliches Handeln beeinflussbar. Sie sind also veränderbar und können durch eine andere, bessere Ordnung ersetzt werden. »Die Entdeckung, dass Ordnung nicht natürlich ist, war die Entdeckung der Ordnung als solcher. Der Begriff der Ordnung trat gleichzeitig mit dem Problem der Ordnung ins Bewusstsein, der Ordnung als einer Sache von Entwurf und Handlung. Ordnung als Obsession.« (Bauman 1995: 18; kursiv i.O.) Bedroht wird die Ordnung von ihrem Gegensatz, dem Chaos, das immer die mühselig aufgerichtete Ordnung hintertreibt oder gar umwirft, zerstört. Als Sinnbild wie auch in der real sich vollziehenden Geschichte ist es gerade der Krieg, der als Ferment des Chaos' immer wieder in Erscheinung trat. Konnte noch unter aristokratischer Herrschaft der Anlass und der unvorhergesehene Verlauf eines Krieges leicht als Ergebnis vorbürgerlicher, überholter politischer Praktiken interpretiert werden, die noch nicht in ausreichendem Maße der Aufklärung unterworfen waren, fielen mit der Durchsetzung der bürgerlichen Gesellschaft derartige Argumentationen immer schwerer. Denn wenn sich das Kriegführen trotz aller Bemühungen auch unter bürgerlichen Vorzeichen nicht wie ein technisches Mittel einsetzen lässt, mit Irrationalitäten durchsetzt und unvorhersehbar bleibt, wenn also alle Versuche der >Einhegung ‘ scheitern, in welcher Beziehung steht dann der Krieg zur bestehenden bürgerlichen Gesellschaftsordnung? Auf diese Frage wurden unterschiedliche Antworten gegeben. In der Tendenz liefen sie aber häufig auf eine Abspaltung des Krieges vom Projekt der Aufklärung, des Fortschritts und der Moderne hinaus. Es fällt auf, wie groß bis in die Gegenwart die Neigung ist, jeden Krieg, dessen Verlauf als unlogisch, irrational oder verwirrend charakterisiert wird, mit einer veralteten historischen Epoche zu identifizieren und, wenn dies nicht möglich ist, weil die Kriegsparteien als moderne allzu kenntlich sind, auf eine Anlage der menschlichen Gattung zurückzuführen.

In der Soziologie war dieses Erbe von Beginn an sehr wirksam. In den meisten theoretischen soziologischen Entwürfen von Gesellschaft gibt es zumindest keinen systematischen Platz für das Militär. Auch praktisch konzentriert sich die Soziologie weitgehend auf zivile, nichtmilitärische und häufig auch nichtstaatlich/staatsferne soziale Phänomene. Bereits $\mathrm{Au}-$ guste Comte und Herbert Spencer vertraten die Auffassung, dass die aufziehende Industriegesellschaft den kriegerischen Charakter der vorausgegangenen Epoche der >militant society` (Spencer) überwinden werde. »Die evolutionistische Annahme eines unaufhaltsamen Verschwindens der

9 Obwohl die drei Begriffe nicht das gleiche Bedeutungsfeld abdecken, ist gegenwärtig der Begriff der Moderne weitgehend an die Stelle der anderen Begriffe getreten. So ist die Rede von der Aufklärung fast gänzlich aus der sozialwissenschaftlichen Sprache verschwunden und führt allenfalls ein Kümmerdasein in der Pädagogik. 
>militant society< mag uns heute als unglaublich optimistisch erscheinen, für das sozialwissenschaftliche Denken des 19. Jahrhunderts, vornehmlich in England und den USA, aber kommt diesen Annahmen eine repräsentative Bedeutung zu.« (Joas 2000: 193) Zwar teilen mitnichten die Begründer und zahlreiche Vertreter der deutschen Soziologie die Auffassungen von Comte und Spencer, - und im Denken beispielsweise Werner Sombarts und Max Webers kam dem Krieg sehr wohl eine wichtige Bedeutung zu doch ist die These Michael Manns, es gäbe eine unterdrückte bzw. verleugnete militaristische Tradition in der (deutschen) Soziologie, »der zufolge Krieg und Rüstung als normale, ja wünschenswerte gesellschaftliche Tätigkeit aufzufassen sind« (ebd.: 205), zu widersprechen. Joas verweist hierzu auf die Heterogenität der Denkansätze, zu denen er unter anderem verschiedene Spielarten des Sozialdarwinismus, den existenziellen Bellizismus eines Georg Simmel und die historische Soziologie Otto Hintzes zählt (ebd. 204f.). Die Heterogenität »sei viel zu groß, als dass sie unter eine nicht- oder antiliberale >militaristische< Tradition subsumiert werden könnten.« (235) Unumstritten ist, dass nach dem 2. Weltkrieg eine Anknüpfung an Theorienbestände, die sich mit dem Krieg auseinander setzten und ihm gar einen wichtigen positiven Einfluss auf die Gesellschaft zusprachen, tunlichst vermieden wurde. In der Bundesrepublik gelang dies, in dem »bei ihrer Kanonisierung zu Klassikern der Soziologie das Werk von Max Webers lange Zeit« ebenso wie »das von Georg Simmel bis heute nur fragmentarisch und unter Ausblendung mancher historischer Untiefen angeeignet wurden.« (Joas 2000: 235) Gleichzeitig vollzog sich eine Hinwendung zu Theorien in denen gefragt wird, wie eine nicht Krieg führende Gesellschaft funktioniert und was sie zusammenhält. In der Hinwendung zu dieser Fragestellung unterscheidet sich die bundesrepublikanische Soziologie kaum von den Trends in anderen Ländern.

Wie stark die Neigung zur Abspaltung des Krieges vom Projekt der Moderne ist, demonstriert gerade eine soziologische Theorie, die dem Krieg eine eminent wichtige Stellung einräumt. Gemeint ist die Theorie von Norbert Elias zur Herausbildung der >abendländischen`Zivilisation, die in den 80er Jahren eine Renaissance erlebte und noch heute das Bild dessen, was Zivilisation meint, beeinflusst. Die wesentliche Dynamik, die den Prozess der Zivilisierung vorantreibt, sieht Elias in den Konkurrenzund Ausscheidungskämpfen zwischen zahlreichen kleinen Herrschaftseinheiten Westeuropas. Von diesen Kämpfen sei ein Zwang zu immer größer werdenden Einheiten ausgegangen hin zum Territorialstaat. Die Zivilisierung beruhe, beginnend mit der Oberschicht, auf anwachsenden Sozialverbänden und damit einhergehenden immer komplexer werdenden Verflechtungen unter den einzelnen Gesellschaftsmitgliedern sowie auf ihrer Angewiesenheit auf das Wohlwollen der herrschenden Autorität(en). Durch die Verlängerung der Handlungsketten habe niemand mehr überblicken können, welche Folgen unüberlegtes Handeln, also ein Handeln, 
das durch unmittelbare Affekte bestimmt ist, auf seine Stellung innerhalb des Sozialverbandes und letztlich in der Gunst der Herrschenden zeitige. War »der Kampffuror [...] eine notwendige Voraussetzung des Erfolgs und des Prestiges für den Mann des Adels«, bestrafte der veränderte Aufbau der Gesellschaft »jetzt Affektentladungen und Aktionen ohne entsprechende Langsicht mit dem sicheren Untergang.« (Bd. 2, 1981: 382f.) Von der Fähigkeit, die eigenen Affekte zu kontrollieren und die sich herausbildenden Regeln im Umgang miteinander zu beherrschen, hing im zunehmenden Maße der Erfolg und die gesellschaftliche Stellung des Gesellschaftsmitglieds ab. Die Kämpfe zwischen den feudalen Herrschaften, so Elias, lösten eine Bewegung zugunsten individueller Selbstzwänge aus, die die Bedeutung sozialer Fremdzwänge zurücktreten lasse. Diese Dynamik markiere den Beginn des abendländischen Zivilisationsprozesses. Eine ähnlich positive Erwartung hegt er an den Krieg zwischen den Staaten. In Analogie sollten diese Kämpfe zur »Bildung von Gewaltmonopolen über größere Teile der Erde und damit, durch alle Schrecken und Kämpfe, zu deren Pazifizierung weiterdrängen« (Bd. 2, 1981: 452). Am Ende der zwischenstaatlichen Kriege stünde die Aufrichtung eines »irdischen Gewaltmonopols, eines politischen Zentralinstituts der Erde« (ebd.). Obwohl diese Theorie Kontingenzen nicht kategorisch ausschließt, sie also keine Linearität notwendig beinhaltet, werden ausbrechende Kriege tendenziell als nicht zum erreichten Niveau der Zivilisation gehörig gezählt. Krisen des Zivilisationsprozesses werden im Wesentlichen auf unzivilisierte Motive der Handelnden und auf ihre vorgeblich vormoderne Gesinnung zurückgeführt. Neben generellen Zweifeln, die sich z.B. gegen die teleologische Implikation seiner Theorie richten und ihr eine Überbewertung des staatlichen Gewaltmonopols bei gewaltfreien Konfliktregulation innerhalb von Sozialitäten vorwerfen (siehe hierzu u.a. Dinges, Althoff und Duerr), bleibt im Rahmen Elias' Zivilisationstheorie ausgeklammert, in welchem Ausmaß die Akteure aufgrund ihrer Zivilisierung zur modernen Kriegführung befähigt sind. »Die Abrichtung zum Soldaten« erscheint bei Elias lediglich als eine »staatlich induzierte und gesteuerte, in der Regel temporäre und auf einen Teil der männlichen Bevölkerung begrenzte Regression auf ein niedrigeres Zivilisationsniveau.« (Bröckling 1997: 16)

\subsection{Soziologie des Krieges}

Um die Militärsoziologie aus ihrer Beschränkung auf eine Organisationssoziologie herausführen, die Gefahr läuft, das Phänomen aus den Augen zu verlieren, von dem die Organisation Militär geprägt wird, forderte 1968 René König eine Soziologie des Krieges. »Militärsoziologie ohne Soziologie des Krieges muss auf die Dauer eine unbefriedigende Tätigkeit bleiben.« (1968: 12) In jüngerer Zeit ist diese Forderung erneuert worden, 
nun aber mehr mit Blick auf die Modernisierungstheorien. Wenn die Soziologie »nicht den Wirklichkeitsbezug verlieren« (2000: 22) wolle, so Knöbl und Schmidt, müsse sie den Krieg in gesellschaftstheoretischen Entwürfen berücksichtigen. Nur eine Soziologie des Krieges könne die Aufspaltung zwischen Barbarei und Moderne verhindern und angemessen die Frage nach dem Anteil der Moderne an dem Phänomen des Krieges stellen. Die Reaktionen auf diese Forderung sind als verhalten zu bezeichnen. Auch dass die Bundesrepublik Deutschland im letzten Jahrzehnt in verschiedenen Kriegen direkt mit dem Einsatz von Truppen intervenierte, hat daran kaum etwas ändern können. Noch am signifikantesten hat sich die Stellung der Militärsoziologie im universitären Lehrbetrieb verändert, da sie vor ein paar Jahren erstmals an einer Universität (Potsdam) zum festen Bestandteil des Hauptstudiums Soziologie wurde. Ab dem Wintersemester 2007/8 wurde hier obendrein ein Masterstudiengang Military Studies mit den Schwerpunkten Militärgeschichte und -soziologie eingerichtet. Die militärsoziologischen Veranstaltungen werden vorwiegend von Mitarbeitern des Sozialwissenschaftlichen Instituts der Bundeswehr durchgeführt. Mit diesem Studienangebot werde, so das Institut auf seiner Internetseite, auf den markant gestiegenen Bedarf »an umfassend ausgebildeten Absolventen mit militärhistorischen, militärsoziologischen und sicherheitspolitischen Kenntnissen außerhalb und innerhalb der Streitkräfte $\ll$ reagiert. ${ }^{10}$

Im Grunde wird in der Soziologie, wie in der gesamten Gesellschaft, eine Haltung eingenommen, die einem »Militarismus als Zuschauersport« (Mann 2000: 42) gleichkommt. Seit 1945 ist demnach die Hauptform des Militarismus in Europa keine gelebte Haltung, sondern eine passiv konsumorientierte. ${ }^{11}$ Dies schließt nicht aus, dass in Krisensituationen, besser gesagt, wenn es in der öffentlichen Wahrnehmung zu einer solchen kommt, sich die eher indifferent verhaltenden Zuschauer in ein Publikum verwandeln, das versucht, in das Geschehen durch leidenschaftliche Artikulationen einzugreifen. Dieses Publikum kann, unabhängig ob es nun die militärische Interventionen ablehnt oder zustimmt, zu einem zumindest kurzzeitig wirksamen Faktor bei außenpolitischen Entscheidungsprozessen werden.

10 Siehe Artikel »Kooperation« Online: http://tinyurl.com/yvcpby; Zugriff: 15.10.07.

11 Dass diese Haltung auch in der Geschichte anzutreffen ist, lässt sich beispielsweise bei Goethe nachlesen. In Faust I legt er einem Bürger nachstehende Worte in den Mund: »Nichts Bessers weiß ich mir an Sonn- und Feiertagen - Als ein Gespräch von Krieg und Kriegsgeschrei, - Wenn hinten, weit, in der Türkei, - Die Völker auf einander schlagen. - Man steht am Fenster, trinkt sein Gläschen aus - Und sieht den Fluß hinab die bunten Schiffe gleiten; - Dann kehrt man abends froh nach Haus - Und segnet Fried und Friedenszeiten.«(1808: 163f.) 
Die in der Bundesrepublik von Seiten einiger Soziologen vorgetragenen Forderung nach einer stärkeren Berücksichtigung der Bedeutung von Gewalt und Krieg ist im Zusammenhang mit der größeren Rolle zu sehen, die der Einsatz des Militärs in der bundesrepublikanischen Außenpolitik seit Anfang der 90er Jahre spielt. Mehr noch als in anderen führenden westlichen Staaten - zu denken ist dabei vor allem an die USA, Großbritannien und Frankreich - wurde in der Bundesrepublik der konventionelle Krieg bevorzugt als Scheitern und Ende von Politik wahrgenommen. Im Rahmen der gegenseitigen Abschreckung sollte der Aufbau von Streitkräften und ihre Ausstattung mit den jeweils modernsten Waffen den Gegner >lediglich` daran hindern, sein konventionelles Militär einzusetzen. In einem Land, in dem das Umschlagen des kalten in einen heißen Krieg höchstwahrscheinlich die menschlichen Lebensgrundlagen zerstört hätte; in einem Land, das zugleich aufgrund seiner Verantwortung für zwei Weltkriege nur Militär für eben die Austragung der Blockkonfrontation in Europa aufstellen durfte, sollte der Satz Clausewitz': »Der Krieg ist eine bloße Fortsetzung der Politik mit anderen Mitteln« (Clausewitz 1832: 210) nicht mehr gelten.

Seit Anfang der 90er Jahre haben sich zahlreiche Politiker in führenden Positionen und auch Offiziere in leitenden Funktionen stark für eine Neubewertung des Militärs als legitimes Mittel außenpolitisches Handelns gemacht und dabei wiederholt betont, dies schließe die Möglichkeit ein, dass die Bundeswehr Kriegseinsätze mit hoher Kampfintensität durchführe müsse (siehe z.B. Bundesministerium für Verteidigung 2003: 25f.). Wenn es auch bislang zu keinem Kriegseinsatz mit hoher Kampfintensität gekommen ist, so lässt sich doch feststellen, dass die Bundesrepublik neben Peacekeeping-Einsätzen sich auch mit eigenen Truppen an Kriegen beteiligte bzw. beteiligt (Kosovo 1999, Afghanistan seit 2003). Was in der Bundesrepublik aber als Novum und Renaissance des Militärs nach dem Ende des Kalten Krieges erlebt wurde, gilt für andere westliche Industriestaaten, die ihre Streitkräfte auch nach dem Ende des 2. Weltkrieges wiederholt außerhalb Europas einsetzten, allenfalls eingeschränkt. So verzichteten die USA, Großbritannien und Frankreich nie darauf, ihr Militär als probates außenpolitisches Instrument zu betrachten und deshalb kann bei ihnen von einer Tendenz zur Militarisierung der Außenpolitik allenfalls in einem graduellen Sinne gesprochen werden. Aus diesem Blickwinkel hat die Bundesrepublik in den vergangenen Jahren einen Anpassungsprozess an das in den anderen führenden westlichen Industriestaaten snormale` Verhältnis zum Militär und Krieg vollzogen.

Vor diesem Hintergrund stellt sich auch die Frage nach der Ausrichtung einer Soziologie des Krieges. Denn es bedarf wohl kaum einer Soziologie, die an bellizistische oder sozialdarwinistische Haltungen anknüpft, wie sie in Deutschland vor dem 2. Weltkrieg en vogue waren. Es bedarf sicher keiner Soziologie, die den Krieg zum Zentrum alles Sozialen 
erklärt. Ebenso kann auf Sinndeutungen verzichtet werden, wie sie Hondrich Anfang der 1990er Jahre präsentierte, als er die Auffassung vertrat, Kriege würden eine sinnvolle Lernlektion für Kollektive bilden. Der Krieg als Lehrmeister für Kollektive zeige ihnen, und dem individuellen Ich, dass »das individuelle Leben nicht das höchste Gut ist« (Hondrich 1992: 42) und halte für sie die Erfahrung bereit, in denen soziale (affektive) Verbindungen und Zusammenhalte gestiftet, aber auch zerrissen werden (ebd.: 43). Sinn mache der Krieg, weil es ohne ihn kein Lernen gebe, das auf eine friedfertige Weltgesellschaft hinführe (ebd.: 9). Die Frage, ob jedem erlittenen Schaden bereits ein Telos zum Besseren innewohnt, kann im Rahmen einer solchen Sinndeutung gar nicht erst formuliert werden. Geradezu ignoriert wird die Frage, ob es nicht genug Erfahrungen mit dem Kriege gegeben hat, so dass weitere Lernlektionen eigentlich überflüssig sein dürften. Und: Es ist eine Sache festzustellen, dass es Menschen immer wieder gelingt, selbst den schrecklichsten Erfahrungen positive Konsequenzen für ihr Leben abzuringen, eine andere ist es, diese Schrecken selber als sinnvoll zu legitimieren.

Gerade in Zeiten einer militarisierten Außenpolitik ist eine akzentuierte und kritische Auseinandersetzung der Soziologie mit dem Zusammenhang von Moderne und Krieg dringend geboten. Eine solche Ausleuchtung wird ihr wohl nur gelingen, wenn sie von einer historisch geleiteten Definition dessen ausgeht, was gegenwärtig Krieg genannt wird. Kriege hat es demnach nicht schon immer gegeben. Sie sind, entgegen allen Verdächtigungen, keine Relikte vormoderner Zeiten. Sie müssen ebenso wenig als ein ewiges Verhängnis der Menschheit aufgefasst werden. Ohne dass sich etwas an der konstitutionellen Fähigkeit des Menschen zum aggressiven Handeln ändern müsste, ist der Krieg an eine spezifische historische und damit auch an eine veränderbare soziale Organisationsform gebunden. Für die gegenwärtige Form des Krieges gilt, dass sie eng mit der Herausbildung des neuzeitlichen Territorialstaates verbunden ist.

Eine Soziologie, die den Krieg als vormodernes Phänomen erachtet oder schlicht so tut, als hätte er nichts mit modernen Gesellschaften zu tun, neigt dazu, die gewaltfördernden Potenzen der Moderne zu unterschätzen. Als damit letztlich unbegriffene Phänomene geraten dann die stattfindenden Kriege zu Schicksalsschlägen, werden z.B. auf biologisch bedingte menschliche Verhaltensmuster oder antiquierte Sozialverhältnisse zurückgeführt. Die Soziologie beraubt sich damit der Möglichkeit, den Anteil moderner Gesellschaftsverhältnisse am Phänomen Krieg zu analysieren und vice versa. Aber ohne eine solche Analyse lassen sich weder die Gefahren noch die Chancen gegenwärtiger Sozialprozesse erkennen und erst Recht nicht beeinflussen. Im Kontext solcher soziologischen Analysen besteht gleichzeitig nicht der Zwang, den Krieg zu einem konstitutiven Element moderner industrieller, kapitalistischer Gesellschaften zu erklären. Vielmehr wäre er als ein Ergebnis auch von solchen sozialen Prozessen 
aufzufassen, die die Gesellschaft als moderne kennzeichnen. Mehr nicht, aber auch nicht weniger. Oder anders ausgedrückt: Mitunter mag es gelingen, den Krieg theoretisch abstrakt aus dem Kontext moderner Gesellschaften auszublenden. Historisch-konkret aber war und ist er mit ihnen zumindest amalgamiert. Wie dies zu verstehen ist, soll an einem Beispiel aus den Wirtschaftswissenschaften verdeutlicht werden. Zwar hatte auch die Soziologie in Gestalt der Theorien Auguste Comtes und Herbert Spencers schon früh die Auffassung vertreten, dass der Krieg und das Militär in einer voll entfalteten Industriegesellschaft überflüssig seien. An diesen Auffassungen knüpft jedoch heute kaum noch jemand an. Anders dagegen verhält es sich mit den Überlegungen Schumpeters, der sich wiederum an Adam Smith anlehnte. Schumpeter vertrat nach dem 1. Weltkrieg die These, der Imperialismus und damit der vorausgegangene Krieg beruhe auf »Kampfinstinkten und Ideen von Herrschaft, auf Mannesherrlichkeit und Siegesglanz am Leben« (1919: 146). Sie seien vorkapitalistischen und damit atavistischen Ursprungs und widersprachen dem >Geist $\prec$ des Handels und des Kapitals, weil jeder Krieg den Freihandel stören würde. Allgemeiner Freihandel, den er für das originäre Ergebnis kapitalistischer Entwicklung hielt, würde deshalb zur friedlichen Beziehung zwischen kapitalistischen Staaten führen. Nicht die industriell-kapitalistische Transformation der Gesellschaft habe also den Krieg zu verantworten, sondern im Gegenteil: Dass diese die Gesellschaft (noch) nicht vollständig durchdrungen habe, sei für den Imperialismus und damit für Kriege verantwortlich. Schumpeters Überlegung führt zu einer weit reichenden und seitdem auch immer wieder aufgegriffenen Abspaltung des Phänomens Krieg von der kapitalistischen Ökonomie. Seine Annahmen könnte man an verschiedenen Stellen auf ihre Stichhaltigkeit hin befragen, doch soll hier lediglich darauf hingewiesen werden, dass sie nicht zu erklären vermögen, weshalb die vorkapitalistischen Herrschaftsmentalitäten im 20. Jahrhundert virulent blieben. Schlimmer noch, sie blenden völlig aus, dass die inkriminierten Herrschaftsmentalitäten, ob sie nun vorkapitalistischen Ursprungs sind oder nicht, ${ }^{12}$ sich sehr wohl als ausgesprochen kompatibel mit modernen politischen Institutionen gezeigt und wesentlich mit zu ihrer Effektivität beigetragen haben.

Wie bei anderen Soziologien stellt sich auch bei einer Soziologie des Krieges die Frage, welches Verhältnis sie zu ihrem Untersuchungsgegenstand einnimmt. Bereits im Zusammenhang mit der bundesrepublikani-

12 Hieran lassen sich einige Zweifel formulieren. Bereits vor dem 1. Weltkrieg formulierte Sombart die These, dass die militärische Organisation nicht nur das Vorbild für die industrielle Produktion gewesen sei, sondern auch die ökonomischen Voraussetzungen für die kapitalistische Entwicklung geschaffen habe. Die These ist zwar nicht nur in ihrer monokausalen Gestalt eine Übertreibung, jedoch wird sich im Zuge dieser Arbeit zeigen, dass sie nicht jeglicher Substanz entbehrt. 
schen Militärsoziologie wurde angedeutet, wie das Verhältnis zum Erkenntnisobjekt unmittelbar auf mögliche Fragestellungen zurückwirkt. Sofern sich eine Soziologie des Krieges nicht ebenso an den Interessen eines Bedarfsträger orientieren will, der an einer Fortschreibung des Krieges interessiert ist oder ein in welchem Maße auch immer bewusstes, affirmatives Verhältnis zum Krieg entwickeln will, wird im Mittelpunkt des Erkenntnisinteresses letztlich die Abschaffung des Krieges stehen müssen. Dies ist kein hoffnungsloses, eher ein utopisches Anliegen. Zwar ist es ziemlich unwahrscheinlich, dass es zukünftig zu keinen Aggressionen und Gewalttätigkeiten zwischen Menschen kommen wird, doch hängt das, was heute für die Gewalttätigkeiten, den Tod und Zerstörung im Laufe eines Krieges verantwortlich ist, von der Organisationsfähigkeit der Krieg führenden Staaten und von politischen Formierungsprozessen ab. Eine kritische Analyse des Krieges wird - ohne die Janusköpfigkeit der Monopolisierung legitimer Gewaltausübung beim Staat, ihre pazifizierende wie ihre gewaltsteigernde Wirkung zu unterschlagen - mit einem Denkverbot über die gegenwärtige staatliche Verfasstheit des Sozialen unvereinbar sein. 


\section{Soldatische Subjekte - eine Begriffsbestimmung}

\subsection{Können Soldaten Subjekte sein?}

Die Rede von soldatischen Subjekten ist heikel. Sie ist geeignet, gleich in zweifacher Weise zu irritieren und Widerspruch hervorzurufen. Heikel ist der Begriff des Subjekts bereits vor einer Annäherung an das Untersuchungsfeld, weil in der Philosophie und in den Sozialwissenschaften heftig um die Frage gerungen wird, wer oder was ein Subjekt ist und was es vermag. Diese Fragen verlieren nicht an Gewicht, wenn, wie dies hier geschieht, dem Begriff noch das Adjektiv soldatisch vorangestellt wird, um zu kennzeichnen, dass die Bedeutung der Subjektivität von Soldaten im modernen Krieg untersucht werden soll. Dieses Anliegen muss irritieren, weil Soldaten überwiegend als Objekte, Instrumente der Herrschaftsausübung wahrgenommen werden. So konstatiert Seifert, dass sich selbst die Militärsoziologie für den Soldat überwiegend nur in instrumentellen Teilaspekten interessiert, »keineswegs aber als `Subjekt $<$, das sich in umfassender Weise mit seinen Lebens- und Berufsbedingungen, gesellschaftlichen und organisationsspezifischen Einflüssen sowie politischen und ideologischen Veränderungen auseinandergesetzt hat. [...] Wenn zur Frage von >Subjektivität` oder >Identität` in der Militärsoziologie überhaupt empirisch geforscht wurde, dann in aller Regel mit den klassischen Einstellungsvariablen oder psychologischen Begriffen« (Seifert 1996: 16), deren Definitionen unklar bleiben und die »in aller Regel nicht gesellschaftstheoretisch interpretiert oder in einen soziologischen Gesamtzusammenhang eingebettet wurden.« (Ebd.) Innerhalb wie außerhalb der Militärsoziologie werde das Subjekt Soldat als passiv angesehen und »unter >objektive< Organisationsstrukturen subsumiert. Handeln und Denken der in den Strukturen befindlichen Personen sind bestenfalls nachgeordnet.« (Ebd.: 21) 
In dieser Arbeit soll eine andere Betrachtungsweise favorisiert werden. Ihr liegt die These zugrunde, dass soldatisches Handeln im Krieg nicht bloß als Ausfluss des Willens der Vorgesetzten gefasst werden kann. Die Soldaten beteiligen sich nicht nur als passive und leidende Wesen am Kriegsgeschehen. Sie treten auch nicht erst dann als mitbestimmende und das Geschehen mit gestaltende Wesen auf, wenn sie sich den Anweisungen ihrer Vorgesetzten widersetzen. Ihr Handeln in derartige eindeutige dichotome Gegensätze zu fassen, bedeutet, Soldaten eine Beteiligung daran, wie Gehorsam zustande kommt, abzusprechen und davon auszugehen, dass sie keinen ihnen zuzuordnenden Anteil am Kriegsgeschehen haben. Indem soldatisches Handeln als das Handeln von Subjekten gekennzeichnet wird, soll der von den Soldaten ausgehende Anteil am Kriegsgeschehen betont werden. $\mathrm{Zu}$ zeigen, dass mit dieser Charakterisierung soldatischen Handelns nicht zwangsläufig das gegenteilige Extrem zur vorherrschenden Bestimmung postuliert werden muss - also die Behauptung aufgestellt werden muss, Soldaten könnten jederzeit umfassend über ihr Handeln selber bestimmen - ist ein Ziel der nachfolgenden Ausführungen. Sie streben keine Gesamtschau der Debatten zum Subjektbegriff in der Philosophie und den verschiedenen Sozialwissenschaften an. Nachdem die Problemstellung umrissen worden ist, die von der Philosophie mit dem Begriff des Subjekts bearbeitet wird, konzentrieren sich die Ausführungen auf soziologische Theorien, die sich mit dem Für und Wider eines Subjektbegriffs auseinandersetzen. Anschließend soll anhand von handlungstheoretisch geleiteten Überlegungen der Frage nachgegangen werden, wie Soldaten als individuelle Subjekte gefasst werden können.

\subsection{Der Subjektbegriff in der Philosophie und Soziologie}

Welchen Einfluss kann der Mensch als einzelnes Wesen, wie in toto, auf sein Geschick nehmen? Diese Frage trieb bereits vor der Philosophie mythische und religiöse Sinndeutungen um. Wenn auch auf höchst unterschiedliche Weise reflektieren die Antworten auf sie, dass das Geworfensein des Menschen in die Welt kein bloßes Faktum ist. Weder erlebt der Mensch sich selber noch die ihn umgebende Welt als völlig starr, als unveränderlich. Mehr noch: Er erfährt, dass er durch sein eigenes Handeln Einfluss auf sein eigenes Leben und andere Wesen nehmen kann. Diese Erfahrung hat einen höchst beunruhigenden, verunsichernden Aspekt, denn sie bedeutet, dass es falsche und richtige Vorstellungen und Handlungen gibt, solche, die man vermeiden muss, weil sie zu Katastrophen führen können, und solche, die unbedingt zu ergreifen sind, um das Leben und Überleben sicherzustellen. Hier für Sicherheiten zu sorgen, die Mannigfaltigkeit der Interpretationsmöglichkeiten und die Anzahl legitimer Hand- 
lungen zu limitieren, war und ist eine der Aufgaben von mythischen und religiösen und als ihr Erbe auch von wissenschaftlich angeleiteten Weltsichten.

Mit der Aufklärung, also dem allmählichen Bedeutungsverlust der Vorstellung, es gäbe jemanden, der für die Menschen definiere, was wahr und falsch ist und der aktiv in den Weltenlauf eingreift, ist die Dringlichkeit der Klärung, inwieweit der Mensch bzw. die Menschen selber fähig sind, ihr Leben zu gestalten, noch gewachsen. Mit der Entgötterung der Welt wurde die Spezies Mensch zum Produkt und Teil eines Gesamtzusammenhanges, der als natura naturans, als selbstzeugende und selbstbewegende Natur, ${ }^{1}$ bezeichnet wird und der sich dem Menschen als unteleologische, stochastische Ordnungszonen präsentiert, »die sich in gewissem Umfang stabil halten und in denen Strukturen mit bestimmten, recht konstant erscheinenden Merkmalen auftreten können.« (Sieferle 1989: 194) Mit der Aufklärung geht die Last der Verantwortung für den Zustand der Welt, die zuvor, wenn auch in unterschiedlichem Ausmaß, von den Göttern getragen wurde, auf die Menschen über. Inwieweit sie fähig sind, diese Last zu tragen, ob und inwieweit sie erkennen können, was die Welt zusammenhält und ob sie Kraft ihrer Erkenntnisse den Lauf der Dinge bestimmen können, wird in der Philosophie seit dem 17. Jahrhundert in den Debatten über das Begriffspaar Subjekt-Objekt verhandelt. Im Laufe der Philosophiegeschichte wurden mit dem Begriff des Subjekts die unterschiedlichsten Erben für den Nachlass der Götter auserkoren. Unter Objekten werden je nach Entwurf konkrete Gegenstände, belebte wie unbelebte, aber auch Erscheinungen, vorgestellte Gedankendinge (Kant), verstanden. Die Heftigkeit, mit der über die jeweilige Angemessenheit der Bestimmung des Verhältnisses von Subjekt-Objekt gestritten wurde und wird, hängt wesentlich mit der Schwere dieses Erbes zusammen. Oder anders ausgedrückt: Sie stehen alle unter dem Verdacht, gottähnliche Ansprüche an das Subjekt zu postulieren und ihnen gleichzeitig nicht zu genügen. Denn ob das Subjekt als einzelnes menschliches Wesen, als Individuum gefasst wird, das kraft seiner Erkenntnisfähigkeit die ihn umgebende Wirklichkeit durchdringen kann (Descartes), oder als Geist, der in der Gestalt der Vernunft es dem Menschen erlaube, die Welt gottgleich zu erkennen (Hegel) oder ob das Subjekt Gruppen, Organisationen, Institutionen oder Bewegungen darstellt, wie z.B. eine bestimmte Partei oder Klasse, die die Wahrheit immer auf ihrer Seite habe, sie alle unter-

1 Nerlich macht darauf aufmerksam, dass dieser Naturbegriff auf der thomistischen Interpretation beruht, in die Gott nicht (mehr) unmittelbar eingreift. Ihr gegenüber stand der sich an Augustinus orientierte Glaube, der keinen Zufall und keine Fortuna kennt. Gottes Entscheidungen, die dem Sterblichen verborgen sind, sind bei ihm für alle Ereignisse verantwortlich. Aufklärung als Nachdenken über den Zufall und über einen Gott, der nach dem Schöpfungsakt so gut wie tot ist, setzt damit für Nerlich in Westeuropa bereits im 13. Jahrhundert ein (siehe Nerlich 1997: $31 \mathrm{f}$ und 86f.). 
scheiden sich wesentlich von Gott darin und sind deshalb entsprechend kritisierbar, dass ') /der Mensch`, der >Staat allmächtig, noch allwissend, noch allgütig sind.« (Sieferle 1989: 195) Auch wenn für das jeweils postulierte Subjekt nicht der Anspruch erhoben wird, es kenne in einem umfassenden Sinne alle Bedingungen seines Seins, sei von diesen Bedingungen unabhängig und könne sie durch sein eigenes Tun verändern, stellt sich mit umso größerem Gewicht die Frage, wann es dann überhaupt als ein Subjekt gedacht werden kann. Was kann dieses Subjekt erkennen, wo liegen seine Grenzen, das heißt wann fängt es an, ein Objekt zu sein, das unfähig ist, bestimmte Bedingungen seines Seins zu erkennen, diesen Bedingungen stattdessen unterliegt? Für die Bestimmung des Begriffs soldatischer Subjekte sind all diese Fragen unmittelbar relevant. Träger soldatischer Subjektivität sind die einzelnen Soldaten, mithin also die Individuen, deren Objektstatus im Allgemeinen als gesichert gilt.

Dass Soldaten kaum im Ruf von Subjekten stehen, hat gute Gründe, wie ein Blick auf Kants Bestimmung des Subjektsbegriffs zeigt, der zugleich paradigmatisch das Problematische am individuellen Subjektbegriff verdeutlicht. Kant postuliert, dass das menschliche Individuum fähig sei, ohne die Leitung eines anderen sich seines Verstandes $\mathrm{zu}$ bedienen, um sein Leben selber zu gestalten. Subjekt zu sein bedeutet bei Kant, sich autonom gegenüber anderen Menschen zu setzen und der eigenen Verstandeskraft zu vertrauen. Aufklärung habe die Aufgabe, die Fähigkeit des Individuums, sich durch seinen eigenen Verstand leiten zu lassen, zu stärken und dadurch selbstverschuldete Unmündigkeit abzubauen. Gefährdet werde die Fähigkeit des Individuums als autonomes Subjekt zu handeln, von seinen (natürlichen) Neigungen, die geeignet seien, dem Verstand Fesseln anzulegen. ${ }^{2}$ Nicht minder gefährlich für die Verstandeskraft seien Verhältnisse, in denen sich Menschen als voneinander Abhängige gegenübertreten. Da der Verstand nur als unbeschränkt reflektierende Urteilskraft, also freie, sich voll entfalten kann und so Vernunft gebiert, verderben nach Kant Herrschaftsbeziehungen sowohl die Urteilskraft der Beherrschten wie der Herrscher. Freiheit und Vernunft verweisen bei Kant aufeinander. Vernünftig zu handeln heißt, so zu handeln, dass die Freiheit, dass umfassende Autonomie, gewahrt bleibt. Das autonome Subjekt unterliegt keinen Notwendigkeiten.

Soldaten als Angehörige einer hierarchisch strukturierten Organisation als Objekte und nicht als Subjekte zu betrachten, scheint an dieser Stelle mit Kants Subjektbegriff grundsätzlich vereinbar zu sein, weil ihr Handeln grundsätzlich vom Willen anderer, ihren Vorgesetzten, bestimmt sein soll. Soldaten bilden geradezu die Antipoden dessen, was er unter einem auto-

2 Kant bezeichnet die Neigung als blind und knechtisch. Jedem vernünftigen Wesen seien die Neigungen »lästig, und wenn es sie gleich nicht abzulegen vermag, so nötigen sie ihm doch den Wunsch ab, ihrer entledigt zu sein.« (1788: 247 (A212)) 
nomen Subjekt versteht, da nicht individuelle Autonomie, sondern Eingliederung und Unterordnung das Soldatsein kennzeichnet. Allerdings verliert dieser Befund an Eindeutigkeit, wenn man zur Kenntnis nimmt, dass Kant neben Geistlichen und Gelehrten Offiziere zu denjenigen zählt, die über ein Eigentum verfügen, gemeint sind vor allem militärische Kenntnisse, womit sie in den Stand eines Bürgers versetzt und folglich auch zu Subjekten werden. (Kant, 1784b: 55) Obwohl die Offiziere noch im 18. Jahrhundert nicht an ihre Dienstherren quasi ihr Leben lang gebunden waren, wie ab dem 19. Jahrhundert - sie konnten ihre Fähigkeiten auch anderen Dienstherren anbieten ${ }^{3}$ - muss diese Charakterisierung überraschen. Solange ein Dienstverhältnis bestand, waren sie ihren Dienstherren zur Treue verpflichtet und sie blieben als Teil der Befehlskette weiterhin Befehlsempfänger und damit unmündige Wesen, deren Handeln durch den Verstand anderer determiniert wird.

Wenn Kant trotzdem Offiziere als Bürger bezeichnet, dann, weil er trotz seiner rigide postulierten Autonomie des Subjekts darum weiß, dass es kein menschliches Individuum geben kann, das völlig autonom gegenüber der es umgebenden Welt ist. Für den Offizier bedeutet das, dass es »sehr verderblich« wäre, wenn er im Dienst über die »Zweckmäßigkeit oder Nützlichkeit« eines erteilten Befehls »laut vernünfteln wollte; er muss gehorchen. Es kann ihm aber billigermaßen nicht verwehrt werden, als Gelehrter über die Fehler im Kriegsdienste Anmerkungen zu machen und diese seinem Publikum zur Beurteilung vorzulegen.« (Kant 1784b: 55f.) Also nur außerhalb seines Dienstes wäre demnach der Offizier ein Subjekt. Kant unterscheidet hier wie auch allgemein zwischen den empirischen vorgefundenen Verhältnissen, in denen die Individuen leben, und einer umfassenden Bestimmung ihrer Freiheit als Subjekte. Denn es ist ihm nicht entgangen, dass die Aussage, Freiheit bedeute, dass das Subjekt keinen Notwendigkeiten unterliegt, bereits mit der von ihm ebenfalls als wahr anerkannten Aussage im Widerspruch steht, alle Ereignisse in Raum und Zeit würden von den Naturgesetzen bestimmt. Kant löst diese so genannte Antinomie, indem er zwischen dem empirisch vorfindbaren Individuum, das den Notwendigkeiten der Naturgesetze unterliegt und beherrscht wird, von Kräften, die außer seiner selbst sind, und dem intelligiblen Wesen unterscheidet, das als Vernunftwesen nach Freiheit, nach Autonomie strebt. Als endliches Wesen sei der Mensch ein begrenztes, aber eines, das unablässig danach strebe, diese Grenzen zu erweitern. Im Rahmen seiner Ontogenese und seiner begrenzten Lebensdauer, sei es als Säugling, Kind, sei es als kranker oder gebrechlicher Mensch, ist er von der Zuwendung

3 Die Tendenz zum Wechsel der Dienstherren scheint jedoch im Verlauf des 18. Jahrhunderts gesunken zu sein (Hohrath 1999: 23). Ihren Anteil an dem Diskurs der Aufklärung, also inwieweit sie durch eigene Publikationen und als »Mitglieder >bürgerlicher Vereinigungen wie Lesegesellschaften und aufgeklärter Sozietäten« mitwirkten, harrt noch der Untersuchung (ebd.: 29). 
Dritter abhängig. Wie die gesamte Gattung müsse das Individuum in dem vernünftigen Gebrauch seines Verstandes erst Erfahrungen machen, sich in ihm üben und sich auch unterrichten lassen. Der Fortschritt beim Gebrauch der Vernunft sei deshalb ein allmählicher Prozess, der schlussendlich sich gar nicht im Individuum, sondern nur in der Gattung vollständig entwickeln könne. (Kant 1784a: 35, A389)

Das autonome Subjekt Kants ist also nicht mit dem empirischen Individuum identisch. Kant abstrahiert vielmehr von dem empirischen Individuum in der Überzeugung, dass dieser Abstraktion eine praktische Bedeutung für das individuelle Handeln zukommt. Es müsse das Ziel des menschlichen Individuums als Vernunftwesen sein, sich seines Verstandes zu bedienen und selbstständig über sein Handeln zu entscheiden und dies bedeutet zugleich entsprechend dem kategorischen Imperativ ${ }^{4} \mathrm{zu}$ handeln, damit sie sich nicht von der eigenen Willkür und den eigenen Launen beherrschen lassen. Auch wenn Kant eindeutig das männliche Individuum, das ökonomisch den Status eines Selbstständigen hat, den Bürger, als besonders befähigt erachtet, aus selbstverschuldeter Unmündigkeit herauszutreten, ändert dies erst einmal nichts daran, dass er prinzipiell für alle Mitglieder einer Gesellschaft annimmt, sie »könnten zu einer Form ökonomischer Unabhängigkeit gelangen sowie sich aus eigenen Stücken zu einem mündigen Bürger und zu einem sittlichen Subjekt entwickeln.« (zur Lippe 1984: 93) $)^{5}$

Bezogen auf die Entfaltung soldatischer Subjektivität bedeutet dies, dass Kant zu Recht die Chance von Offizieren, wie autonome Subjekte zu handeln, größer einschätzen durfte als die von Soldaten im Mannschaftsdienstgrad. Doch auch für Letztgenannte gilt, der »Mensch, und überhaupt jedes vernünftige Wesen existiert als Zweck an sich selbst, nicht bloß als Mittel für beliebige Gebrauche für diesen oder jenen Willen, sondern muss in allen seinen, sowohl auf sich selbst, als auch auf andere vernünftige Wesen gerichteten Handlungen jederzeit zugleich als Zweck betrachtet werden.« (Kant: 1785/86: 59f., BA 64f.) Die Subjektfähigkeit des konkreten Individuums mag unterdrückt werden oder eingeschränkt sein, aber nach Kant kann ihm seine Freiheitsfähigkeit nicht überhaupt genommen werden. Mit Kant kann man folglich noch nicht einmal den rangniedrigsten Soldaten, der zu seiner Zeit ein Sinnbild der Unfreiheit war, das Subjektsein absprechen. Gleichzeitig vermag aber eine derart abstrakte Bestimmung des Subjektstatus von Soldaten nicht befriedigen. Denn sowohl konkret auf die Soldaten, als auch allgemein auf alle empirischen Individuen bezogen, lässt sich dieser Subjektstatus lediglich als ein Potential oder als ein Anspruch von Vernunftwesen, das heißt als ein Stachel wider

4 »Handle so, dass die Maxime deines Willens jederzeit zugleich als Prinzip einer allgemeinen Gesetzgebung gelten könne.« (Kant 1788: 140 (A54))

5 Zur Kritik an Kants Fassung des autonomen Subjekts in seinen geschichtsphilosophischen Schriften siehe zur Lippe (1983: 92f.). 
die Hinnahme von Herrschaftsverhältnissen bezeichnen. Da die Individuen aber zugleich als abhängige und determinierte Wesen >erscheinen`, also als Mittel Objekte für Andere sind, stellt sich die Frage, inwieweit sie jenseits der Abstraktion von der Empirie als Subjekte angesprochen werden können.

Bei der Beantwortung dieser Frage hilft auch Kants Auftrennung zwischen dem gehorchenden Offizier und dem räsonierenden Bürger nicht sehr viel weiter, weil es kaum vorstellbar ist, dass das gleiche Individuum im Denken und Handeln derart abstrakt zwischen seinem Objektstatus und seinem Subjektsein trennen kann. Wie sich das Subjekt-Objekt-Verhältnis im gleichen Individuum vermittelt, dafür vermag aber Kants abstrakte Bestimmung des autonomen Subjekts keine konkrete Antwort zu geben. Dies liegt nicht zuletzt an der Art und Weise, wie bei Kant das Individuum zu seiner Fähigkeit gelangt, Subjekt zu werden. Bei Kant beruht die Subjektfähigkeit auf dem naturgewollten Vermögen, der Naturanlage zur Vernunft, über die das Individuum von Geburt an verfügt. ${ }^{6}$ Sie ist eine Eigenschaft, die vor jedem Verkehr mit anderen Menschen bereits existieren soll. Der Aufklärung fällt deshalb die Aufgabe zu, den Individuen zu helfen, sich von Irrungen loszureißen und das heißt vor allem, ihn darin zu unterstützen, dass er seine Neigungen (von der Faulheit bis hin zur Herrschsucht) zügelt. ${ }^{7}$ Die Vernunft als vorsoziale Fähigkeit zu begreifen, ist im Hinblick auf die postulierte Autonomie des Subjekts zwar konsequent gedacht, doch sollte sich an dieser Begründung und Fassung der Subjektfähigkeit des Individuums eine Kritik entzünden, die nachhaltig auf die sozialen Kräfte hinwies, die auf das Individuum einwirken. Sie konnte zeigen, dass die Entwicklung des Individuums vom Säugling zum Erwachsenen entscheidend von seiner sozialen Umwelt beeinflusst wird. Damit ist auch seine Fähigkeit, sich seines Verstandes zu bedienen, keinesfalls als

6 »Die Natur hat gewollt: dass der Mensch alles, was über die mechanische Anordnung seines tierischen Dasein geht, gänzlich aus sich selbst herausbringe und keiner anderen Glückseligkeit oder Vollkommenheit teilhaftig werde, als die er sich frei von Instinkt, durch eigene Vernunft verschaffen hat.« Kant 1784a: 35, A 390/1))

7 Insbesondere im Rahmen seiner geschichtsphilosophischen Überlegungen gelten die Neigungen jedoch nicht als bloß störende und nur zu negierende Eigenschaft der Menschen: Der Widerspruch zwischen der Neigung sich zu vergesellschaften, »weil er in einem solchen Zustande sich mehr als Mensch, d.i. die Entwicklung seiner Naturanlagen, fühlt«, wie sich zu vereinzeln, d.h. dem Bestreben, dass sich »alles bloß nach seinen Sinne richten zu wollen«, sei der Motor, der die Menschheit aus dem Zustand der Rohheit zur Kultur treibe. »Ohne jene an sich zwar eben nicht liebenswürdigen Eigenschaften der Ungeselligkeit, woraus der Widerstand entspringt, den jeder bei seinen selbstsüchtigen Anmaßungen notwendig antreffen muss, würden in einem arkadischen Schäferleben bei vollkommener Eintracht, Genügsamkeit und Wechselliebe alle Talente auf ewig in ihrem Keimen verborgen bleiben [...] «. (Kant 1784a: 37f, A 392f.) 
eine stabile vorsoziale aufzufassen. Expliziert wurde diese Kritik weniger im Rahmen der Philosophie, als in den seit Beginn des 19. Jahrhunderts entstehenden sozialwissenschaftlichen Disziplinen, zu denen sich die Soziologie gesellen sollte.

An dieser Stelle gilt es festzuhalten: Kants Subjektbegriff, der das Individuum als Subjekt seiner selbst begreift, ist eine Gegenüberstellung von Individuum und Gesellschaft eingeschrieben. Sie betont für das postulierte individuelle Subjekt dessen Autonomie gegenüber dem Sozialen und läuft zumindest Gefahr, die konstitutiven Prozesse, die für die Heranbildung der Fähigkeiten zum eigenständigen Denken und Handeln, die sich erst im Verkehr mit anderen Menschen bilden, zu vernachlässigen. Es kann jedoch kein individuelles Subjekt geben, das absolute Autonomie und eine Souveränität beanspruchen könnte, die in religiösen Weltentwürfen Gott vorbehalten ist. Individuen können bestenfalls eine eingeschränkte, also eine relativ autonome Position gegenüber ihrer Umwelt einnehmen. Diese Relativität zu bestimmen, zu bestimmen, in welchem Maße die Individuen Subjekt wie Objekte sind, ist das Problem, das alle Theorien zu lösen versuchen, die sich fragen, inwieweit Individuen selber über ihr Denken und Handeln im objektiven Wirkungszusammenhang bestimmen. Die Theorien, aber man kann wohl auch sagen, die Praxis der Individuen, bewegen sich zwischen zwei Polen, dem der Subsumtion und dem der Emanzipation. Neben der eben besprochenen Tendenz, die Autonomie des Individuums gegenüber dem Sozialen absolut zu setzen, lässt sich nämlich auch das Gegenteil feststellen, dass die Verbundenheit des Individuums mit der Sozialität derart betont wird, dass das Individuum total durch die sozialen Kräfte determiniert scheint. Theorien, die sich um den zuletzt genannten Pol bewegen, greifen im Grunde auf eine Bestimmung des Subjekts zu, die dem Begriff keineswegs fremd ist, sondern die vor der Aufklärung den Diskurs beherrschte, auf einen Subjektbegriff, der dieses als subiectus, also Unterworfenes, auffasste (siehe Zima 2000: 3). Mit der Infragestellung der Gewissheiten der Aufklärung ist dieser Pol wieder stärker geworden.

Der Zweifel an dem individuellen Subjekt ist geradezu konstitutiv für die Soziologie. Der folgende parcours de force durch die frühen Theorien der Soziologie soll beleuchten, wie im Rahmen unterschiedlicher Ansätze versucht wurde, die gesellschaftlichen Zwänge als Wirkungsgröße auf das Individuum zu berücksichtigen, ohne dass damit impliziert war, dem Individuum die Fähigkeit, Subjekt zu sein, gänzlich abzusprechen.

So unterschiedlich die im 19. Jahrhundert verfassten theoretischen Entwürfe sind, die heute in der Soziologie als maßgeblich für die Entstehung der sozialwissenschaftlichen Disziplin erachtet werden, so eint sie doch das Ziel, weder im Individuum noch in politischen Auseinandersetzungen zwischen Herrschern und Beherrschten die Kräfte zu suchen, die für den gesellschaftlichen Wandel dieser Zeit verantwortlich waren. Sozio- 
logie habe stattdessen, so Auguste Comte, als >Lehre vom Sozialen Gesellschaft als einen Wirkungszusammenhang zu betrachten, der seine eigenen Gesetzmäßigkeiten aufweist, die wie die Naturgesetze der Physik auf das Individuum einwirken. Auf diese Gesetzmäßigkeiten kann bei Comte das Individuum keinen Einfluss nehmen. Allerdings falle der Soziologie, ähnlich wie den Naturwissenschaften, die Aufgabe zu, aus ihren Beobachtungen und Beschreibungen der Gesetzmäßigkeiten zu Erkenntnissen zu gelangen, die es zumindest der politischen Elite erlaube, in die sozialen Prozesse derart zu intervenieren, dass die positive Entwicklung der Menschheit vorangetrieben wird und ungünstige Entscheidungen vermieden werden. Es ist jedoch nicht diese Aufgabenbeschreibung, die es gestattet, viele im 19. Jahrhundert verfassten theoretischen Entwürfe der Soziologie zuzuschlagen, sondern das bei Comte wie bei anderen Autoren zu findende programmatische Erkenntnisinteresse, bislang unbegriffen gebliebene soziale Prozesse zu untersuchen und aufgrund ihrer Analyse einer bewussten politischen Beeinflussung zugänglich zu machen.

Dieses Erkenntnisinteresse lässt sich beispielsweise auch im Werk von Marx finden, der ansonsten nicht mit Comte in der Beschreibung der sozialen Kräfte und den politischen Wirkungen übereingestimmt hätte. Auch bei Marx kann nicht das Individuum frei über die Gestaltung seines Lebens entscheiden, sondern es muss mit anderen Individuen bestimmte soziale Verhältnisse eingehen. An Aristoteles anknüpfend sei der Mensch »im wörtlichen Sinn ein zoon politikon, nicht nur ein geselliges Tier, sondern ein Tier, das nur in Gesellschaft sich vereinzeln kann. Die Produktion des vereinzelten einzelnen außerhalb der Gesellschaft - eine Rarität, die einem durch Zufall in die Wildnis verschlagnen Zivilisierten wohl vorkommen kann, der in sich dynamisch schon die Gesellschaftskräfte besitzt - ist ein ebensolches Unding als Sprachentwicklung ohne zusammen lebende und zusammen sprechende Individuen.« (Marx 1857: 20) An anderer Stelle führt er aus, dass die Individuen ihr Leben gesellschaftlich produzieren müssen. Zur »gesellschaftlichen Produktion ihres Leben gehen die Menschen bestimmte, notwendige, von ihrem Willen unabhängige Verhältnisse ein« (Marx 1859: 8), deshalb sei es »nicht das Bewusstsein der Menschen, das ihr Sein, sondern umgekehrt ihr gesellschaftliches Sein, das ihr Bewusstsein bestimmt (Marx 1859: 9). Die kapitalistische Produktionsweise beschrieb er im »Kapital« als ein von Menschen geschaffenes Sozialverhältnis, das wie eine Naturkraft auf die Individuen wirke, ob sie nun Arbeiter oder Kapitalisten sind. Beide treten sich nur als Personifikationen der ökonomischen Verhältnisse, als Charaktermasken, gegenüber (1867: 100). ${ }^{8}$ Zwar lässt sich argumentieren, dass dieses determinierende Verhält-

8 Mit dieser Darstellung soll nicht behauptet werden, dass das Marxsche Werk für keine weiteren Interpretationen offen ist. Neben dem Frühwerk, das allerdings in großen Teilen erst im 20. Jahrhundert wahrgenommen wurde, und das den Kapitalismus mehr »aus der Perspektive subjektivitätsbildender Arbeit als 
nis in vollem Umfang nur in kapitalisierten Gesellschaften gilt, - womit ein Streit anheben könnte, ob es eine solche Gesellschaft gibt, geben kann bzw. jemals geben wird - jedoch auch ansonsten gilt das Marxsche Diktum, dass die Menschen zwar »ihre eigene Geschichte (machen), aber sie machen sie nicht aus freien Stücken, nicht unter selbstgewählten, sondern unter unmittelbar vorgefundenen, gegebenen und überlieferten Umständen. Die Tradition aller toten Geschlechter lastet wie ein Alp auf dem Gehirne der Lebenden.« (1852: 115) Erst im Zuge der Revolution des Proletariats, das als einzige Klasse an der Aufhebung aller knechtenden Verhältnisse interessiert sei, könne sich die Menschheit aus ihrer Vorgeschichte befreien, das heißt aus sozialen Verhältnissen, die verhindern, dass die Individuen im umfassenden Sinne Subjekte ihrer eigenen Geschichte sind. Die Revolution selber wiederum wird weitgehend als notwendiges Ergebnis der kapitalistischen Entwicklung gefasst, die ihre Totengräber, also die revolutionären Bewegungen, selber erzeuge. Das Kapital nimmt die Gestalt eines Quasi-Subjekts an. Der wissenschaftlichen Theorie fällt dabei die Aufgabe $\mathrm{zu}$, »das ökonomische Bewegungsgesetz der modernen Gesellschaft zu enthüllen«, aber nicht um die »naturmäßigen Entwicklungsphasen« zu überspringen oder wegzudekretieren, sondern um die »Geburtswehen ab(zu)kürzen und (zu) mildern.« (1867: 15f.) $)^{9}$

Die Auffassung, dass wissenschaftliche Erkenntnissen die Aufgabe zukommt, als >Geburtshelfer` für neue, bessere soziale Verhältnis zu wirken, ist wiederum, über alle sonstigen Differenzen hinweg, eine mögliche Interpretation des Werks von Durkheim. Es lässt sich, so Joas, »als den fortgesetzten Versuch betrachten, die Frage nach der Entstehung einer neuen Moral zu beantworten« (Joas 1996: 77). Soziologische Erkenntnis sollte die »spontane Herausbildung einer neuen Moral (fördern), indem sie die Bedingungen für deren Entstehung klärt.« (Ebd.: 89) Die Untersuchung von Moral ist für Durkheim von entscheidender Bedeutung für die Konstitution und den Wandel eines Sozialsystems. Er geht davon aus, dass ein Sozialsystem ohne ein hohes Maß an Konformität seiner Mitglieder nicht bestehen kann, und es im Falle mangelnder Normenkonformität in den $\mathrm{Zu}$ stand der Anomie übergehen muss. Im Gegensatz jedoch zu Theorien, die sich auf Kant beziehen und im Gegensatz zu utilitaristischen Deutungen ist Moral bei Durkheim nicht als ein System von Verhaltensregeln, als Ver-

Entfremdungsverhältnis« (Honneth/Joas 1980: 28f.) kritisiert, gilt auch für das Kapital, dass Marx nie soweit ging, die lebendige Arbeit unwiderruflich in die kapitalimmanente Funktion des variablen Kapitals zu bannen.

9 Es waren nicht erst sozialdemokratische Interpreten oder Lenin, die die Organisation der Arbeiterbewegung in Partei und Gewerkschaften, als Kollektivsubjekte, zum Dreh- und Angelpunkt für den Gang der Geschichte machten. So spricht Marx im Vorwort zur 1. Auflage des Kapitals, aus dem eben zitiert wurde, davon, dass es vom »Entwicklungsgrad der Arbeiterklasse « abhängt, ob sich der Umwälzungsprozess in brutaleren oder milderen Formen vollzieht (1867: 15). 
einbarungen zu sehen, die von und zwischen Individuen getroffen werden. Er betont vielmehr, dass die Moral nicht vom individuellen Ich ausgeht, sondern diesem als von der Gesellschaft bzw. der sozialen Gruppe erzeugte Tatsache gegenübertrete. Eine Untersuchung der allgemeinen Moral sollte nicht mit dem individuellen Bewusstsein beginnen, und ihre Beurteilung dürfe sich nicht an den individuellen »Stimmungen und persönlichen Vorlieben« orientieren, sondern habe sich »auf die so methodisch wie möglich erarbeiteten Kenntnis einer gegebenen Realität [...], nämlich auf die Kenntnis der gesellschaftlichen Realität« (Durkheim 1924: 116) zu stützen. Mit seiner Frontstellung gegen Kantianer und Utilitaristen gelang es Durkheim, die Soziologie als Wissenschaftsdisziplin erstmals mit einem Lehrstuhl an einer Universität zu etablieren, weil er methodisch wie inhaltlich zeigen konnte, dass sie als Lehre vom Sozialen ein eigenständiges Untersuchungsfeld besitzt, indem sie >Soziales mit Sozialem` erklärt. Seine starke Gewichtung der sozialen Tatsachen, nicht nur als das Untersuchungsfeld für die Soziologie, sondern als prägende Gegebenheiten für individuelles Denken und Handeln, sollte in der Rezeptionsgeschichte Durkheims zu anhaltenden Schwierigkeiten führen, denn wie sollte die soziale Bedingtheit und Abhängigkeit des Individuums mit der ihm ebenfalls zugestandenen Eigenständigkeit des Individuums vermittelt werden? Dabei ist kaum zu übersehen, dass für die Soziologie spätestens mit Durkheim der Begriff des Subjekts, insbesondere in Gestalt der Subjektivität, in einen negativen Bedeutungshorizont gerückt ist. Um objektiv, ähnlich wie die Naturwissenschaften, sich den sozialen Phänomenen anzunehmen, müssen Sozialwissenschaftler nach Durkheim das zu Beobachtende als Tatsache, >wie Dinge betrachten, die unabhängig vom individuellen Wollen sind und von den Individuen wie Zwänge empfunden werden. $\mathrm{Ob}$ allerdings Durkheim sich deshalb zum Lobredner des Zwangscharakters der Gesellschaft erniedrigt (Adorno 1967: 270), darf zumindest als umstritten gelten.

Die Lesart, Durkheim als eines Theoretikers, der den Prozess der Verinnerlichung von Normen als notwendiges Zwangsverhältnis der Gesellschaft gegenüber dem Individuum formulierte, fand zwar neben Adorno vor allem in der Rezeption durch Parsons weite Verbreitung, - hier mit positiven Vorzeichen - doch lässt sich unter anderen mit Joas diese Festlegung auch als eine herrschaftstheoretische Verkürzung der Überlegungen Durkheims interpretieren. Durkheims Arbeiten sind unter dem Eindruck sozialer Instabilität entstanden. Er sah die zeitgenössische Gesellschaft in einer Umbruchsituation von einem einfachen Gesellschaftstypus, in dem die gesellschaftliche Integration quasi mechanisch aufgrund direkt wirkender Zwänge erfolgte, hin zu einem komplexen Typus. Als Folge industrieller Arbeitsteilung werde von den Individuen ein Leben in der Stadt, ein Leben in komplexen, funktional differenzierten Gesellschaften verlangt, welches traditionale Bindungen wie stereotypisierende Zwänge schwächt bzw. aufhebt. Für die Individuen eröffneten sich auf diese Weise in einem 
zuvor unbekannten Maße Gestaltungschancen für ihr eigenes Leben. Diesen Prozess bezeichnet Durkheim als Individualisierung. Damit aber die soziale Ordnung nicht zerfällt, was auf Seiten der Individuen Furcht und Unzufriedenheit auslösen muss, hält Durkheim die Herausbildung eines neuen Moraltypus, den der organischen Solidarität, für notwendig. Genauso wenig, wie er eine von Traditionen geprägte agrarische Gesellschaft anstrebt, will er durch die organische Solidarität den oben skizzierten Prozess der Individualisierung wieder rückgängig machen. Die »neue Kooperationsmoral« soll vielmehr die Bedingungen der komplexen Gesellschaft, anders ausgedrückt der modernen Industriegesellschaft, berücksichtigen. Er konzipiert sie nicht als eine von Herrschern auferlegte Zwangsmoral, aber auch nicht als eine freiwillige Vereinbarung zwischen den individuellen Subjekten, die auf diese Weise ihnen akzeptabel scheinende Bedingungen des Umgangs miteinander regeln. Stattdessen soll sie das Kondensat, eine »reflexiv gewinnbare Einsicht in die funktionalen Erfordernisse egalitärer Kooperation« sein (Joas 1996: 90f.). Die herrschaftstheoretische Interpretation Durkheims wird jedoch dadurch begünstigt, dass es Durkheim nicht gelungen ist, darzustellen, wie die Individuen zu ihren reflexiven Einsichten gelangen sollen. Seine Beiträge zu einem umfassenden Handlungsmodell seien, wie Joas schreibt, durch Polemik gegenüber Kantianern und Utilitaristen gekennzeichnet und blieben deshalb auf sie fixiert, wiesen also nicht über sie hinaus. (Joas 1996: 66). ${ }^{10}$

Dass auf eine andere Weise sein Zeitgenosse Georg Simmel das Individuum in seiner Soziologie berücksichtigen konnte, lag daran, dass er anderen sozialwissenschaftlichen Disziplinen, insbesondere der Psychologie und den Wirtschaftswissenschaften, Erkenntnismöglichkeiten über die sozialen Verhältnisse und ihren Wandel zugestand. Die Soziologie habe die Aufgabe, ' gegenüber den andern, wohlbegründeten Wissenschaften, zunächst ihr Recht auf Existenz überhaupt beweisen zu müssen«. (1917: 63) Er betont zunächst, dass Gesellschaft überall da existiert, wo mehrere Individuen in Wechselwirkung miteinander treten. Dieses Aufeinanderbeziehen der Individuen, ihr soziales Handeln, ist für ihn identisch mit dem, was man als Gesellschaft bezeichnen kann. »Alle jene großen Systeme und überindividuellen Organisationen, an die man bei dem Begriff von Gesellschaften zu denken pflegt, sind nichts anderes als die Verfestigungen - zu dauernden Rahmen und selbstständigen Gebilden - von unmittelbaren, zwischen Individuum und Individuum stündlich und lebenslang hin und

10 Joas weist in diesem Zusammenhang darauf hin, dass Piaget an Durkheim kritisierte, dass er die Bildung von Moral beim Kind nur als aufgezwungene darstellen könne (Joas 1996: 91f.). Auch durch die Berücksichtigung seiner Religionstheorie ändert sich an diesem Einschätzung wenig, weil sie »nicht die Weisen (erhellt), wie Handelnde moralische Verpflichtungen auf Situationen beziehen, sondern die Art, wie Handelnde von Idealen angezogen und über sich selbst hinausgehoben werden und wie diese Ideale selbst dem Handeln entspringen.«(Joas 1996: 95; 280f.) 
her gehenden Wechselwirkungen. Sie gewinnen damit freilich Eigenbestand und Eigengesetzlichkeit, mit denen sie sich diesen gegenseitig entgegenstellen können.« (Ebd.: 69f.) Die aus Individuen zusammengesetzte Gesellschaft ist folglich mehr als ihre bloße Aggregation. Die Individuen sind bei Simmel keine hilflosen Wesen, jedoch bedeutet für ihn Gesellschaft, »dass die Einzelnen vermöge gegenseitig ausgeübter Beeinflussung und Bestimmung verknüpft sind.« (Ebd.: 70)

Den Unterschied der Soziologie zu anderen Sozialwissenschaften definiert er in ihrer spezifischen Fragestellung, wie sie sich den individuellen Existenzen annimmt, für welchen Aspekt ihrer Erscheinungen sie sich interessiert. Die Soziologie frage sich, was "geschieht mit den Menschen, nach welchen Regeln bewegen sie sich, nicht insofern sie die Ganzheit ihrer erfassbaren Einzelexistenzen entfalten, sondern sofern sie vermöge ihrer Wechselwirkung Gruppen bilden und durch diese Gruppenexistenz bestimmt werden? So darf sie die Geschichte der Ehe behandeln, ohne das Zusammenleben einzelner Paare zu analysieren, das Prinzip der Ämterorganisation, ohne einen Tag auf dem Bureau zu schildern, die Gesetze und Resultate des Klassenkampfes ergründen, ohne auf den Verlauf eines Streikes oder die Verhandlung über einen Lohntarif einzugehen.« (Ebd.: 71) Die Soziologie sei als eine spezifische Betrachtungsweise, als eine Methode zu begreifen, die sich der Untersuchung der Formen und Typen widme, "wie sich die Individuen und die Gruppen zueinander verhalten, wie das Individuum zu seiner Gruppe, wie die Wertbetonungen [...] hin und her rücken« (ebd.: 76). Ohne die Leistung eines Individuums als einzigartiges Subjekt leugnen zu wollen, gehe es ihr darum, die »Tatsachen der Politik, wie der Religion, der Wirtschaft wie des Rechts, der Kulturstile « danach zu befragen, »wie sie jenseits individuell verantwortlicher Leistungen wie objektiv-sachlicher Bedeutung, als Leistung des Subjekts Gesellschaft begreiflich, als Entwicklungen dieses Subjekts darstellbar sind« (ebd.: 79).

Weniger seiner Theorie als vielmehr seiner Zeitdiagnose ist dagegen seine Feststellung zuzurechnen, dass es um das Individuum als Subjekt zunehmend schlechter bestellt ist. Zwischen der Gesellschaft und dem Individuum sieht er einen umfassenden und tiefgreifenden Zwist angelegt, den die Gesellschaft im zunehmenden Maße für sich zu entscheiden drohe. Der Konflikt beruhe auf dem »Einheits- und Ganzheitstrieb« (ebd.: 123), den die Gesellschaft wie das Individuum für sich beansprucht. »Die Gesellschaft will eine Ganzheit und organische Einheit sein, so dass jedes ihrer Individuen nur ein Glied ist; in die spezielle Funktion, die es als solche zu üben hat, soll es womöglich seine gesamten Kräfte gießen, soll sich umformen, bis es ganz zum geeignetsten Träger dieser Funktion geworden ist« (ebd.: 122). Doch das Individuum wolle ebenfalls »in sich abgerundet sein und nicht nur die ganze Gesellschaft abrunden helfen, es will die Gesamtheit seiner Fähigkeiten entfalten, gleichviel, welche Verschiebungen 
unter ihnen das Interesse der Gesellschaft erforderte.« (ebd.) Durch die uneingeschränkte Konkurrenz der Individuen gegeneinander und ihre arbeitsteilige Vereinseitigung sah er sie in der Gefahr, zu »Trägern einer nach objektiven Normen erfolgenden Ausgleichung von Leistung und Gegenleistung [zu werden], und alles, was nicht in diese reine Sachlichkeit hineingehört, ist auch tatsächlich aus ihr verschwunden.« (Simmel 1958: 26) Für eine unumkehrbare Entwicklung hielt er diese Tendenz jedoch nicht. Ausgerechnet von den Kriegserlebnissen der Soldaten des 1. Weltkrieges erhoffte er eine zumindest zeitweilig wirksame Umkehr. Er erwartete, dass die verfestigten Formen des Lebens, die dem Subjekt keine Entfaltungsmöglichkeit lassen, durch den Krieg aufgebrochen werden. Das Geld habe durch den Krieg seine Bedeutung als oberster Zwecksetzer verloren. Es sei nun von »seiner bisherigen grenzenlosen Leistungsfähigkeit abgeschnitten, zeigt sich als an sich ganz ohnmächtiges Mittel« (1917b: 47). Wer, wie viele Soldaten, erlebt habe, dass »das sonst Wichtigste, das Selbst und seine Erhaltung einmal als bloßes Mittel zu einem Darüberstehenden« [gemeint war die Nation, d.A.] herabgesunken sei, sei für eine Weile vor »jedem Verschwenden der Zwecksetzung an das Unbedeutendere« (ebd.: 49) gesichert.

»Es scheint sicher, dass der Soldat mindestens solange er in lebhafterer Aktion ist, eben dieses Tun als ungeheure Steigerung sozusagen des Quantums von Leben, in unmittelbarerer Nähe zu seiner flutenden Dynamik empfinde, als er es an seinen sonstigen Arbeitswirksamkeiten spüren kann.« (Ebd.: 50)

Diese Erwartungen beruhten nicht auf einer materiellen Untersuchung der Möglichkeiten der Soldaten, sich als Subjekte zu entfalten. Sie waren, um mit Joas zu sprechen, eher »Wunschträume eines Intellektuellen« (Joas 2000: 101).

Im Unterschied zu Simmel schätzte Max Weber sogar die Chancen für eine prinzipielle Umkehr der vorherrschenden gesellschaftlichen Entwicklung und die zukünftigen Gestaltungsmöglichkeiten des Individuums als Subjekt für die Zukunft entschieden pessimistischer ein. Im Kapitalismus seiner Zeit sah Weber den Schrittmacher für eine Bürokratisierung, die zuerst die private ökonomische Initiative unterbinde und anschließend, über den ökonomischen Bereich hinausstrahlend, drohe, im »Verein mit der toten Maschine [...] das Gehäuse jener Hörigkeit der Zukunft herzustellen, in welcher vielleicht dereinst die Menschen sich, wie die Fellachen im altägyptischen Staat, ohnmächtig zu fügen gezwungen sein werden, wenn ihnen eine rein technisch gute, das heißt: eine rationale Beamtenverwaltung und -versorgung der letzte und einzige Wert ist, der über die Art der Leistung ihrer Angelegenheiten entscheiden soll.« (1922: 835) Als einzige Kraft wider die Tendenz zur Bürokratisierung sah Weber ein Phänomen, das er als Eigenschaften einer Persönlichkeit konzipierte, deren Wirksamkeit sich eher biologisch als soziologisch aufklären lasse: das Charisma 
(1922: 8). Charismatische Persönlichkeiten zeichnen sich durch ihre Fähigkeit aus, nichtsoziale Ressourcen, konkret Affekte, zu mobilisieren und an sich zu binden. Charisma ist keine Jedermann-Ressource. Sie setzt vielmehr außeralltägliche Leistungen bzw. Fähigkeiten voraus, durch die es dem charismatisch Begnadeten gelingt, andere Individuen zu seinen Anhängern zu machen, sie also zu beherrschen. Davon, inwieweit es ihm gelingt, seine Anhänger dauerhaft an sich zu binden, hängt ab, ob eine charismatische Persönlichkeit nur eine flüchtige Beziehung zu seinen Anhängern unterhält oder ob es ihr gelingt, diese Beziehung auf Dauer zu stellen und sie sich damit zu einer charismatischen Herrschaft verdichtet. Da die Träger der charismatischen Autorität permanent unter dem Druck der Bewährung stehen und obendrein ihre Leistungen und Fähigkeiten drohen, sich zu veralltäglichen, wenn »der Herr wie die Jünger und Gefolgsleute [...] [nicht] außerhalb der Bande dieser Welt stehen, außerhalb der Alltagsberufe ebenso wie außerhalb der Bande dieser Familienpflichten« (ebd.: 656), unterscheidet sich charismatische Herrschaft grundsätzlich von der bürokratischen in ihrer Instabilität. Gerade weil die charismatische Herrschaft an Außeralltäglichkeit gebunden ist, sei sie »spezifisch das Gegenteil« der »rational im Sinne der Bindung an diskursiv analysierbare Regeln« orientierten bürokratischen Herrschaft und müsse »irrational im Sinne der Regelfremdheit« bleiben (ebd.: 141).

Charismatische Persönlichkeiten bilden für Weber in bürokratisierten Gesellschaften das politische Ferment, das die »Gefahr der Erstickung in einen zunehmend unbeweglicheren System von Interessenkonstellationen« (Mommsen 1974: 53) entgegenwirkt. Sie sind quasi die einzigen Individuen, die noch kraft ihrer eigenen Subjektivität über politische Gestaltungskraft verfügen. ${ }^{11}$ Die Bedeutung des Charismas und damit »die Tragweite individuellen Handelns" (Weber 1922: 681) sieht er aber insbesondere durch die Macht der rationalen Disziplin im Schwinden begriffen. Im Bezug auf das Militär sieht er ausdrücklich in der zunehmenden Versachlichung und Disziplinierung der Soldaten und nicht in der Waffenentwicklung die Umwandlung des mittelalterlichen Kriegers zum bürokratischen Soldaten begründet (ebd.: 683). Nicht ihr individuell differenziertes Handeln und Charisma, hier in Gestalt des Heldenmutes, entscheidet im "Zeitalter der Maschinenkriege« (ebd.: 686) über Sieg oder Niederlage, sondern wie sie als einer Massendisziplin Unterworfene sachgerecht eingesetzt werden.

Nach diesem parcours de force gilt es ein wenig innezuhalten, um das zentrale Argument, das für eine Abwendung vom Individuum als autonomem Agens sozialer Verhältnisse und ihres Wandels sprach, Revue passieren zu lassen. Die Bestimmung des Individuums als ungebundenes Subjekt zeigte sich kaum mit einer Betrachtungsweise vereinbar, die als

$11 \mathrm{Zu}$ Webers Vorstellung einer >plebiszitären Führerdemokratie` siehe Mommsen (1974: 44f.), sowie Joas (1996: 75). 
Lehre vom Sozialen sich den Kräften zuwendet, die nicht unmittelbar auf das Individuum zurückzuführen sind. Durch den Prozess der Disziplinierung der Sozialwissenschaften vorangetrieben, traten die Bestimmungen des Individuums als ein von sozialen Kräften determiniertes Wesen in den Mittelpunkt der Überlegungen. Das Individuum als absolutes Subjekt zu charakterisieren, gilt in der Soziologie als eine unangemessene Gegenüberstellung von Individuum und Gesellschaft. Sofern überhaupt von einem Individuum als handlungsfähigem Wesen gesprochen werden kann, ist es nicht a priori als autonomes Wesen zu fassen, sondern es entsteht erst aus dem Wirken sozialer Kräfte, die wiederum aus dem Wirken des Individuums mit anderen Akteuren gebildet werden.

Mit der Hinwendung zu den sozialen Voraussetzungen des Individuums war aber nicht die Frage vom Tisch, wie sich die Soziologie für individuelles Denken und Handeln interessieren kann, oder anders formuliert, wie sich das Soziale im Individuum vermittelt. Diese Fragestellung ist als anhaltende Herausforderung an die soziologische Theorie zu bezeichnen. Allerdings schürten die Zeitdiagnosen zugleich die Skepsis, ob man angesichts des konstatierten Übergewichts der auf das Individuum wirkenden sozialen Kräfte sinnvoll, gar emphatisch von einem individuellen Subjekt sprechen kann. Und wenn so schon im Allgemeinen die Frage nach einem Individuum als Subjekt zweifelhaft erscheint, muss die nach einem soldatischen Subjekt geradezu als absurd erscheinen.

Die Vorstellung, dass der Subjektbegriff innerhalb der soziologischen Theorie sinnvoll angewendet werden kann, ist umstritten. Die grundsätzlichste Ablehnung erfährt sie von Seiten der Systemtheorie Luhmanns. Sie bündelt zwei zentrale Argumente, die gegen die Verwendung des Subjektsbegriffs sprechen. Zum einen betont Luhmann, dass erst der Bruch mit dem Subjektbegriff »eine wahrhaft >eigenständige` Theorie sozialer Systeme auszuarbeiten« (1984: 234) ermögliche. Mit dem Bruch solle die Soziologie gleichzeitig Anschluss an eine allgemeine Systemtheorie finden (ebd.: 18f.). Als Theorie sozialer Systeme verfüge sie mit dem Systembegriff über ein interdisziplinäres Paradigma, das ihr die Hinwendung zu Ergebnissen aus naturwissenschaftlichen Disziplinen ermögliche. Zum anderen hielt Luhmann die Ausscheidung des Subjektbegriffs für notwendig, um an seine Stelle eine der Empirie angemessenere Begrifflichkeit treten zu lassen. Die Soziologie habe sich vom Subjekt zu verabschieden und an seiner Stelle habe sie selbstreferentielle soziale Systeme zu setzen (ebd.: 51). Wie alle selbstreferentiellen Systeme zeichnen sich soziale Systeme gegenüber ihrer Umwelt durch ihren Eigenbezug, ihre Autopoiesis, aus. Sie seien als Einheit, in Bezug auf ihre Umwelt zu unterscheidende Elemente und Strukturen zu differenzieren, die im Prozess mit sich selber und im Kontakt zu ihrer Umwelt sich reproduzieren. Um als Einheit Bestand zu haben, können Systeme nur selektiv mit ihrer Umwelt in Kontakt treten. Eine Ausdifferenzierung von Systemen komme nur »durch Selbstreferenz 
zustande [...], das heißt dadurch, dass die Systeme in der Konstitution ihrer Elemente und ihrer elementaren Operationen auf sich selbst [...] Bezug nehmen. Sie müssen, um dies zu ermöglichen, eine Beschreibung ihres Selbst erzeugen und benutzen« (Luhmann 1984: 25).

Alle sozialen Systeme seien von einer Vielzahl selbstreferentieller Systeme umgeben. Luhmanns Systemtheorie beansprucht, soziale Prozesse ohne ein Subjekt als ihnen zugrunde liegendes Faktum beschreiben zu können. Um dies sicherzustellen, kennt die Systemtheorie auch kein Individuum. Vielmehr zergliedert sie das Wesen Mensch in zwei von einander geschiedene wiederum selbstreferentielle Systeme, das neurophysiologische und das psychische System, die zwar »für einen Beobachter als eine Einheit erscheinen« (Luhmann 1984: 67f.), aber kein System bilden. ") Mensch « ist nur mehr der Name für eine Kombination unterschiedlicher organisch-psychischer Systeme, die je für sich selbstreferentiell operieren.« (Schroer 2001: 226) Das menschliche Wesen ist damit für Luhmann kein Bestandteil der Gesellschaft bzw. der sozialen Ordnung, sondern es steht außerhalb der sozialen Systeme und gehört zu ihrer Umwelt (siehe Luhmann 1984: 286f.). Wenngleich Luhmann betont, dass der Mensch »als Teil der gesellschaftlichen Umwelt zugleich komplexer und ungebundener zu begreifen (ist), als dies möglich wäre, wenn er als Teil der Gesellschaft aufgefasst werden müsste« (ebd.: 289), so bedeutet dies nicht, dass Luhmann ihn nun quasi als Umweltfaktor zum Subjekt sozialer Prozesse ermächtige. »Dem Menschen werden so höhere Freiheiten im Verhältnis zu seiner Umwelt konzediert, insbesondere Freiheiten zu unvernünftigem und unmoralischem Verhalten.« (Ebd.) Die ihnen >konzedierten` Freiheiten bedeuten deshalb, dass ihre Handlungen im Rahmen von Luhmanns Systemtheorie vor allem als störende, gar die sozialen Systeme gefährdende >Umweltfaktoren ' wahrgenommen werden. ${ }^{12}$

Trotz der behaupteten Angemessenheit des Bruchs der Systemtheorie mit dem Subjektbegriff, fällt es ihr keineswegs leicht, den Bruch umzusetzen. Ein guter Teil aller Kategorisierungen der Systemtheorie zielt ausschließlich darauf ab, ein »Überschwappen der Subjektterminologie« in die Welt der sozialen Systeme »nach Möglichkeit» (Luhmann 1984: 596) zu verhindern. Zwar mag der Begriff des Subjekts missbrauchsanfällig sein, wie Luhmann (ebd.) schreibt, dennoch können viele Soziologien der Systemtheorie mit ihrer Umstellung auf selbstreferentielle Systeme und der

12 Siehe hierzu auch Schroers Luhmann Interpretation (2001: 274f.). Dass ihnen fast keine positive Gestaltungskraft zugebilligt wird, wird auch deutlich, wenn Schroer schreibt, dass nach Luhmann »die Individuen in die Funktionslogik der Teilsysteme nicht mehr steuernd eingreifen können«, was ihnen aber »gleichsam mit der Zurückhaltung der Teilsysteme bei Fragen in der individuellen Lebensführung versüßt [wird], wobei dies von den Individuen nicht notwendig als Befreiung, sondern auch als Überforderung, als >illegitime` oder >unerwünschte Indifferenz` erlebt werden kann.« (Ebd.: 253) 
Zuordnung des Menschen zur Umwelt sozialer Systeme nicht folgen. Sie teilen nicht Luhmanns Auffassung, dass >der Mensch` nicht das Maß der Gesellschaft sein soll. Nicht notwendigerweise muss ja die Idee des $\mathrm{Hu}-$ manismus eine derart naive Gestalt annehmen, wie dies von Luhmann suggeriert wird, dass nämlich die Gesellschaft nach dem Bild des Menschen (»Kopf oben, usw.«; ebd.: 289) geformt sein müsse. Es lässt sich obendrein, der Kritik Zimas folgend, die Frage stellen, ob die Systemtheorie nicht, indem sie den Subjektbegriff durch den des selbstreferentiellen Systems ersetzt, einer »Mythisierung auf >höherer Ebene«« (2000: 325) Vorschub leistet. »In Luhmanns Diskurs verschwindet das Subjekt zwar als transzendentale und individuelle Instanz, setzt sich aber als abstrakter Subjekt-Aktant [...] voll durch: als `Differenzierung〈, >System`, >Operation` oder >Kommunikation`.« Das Problem bestehe weniger in der Abstraktion, die sei in keinem theoretischen Diskurs zu vermeiden, sondern darin, dass Luhmanns Aktanten mythisch seien, "weil sie nicht mit individuellen und kollektiven Subjekten interagieren, [...] diese ersetzen und dadurch deren Funktion verdecken.« (Ebd.)

Während Luhmanns Systemtheorie die Frage, wie sich ein in Gesellschaft lebendes Individuum als Subjekt denken lässt, durch die Streichung des Individuums wie des Subjekts zu beantworten versucht, formuliert Adorno den anderen Pol der Debatte, wie mit dieser Frage umgegangen werden kann. Er insistierte darauf, dass die Gesellschaft sich aus Subjekten »zusammensetzt und durch ihren Funktionszusammenhang sich konstituiert« (Adorno 1969: 295). Er schließt damit nicht an Kants Bestimmung des autonomen Subjekt an, da er festhält, das »Subjekt ist in Wahrheit nie ganz Subjekt, Objekt nie ganz Objekt; dennoch beide nicht aus einem Dritten herausgestückt, das sie transzendierte. Das Dritte tröge nicht minder. [...] An der Zweiheit von Subjekt und Objekt ist kritisch festzuhalten, wider den Totalitätsanspruch, der dem Gedanken inhärent.« (1966: 177)

Das Subjekt ist nicht identisch mit Individuum. "Zum Subjekt wird das Individuum, insofern es kraft seines individuellen Bewusstseins sich objektiviert, in der Einheit seiner selbst wie in der seiner Erfahrungen« (Adorno 1966: 56). Dieser Gedankengang soll anhand der Alltagssprache kurz weiterverfolgt werden, da er für eine Abgrenzung des Individuellen vom Subjektiven geeignet erscheint: Wenn die Rede auf eine individuelle Stärke oder auch Schwäche eines Menschen kommt, auf seine individuelle Begabung oder Schrulle hingewiesen werden soll, dann enthält das Adjektiv individuell zwar einen relationalen Bezug zur Welt, es verweist jedoch noch stärker auf das Moment des Kontingenten, das nur dem angesprochenen einzelnen Wesen eigen ist. Das Adjektiv subjektiv betont dagegen den Bezug des Individuums zur Objektivität und das heißt zu der es umgebenden Sozialität. In die historisch gewachsene Sozialität wird das Individuum 
hineingeboren ${ }^{13}$ und von ihr hängt $\mathrm{ab}$, ob individuelle Eigenschaften sich bei der Entfaltung seiner Subjektivität als förderlich oder hinderlich erweisen, ob, um ein Beispiel anzuführen, die individuelle Hautfarbe die Lebenschancen eines Individuums erhöht oder es durch sie beeinträchtigt wird.

Eine positive Bestimmung dessen, was ein Subjekt ausmacht, über welche Qualitäten es notwendig verfügen muss, hält Adorno für unmöglich. Nur negativ und für die Vergangenheit lasse sich bestimmen, was »ein Mensch an sich sein soll, [er] ist immer nur, was er war: er wird an den Felsen seiner Vergangenheit festgeschmiedet. Er ist aber nicht nur, was er war und ist, sondern ebenso, was er werden kann; keine Bestimmung reicht hin, das zu antizipieren.« (1966: 61)

Adornos Satz, dass sich die Gesellschaft aus Subjekten zusammensetzt, steht zumindest auf den ersten Blick im Widerspruch zu seiner vor allem in der »Dialektik der Aufklärung« (zusammen mit Horkheimer) vorgetragenen Einschätzung, dass die instrumentelle Beherrschung der zu einem Teil der sozialen Welt gewordenen Natur als eine durchrationalisierte Welt wiederum als Naturbeherrschung am Menschen auf ihn zurück wirkt. Die Aufklärung sei kein Befreiungsinstrument von der ersten und zweiten Natur, sondern von Beginn an ein Instrument der Herrschaft. »Was die Menschen von der Natur lernen wollen, ist, sie anzuwenden, um sie und die Menschen vollends zu beherrschen. « (Horkheimer/Adorno 1947: 10) In der modernen (kapitalistischen) Industriegesellschaft wende sich die Weltherrschaft über die Natur »gegen das denkende Subjekt selbst, nichts wird von ihm übriggelassen, als eben jenes ewig gleiche Ich denke, das alle meine Vorstellungen muss begleiten können.« (Ebd.: 32) Dieses Ich sei Produkt eines ökonomischen Apparates, der selbsttätig,

»vor der totalen Planung, die Waren mit den Werten aus[stattet], die über das Verhalten der Menschen entscheiden. Seit mit dem Ende des freien Tausches die Waren ihre ökonomischen Qualitäten einbüßten bis auf ihren Fetischcharakter, breitete sich dieser wie eine Starre über das Leben der Gesellschaft in all seinen Aspekten aus. Durch die ungezählten Agenturen der Massenproduktion und ihrer Kultur werden die genormten Verhaltensweisen dem Einzelnen als die allein natürlichen, anständigen, vernünftigen aufgeprägt.« (Ebd.: 34f.)

Gemeint war damit, dass die sinnliche Wahrnehmungswelt der Individuen tiefgreifend von der Kulturindustrie geprägt werde und deshalb »die Subjekte zu willfährigen Empfängern konformitätserzeugender Sendeinhalte« werden (Honneth 1985: 93). Der Zweifel liegt nun weniger in der Befähigung des (abstrakten) Menschen, sondern in der konkret historisch eingeräumten Chance, von ihr Gebrauch machen zu können. Dass sich in

13 Denkbar knapp formuliert dies Adorno in dem Satz: »Gesellschaft ist vor dem Subjekt.« (1966: 132) 
der »Dialektik der Aufklärung« auch Passagen finden, in denen die Individuen mehr als bloße Objekte der Herrschaft auftreten, beispielsweise, wenn Adorno und Horkheimer schreiben, dass es »der Knecht [ist], dem der Herr nicht nach Belieben Einhalt tun kann« (ebd.: 43), ändert, wie auch später entstandene Schriften zeigen, nichts daran, dass Adorno vor allem deshalb an dem Begriff des Subjekts festhielt, um mit ihm die Tatsache seiner Überwältigung kritisieren zu können. Obwohl und weil das Subjekt kein Realbegriff sei, habe man als Begriff des Denkens am Subjekt festzuhalten, weil man ansonsten Gefahr laufe, dadurch die »Wahrheit, die den Menschen aus dem Mittelpunkt der Schöpfung verjagt und ihn seiner Ohnmacht gemahnt, bekräftigt, als subjektive Verhaltensweise, das Gefühl der Ohnmacht, veranlasst die Menschen, mit ihr sich zu identifizieren, und verstärkt damit weiter den Bann der zweiten Natur.« (1966: 75f.) Die Unfähigkeit der bürgerlichen Gesellschaft, »jener Verein freier Menschen zu werden, dessen Idee ihr gleichwohl teleologisch innewohnt« (Adorno 1967: 271), sei nicht durch Theorie festzuschreiben.

Die Zeitdiagnose Adornos ist nicht unwidersprochen geblieben. Seine Schlussfolgerung resultiere, so Honneth, aus »dem kategorialen Unvermögen einer auf den zivilisatorischen Prozess der Naturbeherrschung fixierten Gesellschaftstheorie, neben der Sphäre des Marktes eine andere Dimension sozialen Handelns systematisch zu erfassen.« (Honneth 1985: 111) Ausgehend von einem idealisierten Bildes des Marktes unter liberalkapitalistischen Vorzeichen, der frei von staatlich-administrativen Eingriffen gewesen sei, konzipiert ihn Adorno als »die eigentliche soziale Sphäre identitätsverbürgenden Handels [...]: in ihr können sich, weil sie mit der wechselseitigen Interessenkalkulation einen Raum für soziale Identitätserfahrung schafft, die zweckrationalen Handlungsstrebungen der individuellen Subjekte mit dem ökonomischen Reproduktionserfordernissen der Gesamtgesellschaft [...] vermitteln.« (Ebd.: 89) Da Adorno andere soziale Orte der Vermittlung von Individuum und Gesellschaft weitgehend unbeachtet lässt, - von den Einrichtungen bürgerlicher Öffentlichkeit über Subkulturen und Organisationen, in denen sozialen Gruppen ihre (ökonomischen) Interessen durchzusetzen versuchen - tritt »das in den Privatraum der Kleinfamilie eingeschlossene Subjekt [...] gleichsam allein vermittels des Marktgeschehens mit der gesellschaftlichen Umwelt in Kontakt.« (Ebd.: 89) Und im Spätkapitalismus stößt hier das individuelle Subjekt auf die beherrschenden Planungsbürokratien, die den Imperativen einer verselbstständigten Systemproduktion folgen und die für das Handeln des Subjekts keine Entfaltungsmöglichkeit lassen. Der Begriff des Subjekts muss jedoch dann keine >bloße wohl auf empirisch vorfindbare Individuen angewendet werden, wenn »die Ebene der kulturellen Eigenleistungen sozialer Gruppen, ja die Sphäre sozialen Handelns überhaupt« (ebd.: 110) nicht einfach übersprungen wird. 
Einen interessanten, aber auch einen nicht ganz einfachen, Zugang, wie man das Individuum als Subjekt bestimmen kann, bieten die Arbeiten Foucaults. Schwierig ist dieser Zugang, weil die Rezeption seines Werks zum Teil sich heftig widersprechende Interpretationen hervorgebracht hat. Das Auftreten dieser Widersprüche vermag allerdings kaum zu verblüffen, wenn man sich vergegenwärtigt, dass Foucault in seinem über mehrere Jahrzehnte entwickelten Werk mit dem Anspruch auftrat, sich im Widerspruch zu den jeweils vorherrschenden Auffassungen in der Psychologie, den Geschichtswissenschaften und der Philosophie $\mathrm{zu}$ befinden ${ }^{14}$ und obendrein ständig die "thematischen Interessen, theoretischen Konstruktionen und methodischen Anleitungen« wechselte (Brieler 1998: 40). So reizvoll eine Auseinandersetzung mit diesen Differenzen sein mag, die beileibe keine Spezialität seines Werkes sind, sondern als Hinweis darauf gewertet werden können, wie schwierig es den unterschiedlichsten sozialwissenschaftlichen Strömungen fällt, die jeweilige Theorie zu ignorieren, sie wird hier nicht stattfinden. Stattdessen soll im Folgenden hervorgehoben werden, inwieweit Foucaults Überlegungen in Bezug auf soldatische Subjekte als fruchtbar erachtet werden.

In den meisten Arbeiten, die sich auf Foucault beziehen, wird das $\mathrm{Zu}$ sammenwirken von (historischen) Wissens- und Machtkomplexen untersucht. Standen bis in den Anfang der 80er Jahre im Vordergrund der Analysen und der Rezeption, wie sich diese als disziplinierend auf die Individuen auswirken, so haben sich seitdem die Betrachtungen stärker der Frage zugewandt, in welchem Ausmaß und in welcher Gestalt sie auch als Ausdruck von >Technologien des Selbst $\iota$, also als Ausdruck der individuellen »Sorge um sich« zu lesen sind. Unabhängig von dieser Schwerpunktverschiebung der Analysen, wird Subjektivität von Foucault als Instanz gefasst, deren Inhalte nicht außerhalb der Geschichte stehen, sondern erst in einem bestimmten Kontext modelliert bzw. hervorgebracht werden. Als einen grundlegenden Antiessentialismus bezeichnet Brieler, der sich eingehend mit den Veränderungen und Schwerpunktverschiebungen des Werks von Foucaults auseinandersetzt, dessen Umgang mit der Frage, was der Mensch sei. Resümierend stellt er fest, dass »)die Formel vom Subjekt [...] immer eine Doppelfigur [meint]: die Gewordenheit des Menschen und sein Umgang mit sich innerhalb dieser Gewordenheit. Der Mensch ist nur als konkret-endliches Subjekt erfassbar, ein elementar geschichtliches

14 So weist Brieler daraufhin, dass Foucault in den 60er Jahren gegen eine Ideengeschichte antrat, die eine Souveränität des Genies gegenüber dem es umgebenden sozialen Verhältnissen behauptete und gegen die Bedeutung von Intentionalität des Handelns durch Individuen sowie von Kollektiven antrat, die zu diesem Zeitpunkt kaum noch vertreten wurde. »Aber Foucault bedarf dieser vergröberten Schattenfiguren zur Profilierung eines Projektes, das in viel stärkerem Maße in die Revolutionierung des geschichtswissenschaftlichen Denkens der 60er Jahre eingebunden ist, als es zugesteht.« (1998: 221) 
Segment.« (1998: 573) Auch Osborne insistiert darauf, dass im Mittelpunkt des foucaultschen Denkens die Frage der »Formbarkeit der menschlichen Vermögen« steht, mit der Menschen ihre eigene Geschichte »mit anderen geschaffen haben, um die Fähigkeiten, durch die Menschen regiert wurden und mit denen sie andere regierten« (Osborne 2001: 12).

Mit seinem Antiessentialismus unterscheidet sich Foucaults Begriff eines Subjekts von solchen Begriffskonstruktionen, die offen oder verdeckt die Fähigkeit, Subjekt zu sein, an Eigenschaften wie ökonomischer Status, Geschlecht und Ich-Stärke knüpfen, die das Individuum erst befähigen sollen, Subjekt zu werden. Bei Foucault gibt es keine Geschichte des Subjekts, die mit seiner Befreiung aus selbstverschuldeter Unmündigkeit (Kant) beginnt und die anschließend von den >Geistern`, die es rief, bedroht oder gar überwältigt wird. Den Prozess moderner Subjektbildung, der nach seiner Auffassung mit dem 17. Jahrhundert einsetzt, sieht er eingebettet in diskursive Ordnungen und Disziplinierungsapparaturen, die aber nicht nur die Individuen unterdrücken, sondern die »Individuen als Macht- und Wissenselemente« (1976: 249) erst herstellen. Dass Foucault die Individuen nicht einfach als von den auf sie wirkenden sozialen Mächten vielfach unterdrückte Wesen fasst, liegt an seiner erläuterungsbedürftigen Konzeption von Macht. Macht ist demnach keine einseitig gerichtete Kraft, die auf ein Objekt einwirkt. Sie bezeichnet vielmehr ein prozessierendes Wechselverhältnis, das das Resultat von mindestens zwei aufeinanderwirkenden Kräften ist - Macht und Gegenmacht. Deshalb ist die Disziplinarmacht, von der Foucault in diesem Zusammenhang spricht, nicht nur destruktiv. Sie sei in $»$ Wirklichkeit produktiv; und sie produziert Wirkliches. Sie produziert Gegenstandsbereiche und Wahrheitsrituale: das Individuum und seine Erkenntnis sind Ergebnisse dieser Produktion.« (1976: 250) Beherrschte Individuen sind als nicht völlig Entmächtigte aufzufassen, denn »die Macht verläuft über sie und durch sie hindurch; sie stützt sich auf sie, ebenso wie diese sich in ihrem Kampf gegen sie darauf stützen, dass sie von der Macht durchdrungen sind.« (1976: 38) Zur Disziplinierung gehört nach Foucault die Selbstbeteiligung der Individuen an ihrer Unterwerfung, das >Einwandern nis, das Sich-Formen. Das »erkennende Subjekt, das zu erkennende Objekt und die Erkenntnisweisen [sind] jeweils Effekte [...] [der] fundamentalen Macht/Wissen-Komplexe« (1976: 39). In seinen späteren Interviews und Texten wird dies mit der Betonung der »Sorge um sich«, die er auch als >Technologien des Selbst` bezeichnete noch deutlicher. Hier schlägt er eine andere Lösung der Frage vor, wie sich die Entstehung eines Subjekts vorstellen lässt. Er betonte neben den Dispositiven des Formens und des Geformt-Werdens ein weiteres eigenständiges Dispositiv des SichFormens. Im Rahmen des Dispositivs des Sich-Formens bestehen für das Subjekt Möglichkeiten, »sich als >anders` als andere wahrzunehmen, 
>selbstverantwortlich Verhaltensweisen eine Wahl zu treffen « (Sarasin 2001: 24) ${ }^{15}$

Ebenfalls in seinen späteren Interviews und Texten betont Foucault, dass Subjektivierung kein Prozess ist, der erst mit dem 17. Jahrhundert einsetzt, sondern

»dass die Menschen im Laufe ihrer Geschichte niemals aufgehört haben, sich selbst zu konstruieren, das heißt ihre Subjektivität beständig zu verschieben, sich in einer unendlichen und vielfältigen Serie unterschiedlicher Subjektivitäten zu konstituieren. Diese Serie von Subjektivitäten wird niemals zu einem Ende kommen und uns niemals vor etwas stellen, das der `Menschく wäre. Die Menschen treten ständig in einen Prozess ein, der sie als Objekte konstituiert und sie dabei gleichzeitig verschiebt, verformt, verwandelt - der sie als Subjekte umgestaltet.«(1996: 85). ${ }^{16}$

Ein derartiger Subjektbegriff ist für die Untersuchung soldatischer Subjekte attraktiv, weil neben dem Hinweis auf die Geschichtlichkeit von Subjektivität nicht normativ vorab entschieden ist, wie Soldaten handeln müssen, um Subjekte zu werden. So wird es möglich, sich nicht auf eine dichotome Sichtweise festzulegen, die auf der einen Seite nur die disziplinierenden, alle unterdrückenden, objektivierenden Mächte erkennen kann, der auf der anderen Seite das tragische oder heroische, aber doch geknechtete und schlussendlich immer Opfer seiende Subjekt gegenübersteht. Eine solche Dichotomie erschwert den Blick auf das Faktum, dass Soldaten auch dann Subjekte sein können, wenn sie befehlskonform handeln. Auch muss das Handeln soldatischer Subjekte nicht von der Intention bestimmt sein, Freiheit für sich und andere anzustreben, sondern es kann dem Ziel dienen, sich selber zu ermächtigen, um an der bestehenden Macht teilzuhaben, Unterdrückung, Schädigung oder den Tod anderer zu erreichen. Prinzipiell soll so vermieden werden, den Begriff des Subjekts nur auf solche Soldaten anzuwenden, die sich durch Aufbegehren gegen die Disziplinarmacht auszeichnen, sei es als Meuterer, als Verweigerer, als Deserteure oder als Kranke. Soldaten sind als Subjekte nicht nur als Opfer und willige

15 An der paradoxen Verknüpfung von Fremd- und Selbststeuerung, für die Foucault Ende der 70er Jahre den Begriff des Regierens verwendete, knüpfen die Überlegungen zur `Gouvernementalität` an. Regieren ist hier keine exklusive Tätigkeit politischer Führungen, sondern jedem Subjekt eigen. Regieren meint in diesem Kontext, die Fähigkeit mit Hilfe der vorhandenen Ordnungs- und Wissenskomplexe sich selber so zu strukturieren, dass man unter den gegebenen sozialen Bedingungen handlungsfähig ist und auf die Handlungsmöglichkeiten anderer Individuen einwirken kann. Siehe hierzu Bröckling u.a. (2000).

16 Foucault setzt sich in diesem zitierten Interview von einer Position ab, die er in den 60er Jahren einnahm und nicht nur vom >Tod des Menschen « im Sinne einer Absage an das transzendentalen Subjekts ausging, sondern die Rede von Herrschaft und Befreiung als lächerlich bezeichnete (Brieler 1998: 577). 
oder unwillige Objekte ihrer Vorgesetzten wahrzunehmen, sondern auch als Akteure im Kriegsgeschehen und das heißt, um einen Ausdruck zu verwenden, der ihre Verantwortlichkeit im Gegensatz zum Opferstatus betont, als Täter. Dies gilt es umso mehr zu beachten, weil in dieser Arbeit soldatische Subjekte im Krieg untersucht werden sollen, gerade also solche Soldaten im Blickfeld zu halten sind, die sich aktiv am Kriegsgeschehen beteiligen. Dabei soll sowohl untersucht werden, wie die Kommandierenden sich auf die Subjektivität der Soldaten beziehen, als auch wie die Soldaten ihre Subjektivität einbringen.

Die vorliegende Untersuchung zieht neben dieser Anknüpfung an Foucaults Verständnis von Subjektivität und der Historisierung des Subjekts ein weiteres Theoriekonzept heran, das in einem gewissen Spannungsverhältnis zu Foucaults Werk steht. Osborne betont, dass

»Foucault eine Art spekulativen Empirismus an[wendet], eine hypothetische Haltung des Als-ob, die darauf hinausläuft, Menschen so zu behandeln, als seien sie potentiell unendlich formbar«, um »diejenigen Machtformen empirisch zu untersuchen, die diese Formbarkeit in der Vergangenheit hervorgebracht haben« (2001: 12).

Als heuristisches Prinzip wird hier zwar der Wert einer Vorgehensweise, die von der unendlich freien Konstruierbarkeit des Subjekts ausgeht, nicht bestritten, um die Historizität von Subjektbegriffen herausarbeiten zu können, und um Fixierungen des Subjekts auf Vergangenes zu vermeiden. Doch scheint die Ablehnung jeglicher Überlegungen, die auf substanzielle Grundlagen von Subjektivität verweisen, zumindest bei einigen Rezeptionen von Foucaults Arbeiten dazu beigetragen zu haben, dass sie sich vom Individuum als eigenständiges Movens verabschiedet haben. Diese Neigung kritisiert in den industriesoziologischen Debatten zur Subjektivierung der Arbeit u.a. Vormbusch, der deshalb für eine sweichere Fassung der Subjektivierungsthese von Foucault plädiert. Mit Blick auf die im angelsächsischen Sprachraum geführten Debatten zur Subjektivierung von Arbeit im Bereich betrieblichen Controllings, kritisiert er Foucault bzw. eine Foucault-Interpretation, für die das Subjekt »kaum mehr als einen leeren Behälter dar[stellt], dessen psychische Verarbeitungs- und Aneignungsmechanismen [...] er [Foucault] nicht näher zu klären versuchte.« (2006: 4)

Die Annahme auch nur einer potentiell unendlichen Formbarkeit der menschlichen Vermögen bietet sich jedoch nicht an, wenn soldatische Subjekte im Kampfeinsatz betrachtet werden sollen, weil Soldaten im Laufe eines Kriegseinsatzes ihren Körper gefährlichen, tödlichen Situationen aussetzen. In den Fokus der Betrachtung rückt damit immer wieder die Leibgebundenheit des Subjekts, über die es weder frei verfügen, noch dessen unendliche Formbarkeit postuliert werden kann. Gerade bezogen auf den Krieg bietet es sich weniger an, die unendliche freie Konstruierbarkeit 
des Subjekts zu betonen, sondern auf die Grenzen einzugehen, die ihm durch seine Leibgebundenheit gezogen sind. Um dies anhand eines Beispiels zu illustrieren, sei hier darauf hingewiesen, dass Soldaten mitunter mit ihrem Kampfeinsatz den Glauben oder die Hoffnung verbinden, sie seien unverwundbar, doch ändert dies nichts daran, dass sie trotzdem verletzungsoffen (Popitz) bleiben (siehe hierzu ausführlich den Abschnitt 5.4.).

Die Betonung der Leibgebundenheit des Subjekts bietet sich obendrein auch deshalb an, weil eine wichtige waffentechnische Entwicklung auf die Substituierung von Soldaten in gefährlichen Situationen abzielt. Sie ist als eine Tendenz zu bezeichnen, die sich im Zuge der Industrialisierung der Kriegführung entwickelte und heute bei den avanciertesten Militärapparaten stark ausgeprägt ist.

\subsection{Soldaten als Handelnde}

Wenn behauptet wird, dass Individuen Subjekte sein können, dann stellt sich die Frage, wie sich diese Fähigkeit ausdrückt? Individuen als Gestalter ihres Lebens zu fassen, heißt ihnen zuzugestehen, dass sie über Fragen, die ihr Leben betreffen, entscheiden können und heißt davon auszugehen, dass ihr Tun zumindest einen konkreten Einfluss auf ihr Geschick hat. Kurz: Individuen als Subjekte zu betrachten, heißt sie als handelnde Wesen anzusehen (siehe hierzu Honneth 1985: 110f.). Allerdings: Nicht jede Handlung ist geeignet, die Souveränität des Individuums als Subjekt zu gewährleisten. Dieser Sachverhalt wird von Luckmann angesprochen, wenn er schreibt: »Handeln macht nicht immer Geschichte, aber es >macht< Gesellschaft.« (1992: 4)

Der Begriff des Handelns ist mit dem Individuum verknüpft. Handeln meint nicht nur eine von der Hand ausgehende Bewegung bzw. ihr Unterlassen. Der Begriff zielt auf jede absichtsvolle (Nicht-)Bewegung des Individuums. Willkürliche oder zufällige Bewegungen, jedes Tun, das keiner Intention unterliegt, werden nicht als Handlung bezeichnet. Der Schlaf fällt deshalb ebenso wenig unter das Handeln wie Muskelreflexe. Sprechen, ob als Flüstern oder Schreien, muss dagegen ebenso wie das Schweigen zu den Möglichkeiten individuellen Handelns gezählt werden. Nicht nur weil das Sprechen weitere Handlungen vorbereitet oder nachbereitet und weil es an die Stelle von anderen Handlungen treten kann, sondern vor allem, weil es ein In-Beziehung-treten zu jemand anderem bedeutet. Handeln ist mehr als Bewegung, insofern es keinen Automatismus darstellt, also vom Individuum selber variiert werden kann. Freilich bedeutet die unterstellte Variabilität des Handelns keine umfassende Befreiung von Restriktionen. So kann man mit Aristoteles zwischen freiwilligen und unfreiwilligen, also erzwungenen, Handlungen differenzieren. »Erzwungen 
ist eine Handlung, deren Prinzip außer uns liegt und zu der der Handelnde oder Leidende nichts beiträgt, z.B. wenn uns ein Sturm irgendwohin verschlägt, oder Menschen, in deren Gewalt wir sind, uns irgendwohin bringen.« (1963b: 233) Doch selbst für erzwungene Handlungen gilt, so führt Aristoteles weiter aus, dass im Moment ihrer Ausführung die Handlung freiwillig erfolgt, weil das »Prinzip der Bewegung der Glieder bei derartigen Handlungen [...] im Menschen selber (liegt), steht es ihm frei, sie auszuführen oder nicht.« (Ebd.: 234) Erzwungene Handlungen zeichnen sich gegenüber freiwilligen dadurch aus, dass die Individuen Handlungsalternativen abwägen müssen, die für die Handelnden ansonsten nicht in Betracht kämen. Angesichts eines Sturmes mag sich eine Schiffsbesatzung entschließen, die Ladung des Schiffes über Bord zu werfen, weil sie auf diese Weise hofft, ein Kentern des Schiffes zu verhindern; doch sie kann sich bis zu dem Augenblick, in dem sie die Ladung über Bord wirft, auch anders entscheiden. Gleiches gilt, wenn an die Stelle eines natürlichen Phänomens wie des Sturms Machtverhältnisse treten, die von Menschen ausgehen: Ein möglicher Extremfall ist hier eine Situation, in dem ein Individuum von einem Machthaber, Aristoteles spricht von einem Tyrannen, bedroht und erpresst wird, dass es selbst oder ihm Nahestehende Schmerzen erleiden müssen, sie und es selbst gar getötet werden, wenn es nicht bestimmte >schimpfliche` Handlungen vollzieht. In einer solchen Situation übt ein Machthaber, so Popitz, vollkommene Macht aus, denn »Herr-Sein über Leben und Tod« stelle die »äußerste Steigerung des HerrSeins über andere Menschen« dar (1992: 53). Doch selbst, wenn die Macht derart vollkommen ist, bleibt sie in einem Punkt unvollkommen, »weil sich die Entscheidung zum Äußersten nicht monopolisieren lässt - jeder kann töten - , und weil die Entscheidung, sich töten zu lassen, anderen nicht genommen werden kann.« (Ebd.: 60)

So sehr das Sich-auch-anders-entscheiden-können als ein Kennzeichen des Handelns zu fassen ist, so offen bleibt selbst in den angeführten Beispielen für erzwungene Handlungen, nach welchen Kriterien sich die handelnden Individuen für die eine oder andere Option entscheiden. Angesichts der Bedrohung, mit dem Schiff unterzugehen, die sich möglicherweise abwenden lässt, wenn man sich der Schiffsladung entledigt, lässt sich die Intention der Handelnden wohl leicht bestimmen, aber nur falls sie sich für das Überbordwerfen der Ladung entscheiden. Jede andere Handlung, wenn sie sich z.B. für das Nichtstun entscheiden, zwingt zu weiteren Fragen nach den Gründen für diese Entscheidung. Die Frage, aufgrund welcher Motive sich Individuen für bestimmte Handlungen entscheiden und in welchem Ausmaß sie dabei vorab bestimmte Ziele verfolgen, sind Grundfragen jeder Handlungstheorie. Doch bevor hierauf eingegangen werden kann, muss auf das Problem aufmerksam gemacht werden, dass sich Handlungstheorie heute in weitaus größerem Maße als früher mit der Skepsis auseinandersetzen muss, ob Handeln überhaupt als eine allein dem 
Menschen zukommende Fähigkeit bezeichnet werden kann. Diese Skepsis stützt sich auf die Beobachtung von Tieren, die zu einer Relativierung der Tier-Mensch-Differenz geführt hat, und auf die Entwicklung technischer Systeme, die Artefakte sind, deren Funktionstüchtigkeit nicht auf permanenten Eingriffen von Menschen beruhen.

Es ist kaum zu ignorieren, dass es auch Tiere gibt, die ihre Bewegungen variieren können, und die, um einen anderen Bedeutungshorizont aufzureißen, intelligent sind. Es gibt viele Tierarten, auch solche, die keine nahen Verwandten des Menschen sind, die nicht als vollständig instinktgebunden bezeichnet werden können. Selbst der Gebrauch von Gegenständen als Werkzeug, der von jedem einzelnen Wesen erlernt werden muss, ist eine Fähigkeit, über die nicht nur der Mensch verfügt. Die Feststellung, dass Intelligenz nicht ausschließlich dem Menschen vorbehalten ist, ist, wenn sie auch in den vergangenen Jahrzehnten durch zahlreiche Beobachtungen in der freien Wildbahn ${ }^{17}$ umfassender abgesichert wurde, keine grundsätzlich neue. Bereits Aristoteles war aufgefallen, das es Tiere gibt, die über Vorstellungskraft verfügen. Ihre Vorstellungskraft sei jedoch im weit größeren Maße an ihr Wahrnehmungsvermögen gebunden, als dies beim Menschen der Fall ist. Diese Ungebundenheit und damit die Fähigkeit, ihr Handeln einem Entscheidungsprozess zu unterwerfen, fehle den Tieren. Ihnen sei es nicht möglich, »unter einer Mehrzahl von Vorstellungen Eine zu verwirklichen. Und dies ist der Grund, dass die Tiere auf einem Schlussverfahren beruhende Entscheidung nicht kennen, auf der der Entschluss beruht.« (1963a: 182). Plessner spricht in diesem Zusammenhang von instinktiv bedingtem Handeln. Es braucht »nicht notwendig ohne Begleitung des Bewusstseins zu verlaufen, der Instinkt tritt nicht an die Stelle des Bewusstseins, sondern er formt und trägt es.« (1928: 262) »Einsicht in Feldverhalte, Einblicke in eine bestimmte Struktur oder Situation des umgebendes Feldes« (ebd.: 276), sei Tieren nicht zu verwehren. Im Unterschied zu Pflanzen seien sogar alle Tiere zum Handeln in der Lage, weil sie zur »Korrigierbarkeit der Bewegungsreaktionen durch die individuelle Vergangenheit des Organismus« (ebd.: 279) in der Lage seien. Die Differenz zwischen Tier und Mensch sieht er in einen Bruch zwischen seinem leiblichen Agieren und seinem handelnden Körper angelegt (vgl. Honneth/Joas 1980: 75; weiteres siehe Abschnitt 5.4.).

In der Phantasie sind intelligente, handelnde Maschinen schon sehr lange präsent. Ihren Niederschlag hat diese Vorstellung in zahlreichen Werken der Science Fiktion Literatur und in entsprechenden Filmen gefunden. Diese Werke wiederum haben nicht unwesentlich zahlreiche Ingenieure und Techniker, die sich mit der Entwicklung neuer Maschinen be-

17 Die meisten früheren wissenschaftlichen Untersuchungen, wie die von Köhler an Schimpansen, fanden unter Laborbedingungen statt; siehe hierzu Plessner (1928): 267. 
schäftigen, inspiriert. ${ }^{18}$ Seit einigen Jahren gibt es nicht mehr nur Maschinen, deren Funktionstüchtigkeit darauf beschränkt ist, zwischen zwei Zustände zu oszillieren - Leerlauf und berechneter Verlauf (Rammert/SchulzSchaeffer 2002: 14) - und dabei zum Beispiel Kraft (Drehmoment) auf eine Welle zu übertragen. Vor allem in den letzten zwei Jahrzehnten konnten technische Systeme entwickelt werden, die selbstständig, also ohne weiteren Eingriff eines Menschen, die ihnen gestellte Aufgabe erfüllen und dabei unter verschiedenen Optionen auswählen können, beispielsweise, wie sie sich im Raum bewegen, um einen bestimmten Zweck zu erreichen. So will der amerikanische Rüstungskonzern Lockheed Martin eine Drohne entwickelt haben, die unabhängig von einem Operator innerhalb des Suchgebiets verschiedene gegnerische Waffensysteme und ihre Schwachpunkte erkennt und unter diesen Zielen das mit der höchsten Priorität attackiert. Da bei einem Einsatz innerhalb eines Suchgebietes gleich mehrere Drohnen gestartet werden, sollen diese Drohnen untereinander erstens ihre Flugbewegung selbstständig aufeinander abstimmen können, so dass sie sich gleichmäßig verteilen und innerhalb des Gebietes einen Schwarm bilden, und zweitens sollen sie in der Lage sein, ihre Ziele so untereinander abzustimmen, dass sie kein Ziel mehrfach attackieren. ${ }^{19}$ Solche Fähigkeiten von Maschinen, die ein Sich-auch-anders-entscheiden-können beinhalten, haben zu soziologischen Debatten über die Frage nach dem Verhältnis von Technik und Handeln geführt. Als exzeptionell und deshalb die Debatten anregend kann das Konzept von Bruno Latour bezeichnet werden, das er insbesondere in den 90er Jahren formuliert hat. Um technische Handlungsträgerschaft empirisch beobachtbar zu machen, wird in dem Konzept von einer Symmetrie zwischen menschlichen Akteuren und Nicht-Menschlichen ausgegangen, die gemeinsam als Aktanten in Handlungsprozessen miteinander interagieren. Jedes Artefakt und nicht nur Menschen können somit >handeln<. Der Vorteil einer solchen Betrachtung liegt darin, dass in das Blickfeld dieser Handlungstheorie rückt - weitaus stärker als dies gemeinhin geschehen kann - welch einen großen Anteil die >Aktivitäten < von Artefakten beim Handeln haben. Dies gelingt nicht zuletzt, weil auf Seiten der Akteure nicht zwischen Handeln und Verhalten differenziert werden muss. Die Interaktion von Mensch-Artefakt kann unter dem Aspekt der

18 Die Entscheidung sein Leben dem Bau intelligenter Maschinen zu widmen, führt beispielsweise Rodney Brooks auf den SF-Film »2001: Odyssee im Weltraum« und auf die Figur des Computers Hal 9000 zurück (2002: 75).

19 Im November 2005 erklärte der Konzern in einer Presseerklärung die Flugtests als erfolgreich abgeschlossen (siehe http://www.lockheedmartin.com/ news/press_releases/2005/LockheedMartinSuccessfullyFlightTes.html; Zugriff 1.9.07). Mit diesem Projekt ist die Erwartung verbunden, dass sich die einzelnen Maschinen relativ kostengünstig hergestellt lassen - der Projektname lautet deshalb auch Low Cost Autonomous Attack System (Locaas). Ungewöhnlicherweise werden die Maschinen als Munition eingestuft. Sie gehören bislang nicht zum Arsenal der US-Streitkräfte. 
aufeinanderbezogenen Beiträge von gleichwertigen Aktanten zum Handlungsverlauf betrachtet werden. Die Stärke dieses Konzept macht aber zugleich auch seine Schwäche aus, weil erkennbare handlungsrelevante Differenzen zwischen Artefakten und Akteuren nicht gewichtet werden können. Die Bedeutung, die Motive und Emotionen für das Handeln haben, die Fähigkeit dem eigenen Tun Sinn zu geben und dadurch wiederum die Handlung zu verändern, bleiben in dem Konzept unberücksichtigt. Ohne für immer ausschließen zu wollen, dass es irgendwann einmal möglicherweise Artefakte gibt, die über solche Fähigkeiten verfügen, muss man feststellen, dass es bis heute keine derartige Maschinen gibt. Die Schwäche des Konzepts soll im Folgenden kurz anhand eines Beispiels illustriert werden, das Latour selber einführt und das im Rahmen dieser Arbeit von Interesse ist: Wie lässt sich das Handeln eines »Hybrid-Akteurs aus Waffe und Schütze« analysieren (1998: 35)? Aufgrund seines Postulats der Symmetrie der Aktanten sind das Gewehr und der Schütze gleichermaßen an der Durchführung einer Handlung, wie dem Töten beteiligt. Sicher richtig ist, dass ein Schütze ohne ein Gewehr nicht schießen kann. Es ist aber schlicht nicht sinnvoll zu behaupten, dass ein Gewehr oder die Kugel irgendeinen emotionalen Zustand annimmt, wenn das Geschoss >sein Z Ziel verfehlt. Mit seiner auf den Schützen konzentrierten Überlegung nivelliert das Konzept, so stellt Lindemann fest, »vollständig die Unterschiedlichkeit des Beitrages, den das körperlich-leibliche Selbst und das technische Artefakt zum Erfolg der Handlung beisteuern. Im Sinne des verteilten Handelns könnte man maximal sagen, dass das Gewehr einen entfernungsüberbrückenden Mechanismus beisteuert. Es wählt nicht selbst das Ziel aus, sondern es limitiert allenfalls die Zielauswahl aufgrund technischer Grenzen, z. B. der Reichweite.« (Lindemann 2005: 132)

Dass die bestehenden Differenzen Menschen und Maschinen nicht durch einen auf Symmetrie angelegten Handlungsbegriff unbeachtet bleiben sollten, fordern inzwischen zahlreiche Debattenbeiträge, die, wenn auch aus verschiedenen Blickrichtungen, vor allem betonen, dass Maschinen nicht in der Lage sind, durch Sinngebungs- und durch Reflexionsprozesse Handlungsbedingungen zu erzeugen bzw. zu verändern (siehe hierzu den Sammelband von Rammert/Schulz-Schaeffer (2002)). Da aus handlungstheoretischer Sicht, so beispielsweise Rammert/Schulz-Schaeffer, nicht behauptet werden kann, dass Handlungsketten allein aus den Tätigkeiten sozialer Akteure entstehen, plädieren sie dafür, die Handlungsträgerschaft von Technik graduell, das heißt je nach ihren beobachtbaren Anteil, konzeptionell zu berücksichtigen. Auf Überlegungen aus diesem Theorierahmen wird in Abschnitt 8.2. zurückzukommen sein.

Jedes Individuum handelt, und die Fähigkeit zum Handeln ist auf das engste mit dem Potential, ein Subjekt zu sein, verbunden. Doch wie oben bereits angedeutet, wird ein Individuum nicht unmittelbar durch die Fähigkeit zum Handeln zu einem Subjekt. So gilt für Soldaten, dass ihnen dieser 
Status nicht zuerkannt wird, obwohl man sagen kann, dass Soldaten handeln. Sie tun dies in einem umgangssprachlichen Sinne, der jedes Tun mit Handeln gleichsetzt. Ihr Tun ist absichtsvoll, unterliegt also bewussten Motiven. Fraglich ist allerdings, inwieweit ihre Handlungen (als Soldaten) als Ausdruck ihres Subjektseins gewertet werden können. Soldaten sind Angehörige einer Institution, die ihre Bewegungen, ihre Sprache, ihren gesamten Alltag in einem Ausmaß reglementiert, zu der es keine Parallele in der zivilen Arbeitswelt gibt. Soldatsein ist trotz aller im 20. Jahrhundert immer wieder konstatierten Tendenzen zur Zivilisierung des Soldatenberufs, die vor allem im Zuge der Technisierung des Krieges beobachtet wurden, nicht zum zivilen Beruf geworden. ${ }^{20}$ Obwohl über die Stichhaltigkeit der Beschreibung Herders, der das Militär seiner Zeit als »eine gedanken-, kraft- willenlose Maschine« bezeichnete, »die ein Mann in seinem Haupte lenkt und die er nur als Pantin der Bewegung, als eine lebendige Mauer bezahlt, Kugeln zu werfen und Kugeln aufzufangen« (1774: 59f.; Pantin (frz.) bedeutet Hampelmann) diskutiert werden kann, werden bis heute Soldaten überwiegend als Objekte wahrgenommen. So stellte Seifert mit Blick auf die Militärsoziologie fest, dass die Soldaten letztendlich Befehle zu befolgen »und, so die tradierte Überzeugung, dabei als Subjekte nicht gesondert in Erscheinung zu treten haben.« (1996: 17) Wie die Beziehung zwischen Handeln und soldatischen Subjekten anders ausgeleuchtet werden kann, soll mit den nachfolgenden Ausführungen weitergeklärt werden.

Wie alle anderen sozialwissenschaftlichen Disziplinen hat auch die Soziologie im weiten Feld des menschlichen Tuns sich einen bestimmten Claim abgesteckt, den sie im Rahmen ihrer Handlungstheorie untersucht. Nicht Handeln in toto, sondern ausschließlich soziales Handeln ist der Gegenstand soziologischer Handlungstheorien. Grundlegend für das Verständnis sozialen Handelns ist hierbei Webers Definition:

»)Handeln` soll [...] ein menschliches Verhalten (einerlei ob äußeres oder innerliches Tun, Unterlassen oder Dulden) heißen, wenn und insofern als der oder die Handelnden mit ihm einen subjektiven Sinn verbinden. >Soziales〈 Handeln aber soll ein solches Handeln heißen, welches seinem von dem oder den Handelnden gemeinten Sinn nach auf das Verhaltern anderer bezogen wird und daran in seinem Ablauf orientiert ist.« (1922: 1)

20 So rechnete bereits Janowitz/Little mit einer >Verzivilisierung` des Militärs, also einer Angleichung der sozialen Organisation des Militärs an die umgebende Gesellschaft, um auf den »phantastischen technischen Wandel« (1965: 35) zu reagieren, doch könne dieser Prozess nie vollständig sein, weil dem die militärische Autoritätsstruktur als »Ausdruck der einzigartigen Ziele, nämlich Kampf und Vorbereitung zum Kampf« (ebd.) entgegenstehe. Siehe hierzu auch Heins/Warburg (2004: 49). 
Im Verlauf der weiteren Erörterung grenzt Weber soziales Handeln vom Verhalten ab, das anderen sozialwissenschaftlichen Disziplinen, wie der Psychologie und der Ethnologie, überlassen bleibt. Gleichartiges Tun mehrerer Handelnder, als Beispiel führt Weber das gleichzeitige Aufspannen von Regenschirmen, wenn es anfängt zu regnen, an, soll außerhalb der Betrachtung bleiben. Ebenso wenig interessiert das Handeln Einzelner, wenn es aus dem Verhalten einer Masse resultiert. Wie ein Mensch in einer eng zusammengedrängten Menge reagiert, gehöre vielleicht zur Psychologie der Masse im Sinne Le Bons, aber nicht zur Soziologie. (Ebd.: 11) Von konstitutivem Interesse für die Soziologie als Soziologie ist demgegenüber soziales Handeln, also ein Handeln, das ein in einem »mehr oder minder unbemerkt >gehabten Sichverhalten zu 〉Objekten«« (1913: 99) meint. Am Rande sei in diesem Zusammenhang notiert, dass Webers Illustrationen sozialen Handelns die Interpretation nahe legen, dass der Handelnde wenig Gutes von diesen >Objekten ২ zu erwarten hat. So heißt es: »Soziales Handeln [...] kann orientiert werden am vergangenen, gegenwärtigen oder für künftig erwarteten Verhalten anderer (Rache für frühere Angriffe, Abwehr gegenwärtigen Angriffs, Verteidigungsmaßregeln gegen künftige Angriffe).« (1922: 11) Er unterscheidet vier Typen, die »jedes Handeln« also »auch das soziale Handeln« bestimmen.

»1. zweckrational: durch Erwartungen des Verhaltens von Gegenständen der Außenwelt und von anderen Menschen und unter Benutzung dieser Erwartung als >Bedingung ২ oder als >Mittel für rational, als Erfolg, erstrebte und abgewogene Zwecke, - 2. wertrational: durch bewussten Glauben an den ethischen, ästhetischen, religiösen oder wie immer sonst zu deutenden - unbedingten Eigenwert eines bestimmten Sichverhaltens rein als solchen und unabhängig vom Erfolg, 3. affektuell, insbesondere emotional: durch aktuelle Affekte und Gefühlslagen, 4. traditional: durch eingelebte Gewohnheit.«(Ebd.: 12) ${ }^{21}$

21 In der Soziologie werden die Emotionen höchst unterschiedlich definiert und gegenüber weiteren Begriffen wie Gefühle oder Empfindungen abgegrenzt (vgl. Neckel 2006: 127f.). In der Psychologie wird eher von Affekten als von Emotionen gesprochen und auch hier gilt, dass die Begriffe unterschiedlich konzipiert werden. Eine wissenschaftlich befriedigende Definition und Theorie der Affekte gilt als bislang nicht gefunden (vgl. Mertens/Waldvogel 2000). Vor diesem Hintergrund wird folgende Unterscheidung vorgenommen: Die Begriffe Affekt und Emotion werden bezüglich des Ausmaßes in dem sie willentlich moderiert können, unterschieden. Affekte treten im Verhältnis zu Emotionen impulsiver auf, werden eindeutiger von physiologischen Veränderungen begleitet und entziehen sich eher der willentlichen Kontrolle des Individuums. Beobachtungen der Säuglingsforschung sprechen dafür, dass die Differenz zwischen Affekt und Emotion auf anthropologische Gegebenheiten verweist. So wurden bei Säuglingen, die nicht älter als ein halbes Lebensjahr waren, mindestens sieben verschiedene Gesichtsausdrucksmuster festgestellt denen sich entsprechende Affekte (Interesse, Überraschung, Ekel, Freude, Ärger, Traurigkeit und Furcht) zuordnen ließen. 
Trotz dieser Differenzierung, trotz des ausdrücklichen Hinweises, dass insbesondere soziales Handeln selten »nur in der einen oder der anderen Art orientiert ist « und obwohl Weber nicht den Anspruch postuliert, er habe eine »erschöpfende Klassifikation« (ebd.: 13) vorgenommen, ist kaum zu übersehen, welche überragende Bedeutung Weber dem zweckrationalen Handeln einräumt. Nur wer zweckrational handelt, wer also sein Handeln »nach Zweck, Mitteln und Nebenfolgen orientiert, und dabei sowohl die Mittel gegen die Zwecke, wie die Zwecke gegen die Nebenfolgen, wie endlich auch die verschiedenen möglichen Zwecke gegeneinander rational abwägt« (ebd.), der kontrolliert umfassend die Handlungselemente Zweck, Mittel und Folge. Alle anderen Handlungstypen werden dem gegenüber als defizitär kategorisiert (siehe hierzu auch Joas, 1996: 63) Sofern Individuen nicht nur subjektiv beanspruchen, zweckrational zu handeln, es ihnen folglich gelingt, ihr Handeln auch »am objektiv Gültigen« (1913: 103) auszurichten, können sie ihr Leben rational gestalten und lassen sie sich im umfassenden Sinn als Subjekte bezeichnen. ${ }^{22}$

Mit seiner Einstufung der Rationalität als dem Kriterium für Handeln steht Weber nicht alleine. Die Tendenz, zumal kompetentes soziales Han-

Diese Gesichtsausdrucksmuster sind in unterschiedlichen Kulturen gleich und sie müssen nicht erlernt werden (vgl. Dornes 2000: 21). In der Literatur werden diese so genannten Primäraffekte oder auch it-emotions von später auftretenden selbstreflexiv me-emotions unterschieden, die für eine innere psychische Struktur des Individuums notwendig sind (vgl. Krause 1990). Gemeint sind Gefühlszustande wie Scham, Schuld, Neid, Empathie, Peinlichkeit und Stolz. Sie sind stark mit dem Erwerb der Sprache und der Symbolisierungsfähigkeit des Individuums verknüpft.

Die Begriffe Emotion und Gefühl werden, Neckels Vorschlag folgend (2006: 128), als semantische Äquivalente verwendet. Hunger, Durst und Schmerz werden dagegen bevorzugt als Empfindung bezeichnet, um den Aspekt des leiblichen Sich-selber-spüren mehr Rechnung zu tragen.

22 Um Missverständnissen vorzubeugen, sei mit Weber darauf hingewiesen, dass »nicht jedes >richtigkeitsrational ablaufende Handeln subjektiv-zweckrational bedingt« sein muss (1913: 106). Ganz sicher war Weber nicht der Meinung, dass in modernen Gesellschaften die Individuen zunehmend zu einem solchen Handeln fähig sind. »Der Fortschritt der gesellschaftlichen Differenzierung und Rationalisierung bedeutet [...] normalerweise, ein im ganzen immer weiteres Distanzieren der durch die rationalen Techniken und Ordnungen praktisch Betroffenen von deren rationalen Basis. Die ihnen im ganzen, verborgener zu sein pflegt wie dem >Wilden « der Sinn der magischen Prozeduren seines Zauberers. « Deshalb verschmälert sich sogar eher die Basis für zweckrationales Handeln: »Der >Wilde〈 weiß von den ökonomischen und sozialen Bedingungen seiner eigenen Existenz unendlich viel mehr als der im üblichen Sinn 〉Zivilisierter.« (Ebd.: 149f.) Letzterer unterscheidet sich vom >Wilden $\mathrm{zu}$ können und durch seine Zuversicht, dass sie nach bekannten Regeln (=rational) beeinflusst werden könnte. Tatsächlich stehe aber das Individuum den Bewegungskräften der Rationalisierung und Bürokratisierung >normalerweiseく ohnmächtig gegenüber. 
deln mit (zweck-)rationalem Handeln zu identifizieren, ist bis tief in das 19. Jahrhundert den meisten Versuchen, menschliches Handeln zu konzeptualisieren, eigen. Ihr ist zugleich insbesondere eine Abwertung affektiver Handlungsmotive eingeschrieben. Bereits bei Hobbes, der von Fetscher als quasi erster moderner Utilitarist eingestuft wird (1984: XX), fällt auf, dass Affekte als Gefahr für das Primat der Rationalität angesehen werden deshalb sind Männer, die unmittelbar von ihren Affekten geleitet werden, nach Hobbes »grundsätzlich auf äußere Hilfe angewiesen [...], wie Frauen und Kinder« (Hobbes 1651: 45). Rationalität entsteht bei Hobbes erst, wenn es dem Individuum gelingt, sich von seinen Leidenschaften soweit zu distanzieren, dass ein Freiraum für das Denken entsteht. »Gedanken sind gleichsam die Kundschafter und Spione der Wünsche, die das Gelände erkunden und den Weg zu den gewünschten Dingen finden sollen [...].« (ebd.: 56) Gleichwohl sieht Hobbes sowohl ein unmittelbar von den Leidenschaften motiviertes Handeln, wie auch ein Handeln, in das rationale Abwägungen eingeflossen sind, als permanente Gefahrenquelle für die soziale Ordnung an, weil das Individuum bei seinem Streben nach einem angenehmen Leben im Konflikt mit anderen Individuen geraten müsse. Gerade weil die Menschen von Natur aus weitgehend mit den gleichen körperlichen und geistigen Fähigkeiten ausgestattet seien, entstehe die Hoffnung, den gleichen Gegenstand besitzen zu können wie ein anderer Mensch. »Und wenn daher zwei Menschen nach demselben Gegenstand streben, den sie jedoch nicht zusammen genießen können, so werden sie Feinde und sind in Verfolgung ihrer Absicht, die grundsätzlich Selbsterhaltung und bisweilen nur Genuss ist, bestrebt, sich gegenseitig zu vernichten oder zu unterwerfen.« (Ebd.: 95) Nur das Abwägen zwischen verschiedenen Leidenschaften ermögliche deshalb eine stabile soziale Ordnung. Um die drei hauptsächlichen Konfliktursachen Konkurrenz, Misstrauen und Ruhmsucht (ebd.) in die Schranken zu weisen, müsse es der Staat verstehen, die Leidenschaften »Todesfurcht, das Verlangen nach Dingen, die zu einem angenehmen Leben notwendig sind und die Hoffnung, sie durch Fleiß erlangen zu können« (ebd.: 98) zu stärken, um die Menschen friedfertig zu machen.

Angefangen von der »frühen politischen Ökonomie und der Moralphilosophie des Utilitarismus« (Joas 2000: 275) gilt im Rahmen eines Denkens, das auf diese oder ähnliche Weise Handlungen konzeptualisiert, nur dann ein Individuum als ein Subjekt, wenn es ihm gelingt, sich von seinen tendenziell widerstreitenden Leidenschaften zu distanzieren, wenn nur das Motiv handlungsbestimmend wird, das eine Mehrung subjektiven oder objektiven Nutzen verspricht; ein Individuum also, das in einer gegebenen Situation die optimalen Handlungen zur Umsetzung seines verfolgten Zweckes auswählt. Dieser gesamte Entscheidungsprozess muss im Idealfall vor dem Vollzug der Handlung abgeschlossen werden, damit von einem rationalen Handeln gesprochen werden kann. 
Aufgrund einer derartigen Konzeptualisierung des Handelns von Subjekten leuchtet es ein, das Handeln von Soldaten nur in einem äußerst eingeschränkten Sinne, wenn überhaupt, als Handeln von Subjekten zu erachten. Individuelles Handeln von Soldaten gilt als befehlsgebunden. Soldatisches Handeln kann deshalb im besten Fall nur als Umsetzung einer Rationalität interpretiert werden, deren Bestimmungen außerhalb ihrer selbst liegt, konkret bei ihren Vorgesetzten. Anders ausgedrückt: Soldaten sollen die Vollstrecker eines anderen Willens sein. Handeln sie freiwillig, ist dies zwar umso besser, doch im Grunde sollen sie auch dann die erteilten Befehle ausführen, wenn sie ihnen widerstreben. Wie gravierend das individuelle zweck-rationale Handeln mit dem eines Vorgesetzten in Konflikt geraten kann, ist besonders in Kampfsituationen deutlich. Vorgesetzte müssen den Tod ihrer Untergebenen billigend in Kauf nehmen, um ihre Ziele zu erreichen. Im Sinne einer zweck-rationalen Operationalisierung ihres Handelns fällt es schwer sich vorzustellen, dass das Risiko schwer verletzt oder gar getötet zu werden, in einem nur halbwegs rationalen Verhältnis zu einem subjektiven oder objektiven Nutzen für das Individuum stehen kann. Selbst wenn man annimmt, dass es Formen sozialer Anerkennung gibt, die den Verlust der eigenen körperlichen Versehrtheit und des eigenen Lebens aufwiegen können, dürfte es einem Soldaten schwer fallen einzuschätzen, welche Bewertung sein Handeln im und nach dem Krieg erfahren wird. Schließlich kann ein Soldat kaum überblicken, welche Bedeutung sein Handeln für den Verlauf des Krieges haben wird, ob er also sein Leben riskiert, um beispielsweise einen kurzfristigen taktischen Vorteil auf dem Schlachtfeld zu erringen, der für den Verlauf des Krieges völlig bedeutungslos ist und an dem sich später niemand mehr erinnern wird, oder ob er eine kriegsentscheidende Handlung vollziehen soll, die zumindest potentiell die Chance enthält, als so genannte Heldentat bezeichnet zu werden. Vor diesem Hintergrund ist es a priori naheliegend zu vermuten, dass das Motiv der Soldaten, sich einem fremden Willen zu unterwerfen, weniger ihrer eigenen Ratio entspringt, als vielmehr sich von Motiven herleiten lässt, die gleich in mehrfacher Beziehung im Hinblick auf das Kriterium Zweckrationalität defizitär sind. Diese Vermutung lässt sich leicht bestätigen: Wenn Soldaten befragt werden, aufgrund welcher Motive sie sich freiwillig zum Dienst als Soldat verpflichtet haben, werden regelmäßig Antworten erhoben, die sich unter Webers Bestimmungen Wertrationalität, Affekte und Tradition einordnen lassen. ${ }^{23}$ Selbst die Rational-Choice-Theorie, die den Begriff der Rationalität strikt auf ein Abwägen zwischen Kosten und Nutzen beschränkt und davon ausgeht,

23 Für das professionelle Selbstverständnis von Soldaten kommen »in Janowitz' Vorstellung Expertentum und Korpsgeist sowie Verantwortungsbewusstsein, was militärisches Handeln« betrifft (Seifert 1996: 108), eine zentrale Bedeutung zu. Weitere Stichworte, die in diesem Zusammenhang fallen, sind Vorstellungen von $\gg$ Kameradschaft $\iota, ~>$ Tapferkeit $\iota$ und $\gg$ Heldentum . 
dass sich ein Individuum für die Handlungsmöglichkeit entscheidet, welche die günstigste Kosten-Nutzen-Bilanz beinhaltet, hat Schwierigkeiten zu erklären, weshalb Individuen sich dem Risiko aussetzen, verletzt und getötet zu werden. Während noch die Entscheidung eines Individuums für den Dienst als Soldat sich im Rahmen der Rational-Choice-Theorie durch selektive Anreize erklärt lässt, die von der besonderen sozialen Anerkennung des Soldatseins bis hin zum sicheren Arbeitsplatz reicht, legt die Theorie für die Beteiligung an gefährlichen Einsätzen nahe, dass die Kosten-Nutzen-Bilanz für den einzelnen Soldaten negativ ausfallen kann (siehe Braun 1985: 121f.; Biehl/Hagen/Mackewitsch 2000: 257). Im Kampf selber mag sich zwar ein Soldat der Situation entsprechend nach zweckrationalen Kriterien für bestimmte Bewegungen entscheiden, doch angesichts der Gefahren und der damit auftretenden Emotionen, wird selbst diese Rationalität grundsätzlich als brüchig eingeschätzt. Brüchig nicht zuletzt deshalb, weil Soldaten während ihres (Kampf-)Einsatzes von Seiten der Organisation verwehrt wird, aus ihrem Abwägen der Kosten und Nutzen die postulierten rationalen Konsequenzen zu ziehen. Als rationale Akteure müssten sie aufhören, Soldaten zu sein.

Während bis heute in den meisten ökonomischen Theorien Handeln nach dem Modell homo oeconomicus konzipiert wird, wonach es dem rationalen Kalkül individueller Nutzenmaximierung unterliegt, bilden in der Soziologie diese Modelle lediglich einen Pol der vorherrschenden Handlungsmodelle. Ihnen stehen Theorien gegenüber, die von der Normativität des Handelns ausgehen. Sie beanspruchen, gegenüber den an der Ratio orientierten Handlungsmodellen eine originäre soziologische Interpretation menschlichen Handels. Grundlage ihrer Überlegungen ist nicht die Annahme eines in der Tendenz von sozialen Bezügen losgelösten Individuums, sondern die Hypothese, dass sich individuelles Handeln innerhalb eines von den Individuen geteilten, also eines sozialen Bezugrahmens, den Normen, vollzieht. Normative Handlungsmodelle haben damit in weitaus geringerem Maße wie die oben beschriebenen an Zweckrationalität orientierten Handlungsmodelle das Problem zu erklären, wie sich Individuen sinnvoll aufeinander beziehen können, ohne, wie bei Hobbes gezeigt, übereinander herzufallen, wenn sie nicht von einem Dritten, bei Hobbes ist das der Staat, daran gehindert werden. Verfolgen die Individuen bei Hobbes lediglich im optimalen Fall zweckrationale Kalküle und ist die soziale Vermittlung ihrer Kalküle zumindest als unsicher zu bezeichnen, gehen normative Handlungsmodelle grundsätzlich davon aus, dass die Individuen durch den Prozess der Verinnerlichung von Normen in eine Gesellschaft integriert werden. Das Individuum, das versucht, sein Handeln nach zweckrationalen Kriterien zu bestimmen, verfolgt demnach nur eine mögliche normative Handlungsorientierung, die für eine bestimmte soziale Ordnung wichtig sein mag, der per se aber keine universelle Bedeutung zukommt. 
Das Militär wird im Rahmen normativer Handlungstheorien als ein soziales System interpretiert, in dem gegenüber der übrigen Gesellschaft andere Normen gelten. So bildet das Militär nach Janowitz, der als ein Nestor der Militärsoziologie gilt, »einen Männerbund, welcher informell in größerem Maße Ausschweifungen im Verhalten duldet als die gemischte zivile Gesellschaft.« (Janowitz/Little 1965: 75) Die Aufgabe des Militärs, die z.B. als die Produktion von äußerer Sicherheit gefasst werden kann, bedingt, dass hier Normen wie Tapferkeit und Heldentum als Statussysteme gelten müssen, die in der übrigen Gesellschaft auf Ablehnung stoßen würden, sollte man versuchen, sie auch hier einzufordern. Die Besonderheiten des Militärs werden als Erfordernisse interpretiert, die unmittelbar aus seiner Aufgabe resultieren - ohne die Anerkennung als Held würden die Soldaten weniger geneigt sein, besondere Gefahren auf sich zu nehmen - und dem Zusammenhalt des Sozialverbandes, der selbst unter extremen Belastungen nicht zerbrechen darf. Für letzteres lautet das zentrale Stichwort soziale Kohäsion. Es wird davon ausgegangen, dass Mannschaften wie Offiziere im Idealfall so enge soziale Beziehungen untereinander unterhalten, wie sie außerhalb des Militärs nur innerhalb einer Familie oder z.B. in Peergroups zu finden sind (siehe hierzu ausführlich in Kapitel 8.1.). Damit die Sozialbeziehungen im Militär diese Qualität annehmen können, muss sich die Normenwelt des Militärs von der umgebenden Gesellschaft unterscheiden, was in zahlreichen Staaten noch dadurch abgesichert wird, dass Militärangehörige einer besonderen Gerichtsbarkeit unterstehen. Die ersten Ausbildungsziele, die alle neuen Angehörigen während ihrer ersten Ausbildungsphase durchlaufen müssen, dienen dem Ziel, die Rekruten »normempfindlich« (Treiber 1973: 72f.) zu machen. Ihnen wird beigebracht, zu gehorchen und wie sie sich in den Verband integrieren können. Um die Prägekraft der militärischen Normenwelt zu erhöhen, werden deshalb vor allem in der ersten Ausbildungsphase die Kontakte der Rekruten zu ihrem vorherigen zivilen Umfeld erschwert.

Normorientierte Handlungsmodelle formulieren Aussagen, wie Individuen handeln müssen, um Soldaten zu sein. Soldatisches Handeln heißt, einer bestimmten Norm entsprechend zu handeln. Derart gerüstet, lässt sich untersuchen, inwieweit Rekrutierung, Ausbildung, Statussystem, die Formierung der Einheiten etc. geeignet sind, die Kampfkraft der Soldaten zu erhöhen und welche Bedingungen möglicherweise dazu führen, sie zu senken. Es lässt sich unter anderem untersuchen, ob und welche Spannung zwischen Militärangehörigen und Zivilisten bestehen, welche Bedingungen für eine Reintegration von Wehrpflichtigen und Berufssoldaten in das Zivilleben erfüllt sein müssen und inwieweit sich Soldaten in einem Rollenkonflikt befinden, z.B. weil für sie in ihrer Berufsrolle als Soldat das für alle geltende Tötungsverbot im Krieg aufgehoben ist und gleichzeitig für sie, in ihrer Rolle als Zivilist, weiterhin gilt. 
Solche normativ geleiteten Fragestellungen an das Handeln von Soldaten prägen die empirische Sozialforschung der Militärsoziologie. Wie oben bereits ausgeführt, werden sie hier eher selten als Subjekte betrachtet. Das ist, wie ein Blick auf die Fragestellungen zeigt, auch konsequent. Soldaten treten in den Fragestellungen nicht als >Zweck an sich selber` (Kant) auf, sondern werden als Mittel zum möglichst effizienten Einsatz von Gewalt betrachtet. Das Handeln der Soldaten wird, ebenso wie die Normenwelt des Militärs, beschrieben und typisiert, um zu klären, inwieweit es dem Zweck dienlich ist, Krieg führen zu können und damit ein effektives Machtinstrument des Staates zu sein. An das soldatische Handeln werden also Erwartungen formuliert, wie ein guter Soldat handelt. Im Mittelpunkt der Fragestellungen steht, welche Bedingungen die Institution schaffen muss, um dieses bestimmte Handeln zu fördern. Die einzelnen Soldaten haben die ihnen zugewiesenen Rollen auszufüllen, sei es als Fahrer, sei es als MG-Schütze oder als Pilot. Als Subjekte treten die Individuen im Rahmen derartiger Untersuchungen nicht auf. Die Individuen werden vielmehr als Träger von Normen- bzw. Wertorientierungen erachtet, die sie im Laufe ihres Lebens verinnerlicht haben und die sich in ihrem Handeln ausdrücken. Unklar bleibt dabei in aller Regel, wie diese handlungsorientierenden Werte entstanden sind und das bedeutet, ob bzw. welchen Anteil die Individuen an ihrer Entstehung und ihrer Veränderung haben.

Vollzieht sich die Bewertung von Handlungen im Rahmen zweckrationaler Handlungsmodelle auf der Achse rational-irrational, so gehen normative Handlungsmodelle von der Skala rollenkonformem und abweichendem Verhalten aus bzw. noch allgemeiner gesagt, sie untersuchen, ob das individuelle Handeln der Normenwelt der sozialen Ordnung entspricht oder ihr widerspricht bzw. sie gefährdet. Wenn auch indirekt bewerten deshalb auch normative Handlungsmodelle individuelles Handeln als rational bzw. irrational. Bezogen auf zahlreiche militärsoziologische Untersuchungen galten in der Regel die Erwartungen, die an die Individuen gestellt wurden, als angemessen und das heißt rational für die Erfüllung der Zwecke des Militärs. Abweichendes Verhalten der Individuen galt demgegenüber zumindest der Tendenz nach als pathologisch (siehe hierzu auch Bröckling 1997: 314f.).

Diese Bewertung soldatischen Handelns lässt sich umkehren, was auch besonders im Zuge politischer Bewertungen geschieht. Abweichendes Verhalten wird dann $\mathrm{zu}$ einem rationalen, moralisch positiv bewerteten Handeln eines Individuums, das sich gegen die einschränkenden militärischen Normen, gegen Verhaltenszumutungen, wehrt und durch sein widersetzliches Handeln zum Subjekt wird. Der Preis für diese normative Bewertung nonkonformen Handelns besteht in einer Eindimensionalität der Betrachtung. Subjekte zeichnen sich demnach durch unangepasstes, dissidentes Handeln aus. Alle Individuen, die befehlskonform handeln, 
werden der Tendenz nach nur als manipulierte Wesen wahrgenommen, deren eigener Anteil an ihrem Handeln systematisch unausgeleuchtet bleibt.

Einen Ausweg aus diesen dichotomen Betrachtungsweisen soldatischen Handelns können Überlegungen zur Kreativität des Handelns bieten. Im Folgenden soll gezeigt werden, wie mit ihnen soldatisches Handeln im Krieg, befehlskonforme Handlungen ebenso wie Handlungen, die den erteilten Befehlen widersprechen, als das Handeln von Subjekten aufgefasst werden können.

Grundlegend für das Vermögen zur Kreativität ist die menschliche Vorstellungskraft. Diese wiederum ist mit Popitz als eine von drei menschlichen Erkenntniskräften zu bezeichnen, deren Zusammenspiel das menschliche Erkenntnisvermögen strukturiert. Ihr kommt zwischen der Wahrnehmung, also der Vielfalt sensorischer Empfindungen und dem Denken eine vermittelnde Funktion zu (Popitz 2000: 84f.). In der Vorstellung bildet sich nicht einfach das zuvor Wahrgenommene ab, vielmehr beruht ihre vermittelnde Funktion darauf, dass sie unter der Mannigfaltigkeit der sensorischen Eindrücke »Bilder der Gegenstände« konstruieren kann (ebd.: 200). Von entscheidender Bedeutung für die Fähigkeit zur Kreativität ist ihre Eigenständigkeit gegenüber dem Wahrgenommenen. In der Vorstellung kann nicht nur Abwesendes präsent gehalten werden, sie kann sich auch nie Wahrgenommenes, also (Noch-)Nicht-Existentes, einbilden. Nur so ist es auch möglich, dass wir uns beispielsweise laufende und mit Menschen sprechende Bäume vorstellen können. ${ }^{24}$ Doch die Vorstellungskraft erlaubt es dem Menschen, nicht nur anthropomorph seine spezifische Weltsicht auf die Welt zu übertragen. Sie befähigt ihn auch, »das Seiende außerhalb seiner selbst als ein Anderssein, als eigenartiges So-Sein zu erfassen.« (Ebd.: 99). Popitz spricht in diesem Zusammenhang von »Allozentrik«, die ihn befähigt, »das Anderssein, die Alterität, >the otherness ¿ des Außer-ihm-Seienden zu ergründen« und die ihn befähigt, »nicht im Gegebenen unterzugehen und die Welt im Licht des AndersMöglichen zu sehen. Die Kategorie des Andersseins macht ihn kreativ.« (Popitz 2000: 100).

Im Rahmen einer Rezeption der Theoriegeschichte legt Joas die wohl derzeit umfangreichste Begründung vor, wie die Kreativität als Handeln zu

24 Wie weit die Eigenständigkeit der Vorstellungskraft geht, ist höchst umstritten. Sicher ist, dass sie wie das Denken nicht von diskursiven Praxen unbeeinflusst bleibt, die ihre Geschichte haben und die eingebettet sind in eine bestimmte Sozialität. Und bei aller Eigenständigkeit der Vorstellungskraft gegenüber der Wahrnehmung, setzen diese Diskurse der Freiheit des Konstruierten Grenzen. Das gilt selbst dort, wo nicht das objektiv Gegebene erkannt, sondern eine von ihm unterschiedene Welt phantasiert werden soll. So wird denn auch von Popitz angemerkt: »Das Ordnungsinteresse von Gesellschaften wird immer zum Versuch führen, Vorstellungsinhalte zu steuern. Vorstellungskontrolle ist ein wesentlicher Baustein sozialer Kontrolle.« (2000: 89) 
reflektieren ist. Er verfolgt mit seinen Ausführungen zwei zu unterscheidende Ziele. Zum einen sei neben den vorherrschenden Handlungsmodellen des rationalen und normativ orientierten Handelns ein drittes Modell zur Untersuchung menschlichen Handelns zu berücksichtigen, das sich dem kreativen Charakter des Handelns zuwendet. Dieses Anliegen verbindet er mit dem weitergehenden Anspruch, dass dieses Modell zugleich die beiden anderen Modelle überwölbe: »Es geht mir nicht nur darum, auf einen weiteren, bisher vernachlässigten Handlungstypus zu verweisen, sondern für alles menschliche Handeln eine kreative Dimension zu behaupten, die in den theoretischen Modellen des rationalen und des normativ orientierten Handelns nur unzulänglich zum Ausdruck kommt.« (Joas 1996: 15) Er begründet diesen weitergehenden Anspruch mit der Kritik, dass sowohl rationale wie normativ orientierte Handlungsmodelle von >rationalen « Handlungen ausgingen. Gegen diesen Ausgangspunkt der Modelle spreche, dass sie auf nicht selbstverständliche Weise Einzelhandlungen gegenüber ihrem Kontext isolierten. »Kontext hat dabei die doppelte Bedeutung, dass zum einen jede Handlung in einer Situation stattfindet und zum anderen einen Handelnden voraussetzt, der nicht nur diese eine Handlung hervorbringt. Schon in der Wahl des Ausgangspunktes könnte also eine theoretisch problematische Ablösung des Handelns von situativen und von biographischen Zusammenhängen angelegt sei.« (Ebd.: 214) Schwerer wiege aber eine weitere Folge dieser Konstruktion: »Jede Handlungstheorie, die hier einsetzt, produziert ein Gegenbild des NichtRationalen. Sie wirft über die phänomenale Vielfalt des Handelns zugleich ein wertendes Raster. Dies gilt unabhängig von der Bestimmung des Rationalitätsbegriffs in der jeweiligen Handlungstheorie.« (Ebd.) Rationalmodelle, worunter Joas alle Handlungsmodelle zusammenfasst, die »Rationalität enger oder weiter, utilitaristisch oder normativistisch fassen« (ebd.: 216), unterstellen »den Handelnden erstens als fähig zum zielgerichteten Handeln, zweitens als seinen Körper beherrschend, drittens als autonom gegenüber seinen Mitmenschen und seiner Umwelt. Eine geringe Konzentration des Handelnden auf zielgerichtetes Handeln, ein Verlust oder ein niedriger Grad an Körperbeherrschung, ein Verlust oder Verzicht auf die Autonomie des Individuums lassen aus dieser Perspektive den Handelnden als weniger rationalen oder nichtrationalen Akteur erscheinen und verringern die Wahrscheinlichkeit, dass seine Handlungen als rational klassifiziert werden dürften.« (Ebd.: 217) Zwar wissen die Vertreter dieser Konzeptionen, dass die Voraussetzungen ihrer Modelle »sehr häufig nicht gegeben sind; sie sind aber gezwungen, die eingeschränkte Gültigkeit solcher Voraussetzungen als Defizite nicht ihrer Theorie, sondern den Handelnden selbst zuzuschreiben.« (Ebd.)

Wenngleich verhalten in einer Fußnote vorgetragen (Joas 1996: 216), trifft diese Kritik, auch handlungstheoretische Modelle, die an Schütz anknüpfen, also zum Beispiel Luckmann, und in ihrer Konstitutionsanalyse 
der Handlung vom Bewusstsein ausgehen. ${ }^{25}$ Demgegenüber macht Joas eine pragmatische Aufklärung des Handelns stark, also eine, die im Handeln selber Gründe für das Handeln eingeschrieben sieht. Einsetzend mit Deweys Kritik an einer Deutung des Handelns (ebd.: 226f.), die Handeln als Mittel zur Verfolgung von Zwecken interpretiert, tritt Joas für eine nichtteleologische Interpretation des Handelns ein. Dem Zweck-MittelSchema, das den Zweck außerhalb des Handlungsprozesses fixiert, billigt Joas nur eine begrenzte Anwendbarkeit zu. Es könne »weder routiniertes noch sinnerfülltes, weder kreatives noch existenziell reflektiertes Handeln« (ebd.: 230) denken. Um den Zweck des Handelns nicht vom Handeln selber abzuspalten, um zu vermeiden, dass »Intentionen, Motive, Werte [...] als Bestandteile einer Innenwelt [erscheinen], die nur durch einen eigenen Akt des Entschlusses auf die Außenwelt einwirken können« (ebd.: 232), gelte es, »die Intentionalität nicht länger als unkörperliches, rein geistiges Vermögen aufzufassen.« Wahrnehmung und Erkenntnis seien

»als Phasen des Handelns aufzufassen, durch welche das Handeln in seinen situativen Kontexten geleitet und umgeleitet wird. Die Setzung von Zwecken geschieht $[. .$.$] nicht in einem geistigen Akt vor der eigentlichen Handlung, son-$ dern ist Resultat einer Reflexion auf die in unserem Handeln immer schon wirksamen, vor-reflexiven Strebungen und Gerichtetheiten. In diesem Akt der Reflexion werden solche Strebungen thematisch, die normalerweise ohne unsere bewusste Aufmerksamkeit am Werke sind. Wo aber ist der Ort dieser Strebungen? Ihr Ort ist unser Körper: seine Fertigkeiten, Gewohnheiten und Weisen des Bezugs auf die Umwelt stellen den Hintergrund aller bewussten Zwecksetzungen, unserer Intentionalität dar. Die Intentionalität selbst besteht dann in einer selbstreflexiven Steuerung unseres laufenden Verhaltens.«(Ebd.: 232)

Durch die Betonung der Körperlichkeit des Handelns erfährt die jeweilige Situation, in denen das Handeln stattfindet, eine grundlegend andere Bewertung. Im Unterschied zu teleologischen Denkweisen, in denen die Bestandteile der Situation nur Bedingungen und Mittel für das zweckgerichtete Handeln lieferten, komme dem Situationsbezug des Handelns eine konstitutive Bedeutung zu. »Um handeln zu können, muss der Handelnde ein Urteil über den Charakter der Situation fällen. Jede Handlungsgewohnheit und jede Handlungsregel enthält Annahmen über den Typus von Situationen, in denen es angemessen ist, nach dieser Gewohnheit oder Regel zu verfahren. Unsere Wahrnehmung von Situationen beinhaltet im Regelfall bereits unser Urteil über die Angemessenheit der Handlungsweisen. So erklärt es sich, dass Situationen nicht nur das neutrale Betätigungsfeld für außersituativ konzipierte Intentionen sind, sondern

25 Bei Luckmann geht jedem Handeln ein mehr oder minder bewusster Entwurf und Entschluss voraus (siehe Luckmann 1992: 49f.). Im Entwurf ist die »Maximierung der Effizienz der Zielerreichung« (Joas 1996: 214) für das Handeln konstitutiv. 
schon in unserer Wahrnehmung bestimmte Handlungen hervorzurufen, zu provozieren scheinen.« (Ebd.: 235) Jedoch komme der Situation nicht ausschließlich eine konstitutive Bedeutung $\mathrm{zu}$, weil es dann keine Intentionalität des Handelns mehr geben könne. Um die Intentionalität des Handelns zu wahren, dürften deshalb Zwecke und Motive des Handelnden nicht als völlig bedeutungslos für das Handeln konzipiert werden und seien als verschränkt mit vorreflexiven Situationsbezügen, das heißt wiederum mit den noch so vagen Zieldispositionen, die sich aus den Bedürfnissen des personalen Körpers ergeben, zu denken. Der Körper bzw. der Leib des Individuums ist konstitutiv an den Situationen beteiligt.

»Handeln setzt dann nicht notwendig Planung voraus, und selbst wenn Pläne vorliegen, ist der konkrete Handlungsablauf von Situation zu Situation konstruktiv zu erzeugen und offen für kontinuierliche Revision. Pläne stellen uns zwar in Situationen hinein, enthalten aber noch keine erschöpfende Antwort auf die Herausforderungen dieser Situationen. [...]; nie ist der Plan das einzige Orientierungsmittel unseres Handelns. [...] Wenn Intentionalität also als selbstreflexive Bewusstwerdung und Beurteilung vorreflexiver Quasi-Intentionen in konkreten Situationen zu denken ist, dann sind Motive und Pläne als Produkte solcher Reflexion aufzufassen und nicht als die real wirkenden Ursachen des Handelns.« (Ebd.: 237)

Durch diese handlungstheoretischen Überlegungen wird die Nützlichkeit rationaler Handlungsmodelle zur Analyse von sozialen Phänomenen nicht in Frage gestellt (siehe Joas 1996: 217). Vielmehr verdeutlichen sie, dass zweckrationales wie normorientiertes Handeln auf kreative Leistungen angewiesen ist. Die Mittel zur Verfolgung eines Zweckes und die Normen müssen erst gefunden, wenn nicht gar erfunden werden. Und sie müssen, zumindest auf lange Sicht, auch veränderten Situationen angepasst werden.

All dies gilt auch für die Ausbildung von Routinen, die, wenn sie als repetitives Verhalten bezeichnet werden, scheinbar weniger zu einem handelnden Wesen als zu einem funktionierenden Automaten passen. Dagegen steht, dass Routinen »konstitutiv [...] für die kontinuierliche Reproduktion der Persönlichkeitsstruktur der Akteure in ihrem Alltagshandeln« (Giddens 1995: 112) sind, mit denen sie »ein Gefühl des Vertrauens und der Seinsgewissheit aufrechterhalten« (ebd.: 37). Anders gesagt: Bewährte Routinen schaffen für das Individuum die Sicherheit, die es benötigt, um zu handeln. Dies wird nicht zu letzt am Handeln in außeralltäglichen, lebensbedrohlichen Situationen deutlich. Das Engagement von Soldaten in lebensgefährliche Situationen, ihr Handeln im Gefecht, hängt entscheidend von den Handlungsmustern ab, die sie im Zuge ihrer Ausbildung erlernt haben und die sie auf das Kampfgeschehen vorbereiten sollen.

Kreativität ist hier nicht auf herausragende künstlerische, schöpferische Tätigkeiten begrenzt, sondern schließt auch alltägliche Handlungen ein, mit denen ein Individuum auf die jeweils gegebene Situation reagiert und 
sie versucht zu beeinflussen, zu verändern. Dies zeigt auch ein Blick auf die drei Wege zur Kreativität, die Popitz unterscheidet, und auf denen die spezifische potentiell produktive Vorstellungsleistung, kurz Phantasie, Neues befördern kann: 1. erkundende Phantasie, worunter suchende, probierende und fragende Bewegungen zu fassen sind, die im Entdecken und Erfinden gipfeln, 2. gestaltende Phantasie, worunter objektbildende, darstellende Handlungen gefasst werden, in deren Verlauf Artefakte technisch und künstlerisch hergestellt, geformt werden und 3. die sinnstiftende Phantasie, in der deutend, begründend, rechtfertigend nach neuem Sinn gesucht wird (Popitz 2000: 3f., 93f.). Soldaten sind zwar kaum mit der Herstellung von Artefakten befasst und ihre Kreativität geht deshalb, zumindest soweit ihre Handlungen als Soldaten betrachtet werden, kaum diesen Weg. Die beiden anderen Dimensionen der Kreativität sind aber für ihr Handeln sehr wohl bedeutsam. Welche große Bedeutung beispielsweise der erkundenden Phantasie gerade im Kriegsgeschehen zukommt, wird deutlich, wenn man sich vor Augen hält, dass der Krieg »das Gebiet des Zufalls« ist (Clausewitz 1832: 234), wodurch der »Handelnde im Kriege die Dinge unaufhörlich anders findet, als er sie erwartet hatte, und es kann nicht fehlen, dass dies auf seine Vorstellungen Einfluss habe.« (Ebd.) Bei Clausewitz wird das Schlachtfeld als Kontingenzraum beschrieben, der für den Handelnden keine Gewissheiten bietet. Alle Entwürfe, Planungen, der Krieg auf dem Papier unterschieden sich vom >wirklichen Krieg` (ebd.: 262) durch die Friktionen, zu denen er auch die Individuen zählt, die Teil der Militärorganisation sind. »Die militärische Maschine, die Armee und alles, was dazu gehört, ist im Grunde sehr einfach und scheint deswegen leicht zu handhaben. Aber man bedenke, dass kein Teil davon aus einem Stücke ist, das alles aus Individuen zusammengesetzt ist, deren jedes seine eigene Friktion nach allen Seiten hin behält.« (Ebd.) Selbst der »unbedeutendste« Soldat sei im Stande, einen »Aufenthalt oder sonst eine Unregelmäßigkeit zu bewirken. Die Gefahren, welche der Krieg mit sich bringt, die körperlichen Anstrengungen, die er fordert, steigern das Übel so sehr, dass sie als die beträchtlichsten Ursachen« (ebd.) von Friktionen anzusehen sei. Allerdings ist es grundsätzlich möglich, dass die soldatischen Subjekte nicht nur störend auf die Kriegsplanungen der Befehlshaber einwirken und den Kampfverlauf für eine Kriegspartei nur ungünstig im Sinne von hemmend und behindert beeinflussen. ${ }^{26}$ Prinzipiell ist auch der umgekehrte Fall möglich, dass heißt sie können durch ihr Erkunden und durch ihre Eigeninitiative den Verlauf eines Gefechts zugunsten der >eigenen` Kriegspartei aktiv beeinflussen. Und in diesem Sinne ist ein einzelner Soldat selbst dann als ein Subjekt zu erachten, wenn er befehlskonform handelt. Inwieweit freilich Kreativität von den Soldaten gegenüber den erteilten Befehlen

26 An dieser Stelle sei darauf hingewiesen, dass der Handelnde bei Clausewitz ein Kommandeur ist, der eigenmächtigen Handlungen seiner Untergebenen skeptisch gegenübersteht. 
akzeptiert bzw. sogar von ihnen verlangt wird, hängt entscheidend von ihrer Position innerhalb der Befehlshierarchie, ihrer Aufgabenstellung und dem jeweiligen Einsatzkonzept ab, konkreter, wie das individuelle Destruktionspotential in den Gesamtverband eingebunden ist. Bezogen auf die historischen Konstellationen wird sich zeigen, dass die Einsatzkonzepte sehr unterschiedlich auf die Kreativität der Soldaten zurückgreifen, in höchst unterschiedlicher Weise den Individuen zugestehen, selbstständig zu handeln. Das jeweils gültige Einsatzkonzept entscheidet auch, welche Gestaltungsmöglichkeiten den einzelnen Soldaten mit einer bestimmten Position innerhalb der Befehlshierarchie zugesprochen werden. Bei aller historischen Varianz lässt sich bislang eine allgemein gültige Faustregel formulieren: Von rangniedrigen Soldaten werden am ehesten kreative Leistungen akzeptiert und auch als solche anerkannt, die auf von den Befehlsgebenden nicht vorhergesehene Situationen reagieren. Sie werden im Hinblick auf ihren kompensatorischen Effekt geschätzt. Mit steigender Position in der militärischen Hierarchie werden dagegen auch zunehmend strukturierende Leistungen nicht nur akzeptiert, sondern sogar gefordert. ${ }^{27}$

Das Handeln von Soldaten im Krieg als kreativ zu bezeichnen, mag befremden, steht doch am Ende einer Handlungskette kein Kunstwerk und zielt es auch kaum auf einen im emphatischen Sinne als creatio zu bezeichnenden Zweck, sondern auf sein Gegenteil: destructio. Doch mit Joas gilt es festzuhalten: »Kreativität als solche ist in dieser Perspektive nicht per se etwas Gutes [oder Schlechtes] «, und ob »eine bestimmte kreative Handlung gut oder schlecht ist, kann nur in einem Diskurs gerechtfertigt werden« (Joas 1996: 288f.). Kreativität kann Zerstörung und Leid hervorbringen. Gesteigerte Destruktivität kann das Ergebnis kreativen Handeln sein.

Bezogen auf die Herstellung von Artefakten ist dies vielleicht besonders leicht nachzuvollziehen: Nicht nur im Niederschreiben eines Gedichts materialisiert sich Kreativität, sondern auch im Bau neuer Waffensysteme. Angesichts der Zahl der Wissenschaftler, die sich mit der Entwicklung neuer Waffen beschäftigen, kann man auch davon sprechen, dass in erheblichem Ausmaß menschliche Kreativität ausschließlich destruktiv gebunden ist.

27 Diese Unterscheidung bezieht sich auf die industriesoziologischen Kategorien kompensatorische und strukturierende Subjektivität (siehe Kleemann, u.a. 2002: 84f.). Zu beachten ist, dass es aber auch kreative Leistungen rangniedriger Soldaten gibt, die sehr wohl für ihr Handeln, wie auf das Geschehen einen strukturierenden Effekt haben, aber deshalb weitgehend unbeachtet bleiben, weil sie als alltägliche Selbstverständlichkeiten menschlichen Handelns gelten. Für den Geltungsbereich der Faustregel ist obendrein zu beachten, dass die Network Centric Warfare zumindest konzeptionell mit ihr bricht (siehe dazu 8.2.3.). 


\section{Zur Geschichte des modernen Soldaten}

\subsection{Das Militär und seine historischen Vorläufer}

Kriege werden von Menschen geführt. Die Fähigkeit, Gewalt auszuüben, mag dem Menschen angeboren sein, für das Kriegführen reicht sie nicht aus. Um in einem Krieg eingesetzt zu werden, gleichgültig an welcher Stelle, ob als gemeiner Soldat oder als Kommandierender, ob zu Lande, zur See oder in der Luft, muss jedes einzelne Individuum auf seinen Einsatz vorbereitet werden, bzw. muss sich vorbereiten. Es ist nicht nur ein Spezifikum gegenwärtiger Kriegführung, sondern ihr allgemeines Kennzeichen, dass die Gewaltausübenden erst Techniken erlernen und trainieren müssen, um gekonnt Gewalt auszuüben. Im Wesentlichen sind dafür zwei Gründe verantwortlich. Erstens handeln die Kämpfenden nicht allein und müssen deshalb ihr Handeln mit dem ihrer Mitstreiter abstimmen. Zweitens werden im Krieg Mittel eingesetzt, deren Handhabung und Beherrschung im nicht-kriegerischen Alltag keineswegs selbstverständlich ist. Mag in neolithischen Jägerkulturen ein gewisser Transfer von der Beherrschung der Jagdwaffe hin zu ihrem Kampfeinsatz möglich gewesen sein und mögen nomadisierende Steppenvölker nach der Beherrschung des Pferdes durch den alltäglichen Umgang mit dem Tier und mit Pfeil und Bogen eine besondere Geschicklichkeit für den Kampf zu Pferd entwickelt haben (siehe McNeill 1984: 23f.), so gilt insbesondere für NahkampfWaffen, wie dem Schwert und der Streitaxt, dass das Training mit ihnen allein auf einen kriegerischen Einsatz abzielte. Der Bogen und auch die Armbrust ließen sich auch zur Jagd verwenden, doch das Schwert, ob kurz oder lang, die Streitaxt, aber auch die ritterliche Lanze als Stoßwaffe, der Spieß der Landsknechte, weisen Konstruktionsmerkmale auf, die bedingen, dass sie sich nur zum Töten von Menschen wirklich eignen.

Der soziale Ort, an dem die im Krieg eingesetzten Menschen die Fähigkeit zum Kriegführen erwerben, ist heute das Militär. Selbst die 
Kämpfer von Guerilla-Truppen durchlaufen in aller Regel eine militärische Ausbildung. Als Organisation wie als Institution organisierter Gewaltausübung ist die Geschichte des Militärs auf das engste mit der Herausbildung neuzeitlicher Staatlichkeit verknüpft. Es ist eine Geschichte, die von der Überlegenheit bereits der Vorläufer des heutigen Militärs, dem Söldnerwesen und des stehenden Heeres, gegenüber anderen Formen der organisierten Gewaltausübung zeugt. Diese Vorläufer schlugen sowohl das feudale Heerwesen, also auch später alle außereuropäischen Institutionen der organisierten Gewalt aus dem Felde. Ihre Erfolge beruhten auf einer Organisationsform, die als das Ergebnis von Modernisierungsprozessen organisierter Gewaltausübung bezeichnet werden kann. Trotz seines heute partiell altertümlich anmutenden Gepräges, - zu denken ist hierbei an Zeremonien wie den Großen Zapfenstreich und an die Grußregeln, die sich in ihrer heutigen Gestalt in den stehenden Heeren des 18. Jahrhunderts entwickelten - ist das Militär als eine moderne Organisation anzusprechen.

Die Herausbildung der gegenwärtigen Form des Militärs war ein hochkomplexer Prozess, der sich über mehrere Jahrhunderte vollzog. Vom 11. bis zum 18. Jahrhundert, dem Zeitraum, der in diesem Kapitel betrachtet wird, hat es keine über mehrere Jahrzehnte währende Phase gegeben, in der sich das Phänomen des Krieges nicht geändert hätte. Bereits für das Mittelalter gilt, dass es ein politisch motiviertes Vorurteil der Aufklärung des 18. Jahrhunderts war, es als ein Zeitalter des technologischen und sozialen Stillstandes einzustufen. Im Allgemeinen für die sozialen Prozesse, wie im Besonderen für das Kriegsgeschehen ist es eher als eine Epoche der Rastlosigkeit und nicht der Stagnation zu kennzeichnen (siehe Mann 1994: 240). Das Militär ist eine europäische `Erfindung〈 deren Entstehung auf einzigartige historische Konstellationen zurückgeführt werden kann. Dies bedeutet nicht, dass seine spezifische Ausgestaltung als Organisation wie als Institution organisierter Gewaltausübung >notwendigerweise ২ bereits zu Beginn des historischen Prozesses feststand. Eine solche Annahme negiert die Bedeutung historischer Zufälle. Die Bedeutung der Kontingenz im historischen Prozess kann am leichtesten in der Gestalt >großer Männer und des Schlachtenglücks, das seinerseits von Wetterbedingungen abhängen kann, illustriert werden (siehe hierzu Mann 1994: 446f.). Zufälle beeinflussen den konkreten Verlauf historischer Prozesse und damit verbunden die Etablierung neuer historischen Konstellationen.

Die in Europa entstandene Form des Militärs ist eine historische Fundsache, die - von Kontingenzen geprägt - sich europaweit, aber regional unterschiedlich in Tempi und Gestalt, entwickelte. Die nachfolgenden Ausführungen beanspruchen nicht, die Komplexität dieses Prozesses nachzuzeichnen. Sie konzentrieren sich auf die Prozesse der Landkriegführung in Westeuropa und auf die Entwicklungen innerhalb des deutschen Reiches und beschränken sich erstens auf die Kampfweise berittener Kämpfer nach der 1. Jahrtausendwende, zweitens auf die Formierung diszipliniert im 
Verband kämpfender infanteristischer Söldner und den damit einher gehenden gravierenden Bedeutungsverlust berittener Streitkräfte, drittens auf den Wandel vom Söldner zum Soldaten und viertens auf die Entstehung der stehenden Heere als die im 17./18. Jahrhundert vorherrschende Form organisierter Gewaltausübung. Dabei beschränken sich die sozialhistorischen Darlegungen in diesem Kapitel weitgehend auf die Bedeutung, die die Subjektivität der Kämpfenden in verschiedenen entscheidenden Stadien auf dem Weg zum Typus des Soldaten hatte. Gezeigt werden soll, wie sich die Anforderungen an die Kämpfenden im Laufe der Jahrhunderte veränderten, welche Konsequenzen sich daraus für ihre historisch spezifische Subjektivität ergaben. Die Organisationen mussten spezifische Antworten auf die Frage finden, wie die Subjektivität ihrer Angehörigen diszipliniert, aber auch wie sie in Anspruch genommen werden kann, damit sie im Kampf bestehen, den Sieg erringen können.

\subsubsection{Die Ritter}

Spätestens seit der 1. Jahrtausendwende wandelten sich im nordwestlichen Europa permanent die Ausrüstung, Bewaffnung und die Zusammensetzung der Heere. ${ }^{1}$ So galt im 11. Jahrhundert ein Ritter, der mit einem langen Kettenhemd und einem Nasalhelm ausgerüstet war, als bestens gewappnet. Drei Jahrhunderte später musste er einen Vollharnisch tragen, wenn er vor den Geschossen und Schlägen seiner Gegner wenigstens halbwegs geschützt sein wollte. Durchgreifend veränderten sich auch die Einsatzformen der Kämpfenden und die eingesetzten Waffen. Die Einführung von Feuerwaffen ab dem 14. Jahrhundert gehört, wenn auch nicht zu Unrecht, lediglich zu den bekanntesten, weil sicher bedeutungsvollsten technischen Umbrüchen in diesem Zeitraum. Ob als Kampfmittel gegen Befestigungsanlagen oder als Handfeuerwaffe - ihr Einsatz setzte bzw. führte zu einer Reihe von Innovationen in den Offensiv- wie in den Defensivkonzeptionen der Kriegsparteien. Die Folgen dieser Änderungen konnten weit über das unmittelbare Kriegsgeschehen hinaus bedeutungsvoll sein. Besonders drastisch betraf dies den Bau von Befestigungsanlagen: Im 11. Jahrhundert

1 Der Motor für die unablässigen Verbesserungen der Waffen und der Rüstung bzw. deren Anpassung an neue Einsatzbedingungen, war die permanente Konkurrenzsituation zwischen den einzelnen Feudalherren. Die Dynamik dieser Konkurrenzsituation werden besonders instruktiv in den Arbeiten von Duby herausgearbeitet. Die expansive Dynamik nach Außen, die dazu führte, dass sich zwischen 950 und 1350 das Gebiet des lateinisch-christlichen Kulturkreises verdoppelte, wird unter anderen in Bartlett beleuchtet. Neben den Ursachen, die sich unmittelbar aus dem feudalen Wirtschafts- und Sozialgefüge speisen, spielen in der Literatur auch Faktoren, wie die klimatischen Bedingungen zwischen dem 9. und 13. Jahrhundert ein gewichtige Rolle, da sie das Bevölkerungswachstum (siehe Duby 1984: 13f. und Mann 1994: 244f.) seit dem 9. Jahrhundert zumindest begünstigten. 
konnte ein Feudalherr eine Burg aus den Ressourcen bauen, die er sich aus seinem lokalen Herrschaftsbereich aneignete und die ihn gut vor dem $\mathrm{Zu}$ griff seiner Konkurrenten schützte. Die Mauern mussten nicht unbedingt aus Steinen gebaut werden und auch nicht sonderlich stark sein, weil die wahrscheinlichsten Gegner, aufständische Bauern und in etwa gleich starke Feudalherren, kaum über die technischen Mittel verfügten, um Palisaden, Wallanlagen bzw. Mauern zu durchbrechen und, da eine möglicherweise langwierige Belagerung als ein riskantes Unternehmen galt, meist nur der Handstreich blieb, um die Burg zu erobern. In der Folgezeit stieg für lokale Feudalherr aber die Gefahr, von Lehnsherrn angegriffen zu werden, deren Herrschaft sich über ein größeres Territorium erstreckte und die deshalb über größere Ressourcen für ihre Kriegszüge verfügten und deshalb auch Belagerungsmaschinen wie Steinschleudern einsetzen konnten. Diese Belagerungsmaschinen, die anfangs unter anderen mit Rückgriff auf antike Vorbilder gebaut wurden, zerschmetterten immer effektiver die Wehranlagen der Burgen. Um dieser Gefahr zu begegnen, wuchsen im Laufe der Zeit die Ansprüche an die Befestigungsanlagen enorm, mussten immer kostspieligere Anlagen gebaut bzw. bestehende Befestigungen umgebaut werden, wenn sie weiterhin vor einem Angriff schützen sollten. Mit den Kanonen war dann aber die Zeit endgültig vorbei, in denen ein kleiner Feudalherr hoffen konnte, sich eine Befestigungsanlage bauen zu können, die ihm als Ausgangs- und Rückzugsstellung im Rücken half, Ansprüche seiner Lehnsherren zu verweigern. Die Burg als Defensivmittel war nicht mehr in der Lage, den neu entwickelten Offensivwaffen standzuhalten. ${ }^{2}$

Über Jahrhunderte hinweg dominierten in Europa berittene Kämpfer die Schlachtfelder. Grundlegend für diese Dominanz war der Vorteil, den der Berittene gegenüber den zu Fuß Kämpfenden durch die Erhöhung und die Kraft des Pferdes erhielt. Aus der Bewegung des Pferdes heraus und von oben herab hatten einer oder mehrere Unberittene dem Schlag mit dem Schwert, dem geworfenen Speer bzw. dem Speerstich wenig entgegenzusetzen. Lediglich wenn sich die Unberittenen, wie bei der Schlacht von Hastings (1066), auf einem Hügel verschanzten und sich als kompakte Masse gegenüber den Reitern formierten, hatten sie eine gewisse Chance, den Berittenen zu widerstehen. ${ }^{3}$ Mit dem 11. Jahrhundert sollte sich der

2 Parker, der im Unterschied zur obigen Darstellung die Veränderungen vor dem 15. Jahrhundert eher als gering veranschlagt, sieht erst für das 15. Jahrhundert das Übergewicht der Defensive, den die Befestigungsanlagen markieren, durch die Erfindung riesiger Belagerungsgeschütze aufgehoben (1990: 26). Im 16. Jahrhundert sei diese Überlegenheit durch umfangreiche und außerordentlich kostspielige Fortifikationen, die sich aber nur große Territorialfürsten und Städte leisten konnten, zumindest wieder teilweise kompensiert worden (ebd.: 30f.).

3 Der Nachteil dieser Formierung war ihre Unbeweglichkeit. Die angelsächsischen Kämpfer bildeten keinen Verband, der in der Lage war, sich geschlossen zu bewegen. Die Formierung war defensiv ausgerichtet. Sowie die Angel- 
Vorteil der Berittenen gegenüber den Unberittenen sogar noch durch die Kombination der Erfindung der schweren Lanze mit dem bereits im 8 . Jahrhundert aus dem Osten übernommenen Steigbügel erhöhen (siehe Keen 1999: 41). Die so ausgerüsteten Reiter klemmten sich die Lanze fest unter die rechte Achselhöhle, »die rechte Hand greift den Schaft hinter den Schwerpunkt, der linke Arm bleibt frei für Zügel und Schild. Reiter und Lanze bilden eine konzentriert zusammenwirkende Einheit, die den Kämpfer gleichsam zu einem >menschlichen Geschoss` werden lässt. Eine derart bewaffnete Reitertruppe konnte dem massierten Feind einen regelrechten Hammerschlag versetzen, dessen Wirkung von der Dynamik und des Angriffs und der Wucht des Aufpralls abhing.« (Ebd.: 42) Dem >Fußvolk^, das einen großen Teil der Heerzüge ausmachte, kam deshalb auf dem Schlachtfeld nur eine untergeordnete Bedeutung zu. Es war diese hinzugewonnene Dominanz im Kampf, die die Sozialfigur des Ritters begründen sollte. ${ }^{4}$

Ein berittener Kriegsmann zu sein, bedeutete nicht unbedingt zum Adel zu gehören, setzte jedoch voraus, dass Pferde unterhalten werden konnten. Jeder bewaffnete Reiter verfügte am besten gleich über mehrere Tiere, die ihn und seine Ausrüstung, von den Waffen über das Schild und die Rüstung tragen konnten und für den Kampfeinsatz trainiert sein mussten. Eine solche kostspielige Ausrüstung setzte wiederum die Verfügung über Land und Bauern voraus bzw., dass ein solcher Grundherr Bewaffnete, die z.B. lediglich über ihre eigene Bewaffnung verfügten, in den Dienst nahm, sie von den Abgabenpflichten freistellte und für ihren laufenden Unterhalt aufkam (Keen 1999: 49). Die Ritter wirkten

»als eine Art Elitetruppe und - womöglich noch wichtiger - als Führungsgruppe, der er [der Feudalherr, d.A.] verantwortliche Aufgaben bei der Bemannung von Burgen und bei Belagerungen übertragen konnte. Gelang es solchen Fürsten, ihren Territorialbesitz zu sichern oder ihren Herrschaftsbereich auszuweiten, stieg ihr Bedarf an Gefolgsleuten.« (Ebd.: 49)

Die Kosten, die die Ausrüstung und der Unterhalt der Pferde verursachte, verhinderte aber, dass selbst Feudalherren, die über große Ländereien verfügten, viele Ritter dauerhaft in ihren Dienst aufnehmen konnten, weshalb

sachsen ihrerseits zum Angriff übergingen, gaben sie ihre kompakte Aufstellung auf und konnten bei einem erneuerten Angriff durch Berittene selten schnell genug eine defensive Verteidigungsformation herstellen. In der Schlacht von Hastings wurden die angelsächsischen Gruppen, die ihre Defensivstellung verließen um die Normannen anzugreifen, von den normannischen Reitern erschlagen (siehe u.a. Delbrück Bd. 3: 170f.).

4 Die Dominanz der so genannten Panzerreiter kommt in einem veränderten Sprachgebrauch zum Ausdruck. Meinte das lateinische Wort miles bzw. milites zuvor »jeden, der Kriegsdienst tat, vor allem den Berufskrieger« (Johrendt 1976: 427) bezeichnet er ab dem 11. Jahrhundert ausschließlich »den berittenen Kriegsmann« (Keen 1999: 47). 
immer eine gewisse Anzahl von ihnen auf der Suche nach einem Dienstherren waren. Für die meisten bewaffneten Reiter war ihre ökonomische und soziale Lage trotz ihrer immensen militärischen Bedeutung prekär. Sie blieben abhängig von der Gunst ihrer Herren und dem Erfolg im Kampf.

Gemessen insbesondere an den späteren Formen der bewaffneten Gewaltausübung erscheinen Ritter wie der Idealtypus eines disziplinlosen Einzelkämpfers, dessen Geschick von seinen individuellen Fähigkeiten im Umgang mit den Waffen und seiner Subjektivität vor allem in Gestalt von Tapferkeit abhing. Wesentlichen Anteil an diesem Bild hat die Troubadourdichtung, deren bevorzugter Protagonist ein junger, lediger Mann ist, der als nachgeborener Sohn mit nichts als einem Schwert, einem »guten Namen und einer Erziehung zum Kriegsabenteuer« ausgestattet ist (Keen 1999: 50), und der bevorzugt im Einzelkampf seine Erfolge erzielt. ${ }^{5}$ Tatsächlich lässt sich der ritterliche Kampf nicht so eindeutig, wie dies in der älteren Literatur häufig geschieht, auf das Duell zwischen jeweils zwei Kämpfenden beschränken. Sie beziehen sich auf einige Quellen, in denen Heerführer über die aufgelöste Ordnung klagten bzw. ihre Reiter vor einem Angriff eindringlich ermahnten, geschlossen den Gegner zu attackieren. Die Schwierigkeiten bei der Durchführung der oben beschriebenen Angriffsweise mit angelegter Lanze, bedeutet jedoch nicht, dass es niemals zu einem koordinierten Zusammenwirken vieler Reiter gekommen ist. Vielmehr ist im Grundsatz davon ausgehen, dass die Reiter versuchten, nicht als Einzelkämpfer, sondern im Verband den Gegner durch einen gemeinsamen Anritt anzugreifen. Diese Angriffweise setzte langwieriges und intensives Training mit dem eigenen Pferd und den anderen Teilnehmern eines Trupps voraus. Geübt wurde diese Kampfweise unter anderem auf den Turnieren, die gleichzeitig mit der neuen Kampfweise aufkamen (Keen 1999: 44). Geübte Reiterverbände waren wohl auch in der Lage, ihren Anritt auf die gegnerischen Reihen mehrfach zu wiederholen. Das Training beruhte auf den privaten Ressourcen der einzelnen Reiter bzw. des jeweiligen Grundherren, in dessen Dienst sie standen (ebd.: 345). Da nur diejenigen Ritter, Knappen bzw. Edelknechte und Sergenten ${ }^{6}$ intensiv

5 Nerlich sieht in der Verherrlichung des Ritterseins, als »das Höchste, was ein Mensch auf dieser Erde erlangen kann, und er verwirklicht es in der Suche und im Bestehen von aventure «, eine Definition des Menschseins, die mehr als jede andere dazu beigetragen habe, die Welt grundlegend und irreversibel von der Vormodernen in die Moderne zu verwandeln (Nerlich 1997: 200). Die Troubadourdichtung, die die Experimental-Existenz des Menschen bejaht, reflektiert die prekäre soziale Lage der Ritter und bot gleichzeitig u.a. Anknüpfungspunkte für die bürgerlichen Kaufleute des 14. Jahrhundert, die ebenfalls ihren Handel auf Plan und Zufall gründeten.

6 Nach Lehnart wird in der militärhistorischen Forschung lediglich zwischen zwei Kombattantentypen unterschieden, den Rittern und den Sergenten, weil der Knappe sich häufig nur durch die Schwertleite vom Ritter unterschied. Die meisten Angehörigen der Ritterschaft blieben ihr Leben lang Knappen, da sie sich die Kosten für die Zeremonie nicht leisten konnten. Bei den Sergenten 
gemeinsam üben konnten, die im Dienst eines Feudalherren standen, dürfte ein gemeinsamer Antritt in Kriegszügen, zu denen sich die Truppen mehrerer Herren zusammenschlossen, schwer durchzuführen gewesen sein. Gemeinsames Handeln als ein aufeinander abgestimmtes, koordiniertes Handeln fiel den Heeren dieser Zeit grundsätzlich schwer, weil die Heerzüge zumindest bis weit in das 13. Jahrhundert hinein keine Institutionen waren, die über verbindliche Dienstvorschriften verfügten. Auch gab es keine eindeutige Kommandostruktur. So verfügte ein nomineller Oberbefehlshaber über »keinerlei Zwangsmittel, seine taktischen Vorstellungen gegen den Willen der anderen Lehnherren durchzusetzen.« (Lehnart 1993: 179) Die nur für eine kurze Zeit formierten Verbände lassen sich als Personenverbände qualifizieren, die durch Verwandtschafts- und Lehnbeziehungen, sowie in zunehmenden Maße durch Vertragsbeziehungen wie der Treueverpflichtung aufgrund von Soldzahlungen und Beuteversprechen, zusammengehalten wurden (vgl. auch Lehnart 1993: 178f.).

Da innerhalb wie außerhalb des Schlachtfeldes der Einsatz der Akteure lediglich durch Face-to-face-Kommunikation koordiniert werden konnte, mussten sich alle Akteure in einem Raum bewegen, in dem sie »in optischer und weitgehender akustischer Verbindung standen « (Kaufmann 1996: 31). Bereits im 9. Jahrhundert wurde nach Verbruggen (1998: 84) durch Trompeten der Abbruch des Lagers angeordnet. Er führt auch Beispiele für taktische Signale durch Bannerschwenken und Trompetenfanfaren an. Delbrück dagegen schreibt, dass er sich nicht erinnern könne, von Signalen im Gefecht in einer »mittelalterlichen Quelle etwas gelesen zu haben.« (Bd. 3, 1920: 347) Lediglich Aufbruch- und Angriffssignale könne er in den Quellen finden. Für die Schlacht gelte aber, dass die Führung nichts will, "als gleichmäßig an den Feind kommen, und nachdem der Kampf begonnen hat, ihn durch das Hochhalten des Banners bis zur äuBersten Intensität durchführen.« (Ebd.: 346) Es habe, so das Fazit Delbrücks, keine über dieses Ziel hinausgehende Taktik in der Schlacht gegeben. Verbruggen, dem in der Tendenz meist die jüngere Literatur folgt, widerspricht dieser Auffassung Delbrücks entschieden (1999: 84f.). Er geht obendrein davon aus, dass die Verbände wiederholt die gegnerischen Truppen angreifen und sich wieder von ihnen lösen konnten (ebd.: 73f.). Erst nachdem ein Anritt nicht mehr möglich war, sei es, weil durch die vorangegangenen Angriffe sich der Trupp nicht mehr formieren ließ, sei es, weil der gegnerische Trupp sich auflöste, spätestens aber wenn kei-

handelt es sich dagegen mehr »um Diener, die wie Ritter bewaffnet waren« (1993: 22) und die dem niederen Adel zuzurechnen sind. Weiter handelte es sich um nachgeborene Söhne von mittelmäßig begüterten Rittergeschlechtern, die kein Erbe zu erwarten hatten, und mitunter auch um Söldner nichtritterlicher Abstammung. Zur weiteren Differenzierung: siehe Lehnart 1990: 19f. Siehe auch Selzer (2001: 340), der in diesem Zusammenhang noch die Möglichkeit einräumt, dass Reiter aus großbäuerlichen Familien stammten. 
ne Lanzen mehr zur Verfügung standen, gingen die Reiter zum Nahkampf mit dem Schwert über.

Bevorzugt griffen sie auf dem Schlachtfeld ihresgleichen an (siehe Delbrück Bd. 3, 1920: 320). Für diese Orientierung sprach aus ihrer Sicht, dass sich ein Ehrgewinn erst im Kampf mit einem mindestens gleichrangigen Gegner einstellte. Obendrein ließ sich mit einem solchen Kampf die Hoffnung auf ein Lösegeld verbinden, wenn es ihnen gelang, den Gegner gefangen $\mathrm{zu}$ nehmen. Im Handgemenge mussten sich die Kämpfenden selbstständig einen Gegner suchen bzw. sich eines Gegners erwehren, und konnten nicht auf einen Befehl für ihr Handeln abwarten, zumal die unmittelbaren Anführer dann in aller Regel selber buchstäblich die >Hände voll $\mathrm{zu}$ tun ' hatten. Im Zuge des Nahkampfes kam es auf die individuellen Fähigkeiten des einzelnen Kämpfers an. $\mathrm{Ob}$ man im Handgemenge einer Schlacht den Gegner überwand, ob man bei einem Überfall oder einer ähnlichen Gewalttat Erfolg hatte, hing von der Findigkeit ab, sich bietende Chancen wahrzunehmen und auszunutzen. Das individuelle Geschick beim Umgang mit der Waffe, die Fähigkeit, die eigenen Kräfte zu mobilisieren sowie Affekte wie Angst und Schmerzen zu kontrollieren, entschieden über den Verlauf des Kampfes. Von den Kämpfenden dieser Zeit, ob als Anführer oder auch als Untergebener, war in all diesen Situationen aktives Handeln gefordert, mit dem die jeweiligen Situationen bewältigt, und das heißt der Gegner überwältigt werden sollte. Der Ausgang eines Zweikampfes wurde entscheidend von der Subjektivität der Kämpfenden und seiner situativen Kompetenz geprägt.

Nun lässt sich das Kriegsgeschehen dieser Zeit weder auf den geschlossenen Lanzenangriff noch auf den Zweikampf reduzieren. Typisch für den Verlauf sowohl eines großen Kriegszuges als auch einer Fehde in dieser Zeit waren weniger große Gefechte, sondern Belagerungen, Überfälle, Plünderungen, die auf die Zerstörung von Hab und Gut des Gegners abzielten, sowie die Gefangennahme seiner Untertanen. Neben dem >Fußvolkı, das in diesem Zusammenhang eine wichtige Rolle spielte, beteiligten sich auch Reiter an diesem Teil der Kriegführung. Entgegen dem Bild des undisziplinierten Ritters hing der Erfolg eines Überfalls auf andere Bewaffnete von der Koordinationsleistung der Angreifer ab. Auch die Verteidigung einer Befestigung setzte die koordinierte Zusammenarbeit ihrer Besatzung voraus. Als Einzelkämpfer, ob nun auf oder außerhalb eines Schlachtfeldes, traten die Ritter nur selten auf.

Beobachten, sich orientieren, entscheiden und der Kampf selber setzten ein Engagement des einzelnen Kämpfers voraus, die spätere Interpreten des Kampfes der Ritter als eine Kampfweise deuteten, die vom individuellen Subjekt ausgehe, hinter denen die Momente des koordinierten Handelns zurücktraten. In den Augen vieler Militärtheoretiker des 19. und 20. Jahrhunderts, stellvertretend für andere sei hier Delbrück genannt, überwog wiederum die Interpretation des ritterlichen Kampfes als disziplinlos, 
weil er bei weitem nicht über die taktischen Finessen ihrer Gegenwart verfügte. Kurz, der ritterliche Kampf diente als Negativbild des mittelalterlichen Kriegsgeschehens in toto, vor dem sich die moderne Kriegführung als rational ausgefeilte, als flexiblere abheben konnte.

\subsubsection{Das Söldnerwesen}

Die Anwerbung von Bewaffneten wie Unbewaffneten gegen Geld, um mit ihrer Unterstützung Kriegszüge zu unternehmen, ist in zahlreichen historischen Quellen belegt. Söldner hat es sowohl in der Antike wie auch später gegeben. Ihre Zahl und ihre Bedeutung für die Kriegführung unterlagen großen Schwankungen. Auch für das europäische Mittelalter werden von den Quellen neben dem feudalen Dienstverhältnis schon früh Soldzahlungen an Teilnehmer von Kriegszügen erwähnt. Unklar ist jedoch, in welchem Ausmaß im mittelalterlichen Europa Söldner angeworben wurden. Sicher ist aber, dass sich insbesondere große Feudalherren nicht einzig auf Bewaffnete verließen, die durch das Lehenskriegswesen ausgehoben wurden, sondern auch Unbewaffnete, zum Beispiel für Schanzarbeiten, anwarben (Baumann 1977: 164f.). Zusätzlich warben sie pedites, also zu Fuß kämpfende Kriegsknechte, an, die sie sowohl als Besatzungen in den Burgen, als Armbrust- oder als Bogenschützen und auf den Schlachtfeldern einsetzten. Selbst Ritter traten schon früh als Söldner auf. Die oben erwähnte prekäre wirtschaftliche Lage vieler Ritter förderte »ihre Wertschätzung herrschaftlicher Entlohnung« (Keen 1999: 50). Diese konnten sich kleine Herrschaften kaum leisten und mussten sich deshalb mit dem Lehensaufgebot zur Austragung ihrer Fehden begnügen. Fraglich ist aber, - da sich die vorhandene Literatur in dieser Frage uneinig ist - ab wann die größeren Feudalherren allgemein dazu übergingen, Geldzahlungen als Anreiz für Kriegsdienste anzubieten. Nach Keen sei dies ab dem 13. Jahrhundert der Fall gewesen (ebd.: 343). Aber bereits für das Zeitalter der Staufer (zwischen 1138 und 1254 stellten die Staufer die deutschen Könige) sieht Wohlfeil das »ritterliche Söldnertum, dessen Vertreter im Kriegsdienst nicht mehr den Ausdruck einer Gesamthaltung und standesgemäßen Betätigung, sondern ein berufsmäßig ausgeübtes Gewerbe sahen, [...] militärisch gleichwertig an die Seite des Lehenskriegswesens« (1966: 325) gestellt. Spätestens ab der 2. Hälfte des 12. Jahrhundert, konkret mit der Anwerbung von Söldnergruppen durch Friedrich Barbarossa für den Kampf mit und gegen die oberitalienischen Städte, sind Söldner als Fußknechte belegt. Die nach ihrem ersten Anwerbegebiet Brabant anfangs als Brabanzonen ${ }^{7}$ bezeichneten Fußknechte waren »wegen ihrer Professionali-

7 Sie wurden von Barbarossa 1166 für seinen Italienfeldzug angeworben und aufgrund ihrer Gewalttaten wurde diese Bezeichnung synonym für zu Fuß kämpfende Söldner. Es lassen sich in der Literatur aber auch andere Bezeichnungen wie Aragoneser und Basken finden, die sich ebenfalls auf die Region 
tät von den Kriegsherren begehrt und wegen ihrer Brutalität von ihren Gegnern gefürchtet« (Lehnart 1993: 72), die wiederum aufgrund ihrer unritterlichen Kampfweise keine Schonung von den Rittern erwarten durften. Lehnart betont, dass die europäischen Monarchen und größere Territorialherren bereits im 13. Jahrhundert zumindest einen Kader von sergents à pied dauerhaft anwarben, um sie im Bedarfsfall durch aufgebotene Bauern und Bürger zu ergänzen. Darüber hinaus stellten sie auch das Gros der Ingenieurtruppen, die für den Bau von Belagerungsmaschinen unentbehrlich waren und von Truppengattungen wie die der Armbrustschützen, die eine spezielle und langwierige Ausbildung benötigten (ebd.: 73). Vielleicht lassen sich alle diese Einzelfeststellungen dahingehend zusammenfassen, dass sich der zunehmende Einsatz von Söldnern, Berittenen wie zu Fuß Kämpfenden, ab der 2. Hälfte des 12. Jahrhunderts allmählich und in Art und Tempi regional unterschiedlich vollzog. Dabei sollte von den Kriegen in Oberitalien eine prägende Dynamik ausgehen, die formbildend auf Westeuropa ausstrahlte. Vor allem dort, wo es ebenfalls zu ähnlich heftigen Kriegen zwischen aufblühenden Städten oder auch zwischen feudalen Herrschaften kam, konnte spätestens ab dem 14. Jahrhundert keine größere Stadt oder kein Feudalherr mehr hoffen, einen Kriegszug siegreich zu beenden, wenn nicht in erheblichem Umfang Söldner angeworben wurden.

Für das Anwerben von Bewaffneten gegen Sold sprachen aus Sicht der Feudalherren wie der Städter gleich mehrere Gründe. Sie beruhten vor allem auf dem Umstand, dass Söldner zumeist keine unmittelbare Beziehung zur jeweiligen Sozialität unterhielten, also Fremde waren. Ihre Fremdheit ist das bis heute meistgenannte Merkmal von Söldnern. Sie stehen dem Prinzip nach außerhalb des Sozialzusammenhangs der Krieg führenden Partei. Von je her war es gerade diese Fremdheit und die ausgehandelte befristete Präsenz der Angeworbenen, die sie für Kriegsparteien außerordentlich attraktiv machte. Mit der Anwerbung verfügten sie über eine soziale Ressource, also militärische Schlagkraft, deren Aufbau sie nicht bezahlten, und die sie auch nicht dauerhaft unterhalten mussten. Gerade wenn die Gegner über ähnliche sozialen Ressourcen verfügten, wie man selber, versprach der Einsatz von Söldnern eine große Überlegenheit auf dem Schlachtfeld, vor allem wenn es diese versäumt hatten - aus welchen Gründen auch immer - selber Söldner anzuwerben. Die Anwerbung von Bewaffneten aus der Fremde bot aber auch jenseits des Schlachtfeldes Vorteile. So konnte die Anwerbung für die ansonsten kriegsverpflichteten Einheimischen eine Entlastung bieten, die umso schwer wog, wenn sich die Kriegskampagnen in die Länge zogen. Auf diese Weise konnten politische und soziale Spannungen in der Kriegspartei gemildert werden. Weil die Söldner außerhalb der Krieg führenden Gesellschaft standen, waren sie nicht in die politischen und sozialen Gegensätze verwickelt, die sich bei-

beziehen, aus denen zumindest ein großer Teil der gemeinten Söldnerrotte ursprünglich stammte. 
spielsweise in den aufblühenden oberitalienischen Städte verschärften und zu heftigen sozialen Kämpfen um die Herrschaft zwischen den verschiedenen Patrizierfamilien, den Handwerkern und den Tagelöhnern führten und ihr Zusammenwirken in nichtkriegerischen wie kriegerischen Angelegenheiten erschwerten.

Durch die Entlohnung sollte kein neues Dienstverhältnis, keine dauerhafte Verpflichtung des Auftraggebers entstehen (vgl. McNeill 1984: 69). Die Söldner wurden schließlich nur für die Dauer einer Kampagne engagiert und sollten anschließend wieder ihrer Wege ziehen. Letzteres sprach auch aus Sicht der Feudalherren für die Anwerbung von Söldnern. Ein Söldner erhob kein Anspruch auf ein Lehen, auf Boden des Grundbesitzers für seinen Dienst. Er reduzierte damit weder die Machtbasis des feudalen Grundbesitzers, noch stieg er selber in den Rang eines Grundbesitzers auf. Unmittelbar stellte die Anwerbung von Söldnern das feudale Herrschaftsverhältnis noch nicht in Frage. Wie ein Blick auf die Studie von Selzer zu den deutschen Söldnern im 14. Jahrhundert in Italien zeigt, stabilisierte sogar das Söldnertum die soziale Lage vor allem der niederadligen Ritter. Nur der Gelderwerb im Krieg ermöglichte es ihnen, ihren Status aufrechtzuerhalten (2001: 340). Nicht minder bedeutsam für den Statuserhalt war allerdings auch der »Ehrerwerb aus der Fremde«, der zu einem Motivbündel zählt, das Familientradition, die Flucht aus der heimatlichen Enge und Abenteuerlust umfasst (ebd.: 341).

Ob allerdings der Soldritter, wie Wohlfeil schreibt, »stärker zu Gehorsam und Disziplin verpflichtet (war) als der Lehensritter« (1966: 326), ist zumindest als generelle Aussage zu bezweifeln, denn »die Treue von Söldnern« und damit auch ihr Gehorsam und ihre Disziplin endete oft dann, wie Selzer schreibt, »wenn sie kein Essen mehr in ihrer Schüssel fanden« (2001: 133). Die erhöhte Abhängigkeit vom Gelde (Wohlfeil 1966: 326) machte sich für die Kriegsherren vor allem dann unangenehm bemerkbar, wenn ihnen das Geld ausging. ${ }^{8}$

Die Fremdheit der Söldner barg also für die Anwerbenden auch Gefahren. Das Spektrum der Gefahren reicht von der einfachen Weigerung zu kämpfen, bis der ausstehende Sold gezahlt ist, über die Drohung, zum Gegner überzugehen, bis hin zur gewaltsamen Entmachtung der Auftraggeber und Machtaneignung durch die Söldner. Selbst ein von Söldnern erfolgreich durchgeführter Auftrag konnte für die Auftraggeber gefährlich werden. Denn auch dann bestand die Gefahr, dass die Söldner nicht abzo-

8 Die französischen und englischen Könige im 100jährigen Krieg (1337-1453) konnten einem Hinweis Selzers zufolge diese Gefahr reduzieren, weil sie zwar ihre Ritter für den Dienst bezahlen mussten, diese jedoch Vasallen blieben. Sie band an ihre Dienstherren noch eine personale Treueverpflichtung. Dieses zusätzliche »Band zwischen Söldner und Dienstherren fehlte im Falle der deutschen Kämpfer in Italien« (Selzer 2001: 133) und bildete dann auch die Ursache über Machiavellis Klage über die Untreue der Söldner (ebd.). 
gen, sondern blieben und ihre Anführer an die Stelle der politischen Eliten traten, die sie ins Land geholt hatten. ${ }^{9}$

Auf Dauer sollte die Anwerbung von Söldnern für die feudalen Herrschaftsstrukturen nicht folgenlos bleiben, da sie die Monetarisierung der Gesellschaft vorantrieb. Nur derjenige, der über Geld verfügte, konnte Söldner anwerben und je mehr Söldner angeworben werden konnten, desto höher waren die Erfolgsaussichten im Kampf. Dies sollte die Zentralisierungstendenzen staatlicher Herrschaft, die Entstehung des neuzeitlichen Staates forcieren, denn von der Größe wie von der staatlichen Durchdringung des Herrschaftsgebietes hing das Ausmaß der Ressourcenschöpfung $\mathrm{ab}$, um Söldnerheere zu finanzieren. Die Bemühungen um eine kontinuierliche Militärfinanzierung können als Movens der Steuerpolitik und damit der Ausbildung eines staatlichen Verwaltungsapparates bezeichnet werden (siehe Mann 1994: 267f.).

Es war aber nicht so sehr das Soldverhältnis als solches, das die ritterliche Kampfweise in Frage stellte. In dieser Beziehung als folgenschwer erwies sich vielmehr erst die zunehmende Befähigung von zu Fuß kämpfenden Söldnern, einen Angriff von mit Lanzen bewehrten Reitern abwehren, und selber auf dem Schlachtfeld zu Angriffsoperationen übergehen zu können. Zwar erlitt auf dem oberitalienischen Kriegsschauplatz bereits 1176 ein Ritterheer des deutschen Kaisers Barbarossa »beim norditalienischen Legnano [...] eine unerwartete Niederlage, als es vergeblich gegen Pikeniere anstürmte, die der Lombardische Städtebund ins Feld geschickt hatte.« (McNeill 1984: 69), doch war damit nur die Defensivfähigkeit von Fußtruppen gegenüber Reiterangriffen angezeigt. Für Angriffsoperationen blieben Reitertruppen noch lange unverzichtbar.

Die ersten im Verband kämpfenden infanteristischen Söldner, die Brabanzonen, waren weniger für den Einsatz auf dem Schlachtfeld vorgesehen, obwohl sie auch dort zum Einsatz kamen und defensive Abwehrformationen bildeten (Lehnart 1993: 72; Delbrück Bd. 3, 1920: 468), sondern vor allem, um durch das Gebiet des Gegners zu ziehen und es zu verwüsten. Allerdings plünderten und >verheerten` sie auch das Land, durch das sie zogen, wenn sie keinen Auftrag dazu hatten. ${ }^{10}$ Im 13. und 14. Jahrhundert befanden sich in Oberitalien zahlreiche Söldnerverbände, die

9 Diese Gefahr lässt sich nicht auf einen bestimmten Ort oder Zeitraum eingrenzen. Ob man die Antike oder das Mittelalter betrachtet oder man sich mit der Geschichte außereuropäischer Zivilisationen beschäftigt, immer wieder stößt man auf Berichte, die von der Gefahr zeugen, dass Fremde, die man für Kriegszüge engagiert hatte, die einheimische politische Elite entmachteten (siehe hierzu auch Heins/Warburg: 50f.).

10 Was neben einem weitgehend folgenlosen Beschluss des Dritten Laterankonzil von 1179 (siehe Delbrück Bd. 3, 1920: 371; Lehnart 1993: 72f.), der ihre Verfolgung und Niedermetzelung legitimierte, auch einige Kriegszüge gegen herumziehende bzw. sich festsetzende Kompanien (z.B. in Südfrankreich) zur Folge hatte. 
von McNeill, die zeitgenössische Redeweise aufgreifend, als Banden bezeichnet werden. Sie seien als »bewaffnete Abenteurer« über die Alpen gekommen und taten »sich unter formlos gewählten Anführern zusammen« (1984: 76). In diesen Verbänden gab es sowohl berittene wie unberittene Bewaffnete. Durch Erpressung bzw. Ausplünderung des flachen Landes hätten sie im Laufe des 14. Jahrhunderts stark zugenommen und >freie Kompanien` gebildet, deren größte 1354 aus »nicht weniger als 10.000 Bewaffneten bestehend und begleitet von einem ungefähr doppelt so starken Tross, durch die fruchtbarsten Gebiete Mittelitaliens [zog]. Sie ernährte sich vom Verkauf des Plünderungsgutes, das nicht an Ort und Stelle konsumiert wurde« (ebd.). Die Etikettierung als >Abenteurer` unterschlägt zwar das Elend als wichtiges Motiv für den Auszug der nichtritterlichen Söldner, sie hebt jedoch zu Recht hervor, dass sich diese Söldnerverbände nicht aus willfährigen und entrechteten Individuen zusammensetzten und sie eine gefährliche Selbstständigkeit nicht nur gegenüber ihren (potentiellen) Auftraggebern aufwiesen. Im letzten Drittel des 14. Jahrhunderts sollte sich eine grundlegende Veränderung des Söldnerwesens vollziehen. Wurden bisweilen im 13. Jahrhundert lediglich einzelne Söldner als Kader für Lehensaufgebote unter Vertrag genommen, gingen nun die oberitalienischen Städte dazu über, mit den so genannten Condottieri Verträge abzuschließen, »die sie verpflichteten, für eine vereinbarte Summe einen Söldnertrupp anzuwerben und zu befehligen.« (McNeill 1984: 77) Die »Kommerzialisierung des Krieges« (Schmidtchen 1990: 45) beendete in Italien nach 1380 die Zusammenschlüsse von Söldnern in >freien Kompanien $<$. Diese Condottieri unterschieden sich von den Anführern der >freien Kompanien` wesentlich durch ihre größere Macht gegenüber den anderen Söldnern. So konnten die Kapitäne der Kompanien keinen Soldvertrag abschließen, dem nicht zuvor die anderen Anführer der einzelnen Abteilungen, aus denen sich die Kompanie zusammensetzte, ihre Zustimmung erteilt hatten. Nun rückte der Condottiere zum alleinbevollmächtigten Kriegsunternehmer auf. Dieser Machtzuwachs drückte sich auch in den Namen der Kompanien aus, die sich nun nicht mehr wie bisher z.B. nach einem Gegenstand, der bei dem Zusammenschluss eine Bedeutung zukam, benannten, sondern den Namen des Condottiere trugen (siehe Selzer 2001: 60). Aus der Sicht der Städte, die sich die Anmietung von Söldnern leisten konnten, boten die Vertragsabschlüsse mit einem Condottiere größere Vertragssicherheit, weil sie durch die Konzentration der Entscheidungsmacht ein kalkulierbareres Gegenüber hatten. Sie brachte zugleich eine Verregelung des Kriegsgeschehen, da die Soldverträge Bestimmungen enthielten, »die genau die Umstände festlegten, unter denen Plünderungen zulässig waren« (McNeill 1984: 76). McNeill betont, dass durch die steuerfinanzierten Soldzahlungen die Gefahr durch umherziehende Banden reduziert wurde, weil die Plündernden unter Vertrag genommen wurden und die Vertragsnehmer den Vorteil hatten, ein Machtinstrument gegen 
andere Städte bzw. Feudalherren in die Hand zu bekommen. Für eine Anwerbung sprach aus Sicht der einzelnen Söldner, reziprok zur Sicht der Städter, dass ein fester Sold der Ungewissheit und den Gefahren des Plünderns vorzuziehen war, zumal das Plündern beim Gegner weiterhin erlaubt blieb und dementsprechend »das Soldatenhandwerk, als es besoldet wurde, nicht ganz seine spekulative ökonomische Dimension« verlor (McNeill 1984: 76).

Jedoch waren durch den Vertragsabschluss mit einem Condottiere nicht alle Gefahren aufhoben, die zuvor von den >freien Kompanien gingen. Die Gefahr, ohne Auftrag zu plündern, die Drohung, den Auftraggeber zu überwältigen, ging nun von den herumziehenden Söldnerzusammenschlüssen auf die Kriegsunternehmer über. Auch die Condottieri konnten die geworbenen Söldner nur dann beisammen halten, wenn sie nach einem Feldzug möglichst bald wieder einen neuen Auftraggeber fanden. Am Frieden hatten die Kriegsunternehmer deshalb prinzipiell kein Interesse. Die geschlossenen Verträge boten für die Auftraggeber also nur einen gewissen Schutz vor Übergriffen, der besonders dann fraglich wurde, wenn der Sold ausblieb. Über hundert Jahre später, also im 16. Jahrhundert, klagte deshalb Machiavelli über die Condottieri:

»Die Führer dieser in Sold genommenen Truppen sind entweder vortreffliche Männer oder nicht. Sind sie ersteres, so kannst du dich darum nicht auf sie verlassen, weil sie, bloß auf ihren eigenen Ruhm bedacht, entweder dich, ihren Herren, oder andere gegen deine Absicht zu unterdrücken suchen. Sind sie es nicht, so ruinieren sie dich ohnehin.«(1513: 83)

Mit letzterem sprach er die aus seiner Sicht schändlichen und betrügerischen Praktiken der Söldnerführer an, Kämpfe zu vermeiden und damit vertraglich zugesicherte Leistung zu verweigern. So warf er ihnen vor, sie trachteten danach, »sich und ihre Soldaten allen größeren Beschwerden zu entziehen und ihnen alle Furcht zu benehmen, indem sie es einführten, dass man in den Gefechten den Feind nicht tötete, sondern gefangen nahm und ohne Lösegeld wieder freigab. Bei Nacht beschossen sie nie die belagerten Orte und ebenso wenig die Belagerten die Lager dieser; ja, sie befestigten nicht einmal ihre Lager mit Palisaden oder Gräben, noch rückten sie im Winter ins Feld. Mit dieser Kriegsordnung vermieden sie Arbeit und Gefahr [...].« (ebd.: 86) Aus Sicht der Condottieri beschrieb er allerdings weniger einen schändlichen als einen haushälterischen Umgang mit den ihnen zur Verfügung stehenden Ressourcen. Angesichts häufiger Wechsel der Auftraggeber wollten sie ihre Ressourcen nicht riskieren und vermieden blutige Gefechte mit ehemaligen oder potentiellen zukünftigen Gefährten. Betrügerische Praktiken, wie z.B. die Forderung von Soldzahlungen für Söldner, die nie angeworben wurden oder schon lange tot waren, schließt all dies freilich nicht aus. 
Durch die Vertragsabschlüsse mit den Condottieri, die im Gegensatz zu den Anführern der >freien Kompanien` meistens aus Italien stammten, wurde auch nicht die Fremdheit der Söldner aufgehoben. Die Söldnerverbände blieben vielmehr weiterhin ein exklusiver Sozialverband, dessen primärer Zweck die organisierte Gewaltausübung war, die professionell vorangetrieben wurde. Von der effektiven Anwendung ihrer akkumulierten Erfahrungen in den Kriegszügen hingen das (Über-)Leben der Condottieri bzw. der Angehörigen des sich später herausbildenden Offizierkorps und ihrer direkten Untergebenen, sowie ihre Position in der Hierarchie ab.

Wie bereits im Zusammenhang mit der Schlacht von Legnano gesagt, waren ab dem 12. Jahrhundert zu Fuß kämpfende Verbände wiederholt in der Lage, einem Ritterheer erfolgreich zu widerstehen (hierzu sind Beispiele in Delbrück Bd. 3, 1920: 491f. zu finden). Auf der anderen Seite standen aber auch noch im 14. Jahrhundert vernichtende Niederlagen (Lehnart 1993: 24). Die frühen Einzelsiege bzw. spätere Dominanz ist nicht auf den Einsatz neuer Waffen zurückzuführen, denn z.B. die primäre Waffe der Schweizer Gewalthaufen waren Langspieße, mit denen prinzipiell auch schon früher Fußknechte ausgestattet waren. Neu war vielmehr die Geschlossenheit, mit der die Truppen kämpften, ihre Disziplin. Die Entwicklung von wirkungsvollen Handfeuerwaffen ab dem 16. Jahrhundert war deshalb zwar nicht bedeutungslos, aber sie sollte >lediglich schon zuvor bewiesene Überlegenheit von geschlossenen Formationen von Fußtruppen drastisch weiter erhöhen.

\subsubsection{Der Gewalthaufen}

Wie im Folgenden an der Disziplinierung im Hinblick auf die Gewaltausübung auf dem Schlachtfeld deutlich gemacht werden soll, hatten alle zu Fuß Kämpfenden ein großes Interesse an einer disziplinierten Kampftechnik. Disziplinierung meint hier eine Rationalisierung der Gewalttätigkeit, die dem Interesse aller Angehörigen des Verbandes entsprach, hing doch vom Erfolg des Verbandes im Kampf der Sieg und oft genug die Unversehrtheit von Leib und Leben ab. Für den Kampf gegen Reiter gilt verschärfend, dass ihnen, ob Bauer oder Söldner »im Falle einer Niederlage der eigenen Partei der fast sichere Tod [...] [drohte], denn sie besaßen im Gegensatz zu ihren berittenen Kampfgenossen keine Möglichkeit, der siegreichen feindlichen Reiterei durch Flucht zu entkommen.« (Schmidtchen 1990: 224) Mit diesem Disziplinierungsprozess nicht identisch waren die Bemühungen, die eine Zunahme direkter Herrschaft über die im Verband eingegliederten Individuen bewirken sollten. Für die Auftraggeber war diese Disziplinierung genauso wichtig wie die Effektivitätssteigerung der infanteristischen Verbände, versprach sie doch ein geringeres Risiko beim Engagement von Söldnerverbänden. 
Auf dem Boden stehend, nicht von Mauern umgeben zu sein und Reiter auf sich zupreschen zu sehen, ist beängstigend. Die Reiter nähern sich mit großer Geschwindigkeit dem eigenen Standort, und durch die Pferde sind sie nicht nur schneller, sondern wirken auch als kompakte Einheit, die viel größer ist als man selber. Gleichgültig, ob sie mit Lanzen oder ob sie mit Schwertern bewaffnet sind, immer stechen oder schlagen sie von oben herab auf den am Boden Stehenden ein. Das verschafft ihnen zusammen mit der Kraft des Pferdes immer todbringende Vorteile. Es zeugt deshalb von einem hohen Maß von Vertrauen des Einzelnen in die Stabilität des Verbandes sowie von seiner Loyalität gegenüber den anderen im Verband, wenn eine zu Fuß kämpfende Gruppe nicht auseinander läuft, nicht jeder Einzelne versucht, sein Heil in der Flucht zu suchen und die Schlachtreihen geschlossen bleiben. Dieses Vertrauen und die Loyalität setzen wiederum intensive soziale Beziehungen zwischen den Angehörigen des Verbandes voraus. Die ersten Söldnerverbände, die über diese Voraussetzungen verfügten, kamen aus dem Gebiet der heutigen Schweiz.

Von anderen »Söldnerbanden der Zeit« (Delbrück Bd. 3, 1920: 685) unterschieden sich die Schweizer nicht durch ihr Handeln auf dem Marsch oder im Lager; sie plünderten »ebenso wüst« (ebd.). Sie unterschieden sich vor allem dadurch, dass sie auf dem Schlachtfeld geschlossene zu Fuß kämpfende Verbände bildeten, die gemeinsam ihre Waffen einsetzten und denen es dadurch gelang, die Räume auf dem Schlachtfeld zu besetzen. Wie ihnen dies gelang, soll im Folgenden aufgezeigt werden.

Neben der Vermutung, dass die Bewegung des Gewalthaufen schon früh durch den Schlag der Trommel koordiniert wurde, basierte das $\mathrm{Zu}$ sammenwirken der einzelnen Kämpfer auf vorher verabredeten Kommandos, auf der Festlegung, wer das Recht hat, zu entscheiden, in welcher Richtung z.B. der Gewalthaufen sich bewegen soll. Eingereiht in den Gliedern der Formation, konnten nur wenige Anführer der einzelnen Unterabteilungen überhaupt in der Lage gewesen sein, das Geschehen zu überblicken. Der Ausübung der Leitungsfunktion kam in der Vorbereitungsphase, also bei der Aufstellung und der Festlegung der Bewegungsrichtung, eine entscheidende Funktion zu. Wenn zwei Gewalthaufen bereits aneinander geraten waren, kam ihr dagegen eine untergeordnete Bedeutung zu, weil dann alles nur noch vom Erhalt der Geschlossenheit des Verbandes abhing.

Die Schlagkraft des Gewalthaufens beruht auf der Kooperation der Söldner. Es handelte sich um eine stark von Hierarchien geprägte Kooperation, die von den einzelnen Söldnern nur wenig mitgestaltet werden konnte. Die einzelnen Angehörigen des Verbandes mussten ihre Kampfweise und -technik, der vorgefundenen Ordnung anpassen.

Die Grundaufstellung des Gewalthaufens bildete ein festgeschlossener Gevierthaufen. An den Ecken war er mehr oder weniger abgerundet. In ihm formierten sie mehrere hundert, mitunter aber auch mehrere tausend 
Kämpfer. Ihre entscheidende Waffe gegen die Reiterei war der Langspieß. Der koordinierte und geordnete Einsatz der Langspieße machte den Gewalthaufen für die Reiterei unüberwindlich und sein Anblick erinnerte, wenn die Bewaffneten ihre Spieße vorstreckten, an einen Igel. Wenngleich Delbrück davon ausgeht, dass es keine gemeinsame Übungen gegeben habe (Bd. 3, 1920: 684), ist kaum vorstellbar, dass das Hantieren mit der mindestens 3 Meter und oft über 5 Meter langen Waffe, die im Verband eingesetzt wurde, nicht gemeinschaftlich geübt wurde, zumal es auf das Zusammenwirken aller ankam. Sicher hat es aber anfangs keine Exerzierregeln gegeben, und die Übungen beruhten auf der Anleitung durch Kriegserfahrene, auf tradierter Kampferfahrung. Dass es also kein solches Regelwerk gab, schließt nicht regelmäßiges Exerzieren aus (siehe Schmidtchen 1990: 232 und Kleinschmidt 1989: 25f.). Gerade die offensive Fähigkeit der Gewalthaufen gegenüber der Reiterei bestand darin, dass er nicht nur defensiv in einer Stellung verharren musste, sondern sich auch auf dem Schlachtfeld bewegen konnte, ohne dass die Formation aufbrach und Lücken entstanden, in die ein Reitertrupp, ohne auf großen Widerstand zu stoßen, eindringen und damit möglicherweise den gesamten Haufen sprengen konnte. Zur Verteidigung vor einem Reiterangriff musste ein Gewalthaufen >nur` die äußeren Reihen dicht geschlossen halten, die »vorderen Spießreihen« fällen,

»wobei in Verbindung mit einem Ausfallschritt das Schaft-ende am Erdboden mit dem zurückgestellten Fuß fixiert und der Spieß in gebückter Körperhaltung bei gestreckten Armen in einem Winkel von ca. $30^{\circ}$ oder aus der Bewegung heraus in einer Art von Hüftanschlag den Angreifern entgegenhalten wurde.« (Schmidtchen 1990: 185)

Am Zusammenhalt der sozialen Organisation des Gewalthaufens sollte die Offensivstärke der Reiterei zerschellen. Dies stellte die Reiterei als Hauptstreitmacht in Frage, weil ihre Dominanz nur in der Bewegung, also in der Offensive zum Tragen kam. Die Reiterei hatte deshalb dem Gewalthaufen in dem Moment nichts entgegenzusetzen, als dieser selber offensiv wurde, also vorrückte. Ist der Angriff eines Reiterverbandes abgewehrt, bleibt ihm außer einem erneuten Anritt keine weitere Option als der Rückzug vom Schlachtfeld. Pferde bleiben nicht stehen, wenn sie attackiert werden.

Die Reiterei bildete fortan nicht mehr die Hauptstreitmacht. Sie verschwand jedoch auch nicht vollständig von den Schlachtfeldern. Jenseits der Schlacht bot die Kraft und Dynamik des Pferdes bei weiträumig und offensiv geführten Feldzügen operative Vorteile, und in der Schlacht selber konnten vor allem überraschende Reiterattacken die gegnerischen Verbände verunsichern und erschüttern. Um diese Vorteile nutzen zu können, waren aber schwer gepanzerte Lanzenreiter ungeeignet, und an ihre Stelle traten leicht gewappnete, mit Lanze bzw. Handfeuerwaffe und Säbel ausgerüstete Reiter. Durch diese Veränderungen wurde die Reiterei gegen- 
über den gepanzerten Lanzenreitern beweglicher, und die neuen Kampftechniken ließen sich innerhalb einer wesentlich kürzeren Ausbildungszeit erlernen. Die Disziplinierung dieser Reiterei, die u.a. bereits von Weber betont wird (1922: 683), zielte auf die Bildung von stabilen taktischen Truppenkörpern, in die ein Reiter bereits nach relativ kurzer Ausbildungszeit eingegliedert werden konnte (siehe auch Delbrück Bd. 4, 1920: 152f. und Regling 1979: 36f.).

Zurück zu den Gewalthaufen: Erheblich schwieriger als die Abwehr eines Reiterangriffs gestaltete sich für einen formierten Gewalthaufen der Kampf gegen gegnerische ebenfalls mit Langspießen ausgerüstete Gewalthaufen. Hier versuchten die Spießer anfangs in den vorderen Reihen die Gegner gezielt zu treffen, was »erheblicher Geschicklichkeit und Muskelkraft bedurfte« (Schmidtchen 1990: ebd.). Im weiteren Verlauf des Gefechts wurden die Langspieße weitgehend nutzlos, weil sich die Haufen miteinander verkeilten und aufgrund der Enge in den vordersten Reihen allenfalls nur noch das Schwert und vor allem die Hellebarde ${ }^{11}$ eingesetzt werden konnten. Entscheidend wurde dann aber vor allem der mechanische Druck, der auf den Leibern der Kämpfenden lastete und der die Geschlossenheit der gegnerischen Reihen zerbrechen sollte. In dieser Phase des Gefechtes schoben und drückten die hinteren Reihen eines Gewalthaufen gegen die vor sich Befindlichen, die wiederum nach vorne zunehmend gepresst miteinander standen und auch Brust an Brust mit dem Gegner aneinander gerieten.

»Da bei einem Gewalthaufen von 50 Mann Tiefe alle nach vorn drückten und von der anderen Seite Gegendruck kam, wurde man gepresst, gedreht und verlor leicht den Boden unter den Füßen. Bisweilen wird das ganze vorderste Glied gestürzt sein. Die Nachdrängenden traten auf die Liegenden oder stürzten über sie. Die hinteren Glieder sahen nicht, was vorn vorging, und schoben weiter.« (Renn 1979: 75$)^{12}$

Es konnte also durchaus passieren, „dass jemand eine Schlacht inmitten eines solchen Gewalthaufens nur als Schiebender oder Geschobener erlebte. « (Schmidtchen 1990: 232) Vor allem wenn die Bewaffneten von den Flanken bedrängt wurden, konnte der Druck so hoch sein, dass sie sich gegenseitig erdrückten. (Verbruggen 1998: 189) Den Gesetzen der Mechanik folgend, wurde die Größe der Verbände für den Verlauf entscheidend, das heißt: Waren die Verbände annähernd gleich groß, war der Ausgang besonders ungewiss. Durch die Formierung mehrerer Haufen konnte aller-

11 Die Hellebarde, in der Literatur auch als Halmbarte oder Halbarte bezeichnet, ist ein offensiv einsetzbarer Mehrzwecklangspieß, der erst im 13./14. Jahrhundert entwickelt wurde, und neben dem Spießen auch zum Hauen aus der 2., 3. Reihe geeignet war.

12 Delbrück meint dagegen, dass man die Berichte, die vom Fallen der ersten Reihe erzählen, nicht wörtlich zu nehmen habe (Bd. 4, 1920: 70). 
dings auch Druck aus unterschiedlichen Richtungen aufgebaut werden und sich damit der gewünschte Erfolg einstellen, den gegnerischen Verband zu zerreißen (Schmidtchen 1990: 233). Einer der Gründe der Kriegsherren, möglichst viele Söldner anzuwerben, lag darin, dass allein die Zahl der eingesetzten Söldner über Sieg oder Niederlage entschied (Delbrück Bd. 4, 1920: 81, 143).

Die ungleiche Entscheidungskompetenz der im Verband Eingereihten und die geringen Gestaltungsmöglichkeiten der meisten Eingereihten über ihren eigenen Kampfeinsatz geben wenig Raum für die Entfaltungsmöglichkeiten von Subjektivität in einem emphatischen Sinne. Gleichzeitig konnten die einzelnen infanteristisch Kämpfenden nur durch die eigene Disziplinierung eine Formation bilden, die die Dominanz der Reiterei brechen konnte. Nur indem sie auf eigensinniges Handeln verzichteten, über die Fähigkeit verfügten, ihr Handeln spezifisch an das Handeln anderer Subjekte zu binden, konnte die angestrebte Geschlossenheit des Verbandes von den Individuen hergestellt werden. Die Einhaltung der Disziplin war für den Einzelnen auch kein irrationales Handeln, da ein Auseinanderlaufen der Formation die Gefahr erhöhte, getötet zu werden. Dies gilt bereits für die Formierung des Verbandes. Von der Schnelligkeit, in der z.B. aus einem Marsch heraus die einzelnen Unterabteilungen und schlussendlich auch die Individuen die igelförmige Aufstellung einnahmen, konnten Sieg oder Niederlage abhängen. Kaum zu gering ist die Bedeutung des Vertrauens zu veranschlagen, die der Einzelne in seine Nachbarn haben musste, dass diese nicht aus den Reihen ausbrachen, wenn Reiter gegen den Verband anritten, wenn sie z.B. mit Armbrüsten aus der Distanz angegriffen wurden oder ein anderer Gewalthaufen auf sie eindrang. ${ }^{13}$

Die Disziplin dürfte angesichts der tödlichen Bedrohungen eine Entlastungsfunktion für die individuellen Subjekte gehabt haben. Denn gerade in gefahrvollen Situationen war jedem Einzelnen wohlvertraut, was er zu tun hatte und was nicht. Und das Leben der Kämpfenden hing elementar vom Zusammenhalt der Formation ab. Bestand zumindest für ritterliche Kämpfer im Kampf unter Gleichrangigen eine gewisse Chance, dass ihr Leben vom Sieger geschont wurde, - allein schon deshalb, weil die Aussicht bestand, von den Angehörigen Lösegeld zu erhalten - ist für die infanteris-

13 In diesem Zusammenhang ist erwähnenswert, dass sich die Söldner aus den gleichen Anwerbegebiete in eigenen Verbänden formierten. Vor allem zwischen den Söldnern aus deutschen und schweizer Gebieten kam es deshalb auch zu Differenzierungen, da sie sich häufig, z.B. in Italien, als Gegner auf dem Schlachtfeld gegenübertraten. »Mit zunehmender Dauer der Kriege griff der Konflikt auch auf die wirtschaftliche Basis der Kriegsknechte über, denn beide Parteien standen immer häufiger in Soldkonkurrenz zueinander.« Durch ihre Kleidung und ihren Habitus, die als identitätsstiftende >Integrationsfermente wirkten, und auch um im Nahkampf die Verwechslungsgefahr zu mindern, versuchten sie sich voneinander abzusetzen (Rogg 1996: 121f.). 
tisch Kämpfenden keine derartige Schonung überliefert. Die von Rogg untersuchten Bildquellen des 16. Jahrhunderts belegen, dass

»unterlegenen Kriegsgegnern kein Pardon gewährt wurde. Welcher Militärunternehmer hätte auch ein Interesse an der Auslösung einfacher Krieger gehabt? [...] $\mathrm{Da}$ die gemeinen Kriegsknechte in der Regel nur das besaßen, was sie bei sich trugen, konzentrierte sich das Beuteinteresse zwangsläufig auf diesen in der Bildüberlieferung bestens dokumentierten Bereich: Kleidung und Waffen.« (Rogg 2003: 125)

Den Getöteten wurde beides abgenommen.

Doch allein auf die Einsichtsfähigkeit der Subjekte verließ sich bereits das eidgenössische Kriegswesen nicht. Abgesichert wurde die Einhaltung der Disziplin durch drakonische Strafen. Die Ende des 15. Jahrhunderts gültigen eidgenössischen Kriegsordnungen bestimmten, dass wer aus der Formation floh oder >Flucht $\iota$ ruft, wer »ohne triftigen Grund, wie z.B. eine Verwundung in der Schlacht, die Formation verließ, sollte auf der Stelle ohne Gnade von seinen Kameraden niedergestoßen werden« (Schmidtchen 1990: 232) bzw. »dessen Leib und Gut« sei dem Richter verfallen (Delbrück Bd. 3, 1920: 686). In diesem Zusammenhang ist auch ein Beschluss auf der Tagsatzung zu Luzern, Anfang 1475, zu sehen, demnach »die Hauptleute Mannschaften schwören lassen [sollen], dass sie nicht plündern, bevor das Gefecht zu Ende ist, und bei der Nachhut sollen eine Anzahl Männer angestellt werden, die darauf achten und jeden auf der Stelle niederstechen, der dawider handelt.« (Ebd.; siehe auch Renn 1979: 63) Das Verbot des Plünderns zeigt zugleich die Lückenhaftigkeit der Disziplinierung an. Sie galt im Übrigen nur unmittelbar für das Schlachtfeld.

Wenngleich man in die Gewalthaufen, mit denen die Schweizer Städte und Kantone den Herrschaftsanspruch der Habsburger abwehrten, «auch Bauernaufgebote hineinstellen [konnte], die von vornherein nur einen mäBigen Willen zur Tat mitbrachten« (Delbrück Bd. 3, 1920: 688), so ermöglichten die zahlreichen Siege gegenüber gepanzerten Reitern, dass Schweizer sehr begehrte Söldner wurden und als >Reisläufer`von vielen Städten und Feudalherren außerhalb der Eidgenossenschaft angeworben wurden. Die vom 14. bis in das 16. Jahrhundert auf den europäischen Kriegsschauplätzen auftretenden Schweizer Gewalthaufen setzten sich aus Freiwilligen zusammen, für die das Söldnerdasein zumindest ein zeitweiliger Beruf war.

Nach der Niederlage eines organisatorisch und taktisch reformierten Ritterheeres unter dem Herzog von Burgund, Karl der Kühne, dem es nicht gelang, gegen die Schweizer Gewalthaufen zu bestehen (1474-1476), wurde die Anwerbung von Söldnern $\mathrm{zu}$ einer Notwendigkeit für die Territorialfürsten und Städte, die sie nur unter der Gefahr des Verlustes des Herrschaftsgebietes ignorieren konnten. Die Reisläufer waren nach diesem Durchbruch sehr begehrt, und um ihren Bedarf zu decken, gingen deshalb 
die Territorialfürsten und Städte sehr schnell dazu über, innerhalb ihrer eigenen Territorien Truppen anzuwerben. Innerhalb des deutschen Reiches wurden ab dem 15. Jahrhundert neben den Reisläufern zusätzlich noch so genannte Landsknechte angeworben, die sich nach dem Vorbild der Schweizer Gewalthaufen formierten. Beide, Reisläufer wie Landsknechte, waren durchdrungen vom Bewusstsein ihrer Überlegenheit gegenüber der Reiterei. Sie seien, so Schmidtchen, "stolz auf ihre Siege [gewesen] und verachteten ihrerseits die dünkelhafte Art der ritterbürtigen Herren, für die sie keine Berechtigung mehr zu erkennen vermochten« (1990: 235). Die Bezeichnung Landsknecht selber, die nach Baumann nur auf Söldner deutscher Herkunft zu beziehen sei (1994: 47), ist Ausdruck dieses Selbstbewusstsein. Während die geläufigeren Bezeichnungen der Kanzleiund Feldschreiber für die Fußtruppen Knechte, Kriegsvolk und ähnliches waren (ebd.), zogen die Anführer wie die Knechte diese Bezeichnung vor. Unter den Schweizern galt es dagegen als Beleidigung, Landsknecht genannt zu werden. Sie zogen die Bezeichnung Reisläufer vor.

\subsection{Vom Söldner zum Soldaten}

Ob sich die Söldner Reisläufer oder Landsknecht nannten, sie gingen mit den Kriegsherren, mit denjenigen, die sie für den Kriegsdienst anwarben, einen Vertrag ein. Sie mussten einen Treueid schwören und eine Feldordnung anerkennen, dafür erklärte sich die andere Seite bereit, einen festgelegten Sold zu zahlen. Dem Inhalt nach waren die Artikelbriefe, die Akte der Musterung

»obrigkeitlich bestimmt, also kein Ausdruck autonomer Selbstdefinition. Doch sie steckten den Rahmen ab auch für eigensinnige Ausdrucksformen und Abgrenzungen der Söldner. So nahmen Söldner neue sprechende Namen an [...] und gründeten damit symbolisch eine neue, von den alten Beziehungen gelöste, Existenz. Die Kleidung der Söldner variierte die allgemeine Mode dergestalt, dass durchaus luxuriöse Extravaganzen mit obrigkeitlicher Billigung die engen ständischen Zuschreibungen sprengte und eine sozusagen autonome Eigen-Ständigkeit demonstrierte.« (Sikora 2003: 222)

Insbesondere die Artikelbriefe vor dem 17. Jahrhundert regelten unter anderem, wie die Beute verteilt wurde, inwieweit einfache Söldner ihre unmittelbaren rangniedrigen Vorgesetzten wählen konnten, und sie gewährten den Söldnern eine weitgehende rechtliche Selbstverwaltung, die z.B. Institutionen eigener Rechtspflege vorsahen (siehe hierzu ausführlich Burschel 1993: 129f. und Baumann 1977: 185f.).

Die Ersetzung von Söldnerheeren durch >eigene Kräfte`, wie es Machiavelli in »Der Fürst« forderte, die sich aus »Untertanen, Bürgern und Gefolgsleuten« (1513: 88) rekrutierten, war nicht möglich. Sein Vorhaben 
scheiterte gleich aus mehreren Gründen: Bezogen auf die Städte scheute das Patriziat zu Recht eine Bewaffnung der Einwohner aufgrund der Spannung und Spaltungen innerhalb der Kommune zwischen den verschiedenen sozialen Gruppen; für die Territorialfürsten wiederum hätte ein Rückgriff auf feudale Dienstverhältnisse bedeutet, ihre Abhängigkeit von den Adeligen zu erhöhen und damit ihre Machtposition zu schmälern. Der schnelle Aufbau großer Truppenkontingente war obendrein durch feudale Dienstverhältnisse nicht in dem Maße zu leisten, wie sie das Söldnerwesen erforderlich machte, zumal die Kriegskampagnen in den Monaten stattfanden in denen die Arbeitskräfte auf dem Land benötigt wurden. Vielleicht der ausschlaggebende Grund aber war, dass sich für Miliztruppen die Chancen auf einen Sieg in dem Maße verringerten, in dem sich das Kriegswesen professionalisierte. Angefangen von der Konditionierung des Körpers und der Psyche eines jeden Bewaffneten auf die im Zuge einer Kriegskampagne auftretenden Belastungen, - was neben der unmittelbaren Gewalterfahrung auf dem Schlachtfeld auch die Entbehrungen auf dem Marsch wie Hunger, Durst und Kälte einschloss - bis hin zum disziplinierten und damit effektiven Waffeneinsatz, der nur durch wiederholte Übungen $\mathrm{zu}$ erreichen war, boten professionelle Söldnerverbände entscheidende Vorteile. Die Professionalität erlaubte es auch, dass sich die Söldner in zunehmend taktisch anspruchsvolleren Verbänden formierten. Etappenweise wurde die Aufstellung in einen, zwei oder drei Haufen zugunsten von kleineren taktischen Verbände aufgegeben, die zum einen wesentlich beweglicher waren, zum anderen aber auch erhöhte Anforderungen an die Kommandeure stellten (siehe Delbrück Bd. 4, 1920: 188f.). Nur wenn die Kommandeure im Umgang mit der Vielzahl der taktischen Einheiten erfahren waren, es verstanden, den Einsatz des Fußvolkes und der Reiterei zu koordinieren, sowie die beste Stellung für die allmählich auf den Schlachtfeldern auftauchende Artillerie zu bestimmen, konnte die Kampfkraft der Armee durch die erhöhte Beweglichkeit tatsächlich gesteigert werden. Die Anforderungen an die Leitung eines Heeres stiegen auch, weil der Erfolg eines Kriegszuges entscheidend vom Umfang des aufgebotenen Heeres abhing. Dies galt schon für die Gewalthaufen: Je größer der eigene Verband, desto eher hielt die gegnerische Formation dem ausgeübten Druck nicht stand.

Mit dem 14. Jahrhundert vergrößerten sich die Heerzüge merklich. Delbrück weist darauf hin, dass die »natürliche Grenze für die Heeresgröße [...] die finanzielle Leistungskraft des Kriegsherren« hätte sein müssen (Bd. 4, 1920: 81), doch diese Grenze konnte in dem Maß überschritten werden, in dem die Kriegszüge sich durch Kredite finanzieren ließen. Und die Kriegsparteien gingen dazu über, sich in der Hoffnung auf einen Sieg weit jenseits ihrer finanziellen Möglichkeiten zu verschulden. Die Hoffnung auf den Sieg »trieb von vornherein beide Parteien über ihre Leistungsgrenze hinaus. Die Größe der Heere wuchs über das mittelalterli- 
che Maß hinaus, nicht nur insofern Kriegsherren da waren, die das bezahlen konnten, sondern weit größer, als sie es bezahlen konnten. Knechte waren ja genug zu haben, auf das Handgeld und auf die weiteren Soldversprechungen hin.« (Ebd.)

Dass es den Kriegsherren nicht schwer fiel, Anwerbewillige zu finden, lag nur zum Teil an der Höhe des Soldes. Vor allem für die Zeit vor 1650 gilt zwar, dass die Soldhöhe für die Söldner, die aus den unteren sozialen Schichten stammten, und sie stellten die Mehrheit, attraktiv war, doch ist auch für diese Zeit vor Übertreibungen zu warnen, denn in den Heerzügen waren die Lebenshaltungskosten extrem hoch und bis in das 18. Jahrhundert war die vollständige Bezahlung des Soldes die Ausnahme und nicht die Regel. (Burschel 1993: 173f., 205) ${ }^{14}$ Allgemein ist Burschel zuzustimmen, der ein Sprichwort der Zeit zitierend (>Landsknecht verkauffen jhre Haut vmb wenig Geld.`) feststellt, dass das Risiko des Söldnerlebens in keinem Verhältnis zur Höhe des Soldes stand (ebd.: 206). Söldner, die durch den Kriegsdienst reich wurden, waren Ausnahmeerscheinungen. Ein einfacher Söldner konnte sich nur dann Reichtum aneignen, wenn es ihm gelang, außerhalb des Schlachtfeldes (hier musste er die Beute abliefern und den Vorgesetzten stand ein überproportionaler Anteil an ihr zu; siehe Burschel: 208f.) alleine oder mit anderen eine ungewöhnlich einträgliche Beute zu machen. Das >kisten fegen Plündern längs der Marschrouten, diente weniger der Bereicherung, sondern schuf die Grundlage für die eigene materielle Versorgung, weil die Soldzahlungen häufig ausblieben (siehe Rogg 2002: 126). Ungewöhnlich war auch der soziale Aufstieg durch den Solddienst. Eine soziale Karriere als Söldner war am ehesten für Handwerker, Gelehrte und Adelige möglich. Sie hatten wesentlich bessere Aufstiegschancen als die zu Fuß kämpfenden Kriegsknechte, die aus den städtischen und ländlichen Unterschichten stammten. Sie verfügten am ehesten über einige Mittel, um eine teure Ausrüstung anzuschaffen und hatten Gelegenheit, Erfahrung im Umgang mit schwierig zu handhabenden Waffen zu sammeln, waren deshalb nicht gezwungen, dauerhaft als einfache Söldner zu dienen. Für Adelige waren die Chancen am größten, bis in die oberen Ränge aufzusteigen, und damit in die Nähe des Territorialfürsten zu rücken. Trotz der demonstrierten autonomen Eigen-Ständigkeit ist deshalb festzustellen: »Das Regiment der Landsknechte durchbrach die ständische Ordnung nicht, es war ihr Abbild.« (Burschel 1993: 202)

Abenteuer, Ruhm und Reichtum, das mag sich so mancher Söldner von seinem Kriegsdienst versprochen haben, doch so wichtig diese oft erwähn-

14 Die Höhe des Soldes wurde neben der Kriegserfahrung wesentlich von Bewaffnung und Rüstung beeinflusst, mit der er sich anwerben ließ. Ein kriegserfahrener Söldner, der z.B. mit einem Schwert und Harnisch ausgerüstet war, erhielt doppelten Sold. Grundsätzlich hatten die Kriegsherren für infanteristische Söldner weniger zu zahlen, als für einen ritterlichen Reiter. 
ten Motive waren, sie können nicht darüber hinwegtäuschen, dass es für die meisten Söldner einen bei weitem profaneren Grund gab, sich anmustern zu lassen. Bereits bei den Schweizer Söldnern des 14./15. Jahrhunderts begannen diese Motive erst zu funkeln angesichts der armseligen und perspektivlosen Verhältnisse der Talschaften, in denen sie ansonsten gezwungen waren zu leben. Die wenigen Detailuntersuchungen, die für einige Gebiete der Eidgenossenschaft vorliegen, zeigen an, dass nach strukturellen Veränderungen der Landwirtschaft, so wurde in einigen Regionen der Ackerbau durch die weniger arbeitsintensive Großviehhaltung verdrängt, ein großer Teil der Bevölkerung in Existenznot geriet (Baumann 1994: 69).

Wenn es im 16. Jahrhundert möglich war, binnen kürzester Zeit Tausende anzuwerben, so lag dies ebenfalls weniger an überschäumender Abenteuerlust, als vielmehr an der Zahl von Menschen in Stadt und Land, die keine Aussichten hatten, durch weniger gefährliche, sprich nichtkriegerische Tätigkeit, ihr Leben zu unterhalten. Ihre Zahl erhöhte sich im 16. Jahrhundert, weil trotz Seuchen und verheerenden Kriegen die europäische Bevölkerung mit Beginn des 16. Jahrhunderts bis zur Mitte des 17. Jahrhunderts stark anwuchs (siehe hierzu Wehler 1987: 69). Dies führte zu einer Verschärfung der sozialen Probleme in den Städten und auf dem Land. Ein Hinweis hierauf ist, »dass die Kaufkraft der Löhne in großen deutschen Städten zwischen 1500 und 1700 um beinahe 50 Prozent zurückging.« (Jütte 2000: 38) Für die europäischen Städte gilt die Schätzung, dass zwischen 5 und 10 Prozent der Bevölkerung - je nach lokalen und temporären Gegebenheiten - nicht in der Lage war, sich selber zu ernähren und deshalb auf Hilfe angewiesen blieb. Ihre Zahl stieg ab dem späten 15 . Jahrhundert (ebd.: 191). Die wenigen Schätzungen, die für ländliche Gebiete vorliegen, »lassen darauf schließen, dass ihre Zahl nicht unter 5 Prozent der Haushaltsvorstände lag.« (ebd.: 68) Die bessere Quellenlage für die Städte erlaubt Jütte auch die Feststellung, dass mehr oder weniger zwei Drittel ihrer Bevölkerung »über nichts als ihre Arbeit verfügten und die man daher oft als die erwerbstätigen Armen bezeichnete.« (Ebd.: 65) Seuchen, Missernten und Kriege trieben lokal die Preise für Lebensmittel rasant in die Höhe und erhöhten die Zahl derjenigen, die sich nicht von ihrer Arbeit ernähren konnten. ${ }^{15}$ Es war die grassierende Armut, die das Reservoir für die Aufstellung der immer größer werdenden Söldnerheere schuf. Und gerade in Kriegsgebieten war die Bereitschaft zum Kriegsdienst besonders hoch.

15 Das Risiko zu verarmen hing obendrein eng mit dem Lebenszyklus der Familie zusammen. Kinder, Auseinanderbrechen der Familie durch Tod oder Trennung der Eltern, sowie das Alter waren die entscheidenden Risikofaktoren. Ohne die Möglichkeit, Rücklagen zu bilden, bedeutete jede Einschränkung der Verdienstmöglichkeiten einen Schritt in Richtung Hunger (siehe Jütte 2000: 48f.). 
Vor dem Hintergrund dieser sozialen Entwicklung verloren die Artikelbriefe im Laufe des 16. Jahrhunderts schrittweise die Eigenschaft, ein Vertrag zu sein, der zwei Seiten, Söldner wie anwerbende Kriegsherren, gegenseitig zu Leistungen verpflichtete. ${ }^{16}$ Sukzessive wurde der Pflichtenkanon in den Artikelbriefen erweitert und damit die Lebensweise der Söldner einer stärkeren Reglementierung unterworfen sowie ihre Rechte beschnitten. Vor dem Dreißigjährigen Krieg wurde ein immer größer werdender Teil der Soldzahlungen in Lebensmittelrationen umgewandelt. Diese Veränderungen stehen im Kontext einer Disziplinierung, der es nicht in erster Linie um die Rationalisierung der Gewaltausübung ging. Vielmehr ging es um eine Disziplinierung der Söldner. Das gewachsene und weiter anwachsende Reservoir von Anwerbewilligen bot den Kriegsherren die Möglichkeit, auf selbstbewusst auftretende Landsknechte, die für den Erhalt ihrer verbrieften Rechte eintraten, zu verzichten. Der Erfolg dieser Disziplinierung drückte sich beispielsweise im sukzessiven Verschwinden der Übernamen, wie Wagehals, Unkraut und Falkenschnabel aus. »Diese trotzigen und ruhmredigen, letztlich der Arbeitsplatzsicherung dienenden Selbstwürdigungen der Landsknechtszeit wurden von denen, die Soldaten ins Feld führten, nicht mehr akzeptiert.« (Burschel 1993: 319) Von den Schreibern wurden nur noch die disziplinierten Vor- und Nachnamen notiert. Und so verschwanden in den Musterrollen des 17. Jahrhunderts die Übernamen. Auf selbstbewusst auftretende Söldner zu verzichten, war für die Kriegsherren opportun, weil in Krisensituationen die Gefahr bestand, zu denken ist hierbei an ausbleibende Soldzahlungen, was bei langen Kriegszügen recht häufig vorkam - dass sie Meutereien förderten. Meutereien wiederum waren bis in die erste Hälfte des 17. Jahrhunderts das Mittel, mit dem die Söldner versuchten, ihren >verbrieften` Rechten Geltung zu verschaffen. Ständig waren die Kriegsherren mit der Drohung konfrontiert, dass die Söldner ihre Kommandos solange nicht befolgen, bis der ausstehende Sold gezahlt oder ein anderes Recht wieder in Kraft gesetzt wurde (siehe Parker 1990: 84). In der zweiten Hälfte des 17. Jahrhunderts ließen neben den Disziplinierungsanstrengungen der Kriegsherren »unterschiedliche Rekrutierungsmethoden, die hohen Verlustraten und eine beträchtliche Mobilität innerhalb der Mannschaften« (ebd.) die Zahl der Meutereien sinken. Die Maßnahmen der Kriegsherren wie die verlustreich geführten Kämpfe, führten zur Auflösung des Zusammengehörigkeitsgefühls unter den Angeworbenen. Interessiert an einer Entrechtung der Söldner waren die Kriegsunternehmer als auch ihre Auftraggeber. Denn eine Zunahme der direkten Herrschaft über die Söldner erhöhte ihre instrumentelle Einsetzbarkeit gerade in schwierigen Situationen.

16 Delbrück spricht in diesem Zusammenhang sogar davon, dass »das demokratische Element ausgeschaltet und durch die einseitige disziplinare Gewalt des Kriegsherren ersetzt« wurde (Bd. 4, 1920: 76). 
Auf die Aufhebung der eigenen Gerichtsbarkeit in Gestalt von Kameradengerichten um die Wende zum 17. Jahrhundert und ihre Ersetzung durch von den Kriegsherren eingesetzte Gerichte (Burschel 1993: 129f.) folgte der Verlust des Rechtes auf eine Mindestdienstdauer, an dessen Stelle unbefristete Dienstverhältnisse traten (ebd.: 135). Eine weitere gravierende Veränderung betraf den zunehmenden Einfluss, den die Kriegsherren auf den Tross gewannen. Zwar mangelte es schon früher nicht an Versuchen der militärischen Führung, die Größe des Trosses zu begrenzen, weil mit der Größe die Beweglichkeit ab- und die Versorgungsprobleme aus dem Land zunahmen, doch scheiterten sie an dem Umstand, dass sie nicht in der Lage waren, die Söldner zu versorgen. Erst als sie anfingen, anstelle von Sold Lebensmittel zu verteilen, was voraussetzte, dass die Kriegsherren zumindest in Teilen die Versorgung der Truppen organisierten, erhöhten sich ihre Chancen, in die Gestalt des Trosses wirksam einzugreifen. ${ }^{17}$ Die Eingriffe betrafen besonders die im Tross lebenden Frauen und Kinder, da der Tross sich nicht länger der obrigkeitlichen Kontrolle der Sitten entziehen sollte.

Um die Bedeutung des Trosses für die Söldner zu erfassen, muss etwas weiter ausgeholt werden. In den Solddienst zu treten bedeutete für die Angeworbenen, dass ihr Alltag vom Kriegsgeschehen geprägt wurde. Solange noch eher kurzzeitige Anwerbungen überwogen, war zwar eine dauerhafte Bindung an einen bestimmten Verband unwahrscheinlich, doch für den Zeitraum ihrer Aufstellung formierten sich die Verbände zu eigenständigen sozialen Gebilden, die gegenüber der sie umgebenden Sozialität ein relatives Eigenleben führten. Sie bildeten quasi eine Nebengesellschaft aus (Bei der Wieden 1996: 97). Ihre Beziehung zum Krieg unterschied diese Nebengesellschaft von der Hauptgesellschaft. Neben den bewaffneten Männern gehörten zu der Nebengesellschaft eine schwankende Zahl Unbewaffneter und eine große Zahl Frauen sowie Kinder. Der Tross war für die Versorgung der Truppe und die Bereitstellung von Materialien für den Kampf, von Rüstung über Munition, unverzichtbar. Deshalb musste auf dem Marsch im Tross im Wesentlichen alles mitgeführt werden, was nicht aus der Umgebung erbeutet werden konnte. Zugleich war der Tross der erste Umschlagsplatz für das Plünderungsgut. Das Plündern durch die Söldner bildete die Grundlage für die reguläre Versorgung der Truppe und gehörte zu den Mitteln der Kriegführung, mit denen die Kriegsherren die wirtschaftlichen Grundlagen des Gegners schwächen wollten. Der Tross

17 Temporär gelang es bereits den Kriegsherren im 17. Jahrhundert die Truppen mit Schießpulver und mit Nahrungsmitteln zu versorgen, vor allem wenn die Versorgung über die Flüsse sichergestellt werden konnte. Dass die Truppen Cromwells nach 1650 Irland und Schottland erobern konnten, führt Parker neben der für die Zeit ungewöhnlichen logistischen Leistung auf die Bereitstellung von Biskuits und Cheshire-Käse zurück, die sehr lange von den einzelnen Soldaten mit sich geführt werden konnten, ohne das sie verdarben (Parker 1990: 102) 
bildete quasi eine bewegliche Stadt, deren Größe eng von dem Heereszug abhing. Er gehörte nur in Teilen zum militärischen Verband. Da die Söldner sich weitgehend selber um ihre Versorgung mit Lebensmitteln kümmern mussten, bestand er zum einen aus Marketenden, die auf eigene Rechnung arbeiteten. Zum anderen aus einer Vielzahl von Personen, die Schenken und `Dienstleistungsbetriebe` unterhielten und die beispielsweise Wagen bereitstellten und reparierten. Hinzu kamen noch sehr viele Frauen, die mit den Söldnern sehr heterogen strukturierte (Zweck-)Gemeinschaften bildeten. Überhaupt waren es häufig Frauen, die für die Versorgung, das Essenkochen, Wäschewaschen und die Pflege von Verwundeten zuständig waren, die aber auch »ihre Männer auf den Raubzügen tatkräftig unterstützten.« (Rogg 2002: 130) Während noch in den ersten Söldnerverbänden der Schweizer von den Bewaffneten selber gekocht wurde (ebd.: 85), betrieben später überwiegend Frauen Garküchen oder kochten für bestimmte Gruppen.

»Darüber hinaus fanden sich Paare, die ihr Leben im Lager und auf dem Marsch miteinander zu meistern versuchten. Das Spektrum der Beziehungen reichte von durch Heirat legalisierte Verbindungen über >wilde Ehen « bis zu Partnerschaften auf Zeit. Vor allem für die sozial randständigen Beziehungen war die Militärgesellschaft oft das einzige Auffangbecken. Manche Lebensgemeinschaft, die außerhalb der obrigkeitlichen Normierung und Moralvorstellungen stand, konnte im rechtseigenen Raum frühneuzeitlicher Heere noch am ehesten auf soziale Akzeptanz hoffen.«(Rogg 1998: 58)

Für die Ausgrenzung von Frauen und Kinder aus dem Tross sprachen aus Sicht der Kriegsherren neben militärtaktischen auch moralische Überlegungen. Gesittet lebende Soldaten, so die Hoffnung, seien auch diszipliniertere Soldaten. Und Soldaten, die keine Lebenspartner hatten, musste man entschieden weniger Sold zahlen. Ein »Kriegsherr, der seinen Söldnern Brot gibt, Kleidung und Unterkunft statt Sold, der engt ihre Freiheitsräume ein, der bindest sie umso fester an sich, der bestimmte ganz entscheidend ihre soziale Zukunft.« (Burschel 1993: 206) Heirat, wie andere soziale Bindungen und Kontakte waren unerwünscht. »Zugespitzt formuliert: [...] die Kriegsherren [...] ließen erkennen, dass ihnen an einer sozialen Zukunft der Soldaten nicht gelegen war - ja, dass sie Soldaten wollten, die als Soldaten starben.« (Ebd.: 320) Zuerst sollten die Kinder und dann die Frauen als Teil der soldatischen Lebensgemeinschaft vom Tross ausgeschlossen werden.

Von der im 16. Jahrhundert einsetzenden Disziplinierung noch lange unberührt blieb das Phänomen der gartenden Söldner. Es trat immer dann auf, wenn Truppen abgedankt, das heißt außer Dienst gestellt, wurden. Die Söldner mussten sich dann entscheiden, ob sie einer friedlichen Tätigkeit nachgehen wollten, versuchen sollten, erneut irgendwo anzumustern, oder ob sie sich selbstständig, mittels Gewalt, Plünderung und Erpressung durch 
das Land schlagen sollten. Vor allem für die zuletzt genannten Möglichkeiten galt, dass sie sich entscheiden mussten, ob sie sich allein, mit ihrer Partnerin oder in einem Trupp auf den Weg machten. In Deutschland des 16. Jahrhunderts waren gartende Söldner eine normale Erscheinung (Burschel 1993: 279).

") Garten` war die zeitgenössische Bezeichnung für das Vagabundendasein, für Bettel und Kleinkriminalität arbeitsloser Landsknechte. Wer im 16. Jahrhundert von gartenden Landsknechten sprach, der meinte Söldner, die auf Hühner- und Gänsejagd gingen, die wilderten und Holz stahlen, die fischten, wo es nicht erlaubt war, und sich als ungebetene Gäste auf Bauernhochzeiten einfanden, die aber auch mit Rache drohten, mit nächtlichem Feuerlegen vor allem, wenn Viatikum und Unterkunft verweigert wurden, ja die immer wieder auch waffenklirrend einforderten, wonach sie verlangten.«(Ebd.: 277f.)

Es war insbesondere die Landbevölkerung, die mit solcherart herumziehenden Söldnern konfrontiert war. Die mit List und Gewalt ihren Unterhalt schöpfenden Söldner gefährdeten die Pazifizierung der Territorien und stellten »das vielleicht vordringlichste Problem der werdenden Staaten dar.« (Bei der Wieden 1996: 102) Bis in die 2. Hälfte des 17. Jahrhunderts gelang es den Staaten trotz zahlreicher territorialer Mandate nicht, das >Garten $<$ zu unterbinden, weil die einzelnen Kriegsherren einerseits ein Interesse an einem schnellen Aufwuchs ihrer Truppen hatten und deshalb an der Präsenz vagabundierender Kriegsknechte interessiert waren und sie andererseits sich nach dem Kriegszug ihrer Truppen wieder schnell entledigen wollten, um ihren Haushalt zu entlasten. Um den eigenen Schaden durch gartende Söldner zu begrenzen und ihn möglichst den Nachbarn zuzufügen, ließen sie ihre Truppen am liebsten weit weg vom eigenen Herrschaftsgebiet abdanken. Lediglich wenn die Kriegsherren beständig Truppen unter Waffen hielten, waren gartende Söldner zu vermeiden, doch dazu fehlte bis ins 17. Jahrhundert die finanzielle Grundlage.

Vor dem Hintergrund der zunehmenden Disziplinierung der Truppe und der Rationalisierung ihrer Gewalt im Rahmen des Gefechtes erscheint das Plündern in ansteigendem Maß als Sinnbild für die Folgen undisziplinierten Handelns der Angeworbenen. Da zugleich die Disziplinierung im 16. Jahrhundert mit der Entrechtung der Angeworbenen einher ging, galt quasi das Plündern als das Moment ihres Handelns, in dem sich am längsten und beständigsten ihre Subjektivität, ohne regulierenden Beschränkungen zu unterliegen, entfaltete. Diese Subjektivität steht zugleich immer in einem tendenziell als gefährlich und irrational wirkenden Bedeutungskontext. Gefährlich, nicht nur weil es sich um eine widerrechtliche, gewaltsame Aneignung von Gütern handelt, sondern auch, weil die Situation, in der sich diese gewaltsame Aneignung vollzieht, mit großen Unwägbarkeiten für alle Beteiligten verbunden ist. Es handelt sich um eine hochgradig von Gewalt gekennzeichnete offene Situation, in der der Plünderer kaum 
sicher sein kann, auf welchen Widerstand er stößt und in der für den Ausgeplünderten kaum abzuschätzen ist, wie weit der Plünderer geht: Raubt er sein Opfer aus und schont er dabei die Lebensgrundlagen des bzw. der Betroffenen, verletzt oder tötet er sogar noch seine Opfer. Irrational, weil im Zuge des Plünderns nicht nur ein Werttransfer stattfindet, die Werte also gar nicht angeeignet, sondern im Zuge der gewaltsamen Aneignung zum Teil schlicht vernichtet werden, sondern auch, weil die Plünderung für den Täter wie für das Opfer ein Ereignis ist, dessen Verlauf von ihren Emotionen entscheidend mitgeprägt wird und in dem wohl kalkuliertes Abwägen von Mittel und Zweck nachrangig die Dynamik des Geschehens prägen.

Parallel zu der Entrechtung der Söldner bemühten sich die Auftraggeber darum, die Kriegsunternehmer enger an sich zu binden. Sie versuchten damit, die Gefahr zu verringern, dass diese den Dienst verweigern oder sie gar von ihnen überwältigt werden. Bannen konnten sie diese Gefahren nicht. Die Gefahr, dass sich die Söldnerführer die politische Macht in einem Gemeinwesen aneigneten, sollte vor allem aufgrund der Konkurrenzsituation zwischen den europäischen Herrschaften abnehmen. Sie zwang die Territorialherren, Truppen in einem Umfang anzuwerben, wie sie keine einzelne >Privatperson` aus den eigenen Mitteln aufstellen konnte. Kriegführen wurde deshalb immer kostspieliger, verlangte die Verfügung über beständige Einnahmen und Bonität gegenüber potentiellen Kreditgebern. All dies fehlte den jetzt sprivaten es zuletzt im Italien des 14. und 15. Jahrhunderts wiederholt vermochten, gewaltsam ihre Auftraggeber von der Macht zu entfernen. Bereits damals brachte ein solches Vorhaben jedes Mal schwere Erschütterungen des politischen Gefüges beispielsweise einer Stadt mit sich, die die neuen politischen Herren wiederum angreifbar machten. In den sich herausbildenden Territorialstaaten des 16. Jahrhundert hätte sich zwar weiterhin ein kommandierender Truppenbefehlshaber an die Stelle eines fürstlichen Souveräns putschen können, doch waren seine Aussichten äußerst gering, sich dauerhaft in dieser Position zu halten. Im europäischen Staatenbildungsprozess hatte nur die Herrschaft Bestand, die es verstand, ohne beständigen Rekurs auf zusammengewürfelte bewaffnete Verbände Macht innerhalb eines Territoriums auszuüben, wenn es ihr jenseits einer räuberischer Praxis gelang, sich monetäre Einnahmen sichern, also ihre Untertanen kontinuierlich zu besteuern. Dies setzte eine als legitim anerkannte Herrschaftsposition und eine funktionierende Finanzverwaltung voraus, das heißt neben der militärischen Macht auch politische und ideologische Machtquellen (siehe Mann 1990: 46f.). Die politische Enthaltsamkeit der militärischen Vorgesetzten der Söldner wurde auch durch die gewachsenen technischen und administrativen Ansprüche gefördert, die zunehmend an sie gestellt wurden. Es bildete sich ein Offizierskorps aus, Fachleute militärischer Gewaltausübung, die überwiegend aus dem Adel stammten. Die im Dienst eines Territorialfürsten stehenden Offiziere einte 
jedoch jenseits ihrer sozialen Herkunft wenig, denn sie stammten meist aus verschiedenen Ländern. Dies minderte zusätzlich die Gefahr, dass das Offizierskorps gefährliche politische Ambitionen für den Souverän entwickelte. Erst mit der Nationalisierung der Armeen im 19. Jahrhundert stieg die Gefahr, die vom Offizierskorps für die politische Elite ausging, wieder an. $^{18}$

Aber selbst für die Zeit nach dem Dreißigjährigen Krieg (1618-1648) kann noch lange nicht von einer Verstaatlichung des Militärs gesprochen werden. Besser wird die Beziehung durch den Ausdruck Verherrschaftlichung bezeichnet. »Auch die späteren königlichen Heere waren eigentlich nur über die Person des Herrschers, der die Werbung und Offiziersernennung monopolisierte und gleichsam Eigentümer und sein eigener Kriegsunternehmer war, nur locker an Land und Staat angebunden. Nicht die funktionale Staatsnotwendigkeit, sondern die Herrschernähe begründete auch die aufgewertete Stellung der Offiziere und Ingenieure, die in frühneuzeitlichen Standesbüchern ganz dicht an den Regenten herangerückt wurden, der die Spitze der Ständeordnung verkörperte.« (Burkhardt 1992: 223)

Der Wandel vom Söldner zum Soldat vollzog sich als ein langsamer Prozess mit fließenden Übergängen. Ein solcher Übergang ist in der Ausrüstung der Söldner zu beobachten. Ursprünglich hatten sie bei ihrer Anmusterung ihre Waffen, Ausrüstungsgegenstände und Bekleidung selber zu stellen. Aber schon für die Mitte des 16. Jahrhunderts bezeugen Dokumente, dass Kriegsherren den Neugeworbenen z.B. Spieße aushändigten, die erst gegen Soldabzug in ihren Besitz übergingen. Sinnvoll für die Kriegsherren waren diese Bereitstellungen, um auch solche Männer rekrutieren zu können, die aufgrund ihrer Armut weder mit einer Waffe noch einem Harnisch zum Musterplatz erscheinen, dafür aber auch gegen geringere Soldzahlungen zu Kriegsdiensten geworben werden konnten (siehe Burschel 1993: 67). Es blieb nicht bei einzelnen Ausrüstungsteilen: Soweit sie sich das leisten konnten, gingen die Kriegsherren langsam dazu über, für die Truppen die komplette Ausrüstung zu kaufen. ${ }^{19}$ Im Laufe des 17. Jahrhunderts sollte sich aus dieser Form der Überlassung von Ausrüstungsteilen ein bis heute gültiges Merkmal des Soldaten entwickeln: Dem Soldat werden lediglich seine Waffe, seine gesamte militärische Ausrüstung und die Uniform überlassen. Sie gehören ihm aber nicht.

Prinzipiell konnte sich damit jeder Mann gegen Sold zum Kriegsdienst verpflichten. Ein Söldner bzw. später ein Soldat musste nicht wie der Rit-

18 Mehr zur Wechselbeziehung zwischen ziviler Führung und dem Militär siehe Heins/Warburg: 50f.

19 Dabei blieb manche Schuld offen, »wenn Tod oder Gefangenschaft den Zahlungsverpflichtungen ein Ende setzten oder wenn sich ihnen der eine oder andere Kriegsknecht durch Desertion zu entziehen wusste.« (Burschel 1993: 67) 
ter einer besonderen sozialen Klasse angehören und über die finanziellen Mittel verfügen, um sich eine Ausrüstung zu beschaffen. Über ungewöhnliche körperliche Eigenschaften mussten die Geworbenen ebenfalls nicht verfügen. Sie mussten sehen, hören und laufen können. Sie mussten über zwei Hände zum Greifen, Halten und Bewegen verfügen. Es hing aber letztlich vom Bedarf und vom Angebot ab, wie wählerisch die Kriegsherren bei der Rekrutierung waren. Deshalb konnte zwischen den Tauglichkeitskriterien, die in den Musterungsordnungen und den Werbepatenten festgelegt waren, und den Eigenschaften sowie Fähigkeiten der tatsächlich Angeworbenen eine erhebliche Kluft bestehen. Für das 17. und 18. Jahrhundert, als gerade in Kriegszeiten der Bedarf bei weitem die Zahl der sich freiwillig Meldenden überwog, bildeten deshalb Krankheit, Invalidität und Alter kein grundsätzliches Ausschlusskriterium (Burschel 1993: 116).

Der Wandel vom Söldner zum Soldaten macht sich auch an der Bekleidung kenntlich. Bis ins 17. Jahrhundert trugen die Söldner im allgemeinen ihre eigene Kleidung, die bei den Landsknechten durch bunte, aufwendige Gestaltung (geschlitzte und gebauschte Stoffe) auffiel und als Ausdruck von Selbstbewusstsein und damit Infragestellung der herrschenden ständischen Ordnung wiederholt heftig von »zivilen Autoritäten« (Bei der Wieden 1996: 95) kritisiert wurde. Die Kleidung der Landsknechte wies zwar schon früh eine Tendenz zur Vereinheitlichung auf, allerdings unter den Vorzeichen eines identitätsstiftenden >Integrationsfermentes` der jeweiligen Kriegergesellschaft und dem Bemühen, Verwechslung im Nahkampf zu vermeiden (siehe hierzu Rogg 1996: 121f.). Mit dem DreiBigjährigen Krieg verschwand die Montur der Landsknechte und die Kriegsherren bemühten sich, selber die Kleidung zu stellen, die bei weitem nicht nur funktionaler sein sollte, sondern auch wesentlich schlichter ausfiel. Sie war zwar nicht bar jeglicher identitätsstiftenden Funktion, doch war sie nun zum >Rock des Königs` geworden.

Der Wandel vom Söldner zum Soldaten ist auch an der Wahrnehmung durch die sie umgebende Gesellschaft abzulesen. Burschel fand in den Schwanksammlungen im 16. Jahrhundert den Landsknecht zumeist als gewitzt, trickreich und weltgewandt beschrieben, der als eine Faszinationsfigur auftritt. In den Schwankbüchern des 17. und 18. Jahrhundert wird der Soldat im Mannschaftsrang fast immer als Tölpel dargestellt, der nicht in der Lage ist, die Wache zu versehen oder die Parole und das Kriegsgeschehen zu verstehen. Burschel sieht in den Schwänken keine Schwejkiaden, also bewusste Widerstandshandlungen der Soldaten. Sie seien ein Anzeichen für einen veränderten Bezug der Soldaten zu dem, was von ihnen verlangt wurde. Die Soldaten seien im Gegensatz zu den Landsknechten nicht mehr in der Lage gewesen, ihr eigenes Tun zu begreifen und hätten sich deshalb närrisch aufgeführt (Burschel 1993: 39f.). Das bedeute, dass sie mit den fremdbestimmten Ansprüche und Erwartungen ihrer Vorgesetzten häufig nichts anzufangen wussten. 


\subsection{Der Soldat in den sstehengebliebenen Heerens}

Abgeschlossen wurde der Prozess der Umformung vom Söldner zum Soldaten in den >stehengebliebenen Heeren` (Burkhardt) nach dem Dreißigjährigen Krieg. Söldner waren die Soldaten weiterhin, doch traten sie einer ungleich stabileren Organisation bei, die auf Dauer ausgerichtet war, deren hierarchische Struktur sich differenzierte und in der die Entrechtung der Söldner abgeschlossen war. Kombiniert mit dem Drill der oranischen Heeresreform ${ }^{20}$ entstand eine disziplinierte Truppe, deren Hauptmacht zu Fuß kämpfende Soldaten bildeten. Bei den Infanteristen fällt der Verbund einer gesteigerten militärischen Effizienz mit gestiegener Kontrolle und Disziplinierung des einzelnen Soldaten besonders ins Auge. Nicht seine individuelle Kampfkraft war gefragt, sondern ihre Integration in einen staktischen Körper` (Delbrück). Das bedeutete, dass, auf dem Schlachtfeld angekommen, die Soldaten einer Einheit wie eine aus vielen Körpern zusammengesetzte Maschine handeln sollten. Um dieses Ziel zu erreichen, wurden die Soldaten einem zeitintensiven Drill unterworfen. Er zielte darauf ab, bei den Soldaten eine konditionierte Routine von Bewegungsabläufen auszubilden, einen Automatismus, der ihre emotionale Beteiligung, an dem, was um sie herum geschah, soweit unterdrückte, dass sie weder vorzeitig ihre Waffen auf den Gegner abfeuerten, noch aus Angst um das eigene Leben aus der Todeszone flohen. Im Zuge des Drills wurde der gesamte Körper eines Soldaten reglementiert. Als entscheidendes Mittel des Exerzierens galt die andauernde Wiederholung der immer gleichen Bewegungen, die in kleine Abschnitte unterteilt wurden und die auf das entsprechende Kommando hin, quasi reflexartig vollzogen werden sollten (siehe hierzu Kleinschmidt 1989: 203f.). Ein weiteres Ziel war die Synchronizität der Bewegungen aller Soldaten einer Einheit. Auf ein Kommando hin hatten also alle Soldaten im gleichen Moment die gleiche Handlung auszuführen. Die in den Reglements vorgesehenen Übungen auf den Exerzierplätzen würden heutige Beobachter »an Taylorismus mehr als ein Jahrhundert vor Taylor« (Bröckling 1997: 71) erinnern. Wichtig waren die gedrillten Bewegungen sowohl für die Vorbereitung des Gefechts, wie für das Gefecht selber.

20 Die oranische Heeresreform war Teil einer allgemeinen Neurezeption antiker und das hieß vor allem römischer Kriegsschriften. Sie griffen bewusst auf die hier ausgebreiteten Vorstellungen zurück und passten sie zugleich den zeitgenössischen Gegebenheiten, wie sie z.B. durch den Einsatz von Handfeuerwaffen gegeben waren, an. Siehe hierzu ausführlich Papke (1979: 122f.) und Bröckling (1997: 32f.). 
Das Maschinenmodell, auf das insbesondere die rangniedrigen Infanteriesoldaten und ihre unmittelbaren Vorgesetzten im Rahmen der Lineartaktik des 18. Jahrhunderts verpflichtet wurden, stellt den umfassendsten Versuch dar, der Subjektivität der allermeisten Akteure auf dem Schlachtfeld möglichst wenig Raum zu gewähren. Dem Modell nach sollten die Soldaten keinen aktiv gestalterischen Einfluss auf das Kampfgeschehen nehmen. Ihre Körper wurden quasi wie Maschinenteile betrachtet, und ihre Handlungen wurden an der Beständigkeit beurteilt, mit der sie die angeordneten Bewegungsabläufe ausführten. Als die Disziplin störende und damit die Absichten des Feldherren durchkreuzende Handlungen galten neben der Verweigerung der Befehlsausführung oder gar der Flucht vor dem Gegner deshalb auch Handlungen wie das gezielte Schießen auf den Gegner und das Ausbrechen aus der Linie, um ihn zu attackieren. Ein individuelles Engagement der Soldaten wurde von ihnen weder verlangt noch galt es als opportun. Das Maschinenmodell setzte auf eine Exklusion soldatischer Subjektivität.

Eine möglichst perfekte Ausführung der Bewegungen wurde ab der 2. Hälfte des 17. Jahrhunderts entscheidend, als sich die Infanterieformationen in Linien aufstellten, damit möglichst die gesamte Feuerkraft der Verbände auf dem Schlachtfeld zum Einsatz kam. Die kleinste taktische Einheit der Infanterie war das Bataillon, das je nach Armee zwischen 300 und 1000 Soldaten umfasste. Bei der Kavallerie war die taktische Grundeinheit die Schwadron, die 100 bis 150 Reiter stark war. Diese Verbände wurden nebeneinander formiert und bildeten lange Linien, nach dem dieses Einsatzkonzept benannt wurde: Lineartaktik. Die einzelnen Verbände formierten sich meist in zwei bis drei, parallel zum Gegner angeordneten Reihen, die in der zeitgenössischen Sprache als Glieder bezeichnet wurden. ${ }^{21}$ Zusammen bildeten diese Reihen ein so genanntes Treffen, denen im Abstand von ungefähr 200 bis 300 Metern mindestens ein weiteres Treffen folgen sollte. In der Mitte der Schlachtformation sollte sich die Infanterie befinden und die Kavallerie hatte an den beiden Seiten, den Flügeln, ihre Stellung zu beziehen.

Für die Anordnung der Verbände auf dem Schlachtfeld zu hintereinander gestaffelten Linien bzw. Treffen kam es bei der Annäherung an die gegnerischen Reihen darauf an, dass die Linien nicht in Unordnung gerieten, vor allem dass keine Lücken in den Reihen entstanden. Wem es am schnellsten gelang, die Verbände in Linien aufmarschieren zu lassen und wessen Soldaten die Waffen am häufigsten abfeuern konnten, hatte einen enormen Vorteil auf dem Schlachtfeld. Damit die Soldaten an >ihrem Platz standen und diesen auch nicht >verließen`, wenn sie sich auf die Gegner zu bewegten, mussten die Bewegungsabläufe vorab festgelegt und

21 Soldaten, die nebeneinander standen, gehörten einem Glied bzw. eine Rang an. Als Reihe oder Rotte wurden diejenigen Soldaten bezeichnet, die hintereinander formiert waren. 
geübt werden. Die Lineartaktik wurde von den Kriegsparteien am erfolgreichsten angewendet, die ihre Soldaten lange und häufig vor ihrem ersten Einsatz drillten. Ihre Anwendung setzte sowohl die strikte Kontrolle der Offiziere über die Mannschaften voraus, wie sie sie zugleich auch erst ermöglichte, weil durch die vorgegebene Strukturierung jede Zuwiderhandlung auffiel. Die strikten Vorgaben führten zugleich dazu, dass die Formationen auf eine gewisse Zahl von Bewegungen festgelegt werden mussten, damit sie nicht in Unordnung gerieten. Obendrein wurde im Laufe des Jahrhunderts der Abstand zwischen den Soldaten, die nebeneinander standen bzw. marschierten, verringert, um die Feuerkraft auf einer bestimmten Fläche zu erhöhen. Beim Durchschreiten eines unübersichtlichen und schwerbegehbaren Geländes zeigte sich eine Schwäche dieser Inflexibilität der Lineartaktik, weil sie hier, wenn überhaupt, nur dann anwendbar war, wenn sich die Formationen außerordentlich langsam bewegten und zugelassen wurde, dass Lücken in den Reihen entstanden. Beim Vorgehen gegen in Linien formierte Gegner bildeten solche Unterbrechungen der Formationen ein schwerwiegendes Handikap, zumal sie die Koordination der Verbände außerordentlich erschwerten.

Als entscheidend für den Verlauf des Gefechtes galt, ob es gelang, auch die unverletzten gegnerischen Soldaten durch den schockartigen Lärm des Salvenfeuers der Gewehre und durch den Anblick der zahlreichen Verletzten und Getöteten derart zu erschüttern, dass sie die Formation verließen (vgl. Delbrück Bd. 4, 1920: 346). Um diese auf die Psyche der Überlebenden zielende Wirkung zu erreichen, mussten sich die Truppen in recht geringer Entfernung zueinander aufstellen, da die Durchschlagskraft der Geschosse des Infanteriegewehrs der Lineartruppen mit zunehmender Distanz sehr schnell abnahm und die gegnerischen Soldaten von ihnen nicht verletzt bzw. getötet wurden. Für das 17. Jahrhundert wird davon ausgegangen, dass die wirksame Schussweite bei 300 Schritten lag. »Das Feuer wurde jedoch erst ab 120 Meter (150 Schritt) eröffnet.« (Regling 1979: 28) Im 18. Jahrhundert erhöhte sich zwar die Schussweite, doch lag die gerade noch wirksame Schussentfernung bei höchstens 400 Schritt (ebd.: 30). ${ }^{22}$ Im Zuge eines Angriffs wurde das Salvenfeuer mit der Drohung kombiniert, gegen die Kontrahenten mit dem Bajonett vorzugehen. »Zum wirklichen Bajonettkampf kam es jedoch fast nie; in dem Augenblick, wo der angreifende Teil wirklich herankam, gab der Verteidiger den

22 Die Entfernungsangabe in Schritt ist nicht eindeutig festgelegt und wird selten in heute gängige Längenmaße umgerechnet. Wenn man die Umrechnung von Regling heranzieht, dann sind 400 Schritt circa 320 Meter. Folgt man dagegen dem Hinweis von Storz (2003: 210), dass man in Deutschland unter einem Schritt den zehntausendsten Teil einer deutschen Meile verstand, 0,75 Meter, dann sind es 300 Meter. Weitere Informationen zur Wirkungslosigkeit des Salvenfeuers und den schlechten Schussleistungen, die mit der Standardwaffe der Linientruppen, der Steinschlossflinte, zu erzielen waren, sind bei Luh zu finden (2004: 135f.). 
Widerstand schon auf.« (Delbrück Bd. 4, 1920: 347) Wenn sich die Soldaten in einem geschlossenen Verband bedrohlich den Angegriffenen näherten, flohen diese meistens, wenn nicht, kam es zum Nahkampf, in dem das Gewehr durch das aufgesetzte Bajonett als Stichwaffe eingesetzt wurde. Auch zur Abwehr von Kavallerieattacken wurde neben dem Salvenfeuer das Bajonett eingesetzt.

Individuelles Engagement und Einsatz waren in der gedrillten Truppe unerwünscht, ja wurden als Fehler interpretiert. Ausharren, Standhalten und Fügung in das Geschick des sicheren Todes galten als ihre paradigmatischen Tugenden (vgl. Kleemeier 2002: 261f.). Die Soldaten hatten sich als Teil eines Truppenkörpers zu engagieren, und nur auf dieses Engagement als integrierter Bestandteil eines Verbandes kam es in der Schlacht an. Individuelles Engagement wurde dagegen von ihnen nicht nur nicht gefordert, es sollte sogar unterbunden werden. So waren die Soldaten in den Linientruppen mit einem Gewehr ausgestattet, mit dem man kaum zielen konnte, und deshalb wurde der gezielte Schuss auch nicht geübt, sondern nur das Salvenfeuer. Das individuelle Abfeuern des Gewehrs auf gegnerische Soldaten konnte den psychischen Eindruck, den das Salvenfeuer hervorrufen sollte, verringern und sollte obendrein auch unterbinden werden, damit die Soldaten nicht die Wirkungslosigkeit einzelner Schüsse beobachten konnten (Luh 2004: 136). Allenfalls wurde in der Ausbildung darauf geachtet, dass die Soldaten die Entfernung zum Gegner richtig einschätzten, damit die Salven nicht in den Boden bzw. über die Köpfe der Gegner geschossen wurden (Sikora 1996: 170). ${ }^{23}$

Die beschriebene Taktik entsprach, so Delbrück, der Zusammensetzung der Armee: »Der gemeine Mann hat nichts zu tun, als zu gehorchen; im Gleichtritt wird er vorgeführt, rechts ein Offizier, links ein Offizier, hinter der schließende; auf Kommando werden die Salven abgegeben, und schließlich in die Stellung des Feindes eingebrochen, wo ein eigentlicher Kampf nicht mehr erwartet wird. Bei solcher Taktik kam es auf den guten Willen des Mannes, wenn er nur in der Hand des Offiziers war, nicht soviel an [...].« (Bd. 4, 1920: 348) Als entrechtete Individuen werden die niedrigrangigen Soldaten von den Kriegsherren nur mehr als Objekte

23 Die schlechte Qualität der Flinten, mit denen die Linientruppen ausgestattet waren, ist nicht ausschließlich dem Stand der Waffentechnik geschuldet. Die Jäger dieser Zeit verfügten über Büchsen mit gezogenen Läufen, die es erlaubten, ein Ziel über weit größere Entfernung treffsicher unter Feuer zu nehmen. Diese Waffen waren zwar teurer als die von den Infanteristen verwendeten, doch der ausschlaggebende Grund für die Beibehaltung der Flinten waren nach McNeill die Bemühungen um eine Standardisierung der Ausrüstung, die wiederum den Drill vereinheitlichen sollte. Jede Neuerung drohte die mühselig erzeugte Ordnung empfindlich zu stören. (McNeill 1984: 129) Luh führt dagegen das Festhalten an der Flinte auf ihre größere Eignung für Repräsentationszwecke und für den Bajonettkampf zurück (2004: 149f.). Mit Büchsen waren viele Soldaten der leichten Truppen ausgerüstet. 
wahrgenommen, die ihnen als Machtinstrumente bedingungslos zur Verfügung stehen sollen. Die einzelnen Soldaten hatten ausschließlich mit ihrem Körper einen Beitrag zum Gefecht zu leisten, der auf Kommando die zuvor festgelegten Bewegungsabläufe abzuspulen hatte, also wie ein totes Ding, ohne einen selbstständigen Anteil am Geschehen zu entwickeln, funktionieren sollte. Diese Vorstellung sollte die Grundlage für die Metapher von der Maschine sein, die seit dem 18. Jahrhundert auf das Militär angewendet wurde. Weil von dem einzelnen Soldat >nur` ein spezifischer körperlicher Einsatz gefordert wurde, der identisch mit dem der anderen Soldaten in der Linie sein sollte, galt jede andere Handlung als störend. Im Rahmen der Lineargefechtsführung konnte individuelles Handeln von Soldaten im Mannschaftsdienstgrad nur als eine unerwünschte Fähigkeit des Individuums interpretiert werden, die es galt, durch den Drill möglichst einzudämmen. Soldaten allenfalls dann als Subjekte zu betrachten, wenn sie nonkonform handeln, hat im Konzept der Lineargefechtsführung seine historischen Wurzeln.

Eine solche Wahrnehmung läuft aber gleichzeitig Gefahr, den Blick zu sehr auf die Seite des Ideals der Herrschaftspraxis zu verengen. Und das heißt, aus dem Blick zu verlieren, in welchem Umfang selbst für konformes Handeln die einzelnen Soldaten ihre Subjektivität einbringen mussten. Die Disziplinierung der Soldaten lastete nicht nur als Zwang auf den Soldaten, sondern befähigte sie auch dazu, unter extremen Belastungen noch handlungsfähig zu bleiben. Obwohl die Soldaten bereits meistens große Strapazen erlitten, bevor sie zu einem Gefecht aufgestellt wurden, - sie waren häufig durstig, hungrig und übermüdet - half ihnen der Drill, nicht zusammenzubrechen und sich nicht von den angesichts der lebensgefährlichen Situation unwillkürlich aufdrängenden Angst- und Wutgefühlen leiten zu lassen. Selbst der Drill im 17. und 18. Jahrhundert war deshalb immer mehr als nur eine Herrschaftspraxis, die im Zweifelsfall aus unwilligen Untertanen gefügige Soldaten schinden und ihre Individualität abschleifen sollte, um sie auf willenlose Befehlsempfänger der Offiziere zu reduzieren. Denn ein Grund, weshalb die Soldaten die »gepanzerte Routine« (McNeill 1984: 122) übernahmen, war die Erfahrung einer tatsächlichen Entlastungswirkung von der Angst, aber auch der Wut über die Lage, in der man sich befand. Gerade deshalb blieben die Soldaten auch im Sinne der Gefechtsführung handlungsfähig, also empfänglich für Kommandos durch die Offiziere. Dies gilt auch für Synchronizität der Bewegungen im Verband, denn das »gelernte Kampfverhalten [wurde normalerweise] durch die geschlossene Formation zusätzlich gestützt, deren praktische Bedeutung über die bloße Kontrolle und Entfaltung der Feuerkraft hinausging. Sie ordnete die einzelnen in einen kollektiven Bewegungsablauf ein. Auf der anderen Seite wird sie den Soldaten ein Quäntchen an Stärke und Sicherheitsgefühl vermittelt haben, vor allem, wenn sie sich gegen den Feind durchsetzte.« (Sikora 1996: 167f.) Die Rou- 
tine war auch kompatibel mit der Abstumpfung, die sich bei den Kämpfenden unwillkürlich einstellte und sich als ein Versuch des Abschließens gegenüber den von Außen andrängenden Eindrücken beschreiben lässt. So wie eine verringerte Fähigkeit zur Empathie gegenüber den Leiden Anderer die Handlungsfähigkeit sicherstellt, so erleichtert die Routine unter diesen Bedingungen das Handeln selber. Damit ist nicht gesagt, dass die Strafen, die auf die Befehlsverweigerung standen, nicht die erwünschte Wirkung bei den Soldaten hatten, Furcht vor den kommandierenden Offizier zu empfinden. Aber gerade in einem Gefecht ist diese Furcht angesichts der lebensgefährlichen Situation nicht mehr als ein Faktor, der das Handeln der Soldaten beeinflusste und die erwünschte Standhaftigkeit der Truppe begünstigte. Neben den drakonischen Strafandrohungen (siehe hierzu Möbius 2004: 344) und dem Drill sind obendrein die Bedingungen eines Schlachtfeldes anzuführen, die wesentlich die Standhaftigkeit und die Stabilität des geschlossenen Verbandes beeinflusste: So schränkte der Lärm und Qualm, der durch die abgefeuerten Gewehre entstand, die Möglichkeiten der einzelnen Soldaten ein, sich auf dem Schlachtfeld zu orientieren und erhöhte umgekehrt eher ihre Neigung, bei der Truppe zu bleiben und nicht alleine in eine ungewisse, womöglich noch gefahrenvollere Situation zu fliehen. Der Hinweis der Offiziere, dass eine Flucht viel gefährlicher sein konnte als das Ausharren bei der Einheit, wird nicht gänzlich seine Wirkung verfehlt haben, zumal tatsächlich im Falle einer Niederlage, die immer durch den Zusammenbruch der Geschlossenheit der Verbände markiert wurde, für die Soldaten der unterlegenen Partei das Risiko, verletzt oder getötet zu werden, enorm stieg. (Sikora 1996: 172; Möbius 2004: 343)

Trotzdem: Dass ein Gefecht genauso verlief, wie es zuvor geübt wurde, war eher eine Ausnahmeerscheinung. Die Exaktheit, mit der die Soldaten auf dem Exerzierplatz ihre gedrillten Bewegungsabläufe vollzogen, stellte sich nur selten auf dem Schlachtfeld ein. So war das von preußischen Offizieren angestrebte Salvenfeuer ein Ideal, dem meistens bereits nach der ersten Salve ein unregelmäßiges »Plackerfeuer« folgte (vgl. Delbrück Bd.4, 1920: 347).

Dass der Drill für die Soldaten mehr war als nur eine fremdbestimmte Schinderei, sie beispielsweise der Ausbildung eines spezifischen Körperschemas positiv gegenüber stehen konnten, zeigen die wenigen autobiographischen Zeugnisse aus der Sicht der einfachen Soldaten. ${ }^{24}$ Sie konnten, worauf Sikora hinweist, als ein »distinguierendes Merkmal von den Soldaten selbst empfunden werden.« (Sikora 2003: 226) So schreibt Bräker, dass sich sein »Aeusseres [...] ziemlich verschönert« habe. »Ich gieng nicht mehr so läppisch daher, sondern hübsch gerade. Die Uniform,

24 Als die mit Abstand am häufigsten zitierte Autobiographie für das Kriegserlebnis der einfachen Soldaten im 18. Jahrhundert ist Bräker zu nennen, der als das Referenzwerk für das 18. Jahrhundert gilt (Sikora 2003: 223). 
die mein ganzes Vermögen war, und eine schöne Frisur, die ich recht gut zu mache wusste, gaben meiner Bildung ein Ansehn, dass dürftige Dirnen wenigstens die Augen aufsperrten.« (Bräker 1789: 519)

So sehr sich durch den Drill die Anwerbepraktiken ändern ließen, konkret er es ermöglichte, dass Individuen eingereiht werden konnten, die zum Dienst gepresst wurden, und so sehr er die Gefechtsführung im 18. Jahrhundert prägte, so sei am Ende dieses Abschnitts auch auf die Grenzen der Disziplinierung hingewiesen. Die neuere historische Forschung hat zahlreiche Differenzierungen am Bild der durch und durch disziplinierten Truppen der stehenden Heere des 18 . Jahrhunderts erarbeitet. ${ }^{25}$ Sie dokumentiert ein Scheitern der Bemühungen, die bewaffnete Macht umfassend zu disziplinieren. Die Grenzen der Disziplinierung markieren, dass auch die Mannschaften der Lineartruppen nicht ausschließlich als fremdbestimmte Objekte, als Maschinenteile, beschrieben werden können.

Der als irregulär eingestufte Teil des Trosses, der auch als »Schattenwelt am Rande der Lagergesellschaft: Spieler, Gaukler, Zigeuner, Wahrsager, Waffenbeschwörer und Wunderheiler, kampfunbrauchbare Invaliden und schließlich Marodeure, die die Not bereits in die Devianz getrieben hatte« (Kroener 1996: 16) bezeichnet werden kann, konnte zwar aufgelöst werden, jedoch blieben eine unbestimmte Zahl Frauen und Kinder bei der Truppe, um weiterhin Aufgaben in der Lebensmittel- und Sanitätsversorgung zu übernehmen. Der Hurenwaibel, ein älterer Landsknecht, der Frauen und Kinder zu beaufsichtigen hatte, konnte abgeschafft werden, die Prostitution nicht. Solange die Versorgung der Soldaten von der militärischen Verwaltung nicht gewährleistet war, gelang die Auflösung der Trossgesellschaft nicht vollständig. Eine starke Verkleinerung des Trosses brachten paradoxerweise die Massenheere zu Beginn des 19. Jahrhunderts. Paradoxerweise, weil der Druck zur Verkleinerung des Trosses mit der Vergrößerung der Heere enorm anstieg, um die Beweglichkeit der Verbände $\mathrm{zu}$ erhalten und sogar $\mathrm{zu}$ erhöhen. ${ }^{26} \mathrm{Da}$ aber diese Heere sich überwiegend aus Wehrpflichtigen zusammensetzten und die wiederum überwiegend junge, ledige Männer waren, wurden diese Soldaten nicht von ihren Angehörigen begleitet. Um diesen Zustand abzusichern, verloren in Preußen 1809 die Frauen und Kinder von Soldaten jeglichen Anspruch

25 Zur den neueren Untersuchungen der frühzeitlichen Militärgeschichte siehe zur Übersicht den Aufsatz von Pröve 2000 sowie Nowosadtko 2002.

26 In Preußen wurde deshalb im Rahmen der Heeresreform beispielsweise das Privileg für Offiziere zur Mitführung von Packpferden gestrichen (Wohlfeil 1964: 166). Durchschlagend erhöht wurde die Beweglichkeit der französischen Revolutionstruppen bzw. des napoleonischen Heeres allerdings durch die Entscheidung, dass sich die Truppe außerhalb Frankreichs bzw. bei raschen Vorstößen in gegnerisches Gebiet wieder aus dem Land zu versorgen hatte (ebd.: 176; Regling 1979: 231f.). Bereits die französischen Revolutionstruppen verspielten mit dieser Versorgungspraxis mögliche Sympathien, die sie sonst in der (Land-)Bevölkerung außerhalb Frankreichs genossen hätten. 
auf Unterstützung (Hagemann 2002: 82f.). Erst im 19. Jahrhundert konnten mit der Verbesserung der Verkehrswege, -mittel und Kommunikationsmöglichkeiten - besonders gravierend wirkte sich der Aufbau von Eisenbahnnetzen und Telegrafen aus - die Soldaten prinzipiell permanent mit Gütern versorgt und der Tross Teil der Militärorganisation werden. In der Kranken- und Verwundetenpflege wurden Frauen allerdings weiterhin benötigt und deshalb geduldet. Ihre Anwesenheit war jedoch zunehmend auf die Ausübung eines Berufes bezogen. Damit wurde das Militär, wenn auch nur für einen kurzen Zeitraum, der bereits mit dem 1. Weltkrieg wieder endete, ein relativ >frauenfreier Raum (zu diesem Thema siehe auch Hagemann/Pröve 1998).

Meutereien gingen in ihrer Zahl zurück, doch an ihre Stelle trat die um so häufiger werdende Desertion, die eine Übermacht der Organisation gegenüber den Einzelnen anzeigt, der seine Ab- und Auflehnung gegenüber den bei der Truppe herrschenden Verhältnissen nur noch durch Ausweichen, Ducken und Flucht auszudrücken vermochte (siehe hierzu umfassend Sikora 1996).

Auch die gartenden Söldner verschwanden, aber nicht so sehr, weil die Fähigkeit zur territorialen Kontrolle der Staaten im 18. Jahrhundert anstieg, sondern weil die Heere unablässig Soldaten suchten und die Söldner, soweit sie tauglich waren, sehr schnell wieder in Dienst treten konnten. Gleichzeitig gab es aber eine Vielzahl ehemaliger Soldaten, zumeist Invaliden, die als marschunfähig galten, und die deshalb im Unterschied zu den gartenden Söldnern nicht umstandslos in die regulären Einheiten der stehenden Heere des 17. und 18. Jahrhunderts zu integrieren waren (Nowosadtko 1997: 13). Zwar schlossen sie sich besonders häufig im Zuge von Kriegen zu Banden zusammen, die die Landbevölkerung drangsalierten, aber ihre direkte Beziehung zum Kriegsgeschehen hatte abgenommen, zumal es keinen >irregulären Tross`mehr gab. Nowosadtko weist darauf hin, dass in den Banden ehemalige Soldaten bis zu 40 Prozent der Mitglieder stellten, die restlichen 60 Prozent aber der kriminalisierten Armutsbevölkerung zuzurechnen seien (ebd.). Die ehemaligen Soldaten gingen damit in der kriminalisierten Armutsbevölkerung auf, die mit Betrug, Diebstahl, Schmuggeln von Waren und mit bewaffnetem Raub auch in Friedenszeiten auf die alltägliche Verfolgungspraxis der Obrigkeiten reagierten. $\mathrm{Ob}$ die abgedankten Soldaten, die zu Räubern wurden, für eine erfolgreiche militärische Sozialdisziplinierung stehen, die sich mit ihrer Überlebensstrategie gegen die Interessen der Obrigkeiten wandten, wie dies Burschel betont, oder ob die militärische Sozialisation nicht eher Verhaltensweisen gefördert hat, die dem Konzept der Sozialdisziplinierung zuwider liefen, das Militär also keine >guten` Untertanen herstellte, wie sich Nowosadtko dies fragt, muss hier nicht entschieden werden. Festzuhalten ist, dass es den Kriegsherren darauf ankam, über eine gefügige Streitmacht zu verfügen, die quantitativ und qualitativ in der Lage war, andere Konkurrenten um 
Macht und Territorien zu besiegen. Hinter diesem Ziel standen alle anderen politischen Kalküle hinten an. Solange die >Gehorsamsproduktion< (Bröckling) innerhalb des Militärs diesem Ziel gerecht wurde, waren sie auch dazu bereit, negative Effekte in der Sozialdisziplinierung der Untertanen durch die militärische Disziplinierung hinzunehmen. Die Gleichung, disziplinierte Soldaten sind auch gute Untertanen, war im 17. und 18. Jahrhundert ein beruhigendes Kalkül für die absolutistischen Herrschaften. Aber auch die gegenteilige Gleichung, disziplinierte Soldaten sind schlechte Untertanen bzw. der Umkehrschluss hätte sie nicht gehindert, die Disziplinierung der Soldaten voranzutreiben. Denn so sehr sie auch an guten Untertanen interessiert waren, schlechte Soldaten konnten sie sich nicht leisten. Und ist es nicht ein bis in die Gegenwart wohlvertrautes Machtkalkül, dass disziplinierte Soldaten dafür sorgen können, dass auch unwillige Untertanen das tun, was von ihnen verlangt wird?

\subsection{Exkurs zum Seekrieg, insbesondere im 18. Jahrhundert}

Obwohl der Gegenstand dieser Arbeit grundsätzlich nur die Landkriegführung ist, soll hier ausnahmsweise und auch nur schlaglichtartig die Seekriegführung betrachtet werden. Die Beobachtung, wie wenig und obendrein wie begrenzt in der Literatur die Subjektivität der Marinesoldaten behandelt wird, regte diese Veränderung des Fokus an.

Ist schon die Führung eines Krieges an Land ein voraussetzungsvolles Unterfangen, so gilt dies in weit stärkerem Maße, wenn der Krieg auf dem Wasser geführt werden soll. Ein Krieg zur See ist an zwei zusätzliche Bedingungen geknüpft: erstens muss die Krieg führende Partei über ein Schiff verfügen und zweitens müssen an Bord dieses Schiffes nicht nur Menschen sein, die kämpfen, sondern auch Menschen, die ein solches Schiff manövrieren können. Bei einem solchen Schiff musste es sich historisch nicht unbedingt um eine spezielle Konstruktion für Kriegszwecke handeln. So pflegten in Nordeuropa die Städte im Mittelalter, »als Träger der Seefahrt und als Wirtschaftsmächte [...], Schiffe für Kriegszwecke nur auszurüsten, wenn das unmittelbar notwendig war. Das war im Kriegsfalle nur selten und vorübergehend der Fall, meist um Truppen und deren Nachschubgüter in das Land des Gegners zu bringen. (Howarth 1979: 18) Territorialherren wie Könige »charterten oder requirierten die Handelsschiffe ihrer Untertanen. Für den Fall, dass sie unterwegs einem Feind begegnen sollten, wurden die mit Kapitän und Mannschaft übernommenen Schiffe provisorisch mit Befestigungen ausgestattet.« (Ebd.) Die Schiffe selber blieben im Grunde unbewaffnet und dienten lediglich als Plattform für Bogenschützen, die die Gegner aus der Distanz beschossen und für Gewappnete, die nach einer Enterung den Gegnern im Nahkampf gegenübertraten. 
Erst als die Schiffe mit Kanonen ausgestattet wurden, erforderte die Seekriegführung in Nordeuropa spezielle Konstruktionen.

$\mathrm{Ab}$ dem 16. Jahrhundert sollte solchen eigens hergestellten Kriegsschiffen, deren Kanonen überwiegend unter Deck an den Breitseiten untergebracht waren, eine kriegsentscheidende Bedeutung zukommen. Sie sollten nach dem 16. Jahrhundert allmählich auch auf dem Mittelmeer die Galeeren verdrängen, die durch Ruder angetrieben und nur zusätzlich mit Segeln ausgestattet waren. ${ }^{27}$ Neben Seeschlachtenbeschreibung und dem Auf- und Abstieg einzelner Seekrieg führender Staaten gehört zu den bestimmenden Themen der Literatur zum Seekrieg der Wandel im Schiffsbau, in der Bewaffnung und der Gefechtsführung. Ein weiteres herausragendes Thema ist die Bedeutung und sind die Differenzen insbesondere zwischen den Verwaltungsorganisationen Englands und Frankreichs im 17. und 18. Jahrhundert, die für den Aufbau und den Unterhalt der Flotten verantwortlich waren. Geradezu verblüffend gering ist dagegen das Interesse, sich mit den Menschen, die auf den Kriegsschiffen lebten, auseinander zu setzen. Den Geschützen wird mehr Aufmerksamkeit gewidmet, als den Menschen, die sie bedienten. So wird eher am Rande der Frage nachgegangen, wie die Besatzungen angeworben wurden, wie sie erlernten, ein Schiff zu manövrieren und die an Bord befindlichen Waffen zu bedienen bzw. einzusetzen. Selbst Keegan, der sich ausdrücklich mit der Kultur des Krieges befasst, schreibt genau genommen nichts über die sozialen Verhältnisse an Bord der Kriegsschiffe. Nach seinen überwiegend technikgeschichtlichen Ausführungen steht lediglich, dass die »Kriegerkultur der Pikeniere und Kavalleristen [...] den Weg aufs Meer gefunden [hatte]. Die Schiffskanoniere standen jetzt dort neben ihren Kanonen mit der Unerschütterlichkeit von Hopliten in der Phalanx.« (1995: 482) Wie dies geschehen sein soll, erfährt der Lesende nicht.

Ausgenommen vom weitgehenden Desinteresse an den Besatzungen sind lediglich die Kapitäne und die Kommandeure von Flottenverbänden. In aller Regel werden nur sie als Subjekte vorgestellt, von deren Planungen und Entscheidungen das Leben ihrer Untergebenen und der Gefechtsverlauf abhängen. Sie treten auch als einzige konturiert als Individuen hervor. Ihre individuellen Charaktereigenschaften können, wie dies bei Tuchman explizit geschieht, aber auch als notwendige Eigenschaften vorgeführt werden, um den Beruf als Kapitäns auszuüben. »Jähzornig«, schreibt Tuchman für das 18. Jahrhundert,

27 Die letzte große Seeschlacht in der sehr viele Galeeren zum Einsatz kamen, wurde 1571 im Mittelmeer bei Lepanto, zwischen dem Osmanischen Reich und der Heiligen Liga, geschlagen. Der Sieg der Heiligen Liga wird unter anderen darauf zurück geführt, dass sie über eine Weiterentwicklung der Galeere, der Galeasse zurückgeführt - einem Schiff, dass sowohl über die Eigenschaften eines Ruder- wie eines Segelschiffes verfügte und sich schwerer Entern ließ. Lediglich in Binnengewässern, an der Küste und Flussmündungen kamen sie noch bis in das 18. Jahrhundert zum Einsatz. 
»das war jeder Seekommandeur zu der Zeit. Es war eine anhaltende Nervenprobe, ein so schwerfälliges Kampfschiff zu navigieren, dessen Antriebskraft der unbeständige und vom Menschen nicht kontrollierbare Wind war und dessen Manöver davon abhingen, dass eine rauhe Mannschaft sofort und mit perfekter Routine auf Befehle reagierte, die die Feineinstellung von Segeln durch eine unendliche Anzahl von Tauen regulierten, die kaum voneinander zu unterscheiden waren.«(Tuchman 1988: 146f.)

Für den gleichen Zeitraum bleiben die übrigen Besatzungsmitglieder in der Literatur gesichtslos. Von den Mannschaften ist meist nur dann die Rede, wenn auf ihre rechtlose Stellung und den Umstand hingewiesen wird, dass ein Teil, der selten quantifiziert ist, mit Gewalt an Bord verschleppt wurde, in die Mannschaft >gepresstく wurde. Gleichzeitig treten sie wie bei Keegan, wenn es um die Gesamtleistung ihres Einsatzes geht, als unerschütterliche und routinierte Befehlsausführende auf.

Leider liegt mir keine Arbeit zur Disziplinierung der Mannschaften an Bord von Kriegsschiffen des 18. Jahrhunderts, geschweige denn eines vorherigen Zeitraums, vor. Selbstverständlich lässt sich vermutlich manches, was zum Drill von Soldaten gesagt wurde, auf die Besatzungen von Kriegsschiffen übertragen, doch bleibt eine gewisse Lücke im Verständnis. Lässt sich ein von der übrigen Sozialität abgeschlossenerer Ort vorstellen als ein Schiff auf hoher See? Setzten nicht das Manövrieren und der Kampf von Segelschiffen in besonderem Maße die Disziplinierung der Besatzungsmitglieder unter einem Kommando voraus? Und ist es nicht fraglich, ob die Mitglieder der Mannschaften bloß als routinierte Befehlsempfänger als den schrecklichen Verhältnissen der Kriegsschiffe Ausgelieferte betrachtet werden können, ohne ihren Anteil zu erörtern? Diese Lücke wird mit den folgenden Ausführungen nicht geschlossen. Sie sollen lediglich auf einige Besonderheiten dieses Themas hinweisen.

Im 17. und 18. Jahrhundert, als Kriegsschiffe über Wochen, mitunter auch über Monate hinweg keine Häfen anliefen, bildeten sie quasi schwimmende Kasernen, und das zu einem Zeitpunkt, als außerhalb Frankreichs die meisten Landsoldaten nicht kaserniert waren. Auf See mussten die Besatzungen über lange Zeiträume hinweg auf engsten Raum zusammenleben. Die Schiffe waren obendrein, im Unterschied zu den Kasernen, auch der Ort, von dem aus die Gefechte geführt wurden. Umgeben von einem lebensfeindlichen Raum, der See, hatte ein einzelnes Besatzungsmitglied keine Möglichkeiten, den Lebensbedingungen an Bord auszuweichen. Eine Desertion war ihm nur möglich, wenn er Landgang erhielt, den deshalb viele Kapitäne den Mannschaften nicht gewährten und stattdessen beispielsweise den Besuch von Frauen auf dem Schiff erlaubten (Whipple 1979: 29). Die Lebensbedingungen konnten je nach Stellung in der Hierarchie sehr unterschiedlich ausfallen, angefangen vom Platz, den die Marinesoldaten zum Schlafen hatte bis hin zu Qualität und Umfang des Essens. So war das Achterdeck, dass unter anderen fast die Hälfte des 
Oberdecks einnahm, wie das gesamte Heck ausschließlich den Offizieren vorbehalten und durfte von den einfachen Seeleuten nur betreten werden, wenn sie hier für eine Aufgabe benötigt wurden (ebd.: 15). Wie hermetisch diese Bedingungen waren, wird beispielsweise an der Unmöglichkeit deutlich, sich an Bord bei langen Seefahrten selber zu verpflegen. Die Mannschaften konnten nur das zu sich nehmen, was zuvor entweder vom Kapitän oder einer speziellen Verwaltung beschafft und eingelagert wurde. Was und wie die Verpflegung an die Mannschaften ausgeteilt wurde, entschied letztlich der Kapitän.

Die enorme Machtfülle eines kommandierenden Offiziers auf einem Schiff ist sicher als die Begründung für die Aufmerksamkeit anzuführen, die ihm in der Literatur zuteil wird. Er wird als Subjekt des Geschehens gezeigt. Er war in allen Entscheidungsprozessen der letztendlich Verantwortliche und zumindest in den führenden europäischen Seestreitkräften stand ihm ein drakonisches Strafreglement zur Verfügung, um Zuwiderhandlungen zu ahnden. Ob aber allein aufgrund von Strafen, vom Fesseln in Fußeisen, über das Auspeitschen bis hin zum Kielholen ${ }^{28}$, die Mannschaften »mit perfekter Routine auf die Befehle« (Tuchman 1988: 146) reagierten, kann bezweifelt werden.

Weiterführend scheint der Hinweis zu sein, dass konkret an Bord britischer Kriegsschiffe des 18. Jahrhunderts die Mannschaft in verschiedene Gruppen aufgespaltet war, die sich gegenseitig belauerten und verachteten. Diese Aufspaltungen setzten zum einen bei den unterschiedlichen Wegen an, die beschritten wurden, um die einzelnen Besatzungsmitglieder für den Dienst zu rekrutieren, und zum anderen an ihren individuellen Fähigkeiten. Je nach ihren Erfahrungen, ihren Fähigkeiten und ihrer körperlichen Verfassung wurde die Mannschaft von den Offizieren in Gruppen eingeteilt, die sich in Aufgabenstellung und Bezahlung unterschieden. Neben Freiwilligen, waren unter den Seeleuten Männer zu finden, die nach einem Quotensystem von den Grafschaften gestellt wurden. Die Grafschaften hätten in dem Quotensystem eine "gute Gelegenheit» gesehen, sich >unerwünschter Elemente` zu entledigen: Landstreicher, Zigeuner, Wilderer, Kriminelle, Geisteskranke und >Aufrührer/ konnten so bequem abgeschoben werden«. (Böndel 1987: 122) ${ }^{29}$ Darüber hinaus wird auf die Praxis hingewiesen, dass besonders in Kriegszeiten Männer durch entsprechende Patrouillen in Hafenstädte an Bord verschleppt und zum Dienst gepresst wurden. Weitgehend unbekannt ist, wie viele Freiwillige, Unwil-

28 Auf französischen Schiffen wurde bis 1789 »ein Tau unter dem Kiel des Schiffes durchgeschoren und der Verurteilte an ihm unter den Rumpf durchgezogen.« (Böndel 1987: 132) Ihm drohte nicht nur der Tod durch Ertrinken, denn der Schiffsrumpf war meist mit rasiermesserscharfen Muscheln überzogen, die ihm tödliche Verletzungen zufügen konnten. Auf britischen Schiffen wurde diese Strafe nicht angewendet (ebd.).

29 Was sich hinter diesen stigmatisierenden Kategorien tatsächlich verbirgt, kann hier nicht geklärt werden. 
lige bzw. Gezwungene sich an Bord der Kriegsschiffe befanden. ${ }^{30}$ Obendrein gab es an Bord von Kriegsschiffen eine erhebliche Anzahl Kinder im Alter zwischen zehn bis fünfzehn Jahren, die als Schiffsjungen auf der niedrigsten hierarchischen Stufe standen.

Das Leben an Bord war häufig durch eine Reihe von Härten gekennzeichnet, die zum Teil den lebensfeindlichen Bedingungen der See, zum Teil den langen Seefahrten geschuldet waren, die z.B. zu einer drastischer Verschlechterung der Lebensmittel- und Wasserqualität führen konnte. Auch die Gefahr sexueller Übergriffe besonders für die Schiffsjungen dürfte, wie bei Böndel angedeutet, in diesem Fall gestiegen sein (ebd.: 123). Die Härten der Lebensbedingungen, die hier lediglich angedeutet sind und zu denen auch noch die Enge an Bord zu zählen ist, dürften die Rivalitäten und Streitigkeiten zwischen, aber auch innerhalb der Gruppen erhöht haben. Man kann es zwar erstaunlich finden, dass es angesichts der Rivalitäten und Streitigkeiten »nicht öfter zu Meutereien kam« (ebd.), doch lässt sich gerade mit Blick auf die heterogene Mannschaftszusammensetzung und ihre Gespaltenheit auch die gegenteilige Auffassung vertreten: es bedurfte wohl schon eines ungewöhnlichen Anlasses, damit sich die Mehrheit der Mannschaft gegen das Regime eines Kapitäns und seiner Offiziere zusammenschloss. Zumal sich an Bord ein Kontingent Seesoldaten befand, das normalerweise von Routineaufgaben freigestellt war und dessen Hauptaufgabe darin bestand, "als Schutzmacht zwischen der Mannschaft und den Offizieren« (ebd.) zu stehen und so eine Meuterei zu verhindern. Ihre Funktion als Puffer zwischen den Mannschaften und den Offizieren drückt sich auch durch die Lage ihrer Unterkünfte aus. Zusammen mit den Seekadetten hatten sie zwischen den Mannschafts- und den Offiziersunterkünften ihr Quartier (Alpers 2004: 197). Zur Mannschaft der Bounty, auf der sich die wohl berühmteste Meuterei, nicht nur des 18. Jahrhunderts, ereignete (1789), gehörten keine Seesoldaten und Kapitän Bligh, ihr Kommandant, dürfte ihre Abwesenheit mehr als einmal bedauert haben (Alexander 2004: 156).

$30 \mathrm{Zu}$ den wenigen Hinweisen, die sich in der Literatur finden lassen, gehört, dass ein Drittel der gesamten britischen Besatzungen, die an der Schlacht von Trafalgar (1805) teilnahmen, gepresst gewesen sei (Whipple 1979: 24). Ohne eine erläuternde Begründung geht Alpers davon aus, dass weniger als 20 Prozent der Besatzungen als freiwillig eingestuft werden können (ebd.: 197). 


\section{Maschine und Leib}

\subsection{Vorbemerkungen}

Wer vom Krieg redet, kommt nicht umhin, auch über Maschinen zu sprechen. Dies gilt nicht erst für das 20. Jahrhundert, in dem Kriegsmaschinen, genauer gesagt Artefakte aus überwiegend industrieller Fertigung, in einem niemals zuvor gesehenen Ausmaß das Kriegsgeschehen veränderten.

Das Wort Maschine geht auf das lateinische machina zurück. Es bezeichnete in der Antike ebenso wie das klassische griechische Wort mechane, Rammen, Katapulte und andere Kriegsgeräte. So zählten auch Türme zu den Kriegsmaschinen, die an Befestigungsanlagen gerollt werden konnten und so den Angreifern die Überwindung der Mauern erleichterten. Den Kriegsmaschinen war gemeinsam, dass sie die Muskelkraft ihrer Bediener enorm verstärkten. Mit ihrer Hilfe konnten Tore aufgebrochen, Mauern überwunden oder zum Einsturz gebracht und Steine oder Pfeile über Distanzen geschleudert werden, die kein menschliches Individuum ohne diese Geräte überwinden konnte. Alle diese Leistungen wurden in der antiken Wahrnehmung als Kunstgriff aufgefasst, als ein künstlicher Effekt, der die Natur überlistete und die Betrachter in Erstaunen versetzte. Dies kommt auch darin zum Ausdruck, dass neben der allgemeineren Bedeutungen von Hilfsmittel, Werkzeug, bevorzugt gerade Vorrichtungen, die im Theater Götter erscheinen und verschwinden ließen, als machina bezeichnet wurden.

In Westeuropa gingen mit dem Untergang des Weströmischen Reichs die zur Herstellung von Kriegsmaschinen notwendigen Kenntnisse verloren. Nur im Byzantinischen Reich wurden diese Kenntnisse tradiert. Das Wort >machina verschwand zwar nicht aus dem Sprachschatz in Westeuropa, bezog sich aber auf stabile Balkenkonstruktionen, wie sie für Baugerüste und Zuschauertribünen verwendet wurden (Popplow 1996: 537). 
Erst mit den Kreuzzügen wurden in Westeuropa die antiken Kriegsmaschinen durch den Kontakt und den Erfahrungsaustausch mit byzantinischen, norditalienischen und armenischen >Kriegsingenieuren` wieder bekannt (Schmidtchen 1982: 93). Doch es wurden nicht nur die antiken Vorbilder kopiert, sondern auch neuartige Kriegsmaschinen entwickelt, um die ständig verbesserten Befestigungsanlagen zu zerstören (Schlunk/Giersch 2003: 104). Insbesondere die Blide, ein in der Antike noch unbekanntes Wurfgerät, wurde noch weit bis in das 15. Jahrhundert gegen Burgen und befestigte Orte eingesetzt. Doch bereits mit dem 14. Jahrhundert deutete sich an, dass auch ihre Tage gezählt waren, weil in den Quellen zunehmend Kanonen erwähnt werden, die vor allem bei Belagerungen eingesetzt wurden. ${ }^{1}$

In der deutschen Sprache taucht das Wort Maschine erstmals im 17. Jahrhundert auf. Es war als Fremdwort aus dem Französischen entlehnt worden und war ausdrücklich auf seinem militärischen Bedeutungshorizont beschränkt, weil es sich um einen Fachausdruck für Werkzeuge der Belagerungskunst und des Festungsbaus handelte. Der Begriff der Maschine verdrängte damit Begriffe wie Antwerk $^{2}$ und Rüstzeug. Dies geschah unter dem Eindruck neuartiger Befestigungsanlagen und Techniken zur Belagerung, die bis heute mit dem Namen des französischen Befestigungsingenieurs Vauban (1633-1707) verbunden werden. Bei diesen Maschinen handelte es sich um Kanonen, die in Stellung gebracht wurden, um eine Befestigung zu bombardieren bzw. um Kanonen, die in der Befestigung selber untergebracht waren, um diese zu verteidigen. Für die Zeitgenossen wurden diese Kanonen zu Maschinen, weil der Festlegung ihres Einsatzstandortes mathematische Berechnungen vorausgingen, die versuchten, geometrische Prinzipien auszunutzen. Aus den konkurrierenden Überlegungen, wie ein Ort am besten zu befestigen und wie er zu attackieren sei, entwickelte sich ein Wettlauf, der im 17. Jahrhundert in beeindruckenden, weil äußerst komplexen und raumgreifenden Strukturen gipfelte, deren Verständnis naturwissenschaftliche Kenntnisse und ein umfangreiches Fachwissen, das des Fortifikationswesens, verlangte. ${ }^{3}$

1 Diese Kanonen wurden wohl bis zu Beginn des 15. Jahrhunderts weniger aufgrund ihrer Zerstörungskraft geschätzt als vielmehr für ihre demoralisierende Wirkung des Geschützlärms, des Mündungsfeuer und des Pulverdampfs auf die Belagerten. Erst im weiteren Verlauf dieses Jahrhunderts wurden die Kanonen zu so ernsthaften Bedrohungen von Befestigungen, dass die Bliden verschwanden (Parker 1990: 27; Eichberg 1989: 421).

2 Einen Fachbegriff der »für technisches Kriegsgerät [stand], das zur Überwindung von Befestigungsanlagen gebraucht wurde« (Schlunk/Giersch 2004: 104).

3 Zur Etymologie des Wortes Maschine siehe Grimmsche Wörterbuch (1960) sowie Schulz/Basler (1942, Bd. 2). Eine Beleg für den oben geschilderten Gebrauch des Begriffs Maschine im 17. Jahrhundert ist Grimmelshausen Simplicius Simplicissimus: »[...] dieser diskurrierte mehrenteils mit mir von allerhand mechanischen Künsten, item von Kriegs- und anderen Maschinen, vom Fortifikationswesen und der Artollerei [...].«(1669: 468) 
Insbesondere im 18. Jahrhundert wurde die Verwendung des Begriffs auf eine Vielzahl Werkzeuge und Geräte ausgedehnt. Dies geschah vor allem dann, wenn sie eine bewegliche innere Struktur aufwiesen, eine Mechanik, die einmal angestoßen, zuvor festgelegte Bewegungen ausführte. In dieser Beziehung unterschieden sich die Maschinen des 18. Jahrhunderts kategorial von denen der Antike, denn die Maschine war zwar stets ein komplexes Artefakt gewesen, doch konnte sie bis dahin auch einen statischen Charakter haben. Das selbstständige Funktionieren unter Energiezufuhr gehörte nicht zum Bedeutungsgehalt des antiken wie des mittelalterlichen Maschinenbegriffs. Die Vorstellung einer statischen, einer starren Konstruktion passte nicht mehr zum neuen Bedeutungsgehalt. Nun wurde die Bewegung, die zuvor festgelegte Abfolge von ineinandergreifenden komplexen Bewegungsabläufen, ihre Berechenbarkeit, zum entscheidenden Merkmal der Maschine. Bereits im 17. Jahrhundert waren die mechanistischen Philosophien auch deshalb von den Uhren und anderen mechanischen Apparaturen fasziniert, weil sie versprachen, »ein brauchbares metaphorische Hilfsmittel zum Verständnis der Natur« (Shapin 1998: 46) zu sein. Die Maschinenmetapher bot sich insbesondere überall dort an, wo man glaubte, geordnete Bewegungsmuster in der Natur zu erkennen. Da den Maschinen nichts »Geheimnisvolles oder Magisches, nichts Unvorhersagbares oder kausal Kapriziöses anhaftete« (ebd.: 48), eignete sich die Maschinenmetapher »als Vehikel für die `Entzauberung der Welt`», von der Weber sprach, »weil sie dem Wunder und dem Wunderbaren jeden Raum entzog. Die Maschinen boten ein Modell für die angemessene Form und Reichweite menschlicher Naturerkenntnis und eine sinnvolle Erklärung der Natur.« (Ebd.) Mehr noch: die Metapher bot sich auch zum besseren Verständnis der vorgefundenen sozialen Verhältnisse an und sollte dazu dienen, die Vorstellung, wie organisatorische, wie bürokratische Prozesse zu optimieren seien, zu prägen.

Im Folgenden soll die folgenreiche Anwendung der Metapher Maschine für das Militär im 18. Jahrhundert herausgearbeitet werden. Es soll zum einen gezeigt werden, welche Voraussetzungen erfüllt sein mussten, damit das Heer überhaupt zur sprichwörtlichen Maschine werden konnte. Dazu wird auf die Betrachtung des Heeres von Machiavelli und Hobbes zur Maschine sowie auf die zahlreichen organisatorischen Veränderungen, die das Kriegswesen vom 16. bis hin zum 18. Jahrhundert erfuhr, eingegangen. Weiter soll näher betrachtet werden, was es für die Subjektivität der Soldaten bedeutete, Teil einer Kriegsmaschine zu sein. Um die Spezifität herauszuarbeiten, wird in diesem Zusammenhang vor allem auf die Überlegungen zur Leibgebundenheit von Subjektivität einzugehen sein. 


\subsection{Die Staatsmaschine}

Den Einsatz von Soldaten unter funktionalen Gesichtspunkten zu betrachten, ist kein Gedankengang, der dem Militär völlig fremd ist. Wer aufgrund seiner Stellung in der Befehlskette andere Soldaten kommandiert, den Einsatz von Gewalt plant und anordnet, der neigt unwillkürlich dazu, seine Untergebenen als Mittel zum Zweck zu erachten, die er einsetzt, um die angestrebten Ziele zu erreichen. Diese Neigung ist umso stärker, je mehr es dem Kommandeur gelingt, sich vom Kriegsgeschehen selber zu distanzieren, was unter anderem bedeutete, am Leiden der Untergebenen keinen Anteil nehmen zu müssen. Den meisten Truppenoffizieren blieb bis in das 20. Jahrhundert eine solche umfassende Distanzierung weitgehend verwehrt, weil sie ihre Untergebenen persönlich auf das Schlachtfeld begleiten und in das Gefecht führen mussten. Anders gestaltete sich die Situation für die Heerführer.

Für die feudalen Ritterheere galt in aller Regel, dass sich selbst ein Oberbefehlshaber gezwungen sah, mit seiner Leibgarde, die ihn umgab, in das Kampfgeschehen einzugreifen. Zugleich war zu dieser Zeit das Schlachtfeld aufgrund der relativ geringen Anzahl von Kämpfenden überschaubar genug, so dass er sich in das Geschehen selber einbringen konnte, ohne das er unbedingt deshalb gleichzeitig Gefahr lief, die Übersicht zu verlieren (Verbruggen 1998: 217f.). Mit der zunehmenden Größe der zu befehlenden Streitkräfte wurde es jedoch für die obersten Truppenführer immer sinnvoller, eine gewisse Distanz zum Geschehen zu halten. Von hier aus ließ sich besser das Schlachtfeld überblicken, und Nachrichten vom Fortgang des Geschehens, die nicht visuell erfassbar waren, erreichten sie eher. Am besten geeignet war dazu ein Ort, der zugleich auch gegenüber dem Terrain auf dem gekämpft werden sollte, leicht erhöht war: der sprichwörtlich gewordene Feldherrenhügel. Von ihm aus konnte ein Oberbefehlshaber am besten den Überblick erhalten und Befehle erteilen, die den Verlauf der Schlacht beeinflussen konnten, nachdem die Kampfhandlungen begonnen hatten. Ab wann die Oberbefehlshaber das Geschehen bevorzugt aus der Distanz verfolgten, ist nicht eindeutig zu bestimmen. Im 17. Jahrhundert galt jedoch das körperliche Engagement eines Oberbefehlshaber auf dem Schlachtfeld bereits als ungewöhnlich und eher als Ausdruck seines persönlichen Führungsstils, quasi als eine Marotte, denn Ausdruck seiner Funktion. Diese Charakterisierung bedeutet nicht, dass das persönliche Engagement des Feldherrn für den Verlauf einer Schlacht bedeutungslos bleiben musste. So griff im Dreißigjährigen Krieg (1618-1648) der schwedische König Gustav Adolf wiederholt sehr wirkungsvoll persönlich in das Kampfgeschehen ein. ${ }^{4}$ Nichtsdestotrotz wurde

4 In der Schlacht von Lützen (1632) sollte ihn ein solcher Einsatz das Leben kosten. 
die aktive Beteiligung eines Oberbefehlshaber an den Kämpfen allmählich zu einem Anzeichen für seine Verzweiflung über den Verlauf der Kämpfe, zu einem Zeichen für den Verlust seiner Führungsfähigkeit oder, wie dies der Militärhistoriker van Creveld zu Ney's (1769-1815) Engagement in der Schlacht von Waterloo (1815) ausdrückte, zum »clear sign of mental derangement« (1985: 53). Gleichwohl zeigten sich bis in das 20. Jahrhundert Oberbefehlshaber persönlich auf dem Schlachtfeld - zumeist um die Soldaten anzuspornen. Ihr Erscheinen auf dem Schlachtfeld nahm den Charakter von Stippvisiten an, die von ihren Untergebenen honoriert wurden, gerade weil die Oberbefehlshaber freiwillig die Gefahren mit ihnen teilten. Und gefahrvoll blieben solche Frontbesuche, weil die Tötung des gegnerischen Oberbefehlshabers bzw. die Ausschaltung der Kommandozentrale bis heute als ein taktisch bedeutendes Kriegsziel gilt.

Noch eindeutiger als für die militärischen Oberbefehlshaber tat sich ihren (zivilen) Auftraggebern eine Kluft zwischen der Planung eines Krieges und seiner Durchführung auf. Sie standen in aller Regel nicht auf dem Schlachtfeld und mussten deshalb die Kämpfe höchstens mittelbar er- und überleben. Für sie konnte ein Krieg ein gewinnbringendes Unternehmen oder Abenteuer sein, er konnte ihre Herrschaft sichern oder erweitern, allerdings konnte eine Niederlage auch ihren Tod herbeiführen. Trotzdem mussten sie nicht ihre gesamte Existenz auf die Austragung gewaltsamer Zusammenstöße ausrichten. Für sie gilt nicht, was Elias für den Krieger betont:

»Der Krieger des Mittelalters liebte den Kampf nicht nur, er lebte darin. Er verbrachte seine Jugend damit, sich auf den Kampf vorzubereiten. Wenn er mündig war, schlug man ihn zum Ritter, und er führte so lange Krieg, als es seine Kräfte nur irgend erlaubten, bis ins Greisenalter hinein. Sein Leben hatte keine andere Funktion.«(Elias Bd. 1, 1981: 269f.)

Die Oberbefehlshaber unterhielten also nicht wie die Krieger der Feudalheere eine existenzielle Beziehung zum Kampf.

Die Möglichkeit, Distanz zum Kriegsgeschehen zu halten, sich nicht auf ein emotional ergreifendes Geschehen, wie den Kampf auf Leben und Tod einstellen zu müssen, kann als wichtige Voraussetzung für eine sachlich abwägende Haltung gegenüber dem Krieg bezeichnet werden. Wem es gelingt, eine solche Haltung einzunehmen, der kann zum Krieg auch eine instrumentelle Beziehung einnehmen, ihn als ein Mittel sehen, um Ziele zu verfolgen, die jenseits der Schlachtfelder liegen. Im vollen Umfang konnte allerdings von einer instrumentellen Beziehung eines Subjekts zum Krieg erst gesprochen werden, als der Krieg zu einer Ressource der (staatlichen) Politik geworden war, sich also politische Macht und militärische Macht von einander unterscheiden lassen. In feudalen Gesellschaften fällt diese Unterscheidbarkeit schwer, weil die politische Macht der Feudalherren 
kaum von ihrer Fähigkeit zu trennen ist, organisierte Gewalt auszuüben. ${ }^{5}$ Die Unterscheidbarkeit ist erst mit der Ausdifferenzierung des Militärs als eigenständige Institution organisierter Gewaltausübung eines Staates, der auch über eigenständige Organisationsressourcen verfügt, hier sind vor allem Legitimität und Finanzmittel zu nennen, gegeben. Die politischen Eliten müssen dann auch nicht unbedingt dem Militär angehören. Zum Instrument der Politik werden das Militär und die Kriegführung erst dann, wenn die Soldaten die Machtkompetenz ihrer politischen Auftraggeber akzeptiert haben und sie als »Offizier« sehen. ${ }^{6}$ Nach dem Untergang des Römischen Reiches waren diese Bedingungen in Westeuropa in vollem Umfang erst mit der Herausbildung der Territorialstaaten und mit dem Unterhalt stehender Heere seit der Mitte des 17. Jahrhunderts gegeben. Mit der Differenzierung zwischen politischen und militärischen Machtträgern konnte der Krieg als Mittel der Politik betrachtet werden und der Maschinenbegriff bezeichnete nun mehr als konkrete einzelne Geräte. Er konnte zur Metapher für das aus Soldaten bestehende Ganze des Heeres werden.

Es ist sicher kein Zufall, dass die erste als modern geltende politische Betrachtungsweise des Krieges nicht aus der Feder eines >Kriegsmannes stammt. Machiavelli, der in seiner Schrift »Der Fürst« darlegte, wie ein Herrscher Gewalt ausüben sollte, um seine Macht zu erhalten und auszubauen, sah die Schlachtfelder seiner Zeit nicht als Soldat, sondern als politischer Beamter, der u.a. als Sekretär für Militärfragen des Florentiner Stadtrates der Zehn mit organisatorischen Problemen der Truppe vertraut war.

Neben seiner pessimistischen Anthropologie sieht Münkler das grundsätzlich Neue an Machiavellis politischer Theorie in seiner »prinzipielle[n] Rechtfertigung einer technizistischen Politikbetrachtung [...], die bei ihm erstmals zu einer diesseitigen begründeten Legitimation des Staates avancierte.« (Münkler 1990: 37) Heer und Krieg waren für Machiavelli unmittelbar mit dem Staat verbundene Techniken der Gewaltausübung. Er erachtete es als die Aufgabe der Führer eines Staates, den bestmöglichen Gebrauch von diesen Techniken zu machen. Ethische Maßstäbe spielen bei seiner Beurteilung des Einsatzes von Gewalt keine Rolle. An ihre Stelle trat der »Imperativ staatlicher Selbstbehauptung« (ebd.). Stabilität, Sicherheit und Ordnung sind deshalb die Kategorien, die seinem Blick auf Herrschaft zugrunde lagen. Machiavelli vermeidet es, pauschal zu definieren, wann, wie und in welchem Ausmaß Gewalt zum Erhalt bzw. zur Erweiterung von Herrschaft einzusetzen ist. Ihren Einsatz macht Machia-

5 Motive, wie die Aussicht sich durch einen Krieg Land anzueignen, Reichtum und Ansehen zu erwerben, reichen also kaum aus, um von einer instrumentellen Beziehung sprechen zu können. Für die Ritter war der Kampf weder Selbstzweck noch bloßes Mittel, um sich Land anzueignen.

6 Das Wort Offizier leitet sich vom lateinischen officiarius ab, das ist jemand, dem ein Amt verliehen wurde oder der einen Dienst ausübt. 
velli abhängig von den jeweiligen konkreten Bedingungen, die eine bestimmte Situation prägen und die darüber entscheiden, ob eine bestimmte Technik zum Erfolg oder Misserfolg führt. In heutiger Terminologie gesprochen: Zweckmäßigkeit ist das Kriterium, das über die Art und Weise der Anwendung von Gewalt entscheiden soll. Wie aber lässt sich Zweckmäßigkeit, das instrumentelle Verhältnis zur Gewalt, bestimmen? Da Machiavellis Entscheidungsträger über keinen institutionellen Apparat verfügen, der qua Prozess eine rationale Entscheidungsfindung erarbeiten kann, blieb die Instrumentalität von den individuellen Fähigkeiten und Dispositionen der Herrschenden abhängig - ihrer virtù. Aber auch die Tugend, die als Instanz dem Subjekt helfen soll, seine Leidenschaften zu zügeln und so zu umsichtigen Entscheidungen befähigt, bewegt sich im Spannungsfeld zwischen fortuna und necessità. Sie stellt allein den Erfolg des Handelnden nicht sicher. Machiavelli, der sich selber als jemanden sah, dem es »durch die Tücke der Zeiten und des Schicksals nicht selber« gegönnt war, »das Gute« anzuwenden (Machiavelli 1513/19: 215), sah im Studium der Geschichte eine gewisse Chance für den »tugendhaften Mann« (ebd.), Einsichten zu gewinnen, die ihn befähigen, sich sicherer innerhalb dieses kontingenten Spannungsfelds zu bewegen. Machiavellis Schriften sind deshalb angefüllt mit Beispielen, die dokumentierten, welch fatale Folgen falsch angewendete Gewalt auf die Herrschaft früherer Epochen hatte.

Vorbild für Machiavellis technizistische Politikbetrachtung war die Medizin und nicht die Mechanik. Hier sieht Stollberg-Rilinger eine große Differenz zwischen Machiavelli und Hobbes. Machiavellis Lehre der Staatskunst formuliere »Handlungsregeln, keine Herstellungsregeln.» (Stollberg-Rilinger 1986: 47) Anders dagegen Hobbes, dessen Metapher Staatsmaschine direkt auf die mechanische Philosophie zurückgriff. Die mechanische Philosophie basierte auf der Idee, dass für die Natur die gleichen Prinzipien gelten, wie sie sich beim Bau und der Wirkungsweise einer Maschine als richtig erwiesen hatten. In Anschluss an Descartes, der den menschlichen Körper mit einer Maschine verglichen hatte, die zwar unvergleichlich besser konstruiert sei als jede Maschine, die der Mensch erbauen könne, stellte Hobbes in seiner Einleitung zum Leviathan fest, dass Menschen auch künstliche Tiere herstellen könnten. Leben sei nur eine Bewegung der Glieder, und er fragte rhetorisch:

»Warum sollten wir dann nicht sagen alle Automaten (Maschinen, die sich selber durch Federn und Räder bewegen, wie eine Uhr) hätten ein künstliches Leben? Denn was ist das Herz, wenn nicht eine Feder, was sind die Nerven, wenn nicht viele Stränge, und was die Gelenke, wenn nicht viele Räder, die den ganzen 
Körper so in Bewegung halten, wie es vom Künstler beabsichtigt wurde?« (1651: $5)^{7}$

Um die Herstellung eines Automaten in Menschengestalt ging es Hobbes freilich nicht. Er bereitet mit dieser Analogie den Lesenden auf seine nächste Überlegung vor: Auf die Feststellung, dass der Mensch in Gestalt des Staates bereits einen künstlichen Menschen konstruiert habe. Postulierte Descartes, dass der Mensch niemals eine künstliche Maschine herstellen könne, die über eine Seele und Verstand verfügt, sah dies Hobbes für den Leviathan bereits als gegeben an. »Die Souveränität stellt darin eine künstliche Seele dar, die dem ganzen Körper Leben und Bewegung gibt, die Beamten und anderen Bediensteten der Jurisdiktion und Exekutive, künstliche Gelenke, Belohnung und Strafe, die mit dem Sitz der Souveränität verknüpft sind und durch die jedes Gelenk und Glied zur Verrichtung seine Dienstes veranlasst wird, sind die Nerven, die in dem natürlichen Körper die gleichen Aufgabe erfüllen.« (Ebd.: 5) Die Annahme, dass der Leviathan mit einer Seele ausgestattet sei, stellte einen erheblichen Bruch mit der Philosophie Descartes' dar, der die Seele, wie die Fähigkeit, sich verständlich $\mathrm{zu}$ machen dem menschlichen Individuum vorbehalten hatte. Hobbes erhebt seinen Leviathan in den Rang eines Gottes, wenn auch eines sterblichen, dessen Verkörperung der Souverän ist. Der Souverän wird in dieser Beschreibung zum großen Beweger, dessen Entscheidungen sich alle Untertanen der großen Maschine zu fügen haben. ${ }^{8}$ Ihre Freiheit »ist daher auf die Dinge beschränkt, die der Souverän bei der Regelung ihrer Handlungen freigestellt hat« (1651: 165). Die Maschinenmetaphorik Hobbes weist damit einen ambivalenten Gehalt auf. Zum einen verlieh ihr die Feststellung, dass sowohl der Werkstoff wie der Konstrukteur des Leviathan der Mensch sei (ebd.: 5), einen ausgesprochen aufklärerischen Gehalt. Staat und Sozialität, Hobbes trennt nicht eindeutig zwischen beiden, waren ein Werk, das zwar nicht unbedingt gegen die Existenz Gottes sprach, aber eines, das eindeutig in der gestalterischen Verantwortung der Menschen lag. Gleichzeitig formulierte er aber einen rigiden Entwurf der Herrschaft von Menschen über Menschen. Frieden und damit Wohlstand,

7 Diese Formulierung ist, wie Fohler feststellt »noch ganz arglos« (2003: 189). Erst im Verlauf des 18. Jahrhunderts sollte sie für viele Rezipienten eine Zumutung werden. »Die immer weiter perfektionierten Apparate, die die Welt bis zum Bersten anzufüllen begannen, ließen statt der anfänglichen Begeisterung offensichtlich immer mehr das Bedürfnis aufkommen, Abläufe im menschlichen Organismus vom Funktionieren der Apparate abzugrenzen.« (Ebd.)

8 Am Rande sei hier vermerkt, dass Hobbes auf diese Weise die bis dahin vorherrschende metaphorische Bezeichnung des Staates als großen Menschen mit der vom Staat als künstlicher Maschine verband, womit die von ihm zur Anwendung gebrachte Maschinenmetapher an der Suggestionskraft der alten Metaphorik partizipierte (siehe Stollberg-Rilinger 1986: 49f. und Bredekamp 2003: 56f.). 
sei nur gegen die Natur des Menschen durchzusetzen. Die Leidenschaften, die leiblichen Affekte der Menschen werden zu Störfaktoren einer rationalen Ordnung erklärt. Zwar überließen die Untertanen ihre Rechte, die ihnen im Naturzustand zustünden dem Staat auch aus Einsicht, damit dieser es »nach seinem Gutdünken zum Schutz aller« anwende (ebd.: 237). Doch nach Überlassung des Rechts, »jeden zu unterwerfen, zu verletzen oder zu töten« (ebd.), müsse dies gegen jeden widerspenstigen Untertan angewendet werden können, um die Furcht der Untertanen und damit die Herrschaft des Souveräns zu sichern. Die Herrschaft des Leviathans bleibt an die Fähigkeit des Staates gebunden, Eintracht unter den Untertanen durchzusetzen und so Aufruhr und Bürgerkrieg zu verhindern. Versage in dieser Beziehung der Souverän, so ist die Überlassung der Gewalt an den Staat zwar hinfällig (ebd.: 171), doch hieran kann aus Hobbes Perspektive niemand ein Interesse haben, da der Preis im Rückfall in den Krieg aller gegen alle bestünde, also im Absinken der Ordnung in Chaos und Wahnsinn.

Bezogen auf den Kriegsdienst führt Hobbes aus, dass von Frauen aufgrund ihrer »natürlichen Ängstlichkeit [...] diese gefährliche Pflichterfüllung nicht erwartet werden kann« (ebd.: 169) und ebenso wenig von Männern mit »weibischem Mut«. Wenn der Staat aber alle Waffenträger benötige oder sie sich anwerben ließen, entfalle diese Rücksichtnahme, da der Erhalt des Staates Vorrang vor jeder individuellen Leidenschaft habe. ${ }^{9}$ »Wer sich [...] als Soldat einschreiben lässt oder Handgeld nimmt« (ebd.), verliert bei Hobbes das Recht, sich auf seine Furchtsamkeit zu berufen. Er hat in die Schlacht zu ziehen, seinen Vorgesetzten zu gehorchen und darf keinesfalls desertieren. Was ein Individuum allerdings dazu motivieren könnte, eine solche Verpflichtung einzugehen, - verstößt es doch gegen das von ihm postulierte Primat der Selbsterhaltung und des Lustgewinns für das Handeln des Individuums - klärt Hobbes nicht auf. ${ }^{10}$

Wollte Hobbes mit der Maschinenmetapher die rationale Konstruktion des Staates als Zwangsordnung des Friedens betonen, und ging es ihm »nicht um dessen konkrete Ausgestaltung, nicht um >Herrschaftstechnologie〈» (Stollberg-Rilinger 1986: 99), so sah dies im Rahmen der deutschen kameralistischen Staatslehre ganz anders aus. Für sie ist allein »der Fürst der Hersteller, sind die Untertanen das Material. Ihr Optimismus des Ma-

9 Hobbes sieht Frauen in gleichen Umfang ihren Leidenschaften ausgeliefert wie Kinder, und konstatiert, dass sie beide deshalb »grundsätzlich auf äußere Hilfe angewiesen sind « (1651: 45). Rationalität und damit die Basis für die Inanspruchnahme von (Menschen-)Rechten kennt bei Hobbes somit nur ein Geschlecht: das männliche.

10 Wenn, wie Kleemeier feststellt, im Hobbesschen Denkhorizont die Existenz von Soldaten nicht erklärt werden kann (2002: 316; 204f.), dann bleibe nur der Verdacht, dass die Individuen aufgrund irrationaler Motive eine solche Verpflichtung eingehen. Der Staat mache sich folglich die Irrationalität einiger Individuen zunutze, um Rationalität für alle durchzusetzen. 
chenkönnens und der Erkenntnisgewissheit, der theoretischen und praktischen Herstellbarkeit, bezieht sich nicht mehr auf den Staat als sociatas civilis, sondern vor allem auf den Staat im konkreten Sinne der fürstlichen Herrschaftsorganisation.« (ebd.: 99f.) Im deutschsprachigen Raum wurde die Maschinenmetapher zuerst von Samuel von Pufendorf (1632-1694) aufgegriffen. Sie wurde zur Zielvorstellung staatlichen Handelns, das, vom Herrschaftswillen des absoluten Souveräns gänzlich durchdrungen, den gesamten gesellschaftlichen Verkehr ordnen, disziplinieren und zur weiteren Machtentfaltung des Staates nutzbar machen sollte. Hobbes staatsphilosophischen Entwurf übernahmen dabei die einzelnen Rezipienten in unterschiedlichem Ausmaß. Seiner säkularen Begründung für die Herrschaft des absoluten Herrschers vermochten sie meist nicht zu folgen. Da Hobbes die Maschinenmetapher als ein heuristisches Modell verwendete, um ein teleologisch offenes Feld zu schaffen, das tabula rasa machte mit traditionellen Erklärungen von Herrschaft, in das er seinen Entwurf setzen konnte, ergab sich für ihn keine Notwendigkeit, auf die Mathematik und andere naturwissenschaftliche Methoden zu rekurrieren. Bei den deutschen Rezipienten dagegen, gab die Mechanik kaum mehr als nur eine sinnfällige Metapher ab. Geometrik, Mathematik und Mechanik sollten ihnen dazu dienen, Herrschaftspraxis zu gestalten. In diesem Zusammenhang ist aber noch ein weiterer deutlicher Unterschied zur angelsächsischen Theorietradition zu betonen, der durch die Rezeption Montesquieus repräsentiert wird. In der angelsächsischen Tradition ist der Regent Teil der Staatsmaschine. In der Kameralistik stand der Regent dagegen stets außerhalb ihres Mechanismus. Seine Macht wird nicht durch ein Konzept der Gewaltteilung begrenzt, sondern stets soll seine eigene Einsicht dafür sorgen, dass er nicht willkürlich, das heißt unsachlich in die Maschine eingreift und mit ihr umgeht. »Die Selbstbeschränkung, die die Kameralisten dem Fürsten vorschreiben, ist zunächst nicht rechtlicher Art, sie ist ein Gebot der Nützlichkeit.« (Stollberg-Rilinger 1986: 139) Die Kameralisten formulierten Klugheitsregeln, die der Fürst um den Erhalt und Ausbau seiner Herrschaft willen befolgen sollte. In ihren Augen war die Staatsmaschine ein Instrument des Subjekts Regent. Außerhalb des Horizonts der kameralistischen Theoriekonzepts blieb, dass die bürokratischen Strukturen eigenmächtig entscheiden und handeln und zum Beispiel in Gestalt der Beamtenschaft als ein realer Machtfaktor gegenüber dem Fürsten auftreten könnten. (Ebd.: 142f.)

Bereits Hobbes hatte die Truppen als ein Teil der allgemeinen Staatsmaschine behandelt, über die der Souverän aber mit höchster Dringlichkeit uneingeschränkt verfügen müsse, um seine als notwendig erachtete furchteinflössende Macht ausüben zu können. Hobbes wandte die Metapher der Maschine aber nie direkt auf das Militär an. Das blieb den Rezipienten im 18. Jahrhundert vorbehalten. Der Logik der konkret auf die Truppen angewandten Metapher entsprach es, dass der Souverän dem Kriegswesen eher 
distanziert gegenüberstand, er keinesfalls Teil der Truppen war. Sie sollten vielmehr bloßes Material für die Umsetzung seiner Ansprüche sein. Als Souverän eines Staates trat nur der Fürst als Subjekt in diesen Theorien auf. Für die Soldaten blieb deshalb nur der Status von Objekten übrig. Dies galt im Grunde auch für die Offiziere, denen er die Kommandogewalt über die Soldaten übertrug. Da im 18. Jahrhundert nur die wenigsten absolutistischen Herrscher selber als Heeresführer ein Kommando übernahmen, galt dies auch für die Oberbefehlshaber, deren Machtfülle gegenüber den Soldaten sich einzig aus dem Auftrag durch den Fürsten ableiten sollte. ${ }^{11}$

Diesen Überlegungen entsprach auch die Vorstellung der Begrenztheit der Kriegsziele. Als ultima ratio eines Souveräns sollte allein ihm die Entscheidung über einen Krieg zufallen. Sein alleiniges Recht über den Einsatz der Truppen zu entscheiden, sollte auch bedeuten, dass er weder auf politische Anteilnahme noch auf Zustimmung der untertänigen Bevölkerung angewiesen sein sollte. Kriege sollten Ausdruck rationaler Überlegungen zur Mehrung bzw. zum Erhalt seiner Macht sein. Vor dem Hintergrund des Dreißigjährigen Krieges (1618-1648), der das eindrückliche Bild eines entgrenzten Krieges mit all seinen Schrecken darstellte, war die Vorstellung, dass Kriege nicht mehr endemisch werden würden, vielfach von den Zeitgenossen als ein großer Fortschritt aufgefasst worden. Tatsächlich wurde das Kriegsgeschehen auf dem europäischen Kontinent von Ausnahmen wie den so genannten Türkenkriegen abgesehen - weitgehend von solchen >eingehegten< Kriegen bestimmt. In ihrem Mittelpunkt standen dynastische Herrschaftsansprüche über Territorien. Die Brisanz der sich gegenseitig ausschließenden Rechtsansprüche über Territorien nährte sich aus den »zeitgenössischen Grundsätzen der Machtarithmetik, worunter denn auch das heute vertraute ökonomische Interesse zählte, parallel neben Größen wie Fläche, Bevölkerung und nicht zuletzt Anerkennung und Reputation.« (Sikora 1996: 292) In den Berechnungen kam die Bevölkerung nur als Population vor, also als ein nach merkantilen Kategorien eingeschätztes Wirtschaftsgut. Ihre Quantität (Zahl von Männern und Frauen) und Qualität (Handwerker, Bauern, etc.) wurde genauso als eine passive Qualität des Gebietes betrachtet wie das hier herrschende Klima und die Qualität des Bodens. Ihre Einstellungen, Meinungen und Orientierungen spielten dagegen keine Rolle. Auf sie wurde keine Rücksicht genommen, wenn es galt, ein Gebiet zur Vermeidung eines Krieges bzw. um den Frieden wiederherzustellen nach Kategorien der Machtarith-

11 Bereits Hobbes vertrat die Auffassung, dass nur dem souveränen Herrn das Recht zufalle, über Krieg und Frieden zu entscheiden. Auch in welchem Umfang Streitkräfte zu mobilisieren sind, falle allein in seine Kompetenz (1651: 141). Er könne zwar Personen mit der Vertretung seiner Souveränität beauftragen, doch müsse ein Befehlshaber abhängig vom Souverän bleiben, weil er ohne »Einsetzung« selber zu einem Souverän werde (ebd.: 141). Einfachen Soldaten, die niemand kommandieren, stünde dagegen kein Anteil an der (Vertretungs-)Macht des Souveräns zu (ebd.: 186). 
metik zu vertauschen oder auch zu teilen. Erst im Rahmen einer nationalstaatlichen Betrachtung von Gesellschaften wurde diese Unbedenklichkeit im Hinblick auf die sozialen Binnenstrukturen, auf lokale Traditionen und auf die Sprache der Bevölkerung problematisch, denn von ihnen hing entscheidend $\mathrm{ab}$, ob sich zumindest Teile der Bevölkerung für >die Nation mobilisieren ließen.

\subsection{Das Heer als Maschine}

Dass die Zeitgenossen des 18. Jahrhunderts die europäischen Truppen als eine Maschine charakterisierten, liegt nicht nur an dem allgemeinen Siegeszug des Maschinenbegriffs als Metapher. Die Vorstellung, die Armee sei eine Maschine, wenn auch eine, die schwer zu regulieren ist und ständig kontrolliert werden muss, weist auf erfolgreich umgesetzte strukturelle Veränderungen des Kriegswesens, auf die folgenreiche Anwendung von Grundsätzen der Mechanik und Arithmetik auf die Formierung der Truppen hin. In bzw. auch vor den Augen der Zeitgenossen hatte sich die Armee in einen komplexen Apparat verwandelt, dessen Konstruktion gänzlich vom strukturschaffenden Herstellungsprozess des Erbauers abhing und in dem seine Zweck- und Zielsetzung eingegangen ist.

Für die im vorangegangenen Kapitel erörterte Disziplinierung ließ sich zeigen, dass der mechanische Handlungsvollzug, der von den Soldaten im 18. Jahrhundert verlangt wurde, ursprünglich nicht zum Vorstellungskanon gehörte. Die Schriften Justus Lipsius' (1537-1606), die den »Oranierprinzen das methodische Gerüst für ihre Reformen« und »mit seinen Kommentaren zu antiken Militärschriftstellern die praktischen Vorlagen« (Bröckling 1997: 47) lieferten, strebten die Durchsetzung einer neuen Sittlichkeit unter den Soldaten an. Im Gegensatz zu anderen Militärtheoretikern seiner Zeit wollte Lipsius das Söldnerwesen überwinden, in dem an ihrer Stelle ein »kleines stehendes Heer von Berufssoldaten (tritt), in das aber nur zuverlässige und charakterlich einwandfreie Männer aufgenommen werden sollen, die in strenger Auswahl unter den Landeskindern gefunden werden.« (Papke 1979: 129) Diese Berufssoldaten sollten frühzeitig rekrutiert und ihnen durch die militärische Ausbildung eine Haltung vermittelt werden, die in sich Tugenden wie Selbstbeherrschung und Mäßigung ausdrückten. Ziel der Disziplinierung war nicht die Unterwerfung der Soldaten, sondern die Vermittlung einer sittlichen Haltung, die in ein Handeln münden sollte, das sich als willigen Gehorsam bezeichnen lässt. (Ebd.) Deshalb galten seine Überlegungen zur Disziplinierung nicht nur den einfachen Soldaten, sondern waren zu aller erst an die Offiziere und ihre Kriegsherren gerichtet (Bröckling 1997: 41).

Das von Lipsius vorgeschlagene Exerzieren der Bewegungsabläufe im Verband, von der Gefechtsaufstellung bis zur Bedienung der Waffen, die 
Standarisierung der Kommandos wurde von den Oraniern und später anderen Kriegsherren aufgegriffen. Kombiniert mit der Untergliederung eines Verbandes in kleinere Einheiten, konnten Truppen aufgestellt werden, die sich gegenüber der zuvor gefürchteten spanischen Armee als überlegen erwiesen. ${ }^{12}$ In einem wichtigen Punkt folgten sie aber Lipsius nicht. Sie formierten ihre Truppen weiterhin aus Söldnern und nicht aus besonders ausgewählten >Landeskindern ২. Die praktizierte Disziplinierung der Söldner zielte auf einen willigen Gehorsam, nicht auf die von Lipsius angestrebte Sittlichkeit der Constantia ab. Doch zugleich formulierte die Constantia, zu deren Bedeutungshorizont Eigenschaften wie Beständigkeit, Beharrlichkeit und Standhaftigkeit zu zählen sind, eine Maxime, die sehr wohl aufgegriffen wurde und die sich in diesem Punkt als ausgesprochen kompatibel zu dem maschinenhaften Vollzug von Bewegungsabläufen durch die Soldaten erwies. Denn Lipsius ging davon aus, dass ein Individuum, um im allgemeinen Lebenskampf standhaft $\mathrm{zu}$ bleiben und rational zu handeln, rationale Härte gegen alle affektiven Bindungen ausbilden sollte. Nur so sei die Sachrichtigkeit des Handelns unter großen Belastungen gewährleistet (siehe Bröckling 1997: 42). Im Ausbildungsziel des Drill, routinierte Bewegungsabläufe bei den Soldaten auszubilden, die soweit irgendmöglich ihre Affekte angesichts der Todesgefahren aus ihrem Handeln verbannen sollten, ist diese rationale Härte präsent geblieben, allerdings ohne dass erwartet wurde, dass die sich hier ausdrückende Ratio ihre eigene ist. »Die oberste Maxime der neostoistschen Ethik, die Verbannung aller Affekte aus dem Handeln, war zugleich der psychologische Ausgangspunkt aller Disziplinierung. Nur wer seine Gefühlsregungen beherrschte, vermochte zu gehorchen - den Gesetzen der Vernunft ebenso wie den Befehlen eines Offiziers. «(Bröckling 1997: 43)

Wie wenig sich die praktizierte Disziplinierung an Lipsius Vorstellung der Vermittlung einer tugendhaften Sittlichkeit orientierte und wie stark die Ausbilder darauf abzielten, die Soldaten zu maschinenhaft wirkenden Bewegungen anzuhalten, wird deutlich, wenn man sich mit Kleinschmidt (1989) die Exerzierreglements des 18. Jahrhunderts anschaut. Mit Blick insbesondere auf ein preußisches Infanterie-Reglement registriert Kleinschmidt, dass in dem Reglement die Körperteile selber zum Subjekt der ausführenden Bewegungen erhoben wurden. Die verbale Verselbstständigung der Körperteile drücke sprachlich das Ziel aus, die Soldaten zu Funktionsteilen einer Maschine zu machen (Kleinschmidt 1989: 245). Sie reflektiere zugleich den optischen Eindruck der sich dem Betrachter einer exerzierenden Einheit bot, wenn die Soldaten ihren eigenen Körper bei der Ausführung der Bewegungen nicht anschauten, dies war ausdrücklich ver-

12 In der Schlacht bei Nieuwpoort, 1600, bewiesen die oranischen Truppen ihre Überlegenheit gegenüber den bis dahin als unwiderstehlich geltenden spanischen Verbänden, die sich noch in einer Variante der alten Söldnerhaufen, den Terzios, zur Schlacht aufstellten (Schnitter/Schmidt 1987: 77f.). 
boten, und die Soldaten eine scheinbare »eigendynamische Bewegtheit am Körper der in Bewegung befindlichen Körperteile« (ebd.: 217) demonstrierten. Die Grundlage des Erfolgs sollte nicht mehr wie bei den Landsknechtshaufen in der Geschlossenheit und der Größe des Verbandes liegen, sondern im perfekten Ineinandergreifen sämtlicher >Rädchen`, zu denen man die einzelnen Soldaten geschliffen hatte (siehe Bröckling 1997: 33)

Ein Truppenverband sollte quasi wie eine von seiner Umgebung abgeschlossene Maschine funktionieren, wie eine Uhr, deren Mechanik auch unter widrigen Bedingungen nicht stockt, nicht innehält. Die angestrebte Gleichförmigkeit aller Bewegungen begünstigte eine zumindest rational anmutende Vorbereitung auf das Kampfgeschehen, da sie die Anwendung von mathematischen Verfahren zur Berechnung der Bewegungen im Feld erleichterte. $^{13}$ Theoretisch ließ sich konkret durch die Anwendung des Strahlensatzes genau berechnen, zu welchem Zeitpunkt eine Einheit an dem für sie bestimmten Platz sich einfinden konnte. Stauungen auf den Wegen, die zur Unordnung in den Reihen führen mussten, sollten so vermieden werden. Als die eigentliche Bewährungsprobe für den wie eine Maschine funktionierende Truppeneinheit ist das Schlachtfeld anzusehen. Die »rücksichtslos vorwärts schreitenden Bataillone (sollten) sich selber mit Zuversicht erfüllen und dem Feind imponieren.«(Jähns 1891: 2513) Solange die Soldaten nach dem festgelegten Muster marschierten und ihre Waffen luden und abfeuerten, galt der Mechanismus des Apparates als intakt, gleich wie hoch die Verluste in den Reihen der Kämpfenden waren. ${ }^{14}$

13 Die vorgeschriebenen Exerzierbewegungen der Soldaten waren neben funktionalen Erfordernissen auch von ästhetischen Vorstellungen geprägt. Kleinschmidt weist darauf hin, dass die einfachen Soldaten im 18. Jahrhundert mit den Fußspitzen auftreten sollten und quasi Tanzschritte ausführten. Dass Auftreten mit der Fußspitze fand als Norm Eingang beim Militär, weil die allgemeine Schuhmode hohe Absätze vorsah, die für eine graziöse, anmutige Körperhaltung sorgen sollten. Schuhe mit hohen Absätzen trugen aber nur Offiziere und nicht die Mannschaften. Noch gegen Ende des 18. Jahrhunderts wurde in französischen Reglements an dem Auftreten mit der Fußspitze festgehalten, nun aber, um die Geschwindigkeit der marschierenden Soldaten zu erhöhen. (1989: 261f.)

14 Und die Zahl der Toten und Verwundeten in einer Schlacht des 18. Jahrhunderts konnte sehr hoch sein und galt gleichzeitig nicht als schlachtentscheidend. Als Sieger einer Schlacht galt, wer am Ende der Kämpfe das Schlachtfeld beherrschte. Wie hoch die Verluste eines solchen Siegers sein konnten, zeigen einige Schlachten des Siebenjährigen Krieges. Preußen publizierte seine Verluste nicht zuletzt aus diesem Grund erst in einem Abstand von über 100 Jahren, 1879, zum Geschehen. Nach diesen Angaben galten beispielsweise über 60 Prozent der preußischen Truppen nach der Schlacht bei Torgau (1760) als tot, verletzt oder als vom Gegner gefangen genommen (= über 15500 Mann). Das gegnerische, österreichische Heer hatte in der Schlacht weniger Tote und Verletzte zu beklagen, galt aber als geschlagen (siehe hierzu ausführlich Lindner 1993: 90f.). 
Attraktiv war das Maschinenmodell für die einzelnen taktischen Einheiten auch deshalb, weil jeder einzelne Soldat als ein austauschbares Teil der Gesamtapparatur angesehen werden konnte. Auf ihre individuellen Motive, ihre Intentionen musste und sollte keine Rücksicht genommen werden. Nur so schien es auch möglich zu sein, in die gleichen Einheiten Individuen mit höchst unterschiedlichen Motiven sunterzustecken . $\mathrm{Ob}$ ein Soldat sich freiwillig anwerben ließ, weil der Betreffende Gefallen am Soldatsein fand oder ob ihn dazu die Not trieb, weil er anders kein Einkommen finden konnte und er nur an eine vorübergehende Notlösung dachte (Sikora 1996: 219), oder ob er >unter die Fahne gezwungen wurde, beispielsweise, weil er als Kriegsgefangener oder als zwangsverpflichteter Untertan >eingereiht $<$ wurde: ${ }^{15}$ Alle sollten zu gleichermaßen funktionierenden >Bestandteilen $<$ gedrillt werden.

Die Intensität, mit der die oranische Reform im ausgehenden 16. und beginnenden 17. Jahrhundert studiert wurde, bedeutete allerdings nicht, dass sie sofort Eingang in die Heeresorganisation fand. Selbst im schwedischen und französischen Heer, das bereits zu Beginn des 17. Jahrhunderts nach dem Vorbild der Oranier ausgebildet wurde, blieb es noch lange um die Disziplin der Truppe schlecht bestellt. Und das Kriegsgeschehen des Dreißigjährigen Krieges sollte noch einmal in vollem Umfang von marodierenden Truppen, die plündernd durch die Gebiete zogen, gekennzeichnet sein. Die Heerzüge des Dreißigjährigen Krieges entsprachen im Verlauf des Krieges sogar immer weniger einer disziplinierten Truppe. Selbst für die schwedischen Truppen gilt, dass sie nach jahrelangem Kriegseinsatz, den hohen Verlusten wie dem Zwang zur Heeresvermehrung gezwungen waren, wieder von einem anfangs recht hohen Standard der Disziplinierung abzurücken. (Regling 1979: 24; Bröckling 1997: 53)

Wie der Blick auf den Dreißigjährigen Krieg zeigt, reichten die neuen Exerzierregeln, der Drill, allein nicht aus, um tatsächlich disziplinierte Truppen zu formieren. Denn man brauchte zur Aufstellung solcher Truppen vor allem Zeit, das heißt man musste die Soldaten dauerhaft und nicht nur für eine sommerliche Kampagne anwerben. Dies setzte wiederum voraus, dass die Staaten permanent über Einnahmen verfügen mussten, die dem Kriegswesen zugeführt werden konnten. Im folgenden soll auf die Maßnahmen eingegangen werden, die erst im Verbund im 18. Jahrhundert dazu führten, dass das Heer tatsächlich als eine Maschine oder um einen anderen Ausdruck zu verwenden, als eine Maschinerie angesehen werden konnte, also als ein Ensemble, das aus mehreren Maschinen besteht, und dessen Ergebnis auf dem Zusammenwirken dieser Maschinen beruht. ${ }^{16}$

15 Zur Rekrutierungspraxis der stehenden Heere siehe Sikora (1996: 216f.) und Papke (1979: 208f.).

16 Zwar wurde bereits im 18. Jahrhundert gelegentlich von einer Maschinerie gesprochen, häufig im Bezug auf Theatermaschinen, doch erst im 19. Jahr- 


\subsubsection{Wechselwirkungen von Staats- und Kriegsmaschine}

Es war das Anliegen der merkantilen und kameralistischen Wirtschaftsund Haushaltspolitik, die nach dem Dreißigjährigen Krieg einsetzte, den Staat des jeweiligen Fürsten zu befähigen, in die Ökonomie des Herrschaftsgebietes zu intervenieren. Nach innen sollte diese Wirtschaftsordnung die alten Gewalten, wie sie vom Adel und städtischen Magistraten ausgingen, gegenüber dem Haushalt des Landesfürsten, der zum Kern des modernen Staates wurde, schwächen. Ideelle Zielvorstellung des Prozesses zur Stärkung der Macht in den Händen des Fürsten war die Konzentration und Monopolisierung aller Herrschaftsressourcen in den Händen einer Person: des absolutistischen Herrschers. Zu ihren Sentenzen gehörten die Förderung des Handels und der Aufbau von Manufakturen im eigenen Land. Die Rohstoffe des Territoriums sollten effektiver ausgebeutet und traditionelle Arbeitsmethoden bzw. -techniken verbessert werden. Neben der Manufakturproduktion, die die Abhängigkeit des jeweiligen Staatsgebiets von Importen senken und Exporterlöse erzielen sollte, war die Ausdehnung und Intensivierung der landwirtschaftlichen Produktion ein maßgebliches Anliegen. In diesen Zusammenhang ist auch die, hier nicht weiter verfolgte, angestrebte allgemeine Sozialdisziplinierung (Oestreich) der Untertanen zu sehen. Die obrigkeitsstaatlichen Interventionen ab der zweiten Hälfte des 17. Jahrhunderts waren eingebettet in die Vorstellung eines Kampfes gegen die als unkultiviert eingestuften und von der Natur hervorgebrachten chaotischen Verhältnisse. An ihre Stelle sollte eine Ordnung treten, die sichtbar von der gestalterischen Kraft des absolutistischen Herrschers durchdrungen und auf ihn zugerichtet sein sollte. Ob es sich um Zeichnungen von Parkanlagen, von städtischen Grundrissen oder um Festungsanlagen handelte, zumeist bemühten sich die Maler, eher Idealisierungen als reale Abbilder zu zeigen. Auf zahlreichen Gemälden von Schlachten wird der zumindest vermeintlich entscheidende Moment des Geschehens dargestellt. Die Bildern zeigen das Geschehen aus der Perspektive der Feldherren bzw. etwas oberhalb ihres Standpunktes. Tatsächlich hielten die Feldherren nun meist einen gehörigen Abstand zum unmittelbaren Kampf, aber ihnen dürfte sich auch dann nur äußerst selten ein so umfassender Ausblick auf das Schlachtfeld geboten haben, wie er auf diesen Bildern gezeigt wird. Genauso wenig haben sich die Schlachten dieser Zeit in so geordneten Bahnen vollzogen, wie die Künstler es den Betrachtern glauben machen wollen. ${ }^{17}$

hundert fand der Begriff vor dem Hintergrund des Einzugs einer Vielzahl von Maschinen in den Betrieben breitere Verwendung (siehe Heyne 1906).

17 Zur Interpretation derartiger Schlachtenbilder siehe Paul: (2004: 31f.) und Jürgens-Kirchhoff (2007: 443f.). 
Neben der barocken Gartengestaltung, dem Tanz und der Reitkunst war es vor allem der Festungsbau, der am augenfälligsten den Gestaltungswille der absolutistischen Herrscher durch die Anwendung von Geometrie ausdrückte. Die Fortifikationen, die große Flächen der Städte und des sie umgebenden Raumes in Beschlag nahmen, sollten aber nicht nur den gegnerischen Truppen den Zugang zur Anlage möglichst erschweren, sondern dienten auch der symbolischen Materialisierung des absolutistischen Herrschaftsanspruchs. Die Orientierung am geometrischen Grundmuster, das aus den Arbeiten Vaubans hergeleitet und an dem bis zum 19. Jahrhundert festgehalten wurde, war so stark, dass Kritiken an der Dysfunktionalität des Grundrisses nicht oder nur unzureichend berücksichtigt wurden. So blieben Vorteile, die sich aus der natürlichen Geländegestaltung ergaben, häufig zugunsten des Erhalts des geometrischen Grundrisses ungenutzt. Durch immer größer werdende Außenwerke sollten zwar die Schwächen des Grundrisses ausgeglichen werden, doch wurden zu ihrer Besetzung auch immer mehr Soldaten benötigt, die damit der Feldarmee entzogen waren. Die Kritiken am Grundriss wie an den größer werdenden Außenanlagen, die, einmal erobert, der Festung selber gefährlich werden konnten, verhallten bis in die letzten Jahrzehnte des 18. Jahrhunderts weitgehend folgenlos (Eichberg 1989: 428f., siehe auch Albrecht 1998: 38f.).

Wenn auch unauffälliger zeigten sich die langfristigen Investitionen in das Kriegswesen im Aufbau von Magazinen, aus denen die Truppen versorgt werden sollten. Es war das Magazinwesen, das die zeitgenössischen Beobachter des ausgehenden 17. und bis in der 90er Jahre des 18. Jahrhunderts von einer Zivilisierung des Krieges sprechen ließ, da sich das Kriegsgeschehen erheblich vom Dreißigjährigen Krieg unterschied. Freilich, neu war die Idee, das Heer aus Magazinen zu versorgen, nicht. Sie wurde zuvor bereits in Einzelfällen praktiziert, z.B. von der spanischen Armee, die eine Heerstraße mit einer Kette von Magazinen zwischen der Lombardei und den Niederlanden errichtete (1567-1620), damit die Soldaten die über 1000 Kilometer lange Strecke ohne große Verluste und ohne auf zeitraubende Requisitionen angewiesen zu sein, zurücklegen konnten (Parker 1990: 89). Ihr Aufbau setzte aber umfangreiche, langfristig kalkulierte und geregelte Einkünfte voraus, also Steuereinnahmen, über deren zielgerichtete Verwendung eine Verwaltung wachen musste. Über dieses Instrumentarium zur Bewirtschaftung des Kriegswesens verfügten in Permanenz erst die absolutistischen Staaten. Das Magazinsystem und die verwaltete Kriegswirtschaft waren wichtige Bausteine zur Einhegung und zum Aufbau größerer Streitkräfte. Die Ausrüstung immer größer werdender Truppenverbände setzte voraus, dass langfristig insbesondere Waffen, Ausrüstungsgegenstände und die Bekleidung der Soldaten gehortet wurden, weil vor der Industrialisierung die Truppen nur in geringem Maße aus der laufenden heimischen Produktion, aufgrund der geringen Produktivität der handwerklichen und manufakturellen Erzeugung, mit den benötigten Uten- 
silien ausgerüstet werden konnten (McNeill 1984: 146). Solche Rüstungsgüter ließen sich zwar grundsätzlich auch im Ausland einkaufen, doch verteuerten sie sich extrem gerade in Kriegszeiten, wenn sie besonders dringend benötigt wurden. Vor dem Magazinwesen sahen sich die Truppenverbände gezwungen, sich aus dem Land zu ernähren, durch das sie zogen bzw. das sie besetzt hielten. Damit wurde meist eine Gewaltdynamik freigesetzt, die zur sprichwörtlich gewordenen Verheerung einer Region führte und mit ihrem `Kahlfressen` enden konnte. Die damit verbundene Zerstörung des gesamten (ländlichen) Reproduktionszyklus' eines Landstrichs ließ sich im Dreißigjährigen Krieg auch nicht durch die Auferlegung von Kontributionen stoppen, die die Besatzungsmacht gegenüber den lokalen Behörden erhob. In Regionen, die bereits von vorangegangenen Heerzügen schwer in Mitleidenschaft gezogen waren, blieb die Beitreibung in der Regel mit soviel Gewaltanwendung durch die Truppen verbunden, dass es für die Opfer häufig ununterscheidbar und unerheblich war, ob die Söldner nun eigenmächtig oder aufgrund eines Auftrages requirierten. Im Dreißigjährigen Krieg sollte deshalb die »Gewalt der eingefallenen Soldateska« schnell die Beitreibungen durch die örtliche $\mathrm{Ob}$ rigkeit überdecken (Papke 1979: 140). Von dieser Gewaltdynamik stachen die im 18. Jahrhundert erhobenen Kontributionen, beispielsweise während des Siebenjährigen Krieges im preußisch besetzten Sachsen, ab. Die Besatzungstruppen setzten hier mit erheblich weniger unmittelbarer Gewaltanwendung die Kontributionen gegenüber den lokalen Behörden durch. Hilfreich war, dass sie keine Forderungen erheben mussten, die die Region vollständig ausplünderten, weil aufgrund langfristigerer Planungen und des Magazinwesens die Notlage bei der Truppe nicht mehr so gravierend war. Statt einem verwüsteten und von Hunger gezeichneten Land, bestand obendrein die Möglichkeit, Kontributionen in Form von Steuern aufzuerlegen, mit denen man den Sold für die Soldaten zahlen konnte. Noch wichtiger aber war, dass mit diesen finanziellen Mitteln dank des Magazinwesens Kriegsmaterialien und Lebensmittel eingekauft und der Truppe zugeführt werden konnten, die außerhalb des Truppenstandorts hergestellt worden waren.

Das kontinentale Vorbild für den Aufbau einer Verwaltung zur Organisation des Magazinsystems gab das französische Kriegsministerium ab, das über eine zivile Struktur verfügte und für die Bewirtschaftung, Ausrüstung und Besoldung der Armee verantwortlich zeichnete, aber in keinem Abhängigkeitsverhältnis zu irgend einer militärischen Stelle stand. »Aufgrund seines besonderen, unbeschränkten Dienstweges« (Papke 1979: 166) förderte das Kriegsministerium aktiv die Produktion von Rüstungsgütern, plante und beaufsichtigte den Bau von Festungen und Arsenalen und wachte in einem zuvor undenkbaren Ausmaß über die Verwendung der eingesetzten Mittel. Die geordnete Bewirtschaftung und Besoldung der Truppe ermöglichte zugleich den Aufbau von Armeen, die bei den führen- 
den Militärmächten nun nicht mehr in die Zehntausende, sondern in die Hunderttausende gingen. ${ }^{18}$

War es bei Descartes die res cogitans, die den menschlichen Körper eines Individuums steuern und mit deren Hilfe es die natürlichen Beweggründe erkennen und zu seinen Gunsten anwenden sollte, und erfüllte bei Hobbes der Souverän diese Aufgabe innerhalb der künstlichen Maschine Staat, so fiel in der Militärmaschine dem Feldherrn diese Stellung zu. Sofern er nicht selber zugleich der Souverän war, übernahm er stellvertretend für ihn das Kommando über den ihm unterstehenden Verband. Er sollte das bewegende Prinzip der Maschine sein, die ordnende wie steuernde Macht. Nur er und sein Pendant auf der gegnerischen Seite sollten im Krieg als Subjekte agieren. Dem Feldherrn fiel die konzeptionelle Aufgabe zu, einen optimalen Gebrauch von der Maschine Heer zu machen. Ihm fiel letztendlich die Entscheidung über den Einsatz der Truppe auf dem Schlachtfeld zu. Neben der »Anwendung besonderer Kunstmittel« (Clausewitz 1832: 359), beispielsweise die Streitkräfte in einer bestimmten Ordnung aufzustellen, wurde ihre individuelle Leistung nach ihrer Fähigkeit beurteilt, frühzeitig zu erkennen, wo sich bei der Umsetzung der Planungen Probleme einstellten, ob sie in der Lage waren, ihre Planungen entsprechend zu korrigieren, bevor der Gegner sie zu seinen Gunsten ausnutzt und ob sie ihrerseits Fehler des Gegners zu ihrem Vorteile wenden konnten. Solcherart herausragende Leistungen wurden als Feldherrengenie gefeiert. Besonders gegen Ende des 18. Jahrhunderts sollte die Frage, worin das Talent des Feldherrn bestehe, Gegenstand heftiger Debatten sein, die bis ins 19. Jahrhundert anhielten. Umstritten war, inwieweit das Talent auf Kenntnis der Kriegsregeln beruhe, die aus der Vorstellung des Heeres als Maschine gewonnen wurde, und inwieweit es mehr angeborenem Können, Erfahrung und Intuition entspringe. Selbst Henry Humphrey Evans Lloyd (1720-1783), der am häufigsten im Zusammenhang mit der Mathematisierung der Kriegführung zitiert wird, unterteilte die Kriegswissenschaften in einen erlernbaren Teil und einen der »weder in Regeln gepresst noch mit Hilfe des Studiums oder der Erfahrung, sondern einzig und allein durch Intuition und Genie bewältigt werden könne.« (Regling 1979: 144). Jedoch hat bei ihm der intuitive Teil lediglich einen gewissen proklamatorischen Stellenwert, weil bereits die richtige Anwendung der Regeln den Erfolg garantiert (ebd.). Den anderen Pol der Debatte formulierte Georg Heinrich von Berenhorst (1733-1814), der »glaubte, dass es seit der Erfindung der Feuerwaffe [...] nicht mehr möglich sei, feste Prinzipien und Regeln für die Kriegführung aufzustellen.« (Regling 1979: 237) Ausschließlich Kriegserfahrung, Intuition und Genialität verlangte er von den Kommandeuren. Er stellt damit die Vorstellung in Frage, dass das Heer

18 Was allerdings nicht ausschloss, dass die Armeestärke für die einzelnen Staaten im Laufe weniger Jahre starken Schwankungen unterlag (siehe Kroener 1996: 7f.). 
vom einfachen Soldat bis hin zu seinem Oberbefehlshaber wie eine Maschine funktionieren könne.

Die angestrebte monopolisierte Kontrolle des Gewaltpotentials in den Händen der Feldherren und die Prämisse, dass sie einen möglichst rationalen Gebrauch von den ihnen zur Verfügung stehenden Mittel machen sollten, bedeutete nicht per se eine Abnahme der Gewalttätigkeit des Kriegsgeschehens. Sie bedeuteten vor allem erst einmal nur eins: Dass Gewalt ausschließlich aufgrund von Befehlen ausgeübt werden sollte. Das Ausmaß der Zerstörungen, welches Haus angezündet, beschossen oder ausgeplündert wird, wer gefangen und wer getötet wird, wer, wo und wann sein Leben im Kampf einsetzt, sollte von den rational geleiteten Entscheidungsprozessen der Kommandeure abhängen und nicht von den einzelnen Soldaten, die im Zweifelsfall nur ihren >rohen Leidenschaften würden. Diese Ratio enthielt per se keine humanen Maßstäbe, sondern war mit den Interessen des Kriegsherren verknüpft. Sie verfügte über keinen Begriff sozialer Verantwortung und stand ihren sozialen Folgen so lange gleichgültig gegenüber, wie sie nicht absehbar oder zu Fragen des Machterhalts und -ausbaus wurden. Es handelte sich um eine Rationalität, die moralische, ethische Normen entbehrte und kein »grundsätzliches Argument gegen den Mord vorzubringen« (Horkheimer/Adorno 1947: 127) vermochte, wenn er machtpolitisch geboten schien. Deshalb »lässt sich mit zunehmender Rationalisierung des Kriegswesens zunächst eine Zunahme des nach strategischen Gesichtspunkten gezielten Terrors feststellen« (Regling 1979: 18). Gerade die Streitkräfte, die zu ihrer Zeit am stärksten von der oranischen Heeresreform und der bürokratischen Kontrolle des Absolutismus geprägt waren, die französischen Truppen unter Ludwig XIV. bzw. unter seinen Heerführern Turenne und Mélac, »wurden berüchtigt durch Verwüstungen und darauf zurückzuführende >Depopulationen`» (ebd.). Die fortschreitende Einhegung des Krieges im 18. Jahrhundert basierte auf der sich durchsetzenden Erfahrung, dass die Verwüstung von Gebieten, um deren Besitznahme im Rahmen der Kabinett- bzw. Erbfolgekriege gekämpft wurde, nicht im Interesses des Siegers war.

Gezähmt wurde das Kriegsgeschehen weiter durch das Bemühen zahlreicher Feldherren, entscheidende militärische Konfrontationen mit dem Gegner zu vermeiden. Eine Schlacht zu schlagen, bedeutete, das Risiko einzugehen, innerhalb weniger Stunden die mühsam formierte Streitmacht zu verlieren. Selbst der Sieger konnte sich nicht sicher sein, ob er einen Nutzen mit seinen meist ebenfalls angeschlagenen Verbänden aus dem Debakel des Unterlegenen ziehen konnte. Zu groß waren die Unwägbarkeiten und der trotz aller Rationalisierungsbemühungen möglicherweise verbleibende schlachtentscheidende Zufall. Und die Aussicht, durch einen womöglich >teuer erkauften`Sieg den Kriegsverlauf entscheidend zu beeinflussen, war eher gering. Unter den Feldherren entwickelte sich deshalb eine gewisse Scheu vor der Schlacht. Einer Scheu, der sie auch insofern 
nachgeben konnten, weil die Versorgung der Streitkräfte aus Magazinen ihnen ermöglichte, durch Truppenbewegungen, dem Manövrieren, Einfluss auf den Kriegszug des Gegners zu gewinnen.

Aus operativer Sicht ermöglichte das Magazinsystem zum einen, dass die Streitkräfte durch Gebiete geführt werden konnten, die zu öde oder zu arm waren, um sie zu ernähren, und Belagerungen nun nicht mehr aufgehoben werden mussten, wenn die Umgebung ausgeplündert war. Zum anderen schränkte es aber auch die Bewegungsmöglichkeiten der Heerzüge stark ein, denn wo keine Verbindung mehr mit den Magazinen hergestellt werden konnte, waren die Truppen auf das angewiesen, was sie mit sich führten bzw. was sie requirierten. Diese Einschränkung war allerdings solange kein grundsätzliches Problem, wie sie für alle Kontrahenten gleichermaßen galt, also symmetrisch verteilt war.

Lloyd, der im letzten Drittel des 18. Jahrhunderts ein viel gelesener Militärtheoretiker war, fasste knapp die mit dem Manövrieren verbundene Hoffnung in den Satz zusammen: Wer »sich auf diese Dinge versteht«, gemeint waren mathematische und topographische Kenntnisse, »kann Kriegsunternehmungen mit geometrischer Strenge einleiten und beständig Krieg führen, ohne jemals in die Notwendigkeit zu kommen, schlagen zu müssen.« (Zitiert nach Schnitter/Schmidt 1987: 162) Beim häufig langwierigen Manövrieren versuchten die Kontrahenten, die vorteilhafteste Position zu erringen. Beispielsweise wurde mit der Bedrohung der Versorgungswege, gar ihrer Unterbrechung, die Hoffnung verbunden, der Gegner werde dadurch gezwungen sein, seinen Vormarsch aufzugeben. Neben dem Marschieren spielte deshalb in den Kriegen des 17. und 18. Jahrhunderts auch der Kampf um Festungen eine gewichtige Rolle. ${ }^{19}$ Belagerungen boten obendrein den Feldherren dieser Zeit eine willkommene Gelegenheit, über Wochen und Monaten hinweg die Truppe als ein außenpolitisches Demonstrations- und Repräsentationsmittel einzusetzen (Luh 2004: 11). Von ihnen aus ließen sich die Versorgungswege beherrschen, und sie beherbergten auch Magazine. In welchem Ausmaß ein Feldherr die große Konfrontation mit dem Gegner vermied, hing allerdings auch davon ab, inwieweit er für einen Fehlschlag verantwortlich gemacht werden konnte. »Ob Schlacht oder nicht - das hing in jener Zeit entscheidend von der Stellung des Feldherren ab. Karl XII. von Schweden, Peter I. von Russland und Friedrich II. von Preußen waren Herrscher und Feldherren in einer Person und damit freier in ihren Entschlüssen beim Einsatz der Armee.« (Schnitter/Schmidt 1987: 73) Wer rechenschaftspflichtig gegenüber dem Hof oder Kriegsrat war, der tat gut daran, mit der >ultima ratio regum`, die-

19 Belagerungen und Gefechte um befestigte Orte waren nach Auffassung von Luh häufiger als Schlachten. In der Zeit zwischen Mitte des 17. und Ende des 18. Jahrhunderts seien vermutlich auf eine Schlacht bzw. größeres Gefecht zwei Belagerungen gekommen (2004: 80). 
se Worte schmückte die preußischen und französischen Geschütze der Zeit, vorsichtig umzugehen. ${ }^{20}$

Über die >Zähmung der Bellona` (Gerhard Ritter) dürfen aber die Aspekte der Kriegführung im 18. Jahrhundert nicht unerwähnt bleiben, die nicht der rational begrenzten Gewaltanwendung entsprachen. So waren Requisitionen, weniger vornehm ausgedrückt, die Ausplünderung aller, die auf dem Weg des Heeres lagen, mit der Versorgung der Truppen aus den Magazinen nicht gänzlich aus der Welt, sondern lediglich in ihrem Umfang reduziert, solange die Versorgung der Truppen gewährleistetet blieb. Doch selbst dann konnte zum Beispiel das Futter für die Pferde nur durch die Beschlagnahme bei den Bauern beschafft werden, weil es für dieses leichtverderbliche Massengut keine ausreichende Transportkapazität gab. Und trotz strengster Verbote plünderten weiterhin einzelne Soldaten ebenso wie kleine Trupps insbesondere die Landbevölkerung aus, wann immer sich dazu eine Gelegenheit bot. Eine Ursache für dieses Plündern war, dass die Versorgung der Truppen aus den Magazinen selten tatsächlich gut funktionierte. Je weiter sich ein Kriegszug von den Grenzen eines Krieg führenden Staates entfernte, desto unzureichender konnten die Soldaten mit dem Lebensnotwendigsten versorgt werden (zu den Mängeln des Magazinwesen siehe Luh 2004: 13f.). Trotzdem, die Gelegenheiten zum Plündern schwanden, weil die Kriegsherren nun die Soldaten nicht mehr regelmäßig zur Requirierung ausschickten bzw. meist nur bestimmte Truppenverbände, so genannte leichte Truppen (siehe Kapitel 6). Eine funktionierende Versorgung aus den Magazinen vorausgesetzt, ließen die Offiziere ihre Soldaten nicht ausschwärmen, um die Kisten der Bauern `zu fegen`, da ohne Requirierungen die Kontrolle über die Truppe leichter und dauerhafter aufrecht zu erhalten war. Das Risiko, dass sich die Soldaten an Gewalttaten gegenüber weitgehend wehrlosen Gegnern, den Bauern, gewöhnten, und deshalb später die Begegnung mit gegnerischen Soldaten scheuten, wurde damit ebenfalls gemindert (McNeill 1984: 146; Regling 1979: 19).

Während die Bemühungen der Kriegsherren um die absolute Kontrolle des Gewaltpotentials der Soldaten nichts an Eindeutigkeit zu wünschen übrig lassen, zeichnete sich ihr Verhältnis zur Bevölkerung der Kriegsregion durch eine gewisse Ambivalenz aus. Den Normen nach hätte es eine klare Trennung zwischen den Krieg führenden Truppen und der sie umgebenden Bevölkerung geben müssen. Als Ideal galt eine Kriegführung, die es insbesondere der Landbevölkerung erlaubte, zwischen den Gefechten die Felder

20 Die erwähnten Kriegsherren, denen in Personalunion als Feldherren Truppen direkt unterstanden, waren risikobereiter als die allermeisten rechenschaftspflichtigen Kommandeure. Das führte aber auch dazu, dass im 18. Jahrhundert z.B. die Kontrahenten des preußischen Königs Friedrich II. ihre Feldherren »immer wieder zur Schlacht gedrängt und das preußische Heer, nicht irgendwelchen Landgewinn, als das eigentliche Objekt der Kriegführung bezeichnet« haben (Delbrück Bd. 4, 1920: 499). 
zu bestellen und unbehelligt von umherstreifenden Verbänden zu bleiben. Erreicht wurde dieses Ideal nur in den allerwenigsten Fällen. Unterhalb der Schwelle des unmittelbaren Kampfes gegen feindliche Soldaten erwarteten die Kriegführenden sehr wohl eine Beteiligung der Bevölkerung - aber ausschließlich auf jeweils ihrer Seite. In umkämpften Gebieten konnte deshalb die Bevölkerung leicht in zwickmühlenartigen Situationen geraten. Da auch für die europäischen Kriegsschauplätze vor dem 19. Jahrhundert selten halbwegs verlässliches Kartenwerk zur Verfügung stand, waren die Kommandeure darauf angewiesen, durch die Einwohner detaillierte und richtige Informationen über die örtlichen Gegebenheiten sowie die Bewegungen des Gegners zu erhalten. Clausewitz' Feststellung, dass die »kleinste Patrouille, jede Feld- und Schildwache, jeder versendete Offizier [...] mit ihren Bedürfnissen um Nachrichten über Feind, Freund und Gegner an den Landesbewohner verwiesen« (Clausewitz 1832: 638) waren, weist auf ein auch jenseits der Frage nach den topographischen Gegebenheiten bis in die Gegenwart gültiges schwerwiegendes Problem der Kriegführung hin. Ortsansässige wurden auch aktiv für Kundschafterdienste herangezogen. In Ausnahmefällen sind vor allem für die erste Hälfte des 18. Jahrhunderts und hier besonders für den Österreichischen Erbfolgekrieg (1740-1748) erfolgreiche Versuche verzeichnet, »nach Hunderten zählende Volksaufgebote zu mobilisieren und zu bewaffnen.« (Rick 1999: 126) Meist verliefen die bewaffneten Zusammenstöße zuungunsten der Zivilisten, deren Angehörige sich anschließend vor der Rache des Militärs fürchten mussten (ebd.: 127). Auch im Falle der Verweigerung von Unterstützungsleistungen, der Weitergabe falscher Informationen, gar Widerstand bei der Nutzung der vorhandenen zivilen Infrastruktur und Aneignung vorhandener Güter reagierte das Militär mit handgreiflichen Repressalien. Den Einwohnern belagerter Städte ging es in dieser Beziehung nicht besser. Ihre aktive Unterstützung, zum Beispiel bei Schanzarbeiten in der Stadt, sowie die bereitwillige Überlassung der zivilen Infrastruktur für die Belange der Verteidigung galten aus Sicht der Militärs als selbstverständlich. ${ }^{21}$

\subsection{Der maschinelle Körper und der Leib}

Wenngleich auch im 18. Jahrhundert die Metapher vom Soldaten als Rad einer Maschine nicht annähernd mit dem realisierten Stand der Disziplinierung zur Deckung gebracht werden konnte, sollte dieses Bild bis heute die Vorstellung vom Soldaten nachhaltig prägen. Es wurde im 18. Jahrhundert verwendet, um einerseits zu betonen, wie weit sich das zeitgenössische Kriegsgeschehen von den Exzessen des Dreißigjährigen Krieges entfernt

21 Zur Inanspruchnahme von Zivilisten im Zuge einer Belagerung siehe Hohrath (1996: 321f.). 
habe, aber auch um Kritik an der Militärorganisation zu formulieren. Neben den Zweifeln an der Verregelbarkeit des Krieges, die in militärtheoretischen Schriften erhoben wurden, verwendete unter anderem Herder die Metapher vom Militär als Maschine, um es als gekauftes und selber willenloses Instrument zu beschreiben, über das ein Mann, der Kriegsherr, verfügte (Herder 1774: 59f.). Auch heute noch wird auf die Maschinenmetapher zurückgegriffen, wenn es gilt, die Instrumentalisierbarkeit der Militärorganisation und der Soldaten für politische Zwecke durch ein griffiges Bild zu kennzeichnen. Die ungebrochene Attraktivität der Metapher ist zum einen sicher dem Gedanken an die Instrumentalisierbarkeit des Militärs geschuldet. Zum anderen soll mit ihr auf das Kraftpotential des Militärs hingewiesen werden, das aus der Kooperation und der Arbeit an Kriegsmaschinen entsteht und das jenseits des Vermögens menschlicher Individuen liegt. Dieses Kraftpotential ist auf Destruktivität ausgerichtet. Zwar können militärische Maschinen und auch die Truppenverbände beispielsweise eingesetzt werden, um Menschen aus Notlagen zu befreien, zu denken ist hierbei an die Seenotrettung und an Evakuierungen vor Naturkatastrophen, doch zur Durchführung solcher Einsätze müssen weder die Maschinen noch die Soldaten mit Waffen ausgestattet werden. Das originäre Kraftpotential des Militärs ist in seiner Fähigkeit zur Destruktivität zu sehen, die von keinem anderen Sozialverband erreicht wird. Dem sich im 19. Jahrhundert herausbildenden Sprachduktus folgend, wird heute mitunter auch von der Militärmaschinerie gesprochen. Meist soll damit die Komplexität der Organisation hervorgehoben werden.

Einen besonderen Stellenwert nimmt heute der Begriff der Maschine im Zusammenhang mit der militärischen Ausbildung ein. Er bezeichnet hier weniger die Kooperation mehrerer Soldaten, sondern zielt auf das Körpertraining des einzelnen Soldaten und auf seine mentale Vorbereitung für das Kriegsgeschehen. »Die militärische Ausbildung«, so der Militärsoziologe Franz Kernic,

»und das damit verbundene Körpertraining bezweckt nichts anderes als die völlige Ausrichtung des Menschen zum Kampf, die Transformation eines Individuums in eine Kampfmaschine. Der Körper des Soldaten ist zugleich >Verkörperung « dieser auf den Krieg ausgerichteten Maschine >Mensch`. Die Anwendung militärischer Gewalt ist in ihrer empirischen Form eine Gewalt der Körper gegen Körper, die auf eine Automatisierung und Radikalisierung von Gewalthandlungen drängt.«(Kernic 2003: 211f.)

Die Ausbildung ziele auf die Ausschaltung jeglichen Denkens, um damit die Kampfabläufe zu beschleunigen.

Diese Verwendungsform des Maschinenbegriffs unterscheidet sich eklatant vom Gebrauch, der im 18. Jahrhundert von der Metapher gemacht wurde. Sie deutet eine ganz andere Vorstellung an, welche Stellung und Aufgabe der einzelne Soldat im Gefecht haben soll. Auf diese Verände- 
rungen wird im weiteren Verlauf der Arbeit noch einzugehen sein. Hervorzuheben ist an dieser Stelle die Differenz in den Ausbildungszielen. Im 18. Jahrhundert wurde beim Drill nicht an eine individuelle Kampfmaschine gedacht, sondern an die Eingliederung des Individuums in einen Verband. Der Verband sollte als Maschine wirken. Der Beitrag des einzelnen Soldaten zum Ganzen lag, um im Assoziationsrahmen der Metapher zu bleiben, auf der Ebene eines Maschinenteils, eines Rädchens innerhalb eines großen Getriebes. $^{22}$

Untersuchte dieses Kapitel vor allem die Frage, wie die Metapher Maschine im Hinblick auf den Sozialverband Militär verwendet wurde, gehen die nachfolgenden Ausführungen darauf ein, wie der Maschinenbegriff die Vorstellungen soldatischer Subjektivität beeinflusste. Der Gedanke, dass der menschliche Körper als eine Maschine aufzufassen ist, provozierte von Beginn an die Frage, welches Verhältnis ein Subjekt zu seinem Körper hat, ob und inwieweit seine Subjektivität von dieser Maschine abhängt. Zur die Untersuchung dieses Themas sollen in einem ersten Schritt die philosophischen Grundlagen dieses Gedankens ausgeführt werden. Im Mittelpunkt steht dabei die Theorie Descartes zum Verhältnis des Geistigen zum Körper und umgekehrt des Körperlichen zum Geist. Sie berühren unmittelbar, wie zu zeigen sein wird, die Frage, inwieweit das Individuum als Subjekt bzw. inwieweit es als Träger von Subjektivität und Urheber von Handlungen betrachtet werden kann. Descartes' Philosophie führte zu einer Vielzahl theoretischer Entwürfe, verfasst von Philosophen wie von Medizinern, die dem cartesianischen Körper-Geist-Dualismus entweder mehr eine idealistische oder materialistische Wendung gaben. Auf diese, bis heute nicht beendeten, Debatten näher einzugehen, sprengt den Rahmen der vorliegenden Arbeit. Vor dem Hintergrund der bis heute fortgesetzten Anwendung der Maschinenmetapher auf Soldaten, sei es als Kennzeichnung ihres Objektstatus, sei es um ein bis heute gültiges Ziel des Kampftrainings zu beschreiben, und weil Soldaten im Gefecht >Leib und Leben` riskieren, kann aber auf eine Bestimmung des Anteils des Körpers an der Konstitution von Subjektivität der Soldaten nicht verzichtet werden. Dazu soll in einem zweiten Schritt die Überlegungen Helmuth Plessners zur Leiblichkeit des Menschen herangezogen werden. Seine phänomenologische Betrachtungsweise des Leibes wird präferiert, weil sie am ehesten geeignet zu sein scheint, unfruchtbare Gegenüberstellungen von Körper und Geist zu

22 Zur Vergegenwärtigung: Wenn einzelne Teile einer technischen Apparatur dazu beitragen, dass eine Maschine funktioniert, ein Bolzen oder eine Schraube, werden sie aufgrund ihres Beitrages selber nicht als Maschine erachtet. Als Maschinen werden komplexe Apparaturen bezeichnet, in denen Prozesse zumindest in Teilen selbsttätig ablaufen und die als Entität wenigstens eine bestimmte funktionale Aufgabe erfüllen. Maschinen sind artifizielle Selbstbeweger (Popitz 1995: 31). 
vermeiden und einen klärenden Beitrag für das Verhältnis von Körper und Maschine zu leisten.

\subsubsection{Der Körper als Maschine}

Den Körper von Soldaten als eine Maschine zu betrachten, kann trotz der oben erwähnten Einschränkung, an eine Betrachtungsweise des Individuums anknüpfen, die dem 18. Jahrhundert vertraut war. Dass der menschliche Körper wie eine Maschine funktioniere, ist ein Gedanke, der bis heute mit der cartesianischen Philosophie verbunden ist. Descartes hatte den menschlichen Körper ebenso wie die Körper aller Lebewesen den Dingen zugerechnet, die physikalischen, und das meinte mechanischen Gesetzmäßigkeiten unterliegen. Verbunden war mit dieser Vorstellung eine Hoffnung: Die Welt durch diese Bestimmung klarer und verständiger zu begreifen, als dies bislang geschehen war; klärende Erkenntnisse zu produzieren, die Wahres von Falschem zu unterscheiden vermögen und damit dem Chaos der Meinungen und Machtkompromisse Einhalt zu gebieten. ${ }^{23}$ Descartes setzte dabei auf die mathematische Bestimmung der Zustände bzw. Ausdehnung aller Dinge (Größe, Gewicht und Figur; ihre Gestalt) ebenso wie ihre Veränderungen (Bewegung). Diese Vorstellung stellte einen Affront gegenüber der aristotelischen Philosophie dar, die zwischen Natur und Artefakt unterschied. Es galt als unstatthaft, die vom Menschen vorgefundenen Verhältnisse und Objekte mit den von ihm hergestellten Dingen zu vergleichen. "Schon der Wunsch, dies zu tun, galt als frevelhaft, denn die Weltordnung war göttlich, und der Mensch hatte nicht das Recht, es den Göttern gleichtun zu wollen.« (Shapin 1998: 42)

Die cartesianische Welt der res extensa ist als ein alles umfassender Maschinenpark zu begreifen. Abgetrennt von dieser Welt ist die res cogitans, die denkende Substanz. Die Fähigkeit zum vernünftigen Denken gilt Descartes als ein von Gott verliehenes Privileg an den Menschen, das ihn kategorial vom Tier unterscheidet (Descartes 1637: 107). Er teilt zwar mit den Tieren den maschinellen Körper, aber als vernünftiges Wesen, als Subjekt, kann er die Welt der Objekte erkennen, kann er zu subjektiv-gewissen Wahrheiten vordringen, ohne auf seinen Körper angewiesen zu sein. ${ }^{24}$ Die Erkenntnisfähigkeit des Individuums ist als die eines körperlosen egos konzipiert, das auf den eigenen Körper wie auf eine Außenwelt zu schauen vermag, ohne aber auf dessen Empfindungen, Eindrücke, Leiden und Begehren angewiesen zu sein. Deshalb sieht Bernhard Waldenfels das wesentliche Moment »an der Unterscheidung von res extensa und res cogi-

23 Vergleiche hierzu Schnädelbach (2000), der in seinem Aufsatz versucht die Situation und Motive gegenüber einer allzu leichtfertigen Abbürstung Descartes' stark zu machen.

24 Die res cogitans verbindet sich hier mit der Vorstellung der unsterblichen Seele, die den Tod des Körpers zu überleben vermag. 
tans [...] darin, dass die eine Substanz ohne die andere existieren kann. Ein Körpermechanismus kann als Mechanismus abrollen, ohne sich innerlich auf Erlebnisweisen zu beziehen, und umgekehrt treten Erlebnisse unabhängig von der Körpermaschine auf. Zwischen Körpermaschine und Denkwesen sind bloß kontingente Beziehungen denkbar.« (Waldenfels 2000: 244) Allerdings wendet sich Descartes deutlich gegen die aristotelische bzw. platonische Vorstellung, dass die res cogitans im Körper wie ein Steuermann in seinem Schiff wohnt, »außer vielleicht, um seine Glieder zu bewegen« (Descartes 1637: 109). Die »vernünftige Seele« sei mit dem Körper »viel enger verbunden und vereinigt [...], um darüber hinaus den unsrigen ähnliche Gefühle und Begierden zu haben und so einen wirklichen Menschen zu bilden.« (Ebd.) Doch die aus der »Vereinigung und gleichsam Vermischung des Geistes mit dem Leibe« entstehenden »Empfindungen wie Schmerz, Hunger, Durst und dergleichen (seien) nichts anderes als undeutliche Modi des Denkens« (Sechste Meditation, zitiert nach Specht 1966: 125), die zwar als Passionen die Herrschaft der vernünftigen Seele über den Körper in Frage stellen, die aber auch jeder Mensch überwinden könne, wenn er lerne vernünftig zu denken. Descartes entwickelt in diesen Zusammenhang die Vorstellung, dass es jedem Menschen, »[...] selbst Leuten mit ganz schwachen Seelen« möglich sei, »eine höchst absolute Herrschaft über alle ihre Passionen zu erlangen, falls man genügend Mühe aufwendet, sie abzurichten oder anzuleiten.« (Zitiert nach Specht 1966: 128) Das wirksamste Mittel für die Befreiung des Geistes »von der Gemütsbestimmung und der Einrichtung der Organe« sieht er aber weder in der Dressur noch in der Erziehung, sondern in der Medizin. Hier könne in der Zukunft ein Mittel zu finden sein, das neben der »Bewahrung der Gesundheit [...] die Menschen ganz allgemein weiser und geschickter werden ließe« (Descartes 1637: 117) Über die Lehre vom (menschlichen) Körper-Geist-Dualismus sollte sich schnell eine Kontroverse entwickeln. In der Philosophie, aber nicht weniger in der Medizin des 17., 18. Jahrhunderts entspann sich ein Streit, der im Grunde bis heute anhält, und der sich um die Fragen dreht, in welchem Verhältnis der Geist zum Körper steht und wie im Geist das Körperliche zu finden sei.

In der cartesianischen Philosophie ist eine Abwertung des Körpers gegenüber dem Geist angelegt. Auch wenn ungeklärt bleibt, wo und wie der Geist im Körper steckt und postuliert wird, dass das Denken unabhängig vom Körper existieren könne, die Bedürfnisse, Begehren und Leidenschaften, die vom Körper ausgehen, bedrängen, ja peinigen den Denkenden, hindern ihn an seinen Erkenntnisprozess. Allen vom Körper ausgehenden Emotionen wird ein positiver Anteil an den höchsten geistigen Prozessen, zu denen Menschen fähig sind, abgesprochen. Anders als der Geist ist der Körper hinfällig, zerstörbar, kurz: er ist sterblich. Ihm gegenüber hat der Geist, da er Teil der Natur ist, den Grundsatz »maître et possesseur de la nature« (Descartes 1637: 114) anzuwenden, also ein Herr- 
schaftsverhältnis aufzurichten. Dieser Umgang des Cartesianismus mit dem menschlichen Körper, ist in der Geschichte der Philosophie allerdings kein Novum. ${ }^{25}$ Schnädelbach schreibt, dass er sich

»wohl deswegen so tief in unser vorphilosophisches Vorverständnis unserer selbst eingegraben [hat], weil er hier [im Bezug auf die Ansichten von Geist und Körper, Subjekt und Objekt; d.A.] viel weniger revolutionär war, als er sein wollte, sondern nur uralte Selbstverständlichkeiten unseres abendländischen Selbstverständnisses neu formulierte« (2000: 195).

Gleichwohl handelt es sich um eine äußerst wirkungsmächtige Neuformulierung, die trotz der Kritik am Cartesianismus, zu dem sich heute wohl kaum noch jemand bekennen mag, kaum an Wirkkraft verloren hat. So liegen wohl cartesianische Vorstellungen »der Auffassung jener Neurowissenschaftler zugrunde, die behaupten, Geist lasse sich ausschließlich durch Gehirnereignisse erklären, so dass man den Rest des Organismus sowie die physische und soziale Umwelt getrost ausklammern könne - einschließlich des Umstands, dass ein Teil der Umwelt das Ergebnis vorausgehender Handlungen ist.« (Damasio 1997: 331f.)

Der Dualismus von Körper und Geist erfährt in solchen Interpretationen eine monistische Wendung, wird doch der Geist gegenüber dem Körper letztlich zum dominanten Prinzip erklärt. Monistische Interpretationen in der umgekehrten Richtung, also in Richtung des Körpers, lassen sich ebenfalls schon bald als Reaktion auf Descartes Theorie finden. Sicher am radikalsten beschritt im 18. Jahrhundert La Mettrie diesen Weg, indem er sie nur als Bezeichnung für das Denkvermögen gelten ließ (vgl. La Mettrie 1747: 67) und geistige Verfassungen auf körperliche Zustände zurückführte. Er vertritt die Ansicht, dass Menschen »nur Tiere und in aufrechter Haltung dahinkriechende Maschinen sind « (1747: 85f.). Zwischen Tieren und Menschen gebe es lediglich graduelle Unterschiede (ebd.: 38), die einzig in der jeweiligen Struktur der organisch aufgebauten Materie begründet liegen. Zugleich führt er insbesondere auf den organischen Aufbau des menschlichen Gehirns die Überlegenheit des Menschen gegenüber den Tieren zurück (ebd.: 43f., 82f.). Der Zustand der Maschine Mensch wird von ihm vor allem als Ergebnis der äußeren materiellen Einflüsse, wie dem Klima und der Nahrung, bestimmt. Er scheut dabei nicht vor Formulierungen zurück, die den Eindruck erwecken, dass das menschliche Handeln vollständig von den materiellen Lebensbedingungen determiniert sei. So schreibt er, dass ein Soldat, dem man nur Wasser gebe - um eines seiner zahlreichen Beispiele anzuführen - aus der Gefahr fliehen würde. Würde man dagegen seine »Gefäße mit kräftigen Säften, stärkenden Flüssigkeiten« füllen, werde der Soldat »plötzlich verwegen und eilt beim

25 Siehe beispielsweise Platons Ausführung zum Verhältnis von Geist und Körper in der Phaidon. 
Lärm der Trommeln fröhlich in den Tod.« (Ebd.: 26) Kurz: Wie der Mensch sich ernähre bzw. ernährt werde, so handelt er auch. Obwohl La Mettrie schreibt, der »menschliche Körper ist eine Maschine, die sich selbst ihre Federn aufzieht« (ebd.), ist innerhalb seines Werkes keine Stelle zu finden, der dieses Selbst näher bestimmt, da er vor allem betonen will, dass es nichts außer der organischen und anorganischen Materie gibt. ${ }^{26}$

Es war wohl gerade diese Leerstelle, die dazu beitrug, dass er zur Unperson der Philosophie des 18. Jahrhunderts wurde. Der Vorwurf lautet, er habe den Menschen als Empfindungsmaschine konzipiert, die vollständig von ihrer materiellen Umwelt determiniert wird. Ein weiterer Grund, der seine Zeitgenossen auf Distanz gingen ließ, ist seine rabiat-provokative Verwendung der Maschinenmetapher. Trotz der Faszination, die menschenähnliche Automaten auslösen konnten, vollzog die Metapher im Laufe des 18. Jahrhunderts einen Wandel. Ihre Verwendung für kosmologische, politische und biologische Zusammenhänge büßte an Erklärungskraft ein und stand zunehmend in der Kritik. Den Hintergrund für diese Entwicklung bildete der Anspruch des Bürgertums gegenüber dem Absolutismus, nicht mehr länger als Untertanen, also als bloße Objekte von Herrschaft, zu gelten, sondern Subjekte ihrer Geschichte zu sein. So ungebrochen die Verknüpfung der Metapher Maschine mit Kraft und ähnlichem mehr blieb: »Es entfaltete nunmehr seine Wirkung als Gegenbild zu Freiheit, Spontanität und Kreativität, die zentral für die Selbstbeschreibung des Menschen des 18. und 19. Jahrhunderts wurden.« (Meyer-Drawe 1996: 26) Den Maschinen haftete fortan etwas >Knechtisches` an, dem die >freien Geister`(Jean Paul) gegenüberstanden (ebd.). Als Maschinen wollte sich gerade die aufgeklärten bürgerlichen Individuen des 18. Jahrhunderts nicht bezeichnen lassen und lehnten entsprechend La Mettrie's Schrift vehement $\mathrm{ab}$.

\subsubsection{Der Leib}

Die Versuche, auf den cartesianischen Dualismus mit monistischen Wendungen zu antworten, "was auf Basis des körperlichen oder des seelischgeistigen Seins oder schließlich einer dritten, beide dann umfassenden Wirklichkeit, etwa des Lebens geschehen kann und auch geschehen ist« (Plessner 1941: 232) sind nach Plessners Auffassung gescheitert. Als gar

26 Eine nähere Bestimmung kann man allenfalls in seinen Ausführungen zur Einbildungs- und Vorstellungskraft des Menschen sehen. Sie sei »das wunderbare und unbegreifliche Ergebnis des organischen Baus unseres Gehirns« (43). Die Differenz zwischen Mensch und Tier führt er aber nicht allein auf die angeborenen Fähigkeiten des Menschen zurück. Vielmehr sei der Mensch »bis zu einem gewissen Alter mehr Tier [...] als sie, da er bei der Geburt weniger Instinkt mitbringt als sie.« (Ebd.: 50) Das »Wunder der Erziehung « führe dazu, dass sich der Mensch »auf eine höhere Stufe und schließlich über die Tiere erheben kann.« (Ebd.: 51) 
verfehlt stuft er Haltungen ein, die den Dualismus »als künstliche Schwierigkeit, als unnötige Konstruktion, als Missverständnis zu destruieren« (ebd.: 233) suchen, weil es keine »noch problemlose, ursprüngliche Schicht des Daseins und Existenz« (ebd.) gibt. In Sprache, Handlung, Gestaltung und Gebärde »fügt sich der menschliche Leib den Antrieben und Intentionen seelisch-geistiger Art. Er geht mit, er lässt sich prägen, er trägt, und eben weil er so fügsam ist, beansprucht er auch keine andere Rolle als die der Materie des verkörpernden Stoffs, des willfährigen Darstellungsmittels.« (Ebd.: 234) Ganz dem dualistischen Schema der Herrschaft des Geistes über den Körper entsprechend, könne er über ihn »bis an die Grenzen von Krankheit und Tod« (ebd.) instrumentell verfügen. Gleichzeitig gebe es aber auch Phänomene, die auf die Expressivität des Leibes verweisen, in denen eine »unübersehbare Emanzipiertheit des körperlichen Geschehens von der Person« (ebd.: 236) zum Ausdruck kommt. In mimischen Gebärden, die sich besonders im Gesicht zeigen, aber auch den ganzen Körper betreffen können, drücken sich im Unterschied zur intentional verwendeten Sprache und den Gesten emotionale Zustände unmittelbar aus. Im Unterschied zur Geste, die etwas ausdrückt, »indem der Mensch mit ihr etwas meint, so hat der mimische Ausdruck (gleich dem physiognomischen) eine Bedeutung, indem sich in ihm eine Erregung (ein Zustand oder eine Aufwallung des Innern) spiegelnd äußert.« (Ebd.: 259) Von den körperlichen Expressionserscheinungen, den morphologischen Außenkomponenten, lassen sich die emotionalen Zustände wie Freude, Zorn, Trauer und Angst nicht abtrennen oder beliebig in sprachliche Ausdrücke oder Gesten überführen. »Freude ohne Dehnungs- und Weitungsempfindungen in der Brustgegend ist keine Freude.« (Ebd.: 261) Der Mensch habe aufgrund dieser zwei verschiedenen Aspekte seines Verhältnisses zu seinem Leib kein ein-, sondern ein doppeldeutiges Verhältnis, das »einen realen Bruch für sein Dasein bedeutet.« (Ebd.: 235) Der Mensch »ist zugleich Körper und im bzw. mit einem Körper. Für das In- und Mitsein sagt man auch: einen Körper (Leib) haben. [...] Bald steht die menschliche Person ihrem Körper als Instrument gegenüber, bald fällt sie mit ihm zusammen und ist Körper. Wo immer es auf Beherrschung der körperlichen Mechanismen ankommt, beim Handeln und Sprechen, in der Zeichengebung, in Gesten und Gebärden, erfährt der Mensch die Doppeldeutigkeit physischen Daseins.« (Ebd.: 373)

Ein Leib zu sein und einen Körper zu haben, dieser Doppelaspekt der menschlichen Existenz unterscheidet für Plessner die menschliche Lebensweise spezifisch von anderen Formen organischen Lebens. Fundiert sieht er die Sonderstellung in der biologischen Konstitution und der Ontogenese des Menschen, die ihn zu einer exzentrischen Positionalität gegenüber seiner Umwelt befähigt. Diese begriffliche Bestimmung beruht auf seinem Versuch, alle unorganischen Objekte von lebenden Organismen zu unterscheiden und durch ihre Beziehung zu der sie umgebenden Welt zu 
charakterisieren. Anorganische Objekte haben demnach keine eigene Grenze zu ihrer Umwelt. Der »unbelebte Körper [...] ist, soweit er reicht. Wo und wann er zu Ende ist, hört auch sein Sein auf.« (Plessner 1928: 129) Die Grenzen zwischen anorganischen Körpern verlaufen zwischen den einzelnen Objekten. Sie ist nicht wie bei organischer Wesen Teil ihres Körpers. Organische Körper sind keine in sich ruhenden Entitäten, sondern stehen in einem aktiven Austauschverhältnis zu ihrer Umgebung. Phänomenologisch »unterscheiden sich die lebendigen von den unbelebten als raumbehauptende von den nur raumerfüllenden Körpern.« (1928: 131) Das organische Wesen »erscheint gegen seine Umgebung gestellt. Von ihm aus geht die Beziehung auf das Feld, in dem es ist, und im Gegensinne die Beziehung zu ihm zurück.« (Ebd.) Anders als Pflanzen, die als verwurzelte und offene Lebensform ${ }^{27}$ unselbstständig in sich ruhen, vollziehen Tiere ihre Austauschprozesse aus der Mitte ihrer Lebensform heraus. Da sie als freibewegliche Organismen sich »von Platz zu Platz bewegen« und in »Angriff und Verteidigung, unter beständig wechselnden Umständen Nahrung, Beute, Begattung« (1928: 233) sind, sind sie zu aktivem Verhalten gegenüber ihrer Umwelt gezwungen. Aufgrund dieser Charakteristika nehmen Tiere eine zentrische Positionalität ein. Ähnlich wie Menschen können Tiere unterscheiden, was ihnen als Objekte gegenübertritt und was zu ihnen selbst gehört. Sie können auch instrumentell ihren eigenen Leib einsetzen, doch vollziehen sie diese Fähigkeit, »ohne um sie zu wissen und zu ihr ein Verhältnis erst finden zu müssen.« (1941: 246) »Das Tier lebt aus seiner Mitte heraus, in seine Mitte hinein, aber es lebt nicht als Mitte. Es erlebt Inhalte im Umfeld, Fremdes und Eigenes, es vermag auch über den eigenen Leib Herrschaft zu gewinnen, es bildet ein auf es selbst rückbezügliches System, ein Sich, aber es erlebt nicht - sich.« (1928: 288) Es geht unmittelbar und nicht relativierbar im >Hier-Jetztく auf (vgl. 1941: 246). Dem tierischen Individuum bleibt damit sein Selbst-Sein verborgen. »Sein Körpersein trennt sich ihm nicht von seinem Haben des Körpers. Es lebt zwar in der Trennung - keine Bewegung, kein Sprung (dem die Schätzung der Distanz vorangeht) wäre möglich ohne sie. Auch das Tier muss seinen Leib einsetzen, situationsgemäß einsetzen, sonst erreicht es sein Ziel nicht.« (1941: 242) Die Differenz besteht folglich in der Bewusstheit des Bruchs. Als Wesen, das sich nicht selber erkennen und sein eigenes Sein reflektieren kann, fehlt ihm damit das Kriterium des Subjektsein: es ist kein sich selbst bewusstes, handelndes und erkennendes Ich, dass sich

$27 \gg$ Offen ist diejenige Form, welche den Organismus in allen seien Lebensäußerungen unmittelbar seiner Umgebung eingliedert und ihn zum unselbständigen Abschnitt des ihm entsprechenden Lebenskreise macht.« (1928: 219) Als offene Formen sind Pflanzen, wenigstens in sehr vielen Fälle, nie fertig « (ebd.: 221), d.h. sie nehmen keine Form an, die als >ausgewachsen net werden kann. Geschlossene Lebensformen nehmen vorwiegend mit von der Umwelt abgekammerten und stark differenzierten und relativ selbstständigen Organen Kontakt mit der Umwelt auf (vgl. 1928: 233). 
vom Objekt (von lateinisch obiectum: das Entgegengeworfene) als dem Nicht-Ich abhebt (Selbstbewusstsein).

Verantwortlich für die exzentrische Position des Menschen, seine »vermittelte Unmittelbarkeit« (1941: 248) werden konstitutionelle Besonderheiten gemacht, die seine Fähigkeiten in Kontakt mit seiner Umwelt zu treten nachhaltig prägen. Hervorzuheben sind in diesem Zusammenhang die ontogenetisch verfrühte Geburt und der aufrechte Gang, der das Wahrnehmungsfeld vergrößerte und ermöglichte, dass die Hände vielseitig verwendbar wurden. Der Nicht-Festlegung der Hand auf eine Aufgabe und die Komplexität der Hand-Augen-Koordination wird wiederum eine stimulierende Wirkung auf die Entwicklung des Großhirns zugeschrieben. Zusammen mit den relativ schwach ausgebildeten Instinkten liege der biologische Sinn des frühen Kontakts des Kindes mit der Außenwelt darin, dass das Individuum dadurch im Stadium höchster Bildsamkeit aufgrund eigener Erfahrungen selber die notwendigen Fähigkeiten erwirbt, um sich in seiner Umgebung behaupten wie anpassen zu können (vgl. Plessner 1961: 164f.). So verfügen Menschen anstelle einer Erbmotorik über »eine Erwerbsmotorik mit einer von keinem Tier, auch nicht von den uns nächstverwandten Anthropoiden erreichten Variabilität und Nuancierungsfülle.« (Ebd.: 166) Die Folge für seine physische Existenz ist ein Bruch: Er lebt »als Leib im Körper« (1941: 238). Von Geburt an aus seinem Leib heraus lebend ist der Mensch zugleich zeitlebens gezwungen zu lernen über ihn als seinen Körper zu verfügen.

Das Verhältnis des Leibes zum Körper ist kein einmal fixiertes und überhistorisches Verhältnis. Ontogentisch wird dies deutlich, wenn man sich bewusst macht, dass jeder Mensch zum Zeitpunkt seiner Geburt nur in sehr bescheidenen Maße über seinem Leib als Körper verfügt. Wenn auch nach der Geburt die Fähigkeit den Leib als Körper zu beherrschen steigt der Leib verschwindet nie. Und diese Fähigkeit, kann auch wieder durch Krankheit und Alter schwinden. "')Ich bin, aber ich habe mich nicht<, charakterisiert die menschliche Situation in ihrem leibhaften Dasein.« (1961: 190)

Das menschliche Individuum wird mit einem bestimmen genetischen Potential geboren, aber inwieweit es dieses Potential ausschöpfen kann, ist nicht mit seiner Zeugung entschieden, sondern wird bereits pränatal von dem beeinflusst, was seine Mutter isst und trinkt, unter welchen Bedingungen sie das Kind austrägt. Damit sind aber lediglich einige, letzlich sozial bedingte Faktoren benannt, die die Modellierbarkeit des Verhältnisses Leib und Körper und damit auch seine Fähigkeiten, als Subjekt zu handeln, beeinflußen. Zu den weiteren Faktoren gehören nicht zuletzt die Anwendung sozialer Praktiken - zu denken ist hierbei an Übungen, die beispielsweise die Muskulatur des Subjekts betreffen - die Kenntnis von sozialen Techniken und auch Techniken, die inversiv oder additiv auf den Körper wirken. Ein genaues Bestimmungsverhältnis - soviel Prozent ist angeboren, soviel 
Prozent lässt sich durch Übung zurückführen, lässt sich allenfalls auf einzelne leibliche Dimensionen z.B. im Hinblick auf die Muskulatur bestimmen. Weitere konkreter Angaben sind kaum möglich bzw. treffen nur für ein bestimmtes Individuum zu. Der gegenwärtige Kenntnisstand, zum Beispiel über die menschliche Physiologie erlaubt keine weitergehendere Aussagen. Dieser Kenntnisstand vergrößert sich, aber es ist nicht abzusehen, ob er jemals als abgeschlossen gelten kann. Derzeit ist er es sicher nicht. Wenn man so möchte, ist es die Kreativität, hier besonders als Ergebnisse der erkundenden Phantasie (Popitz), die eine Fixierung des gegenwärtigen Kenntnisstandes und damit eine Bestimmung der Anteile angeboren, erworben - prinzipiell unmöglich macht.

Die ontogenetische Konstitution des Subjekts vollzieht sich auf der Basis jeweils spezifischer, sozialhistorisch gewachsener Formungs- und Formierungsprozessen, die für das Individuum sowohl in Gestalt von Fremdals auch als in Gestalt von Selbstzwänge auftreten. Der Körper ist also eine soziale Konstruktion.

Die Verschränkung und der gleichzeitige Bruch von Leib und Körper prägen elementar die individuellen Sprach- und Handlungskompetenzen. So wird die Fähigkeit, sich die Sprache anzueignen und zu gebrauchen, auf die Begabung »von sich abzusehen und sich in ein anderes Wesen versetzen zu können« (1961: 176), zurückgeführt. ${ }^{28}$ Sie begründet auch die Befähigung zum selbstständigen Handeln, zu einem Handeln, dass nicht durch die Motorik und den Instinkt vorgezeichnet ist, und damit die Fähigkeit des Menschen, die Welt als einen offenen Raum zu begreifen, der durch das eigene Handeln gestaltet werden kann (vgl. 1961: 182). »Als exzentrisch organisiertes Wesen muss er sich zu dem, was er schon ist, erst

28 Das Verhalten Anderer zu imitieren, weist Tomasello eine bedeutende Rolle bei der kulturellen Entwicklung zu. Imitieren meint hier Nachmachen im Unterschied zu Mitmachen (vgl. Plessner 1961: 175). Es setzt voraus, dass das Verhalten der Anderen als in Zielen und Mitteln gegliedertes verstanden wird. Selbst bei nichtmenschlichen Primaten ist diese Fähigkeit kaum zu finden, weil sie ihre Artgenossen zwar »als Lebewesen auffassen, die zu spontanen Selbstbewegungen fähig sind«, aber nicht als »intentionale Akteure verstehen, die Ziele verfolgen, oder als geistbegabte Akteure, die die Welt repräsentieren. « (Tomasello 2002: 32) Tomasello interpretiert das Imitationslernen als eine sozial stärker orientierte Form des Lernens als beispielsweise das Emulationslernen, das sich an Veränderungen des Zustands der Umgebung orientiert und nicht am Verhalten oder eine Verhaltensstrategie eines Artgenossen (ebd.: 41). Die kulturelle Entwicklung beruht, nach Auffassung Tomasellos auf dieser spezifischen kognitiven Fähigkeit. Sie erst ermöglicht die soziogenetische Weitergabe und damit die Weiterentwicklung von materiellen und symbolischen Artefakten (ebd.: 69). Die kulturelle Entwicklung wird damit freilich nur grundsätzlich möglich. Devolutionen sind keineswegs ausgeschlossen. Dass beispielsweise die Herausbildung der Schrift von lokalen Sonderbedingungen abhing, die Menschen zwang in sozialen Interaktionsnetzen zu leben, denen sie sich nicht leicht entziehen konnten und die auf Dauer ausgerichtet waren, zeigt Mann (1990) auf. 
machen.« (1928: 309) Weder lebt er »einfach das zu Ende, was er ist, er lebt sich nicht aus (das Wort in seiner Unmittelbarkeit radikal verstanden), noch macht er sich nur zu dem, was er ist." Er ist »konstitutiv heimatlos« (ebd.: 310). Gerade aufgrund seiner relativen Instinktschwäche und physischen Ungebundenheit gegenüber (ökologischen) Umweltbedingungen ist das Individuum zugleich auf sich allein gestellt aber nicht (über)lebensfähig und benötigt »ein Komplement nichtnatürlicher, nichtgewachsener Art« (ebd.), also einen Sozialverband, der es ihm ermöglicht sich den jeweiligen Bedingungen seiner ökologischen Umwelt anzupassen, indem sie ihn mit einer sozial geprägten Welt umgibt. ${ }^{29}$ Die menschliche Existenzform zwinge deshalb die Individuen in Verhältnissen »natürlicher Künstlichkeit« zu leben. »Erst innerhalb eines kulturell geprägten Daseinsrahmens findet der Mensch ein zu Hause. [...] Unter dem Zwang, sich der offnen Wirklichkeit zu stellen und ihrer Unvorhersehbarkeit Herr zu werden, ergibt sich überall eine künstliche Horizontverengung, die wie eine Umwelt das Ganze menschliche Lebens einschließt, aber gerade nicht abschließt.« (1961: 185f.). Als künstliche Welt, als eine von Menschen geschaffene Welt, bleibt sie immer veränderbar, das heißt offen.

Zum eigenen Leib ein instrumentelles Verhältnis zu haben, gehört zu den grundlegenden Fähigkeiten, die das menschliche Dasein prägen. Das Maschinenhafte ist »nicht nur mögliches Objekt, sondern eine Struktur unserer Existenz.« (Meyer-Drawe 1996: 194) Es ist die Basis für ein Handeln, das nicht triebgesteuert oder eingebettet ist in einer unmittelbar gegebenen Bedürfnisstruktur. Das individuelle Subjekt ist wesentlich ein an seinen Leib gebundener und durch seinen Leib hindurch Handelnder. Langfristig geplantes Handeln, die Vorstellung von Zeitlichkeit, das bewusste Festhalten an Zielen, die nicht kongruent zu den aktuellen Bedürfnissen sind, haben hier ihre Wurzel. Erst der Bruch und die gleichzeitige Verschränkung von Leibsein und Körperhaben, ermöglicht es dem Individuum, auf die vorgefundenen Bedingungen flexibel eingehen zu können, auf sie bewusst durch eigenes Handeln zu reagieren und sie dadurch $\mathrm{zu}$ verändern und gar neu zu gestalten.

Die Leiblichkeit des individuellen Subjekts ist durch drei Dimensionen gekennzeichnet. Sich selber und die umgebende Welt wahrzunehmen und fühlen zu können, sind leibgebundene Fähigkeiten, die es dem Subjekt ermöglichen, die Welt zu erschließen. Hierzu gehören auch die dabei entstehenden Affekte und Emotionen. Eine Aussage wie ses ist kalt<

29 Bereits Herder hatte einen Zusammenhang zwischen der Hervorbringung von Kultur und der relativen Instinktschwäche konstatiert: »Das des Lernen fähige Geschöpf muss lernen, weil es weniger von der Natur weiß: es muss sich üben, weil weniger von Natur kann; es hat aber auch durch seine Fortrückung, durch die Verfeinerung und Verteilung seiner Kräfte neue Mittel der Wirksamkeit, mehrere und feinere Werkzeuge erhalten, die Empfindungen gegen einander zu bestimmen und die bessere zu wählen.«(1791: 104) 
spricht »über die Dinge der Welt und nicht bloß über mich.« Sie enthält also auch eine Aussage über den Selbstbezug, da der Leib sich in der Kälteempfindung auf sich selbst bezieht. »Frieren bedeutet immer auch Sichempfinden und nicht bloß ein Registrieren vorhandener Qualitäten.« (Waldenfels 2000: 11) Neben dem Welt- und Selbstbezug prägt als dritte Dimension der Fremdbezug die Leiblichkeit des Individuums. Als ontogenetische Frühgeburt erfährt sich das Individuum selber immer im Kontakt mit anderen Menschen. Die Entwicklung des Selbstbezugs ist auf das Engste mit der Interaktion mit Anderen verknüpft. Im Selbstbezug ist deshalb ein Fremdbezug eingeschrieben (vgl. Waldenfels 2000: 266). Zwar wird dadurch der Einzelne »nicht bloß Teil eines Ganzen (etwa einer Familie, einer Nation, einer Kultur), er hat durchaus Eigenes, aber dies Eigene immer in Abhebung von Fremden.« (Waldenfels 2000: 287) ${ }^{30}$

An der Dimension des Körperhabens des Subjekts setzten die Drillpraktiken des 17. und 18. Jahrhunderts an. Dies sei mit einem Blick auf die Dressur von Tieren verdeutlicht. Die Dressur beruht vor allem auf Belohnungen in Form von Nahrung, die ein Tier erhält, wenn es die Handlung ausgeführt hat, die vom Dompteur erwartet wurde. Ein sattes Tier lernt weder die von ihm erwarteten Handlungen, noch führt es die >Kunststücke im Zuge einer Vorstellung vor. Würden Soldaten nur im `Hier-Jetzt $<$ leben, hätte die wie auch immer formierte Körpermaschine den meist strapaziösen Weg auf das Schlachtfeld kaum überstanden und wäre spätestens beim ersten Anzeichen der drohenden Todesgefahren auseinander gelaufen. Die Soldaten konnten, ohne selber aggressiv gestimmt zu sein, ohne Bereitschaft, das Leben im Gefecht riskieren zu wollen, auf das Schlachtfeld geführt werden und ihnen konnte befohlen werden, dass ihre Körper die einstudierten Bewegungen ausführten. Aber auch in einer anderen Beziehung war die Körpermaschine auf die Fähigkeiten zum Subjektsein der Individuen angewiesen. Auch die eingedrillten Handlungsabläufe von Soldaten sind nicht frei von einer Einbettung in konkrete Situationen. ${ }^{31}$ So verregelt ihr Handeln innerhalb des Verbandes ablaufen sollte, so engmaschig die Reglements waren, kreative Eigenleistungen des Individuums blieben unverzichtbar, weil jede Handlung immer auch etwas Neues birgt, das der Handelnde bei der Ausführung von Routinen beachten muss. Trotz minutiöser Regelungen blieben deshalb für die konkret Handelnden Lücken, die sich aus der Komplexität und Kontingenz der Situation ergaben und die von den Soldaten und ihren Vorgesetzten gefüllt werden mussten,

30 Für Merleau-Ponty ist darum das Individuum das Ergebnis eines Differenzierungsprozesses, dessen Individierungsgrad und Indivierungsweise von Kultur zu Kultur unterschiedlich ausfällt (vgl. Waldenfels 2000: 287f.).

31 Zur Bedeutung der Situation für das Handeln siehe die Ausführungen zu Joas in Kapitel 3. 
um beispielsweise im Feld mit dem Verband voranzuschreiten. ${ }^{32}$ So mussten die Soldaten bei der Ausführung eines gegebenen Kommandos als Handelnde die jeweiligen Bedingungen im Raum berücksichtigen, wenn sie nicht ins Stolpern geraten wollten. Zwar vermieden die Befehlshaber der Truppen unwegsames Gelände, aber dadurch verwandelten sich die Schlachtfelder trotzdem nicht in geplättete Exerzierplätze. Gerade die bis heute kaum bewältigten Schwierigkeiten, denen sich Konstrukteure von Automaten gegenüber sehen, wenn ihre Artefakte jenseits des Laborraums am Boden eine gewisse Wegstrecke überwinden sollen, zeigen an, in welchem Ausmaß selbst der gedrillte Verband auf die leibgebundene Subjektivität der Soldaten angewiesen war.

Vor diesem Hintergrund lässt sich die Wirkung des Drills noch etwas genauer bestimmen, als dies bislang geschah. Durch den Drill wurde der Versuch unternommen, sich die körperlichen Potenzen der Soldaten anzueignen und sie in Absehung ihrer sonstigen Handlungskompetenzen als Destruktionskräfte dienstbar zu machen. Als Objekte der Macht sollten sie quasi wie tote Objekte, die völlig unter dem Kommando des Befehlshabers stehen, funktionieren. Aus diesem Blickwinkel betrachtet, mutet es kurios an, dass der Drill ohne den Bezug zur Fähigkeit des Menschen, eine exzentrische Position einzunehmen, nicht auskam. Ohne den Bruch von Leibsein und Körperhaben hätten die Soldaten im Zuge des Drills kein spezifisches Körperschema, keine Routinen ausgebildet, die sie im Gefecht, auf entsprechende Kommandos hin, hätten vollziehen können. $\mathrm{Zu}$ Subjekten ihrer Handlungen sollten die Soldaten also gerade dort nicht werden, wo von ihnen erwartet wurde, dass sie Handlungen vollziehen, die in keinem Reglement festgelegt waren. Wo Leerstellen im Reglement existierten oder die Kontingenz der Situationen Leerstellen erzeugte, sollten ihre Handlungen sich lediglich als Lückenbüßer entfalten. Alle weitergehenden autonomen Handlungen wurden als Störung des Bewegungsablaufes gewertet.

Von den Soldaten im Mannschaftsdienstgrad wurden also lediglich passiv-kompensatorische Eigenleistungen erwartet. Der Konzeption nach sollte dies auch bei ihren unmittelbaren Vorgesetzten nicht anders sein. Sie hatten als >Transmissionsriemen` zwischen den Befehlen der Oberbefehlshaber und den einfachen Soldaten zu wirken. Doch jenseits der Konzeption wurde von ihren Vorgesetzten, den subalternen Truppenoffizieren, etwas mehr erwartet, als befohlene Bewegungsabläufe auszuführen. Um ihrer Aufgabe gerecht zu werden, mussten sie die ihnen erteilten Kommandos an ihre Untergebenen übermitteln und sie an den Gegner heranführen. Auf

32 Ausführen ließ sich dieser Gedanke ebenso am Laden und Feuern der Waffen. Was ist zu tun, wenn der Ladestock durch einen Stoß zu Boden fällt, was soll der Soldat tun, wenn die Pulverpatrone beim Aufbeißen zerreißt? All diese Lücken müssen für die Verfasser der Reglements eine Quelle anhaltender Verzweiflung gewesen sein. 
dem Schlachtfeld, angesichts der tödlichen Gefahren, die vom Gegner ausgingen, spielte neben den ihnen zur Verfügung stehenden Sanktionsmöglichkeiten gegenüber den einzelnen Soldaten ihre Fähigkeit, ihre Untergebenen durch >gutes Zureden` zu motivieren eine wichtige Rolle, um die Soldaten daran zu hindern, den Anordnungen zuwiderzuhandeln oder gar wegzulaufen. Neben der Anrufung an die Ehre der Soldaten, die Erinnerung an ihre Verpflichtung, bei der Fahne zu bleiben, wiesen die Offiziere auf ihre zumindest vermeintlich höhere Überlebenschance hin, wenn sie beim Verband blieben (Möbius 2004: 343). ${ }^{33}$ Von den Truppenoffizieren wurde obendrein Engagement erwartet, wenn sie »im Verlauf der hin- und herwogenden Schlacht in die Lage (kamen), als Führer einer Teileinheit selbstständig handeln zu müssen« (Regling 1979: 54). Ihre Entscheidungen und Handlungen in solchen Situationen hatten aber immer den Charakter eines Notbehelfs. Dies wurde auch durch die lineare Gliederung der Verbände unterstrichen, die ihre Gestaltungsmöglichkeiten des Gefechts sehr begrenzte. Denn die ihnen unterstehenden Teilverbände wurden in einer Linie zum Gegner aufgestellt und waren darauf konditioniert, den gleichen Befehl auszuführen. Die subalternen Offiziere verfügten also nicht über Truppen, die sie als Reserve aus der >Tiefe des Raums` bereithalten und für eine von ihnen zu bestimmende Aufgabe einsetzen konnten. Über diese Möglichkeit verfügte lediglich der Oberkommandierende eines eigenständigen Truppenverbandes. Diese Gliederung der Verbände sicherte im Grunde die Befehlsgewalt des Oberkommandeurs ab und ermöglichte ihm, auf jede seiner Einheiten zuzugreifen und sie seinem Gusto entsprechend einzusetzen (siehe hierzu u.a. Leistenschneider 2002: 51). Durch den wirkungsvoll eingeschränkten Gestaltungsspielraum seiner Untergebenen blieben diese auf seine Anweisungen angewiesen.

Eine etwas größere Unabhängigkeit vom Willen des Oberkommandeurs fiel insbesondere den lokalen Kommandeuren von Kavallerieverbänden zu, weil von ihnen verlangt wurde, dass sie »in Bezug auf den richtigen Ansatz der Kräfte, im Erkennen des richtigen Augenblicks für das Eingreifen und die Fähigkeit zur raschen Reaktion auf alle Lageveränderungen« (Regling 1979: 54) selbstständig entscheiden können. Um den Vorteil der Reiterei, ihre Schnelligkeit, auszunutzen, wurde auf zeitraubende und dann womöglich wieder hinfällig gewordene Rücksprachen mit den Oberkommandierenden verzichtet. Der größere Gestaltungsspielraum der Kavallerieoffiziere gegenüber dem der Infanteristen unterfütterte den höheren Nimbus, den die Reiterei genoss, weshalb sie als die Waffengattung des Adels und damit als Elite galt, was wiederum noch im 19.

33 Nach Möbius lassen sich alle drei Themenkomplexe der verbalen Kommunikation zwischen Soldaten und Offizieren rekonstruieren. Die Gewichtung der einzelnen Themen bei den Soldaten falle zwar schwer, aber im Mittelpunkt ihrer Überlegungen stand »ein professionell verstandenes Überlebensinteresse« (Möbius 2004: 352). 
Jahrhundert dazu führte, dass die Chancen für Bürgerliche, im preußischen Heer beispielsweise eine Offiziersstelle als Regimentskommandeur der Kavallerie zu erhalten, gering waren (siehe Messerschmidt 1975/76: 63f.).

Die Körper der Soldaten als Objekte zu betrachten, ist die Sicht der Vorgesetzten auf die Körper ihrer Untergebenen. Es ist eine Sichtweise, die sich die betroffenen Individuen nur eingeschränkt zu Eigen machen können. Zwar können auch sie ihren Körper als ein Ding unter Dingen interpretieren, doch als eigner Körper unterscheidet er sich radikal von allen anderen Dingen. Der eigene Körper lässt sich zwar willentlich wie ein Instrument verwenden, doch eine durchgängige instrumentelle Interpretation des Körpers scheitert an einer wesentlichen Eigenschaft des Körpers für das Subjekt. Er ist nicht austauschbar. Nur durch ihn hindurch lebt das Subjekt. Das Auge ist deshalb auch kein bloßes Organ als Werkzeug des Sehens, es ist das Sehen, so wie das Ohr das Hören ist (vgl. Waldenfels 2000: 378). Nur durch den Leib erfährt sich und handelt das Subjekt. An seinen Leib gebunden zu sein, heißt, aus diesem Blickwinkel betrachtet, auch an ihm gefesselt zu sein.

Der Leib reagiert unwillkürlich auf die Bedingungen, denen er ausgesetzt ist. Da die vom Leib ausgehenden Affekte und Emotionen sich nur in einem gewissen Umfang konditionieren und formen lassen, lässt sich ihr Einfluss auf die Kognitionsfähigkeit und Handlungen des Subjekts nicht restlos aufheben. Dies wird besonders eklatant, wenn der Leib ein Zuwenig oder ein Zuviel von der Welt erfährt. Durch zuwenig Schlaf bekommt er etwas Lastendes, und der Körper kann nicht mehr in gewohnter Weise seine Funktionen erfüllen. Erfährt der Leib ein Zuviel beispielsweise an physikalischer Energie, wird er verletzt, kann es geschehen, dass das Subjekt die Kontrolle über einen Teil oder gar über den ganzen Körper verliert. Durch die sich dabei meist einstellenden Schmerzen erfährt es etwas über seinen Zustand, spürt es sich selber, doch es kann seinen Leib auch als ein ihm sich entziehendes Phänomen erleben. Die Fähigkeit, zum Körper ein instrumentelles Verhältnis zu haben, kann aufgrund von Schmerzen, die auch von Krankheiten, großem Hunger und Durst ausgelöst werden können, verloren gehen und die Fähigkeit zur exzentrischen Positionalität zumindest zeitweise aufheben. Aber auch ein emotionaler Zustand wie die Wut kann dazu führen, dass das Subjekt nicht mehr Herr seiner selbst ist und `wie von Sinnen Emotion, dass vom Betreffenden als Kontrollverlust erlebt wird, wenn er also von seiner Wut beherrscht wird und entsprechend aggressiv >ohne Rücksicht auf Verluster handelt, lässt sich mit Plessner als eine Schwächung des Menschen als Person werten. Als eine Person definiert Plessner ein Individuum, das »Subjekt seines Erlebens, seiner Wahrnehmung und seiner Aktionen, seiner Initiative« (1928: 293) ist. Einen Zusammenbruch als Person erlebt das Subjekt, wenn es sich in einer (lebens-)bedrohenden Situation befindet, die seine Handlungskompetenzen überfordert, - sie 
wird von ihm als derart widersprüchlich und mehrdeutig empfunden - dass es zu keiner konsistenten Handlung findet. In solchen Situationen kapituliere der Mensch als Person und verliere seinen Kopf. Er werde von einem Schwindel erfasst, der aus seiner personalen Desorientierung und Desorganisation resultiert und sich in physischen Reaktionen wie Schweißausbruch, Übelkeit, Erbrechen und Ohnmacht ausdrückt. Davon zu unterscheiden sind Situationen, in denen sich Personen zwar ebenfalls in einer unbeantwortbaren, aber bedrohlichen Lage befinden. Solche Situationen können bei ihnen die expressiven Ausdrucksreaktionen Lachen und Weinen hervorrufen. Obwohl sich hier die körperlichen Vorgänge emanzipieren, und der Mensch »das Verhältnis zu seiner physischen Existenz verloren [hat], sie entzieht sich ihm und macht gewissermaßen mit ihm, was sie will« (1941: 274), werden das Lachen und Weinen von Plessner als Reaktionen interpretiert, mit denen sich das Subjekt als Person behauptet. Er kapituliere nicht als Person, werde doch das Überwältigt- und Geschütteltsein nicht bloß erlitten, »sondern wie eine Gebärde, wie eine sinnvolle Reaktion verstanden. Man lacht und weint nur in Situationen, auf die es keine andere Antwort gibt.« (Ebd.: 359; siehe auch Honneth/Joas 1980: 80f. bzw. Joas 1996: 249f.)

Affekte und Emotionen präformieren Handlungen. Dass Affekte und Emotionen das Handeln von Individuen beeinflussen können, ohne dass sie sich unbedingt zuvor für die jeweilige Handlung entschieden haben, schränken zwar die Fähigkeit des Menschen ein, jederzeit durch bewusste Entscheidungen über sein Handeln zu bestimmen, doch zugleich ist dieser Einfluss von Affekten und Emotionen kein Zeichen individueller Unvernunft. »Um vernünftig reagieren zu können, muss man zunächst einmal ansprechbar sein, >bewegt` werden können; und das Gegenteil solcher Ansprechbarkeit des Gemüts ist nicht die so genannte Vernunft, sondern entweder Gefühlskälte - gemeinhin ein pathologisches Phänomen - oder Sentimentalität, also eine Gefühlsperversion.« (Arendt 1970: 65) Negative Bewertungen des Einflusses von Affekten und Emotionen neigen dazu, ihre Bedeutung für das Erkennen der Situation, in dem sich das Individuum befindet, mit welchen Gegebenheiten es konfrontiert ist, zu unterschlagen. Dies gilt auch für Empfindungen wie den Hunger und den Durst, die jeweils dem Individuum anzeigen, in welcher Verfassung sich sein Leib befindet. Durch die Empfindung des Schmerzes, die einher gehen kann mit dem Affekt der Angst, werden obendrein seine physischen Kräfte mobilisiert, die das Individuum unter Aufbietung aller seiner Kräfte befähigt, der Ursache für das Auftreten des Schmerzes zu begegnen. Da es bei der Vermeidung bzw. Abwehr von Außen auf den Körper/Leib einwirkenden Verletzungsursachen häufig auf die Reaktionsgeschwindigkeit ankommt, ist es nicht irrational, wenn keine bewusste Entscheidung über das Für und Wider einer Handlung getroffen wird, um die Reaktionsgeschwindigkeit zu erhöhen. $\mathrm{Zu}$ denken ist dabei beispielsweise an die unwillkür- 
liche Reaktion einer Hand, wenn sie überraschend einen heißen Gegenstand berührt. Die Bedingung dieser schnellen Reaktionsweise wird mit Blick auf die neurobiologischen Prozesse deutlich, die beim Angst-Affekt auftreten und dessen Verlauf als gesichert gilt (Schüßler 2002: 207f.). Demnach ist zwischen einer thalama-amygdalären Bahn der Verarbeitung des Angstreizes, die zu einer direkten emotionalen Reaktion auf den Reiz führt und einer Verarbeitung des Wahrgenommenen unter Einbeziehung des Kortex zu unterscheiden, die langsamer erfolgt, aber erst die Bewusstwerdung des Angstreizes ermöglicht und deren Zugriff auf Gedächtnisinhalte genauer ist. Beide Verarbeitungsschemata finden parallel statt, aber eine bewusste Modifikation der Reaktion auf einen emotionalen Reiz ist nur über die thalamo-kortiko-amygdaläre Verbindung möglich. Man kann unwillkürliche Reaktionen des Leibes, seine zahlreichen Empfindungen und die physische Mobilisierung der Affekte auf hirnphysiologische Strukturen zurückführen, die älter als der Kortex sind, und man mag sie deshalb abschätzig als archaische Relikte bewerten - ohne sie würde sich jedoch die Reaktionsgeschwindigkeit der Individuen auf Gefahren verringern, und ihre Verletzungsgefahr steigen und das kann für das Individuum tödliche Folgen haben.

Wie physische Bedürfnisse, die sich in Hunger, Durst und Müdigkeit ausdrücken, auf ein Individuum wirken, wie sehr sein Handeln von Empfindungen wie dem Schmerz, Affekten wie Angst und Ekel, sowie von Emotionen wie Freude und Wut geprägt wird, hängt vom jeweiligen situativen Kontext ab. Zum situativen Kontext gehört, ob und inwieweit das Individuum auf diese Situation vorbereitet wurde, ob die Situation für das Individuum noch als Subjekt beantwortbar erscheint. Soldaten sollten und sollen in Extremsituationen, also Situationen in denen sie häufig an ihrer physischen Belastungsgrenzen stehen, und in denen womöglich widerstreitende Affekte und Emotionen wie Angst und Wut auf ihre Person einwirken, nicht verzweifeln und ihre Orientierung verlieren. Sie sollen auch nicht weinen und nicht lachen, sondern den erteilten Befehlen entsprechend handeln, auch wenn dies zu ihrem Tod führen mag. Deshalb ist ein bis heute gültiges Ausbildungsziel von Soldaten, sie gegen den Ansturm ihrer Gefühle zu wappnen. Dieses Ziel soll heute nicht mehr durch den Drill des 18. Jahrhundert erreicht werden. So geht es im Kampftraining neben dem Erlernen der jeweiligen Techniken darum, die Belastungsgrenzen der Soldaten durch Körpertraining zu verschieben. Zugleich werden sie aber durch das Körpertraining auch an ihre Belastungsgrenzen herangeführt und von ihnen wird verlangt, dass sie in der Nähe dieser Grenze Erfahrung mit dem Umgang ihrer Affekte und Emotionen machen, um sie in der Kampfsituation zu kontrollieren. Außerdem sollen im Zuge der 
Ausbildung Handlungsroutinen etabliert werden, in der Hoffnung, dass sie auf diese während des Kampfeinsatzes zurückgreifen. ${ }^{34}$

Das ideale soldatische Handeln im Kampf wird noch immer mit der Metapher der Maschine assoziiert. Denn bei einer Tätigkeit keine Gefühle zu zeigen, nicht zu ermüden, nicht mit (Un-)Lust kämpfen zu müssen und über keine Affekte zu verfügen, die sich auf das Handeln auswirken, gilt nicht umsonst als Kennzeichen der Tätigkeit technischer Artefakte, von Maschinen also.

34 Darum erinnert die militärische Ausbildung in einigen Bereichen auch heute noch an den Drill. So soll durch häufiges Schießtraining die Trefferquote der Soldaten verbessert und ihre Bereitschaft erhöht werden von der Waffe Gebrauch zu machen (siehe Grossman 1995: 252f.). 


\section{Soldatische Subjektivität zwischen Kontrolle und Eigensinn}

\subsection{Subjektivität als Innovationsressource}

Das Maschinenmodell der Lineartaktik setzte auf eine Exklusion soldatischer Subjektivität. Es führte zu einem enormen Anstieg der Destruktionsmacht in den Händen der Kriegsherren. Die Stärke der Lineartaktik entfaltete sich in der Schlacht und »Schlachten«, so Friedrich II., »entscheiden das Schicksal eines Staates.« (1748: 104) Eine auf die Lineartaktik ausgerichtete Streitmacht sollte dem Modell nach dem Feldherr beim Angriff wie bei der Verteidigung als ein von ihm dirigierbarer Gesamtverband zur Verfügung stehen. Welche Motive die einzelnen Soldaten hatten, als sie das Schlachtfeld betraten, ob sie sich freiwillig in die Reihen eingegliedert hatten oder unter Zwang, ob sie die Gegner verabscheuten, sie ihr Handeln und das ihres Feldherren als gottgewollt ansahen, ob sie Angst vor Verletzung und Tod hatten oder sich sogar auf den Kampf freuten, konnte solange als nebensächlich gelten, solange der Verband den Befehlen des Feldherren folgte, solange er seine `Funktion` erfüllte. Zweifelsohne spielten zwar die Motive der Soldaten und auch die im Zuge des Kampfes unwillkürlich auftretenden Affekte und Emotionen für den konkreten Verlauf des Kampfes eine wichtige Rolle, weil sie darüber entschieden, unter welchen Umständen die Disziplin zusammenbrach. Und es fehlte deshalb auch nicht an Versuchen, in Krisensituationen die Soldaten, beispielsweise durch das persönliche Auftreten des Feldherrn, zu besonderen Leistungen zu motivieren, damit sie aller Widrigkeiten zum Trotz bei der Fahne blieben. Aber auch für Faktoren, die die Kampfkraft einer Armee erhöhten, standen nicht nur im Ruf, unbeständig und unberechenbar zu sein, sondern konnten nur dann die Kampfkraft tatsächlich erhöhen, wenn sie sich diszipliniert entfalteten. 
Entsprechend der mechanischen Konzeption führte die Lineartaktik zu einer Erstarrung der Gefechtsführung, die sich gerade mit ihrer zunehmenden Perfektion bereits im 18. Jahrhundert als mangelhaft vor allem jenseits großer Gefechte herausstellte. Für den Einsatz im so genannten kleinen Krieg waren Lineartruppen ungeeignet, weil dieses Einsatzszenario, neben einer leichteren Bewaffnung und stark reduzierter Marschausrüstung von den Soldaten verlangte, dass sie sich als Subjekte im Kampf aktiv engagierten. Ein solches Engagement setzte auf Seiten der Kommandeure ein weitaus größeres Vertrauen in die Bereitwilligkeit und Eigeninitiative der Soldaten voraus, als es im Allgemeinen von den Soldaten in den Lineartruppen erwartet wurde. Auf Seiten der Untergebenen wiederum musste ein weitaus höheres Maß an Einverständnis mit den Zielen des Kampfes wie mit den erteilten Befehlen vorliegen. Die Handlungsfähigkeit von Individuen als Subjekte aktiv zu nutzen, bedeutete im 18. Jahrhundert unter den Vorzeichen der Lineartaktik eine Innovation in der Kriegführung. Neu war nicht die Formierung von Verbänden, die man aufgrund des Marschgepäcks - verhältnismäßig wenig Proviant und Ausrüstung, sowie selten Geschütze - als leichte Truppe bezeichnet und die beispielsweise von den Habsburgern bevorzugt an der österreichischen Militärgrenze zum Osmanischen Reich rekrutiert wurde. Neu waren auch nicht die Einsatzszenarios, wie der Überfall auf einen Versorgungstrupp des Gegners. Neu war, dass trotz gegenteiliger Bemühungen, die der Einhegung des Krieges dienten, die die Lineartaktik als zentrale taktische Einsatzkonzeption hatte, auf leichte Truppen nicht nur nicht verzichtet wurde, sondern ihnen sogar eine besondere Bedeutung im Gesamt-Kriegsszenario zukam. Das Kriegsgeschehen jenseits der Schlachten, dass weitgehend dem kleinen Krieg zugerechnet wurde, gehörte zum bevorzugten Einsatzgebiet der leichten Truppen. Mit ihrem Einsatz sollte den Schwächen in der gegnerischen Kriegführung begegnet werden, die mit der Vorherrschaft der Lineartaktik entstanden waren und durch diese nicht geschlossen werden konnten. Der kleine Krieg und der Einsatz leichter Truppen verlangte ein konzeptionell anderes Verhältnis zur soldatischen Subjektivität.

Wenn auch die Zeitgenossen den kleinen Krieg häufig »als ein Restbestand des irrational Chaotischen« (Kunisch 1973: IX), quasi als Rückfall in alte, überwunden geglaubte Zustände, werteten, so ist zu beachten, dass es sich bei diesen Verbänden in der Regel um keine >wildgewordene Soldateska` handelte, wenn sie beispielsweise in einer Region Streifzüge unternahmen und Vieh stahl. Nicht alle Plünderungen, Brandschatzungen und Drangsalierungen - die Folter (um Informationen abzupressen), Vergewaltigung und das Totschlagen umfassten - wurden zwar von den Kriegsherren gutgeheißen, doch die meisten Gewalttaten der leichten Truppen, unter denen vor allem die ländliche Bevölkerung litt, waren explizit Bestandteil des ihnen erteilten Auftrags. Sie sollten Nahrungsmittel besorgen und das Gebiet, in dem sie operierten, beunruhigen, um die geg- 
nerischen Truppen zu schädigen. Exzesse, wie die Brandschatzung der oberpfälzischen Ortschaft Cham 1742 (siehe Rink 1999: 8f.), bildeten lediglich die Spitze einer Kriegführung, deren Erfolge darauf beruhte, dass sie den Gegner gerade eben nicht nur auf dem Schlachtfeld attackierte und gegen die Regularien des eingehegten Krieges verstieß.

Die Erfolge der leichten Truppen zwangen die europäischen Kriegsparteien zu einer paradoxen Reaktion. Denn zum einen wollten sie auf die Vorteile, die die Kriegführung mit leichten Truppen versprach, nicht verzichten und sie warben spätestens seit dem Österreichischen Erbfolgekrieg (1740-1748) entsprechende Verbände an bzw. verstärkten ihre Kontingente. Zum anderen hielten sie aber am Ziel der Einhegung des Krieges fest, da nur sie versprach, dass der Krieg ein rationales politisches Instrument in den Händen der Fürsten blieb. Es mangelte darum nicht an Bemühungen, die leichten Truppen, dieses Element des Chaos, berechenbar zu machen und ihren Handlungsspielraum einzugrenzen. So wurden Reglements erlassen, in denen für die kommandierenden Offizieren detaillierte Handlungsanweisungen formuliert wurden und die Angehörigen der leichten Truppen einem Drill unterworfen, damit sie auch auf dem Schlachtfeld als >rangierte< Truppenteile eingesetzt werden konnten. Es wurden immer mehr leichte Truppen aufgestellt, die nicht nur eigens für einen bestimmten Krieg angeworben, sondern die nun dauerhaft formiert wurden und deshalb zu einem Teil des stehenden Heeres zu zählen sind. $\mathrm{Zu}$ vollwertigen Kampfverbänden für die Feldschlacht wurden die infanteristischen leichten Truppen trotz des Drills nicht, weil, so das allgemeine Urteil, sie sich durch das gegnerische Feuer schneller erschüttern ließen als Linienregimenter. Die Bemühungen, die leichten Truppen zu disziplinieren und zu reglementieren, führten dazu, dass einige Verbände in den Rang von Eliteeinheiten aufrückten, zugleich wurden aber auch Klagen laut, dass über all das Exerzieren die primären Aufgaben der leichten Truppen, wie die Ausbildung für das »Patrouillien, Partheyen und Vorposten«, vernachlässigt werden (zitiert nach Rink 1999: 173; siehe auch Kunisch 1973: 41). Eine tatsächlich veränderte Praxis des kleinen Krieges brachte diese Bemühungen nicht mit sich. Weder konnten die leichten Truppen unter die permanente Kontrolle der Befehlshaber gebracht werden, noch wurde die Einhegung des kleinen Krieges auch im Sinne einer Rationalisierung wirklich angestrebt, denn die hier gemachten Erfolge beruhten ja gerade auf dem Umstand, dass die Truppen gegen die bestehenden Regeln verstießen. "Sowohl« die Tatsache, dass die leichten Truppen besonders von und aus dem Land lebten, "als auch die Praxis, wie dies geschah, wurde von den Theoretikern und Praktikern des kleinen Krieges ausdrücklich gebilligt. Hinsichtlich der hierbei vorgenommenen Requisitionen, Geiselnahmen und Repressaliendrohungen bedauerten manche Autoren Land und Bevölkerung, doch alle gaben dann Regeln an, wie diese Maßnahmen am besten auszuführen seien.« (Rink 1999: 391) 
Der kleine Krieg genoss er bis zu den Koalitionskriegen (1792-1805/7) bei vielen Zeitgenossen nur das Ansehen einer »taktischen Ausnahmemaßnahme« (Kunisch 1973: IX). Er galt als unvereinbar mit dem >großen Krieg, und er sollte keinen Eingang in dessen Konzeption finden. In den Jahren nach dem Siebenjährigen Krieg (1756-63) nahm allerdings die Zahl der Kritiker an der Lineartaktik zu. Vor allem in Frankreich, dessen Truppen im Krieg von der preußischen Armee mehrfach besiegt worden waren, wurden Überlegungen angestellt, ob und welche Elemente der Kleinkriegführung für die Einsatzkonzeption der gesamten Streitkräfte übernommen werden können, damit bei einem erneuten Waffengang auch die preußischen Truppen, die weiterhin an der Lineartaktik orientiert blieben, geschlagen werden können. ${ }^{1}$ Auftrieb erhielt die Kritik an der Lineartaktik in und außerhalb Frankreichs auch von der oben erwähnten allgemeinen Neubewertung der Maschinenmetapher. Die an einem mechanischen Modell orientierten Bewegungsabläufe der Truppen wurden nun nicht mehr mit der Vorstellung von Kraft, Ordnung oder Natur assoziiert, sondern zunehmend auch mit Attributen wie erstarrt und leblos versehen, und nicht zuletzt wurde es zum Sinnbild von Unfreiheit und Unterdrückung alles Lebendigen (siehe hierzu Kunisch 1992: 161f.; Kleinschmidt 1999: 64f.). Die Anwendung der Lineartaktik, so ihre französischen Kritiker, setze sklavische Furcht voraus, die nur mit monarchies despotiques vereinbar sei, »zu der auch die preußische gezählt wurde, während in den monarchies modérées, zu der man die bourbonische Herrschaft in Frankreich rechnete, der bewusste Einsatz freiwillig geworbener Soldaten möglich sein sollte.« (Kroener 1998: 17)

So wichtig zahlreiche taktische und technische Verbesserungen in der französischen königlichen Armee nach 1763 waren - sie betrafen so unterschiedliche Bereiche wie die organisatorische Struktur (Divisionsgliederung) und die Entwicklung leichterer Kanonen, womit die Voraussetzung für eine Feldartillerie geschaffen wurde, »die mit der marschierenden Infanterie Schritt halten und daher eine wichtige Rolle auf dem Schlachtfeld übernehmen konnte« (McNeill 1984: 153) - zum Tragen kamen sie erst mit der Französischen Revolution. Erst die Revolution schuf die Voraussetzung zur allgemeinen Mobilisierung, der levée en masse (1793), und sie sorgte dafür, dass nach 1789 »innerhalb weniger Jahre fast 90 Prozent des königlichen Offizierskorps die Armee und häufig auch Frankreich« (Kroener 1998: 19; siehe auch Mann 1998: 277) verließen. Mit diesem Offizierskorps wäre der nach 1789 erfolgte Bruch mit der Lineartaktik kaum derart radikal vollzogen worden. An die Stelle des Adels, dem

1 Es gab allerdings auch den Versuch, preußische Disziplinarstrafen, wie das Spießrutenlaufen, in die französische Armee einzuführen. Der Kriegsminister, Claude Louis de Saint Germain (1707-1778), der für dieses Vorhaben stand, sollte aber gerade an dieser Frage scheitern (siehe Kroener 1998: 17; Delbrück Bd. 4, 1920: 511). 
fast alle Ränge vom Leutnant aufwärts vorbehalten waren, traten »teils durch Wahl, teils aufgrund des Dienstalters, befähigte Unteroffiziere und bürgerliche Subalternoffiziere« (Kroener 1998: 19), die zuvor kein Chance hatten, bis in die höchsten militärischen Kommandopositionen, aber auch politischen Ämter, zu gelangen. Sie bildeten einen mit den Verbesserungen vertrauten Kader, der schließlich die napoleonische Armee formen und prägen sollte.

Außerhalb Frankreichs sollten die zahlreichen Niederlagen gegen Truppenkontingente der französischen Regierung nach 1792 und später gegen die napoleonischen Truppen grundlegende Revisionen der Lineartaktik erzwingen und zu neuen taktisch-operativen Einsatzkonzepten auch für den >großen Krieg` führen. Neben dem Beispiel, das durch die französischen Streitkräfte gegeben wurde, spielten auch hier die mit dem Einsatz leichter Truppen gemachten Erfahrungen eine wichtige Rolle (siehe Rink 1999: 266f und 393f.). Diese Veränderungen in der Kriegführung, die durch die Französische Revolution bzw. später europaweit durch die Koalitionskriege angestoßen wurden, sind von den Zeitgenossen selber als außerordentlich empfunden worden (Sikora 1999: 153). Auch in der späteren Wahrnehmung wird meist ein grundlegend verändertes Kriegsbild für die darauf folgenden Jahre konstatiert. So wird festgestellt, dass in den Koalitionskriegen zwei verschiedene Kriegsauffassungen aufeinander geprallt sind (Bröckling 1997: 90). Der »Mobilisierung der Leidenschaften« auf Seiten der für die französische revolutionäre Regierung kämpfenden Truppen stand die »Fabrikation disziplinierter Individuen auf systematischer Ausschaltung aller spontaner Regungen« gegenüber (ebd.: 91).

Mit der Französischen Revolution endete die Ära der Kabinetts- und Erbfolgekriege. An ihre Stelle sollten in der Schlussphase der Napoleonischen Kriegen (1805-1815) von Nationalstaaten geführte Kriege treten. Es galt nun nicht mehr, die Bevölkerung aus den Sphären der (Staats-)Politik herauszuhalten, vielmehr sollte nun die männliche Bevölkerung des Landes in einem bis dahin unbekannten Ausmaß für den Soldatendienst mobilisierbar, sprich rekrutierbar werden. Die Angst, dass die Koalitionstruppen die Errungenschaften der Französischen Revolution wieder rückgängig machen würden, wenn es ihnen gelänge, in Paris einzumarschieren, bildete die Voraussetzung für die levée en masse (1793). Sie schuf eine zuvor quasi unbekannte Bereitschaft zum Waffendienst, auf der später auch die Institution einer allgemeinen Wehrpflicht für die männliche Bevölkerung beruhte. Auch die Gegner der französischen Republik bzw. des napoleonischen Kaiserreichs sahen sich gezwungen, wenn auch zum größten Teil vorerst nur bis zum Ende der Napoleonischen Kriege, große Teile der männlichen Bevölkerung einer solchen Verpflichtung zu unterwerfen. Die erfolgreiche Durchsetzung dieser Verpflichtung gegenüber der Bevölkerung wiederum setzte zahlreiche administrative Veränderungen des Staates voraus, einen tief greifenden Umbau des politischen und sozialen 
Gefüges von Staat und Gesellschaft. Es wird im Folgenden nicht möglich sein, im Detail auf diese Veränderungen einzugehen.

Nachdem im Abschnitt 6.2. näher auf den kleinen Krieg und die leichten Truppen eingegangen und beleuchtet wird, weshalb die an das Subjekt gebundenen Fähigkeiten unverzichtbar für die Kleinkriegführung waren, konzentriert sich die Darstellung im Abschnitt 6.3. auf spezifische Veränderungen der Einsatzkonzeptionen der Soldaten, die ihre Stellung als Subjekte betreffen. Dabei ist zu berücksichtigen, dass die Freiwilligkeit der Soldaten, die Bereitwilligkeit, mit der sie sich mit den Zielen des Kampfes identifizierten, zwar die Bereitschaft, gegen den Gegner zu kämpfen erhöhte, für sich genommen jedoch keine Garantie für einen Sieg auf dem Schlachtfeld bot. Dies galt bereits für die Freiwilligen der levée en masse. Durch die Freiwilligen konnten zwar die französischen Truppen wesentlich zahlreicher den Koalitionstruppen entgegentreten, aber auch die freiwillig erbrachte individuelle Kampfkraft musste koordiniert und strukturiert werden, einer gemeinsamen Lenkung unterstehen, sich also als disziplinierte entfalten, damit sie dem gegnerischen Verband nicht nur numerisch überlegen war. Als Teil einer koordinierten Kampftätigkeit eines Sozialverbandes blieben die Freiwilligen auf spezifische Weise von den Nachrichten abhängig, über die die Leitung des Sozialverbandes verfügte, von deren Planungen für das Kampfgeschehen, von deren Beobachtungen, wie der Gegner operierte, wie sich die eigenen Verbände schlugen, sowie den Entscheidungen, die aus all den Planungen und Beobachtungen folgten. ${ }^{2}$ Ohne die nur unter dem Ancien Régime geschulten Offiziere und die von ihnen vorangetriebenen Reformen der Armeestruktur und -organisation wären die »schieren Massen« der levée en masse auf dem Schlachtfeld nicht lenkbar gewesen und hätten »nicht die Siege errungen, die den Revolutionsheeren tatsächlich zufiel.« (McNeill 1984: 149) Selbst wenn Individuen freiwillig kämpfen, müssen sie sich einem Kommando unterstellen und sich auf einen bestimmten Handlungsrahmen festlegen lassen, damit die Kohäsion des Sozialverbandes, sowie eine effektive Anwendung ihrer Destruktionskraft gewährleistet ist. Die Einsatzkonzepte sahen deshalb nicht nur vor, bestimmte Fähigkeiten der Subjekte aktiv für die Kriegführung zu nutzen. Neben einer gewissen Öffnung von Handlungsspielräumen für die Individuen hielten die Einsatzkonzepte an Momenten des Ausschlusses von Subjektivität fest. Für die Exklusion soldatischer Subjektivität sprachen aber auch noch zwei weitere Gründe.

2 Für van Creveld (1985) sind Kommandeure einer Armee neben den unmittelbar auf den Kampf bezogenen Leistungen, die »the maximum of death and destruction on the enemy within the shortest possible period of time and at minimum loss to itself« (ebd.: 6) organisieren sollen, auch für die Beschaffung aller Dinge verantwortlich ohne die es keinen Zusammenhalt der Armee geben würde, wie beispielsweise die Versorgung mit Nahrungsmitteln. Dieser Aspekt bleibt im Weiteren weitgehend ausgeblendet. 
1. Die taktisch-operativen Konzepte, die sich im Zuge der Koalitionskriege bzw. Napoleonischen Kriege durchsetzten, setzten auf eine größere Bereitschaft der Soldaten, sich im Kampf zu engagieren, aber sie verließen sich nicht ausschließlich auf die freiwillig erbrachten Kampfleistungen der Individuen. Die Erfolge der französischen Truppen wären zwar ohne die ungleich größere Identifikation der Soldaten mit den Kriegszielen, als sie bei den Söldnerverbänden der absolutistischen Fürstenstaaten üblich war, nicht errungen worden, aber auf Zwangsrekrutierte wurde bei der Aufstellung der Armeen nicht verzichtet. Bei der Ausbildung der Soldaten und in den neuen Führungskonzepten mussten die Kriegsparteien folglich berücksichtigen, dass zahlreiche Soldaten nur unter Zwang ihren Kriegsdienst ableisteten und ihr Leben im Kampf riskierten.

2. Ein weiterer Grund für die Exklusion soldatischer Subjektivität lag in der Möglichkeit begründet, dass die Leidenschaften für den Kriegseinsatz, beispielsweise in Form der patriotischen Gesinnung, >für das Vaterland zu kämpfen und zu sterben`, im entbehrungsreichen Kriegsalltag und erst recht in lebensgefährlichen Extremsituationen des Kampfeinsatzes schwinden konnte. Ein Indikator für ein Nachlassen solcher Leidenschaften ist die Desertion. Doch auch wenn die Soldaten sich nicht von der Truppe entfernen, mussten die Kommandeure damit rechnen, dass die Soldaten auf andere Weise ihren Unmut ausdrückten.

An erster Stelle ist hier die Möglichkeit zu nennen, dass ein Soldat gegenüber seinen Vorgesetzten den Gehorsam aufkündigt. Für diesen Fall steht den Vorgesetzten eine Reihe von Sanktionsmöglichkeiten zur Verfügung, um den Soldaten zum Gehorsam zu zwingen bzw. um ihn exemplarisch zu bestrafen und damit zu verhindern, dass weitere Soldaten sich sein Handeln zum Vorbild nehmen. Befehlsverweigerung oder gar die Teilnahme an einer Meuterei galten und gelten beim Militär als die schwerwiegendsten Verfehlungen, die ein Soldat begehen kann. Sie wurden und werden als Gefahr für den Bestand der gesamten Organisation gewertet und können bis heute schwerwiegende Strafen nach sich ziehen. Die härtesten Strafen waren und sind für den Fall vorgesehen, dass sich die Befehlsverweigerung unmittelbar auf den Kampfeinsatz bezieht.

So gefürchtet die offene Verweigerung eines erteilten Befehls ist, als kaum minder gefährlich gelten die verdeckten Formen des Ungehorsams. Sie sind dann zu befürchten, wenn sich die Untergebenen von ihren Vorgesetzten unbeobachtet fühlen, und reichen von der nur schleppenden oder nachlässigen Ausführung eines Befehls bis hin zu seiner Missachtung. Mit dem Abrücken von der Lineartaktik, der neuen Wertschätzung freiwilligen Engagements und der Eigeninitiative von rangniedrigen Soldaten sollten auf dem Schlachtfeld die Chancen, solche verdeckten Formen des Ungehorsams zu praktizieren, steigen. Bei aller Wertschätzung, die das freiwillige Engagements und die Eigeninitiative rangniedriger Soldaten nach der Französischen Revolution erfuhr, die Furcht vor dieser Kehrseite 
soldatischer Subjektivität fand ihren Niederschlag in einem bis heute anhaltenden unablässige Kontrollbedürfnis gegenüber den Soldaten. Der Alptraum eines jeden Vorgesetzten, dass die Untergebenen nicht gehorchen, wenn er ihre Handlungen nicht beobachten kann, förderte ein Festhalten an >geschlossenen Truppenkörpern` (Delbrück), an Einsatzformen, die die Sichtbarkeit der Soldaten für die Vorgesetzten garantieren sollten. Das Bemühen, unablässig das Handeln der Soldaten zu kontrollieren und zu sanktionieren, um den Eigensinn soldatischer Subjektivität zu begrenzen, konnte wichtiger sein als die Vermeidung von Verlusten und die Steigerung von Kampfkraft.

\subsection{Die leichten Truppen und der kleine Krieg}

Die Anwendung der Lineartaktik führte zu einer Spezialisierung vor allem bei den Infanterieverbänden. In ihrer Ausbildung wurden die Infanteristen auf den Einsatz in der geschlossenen Formation vorbereitet. Durch den Drill sollte sowohl ein Höchstmaß an Perfektion bei der Ausführung der angeordneten Bewegungsabläufe erreicht sowie ihre Standfestigkeit im Gefecht erhöht werden. Es erschien deshalb wenig opportun, die Soldaten auf verschiedene Gefechtssituationen vorzubereiten, zumal die Gefechte jenseits einer offenen Feldschlacht spezifische Anforderungen an die Struktur und die Bewaffnung der Verbände stellten und, was vielleicht noch schwerer wog, hier die Soldaten Handlungsweisen zeigen mussten, die der Prägung auf die Lineartaktik diametral widersprachen. ${ }^{3}$ Je mehr ein Verband durch seine Ausbildung und Ausrichtung primär auf den Einsatz in der Schlacht vorbereitet wurde, desto eher wurde es sinnvoll, für die Aufgaben jenseits der Schlacht ebenfalls dafür spezialisierte Verbände heranzuziehen. Es ist kein Zufall, dass die Hochphase des kleinen Krieges als taktisches Instrument der Kriegführung und die leichten Truppen als deren bevorzugte Träger mit der vollständigen Ausformung der Lineartaktik sowie der Reglementierung der Heere, die in »starrer Ordre de Bataille nicht nur kämpfte[n], sondern auch marschierte[n], lagerte[n] und die taktische, vielfach an die Stelle von Feldschlacht tretenden Manöver ausführte[n]« (Kunisch 1973: 6), zusammenfiel. Sie umfasste den Zeitraum von circa 50 Jahren zwischen dem Österreichischen Erbfolgekrieg (1740-1748) und dem Beginn der Koalitionskriege (1792). Die zunehmende Bedeutung, die

3 Dies schloss einen Wechsel von einem Linienverband beispielsweise zu einem Freikorps keineswegs aus. So berichtet Dreyer, dass er und andere preußische Soldaten seines Regiments im Siebenjährigen Krieg von seinem Vorgesetzten an ein Freibataillon >vertauscht « wurden. »Das war mir auch ganz recht, denn die Wahrheit zu sagen, unter der Muskete hatte ich nicht viel getaugt; ich liebte die Freiheit zu sehr« (Dreyer 1810: 23). Er wurde `Chef^ einer 27köpfigen >Streifparthie`, deren Bewaffnung und Ausrüstung er dem geänderten Auftrag anpasste. 
die leichten Truppen in dieser Zeit gewannen, kündete von den Schwächen der Lineartaktik und dem Bemühen, sie zu überwinden.

Der Versuch von Rink, mit einer an der Heeresdienstvorschrift der Bundeswehr orientierten Terminologie die typischen Aufgaben des kleinen Krieges zu benennen, macht vor allem deutlich, was der kleine Krieg nicht war: unbedeutend und randständig. »Der Kleine Krieg umfasst alle Bereiche der `Allgemeinen Aufgaben im Einsatzı, vor allem das Halten oder Herstellen von Verbindungen, die Sicherung, Gefechtsaufklärung und Geländeerkundung.« (Rink 1999: 85f.). Weiterhin umfasste er, so Rink, das >Lösen vom Feind`, das Begegnungsgefecht, und den Jagdkampf. ${ }^{4}$ Aus dem Blick einer solchen Aufgabenbeschreibung gerät leicht, dass die Unternehmungen im kleinen Krieg des 18. Jahrhunderts nicht nur auf die gegnerischen Soldaten zielten, sondern auch auf die Zivilbevölkerung. Die (ländliche) Zivilbevölkerung wurde von den Angehörigen der leichten Truppen nicht nur drangsaliert, weil die Verbände nicht über einen Tross verfügten und sich deshalb >aus dem Land ernähren Beute machen, also aus gewaltsam angeeigneten Gütern einen privaten Nutzen ziehen wollten. ${ }^{5}$ Die Beitreibung von Kontributionen wie das >Ausfouragieren` von Landstrichen, um den gegnerischen Truppen das Marschieren durch die verwüstete Region zu erschweren (siehe Rink 1999: 171), ${ }^{6}$ konnten ebenso Teilziele der Operationen im gegnerischen Gebiet sein.

Die Größe der Verbände variierte sehr stark. Ein Verband konnte 20, aber auch mehrere 100 Mann umfassen (ebd.: 83f.). Es konnte sich um infanteristische oder auch um berittene Soldaten handeln. Der Anteil dieser beiden Truppengattungen an den leichten Truppen schwankte von Kriegspartei zu Kriegspartei. So bestand bei der preußischen Armee die Masse

4 Unter Begegnungsgefechten sind Kämpfe zu verstehen, in denen die Gegner aus der Bewegung heraus aufeinander treffen. Beide Seiten verfügen deshalb auch nicht über Stellungen, von denen aus sie den Gegner attackieren bzw. von denen sie sich verteidigen können. Unter einem Jagdkampf sind Operationen innerhalb des vom Gegner kontrollierten Gebietes zu verstehen. Sie dienen der Aufklärung und sollen zugleich den Gegner durch Handstreiche und Hinterhalte schädigen und verunsichern.

5 Dass die Bezeichnung Husar für eine der bekanntesten Reiterverbände, die den leichten Truppen zugerechnet werden, nicht nur auf das ungarische Zahlwort für zwanzig (húsz) zurückgeführt wird, sondern ebenso häufig auf das ungarische huszár für Straßenräuber und damit auf das mittellateinische cursarius für Seeräuber ist dieser Praxis der leichten Truppen geschuldet (siehe Duden >Etymologie`, hrsg. von Drosdowsi (1989)). Aus Sicht der Landbevölkerung dürften die Differenzen zwischen lizenziertem und illegalem Raub unerheblich gewesen sein.

6 Eine derartige Zielsetzung ist in der Heeresdienstvorschrift nicht zu finden. Es handelt sich bei solchen Maßnahmen nach heutigem Rechtsverständnis um Kriegsverbrechen. Siehe beispielsweise II. Zusatzprotokoll zu den Genfer Abkommen vom 12.8.1949; § 13, Schutz der Zivilbevölkerung. 
der leichten Truppe aus Kavallerie, während die habsburgerische Armee über sehr viele infanteristische Verbände verfügte (ebd.: 166). Mitunter wurden im Rahmen der Kleinkriegführung auch »kombinierte Verbände aus leichten und regulären Truppen gebildet und mit Artillerie ausgestattet « (Kunisch 1973: 19f.), so genannte Detachements, die in der Lage sein sollten, den gegnerischen Verbänden offensiver gegenüberzutreten und ihnen »an Stellen Schaden zuzufügen, die außerhalb des begrenzten Operationsfeldes der kleinen Truppenabteilungen lag.« (Ebd.) Beim preußischen Heer wurden insbesondere Grenadier- und Füsilierregimenter ${ }^{7}$ zur Sicherung großer Marschkolonnen vor Angriffen leichter Truppen eingesetzt, weil es über zu wenige infanteristische leichte Truppen verfügte, um ihnen ebenfalls mit leichten Truppen entgegenzutreten. Die Husaren hatten in diesem Fall über den Standort des Gegners aufzuklären und für die weitere Sicherung des Verbandes zu sorgen, während die Linienregimenter in ihrer geschlossenen Formation, die in zerstreuter Fechtweise kämpfenden leichten Truppen des Gegners angriffen. Diese spezifische Gefechtssituation erlaubte es den Linientruppen wohl auch, die ansonsten kompakte Formation zu lockern. ${ }^{8}$

$\mathrm{Zu}$ den leichten Truppen gehörten sowohl Verbände, die zum stehenden Heer zu rechnen sind, aber auch solche, die erst im Zuge eines Krieges formiert wurden. Vor allem die ad hoc angeworbenen bzw. aufgestellten Verbände genießen in der Literatur einen überwiegend schlechten Ruf. In ihnen habe sich »alles mögliche Gesindel, dem es vor allem um das Beutemachen ging« (Regling 1979: 59) gesammelt. Und Delbrück schreibt, dass die preußischen Freikorps bzw. Freibataillone ${ }^{9}$, die im Zuge des Siebenjährigen Krieges aufgestellt wurden, aus »Abenteurern, Deserteuren, Vagabunden (bestanden), die sich von der regulären Infanterie nur dadurch auszeichneten, dass ihnen das fehlte, was diese stark machte, nämlich die Disziplin.« (Bd. 4, 1920: 364) In diesen abschätzigen Urteilen klingt die zeitgenössische Auffassung von einer >zivilisierten` Kriegführung nach, die in der Kleinkriegführung einen Rückfall in die Barbarei sah, die deshalb auch am besten von rückständigen Völkern wie den Kroaten beherrscht werde (siehe Rink 1999: 100). Der Umstand, dass sie die Konfrontation mit regulären Truppen mieden, führte zu weiteren moralisch

7 Bei den Grenadieren handelte es sich um Soldaten, die sich freiwillig gemeldet hatten, Handgranaten auf die Gegner zu werfen, was für die Werfer recht gefährlich war. Füsiliere waren Infanteriesoldaten, die mit kürzeren und deshalb leichteren Gewehren ausgestattet waren. Man kam nicht als Rekrut zu diesen Verbänden, sondern erst, nachdem man sich schon längere Zeit als Soldat bei der Truppe befand.

8 Ich greife hier einen Hinweis von Sascha Möbius auf, der von einer größeren Flexibilität der Lineartaktik in der Praxis ausgeht, als sie sich aus dem Studium der Reglements ableiten lässt.

9 Als Freibataillone wurde Verbände bezeichnet, die keinem bestimmten Regiment zugeordnet waren. 
entwertenden Äußerungen, die sich dann insbesondere auf die leichten Truppen des Gegners bezogen. So klagte der preußische Kommandeur Ferdinand von Braunschweig (1721-1792) die gegnerischen Panduren und Kroaten im 2. Schlesischen Krieg (1744/45) an: »Sie haben uns mit ihren Flinten zwei Leute verwundet, indem sie immer wie Diebe und Räuber hinter Bäumen versteckt sind und sich nie im offenen Felde zeigen, wie es braven Soldaten geziemt« (zitiert nach Kunisch 1973: 27). ${ }^{10}$

Bei den leichten Truppen befanden sich grundsätzlich keine zum Dienst gepressten Soldaten. In den Freikorps befanden sich aber vermutlich tatsächlich viele Deserteure, für die ihre Zugehörigkeit zum jeweiligen Freikorps nur eine Durchgangsstation für eine weitere Flucht zur nächsten Kriegspartei war. Für sie gilt, wie für viele andere Soldaten, dass sie nicht durch die Anwendung unmittelbarer Gewalt >unter die Fahne` gezwungen werden mussten, weil sie aus zivilen Lebensbezügen heraus gefallen waren. ${ }^{11}$ Mag bei zahlreichen Angehörigen der leichten Truppen auch das Motiv nach einem Abenteuer und ähnliches mehr eine gewisse Rolle gespielt haben, so wird bei ihnen das Soldatentum, wie bei den Schweizer Söldnern des 14./15. Jahrhunderts (siehe Abschnitt 4.3.), vor allem aufgrund der Armut und den mehr als bescheidenen Perspektiven, das für sie ein Leben jenseits des Kriegsdiensts bereit hielt, anziehend gewirkt haben. In den Augen vieler ihrer adligen Offiziere galten diese Angeworbenen, die wenig Anlass hatten, riskante Befehle ihrer Vorgesetzten auszuführen, aufgrund ihrer Unzuverlässigkeit oft als »Abschaume des menschlichen Geschlechts« (Rink 1999: 105, der hier Johann von Ewald zitiert). Ein solch negatives Urteil galt nicht für Truppen wie die preußischen Jäger. Sie galten als Elitetruppe, weil sie relativ zuverlässig die ihnen erteilten Befehle ausführten. In ihren Praktiken im kleinen Krieg unterschieden sie sich aber prinzipiell nicht von den anderen leichten Truppen. Rekrutiert wurden die Jäger unter den einheimischen Forstbeamten-Anwärtern, deren Väter häufig bereits im Forstdienst arbeiteten und die mit ihrer Dienstableistung die Aussicht auf eine Anstellung verbanden, was vermutlich entschieden ihre Loyalität erhöhte. Sie waren »allein dadurch über die Kameraden der anderen Waffengattungen herausgehoben [...], dass sie nicht den zunehmend als entehrend empfundenen Körperstrafen unterworfen waren.« (Regling 1979: 61)

10 Wie sehr solche moralischen Entrüstungen nur die Praxis des Gegners im Auge hatte, wird daran deutlich, dass bereits fünf Jahre zuvor der preußische König Friedrich II., also der Landesfürst von Ferdinand, mit den Jägern eine Einheit aufgestellt hatte, die als Scharfschützen bevorzugt gegnerische Offiziere erschoss (siehe hierzu auch Luh 2004: 147f.).

11 Zur Herkunft der freiwilligen Soldaten siehe Sikora (1996: 218f.). Der Eintritt in die Armee markierte häufig keine Lebensperspektive im Sinne einer Berufswahl, sondern war als eine begrenzte Lebensphase, als eine vorübergehende Notlösung gedacht. 
Eine andere Sonderstellung nahmen die Verbände ein, die aus Kosaken und anderen Grenzvölkern zusammengestellt wurden. Es war vor allem der wirkungsvolle Einsatz kroatischer Verbände auf Seiten der Habsburger Monarchie im Österreichischen Erbfolgekrieg, der die anderen europäischen Staaten dazu animierte, ihrem Beispiel zu folgen und ebenfalls leichte Truppen auszuheben.

Die Kampfweise der >Kroaten Kämpfe an der Militärgrenze zum Osmanischen Reich etabliert, und die Einsatzbereitschaft der Grenzsoldaten beruhte auf zahlreichen Privilegien, die ihnen gewährt wurden (siehe Sikora 1996: 254). Ihre Rekrutierung in der Grenzregion sorgte für ein hohes Maß an sozialer Homogenität, die einher ging mit verwandtschaftlichen Bindungen und die für eine soziale Kohäsion der Verbände sorgte, um die die anderen Kriegsparteien die Habsburgermonarchie beneideten. »Diese besondere $>$ Kette $<$ unterwarf die einzelnen Soldaten den engen Regeln traditionell geprägter Wertvorstellungen, deren Verletzung zugleich mit harten Sanktionen bestraft wurde.« (Ebd.: 309) Die Loyalität der Kroaten galt aber in erster Linie der eigenen Gruppe und nur in zweiter Linie richtete sie sich »auf die Habsburger Kriegsherren, denen sie durch vertragliche Verpflichtungen und durch den Schutz ihrer Privilegien verbunden waren.« (Ebd.) Wenn diese Vereinbarungen verletzt wurden, dann war es schnell mit ihrer Loyalität zu den Habsburgern vorbei. Aber auch für diesen Fall lässt sich eine Besonderheit der Kroaten ausmachen. Sie liefen dann nicht zur gegnerischen Kriegspartei über, sondern kehrten in die Grenzregion zurück.

Wenn die leichten Truppen nicht eigenständig operierten, um zum Beispiel im vom Gegner beherrschten Territorium dessen Versorgungswege unsicher zu machen, hatten sie die Aufgabe, für die Hauptstreitmacht Patrouillen durchzuführen und vor dem Feldlager der Armee Vorposten zu beziehen. Sie sollten auf diese Weise das eigne Heer und dessen Versorgung vor Angriffen gegnerischer leichter Truppen schützen und Informationen über die Stärke, Planungen und den Standort der Armee des Gegners gewinnen. Die Präsenz der leichten Truppen im Umfeld der Armee galt aber nicht nur der Abwehr überraschender Operationen des Gegners und der Erkundigung des näheren Umfeld. Durch ihre Anwesenheit sollten die eigenen Soldaten von einer Desertion abgeschreckt bzw. an der Flucht gehindert werden. So wies beispielsweise der preußische König Friedrich II. seine Truppenkommandeure an, Husaren-Patrouillen um das Lager >gehen` zu lassen und beim Marsch durch bewaldetes Gelände (»wenn die Infanterie ein Holtz passiret«) an dessen Seite aufzuziehen (Friedrich II. 1747: 4). Die gleiche Aufgabe wurde ihnen zumindest wiederholt bei den preußischen Truppen zugewiesen, wenn die Linientruppen eine Schlacht schlugen. Meistens hatten sie dann dafür zu sorgen, dass die >Ausreißer` wieder auf das Schlachtfeld zurückkehrten, und es wird sogar in einem Fall davon berichtet, dass sie hinter der Infanterie Stellung bezie- 
hen sollten, um die Soldaten in die Schlacht zu treiben (siehe Möbius 2004: 344; Regling 1979: 63). ${ }^{12}$

Auf dem Schlachtfeld galten vor allem die infanteristischen Verbände der leichten Truppen wenig. Ihnen wurde nur eine geringe Kampfkraft in der Feldschlacht zugesprochen. Auch galt mit der Ausbildung der Lineartaktik ihr Einsatz als Plänkler, der zuvor eine Domäne von leicht bewaffneten und in zerstreuter Gefechtsweise kämpfenden Verbänden war, als unpraktikabel. Das Ausschwärmen vor die eigenen Linien, die für Plänkler typischen Attacken auf den Gegner, die in seinen Reihen Unruhe hervorrufen sollten sowie das schnelle Zurückweichen, bevor dieser massiv gegen die Plänkler vorgehen konnte, drohte nun bei den eigenen Soldaten für Verwirrung zu sorgen, wenn die Plänkler versuchten, sich hinter die dicht an dicht in Linie stehenden Soldaten zurückzuziehen, bevor die Konfrontation zwischen den in geschlossener Formation stehenden Verbände begann. Ihr Einsatz als geschlossener Verband auf dem Schlachtfeld galt als Notbehelf, weil man davon ausging, dass ihre geschlossene Formation schneller als bei den Linienregimentern zerbrach. Damit ihre Geschlossenheit in einer Schlacht länger erhalten blieb, wurde deshalb beispielsweise vorgeschlagen, sie von Linientruppen einzurahmen (Kunisch 1973: 21). Eine etwas größere Rolle auf dem Schlachtfeld spielten die berittenen Verbände der leichten Truppen. Je »mehr Wert auf Schnelligkeit und Länge der Reiterattacke gelegt wurde, « weil die Erfahrung gezeigt hatte, dass schnell ausgeführte Attacken mit Säbeln und anderen Blankwaffen bei Infanteristen mehr Angst auslösten, als wenn sie mit Schusswaffen angriffen, und damit ihre Chancen stiegen, in die gegnerischen Linien einzubrechen, »desto mehr empfahl es sich, hierfür die leichten Reiter heranzuziehen« (Regling 1979: 62). Dazu mussten die Verbände allerdings eine besondere Ausbildung erfahren, die sie zur Attacke in einer geschlossenen Formation befähigen sollte, und deshalb wurden nur einige dauerhaft formierte Kavallerieeinheiten wie die preußischen Husaren auf dem Schlachtfeld nicht nur zum Flankenschutz eingesetzt, sondern auch um den Gegner anzugreifen (ebd.).

Hinterhalte, Überfälle und das Gefecht aus gedeckten Positionen heraus gehörten $\mathrm{zu}$ den bevorzugten Gefechtsformen der leichten Truppe. »Ihre Stärke waren Beweglichkeit, Anpassungsfähigkeit, Listigkeit und

12 Spuren dieser Tätigkeit der leichten Truppen haben sich bis heute im Sprachgebrauch erhalten. Die Bezeichnung >Feldjäger` für die deutsche Militärpolizei geht auf die preußischen Jäger des 18. Jahrhunderts zurück. Abgesehen von Verbänden wie den preußischen Husaren und Jägern waren Desertionen bei den Soldaten der leichten Truppen keineswegs selten. Nach einer Liste, die den »Gesammt-Abgang « des im hannoverschen Dienst stehenden Lucknerschen Husarenkorps verzeichnet - es wurde im Siebenjährigen Krieg angeworben und bestand zwischen 1757 und 1762 - sind über 40 Prozent der Husaren desertiert (Horstmann 1997: 181). Die aufgelöste Gefechtsweise habe bei den Freikorps die Desertion begünstigt, so Kunisch (1973: 30). 
Dreistigkeit, die Voraussetzungen der sprichwörtlichen Husarenstreiche.« (Sikora 1996: 41) Zu ihrer Anpassungsfähigkeit gehörte, dass sie es vermieden, sich in lang anhaltende Gefechte verwickeln zu lassen, bei denen die Gefahr extrem hoch war, vom Gegner mit überlegenen Kräften festgesetzt und anschließend aufgerieben zu werden. Nicht Standhaftigkeit war darum die Tugend, auf die es ankam, sondern die Fähigkeit, sich vom Gefechtsfeld zurückzuziehen: Hinter natürliche Barrieren, wie Flüsse oder in Wälder bzw. zu den eigenen Hauptverbänden. Was bei den Linientruppen als ehrlose Flucht galt, schuf bei den leichten Truppen erst die Voraussetzung für weitere Unternehmungen gegen den Gegner. Für eine erfolgreiche Kleinkriegführung mussten die leichten Truppen ihr Handeln an die vor Ort angetroffenen Bedingungen anpassen können. Sie verlangte von ihnen als Angreifende, dass sie die Gegebenheiten der Topographie nutzten, die klimatischen Bedingungen berücksichtigten. Sie verbargen ihre Gegnerschaft, indem sie sich verkleideten, und sie optimierten den Erfolg des Unternehmens, wenn sie sich spontan ergebende Chancen nutzten und auch auf unerwartet auftauchende Gefahren reagieren konnten. ${ }^{13}$ Nur wenn alle an der Unternehmung Beteiligten große Sorgfalt walten ließen, war es möglich, den Gegner zu überraschen. Das Ideal eines gelungenen Überfalls beziehungsweise Hinterhalts bestand in der völligen Überrumpelung des Gegners, so dass die Angegriffenen sich ohne Gegenwehr ergaben. List und Überraschung sind deshalb in der Kleinkriegführung nicht nur das Werk der Dispositionen eines Vorgesetzten, sondern hingen vom Handeln aller Akteure ab.

Die Vorgesetzten erteilten zwar vor Überfällen und dergleichen Unternehmungen Befehle, ihre Kontroll- und Sanktionsmöglichkeiten wurden aber durch den Typus dieser Operationen eingeschränkt. Im Vorfeld eines Angriffs mussten sich die Soldaten im Raum verteilen, um beispielsweise aus verschiedenen Richtungen gleichzeitig angreifen zu können, und die Möglichkeiten nutzen, sich im Gelände zu verstecken, um den Gegner überraschen zu können bzw. ihm möglichst kein Ziel zu bieten. Die Offiziere konnten deshalb zu den ihnen unterstellten Soldaten keinen permanenten Sicht-, möglicherweise auch keinen Rufkontakt aufrechterhalten. Es konnte darüber hinaus auch geschehen, dass die Soldaten - ohne Rücksprache mit ihren Vorgesetzten halten zu können - auf unvorhergesehene Ereignisse reagieren, also Eigeninitiative entwickeln mussten, um den Erfolg des Unternehmens nicht zu gefährden. Im kleinen Krieg galt es nicht, nach starren Regeln zu handeln, sondern (vom Gegner) unvorhergesehene Situationen zu erzeugen und selber mit unerwarteten Konstellationen fertig zu werden. Die Anführer der leichten Truppen mussten von ihren Unterge-

13 So berichtet Dreyer, er habe als Angehörige seines Kommandos, die Soldaten ausgewählt, die ihm am »klügsten, kühnsten und schlauesten, die im Stande waren, sich in jede Form zu schmiegen, jede Gestalt anzunehmen« (1810: 27) erschienen. 
benen verlangen, dass sie ihre leibgebundenen sensorischen Fähigkeiten, wie das Hören, Sehen und Riechen nutzten, um die Situation wahrzunehmen. Sie mussten sich ihrer Fähigkeit bedienen, das Wahrgenommene in Beziehung zu den intendierten Taten zu setzen, die jeweilige Situation stets neu zu reflektieren und sie gegebenenfalls durch das eigene Handeln abermals zu verändern. Die Bewältigung der offenen Situationen, die im kleinen Krieg immer wieder entstanden, verlangte von den Angehörigen einen kreativen Umgang mit der neu entstandenen Situation. Dies konnte wiederum nur gelingen, wenn sie, um Plessners Terminologie aufzugreifen, ihre Fähigkeit als freibewegliche Organismen zu einem aktiven Verhalten gegenüber ihrer Umwelt entfalten, als eigensinnige Subjekte das Geschehen mitgestalteten.

Der kleine Krieg verlangte sowohl von den ansonsten subalternen Offizieren wie von ihren Untergebenen ein im Rahmen der Lineartaktik unbekannt hohes Maß an Eigeninitiative. Die Anführer eines selbstständigen Kommandos mussten in die Fähigkeiten und auf die Bereitschaft zum Engagement ihrer Untergebenen vertrauen, die wiederum zuverlässig unter den gegebenen Umständen und im Sinne des Auftrags zu handeln hatten. Die Untergebenen ihrerseits mussten auf die Fähigkeiten ihres Vorgesetzten bauen, dass er die richtigen Dispositionen für die Operationen trifft. Es wird deshalb in der zeitgenössischen Literatur betont, dass sich der Umgang der Offiziere mit den Soldaten nicht auf eine bloße Dienstaufsicht beschränken dürfe. Um die Einsatzbereitschaft der Untergebenen auch unter widrigen Bedingungen zu erhalten, müssten sie die Schwächen wie die Stärken der einzelnen Soldaten kennen lernen und verstehen, sie zu motivieren (siehe Rink 1999: 109f.). Die zahlreichen Klagen über die Unzuverlässigkeit der Angehörigen der leichten Truppen zeigen an, wie häufig das Zusammenspiel all dieser Bedingungen nicht gelang.

Die hier dargelegte Kleinkriegführung des 18. Jahrhunderts teilt mit dem Kampf der Guerilla, die nach allgemeiner Lesart mit dem 19. Jahrhundert einsetzte, ${ }^{14}$ dass sie nicht geeignet war, die gegnerischen Streitkräfte zu zerschlagen. Sie unterschied sich aber von der heutigen Kleinkriegführung darin, dass sie von den Krieg führenden Staaten selber betrieben wurde und ihr in den Augen der zeitgenössischen Kriegsherren allenfalls eine unterstützende Aufgabe im Rahmen des eingehegten Krieges zufiel. Über den Ausgang des Krieges sollten die Kämpfe entscheiden, in denen sich ihre Linienverbände gegenüberstanden. Die spezifische Verschränkung des >kleinen` mit dem >großen` Krieg im 18. Jahrhundert, seine

14 Die Bezeichnung Guerilla geht auf das spanische Wort für Kleinkrieg (guerrilla) zurück. Es fand erstmals im Zuge der Kämpfe auf der iberischen Halbinsel gegen die napoleonischen Truppen (1808-1813) Eingang in die deutsche Sprache und wurde in der 2. Hälfte des 20. Jahrhunderts vor allem aufgrund zahlreicher Guerilla-Bewegungen in Mittel- und Lateinamerika erneut gebräuchlich. 
Rezeption als ein Krieg der Unzivilisierten, der Wilden, erleichterte es aber zugleich auch, die Prinzipien der Kleinkriegführung als Steinbruch für neue Konzeptionen der Streitkräfte zu nutzen. Nötig wurden innovative Konzepte in dem Moment, als die Armee nicht länger ausschließlich ein Instrument in den Händen der Fürsten zur Verfolgung dynastischer Herrschaftsansprüche sein konnte. Ohne eine >Mobilisierung der Leidenschaften`, ohne ein bis dahin im >großen « Krieg nicht gewolltes Engagement der Soldaten, ohne ihre Einbeziehung als aktiv Handelnde, waren nach der Französischen Revolution in Europa keine Kriege mehr zu gewinnen.

\subsection{Transformationen und Kontinuitäten}

Dass die Lineartaktik Schwächen aufwies, wurde schon im 18. Jahrhundert gesehen. Es fehlte deshalb auch nicht an Kritik und Vorschlägen, wie ihre Mängel zu beheben seien. Anstöße für Veränderungen der dominanten Einsatzkonzeption speisten sich aus sehr unterschiedlichen Quellen. In Frankreich trieben die Niederlagen im Siebenjährigen Krieg gegen das preußische Heer zahlreiche Reformmaßnahmen voran. Weitere Anstöße kamen von den Erfahrungen, die in den Kämpfen auf dem nordamerikanischen Kontinent gemacht wurden. So hatten die britischen Truppen vor allem aus dem britisch-französischen Krieg zwischen 1754 und 1763 und dem Unabhängigkeitskrieg (1776-1783) die Konsequenz gezogen, ihre Truppen nur noch in zwei und nicht wie sonst üblich in drei Reihen in Linie aufzustellen. Auch wurde der Abstand zwischen den Soldaten, die nebeneinander und hintereinander standen, vergrößert, damit die so gruppierten Soldaten im ansonsten unwegsamen Gelände vorrücken konnten. Die Entscheidung zur Auflockerung der Formation wurde auf dem nordamerikanischen Kriegsschauplatz dadurch erleichtert, dass hier keine Attacken schwerer Reiterei zu erwarten waren. Obendrein wurden ungewöhnlich häufig in Linie kämpfende Verbände mit leichten Truppen zusammen eingesetzt (Möbius 2004b). Durch die häufige Kombination leichter Truppen mit Linienverbänden machten die britischen Truppen und insbesondere deren Offiziere intensive Erfahrungen, wie die Lineartaktik flexibilisiert werden kann, was aber bis auf Ausnahmen, wie die der hessischen Verbündeten, vorerst keine Auswirkungen auf die Kriegspraktiken auf dem europäischen Kontinent hatte. ${ }^{15}$

Ähnlich folgenlos für die Einsatzkonzeptionen auf dem Kontinent blieb auch die eigenständige Rolle, die der kleine Krieg im Kampf der Siedler gegen die britischen Truppen und ihre Verbündeten spielte. Eigen-

$15 \mathrm{Zu}$ den hessischen Söldnern, siehe Möbius: 2004b; Regling schreibt, dass die europäischen Offiziere, die aus den USA zurückkehrten, aufgrund ihrer Erfahrungen sich später für Militärreformen aufgeschlossen zeigten. Sie gehörten oft der leichten Infanterie an (1979: 155). 
ständig war der Kleinkrieg, weil er nicht bzw. nur in Teilen in den Kampf der Linientruppen eingebettet war. Die Operationen dieses Kleinkrieges wurden überwiegend von Akteuren ausgeführt, die nicht dem militärischen Oberkommando der Continental Army unterstanden. Sie rekrutierten sich aus lokalen Milizen, die von den Kolonisten als Selbstschutz gegen Angriffe von Eingeborenen und im Zuge des Britisch-Französischen Krieges gegen französische Truppen aus Kanada organisiert wurden. Die Milizen bildeten in der Fläche der zukünftigen Bundesstaaten das Rückgrat des militärischen Widerstandes gegen die britischen Truppen. Als lokale Milizangehörige gehörten sie nicht zur Militärorganisation des Bundeskongresses. Sie ließen sich deshalb nicht oder nur sehr schwer durch Aufträge und Weisungen von Seiten der Continental Army in die militärischen Planungen einbinden, was zu entsprechenden Klagen über Disziplinlosigkeit und Insubordination führte. Trotz der ersten Erfolge der Milizverbände gegen britische Truppen, die viel Aufmerksamkeit auf sich zogen, hatten sie auf die konzeptionellen Überlegungen zum europäischen Militär allenfalls einen geringen Einfluss, weil der Erfolg der nordamerikanischen Siedler sich auf die hier herrschenden besonderen Bedingungen des Kriegsschauplatzes zurückführen ließ. Hierzu gehörte, dass es den Siedlern möglich war, sich aus den Städten an der Küste vor der überlegenen britischen Streitmacht zurückzuziehen und den Kampf im unwegsamen Landesinneren fortzusetzen. Die Annahme, diese Form des Kleinkrieges sei für die europäischen Kriege irrelevant, wurde durch die Wahrnehmung Nordamerikas als einem >zivilisationsfernen ‘ Land begünstigt. Der hier praktizierte Kleinkrieg und damit enthegte Kriegszustand erlaube deshalb, so die Argumentation, keine Rückschlüsse für das zivilisierte Europa (Regling 1979: 154). Ein weiterer Grund, dem Kleinkrieg nicht viel Aufmerksamkeit zu widmen, ist in dem Umstand zu sehen, dass der Unabhängigkeitskrieg am Ende durch eine Belagerung und durch Gefechte zwischen den englischen Truppen und der Continental Army und ihren französischen Verbündeten entschieden wurde (Yorktown 1781). Im Übrigen entsprach die geringe Beachtung, die der Kleinkrieg in Europa erfuhr auch dem Interesse der politischen Führung der USA. Sie stand ihm von Beginn an selber skeptisch bis ablehnend gegenüber, weil sie sich von ihm keinen Erfolg gegen die britischen Kolonialtruppen versprach und fürchtete, er könne ein Hindernis für die Anerkennung durch die europäischen Staaten sein. Es gehörte auch nicht zum Selbstverständnis der militärischen Führung, den Gegner in einen Abnutzungskrieg $\mathrm{zu}$ verwickeln und $\mathrm{zu}$ schwächen, auch wenn George Washington (1732-1799) widerstrebend einsah, »dass die Partisanen ihn [Washington, d.A.] wesentlich entlasteten und dem Unabhängigkeitskampf stets neue Kräfte und Impulse zuführten.« (Schmidt 2003: 170) Nach dem Krieg erschien es ebenfalls wenig opportun, die Bedeutung des Kleinkrieges für die Unabhängigkeit zu betonen, hatte er doch in weiten Teilen des Landes zu bürgerkriegsähnlichen Ver- 
hältnissen mit zahlreichen Gewaltexzessen geführt und seine Spuren in der politischen Kultur hinterlassen. So waren in den 80er Jahren viele ehemalige Milizionäre an agrarischen Sozialbewegungen beteiligt, die ihrem Protest mit Waffengewalt Ausdruck verliehen (siehe Schmidt 2003: 171; Krippendorff 1985: 97f.).

Die Continental Army, die »für die Zeitgenossen der sichtbare Ausdruck des Unabhängigkeitswillens der Nordamerikaner« (Wohlfeil 1964: 35) war, unterstand dem Bundeskongress. Ihre Hauptstreitkräfte sollten aus Linientruppen bestehen. Hierzu wurden Rekruten angeworben, die sich dauerhaft zum Kriegsdienst, das bedeutete »auf drei Jahre oder Kriegszeit«, verpflichteten.

»Man verließ sich nicht nur auf das patriotische Gefühl, sondern zahlte einen hohen Sold und versprach den neuen Liniensoldaten, sie nach dem Kriege mit beachtenswertem Landbesitz zu belohnen. [...] Kongress und militärische Oberbefehlshaber mussten sich der antiabsolutistischen Haltung der Bürger beugen und sich bemühen, die unumgänglichen militärisch-technischen und taktischen Erfordernisse für den Kampf gegen eine intakte Linienarmee mit dem rationalen und materiellen Denken der Masse der Siedler zu verbinden.« (Wohlfeil 1964: 34)

$\mathrm{Zu}$ den militärisch-technischen und taktischen Erfordernissen gehörte die Formierung der Truppe zu einem geschlossenen Verband, der nicht auseinander lief, wenn er von gegnerischen Linientruppen angegriffen wurde und der dazu in Lage war, selber in Linie formierte Gegner vom Schlachtfeld zu vertreiben. Dazu mussten die Soldaten der Linientruppen des Bundeskongresses zumindest über ähnliche Eigenschaften wie ihre Gegner verfügen. Die nordamerikanischen Liniensoldaten hatten im Grunde die gleichen Gewehre wie ihre Kontrahenten und sie sollten auch ähnlich gedrillt werden. Obwohl in der Literatur immer wieder der Hinweis zu finden ist, dass das Ausbildungsreglement der Continental Army von einem ehemaligen preußischen Offizier verfasst wurde, Friedrich Wilhelm von Steuben (1730-1794), der auf eine lange preußische Militärkarriere zurückschauen konnte ${ }^{16}$ und der der Armee preußische Disziplin beigebracht habe, ließen sich die Rekruten wohl nicht nach den in Europa vorherrschenden Vorstellungen drillen. 〉Preußischeく Disziplin konnte er jedenfalls nicht durchsetzen. Zur Ausbildungsgrundlage wurde das Reglement erst, nachdem von Steuben eine Kompanie Freiwilliger persönlich ausgebildet hatte und dieser Verband entscheidend zum Sieg der Continental Army in einer Schlacht beitrug. Nach diesem Erfolg wurde von Steuben zum Gene-

16 Als er sich in Frankreich für die Bundesarmee anwerben ließ, war diese Karriere in Preußen allerdings schon lange beendet. Im Siebenjährigen Krieg war er unter anderen einem Freibataillon zugeteilt gewesen. 
ralinspekteur berufen und ihm die Verantwortung unter anderem für die Ausbildung der Truppe übertragen. ${ }^{17}$

$\mathrm{Zu}$ den Anpassungen, die die US-Offiziere vollziehen mussten, um die Rekruten zu drillen, gehörte, dass sie auf ihre Untergebenen in einem für sie unbekannten Ausmaß einzugehen hatten, um sie von der Notwendigkeit ihrer Unterweisungen zu überzeugen. Zumindest ist dies der Eindruck, der entsteht, wenn man die Klage von Steubens liest, die er an den preußischen General Gaudi (1725-1788) Jahre nach dem Krieg richtete. Er solle nicht glauben, »dass in unserer Armee [gemeint ist die Continental Army, d.A.] die preußische Elementarschule, Kriegsbildung, Taktik und Mannszucht in allen Theilen von mir eingeführt worden sey. Wenn ich es versucht hätte, würde man mich gesteinigt haben, und ich wäre doch nicht damit zustande gekommen.« Er möchte nicht, dass dem preußischen General das Reglement je in die Hände falle, weil es zu sehr wider seine Absichten und zu sehr seiner »eigenthümlichen Lage« geschuldet sei. Den Amerikanern fehle der »kriegerische Geist«, den man von den Soldaten in Preußen, Österreich oder Frankreich erwarten könne, der sich darin äußere, dass man zu ihnen sage könne: »Mache das! Und er machts. Dem meinigen musste ich dagegen zuerst sagen: Dies und das ist der Grund, warum Du dieses oder jenes machen sollst, und dann erst machte ers. « (Brief an General Friedrich Wilhelm von Gaudi, zitiert nach Jähns 1891: 2606f.) Als vorbildhaft für die Zukunft sah von Steuben sein Reglement also selber nicht an. Die Einsichtsfähigkeit der Soldaten zu berücksichtigen, der Zwang, ihnen die Gründe für seine Anweisungen darzulegen, missfiel ihm und geschah nur, weil er fürchtete, dass ansonsten die Ausführung der Befehle verweigert würde. Für ihn war weiterhin der widerspruchslose, sofortige und deshalb automatische Vollzug eines erteilten Befehls das Kennzeichen einer >kriegerischen Gesinnung wie ein Soldat zu handeln habe, war vermutlich am Ausgang des 18. Jahrhunderts die vorherrschende Einstellung hochrangiger Offiziere, weshalb

17 Sein Reglement orientierte sich weniger an dem damals gültigen preußischen, sondern griff aus Frankreich stammende Verbesserungsvorschläge an der Lineartaktik auf, die später auch von der französischen Revolutionsarmee übernommen wurden. Sie zielten auf eine Dynamisierung und größere Variabilität der Bewegungsabläufe. »Statt fester Abläufe exerzierten die Soldaten bestimmte Bewegungen wie Marschieren und Wenden und die erforderlichen Griffe zum Laden und Feuern in der Weise, dass sie sie jederzeit und unabhängig von einem bestimmten Handlungsablauf, je nach Befehl, ausführen konnten. An die Stelle komplizierter, vorgeplanter Handlungsabläufe traten somit Einzelhandlungen als individuelle Versatzstücke, die nach Bedarf in unterschiedlicher Weise zu variablen Handlungsabläufen komponiert werden konnten. Diese Variabilität wiederum erweiterte die Möglichkeiten zur Gestaltung der Schlachtabläufe unter Berücksichtigung der aktuellen Lage und der Konzeption wie auch die Anwendung unkonventioneller Strategien und nicht-regelkonformer Taktiken auch und gerade durch reguläre Einheiten«. (Kleinschmidt 1996: 66) 
auch viele Bestrebungen, die Einsatzkonzeptionen so zu ändern, dass sie der individuellen Subjektivität einen größeren Raum zur Entfaltung gewährten, an ihnen scheiterten bzw. nur in Teilen umgesetzt wurden. Erst die Französische Revolution schuf die politischen, wie die sozialen Voraussetzungen für einen Wandel der taktischen Einsatzkonzeption in Frankreich und später dann bei den anderen europäischen Armeen.

Eine augenfällige Abweichung in der Gefechtsweise der französischen Revolutionstruppen wurde durch die Auflösung des Gegensatzes von geschlossener Formation und aufgelöster Gefechtsweise markiert. Die Koalitionstruppen begegneten nach 1793, dem Jahr, in dem die leveé en masse ausgerufen wurde, keinen französischen Linientruppen mehr, die ihnen ausschließlich in geschlossener Formation gegenübertraten, vielmehr sonderten sich aus den Verbänden Gruppen ab, die so genannte Schützenschwärme bildeten und die die Linientruppen angriffen. Dieses Phänomen ergab sich nicht aus einem geänderten Reglement. In der Literatur herrscht Einigkeit darüber, dass das Tiraillieren sich aus dem geringen Ausbildungsstand der schnell rekrutierten und eingesetzten Soldaten und ihrer großen Bereitschaft, in Gruppen oder auch Einzeln den Gegner zu attackieren, ergab. Es handelt sich anfangs um eine improvisierte Gefechtsweise. Sie oszillierte zwischen Angriff und Rückzug. ${ }^{18}$ Die Soldaten griffen auf diese Weise die gegnerischen Linien wiederholt an und wurden dabei zugleich von den hinter ihnen stehenden Verbänden solange verstärkt, »dass von dem Bestand der Bataillone gelegentlich nur noch die Fahnensektion übrig blieb.« (Jähns 1891: 2597) Vor allem für die Improvisationsphase gilt, dass es unklar war, was geschehen sollte, wenn ein auf diese Weise geführter Angriff scheiterte. Es gab noch keine Regeln, um mit einer solchen Krise umzugehen. Dass sollte sich zwar bald ändern, doch es bestand weiterhin die Gefahr, dass die Soldaten >nach vorne durchgingen`, dass also die Befehlshaber der Verbände die Kontrolle über die im Gefecht verwickelten Soldaten und Truppenoffiziere verloren und nicht mehr in das Geschehen dirigierend eingreifen konnten. Selbst nachdem Regeln für die Vorgehensweise der Schützenschwärme gefunden wurden, blieb es für die Befehlshaber schwierig, das Kampfgeschehen zu steuern. Es hing vom Ausbildungsstand der Soldaten und der Offiziere ab, wie gut das Vorgehen der Schützenschwärme koordiniert werden konnte: Ob sich ein Rückzug in einer Flucht verwandelte und die Soldaten ihre Angriffsrichtung änderten. Dieses Problem sollte sich Jahrzehnte später noch steigern, weil die zerstreute Gefechtsweise zunehmend bedeutete, dass sich der Abstand zwischen den Soldaten vergrößerte. Im ausgehenden 18. Jahrhundert war der Abstand zwischen den Tirailleuren aber noch relativ gering. Sie blie-

18 Den schnellen Wechsel zwischen Angriff und Deckungssuchen bzw. Rückzug sollte wohl auch die Bezeichnung Tiraillieren benennen. Das französische tiraillement bezeichnet heute noch das Hin- und Herzerren, beispielsweise beim Tauziehen. 
ben meist in Sicht- und Rufkontakt zu einander und zu den sie begleitenden Offizieren. Die einzelnen Bewegungen der Soldaten ließen sich jedoch nicht durch Kommandos steuern und ein normabweichendes Handeln, insbesondere eine verdeckte Verweigerung, weiter nach vorne zu gehen, hatte gute Chancen, unentdeckt zu bleiben, weil ein Offizier nur die Soldaten kontrollieren und zur Ausführung seiner Befehle anhalten konnte, die sich in seiner unmittelbaren Nähe befanden. Die verringerte Chance, das Handeln der Untergebenen erfolgversprechend kontrollieren und dirigieren $\mathrm{zu}$ können, gekoppelt mit der größeren Angewiesenheit auf die individuelle Bereitschaft der Soldaten zum Kampf, - was auch einschließt, dass sie untereinander darauf achteten, das sich keiner aus dem Kampf zurückzieht - bildete die Quelle, aus denen sich die Vorbehalte von Offizieren gegen diese Gefechtsform bis in das 20. Jahrhundert speisten. Die Vorbehalte sind von der Sehnsucht nach einer Rückkehr zu einer umfassenden Kontrolle über die Untergebenen bestimmt und der Skepsis, den Soldaten während eines Gefechtes noch Befehle geben zu können.

Die Gefechtsweise der französischen Tirailleure erzielte indes »hervorragende Erfolge, aber die Überraschung und Bestürzung [auf Seiten der Koalitionstruppen, d.A.], die sie anfänglich verursachten, nutzten sich ab.« (Regling 1979: 203) Die Koalitionstruppen lernten, den Angriffen standzuhalten, und entwickelten ihrerseits eine Taktik, um den Angriffschwung der Tirailleure zu brechen, in dem sie ein Treffen, also eine Linie, vor das 2. Treffen setzten. Erst im 2. Treffen befanden sich die Hauptstreitkräfte, die geschlossen und in Linie gegen die Tirailleure vorgehen sollten und denen es wohl auch in der Regel gelang, sie zu vertreiben (siehe Jähns 1891: 2597). Der anhaltende Erfolg geschlossener Verbände gegen auch mit Enthusiasmus kämpfende Tirailleure hatte seinen Grund: Verantwortlich für die anhaltend überlegene Kampfkraft geschlossener Verbände war die Bewaffnung der Tirailleure mit Vorderladergewehren, die, weil sie nach jedem Schuss neu geladen werden mussten, nicht so viele Schüsse auf die Gegner abfeuern konnten, dass die anrückenden geschlossenen Verbände aufgrund zahlreicher Verwundeter und Toter `zerfielen`.

Der Schützenschwarm konnte deshalb nicht die einzige Gefechtsweise bleiben, mit denen die französischen Truppen gegen die in geschlossener Formation antretenden Verbände der Koalitionsstreitkräfte kämpften. Sie mussten ihrerseits geschlossene Formationen bilden. Da die ungeübten Soldaten der Revolutionstruppen aber keine Linien bilden konnten, bildeten die Tirailleure entweder so genannte Kolonnen bzw. zogen sich auf Positionen zurück, an denen viele Soldaten in kompakten Verbänden beieinander waren. Im Laufe des 18. Jahrhunderts waren verschiedene Varianten von Kolonnen im Rahmen von Gefechtsübungen getestet, jedoch ebenso häufig als Gefechtsformationen verworfen worden (Regling 1979: 161f.). Nur als regelwidrige Ausnahmeerscheinung kämpften Soldaten deshalb auch schon vor den Koalitionskriegen aus einer Kolonne 
heraus auf dem Schlachtfeld. Dies geschah immer dann, wenn es den Soldaten, die in Kolonnen marschierten und sich auf diese Weise dem Schlachtfeld näherten, nicht mehr gelang - aus welchen Gründen auch immer - vor der Begegnung mit den Kontrahenten ihre Formation zur Linie auszudünnen. Neu war deshalb an der französischen Kolonnentaktik im Grunde nur, dass die Soldaten eine kompakte Formation aus mehreren Reihen hintereinander grundsätzlich auch im Moment des Angriffs auf dem Schlachtfeld beibehielten. Die Schützenschwärme und die Kolonnentaktik waren beide das Ergebnis praktischer Improvisation, mit der auf die Herausforderung reagiert wurde, wie man mit ungeübten Truppen gegen gedrillte Linientruppen kämpfen kann (siehe Wohlfeil 1964: 171f.). Die Umgestaltung einer Marsch- zu einer Angriffskolonne war für die ungeübten französischen Soldaten ungleich einfacher durchzuführen. ${ }^{19}$ Sie bot den Vorteil für die Truppenoffiziere, dass sich die Formation leichter strukturieren ließ und sie auch nicht gleich zerbrach, wenn die Reihen der Kolonne durcheinander gerieten. Die Verbände konnten in der Kolonnenformation deshalb auch leichter als die Linie ein mit Hindernissen durchzogenes Gelände durchschreiten und waren darum beweglicher und schneller als in Linie formierte Verbände. Diese Schnelligkeit sollte wiederum einen entscheidenden Vorteil in dem Moment sein, als es galt, im Laufe eines Gefechts Truppenbewegungen auszuführen, um an einem für den Gegner möglicherweise unerwarteten Punkt die eigenen Kräfte zu konzentrieren und die Verbände des Gegners durch diese Schwerpunktbildung zu schlagen.

Durch die Kolonnentaktik entstanden Lücken zwischen den Verbänden und in diese Lücken konnten sich nicht nur die Tirailleure zurückziehen, sondern die Lücken schufen auch Raum für ein zuvor unbekanntes Ausmaß an Flexibilität für die Artillerie. Im Rahmen der Lineartaktik verharrten die Geschütze während einer Schlacht meist nicht nur wegen ihrem Gewicht an einer zuvor festgelegten Position. Ihre feste Position ergab sich auch durch das Prinzip, dass die einmal zum Einsatz gebrachten Verbände in ununterbrochenen Linien formiert waren und es keine Unterbrechungen geben sollte. Nun konnte auch im Laufe einer Schlacht die Artillerie ihre Stellung wechseln und Position zwischen zwei Kolonnen beziehen.

Die Kolonnentaktik bot allerdings nicht nur Vorteile. Ein gravierender Nachteil der Kolonne gegenüber der Linie war, dass ein großer Teil der in ihr formierten Soldaten nicht ihre Gewehre einsetzen konnten. Die gleiche Anzahl der Soldaten entwickelten folglich, wenn sie in der Kolonne for-

19 Eine gewisse Transformation war notwendig, weil die Formation für das Gefecht zwar mehrere Glieder tief stand, aber die Aufstellung zu den gegnerischen Verbänden hin breiter war. Die Kolonne als Gefechtsformation muss man sich also ein Rechteck vorstellen dessen eine längere Seite auf die Gegner hin ausgerichtet war. 
miert waren, eine wesentlich geringere Feuerkraft, als wenn sie in Linien aufgestellt waren. Zugleich waren sie in der Kolonne noch leichter zu beschießende Ziele. Dies galt insbesondere für die Artillerie, die nun mit jedem Schuss mehr Soldaten verletzen und töten konnte. »Aus diesem Grunde«, so Regling, »empfahl sich die Kolonnentaktik für die immer noch verhältnismäßig kleinen stehenden Söldnerheeren zur Zeit des Absolutismus nicht« (1979: 168), sondern erst für die wesentlich größeren und weniger intensiv ausgebildeten Soldaten und damit auch leichter ersetzbaren Wehrpflichtheere des 19. Jahrhunderts.

Erfolgreich konnte die Kolonnentaktik mit dem Schützenschwarm nur kombiniert werden, weil zumindest ein großer Teil der Soldaten zuverlässig und mit Engagement die Gegner bekämpfte. Da das Handeln der Soldaten als Tirailleure nicht im Detail durch Kommandos dirigiert werden konnte, entstand für sie eine offene Handlungssituation, die sie mit Eigeninitiative zu füllen hatten. Eine ähnliche Vergrößerung des Handlungsspielraums ist auch für die Truppenoffiziere festzustellen, die das Kommando über eine Kolonne innehatten. Der Vorteil der Kolonnentaktik, schneller auch schlecht begehbares Terrain zu durchqueren, ließ sich dann zur Erzeugung einer größeren Dynamik nutzen, wenn auch diese Truppenoffiziere der Infanterie, ohne auf weitere detaillierte Instruktionen des Oberbefehlshabers zu warten, auf eine vorgefundene Situation reagierten und beispielsweise selber entschieden, wie sie ein bestimmtes Terrain am besten durchqueren. Wie groß ihre Freiheit zur Improvisation war, hing entscheidend von der Frage ab, wie ihre Fähigkeit eingestuft wurde, bei aller Improvisation nicht der >allgemeinen Befehlslage « zuwider zu handeln oder wie stark das Kontrollbedürfnis der Vorgesetzten gegenüber ihren Untergebenen war (siehe hierzu auch Abschnitt 7.1.).

Die kontinentalen Gegner der napoleonischen Herrschaft in Westeuropa verstanden es im Laufe einiger Jahre, ihrerseits Leidenschaften gegen die napoleonische Herrschaft zu mobilisieren. Sie konnten sich dabei auf den Unwillen in der Bevölkerung beziehen, den die zahlreichen Pressionen im napoleonischen Machtbereich auslösten, und die wiederum ihre Gründe nicht zuletzt in den unaufhörlichen Kriegszügen des Kaiserreichs hatten. Gleichzeitig veranlassten sie mehrere Reformen, um die Motivation der Soldaten zu erhöhen.

$\mathrm{Zu}$ den spezifischen militärischen Reformen in Preußen gehörten die Einschränkung der Prügelstrafe und die Abschaffung des Spießrutenlaufes (1808). Damit sollte auf solche als entehrend angesehenen Strafen verzichtet werden, die das Ansehen von Soldaten insbesondere im Bürgertum herabsetzten (Gneisenau 1808: 98). Die Reform glich »die Erziehungshilfen und die Militärstrafen dem bürgerlichen Rechtsempfinden an, da sie davon ausgingen, dass jeder Soldat eine persönliche Ehre besitze.« (Wohlfeil 1966: 132f.) An die Stelle des Prügelns traten eine Reihe von Sonderdiensten, wie die Einteilung zu Strafwachen sowie die Verhängung 
eines dreistufigen Systems von Arreststrafen. Ziel der Reform war es, »auch die Söhne des gebildeten und besitzenden Bürgertums zu den Waffen« (Bröckling 1997: 115) einzuberufen, ohne dass sie sich durch die Heranziehung der Gefahr ausgesetzt sahen, entehrt zu werden. Auch für sie könne der Dienst als Soldat zu einer ehrenvollen Verpflichtung werden, so Gneisenau, wenn sie sich zukünftig nicht mit einem Strafsystem konfrontiert sehen, dass für »rohere Naturen und für ein roheres Zeitalter geschaffen worden war«. Es galt die »wohlerzogene[n] junge[n] Männer vor der Möglichkeit zu schützen, von übel wollenden Vorgesetzten misshandelt zu werden« (1808: 98).

Eine andere Maßnahme, die die individuelle Einsatzbereitschaft im Kampf erhöhen sollte, betraf die Neubewertung des Verhaltens vom Soldaten im Kampf. Für den Kampf der geschlossenen Formationen - ob Linie oder Kolonne - blieben die Tugenden gültig, die im Rahmen der Lineartaktik gepflegt wurden. Für den Kampf in der zerstreuten Ordnung wurden dagegen andere Tugenden wichtiger. Ausharren, ertragen und mitmachen reichte für die Einsatzanforderungen der Schützen nicht. Hier waren obendrein Eigeninitiative, Geschicklichkeit bei der Ausnutzung des Geländes und vielleicht auch Einfallsreichtum, vor allem aber die individuelle Bereitschaft gefordert, sich aus eigenem Entschluss heraus in gefährliche Situationen zu begeben bzw. sie aufgrund des eigenen Handelns erst zu schaffen. Unter den Vorzeichen der Lineartaktik beschränkten sich die Gelegenheiten zu solch einem Handeln von Soldaten auf Randphänomene des Kriegsgeschehens. $\mathrm{Zu}$ denken ist dabei an den kleinen Krieg oder, wenn ein Soldat bei der Erstürmung einer Befestigungsanlage als erster eine gegnerische Schanze überwand. Mit der Implementierung des Tirallierens in den >großen Krieg wurden diese Gelegenheiten nicht nur zahlreicher, mindestens genauso wichtig war, dass solche Handlungen eine höhere Wertschätzung erfuhren und die Soldaten zu solch einem Handeln motiviert werden sollten. Signifikanter Ausdruck dieser höheren Wertschätzung war, dass erstmals mit der Französischen Revolution Tapferkeitsmedaillen geschaffen wurden, die auch an Soldaten im Mannschaftsrang vergeben wurden. Zuvor erhielten Soldaten im Mannschaftsdienstgrad, wenn überhaupt, Geldgeschenke, selten wurden sie auch befördert. Geldgeschenke und Beförderungen wurden auch den Offizieren gewährt. Militärische Auszeichnungen dagegen blieben vornehmlich ranghohen Offizieren vorbehalten. Mit so genannten Hausorden wurden nur adlige Offiziere ausgezeichnet, weil sie ihre Träger dem Herrscherhaus nahe rückten, was sie zur besonderen Treue verpflichten sollte, wie das bei der Verleihung des Schwarzen-Adler-Ordens (Preußen) der Fall war. Nicht weniger exklusiv war die Auszeichnung mit einem Ritterorden. Der so Prämierte wurde nicht nur mit einem öffentlich zu tragenden Insignium ausgestattete, er wurde zugleich in einen weltlichen Ritterorden aufgenommen, der dem amtierenden Herrscherhaus verpflichtet war. Erst mit 
den im 17. und vor allem im 18. Jahrhundert geschaffenen militärischen Verdienstorden wurde die Möglichkeit geschaffen, auch bürgerliche Offiziere auszuzeichnen. So stiegen nicht dem Adel angehörende Offiziere, die den österreichischen Maria-Theresa-Orden erhielten, durch die Verleihung automatisch in den Adelstand, genauer gesagt in den Ritterstand, auf. ${ }^{20}$ Dem Beispiel des französischen Auszeichnungswesens folgend, vergrößerten deren Kriegsgegner ab den 90er Jahren des 18. Jahrhunderts den Kreis der Auszuzeichnenden entschieden. In Preußen wurde erstmals 1813 mit dem Eisernen Kreuz ein Verdienst- und Erinnerungszeichen geschaffen, das prinzipiell niemanden aufgrund seiner sozialen Herkunft, konfessionellen Bindung oder militärischen Ranges von der Verleihung ausschloss. Das einzige Kriterium, das der Vergabe zugrunde gelegt wurde, waren besondere individuelle Einzelleistungen im Kampf. Die Aussicht, mit einem Eisernen Kreuz ausgezeichnet zu werden, sollte vor allem Soldaten im Mannschaftsdienstgrad und niedrigrangige Offizieren ${ }^{21}$ zur höheren Einsatzbereitschaft motivieren, also zu einem Handeln, das für sie mit größeren Gefahren verbunden war, verletzt und getötet zu werden. Und in den Kirchen sollten >Ehrentafeln` angebracht werden, die alle Getöteten, die zur Gemeinde gehörten, namentlich aufführten. An erster Stelle seien, so legte der königliche Erlass fest, jene >Krieger〈 zu nennen, die »den Tod für das Vaterland in Ausübung einer Heldenthat« gefunden hatten (zitiert nach Hagemann 2002: 498).

Doch trotz aller Bemühungen, unter den Soldaten eine >kriegerische Gesinnung«(Scharnhorst) zu entfachen, kam auch diese Mobilisierung, ähnlich wie dies auch für Frankreich gilt, ${ }^{22}$ nicht ohne Zwangsrekrutierungen aus. Gleichermaßen gilt, dass sich die Fluchtversuche von Soldaten bei den reformierten Heeren bei Rückzügen, aber auch vor dem Höhepunkt des später als $>$ Befreiungskrieg ${ }^{23}$ verbrämten Kriegsgeschehens, der so genannten Völkerschlacht bei Leipzig (1813), häuften. Sie deuten darauf hin, so Sikora, dass »die Einheiten noch wenig stabil gewesen sein dürften, [...] [und] dass der Enthusiasmus offenbar in vielen Fällen die Konfrontation mit den Kriegsbelastungen nicht überstand.« (1996: 361) ${ }^{24}$

20 Zur Geschichte des Auszeichnungswesens siehe Merta. Hinweise auf Geldgeschenke an preußische Soldaten und Offiziere im Siebenjährigen Krieg, beispielsweise für eroberte Kanonen, sind in Möbius (2004: 339f.) zu finden.

21 Für Oberbefehlshaber einer Armee war das so genannte Großkreuz geschaffen worden, das für eine gewonnene Schlacht und ähnliches verliehen wurde. Darüber hinaus wurden in Preußen auch noch »Ehrenzeichen« an alle Kriegsteilnehmer verliehen (Hagemann 2002: 451f.).

22 Über den Anteil der französischen Deserteure und Verweigerer zwischen 1793 und 1815 informiert Sikora (1996: 359f.).

23 Zur mythischen Aufladung der Kriegszüge zwischen 1813 und 1815 siehe u.a. Wehler (Bd. 1, 1987: 525f.)

24 Beim Freiwilligen-Verband des Lützowschen Korps scheint die Begeisterung sogar besonders rasch nachgelassen zu haben. Dass dieser Verband eine überdurchschnittliche Desertionsquote aufwies, bei der Infanterie desertier- 
Die Kolonnentaktik und der Schützenschwarm wurden im Laufe der Koalitionskriege bzw. der Napoleonischen Kriege von allen Kriegsparteien mehr oder weniger übernommen. ${ }^{25}$ In den europäischen Armeen wurden unterschiedliche Organisationsstrukturen entwickelt, damit die Verbände als geschlossene Formation kämpfen und ein Teil der Soldaten einen Schützenschwarm bilden konnten. So gliederte das preußische Heer seine Infanteriebataillone bis zum Deutsch-Französischen Krieg (1870-1871) derart, dass ein Teil der Infanteristen als Schützen einen Schwarm bildeten, der der übrigen Einheit voranschritt und dem die anderen Soldaten in der geschlossenen Formation der Kolonne folgten (eine ausführliche Beschreibung der Organisationsstruktur findet sich unter anderem bei Walter 2003: 147f.). Insbesondere die britischen Truppen hielten sogar noch bis zum Ende des 19. Jahrhunderts an der geschlossenen Formation der Linie fest. Spezielle leichte Truppen, die als Eliteeinheiten angesehen wurden, gab es immer noch, doch galt nun die Gefechtsweise der Tirailleure als ein wichtiger Bestandteil des >großen`Krieges, und sie sollte immer mehr zum Bestandteil der Ausbildung aller Infanteristen werden.

Der Drill verschwand also aus der Ausbildung der Rekruten nicht. Sowohl beim Hantieren mit der Waffe als auch für die Bewegung in geschlossenen Formationen waren exakt auszuführende Bewegungsabläufe einzuhalten. Noch in den 50er Jahren des 19. Jahrhunderts, so die Klage des preußischen Offiziers und Militärschriftstellers Wilhelm Rüstow (1821-1878), wurde die Leistung eines Vorgesetzten nicht nach der Leis-

ten über 24 Prozent der Soldaten - ansonsten entfernten sich ein bis fünf Prozent der Freiwilligen von den preußischen Truppenverbänden zwischen 1813 und 1815 (Bröckling 1997: 125) -, hing wohl aber damit zusammen, dass viele Freiwillige nicht aus Preußen stammten und ihnen als Ausländer eine Flucht leichter fiel als Einheimischen. Sie mussten im Gegensatz zu Einheimischen nicht damit rechnen, dass sich Strafverfolgungsbehörden an ihre Angehörigen wenden, wenn sie desertieren, um sich nach ihrem Verbleib zu erkundigen und ihnen mit formellen oder informellen Sanktionen zu drohen. Dass es einen Zusammenhang zwischen Sanktionsmöglichkeiten und Desertionsneigung gibt, zeigt die Verweigerungsquote in Frankreich an. Sie war in den Gebieten am höchsten, wo noch »traditionelle Lebensformen kleiner Dorfgemeinschaften, unberührt von den politischen Machtzentren« (Sikora 1996: 360) vorherrschten und es noch zahlreiche Versteckmöglichkeiten gab. Weitere Informationen zu Desertionen aus anderen Armeen als der preußischen und französischen zwischen 1792 und 1815 finden sich in Sikora (1998).

25 Vor allem gegen das Tiraillieren waren große Widerstände zu überwinden. In einen um die Jahrhundertwende anonym erschienenen Aufsatz, wird beispielsweise das Tiraillieren als eine »dem Erhaltungsinstinkt in uns am allermeisten« entsprechende Fechtart eingestuft. Da aber der Krieg entgegen der »menschlichen Natur" sei, mache das Tiraillieren die Soldaten »unkriegerisch«. Der Soldat lerne die Gefahr geschickt zu vermeiden, aber nicht zu verachten und Linientruppen würden deshalb durch das Tiraillieren verdorben (zitiert nach Jähns 1891: 2555f.). 
tung seiner Truppe im Schützengefecht beurteilt, sondern nach der Tüchtigkeit im Linienexerzieren. »Der Rekrut wird wie vor 50 Jahren nur als Exercier-Maschine ausgebildet« (zitiert nach Storz 2003: 224). Das Festhalten an der geschlossenen Formation als taktische Einsatzform im Gefecht wurde mit dem Hinweis auf verschiedene Gefechte begründet, in denen die gegnerische Formation zerbrach und die Soldaten flohen, wenn es dem vorrückenden geschlossenen Verband gelang, sie mit dem aufgepflanzten Bajonett anzugreifen. Die Waffenwirkung der Gewehre hatte sich zwar bereits in der 1. Hälfte des 19. Jahrhundert verbessert, doch vertraten weiterhin einige Militärtheoretiker und -praktiker die Einschätzung, dass ein Angriff in geschlossener Formation immer noch erfolgreich durchgeführt werden könne, wenn der Bajonettangriff mit großer Geschwindigkeit vorgetragen wird, weil dann der Feuerbereich der gegnerischen Waffen schnell überwunden und die Soldaten nicht sehr lange der todbringenden Waffenwirkung ausgesetzt seien. Bereits aber in den 60er Jahren verlor diese Argumentation mit den ständigen Verbesserungen der Waffentechnik entschieden an Plausibilität, da der Raum, in dem die Waffen ihre Wirkung entfalten konnten, immer größer wurde und die Gewehre pro Zeiteinheit immer mehr Geschosse abfeuern konnten.

Attraktiv blieb diese Argumentation noch lange bei den Kavalleristen, weil der Hinweis auf die durch das Pferd erreichbare Geschwindigkeit, ihren Fortbestand als Waffengattung am überzeugendsten zu legitimieren schien (siehe Storz 1992: 269f.). Im Unterschied zur Infanterie, die wenigstens einige Konsequenzen aus der immer effektiveren Waffenwirkung des Infanteriegewehrs zog, zu der dann auch noch der verstärkte Einsatz von Artilleriegeschützen trat (siehe hierzu ausführlich in Abschnitt 7.1.), beruhte das Festhalten an der Reiterattacke mit dem Säbel oder der Lanze auf einer weitgehenden Ignoranz der Feuerwirkung, die die Waffen von Infanteristen inzwischen entwickeln konnten. Der Glaube an die Unwiderstehlichkeit einer Reiterattacke lässt sich als Ausdruck des Bemühens interpretieren, einen drohenden Statusverlust als Waffengattung abzuwenden. Aber nur vor dem Hintergrund einer im Kern romantischen Vorstellung - rücksichtslos eingesetzte physische (männliche) Stärke könne alle Hindernisse überwinden, die angewandte Technik aufbauen kann konnte ein solcher Glaube eine gewisse Überzeugungskraft entwickeln (Storz 1992: 181).

Im Laufe des 19. Jahrhunderts erfuhr der Drill einen langsamen und vielfach unbemerkten Bedeutungswandel. Der Drill wurde als Kampftechnik in dem Maße überflüssig, in dem die Infanteristen nicht mehr in geschlossenen Formationen kämpfen sollten. Trotzdem wurden Soldaten weiterhin im Rahmen ihrer Ausbildung dazu angehalten, auf entsprechende Kommandos hin bestimmte Bewegungen ausführen. Und noch heute werden grundsätzlich alle Soldaten, unabhängig ob sie anschließend bei der Marine, bei der Luftwaffe, bei der Artillerie, etc. eingesetzt werden, vor al- 
lem in ihrer ersten Ausbildungsphase gedrillt. Der Grund hierfür ist bereits im 19. Jahrhundert das inhaltliche Auseinandertreten von Haltungs- und Funktionsdisziplin, das im Rahmen industriesoziologischer Studien erst im Zusammenhang mit der Technisierung des Militärs im 20. Jahrhundert beschrieben wurde.

Vor der Technisierung des Militärs sei die Beziehung zwischen Zeichen und Reaktion eindeutig geregelt gewesen. Der Grundsatz lautete: »Befehle und Kommandos sind die einzigen Informationen, auf die der Soldat reagieren darf« (Heiseler 1966: 89). Mit der Technisierung wurde diese Beziehung "mehrdeutig; neben dem Befehl, der eine eigentümliche Sonderstellung behält, treten immer mehr andere Informationen auf, die zu dem arbeitenden Soldaten nicht über seinen Vorgesetzten gelangen und zum Teil ihm allein, nicht seinen Vorgesetzten zugänglich sind; Befehle die sich auf die Tätigkeit selbst beziehen, werden ersetzt durch solche, die sich auf das Ziel der Tätigkeit beziehen.« (Ebd.: 119) Komplexe technische Artefakte lassen sich nicht funktionsgerecht bedienen, wenn die Soldaten nach starren Zeichen-Reaktions-Schemata handeln müssen. So macht es wenig Sinn, einen Soldaten ein Auto fahren oder ein Geschütz auf ein Ziel ausrichten zu lassen, etc., wenn er sich dabei nur auf die Informationen beziehen darf, die er von seinem Vorgesetzten erhält. Eine solche Restriktion würde bedeuten, um dies am Beispiel des Autofahrens zu verdeutlichen, ihn quasi die Augen zu verbinden, damit er ausschließlich aufgrund der Anweisungen seines Vorgesetzten den Gashebel drückt, die Schaltung betätigt und das Lenkrad bewegt. Der Vorgesetzte wäre in einem solchen Szenario mit nichts anderem beschäftigt als entsprechende Anweisungen zu geben. Und er würde vermutlich schneller und sicher das Ziel seiner Fahrt erreichen, wenn er sich selber hinter das Steuer des Fahrzeuges setzt. Um also eine effektive Bedienung dieser Maschinen zu gewährleisten, muss den Soldaten erlaubt werden und sie müssen dazu fähig sein, bei der Umsetzung einer Anweisung, wie >Fahren sie von A nach $\mathrm{B} \prec$, auf die vielfältigen Sinneseindrücke (visuelle, auditive, physiosensorische ${ }^{26}$ ), die sie während der Fahrt über ihren Leib/Körper machen, zurückzugreifen und in entsprechende (erlernte) Akte zur sach- und situationsgerechte Bedienung umzusetzen. Ihr eigener Leib/Körper muss eine eigenständige Informationsquelle sein dürfen und sie müssen von ihren Sinneseindrücken aktiv Gebrauch machen, um die von ihnen geforderte Leistung, hier das Fahren eines Autos, leisten zu können. Diese strukturierenden Leistungen der Soldaten wurden von Heiseler als mit Rücksicht auf das gegebene Ziel sachgerechte Improvisationen bezeichnet (1966: 120).

26 Gemeint sind damit Empfindungen, die beim Fahrer durch die Vibrationen des Fahrzeugs ausgelöst werden, und ihn über den Zustand des Motors und die Straßenverhältnisse informieren können. Für das sichere Manövrieren des Gefährts ist es von entscheidender Bedeutung, dass der Fahrer seine psychisch empfundene Körpergrenze den Umrissen des Vehikels anpassen kann. 
Solche sachgerechten Improvisationen waren aber schon vor der Technisierung der Streitkräfte für Soldaten unerlässlich, die als Tirailleure kämpften, wenn sie im Terrain Deckung suchten und gegnerische Soldaten beschossen. Nicht erst mit der Technisierung des militärischen Alltags im 20. Jahrhundert mussten militärische Vorgesetzten akzeptieren, wenn auch mitunter ausgesprochen widerwillig, dass eine Steigerung der Kampfkraft nur möglich ist, wenn ihre Untergebenen neben den erteilten Befehlen auch die eigenen sinnlichen Wahrnehmungen für ihr Handeln berücksichtigen. Der Entscheidung, die Infanterie nicht mehr in geschlossenen Verbänden kämpfen zu lassen, lag die Einsicht zugrunde, dass aufgrund der Entwicklungen der Waffentechnik nur eine zerstreute Gefechtsweise für den Kampf geeignet ist. Die zerstreute Gefechtsweise bedeutete zugleich, der Subjektivität der Soldaten einen größeren Entfaltungsspielraum zuzubilligen. Für die Befehlshaber der Infanteristen stellte sich damit die Frage, wie sie sicherstellen konnten, dass trotz dieses größeren Handlungsspielraums für den einzelnen Infanteristen, die Soldaten das taten, was sie von ihnen forderten. Im Zuge der umfassenden Technisierung des Militärs im 20. Jahrhundert sollte diese spezifische Problemstellung zu einer allgemeinen des Militärs werden, da sich die Handlungsfelder, in denen sich das Handeln der Untergebenen noch sinnvoll durch detaillierte Anweisungen der Vorgesetzten reglementieren ließ, entschieden verkleinerten.

In dem Maße, in dem der Drill seine Funktion verlor, die Soldaten für das Gefecht auszubilden, wuchs seine Bedeutung für die Herstellung einer bestimmten Haltung bei den Soldaten. Gerade aufgrund der zunehmenden Fragilität des Zusammenhangs eines eindeutigen Zeichen-ReaktionsSchemata wurde für die Truppenoffiziere die Frage umso dringender, wie sie sicherstellten, dass ihre Untergebenen ihre Anweisungen befolgten. Gedrillt wurde nun immer weniger im Sinne einer Gefechtsausbildung, dafür aber, um die Soldaten auf einen Habitus festzulegen, der ihre Unterordnung und Folgebereitschaft gegenüber den Befehlen ihrer Vorgesetzten garantieren sollte. ${ }^{27}$ In Preußen führte um die Jahrhundertmitte des 19. Jahrhunderts das inhaltliche Auseinandertreten der Funktions- und Haltungsdisziplin dazu, dass die Rekrutenausbildung von zwei Polen bestimmt wurde: der Formal- bzw. Exerzierausbildung und der Gefechtsausbildung. »Die Formalausbildung beinhaltete im Wesentlichen die Marschdisziplin, die Einübung von Schrittfolgen, Evolutionen [damit sind Bewegungen geschlossener Truppenkörper gemeint, d.A.] und den Umgang mit dem Gewehr« (Kaufmann 1996: 124). Die Gefechtsausbildung umfasste das Schießen mit dem Gewehr, das Training, wie im Gelände Deckung zu suchen und $\mathrm{zu}$ verlassen sei und wie auf Befehle und Zeichen der Vorgesetzten zu reagieren sei. Die Befürworter einer umfassenden und

27 Zur innenpolitische Intention mit der in Preußen am Drill festgehalten wurde, siehe Bröckling (1997: 141f.); zum militärischen Habitus nach der Reichsgründung (1871) in Deutschland siehe Wehler (Bd. 3, 1995: 882f.). 
zeitintensiven Formalausbildung versprachen sich vom fortgesetzten Drill die Ausprägung eines Habitus bei den Soldaten, der bei ihnen eine »reflexartige Gehorsamsbereitschaft erzeugen« sollte, ohne die nach Auffassung führender Militärs, »eine Truppe nicht zu führen war.« (Storz 1992: 116) Gerade die größere Feuerwirkung der Waffen, die zur Aufgabe der geschlossenen Formation als Einsatzkonzept geführt hatte, wurde als ein Argument angeführt, um die Soldaten weiterhin zu drillen, weil sie nur durch eine strikte Disziplinierung ihres Körpers den körperlichen wie psychischen Belastungen des Gefechts gewachsen seien. Die Rekruten sollten nun aber nicht mehr zu einem Teil einer Gesamtmaschine >geschliffen werden, vielmehr sollte bei ihnen das instrumentelle Verhältnis gegenüber ihrem eigenen Leib verstärkt werden. Wenn sie unbeeindruckt von der Waffenwirkung blieben und ihren Affekten und Emotionen keinen Ausdruck verliehen, so das Kalkül, seien sie auch weiterhin empfänglich für die Befehle ihrer Vorgesetzten. Die hier angestrebte Haltungsdisziplin, die sich beispielsweise in einen Topos wie sblinder Gehorsam kleidete, zielte auf eine als unerschütterlich gedachte ")Eingeübtheit< des kritik- und widerstandslosen Massengehorsams« (Weber 1922: 29). Sie konvergierte zugleich in einer spezifischen Vorstellung von Männlichkeit, die den Anpassungsprozess an einen stark reglementierten und entbehrungsreichen militärischen Alltag als Bewährung auffasst. Im ausgehenden 19. Jahrhundert wurde die beim Militär erfahrene Disziplinierung von zahlreichen Zeitgenossen - vor dem Hintergrund der in den meisten europäischen Staaten durchgesetzten Allgemeinen Wehrpflicht - zu einem unverzichtbaren Bestandteil männlicher Sozialisation aufgewertet. Insbesondere im deutschen Kaiserreich wurde der Ausdruck Disziplin zum Synonym einer Manneszucht, die als ein unentbehrlicher Bestandteil männlicher Sozialisation galt. ${ }^{28}$ Nur wer gelernt hatte, seinem Vorgesetzten zu gehorchen, es verstand den militärischen Normen gemäß zu sprechen und sich zu bewegen und auch unter großem emotionalem Stress >Haltung zu bewahren, nur wer also normierte Verhaltensformen ein- und Emotionen zurückhalten konnte, galt als ein Mann, dem Respekt zu zollen war und demgegenüber sich unmännliche (=>schwächere $<$ ) Individuen unterzuordnen hatten. ${ }^{29}$

28 Bereits das Grimmsche Deutsche Wörterbuch weist zwar Manneszucht bzw. Mannszucht als disciplina militaris aus, aber es enthält noch keinen Hinweis auf die militärische Ausbildung als Teil männlicher Sozialisation.

29 Über die Literatur, die sich aus einem historischen Blickwinkel militärischer Männlichkeitskonzepte annimmt, gibt Nowosadtko (2002: 221f.) einen Überblick. Dass die Bedeutung der Disziplin in den Männlichkeitskonzepten in den einzelnen Staaten variierte, deuten die Ausführungen von Storz an (1992: 128). Disziplin sei, so das Militärwochenblatt in einer Ausgabe von 1912, eine deutsche nationalspezifische Lösung »für das Problem, die Truppe auf das moderne Gefecht vorzubereiten« (ebd.). In Frankreich werde dagegen auf »Elan und Findigkeit« und in Russland auf »Standhaftigkeit und Folgsamkeit« gesetzt. 
Umstritten war innerhalb des kaiserlichen Heeres, welchen Umfang die Formalausbildung gegenüber der eigentlichen Vorbereitung auf das Gefecht einnehmen sollte. Aufgrund eines allzu zeitintensiven Drills würde, so die Befürchtung der Kritiker, kaum noch Zeit übrig bleiben, die Soldaten und ihre unmittelbaren Vorgesetzten auf die Bedingungen des modernen Schlachtfelds vorzubereiten und sie in den hier angemessenen Verhaltensweisen zu unterrichten. Anstatt sich flexibel auf die jeweiligen Bedingungen des Gefechts einzustellen, bewegten sich die Soldaten und ihre unmittelbaren Vorgesetzten entsprechend des Drills als Glied einer Schützenkette. Wie soll ein Soldat, der in der Formalausbildung dazu angehalten wurde, seine Sinne gegenüber den Eindrücken des Gefechts zu verschließen, gleichzeitig die Sinne entwickeln, »deren der Soldat am meisten bedarf, Auge und Ohr« (Rüstow 1864: 389), um im Terrain Deckung zu suchen und den Gegner zu beschießen? ${ }^{30}$ Unter dem Eindruck des Russisch-Japanischen Krieges (1905) wurde zumindest versucht, diesen Widerspruch zu mildern, indem die Truppenoffiziere angewiesen wurden, also die Kompaniechefs bzw. Zug- und Gruppenführer, die Gefechtsausbildung auf Kosten des Drills erheblich zu intensivieren (Storz 1992: 120).

Am Schluss dieses Abschnitts gilt es, noch kurz auf eine weitere grundlegende Veränderung des Militärwesens einzugehen, die sich im Anschluss an die Französische Revolution vollzog. Für Huntington gab es vor 1800 das Militär schlicht nicht als Profession. »Officers behaved und believed like aristocrats rather than like Officers.« (1957: 28) Selbst wenn man sich nicht diesem pauschalen Urteil anzuschließen vermag, so ist doch unbestreitbar, dass für die Offiziere zunehmend Sachkenntnisse zur unverzichtbaren Voraussetzung für ihre Tätigkeit wurden und zugleich der soziale Status qua Geburt immer weniger ausreichte, um leitende Positionen beim Militär einzunehmen. Für den gleichen Zeitraum berichtet van Creveld von einer Revolution in der Kriegführung, die auf einen Anstieg der »human energy« ähnlich einer Supernova zurückzuführen sei (1985: 62). Mit dieser euphorischen Formulierung charakterisiert er die von $\mathrm{Na}$ poleon (1769-1821) letztlich geprägte militärische Kommandostruktur des französischen Heeres. Ähnlich wie die Gefechtsweise der Tirailleure und die Kolonnentaktik zeigte sich diese Kommandostruktur gegenüber anderen Formen als überlegen und gab deshalb wichtige Anstöße für organisatorische und administrative Veränderungen anderer europäischer Streitkräfte.

Obwohl die Kommandostruktur des französischen Heeres stark von und auf die Person Napoleons zugeschnitten war, kann sie nicht als sein alleiniges Werk bezeichnet werden. Vielmehr verstand er, wie bereits auch

30 Rüstow plädiert hier für eine Ausbildung, die darauf abzielt »den Körper abzuhärten und zu stählen, ihn gelenk und geschmeidig zu machen« (1864: 389) und jeden Soldaten zum Tiraillieren befähigen sollte. 
andere Armeeführer der Französischen Republik vor ihm, Nutzen aus den Reformen der französischen Streitkräfte nach 1763 zu ziehen bzw. sie umzusetzen. Hierzu gehörte vor allem die Zusammenfassung der Heeresverbände in so genannten Divisionen. In einer Division wurden verschiedene Truppengattungen unter einem Kommando vereint. Die Vereinigung von Infanterie, Kavallerie, Artillerieeinheiten und Hilfstruppen wie Pioniere unter einem Kommando erlaubte es, dass eine Division als eigenständiger Kampfverband operieren konnte (McNeill 1984: 149). Das Neue an der Strukturierung der Streitkräfte in Divisionen war, dass die so entstandenen Verbände nicht mehr wie bisher ad hoc zur Bewältigung einer bestimmten Aufgabe zusammengestellt wurden, sondern dass die unterschiedlichen Truppen beständig unter einem Oberbefehl zusammengefasst blieben. Die Organisations- wie die Kommandostruktur blieb also fortan auch erhalten, wenn kein Feldzug unternommen wurde. Diese permanent beibehaltene Organisations- und Kommandostruktur hatte weitreichende Folgen. Scharnhorst, der mit Hinweis auf die Überlegenheit der französischen Armee um 1801 für eine Reform der hannoverschen Armee eintrat, hob in einer Denkschrift hervor, dass die Führung

"gewissermaßen so vielen Generalen aufgetragen, als Divisionen in der Armee vorhanden sind; jeder dieser hat seinen General-Stab und also eine Menge Gehülfen. Es werden demnach bey jeder Bewegung, bey jeder Action eine große Menge der vorzüglichsten Officiere in der Armee in Thätigkeit gesetzt, um die verschiedenen Theile zweckmäßig zu leiten. Alle diese Officiere werden immer in diesem Geshäft gebraucht und bekommen also in der Ausrichtung desselben bald eine große Fertigkeit. Der commandirende General erliegt nun nicht unter der Last der Anordnungen einzelner Theile, er hat jetzt Ruhe und Zeit, seinen Blick aufs Ganze zur richten, er kann jetzt sehr leicht nach seinen Absichten Zusammenhang und Einheit in der Bewegung und die Ausrichtung der verschiedenen Divisionen bringen und sich ganz den strategischen und tactischen Entwürfen überlassen.«(1795-1801: 776)

Die arbeitsteilige Strukturierung des Kommandos, die zunehmende Vertrautheit der Offiziere miteinander und mit ihren Aufgaben, sowie die Kenntnisse über die Fähigkeit ihrer Untergebenen, erhöhten die Schlagkraft der Verbände beträchtlich. Obendrein konnte ein in Divisionen unterteiltes Heer mit der prinzipiell vielgliedrigen Kommandostruktur sich wesentlich schneller auf überraschend vorgefundene Verhältnisse beim Marschieren und auf dem Schlachtfeld einstellen. Erst mit der Einteilung eines Heeres in Divisionen ließ sich das Moment des Zufalls, das sich im Verlauf eines Gefechts einstellte, systematisch ausnutzen, weil nun erst die Verbände überhaupt dazu fähig waren, auf Imponderabilien zu reagieren.

»Anders als in der rangierten Schlacht bestand nicht die Absicht, das Gefecht in allen Teilen nach vorgefaßtem Plan sablaufen $<$ zu lassen, vielmehr diente die Be- 
weglichkeit und relative Selbstständigkeit der Heeresteile der Ausnutzung von Lagen, wie sie erst während des Gefechts entstanden, also nicht vorauszusetzen waren.«(Regling 1979: 220)

Auf die Gliederung der Streitkräfte in Divisionen wiederum konnten sich übergeordnete Kommandostrukturen abstützen. Jeweils mehrere Divisionen ließen sich beispielsweise in ein Korps zusammenfassen, das über einen Kommandostab verfügte. Die Korps konnten von einem Armeestab befehligt werden, der letztlich von der Gesamtleitung der Streitkräfte seine Anweisungen erhielt. Erst diese linienförmige und vielgliedrige Kommandostruktur erlaubt es, dass die Bewegungen von mehreren Hunderttausend Soldaten, über die jeweils die Kontrahenten in den Napoleonischen Kriegen verfügten (ebd.: 219), koordiniert werden konnten.

Die Organisation der Streitkräfte in Divisionen, die permanente Institutionalisierung übergeordneter Kommandostrukturen und das Bestehen auf Kontinuität erhöhte in allen Teilen eines solchen Heeres den Druck, homogenere Organisations- und Kommandostrukturen $\mathrm{zu}$ etablieren, weil die Homogenität sowohl die Koordination durch die übergeordneten Stäbe erleichterte, als auch den Offizieren die Eingewöhnung in die Arbeitsabläufe bei unvermeidlicher Fluktuation in den Stäben erleichterte. Die von Scharnhorst beschriebene Entlastung von zahlreichen Anordnungen, die ein Oberkommandierender bislang treffen musste, konnte sich nur einstellen, wenn er sich darauf verlassen konnte, dass seine generellen Anweisungen auf eine von ihm erwünschte Weise auch umgesetzt wurden. Nur eine eingespielte, arbeitsteilige Arbeitsorganisation bot eine ausreichende Gewähr dafür, dass die Stäbe Routinen zur Informations- und Befehlsweitergabe entwickeln konnten.

Der Ausbau der übergeordneten Kommandostruktur, die für sehr unterschiedliche Aufgabenbereiche zuständig sein konnte, angefangen von der Personalplanung über die Versorgung der Truppe, die Marschrouten der Heeresverbände bis hin zur Koordinierung ihres Kriegseinsatzes, erforderte qualifiziertes Personal. Neben der grundsätzlichen Fähigkeit wie der Weitergabe von Informationen und Befehlen in verschrifteter Form, die überhaupt erst unter Napoleons Oberbefehl üblich wurde, mussten die Offizieren in den einzelnen Kommandostäben mit den Regularien vertraut sein, wie Berichte und Anweisungen zu verfassen sind. Sie mussten darüber hinaus über Spezialkenntnisse, beispielsweise in Fragen der Logistik, verfügen. Dieses Fachwissen wurde immer wichtiger, um den Einsatz der Streitkräfte vorzubereiten und zu koordinieren. All diese Anforderungen, kombiniert mit der Permanenz der Aufgabenstellung, bildeten das soziale Substrat für die von Huntington betonten drei wesentlichen Merkmale der 
Professionalisierung der Offiziere: Fachwissen, Verantwortungsbewusstsein und Berufsethos. ${ }^{31}$

Während im 18. Jahrhundert ein Feldherr ohne einen ihn unterstützenden Stab detaillierte Befehle für jeden seiner ihm unterstehenden Verbände geben musste, wurden im 19. Jahrhundert die Oberbefehlshaber mit dem Aufbau permanenter Stäbe weitgehend von solchen Detailanweisungen entlastet. Sie konnten zwar weiterhin einem bestimmten Verband unter Umgehung der Stäbe Befehle erteilen, aber ein solches Durchgreifen gehörte nicht zu seiner Kernaufgabe. Einem Oberbefehlshaber eines Heeres oder aller Streitkräfte eines Staates fiel die Aufgabe zu, mit dem ihm zur Verfügung stehenden Stab Dispositionen an die untergeordneten Kommandostrukturen zu entwerfen. Abhängig von der Größe des Operationsgebietes war er dabei auch immer mehr auf die eingehenden Berichte angewiesen, weil er sich beispielsweise bei einem Kampfgeschehen, das sich dutzende Kilometer entfaltete, kaum noch selber durch eigenen Augenschein, den »coup d'oeil« wie ihn Clausewitz nannte (1832: 234), also seinen Feldherrenblick, ein Bild vom Geschehen machen konnte. Der Feldherr, der als einziger im Heer quasi ein Subjekt sein sollte, dessen meist mündlich erteilter Befehl die Maschine Heer steuern sollte, verschwand. An seine Stelle trat ein Oberbefehlshaber, dem eine Vielzahl von Kommandeuren unterstand, mit denen er über seine eigenen oder auch weitere Kommandostäbe in Verbindung trat und die gemessen an der Konzeption der Heeresführung des 18. Jahrhunderts relativ eigenständig selber Dispositionen für die ihnen unterstehenden Verbände zu treffen hatten. Wenn man möchte, kann man sagen, dass im 19. Jahrhundert die Befehlsgewalt beim Militär einer komplexen, immer professionelleren Apparatur übergeben wurde, die aus verschiedenen, aber funktional aufeinander bezogenen einzelnen >Maschinen fehlshaber, der darauf verzichtete, selber das Geschehen in Augenschein zu nehmen und sich stattdessen den Informationen und Lageeinschätzungen anvertraute, die er von seinem eigenen Stab und den untergeordneten Kommandostellen erhielt.

31 In Wehrpflichtarmeen beschränkt sich die Professionalisierung auf das Offizierskorps und auf Unteroffiziere mit sehr langen Dienstzeiten. Bei den Mannschaften lässt sich gegenüber den Söldnerheeren dagegen eine Entprofessionalisierung feststellen. 


\section{Entstehung und Folgen des modernen Gefechtsfeldes}

\subsection{Die Entstehung des modernen Gefechtsfeldes und die Auftragstaktik}

Im folgenden Abschnitt wird von der so genannten Auftragstaktik die Rede sein, die als spezifisch preußisch-deutsche Einsatzkonzeption im letzten Drittel des 19. Jahrhunderts entwickelt wurde. In ihr flossen Erfahrungen und Lehren ein, die das preußische Militär aus den vorausgegangenen Kriegen zog, und sie beanspruchte auch, die adäquate Antwort auf die Waffenentwicklung der vorausgegangenen Jahrzehnte zu sein. Die Entwicklung der Auftragstaktik wurde entscheidend durch die Beobachtung angestoßen, dass die neuen Waffen den Truppen, die als gut sichtbare Formationen kämpften, große Verluste zufügten. Sie reagierte auf das immer dringender werdende Problem, dass diese Formationen buchstäblich unter der Waffenwirkung >zerfielen

Die Auftragstaktik wird in zahlreichen Publikationen als eine bahnbrechende Führungskonzeption eingestuft, die sich bereits vor dem 1. Weltkrieg gegenüber der so genannten »Normaltaktik« als überlegen erwiesen habe und mit der das preußisch-deutsche Heer 1914 in den 1. Weltkrieg zog (Leistenschneider 2002: 146). Nach Auffassung des amerikanischen Militärschriftstellers Trevor N. Dupuy bildete sie sogar das »Hauptelement« für die qualitative Überlegenheit der deutschen Truppen bis 1945 (zitiert nach Leistenschneider 2002: 1f., ähnlich van Creveld 1989: 203f.). Auch die Streitkräfte der Bundesrepublik Deutschland berufen sich auf die Auftragstaktik. Von besonderem Interesse ist die Auftragstaktik im Rahmen der Fragestellung dieser Arbeit, weil sie den Anspruch erhebt, den einfachen Soldaten wie ihren subalternen Vorgesetzten einen maximalen Gestaltungsspielraum für selbstständiges Handeln unter militärischen Bedingungen zu gewähren, das heißt unter der Bedingung, dass ihr eigen- 
ständiges Handeln die zentrale Koordination der Gefechtsführung nicht konterkariert.

In den anschließenden Abschnitten dieses Kapitels geht es um die Frage, welche Folgen die Industrialisierung des Krieges auf die soldatischen Subjekte hatte. Untersucht wird diese Frage vor allem anhand der Verhältnisse, die sich im Laufe des 1. Weltkrieges an der Westfront herausbildeten. Trotz aller Besonderheiten dieser Kämpfe, die vor allem auf den Stellungskrieg, also dem jahrelangen Kampf im gleichen Raum, zurückgingen, muss davon ausgegangen werden, dass auch in späteren Kriegen die industrialisierte Kriegführung ähnlich auf das Kriegserlebnis der Soldaten wirkte.

Nach den Napoleonischen Kriegen begann eine Epoche in den europäischen Staaten, die in den Geschichtswissenschaften überwiegend mit dem Begriff Restauration umschrieben wird. Auch in der historiographischen Militärpublizistik ist diese Charakterisierung für die Prozesse beim Militär unisono anzutreffen. Allerdings bedeutete die Restauration für das Militär ebenso wenig wie für die gesellschaftlichen und politischen Verhältnisse für die Ökonomie gilt sie sogar überhaupt nicht - eine Wiederherstellung der Verhältnisse, wie sie vor der Französischen Revolution herrschten. Ein Zurück zur Lineartaktik des 18. Jahrhunderts gab es nicht, wenngleich, wie Leistenschneider dies für die preußische Armee feststellt, die Treffengliederung nun wieder strenger gehandhabt wurde, das Exerzier-Reglement für die Infanterie um zahlreiche Zusätze ergänzt wurde und hier deshalb ein starrer Schematismus Einzug hielt. Auch wurde wieder in der Friedensausbildung sehr viel Wert auf die Evolutionen gelegt, die den Bewegungen der geschlossenen Verbände, wie Kritiker dieser Entwicklung meinten, etwas »Parademäßiges« verlieh (Leistenschneider 2002: 35f.).

Anstöße zu einer Veränderung der Einsatz- sowie zu neuen Führungskonzeptionen ergaben sich im gesamten 19. Jahrhundert nicht aus einem ähnlichen politischen Umbruch, wie ihn die Französische Revolution markierte, sondern waren das Ergebnis zahlreicher technischer Innovationen und des Wettrüstens zwischen den europäischen Großmächten.

Nach 1815 vereinbarten die führenden europäischen Großmächte (hierzu zählten Frankreich, Britannien, Preußen, Österreich und Russland) untereinander eine Außenpolitik stabiler Machtbalancen, um eine Neuauflage eines umfassenden Krieges zwischen den Großmächten zu vermeiden. Es sollte nicht noch einmal zwischen diesen Staaten zu einem umfassenden Krieg ähnlich den Napoleonischen Kriegen kommen, um die Fragilität der inneren Stabilität der sozialen und politischen Verfassung dieser Staaten nicht zu erhöhen (Mann 1998: 177f.). Durch dieses Arrangement wurde aber nicht die Konkurrenzsituation zwischen den Staaten aufgehoben. Die Konkurrenzsituation wie die Bemühungen um den Erhalt des bestehenden Machtgleichgewichts bedingten, dass die Staaten versuchten, ihre Streitkräfte mit den jeweils neusten Innovationen im Bereich des Transport- 
wesens, der Kommunikation und der Waffentechnik auszurüsten bzw. für sie nutzbar zu machen (siehe hierzu McNeill 1984: 199f.). Besonders in der 2. Hälfte und dann noch einmal verschärft im letzten Drittel des 19. Jahrhunderts bis zum 1. Weltkrieg, als der oben benannte Konsens nach dem Deutsch-Französischen Krieg (1870-71) zwischen den Großmächten immer brüchiger wurde, sollten diese technischen Innovationen das Kriegsbild grundlegend ändern. Mit neuen Einsatz- und Führungskonzeptionen versuchten die Armeen, Konsequenzen aus den Effekten, die die neu entwickelten Waffen im Gefecht bewirkten, zu ziehen. Zu diesen Konsequenzen gehörte das Verschwinden der geschlossenen Truppenverbände von den Schlachtfeldern, die sich aufrecht gegenüberstanden bzw. aufeinander zu bewegten, sowie die deutsche Auftragstaktik.

Insbesondere ab der 2. Hälfte des 19. Jahrhundert machten sich die Auswirkungen der technischen Innovationen der Waffentechnik auf dem Gefechtsfeld bemerkbar. $\mathrm{Zu}$ dieser Zeit wurde zugleich die industrielle Massenfertigung von Handfeuerwaffen möglich, die es gestattete, binnen relativ kurzer Zeit die Streitkräfte eines Staates mit jeweils neuen und verbesserten Gewehrtypen auszurüsten. Allmählich wurden alle Soldaten mit Gewehren ausgestattet, die einen gezogenen Lauf hatten und mit denen präzise über große Entfernungen geschossen werden konnte. Eine kurze Zeitlang sah es sogar danach aus, als ob die neuen Gewehre die Artillerie überflüssig machen würden, weil die Waffenwirkung der Infanteristen mit 300 bis 500 Metern fast an die der Artillerie herankam (300-600 Meter). Doch auch die Artillerie sollte in immer schnellerer Folge und über größer werdende Entfernung ihre Geschosse wirkungsvoll einsetzen können. So konnte beispielsweise die deutsche Feldartillerie im Deutsch-Französischen Krieg französische Truppen mit Granaten und Schrapnells aus 3800 bzw. 2200 Meter Entfernung unter Beschuss nehmen (Regling 1979: 346). Durch die Verbesserungen der Gewehre und der Artillerie wurde der Angriff in geschlossenen Gefechtsformationen auf in Deckung liegende Soldaten für die Angreifer zu äußerst verlustbringenden Unternehmungen. Die Soldaten boten in den geschlossenen Formationen nicht nur auf weite Entfernung hin gut sichtbare und deshalb leicht zu beschießende Ziele, ihre Annäherungsgeschwindigkeit an die gegnerischen Stellungen hing obendrein, wenn die Formation erhalten bleiben sollte, vom langsamsten Soldaten der Formation ab, womit sich prinzipiell der Zeitraum verlängerte, der benötigt wurde, um die Zone zu durchqueren, die der Gegner unter Feuer nehmen konnte. Und diese Zone nahm mit den ständig verbesserten Gewehren an Ausdehnung zu. Wenn die Verteidiger auch noch mit von hinten ladbare Gewehren ausgestattet waren, ${ }^{1}$ stieg die Wahrscheinlichkeit,

1 Die Umrüstung von Vorder- auf Hinterladergewehre setzte in Preußen ab 1840 ein. Es dauerte aber über 20 Jahre bis sie sich in den europäischen Armeen gegenüber den Vorderladergewehren durchgesetzt hatten. Ab den 70er Jahren des 19. Jahrhunderts galten alle Vorderladergewehre als überholt (Storz 2003: 
dass sie innerhalb der Feuerzone mehrfach von jedem gegnerischen Soldat beschossen wurden. Angreifende hatten diesem Beschuss gleichzeitig wenig entgegenzusetzen, zumal Soldaten, die über Hinterlader verfügten, ihre Waffen sogar im Liegen laden konnten.

Selbst bei Inkaufnahme hoher Verluste bei den eingesetzten Verbänden wurde es deshalb immer unwahrscheinlicher, dass dicht formierte und aufrecht gehende Soldaten erfolgreich gegen eine gegnerische Position vorgehen konnten. Trotzdem wurden in den Reglements nur zögerlich Konsequenzen aus dieser Entwicklung gezogen, um die Zahl der Verwundeten und Getöteten zu verringern. Eine erste Anpassung an die neuen Bedingungen des Gefechts ist um die Jahrhundertmitte in der Aufwertung kleinerer Verbände zu taktischen Einheiten zu sehen. Bildete bislang die Bataillonskolonne die entscheidende taktische Einheit, wurde sie nunmehr zu einer Versammlungsformation. Das preußische Reglement von 1847 sah beispielsweise die Einführung der Kompaniekolonne vor (bis zum 1 . Weltkrieg umfasste eine preußische Kompanie ungefähr 250 Soldaten, siehe Gudmundsson: 19), durch die die einzelnen im Kampf eingesetzten geschlossenen Verbände kleiner wurden. Wenngleich diese Regelung anfangs nur als ein Ausnahmefall für durchschnittenes und unübersichtliches Terrain vorgesehen war, wertete sie die Kompanie von einer administrativen zu einer taktischen Einheit auf. Die Kompaniekolonne erhöhte die Flexibilität der Gefechtsführung erheblich, weil der Kompaniechef, »der bisher eher ein >besserer`Zugführer gewesen war, [...] ein abgegrenztes Feld eigener Tätigkeit während des Gefechts (erhielt), auf dem er Eigeninitiative entfalten konnte.« (Leistenschneider 2002: 38) Dies führte in den höheren Offiziersrängen zur Klage, dass durch diese Regelung die Steuerbarkeit des Kampfes erschwert werde. Der gewährte Handlungsspielraum für die kommandierenden Offiziere von Kompanien vergrößerte die Anforderungen auf der Ebene der Bataillone, um die einzelnen Verbände zu koordinieren und erforderte auch eine gründlichere Ausbildung der nachgeordneten Offiziere. In welchen Formen trotz der größeren Effektivität des Gewehr- und Artilleriefeuers so viele Soldaten versammelt werden können und wie die Befehlshaber die Kontrolle über die Gefechtsführung behalten, diese Fragen »bestimmten die militärische Diskussion ununterbrochen von den 1850er Jahren bis zum 1. Weltkrieg.« (Storz 2003: 216)

Wie bereits bei der Aufwertung der Kompanie stießen alle Versuche, das Reglement und die Organisation an die neuen Bedingungen des Gefechts anzupassen, auf starke Vorbehalte bei den höheren Offizieren. Sie wurden als ein Zerfall der Kommandostruktur interpretiert, die gerade bei

210f.). Begünstigt wurde die Durchsetzung des Hinterladers durch die Entwicklung bei der Munition. Die Einführung der Metallpatrone (ab 1860), die Zünd-, Treibladung und Geschoss vereinte, erlaubte dann, dass die Gewehre mehrere Geschosse aufnehmen konnten und sich die Ladezeit abermals drastisch verringerte. 
verlustreichen Angriffsoperationen die Gefechtsführung in Frage stellen. Die Anpassungen erfolgten daher zaghaft. So wurde von der preußischen Armeeführung aufgrund der Erfahrungen aus den vorausgegangenen Kriegen 1869 die Kompaniekolonne zur Hauptgefechtsform der Infanterie erklärt. Doch auch diese Gefechtsform musste im Deutsch-FranzösischenKrieg aufgrund der Feuerwirkung, die die französische Infanterie mit ihren Hinterladergewehren entwickelte, aufgegeben werden, weil die Zahl der Verwundeten und Toten sehr hoch war, wenn die Kompanien als Kolonne angriffen. Dort, wo die preußischen Verbände versuchten, die Kolonnentaktik anzuwenden, wie beim Angriff auf Saint-Privat (18.8.1870), starben von den eingesetzten 15.000 Soldaten binnen höchsten 2 Stunden »fast alle Offiziere und 5114 Mann« (Engels 1877/1894: 157/602). ${ }^{2}$ Trotz des Sträubens der Offiziere hätten jedoch die Soldaten zur einzigen Gefechtsform gefunden, die sich aufgrund der Waffenwirkung bewährt habe: die aufgelöste Formation und der Laufschritt im Wirkungsbereichs des gegnerischen Feuers (ebd.: 603). Aus Sicht der Offiziere, die die Kompanien bzw. noch größere Verbände befehligten, handelte es sich bei dieser Gefechtsweise jedoch um einen »Schützenbrei« (Kühlich 1995: 349). Die sich bei »Feindberührung in Windeseile« (Leistenschneider 2002: 47) in Schützenschwärmen auflösenden Verbänden waren von ihnen kaum steuerbar, das heißt sie konnten kaum beeinflussen, ob die Soldaten im Mannschafts- und Unteroffiziersrang im Feuer liegen blieben, flohen oder nach Vorne >durchgingen. Vor allem letzteres wurde nach dem Krieg in der Militärpublizistik beklagt, weil die Verbände kaum »noch geschlossen zum Angriff angesetzt werden (konnten). Statt dessen kam es zum tropfenweisen und verzettelten Einsatz der an der Schlacht beteiligten Truppenteile« (Leistenschneider 2002: 50). Die »unteren Führer«, gemeint sind wohl insbesondere die Unteroffiziere, hätten durch ihre »Eigenmächtigkeiten« Gefahren für den Ausgang der Gefechte heraufbeschworen, die abermals zu großen Verlusten beigetragen hätten (ebd.). ${ }^{3}$

2 Engels Berechnung beruht auf Zahlen aus der offiziellen Darstellung der Geschichte des Deutsch-Französischen-Krieges. Trotz der katastrophalen Verluste wurde später in populären Darstellungen die Gefechtsführung in massierten Kolonnenformationen, die meist ohne Artillerievorbereitung ausgeführt wurden, als heldenhaft verklärt und prägten auf diese Weise das Kriegsbild vor dem 1. Weltkrieg. Walter dagegen nennt das oben erwähnte Gefecht des preuBischen Gardekorps einen Suizidangriff (Walter 2003: 597). Zu den Verlusten im gesamten Krieg auf Seiten der deutschen Truppen, siehe auch Kühlich (1995: 394f.).

3 Die Vermeidung von Verlusten konnte allerdings auch ein Motiv für solche Angriffe sein. Die Soldaten waren, schreibt Kühlich, »in der Regel wohl nicht [...] so sehr vom Kampfeseifer beherrscht«, vielmehr griffen sie an, um so »dem passiven Ertragen des französischen Beschusses « (1995: 351) zu entgehen. Anstatt im französischen Abwehrfeuer auszuharren - die Gewehre der französischen Soldaten hatten eine größere Reichweite als die ihrer Gegner - 
Trotz dieser Erfahrung blieben die preußischen Vorschriften zur Gefechtsführung und die für das Gefecht vorgesehene Truppengliederung, die nach 1871 für die deutschen Truppen allgemeinverbindlich wurden, und die Ausbildung der Soldaten prägten, bis 1888 weitgehend unverändert. Der erfolgreich beendete Krieg gegen Frankreich erhöhte die Bereitschaft zu einer Militärreform nicht, doch sollte die Einsicht in ihre Notwendigkeit mit den Jahren aufgrund der Kriegserfahrungen anderer Streitkräfte sowie der weiteren waffentechnischen Entwicklung steigen. ${ }^{4}$ Das 1888 erlassene neue Exerzierreglement für die Infanterie sah ein neues Führungsverfahren der Verbände vor, das später als Auftragstaktik bezeichnet wurde, änderte die Truppengliederung für das Gefecht und sah von der Festlegung der Gefechtsformen ab. ${ }^{5}$

Mit dem neuen Exerzierreglement sollte die Infanterietaktik ausdrücklich den Gefechtsbedingungen angepasst werden. Es griff dazu auf die nicht nur im preußischen Generalstab herausgebildete Praxis zurück, dass die Kommandeure von Teilverbänden einer Armee eine gewisse Entscheidungsfreiheit benötigten, um auf die vor Ort vorgefundenen Verhältnisse flexibel reagieren zu können, weil durch das Warten auf die Entscheidung des immer häufiger weit entfernten obersten Feldherren unvorhergesehene Chancen vertan wurden bzw. Gefahren entstanden. Anstatt den jeweiligen Kommandeuren detaillierte Anweisungen zu erteilen, war es deshalb sinnvoller, wenn der zentrale Kommandostab sich darauf beschränkte, den Heerführern Aufträge zu erteilen, die Anweisungen enthielten, die sie unbedingt bei ihrem Vorgehen zu berücksichtigen hatten, die ihnen aber auch einen Entscheidungs- und Gestaltungsspielraum einräumten. In diesem Sinne sprach der preußische Generalstabschef Moltke (1800-1891) vom >Auftragsverfahren`, das einem kommandierenden General die Entscheidungen überlässt, welchen Weg er einschlägt, um sein Korps an den Gegner zu führen. Er erteilte den höheren Truppenoffizieren deshalb keine Befehle, sondern >Direktiven`. Damit bezeichnete er allgemein gehaltene Anweisungen, die die Kommandeure über das Ziel und den Zweck der von ihnen auszuführenden Operationen informierten, aber keine Bestimmungen enthielten, wie sie mit den ihnen unterstehenden Verbände vorgehen sollten. Moltke reagierte mit diesem Verfahren auch auf eine zweite

versuchten sie durch ihre Angriffe in eine Position zu gelangen, von der aus sie ihre Gewehre einsetzen konnten.

4 Entscheidend verbessert wurde in dieser Zeit die Tarnung der aus einer Deckung herausschießenden Soldaten, durch das in den 80er Jahren entwickelte rauchschwache Pulver. Markierte bislang jeder Soldat mit dem ersten Schuss seine Position durch eine aufsteigende Rauchwolke, stieg nun seine Chance lange Zeit unentdeckt zu bleiben. »Die Kämpfe wurden unübersichtlicher.« (Storz 1992: 26)

5 Walter weist darauf hin, dass 1870, und man muss ergänzend festhaltend, auch in den Folgejahren, die anderen europäischen Streitkräfte ihre Infanterie ebenfalls auf »rückständige« Taktiken festgelegt hatten (Walter 2003: 598). 
Problemlage, die sich beim preußischen Militär aus der möglichen Differenz zwischen militärischer Position in der Befehlskette und dem Rang in der Adelshierarchie ergab. Als Generalstabschef war Moltke

»weder nominell oberster Kommandoführer - dies war der König - noch eine Autorität, die von den Armeeführern jederzeit eine unproblematische Unterordnung unter ihre Entscheidungen erwarten konnte. Die Armeeführer mussten auch nach dynastischen Gesichtspunkten ausgewählt werden - und ein Kronprinz konnte qua Geburt kaum anders als empfindlich auf Befehle reagieren. Die regelmäßige Begründung von Entscheidungen und ein vorsichtiger Umgang in Fragen von Kompetenzbereichen der Armeekommandos war eine Strategie, sich eines entsprechenden Gehorsams zu versichern.«(Kaufmann 1996: 98)

Mit dem Exerzierreglement galten die Prinzipien des Auftragsverfahrens nicht mehr nur für hochrangige Truppenoffiziere, sondern für alle Hierarchieebenen bei der Infanterie. Selbst den Anführern von Zügen und sogar Gruppen, also niedrigrangigen Offizieren sowie Unteroffizieren, wurde ein Entscheidungs- wie Gestaltungsspielraum zugebilligt. Der gewährte Entscheidungs- und Gestaltungsspielraum bezog sich auch nicht mehr nur auf den Weg, den der Verband nahm, um an ein bestimmtes Ziel zu gelangen, sondern betraf unmittelbar die Gestaltung des Gefechts. Motiviert wurde der erweiterte Geltungsbereich der Prinzipien des Auftragsverfahrens durch die Feststellung, dass es nicht mehr möglich war, große Truppenverbände durch restriktive Vorgaben ins Gefecht zu führen, da sie ihre Geschlossenheit aufgrund der Feuerwirkung der gegnerischen Waffen verloren. Durch die Auftragstaktik sollte das Kampfgeschehen, das in eine Vielzahl von unüberschaubaren Einzelgefechten zu zerfallen drohte, deren Verlauf entscheidend von den vor Ort getroffenen taktischen Entscheidungen bestimmt wurde, in einen übergeordneten Operationsrahmen eingebunden werden.

Damit den Offizieren und Unteroffizieren aller Hierarchieebenen überhaupt die Kompetenz zu taktischen Entscheidungen eingeräumt werden konnte und trotzdem eine gewisse Geschlossenheit des Vorgehens gewahrt blieb, wurden die bislang gültigen Kommandoverhältnisse und die Gliederung der Verbände umgestaltet: ${ }^{6}$ Bislang waren die Kommandoverhältnisse und die Verbände horizontal strukturiert bzw. gegliedert, das heißt alle Verbände, die einem Kommandeur unterstanden, waren wie in den Zeiten der Lineartaktik so aufgestellt, dass sie nebeneinander standen und so genannte Treffen bildeten. Die Ausrichtung der Treffen orientierte sich an der Richtung, in der die gegnerischen Verbände vermutet wurden. Dadurch verloren insbesondere die Befehlshaber von übergeordneten Truppeneinheiten, Leistenschneider führt konkret die Regimentskommandeure an, die

6 Die nachfolgenden Ausführungen orientieren sich an der Darstellung von Leistenschneider 2002: 51f. 
Möglichkeit, auf die ihnen unterstehenden Truppenteile (die Bataillone) Einfluss zu nehmen. In die Gefechte konnten sie allenfalls auf der Ebene einzelner Kompanien, durch ihre persönliche Präsens und quasi in der Funktion eines Kompaniechefs, eingreifen. Erst die vertikale Gliederung der Verbände und Strukturierung der Kommandoverhältnisse ermöglichte es, dass nicht alle Verbände, die ihnen unterstanden, gleichzeitig und weiträumig verstreut im Kampfgeschehen verwickelt waren. So unterstanden ihnen Verbände, über deren Einsatz sie in ihrer Funktion als Regimentskommandeur noch im Verlauf eines Gefechts entscheiden konnten. Die Umstrukturierungen bedeuteten eine enorme Stärkung der Handlungsmöglichkeiten oberhalb der Kompaniechefs und bildeten die Basis für die vom Reglement vorgesehene Führung des Gefechts nach Kommandoeinheiten (Leistenschneider 2002: 72f.).

Jede Kommandoeinheit hatte einen eigenen Aufgabenbereich. So

»grenzt die Brigade ihre Kampfaufgaben klar voneinander ab und verteilt sie unter ihre beiden Regimenter [jede Brigade setzte sich damals aus zwei Regimentern zusammen, d.A.]. Entsprechend verfährt das Regiment mit seinen Bataillonen, das Bataillon mit seinen Kompanien, die Kompanie mit ihren Zügen. Jede Kommandoeinheit erhält dadurch ihr eigenes, klar abgegrenztes Feld eigener Tätigkeit und selbstständiges Dispositionsvermögens.« (Leistenscheider 2002: 74)

Die von der Auftragstaktik gewährte »Freiheit der Form« (ebd.: 5) war auf das engste mit einem "')strengen Gehorsam`gegen die Absicht des übergeordneten Führer« (ebd.: 83) verbunden. Dieser Gehorsam sollte als Regulativ der Selbsttätigkeit der Untergebenen wirken und verhindern, dass durch Eigenmächtigkeiten der Zweck der Operation verfehlt wird. Mit der Auftragstaktik verschwand auch nicht der unbedingt auszuführende Befehl aus dem militärischen Alltag. Vielmehr bot es sich an, im Zusammenhang mit der Auftragstaktik zwischen drei verschiedenen Befehlsformen zu unterscheiden.

- Die Direktive, die in der Hierarchie der Befehlsformen am höchsten steht und das Kernelement der Auftragstaktik bildet und die Untergebenen über den Zweck der Operation sowie die Absichten des Vorgesetzten in Kenntnis setzt.

- Der Befehl, der die Untergebenen anweist, was sie zu tun haben. Bei der Befehlserteilung gehören im Grunde Direktive bzw. Auftrag und der Befehl zusammen, denn der Befehl ist quasi eine Handlungsanweisung, was vom Untergebenen zu unternehmen ist, um den Auftrag auszuführen. Er sollte aber so abgefasst bzw. formuliert werden, dass er möglichst wenig festlegt, wie der Befehl auszuführen ist (ebd.: 90).

- Das Kommando, das »reglementarisch festgesetzte Befehlswort« (ebd.: 87), gewährt dagegen »keinerlei Spielraum bei der Ausführung« (ebd.). Nach dem Reglement sollte es »nur noch für die niedrigsten Einheiten 
im Gefecht nutzbar (sein): für die Gruppe und den Zug, gelegentlich auch für die Kompanie.« (Ebd.) Durch die Auftragstaktik wurde das Kommando auf allen übergeordneten Hierarchieebenen des Militärs durch die Kombination von Auftrag und Befehl ersetzt, und es sollte sogar selbst auf der Ebene des Zuges sowie der Gruppe an Gewicht verlieren, weil es immer weniger sinnvoll war, die Bewegungen jedes einzelnen Soldaten im Gefecht festzulegen.

Um die »Freiheit der Form« sicherzustellen und gleichzeitig den jeweiligen Vorgesetzten eine Kontrolle über den Verlauf des Gefechts zu ermöglichen wurde der Grundsatz postuliert, dass die Vorgesetzten eine »Befehlspflicht« gegenüber ihren Untergebenen haben, die wiederum ihnen gegenüber meldepflichtig sind (ebd.: 91). Damit das Prinzip des Gefechts nach Kommandoeinheiten gewahrt blieb und die Selbstständigkeit der Untergebenen nicht durch permanente Befehle übergeordneter Hierarchieebenen verletzt wurde, legte man auf die »Einhaltung des Dienstweges bei der Befehlsgebung« (ebd.) großen Wert. Nicht jeder höherrangige Offizier hatte also ohne zwingenden Grund das Recht, einem rangniedrigeren Offizier einen Befehl zu erteilen. Auch der »)Durchgriff durch eine Kommandoebene« (ebd.) war nur in Ausnahmefällen, wie Fehler bei der Ausführung eines Auftrags oder einer unvorhergesehenen Lageänderung, gestattet.

Die Umsetzung des Reglements erhöhte die Anforderungen an die Offizier und Unteroffiziere enorm, weil »die auf äußere Gleichmäßigkeit zielende Anwendung eines Schemas, für die Kommandostimme und stramme Haltung des Unterführers vielleicht noch genügen würde« (ebd.: 92), nicht mehr ausreichten. Von ihnen wurde, so Leistenschneider, nicht mehr eine passive Disziplin, „die durch die Brechung des Willens jedes einzelnen Soldaten, notfalls mit Hilfe harter Strafen«, sondern aktive Disziplin erwartet. Das »Wesen der aktiven Disziplin« liege darin, »dass jeder Soldat an seinem Platz mit Hingebung seiner ganzen Person die Absichten seines Vorgesetzten zu verwirklichen sucht. Eine solche Disziplin bleibt auch dann wirksam, wenn der Führer ausgefallen ist. Die passive Disziplin, die abwartet und nur auf Kommando reagiert, genügt diesen Anforderungen nicht. Das gleich gilt für den selektiven Gehorsam, bei dem sich der Untergebene gleichsam ein >Wahlrecht $`$ in Sachen Gehorsam herausnimmt. Selektiver Gehorsam ist Ungehorsam; darin liegt eine ernsthafte Gefährdung der Auftragstaktik.« (Ebd.: 95f.)

Mit der Erteilung von >Aufträgen spielraum sowie dem Bedeutungsverlust für schematisch auszuführende Kommandos sollten die Befehlshaber flexibler als bisher auf das unüberschaubare Gefechtsfeld und das Kampfgeschehen reagieren können, ohne zugleich das Ziel der Operationen aus den Augen zu verlieren. Kurz: sie diente der Kontingenzbewältigung. Sie richtete sich an alle Soldaten, 
denen die Macht zugebilligt wurde, anderen Soldaten Befehle zu erteilen. Um ihre Wirkung zu veranschaulichen, ist es sinnvoll, die Rangschichtung des Militärs mit dem Handlungsspielraum für das Kampfgeschehen zu vergleichen, der den Soldaten je nach Zuordnung ihres Ranges zugebilligt wurde. Die graphische Darstellung der Rangschichtung in dieser Zeit entspricht in etwa einer Pyramide mit einer sehr breiten Basis, in der sich die meisten Soldaten im Mannschaftsdienstrang befinden. Der Handlungsspielraum, der den einzelnen Rängen zugebilligt wurde, lässt sich ebenfalls als eine Pyramide darstellen, deren Spitze aber nach unten weist. Je näher man der Spitze der umgekehrten Pyramide kommt, also je niederer der militärische Rang der Soldaten ist, desto weniger wird von ihnen aktivstrukturierendes Handeln erwartet. Die Dimension aktiv-strukturierend, die beim Oberbefehlshaber ihr Maximum hat, wird zunehmend durch die Dimension passiv-kompensatorisch ersetzt, das für ein Handeln steht, das reaktiv mit dem Geschehen umgeht und Lücken in der Befehlslage schließen soll. Vor dem Exerzierreglement von 1888 drang die Spitze dieser Pyramide nicht in die Basis der Rangschichtung vor.

Durch die Auftragstaktik erweiterte sich der Handlungsspielraum jenseits des Oberbefehlshabers. Die Pyramide >Handlungsspielraum ২ bekam quasi einen Bauch, da auf allen Ebenen der Handlungsspielraum größer und nun selbst von den rangniedrigen Offizieren erwartet wurde, dass sie als Subjekte einen gegebenen Auftrag aktiv durch eigene Entscheidungen und Handlungen strukturieren. Selbst an Soldaten im niedrigsten Mannschaftsdienstrang wurde nun konzeptionell die Erwartung herangetragen, dass sie an Stelle ihre Vorgesetzten treten, wenn diese im Zuge des Kampfgeschehens verletzt oder getötet wurden.

Innerhalb des preußisch-deutschen Offizierskorps war das Reglement umstritten. In einer über Jahre sich hinziehenden Debatte traten zahlreiche Offiziere gegen eine Führung des Gefechts nach Kommandoeinheiten und für die Festlegung eines Gefechtsschemas ein, um die Selbsttätigkeit der Untergebenen zu beschränken, weil sie der Auffassung waren, dass nur ein normiertes und eingedrilltes Schema eine räumlich und zeitlich einheitliche Gefechtsführung sicherstellt. Durchsetzen konnten sich die Kritiker des Reglements nicht. Vor dem Hintergrund des Burenkrieges sowie des Russisch-Japanischen Krieges (1904-1905) erfuhr das »Exerzier-Regle ment für die Infanterie« stattdessen 1906 eine Bestätigung, und es wurde sogar bestimmt, dass in »der gesamten Ausbildung [...] auf Selbständigkeit der Führer und des einzelnen Schützen [sic! d.A.] hinzuarbeiten« ist (Ex.-Regl. 1906: 78, § 251). Die Auftragstaktik mag deshalb, wie Leistenschreiber schreibt, vor dem 1. Weltkrieg »im Führungsdenken der preußisch-deutschen Armee verankert« (ebd.) gewesen sein, ob jedoch in der Gefechtsausbildung im Besonderen wie im Truppenalltag im Allgemeinen davon viel zu bemerken war, ist aus einer ganzen Reihe von Gründen zu bezweifeln. 
Wie oben bereits ausgeführt, waren die Ausbildung weiterhin und der Truppenalltag vom Drill geprägt und damit an den Disziplinarvorstellungen der >passiven $<$ Disziplinierung. Und dies trotz der Vorschriften, die die Ausbilder anwiesen, die Soldaten zu »selbständigem Denken und Handeln« (Felddienstordnung von 1908, zitiert nach Borgert 1979: 486) zu erziehen. Der Drill sollte demnach die Soldaten zu einem »aus Einsicht geborenen gegebenenfalls unbedingten Gehorsam, wenn es der militärische Auftrag gebietet« (Borgert 1979: 487), befähigen. Von einer Umsetzung dieser Ausbildungsideale kann allenfalls bei der Offiziersausbildung gesprochen werden. Für die Ausbildung von Mannschaften und Unteroffizieren galt, dass das »Changieren zwischen Gehorsam und Drill einerseits, funktionsbezogener Ausbildung und Selbstständigkeit andererseits, [...] sich tendenziell zur Seite von Gehorsam und Drill« neigte (Kaufmann 1996: 126). Aus Sicht zumindest eines großen Teils des kaiserlichen Offizierskorps, wohl aber auch der Unteroffiziere, - ihr Umgang mit Rekruten spielte in den Klagen über Soldatenmisshandlungen vor dem 1. Weltkrieg eine große Rolle - sprach neben dem allgemeinen Misstrauen an der Einsatzbereitschaft der Soldaten im Kampf auch noch ein innenpolitischer Grund für rigide Kontrolle und Gehorsamseinübungen. Das Heer sah sich als Garant der politischen Machtverhältnisse, der bei detailliert ausgearbeiteten Staatsstreich- und Bürgerkriegsszenarios die sozialistischen $>$ Reichsfeindeく bekämpfen sollte (Bröckling 1997: 174). Ohne das >erzieherische Wirken von Offizieren und Unteroffizieren, so die Befürchtung, würden insbesondere die aus der Industriearbeiterschaft rekrutierten Soldaten, deren Anteil im Heer von Jahr zu Jahr stieg, sich womöglich weigern, ihre »eigenen Verwandten, Brüder, ja Eltern niederzuschießen« (Wilhelm II, anlässlich einer Rekrutenvereinigung 1891, zitiert nach ebd.: 178). ${ }^{7}$

Die geringe Relevanz der Auftragstaktik für die Mannschaften und die Unteroffiziere wird auch mit Blick auf das zentrale Element der Gefechtsausbildung deutlich. Das operative Einsatzkonzept der Infanterie war offensiv ausgerichtet. Obwohl die waffentechnologische Entwicklung die taktische Defensive gestärkt hatte, hielten die europäischen Armeen an der Vorstellung fest, dass Infanteristen, wenn auch unter großen Verlusten, das Abwehrfeuer von Hinter- und Mehrfachladern, von Artilleriegeschützen und schließlich auch des Maschinengewehrs überwinden und Defensivstellungen erobern könnten. Verantwortlich für dieses Festhalten war die Angst vor einem lange andauernden und deshalb zermürbenden Krieg, den derjenige gewinnen würde, der über die größeren Reserven verfügt. Einen solchen Krieg wollten aber die Kriegsparteien möglichst vermeiden, da die Mobilisierung aller Reserven von einer allgemeinen Zustimmung in der Gesellschaft abhing, deren man sich keineswegs sicher sein konnte. Vielmehr wurde befürchtet, dass eine allgemeine Mobilisierung der Gesell-

$7 \mathrm{Zu}$ »speziellen Vorkehrungen, um eine >Infizierung « der Truppe mit sozialdemokratischen Lehren zu verhindern«, siehe Bröckling 1997: $181 \mathrm{f}$. 
schaft im Zuge eines langen Krieges zu sozialen Unruhen führen, gar Revolution auslösen kann. Entsprechende Voraussagen gewannen mit der Russischen Revolution von 1905 an Plausibilität, die von der sich abzeichnenden Niederlage der russischen Streitkräfte gegen die japanische Flotte und Armee und der damit verbundenen Wirtschaftskrise ausgelöst wurde. Nur eine offensive Kriegführung bot aus Sicht der deutschen Militärplaner eine Gewähr für einen kurzen Krieg. Die gehörte auch zu den strategischen Kernüberlegungen ihres französischen Pendants. ${ }^{8}$ Um die Soldaten optimal auf die geplante offensive Kriegführung ${ }^{9}$ vorzubereiten, konzentrierte sich die Gefechtsausbildung auf eine einzige Gefechtsform, den Angriff. ${ }^{10}$ Selbst Übungselemente, die defensiven Charakter hatten, wie das Suchen von Deckung und das Eingraben, wurden nur als ein Übergang zum Angriff gedacht (siehe Storz 1992: 173f.). So sind die Bestimmungen des Reglements von 1906 zur Verteidigung nicht nur, gemessen an den Ausführungen zum Angriff, sehr knapp gehalten, sie enthielten auch den Satz, eine »Verteidigung, die nur einen Angriff abweisen, sondern einen entscheidenden Sieg herbeiführen will, muss mit angriffsweisem Verfahren gepaart sein.« (Ex.-Regl. 1906: 112, § 398) Das Schanzen sollte den Infanteristen bevorzugt dazu dienen, sich der gegnerischen Stellung anzunähern, wenn das Terrain vor der gegnerischen Stellung keine natürliche Deckung bot. Das Reglement verbot zwar »jede Schematisierung des Angriffsverfahrens« (Ex-Regl. 1906: 102, § 351), jedoch fällt es schwer, die Auffassung Leistenschneiders zu teilen, dass die detaillierten Anweisungen lediglich »eine sichere Handhabe für die Ausbildung, ohne allerdings die Freiheit in der Wahl der Mittel einzuschränken«, (ebd.: 135) boten, zumal sie auch ganz grundsätzliche Vorstellungen zum taktischen Vorgehen beinhalteten. Die Offiziere hatten mit ihren Untergebenen in dicht formierten Schützenschwärmen, das Reglement spricht in diesem Zusammenhang von `Schützenlinien`, aus möglichst kurzer Distanz die gegnerischen Soldaten zu beschießen, um »den Feind zu erschüttern« (Ex-

8 Siehe zu diesem Themenkomplex, dass Fazit von Storz zur Auswertung der europäischen Streitkräfte des Russisch-Japanischen Krieges (1992: 158f.), insgesamt auch Dülffer, sowie zu Frankreich Ferro: 61f.; einen Überblick gibt auch Wortmann (1998: 26f.).

9 Auf der strategischen Ebene schlug sich auf deutscher Seite die offensive Ausrichtung im Schlieffenplan nieder, der einen schnellen Sieg im Westen vorsah. Zwar schätzten vor dem 1. Weltkrieg führende Militärs seine Erfolgsaussichten zunehmend pessimistischer ein, aber am Basiskonzept hielten sie trotzdem fest. Zum Schlieffenplan: Ritter (1956), Wallach (1970), Förster (1994) und Kaufmann (1996: 129f.); zur Rationalität der Kriegszenarios siehe auch Warburg (1999: 104f.).

10 Die intensiven Marschübungen sollten die Marschleistung der Verbände erhöhen, und standen ebenfalls im Dienst der zu führenden Offensive, da die Eisenbahn die Truppen überwiegend nur an den Ausgangspunkt der Operationen bringen konnte und die Motorisierung der Infanterie war der Zukunft vorbehalten. 
Regl. 1906: 100, § 343). Wenn die Vorgesetzten in der vordersten Linie oder auch weiter hinten befindliche Truppenoffiziere zur Auffassung gelangt sind, man habe durch das eigene Feuer den Gegner psychisch zermürbt, sollten die Infanteristen durch den Sturmangriff in die Stellung des Gegners einbrechen. Der Sturmangriff bildete die Klimax des gesamten Angriffs. »Im Sturmlauf mit der blanken Waffe wird die Überwindung des Gegners besiegelt.« (Ebd.: 95, § 324) Zahlreiche Ausführungen zum Angriffsverfahren forderten zu unterschiedlichsten und nicht immer widerspruchsfreien Interpretationen heraus« (Borgert 1979: 484). Passagen, die geeignet waren, den Offizieren nahe zu legen ihre Untergebenen im Raum zu verteilen, die gegnerischen Stellungen nur aus einer selber gegrabenen Deckung heraus zu attackieren und sich mit dem Entschluss zum Sturmangriff Zeit zu lassen, wurden konterkariert durch Sätze, die beispielsweise das Aufgeben der geschlossenen Ordnung zu einem Übel erklärten (ExRegl. 1906: 100, § 342), oder Leitsätze wie die folgenden: »Unausgesetzter Drang nach vorwärts und das Bestreben, es dem Nachbar hierin zuvorzutun, muss alle Teile der Angriffstruppe beseelen.« (Ebd.: 96, $\S$ 327). Und an einer anderen Stelle wurde bestimmt: »Den ihr innewohnenden Trieb zum angriffsweisen Vorgehen muss die Infanterie pflegen; ihre Handlungen müssen von dem einen Gedanken beherrscht sein: Vorwärts auf den Feind, koste es was es wolle! « (Ebd.: 81, § 265) Die hier geforderte Opferbereitschaft erhöhte sicher die Neigung der Offiziere, auch in der Gefechtsausbildung an die als >unerschütterlich` gedachte Haltungsdisziplin ihrer Untergebenen anzuknüpfen und darüber die gleichzeitig vom Reglement geforderte Ausbildung des Schützen zur Selbsttätigkeit zu ignorieren.

Es entstand ein Dilemma zwischen der angestrebten offensiven Kriegführung und der Einsicht, dass die neuen Waffen die taktische Defensive stärkten. Verlustreiche infanteristische Angriffsoperationen konnten nur vermieden werden, wenn sich die Soldaten langsam, Deckung suchend und im Raum verteilt den gegnerischen Stellung näherten und sie möglichst vom Feuer der Artillerie unterstützt wurden. All dies kostete aber Zeit, die aber als nicht vereinbar mit dem angestrebten »Offensivdrang« (Borgert 1979: 432) der Infanterie galt. Nicht die Vermeidung von Verletzten und Toten, sondern eine gesteigerte Bereitschaft, große Verluste hinzunehmen, resultierte paradoxerweise aus der Kenntnis der Waffenwirkung. Wer aber traditionelle soldatische Tugenden wie >Opferbereitschaft $\iota,>$ Kühnheit $\iota$ und $>$ Mannesmut $<$ zu Garanten eines offensiv geführten Infanteriegefechts erklärte und unbedingt >Moral und >Sittlichkeit` zu überlegenen Kräfte gegenüber der gestiegenen Letalität der Waffen stilisierte, der neigte unwillkürlich dazu, die Wirkung der Technik zu unterschätzen.

Die Gleichzeitigkeit der Einsicht in die Wirkungsweise der Waffentechnik und Festhalten an einem antiquierten Kriegsbild kam symptomatisch bei der Uniformierung der Soldaten zum Tragen. Die deut- 
schen Soldaten wurden vor dem Krieg mit feldgrauen Uniformen ausgestattet, erhielten also eine unscheinbare, unauffällige Bekleidung, damit die Gegner ihre Position im Gelände wesentlich schwerer ausmachen und die Soldaten sich möglichst lange dem tödlichen Abwehrfeuer entziehen konnten. Trotz diesem Ziel wurde jedoch an der Pickelhaube festgehalten, die durch ihre Spitze eine gut sichtbare künstliche Erhöhung auf dem Kopf der Soldaten schuf. Lange bevor ein so behelmter Soldat aus seiner Deckung etwas sehen konnte, gab er sich als deutscher Soldat zu erkennen und bot seinen Kopf als Zielscheibe an. Ohne jegliche militärische Rechtfertigung war die Pickelhaube einzig und allein ein Zugeständnis an den deutschen Kaiser Wilhelm II., der ein Faible für imposante Uniformen hatte und sich nur widerwillig mit dem schmucklosen Erscheinungsbild der Soldaten abfinden konnte. ${ }^{11}$ Aber auch die Offiziere reagierten zurückhaltend auf die neuen Uniformen, weil sie keine distinguierenden Merkmale zu den Soldaten im Mannschaftsdienstgrad aufwies. Deshalb gewährte das Kriegsministerium ihnen das Tragen besonderer und auffälliger Abzeichen und dies obwohl die britischen Erfahrungen im Burenkrieg (1899-1902) sowie der eigenen Kolonialtruppen im heutigen Namibia lehrten, dass ihre Erkennbarkeit sie zu bevorzugten Zielen der Gegner machte, weshalb zumindest vereinzelt eine Angleichung der Offiziers- und Mannschaftsbekleidung verlangt wurde (Storz 1992: 287f.). Das Argument, die Offiziere könnten ihr Risiko, verletzt oder getötet zu werden verringern, wenn sie sich nicht von den Mannschaften optisch unterschieden, blieb unberücksichtigt. Es scheiterte am Distingierungsbedürfnis der Offiziere. In ihm drückte sich die unter Offizieren weit verbreiteten Vorstellung von Tapferkeit aus, die sie wiederum für unabdingbar für die Gefechtsführung erklärten. ${ }^{12}$ Ihre optische und akustische Präsens sollte die >Manneszucht ihrer Untergebenen garantieren, ihre weithin sichtbaren Taten sollten die Mannschaften motivieren, sie anspornen, ihren Vorgesetzten zu folgen und gleiches zu tun. Die Sichtbarkeit der Tapferkeit sollte motivierend auf die Untergebenen wirken, und sie sollte zugleich die Anerkennung durch die Vorgesetzten sicherstellen. Von der Sichtbarkeit des Kommandeurs ging zugleich eine kontrollierende Wirkung aus, mussten doch die Soldaten davon ausgehen, dass er sie sehen konnte, wenn sie ihn sahen. So heißt es denn auch im Reglement: »Er [der Offizier, d.A.] hält die Truppe in schärfster Manneszucht und führt sie selbst nach gewaltigen Anstrengun-

11 Siehe Storz (1992: 287f.). In Frankreich stieß die Einführung unscheinbarer Uniformen sogar auf öffentlich artikulierte Ablehnung (ebd.: 291).

12 Für überproportional hohe Verluste an Offizieren, beispielsweise im Deutsch-Französischen Krieg (Zahlen sind bei Kühlich 1995: $397 \mathrm{zu}$ finden) macht Rohkrämer »leichtsinnige Tapferkeit« (1990: 95) verantwortlich. Dass sie aber kein spezifisch deutsches Phänomen war, zeigt an, dass auch auf britischer Seite die Uniformen der Offiziere bis 1915 deutlich erkennbare Unterscheidungsmerkmale aufwiesen (Storz 1992: 292f.; siehe auch Keegan 1991: 283f.). 
gen und schweren Verlusten zum Siege.« (Ex-Regl. 1906: 81, § 266) Aber durch die Präferenz der akustischen und optischen Sichtbarkeit wurde der Handlungsspielraum, den der Schützenschwarm, aber auch die Auftragstaktik den einzelnen Soldaten prinzipiell geboten hätte, unweigerlich eingeschränkt. $^{13}$

Wie sehr die Defensive durch die technischen Innovationen gestärkt wurde, zeigte sich im Verlauf des 1. Weltkrieges im Phänomen des Stellungskrieges. Im Westen kamen die Angriffsoperationen der deutschen Truppen zum Stillstand, nachdem die Verbände sehr hohe Verluste erlitten hatten, und es mit den verbliebenen Kräften nicht gelang, die gegnerische Frontlinie zu durchbrechen. Die deutschen Streitkräfte verzeichneten in den ersten drei Kriegsmonaten im Westen die höchste Verlustrate des gesamten Krieges. Sie »betrug 12,4 Prozent im August und 16,8 Prozent im September 1914. Über den ganzen Kriegsverlauf bis zum Juli 1918 lag die durchschnittliche Monatsquote im Westen dagegen nur bei 3,5 Prozent. Einen Anstieg der Verlustzahlen der den Verhältnissen der ersten Kriegsmonate gleichkam, hatten erst wieder die Frühjahrsoffensive des Jahres 1918 und noch stärker die Rückzugskämpfe der letzten Kriegsmonate zur Folge.« (Ziemann 2004: 156) ${ }^{14}$

In den ersten beiden Kriegsjahren des 1. Weltkrieges spielte die Auftragstaktik als Teil einer taktischen Einsatzkonzeption nur eine geringe, aber allmählich stärker werdende Rolle (Borgert 1979: 513). Mit der Ablösung der zweiten Obersten Heeresleitung unter von Falkenhayn (Ende August 1916) sollte sie jedoch einen gewichtigen Bezugspunkt in den unter Ludendorff durchgesetzten Vorschriften zur Verteidigung von Stellungen und später dem entwickelten Reglement zur Angriffsführung (siehe Abschnitt 7.3.) bilden.

Doch bevor auf diese Veränderungen eingegangen wird, sei hier noch einmal das Spezifikum der Auftragstaktik betont: Nach Leistenschneider sollte die Auftragstaktik durch den Verzicht einer umfassenden Reglementierung der Ausbildung und des Gefechts bei der Befehlserteilung die »Freiheit der Form« ermöglichen (Leistenschneider 2002: 5). Durch sie sollte für die Kriegführung ein Maximum soldatischer Subjektivität bei den Vorgesetzten mobilisiert werden. Der ihnen gewährte Handlungsspielraum diente der Bewältigung der Kontingenz des Kriegsgeschehens, zu allererst des infanteristischen Kampfgeschehens. Durch die Gleichzeitigkeit des Verzichts auf Reglementierungen und der auf den Vorgesetzten lastenden Pflicht, Befehle zu erteilen, wurde die Auftragstaktik zu einem

13 Bereits 1893 charakterisierte ein us-amerikanischer Militärbeobachter das Verhältnis Kontrolle und in Kaufnahme von Toten beim deutschen Militär mit den Worten: »They prefer to lose man than lose control of the officer over them.« (Zitiert nach Gudmundsson 1989: 1)

14 Bei diesen Zahlenangaben ist zu bedenken, dass die Verlustquote bei den Kampfverbänden weit höher liegen konnte. 
Subjektivierungskonzept. Seine Umsetzung scheiterte aber weitgehend insbesondere am Kontrollbedürfnis gegenüber den Subalternen und an einer Kriegskonzeption, in deren Zentrum schnell auszuführende und ohne Rücksicht auf Verluste durchzuführende Angriffsoperationen standen.

\subsection{Der industrialisierte Krieg}

Der 1. Weltkrieg gilt allgemein als erster industrialisierter Krieg. Indes wirkte sich die Industrialisierung der Gesellschaften und damit verbunden die verbesserten Transport- und Kommunikationstechniken schon zuvor auf das Kriegsgeschehen aus. So war es im Krim-Krieg (1854-56) das verbesserte Nachschubwesen, das den Krieg entschied. Die Kontrahenten konnten sich nicht aus dem umliegenden Land versorgen und mussten deshalb alles über eine Entfernung von einigen tausend Kilometern dem Kriegsgeschehen zuführen. Die russischen Truppen, die in der Festung Sewastopol von französischen und englischen Truppen fast ein Jahr lang belagert wurden, konnten zwar über Land versorgt werden, doch erwies sich dieser Umstand nicht als ein Vorteil, weil ihnen hierfür kein Eisenbahnnetz zur Verfügung stand. Während deshalb der zaristische Staat auf Pferdefuhrwerke zurückgriff, wurden die alliierten Truppen über See mit Gütern versorgt. Für den Transport der Güter und Truppen auf den letzten Kilometern zwischen Hafen und Frontlinie wurde eigens eine Schmalspureisenbahn gebaut. Der Transport über See erwies sich für die alliierten Truppen als ein großer Vorteil, da er den Transport von Massengütern begünstigte. Und diesen Vorteil konnte der zaristische Staat nicht einmal durch die Beschlagnahmung von bis zu 125.000 Bauernkarren ausgleichen. Ungenügend versorgt, in den letzten Tagen mit bis zu 52.000 Granaten am Tag beschossen, gaben die russischen Truppen die stark zerstörte Festung am Ende auf (siehe McNeill 1984: 204f., Gitermann 1987: 70f.).

Auch im US-amerikanischen Sezessionskrieg (1861-65) hatte das durch die Eisenbahn revolutionierte Nachschubwesen einen entscheidenden Einfluss auf das Kriegsgeschehen. Armeen in einer Stärke von 100.000 Mann konnten jahrelang in zum Teil dünn besiedelten Regionen kämpfen, weil sie ihren Nachschub durch Eisenbahnen aus einer Entfernung von mehreren hundert Kilometern bezogen. Die Südstaaten gewannen zwar zu Beginn des Krieges die Schlachten, da sie mit gewiefteren militärischen Befehlshabern aufwarteten und über hoch motivierte Truppen verfügten, doch den Krieg verloren sie, weil die Nordstaaten ihr größeres industrielle Potential gegenüber dem eher agrarischen Süden durch ein besser ausgebautes Eisenbahnnetz ausspielen konnten. Die Fähigkeit, geschlagene Armeen schnell wieder aufzubauen, diese mit mehr und besserem Kriegsmaterial, mit Lebensmitteln, usw. zu versorgen, entschied den Krieg. Nachdem die Unionstruppen durch die Besetzung 
Georgias die konföderierten Eisenbahnlinien unterbrachen, kapitulieren die Südstaaten (siehe McNeill 1984: 216).

In den genannten Kriegen bauten die Soldaten bereits Gräben, um sich vor dem gegnerischen Gewehr- und Artilleriefeuer zu schützen. Im Sezessionskrieg wurde es

»ab 1864 zur Regel, dass sich die Truppen eingruben, wohin immer sie kamen. [...] Grabensysteme veränderten das Gesicht der Schlacht. An die Stelle kurzer, heftiger Zusammenstöße traten zunehmend wochenlange Feuergefechte, die von den oft weniger als 100 Meter voneinander entfernten Gräben aus geführt wurden. Sturmangriffe, die das Patt durchbrechen sollten, waren hochriskante Unternehmen, die eine massive personelle Überlegenheit erforderten, um Chancen auf Erfolg zu haben.« (Walter 2004: 206)

Mit Beginn des 20. Jahrhunderts war die Industrialisierung des Krieges bei den avanciertesten Streitkräften praktisch vollzogen, und die Tragweite dieses Prozesses war im Russisch-Japanischen Krieg (1905) und in den Balkankriegen (1912/13) unübersehbar geworden. Es war deshalb auch weniger die Neuheit der Phänomene, die den Ruf des 1. Weltkrieges als ersten industrialisierten Krieg begründeten, als vielmehr der Umstand, dass sich in diesem Krieg die führenden Industriestaaten über Jahre hinweg bekämpften. Mit dem 1. Weltkrieg endete das 19. Jahrhundert und das `Zeitalter der Extreme` (Hobsbawm) begann.

Die industrielle Kriegführung machte sich besonders eindrücklich in den Stellungskämpfen an der Front bemerkbar, in der deutsche Truppen zunächst französischen und englischen und ab 1917 auch amerikanischen Verbänden gegenüberstanden. Auf diesem Kriegsschauplatz setzten die führenden Industriestaaten den größten Teil ihrer Truppen und die ihnen zur Verfügung stehenden materiellen Ressourcen ein. Aber nicht nur hier gruben sich Truppen ein und standen sich die Gegner mitunter nur wenige Meter voneinander getrennt gegenüber. Auch im alpinen Kriegsgebiet entwickelten sich ähnliche Verhältnisse wie in der (deutschen) Westfront. Und selbst in den osteuropäischen Kampfzonen, wo die Kontrahenten zwischen 1914 und 1917 große operative Bewegungen durchführten, entwickelten sich sofort Stellungskämpfe, wenn die Angriffe an der gegnerischen Abwehr scheiterten.

Die Frontbildung im 1. Weltkrieg war ein neuartiges Phänomen. Zuvor bildeten sich Fronten, also Kampflinien in denen sich die Gegner ständig gegenüberstanden, nur punktuell, wenn eine gegnerische Stadt oder Festung belagert wurde. Die Ausbildung von Fronten war unmittelbarer Ausdruck der Industrialisierung, weil nur aufgrund der im 19. Jahrhundert entschieden verbesserten und ausgebauten Straßen und dem Aufbau von Eisenbahnnetzen die Truppen kontinuierlich mit Nachschub an Waffen und Munition aus den industriellen Zentren und aus den Agrargebieten mit Lebensmitteln versorgt werden konnten. Durch das Transportwesen konnte 
in einem zuvor unbekannten Ausmaß die Ökonomie der Krieg führenden Gesellschaften, ihre Produktivkraft permanent zum Unterhalt des Kriegsgeschehens herangezogen werden. Durch die permanente Anbindung der Front an die Gesellschaft wurde diese zum Hinterland der Front.

Im Westen wurde über vier Jahre hinweg um fast die gleichen Räume gekämpft. Die Stellungskämpfe im Westen waren Ausdruck einer Pattsituation, die zwischen den Kriegsgegnern bestand. Sie zeigten an, wie erfolgreich es den Staaten Deutschland, Frankreich und England gelang, ihre gesellschaftlichen Ressourcen für den Krieg zu mobilisieren. Da ein großer Teil des Transportwesens der Kriegsparteien auf dem Eisenbahnnetz beruhte, das im Nahbereich der Front beispielsweise um Schmalspurbahnen ergänzt wurde, erleichterten die starren Frontlinien sogar die $\mathrm{Zu}$ führung neuer Truppen, Waffen und Munition. Jede Bewegung der Truppen weg von den Endpunkten der auf Schienenstränge ausgerichteten Nachschubwege hingegen erschwerte ihre Versorgung. Der technologische Entwicklungsstand begünstigte also abermals die Defensive. ${ }^{15}$

Im Stellungskrieg an der Westfront bildeten sich zahlreiche Merkmale aus, die sich in allen seitdem mit industriell gefertigten Waffen und auf Industrieressourcen abgestützten Kriegen wieder finden lassen. Die lang anhaltenden Stellungskämpfe gehören ausdrücklich nicht dazu. Wie bereits auf dem östlichen Kriegsschauplatz des 1. Weltkrieges zeigen sie eher die Erschöpfung der Kriegsparteien an. Zwar beginnen Soldaten sofort, in der Erde Schutz vor dem gegnerischen Feuer zu suchen, wenn ein Gebiet auch nur für kurze Zeit umkämpft ist, doch lang anhaltende Stellungskämpfe entwickelten sich nur, wenn die Kriegsparteien >erschöpft ‘ sind, also keine Partei über derart überlegene Kräfte verfügt, dass sie eine verteidigte Stellung überwinden kann. Zuletzt kam es im Krieg zwischen den Irak und Iran (1980-88) und zwischen Eritrea und Äthiopien (1998-2000) zu solchen Stellungskämpfen.

Verantwortlich für den Bedeutungswandel des Stellungskrieges sind zum einen technologische Entwicklungen, die die Offensivstärke insgesamt erhöhten. So wurde es mit dem Bau von Panzern wieder möglich,

15 Diese Feststellung lässt sich auch für die eingesetzten Kommunikationstechniken treffen. Bis 1918 stützte sich die Kommunikation zwischen der Front und den rückwärtigen Stellungen weitgehend auf drahtgestützte Techniken ab. Dies machte sich bei der deutschen Frühjahrsoffensive bemerkbar. Ein Kernelement der Offensive, das Zusammenwirken von Artillerie und Infanterie, scheiterte, nachdem es den deutschen Infanterieverbänden gelungen war, in die gegnerische Front einzubrechen und damit auf Meldegänger, Leuchtraketen angewiesen waren, um Artillerieunterstützung anzufordern. Mit den wenigen mitgeführten Funkgeräten wurden nur wenige und obendrein häufig verstümmelte Funksprüche gesendet, vermutlich, weil die Mannschaften snach den anstrengenden Märschen kaum in der Lage waren, die benötigten Stromstärken [für den Sendebetrieb, d.A.] mit Hilfe von Tretgestellen zu erzeugen.« (Kaufmann 1996: 254) 
einen von der gegnerischen Artillerie beschossenen Raum ohne große Verluste zu durchqueren und durch den Einsatz von im Fahrzeug eingebauten Maschinengewehren und Kanonen die Verteidiger einer Stellung in Deckung zu zwingen. Die Infanterie verlor durch die Panzerwaffe entscheidend an Defensivstärke. Die allmählich und immer umfassender betriebene Motorisierung der Verbände verringerte darüber hinaus ihre Abhängigkeit vom Schienennetz bei offensiven Operationen und beschleunigte zugleich das Tempo der möglichen Bewegungen. Ausgenutzt werden konnte diese beschleunigte Bewegungsfähigkeit der Kampfverbände erst, als sie mit Funkgeräten ausgestattet wurden. Auf der Kommunikation per Funk basierten deshalb auch Einsatzkonzepte, die für offensive Operationen von motorisierten Verbänden, Panzer und Infanterie, entwickelt wurden und die auch die Koordination des Einsatzes von Bodenund Luftstreitkräfte ermöglichen sollten, nachdem die am Boden operierenden Einheiten durch die gegnerischen Linien durchgebrochen waren. ${ }^{16}$ Gegen Ende des 2. Weltkrieges standen dann erstmals zumindest vereinzelt den Streitkräften der westlichen Alliierten leistungsfähige und sprichwörtlich handlich gewordene Funkgeräte zur Verfügung, die selbst von einzelnen Infanteristen getragen werden und mit denen sie Unterstützung von Artillerie oder Flugzeugen anfordern konnten.

Obwohl also der Stellungskrieg eine Ausnahmeerscheinung wurde, teilen der 1. Weltkrieg im Allgemeinen und die Kämpfe an der Westfront im Besonderen mehr Merkmale mit den nachfolgenden als mit den früher geführten Kriegen. Bereits bei oberflächlicher Betrachtung des Kriegsgeschehens zeigt sich, dass die Zeiten vorbei waren, in denen gut sichtbare, bunt uniformierte Truppenverbände aufmarschierten und sich gegenseitig bekämpften. Doch mit dieser äußerlichen Differenz sind die Folgen der industrialisierten Kriegführung für das unmittelbare Kriegsgeschehen nicht hinreichend bestimmt. Im Folgenden sollen deshalb weitere gravierende Änderungen skizziert werden.

- Die industrialisierte Kriegführung ermöglicht eine zuvor weitgehend unbekannte Permanenz der Kampfhandlungen. Schranken für das Kriegsgeschehen, wie sie zuvor von natürlichen Zyklen, wie den Wechsel der Jahreszeiten, den Übergang vom Tag auf die Nacht oder auch dem Wetter gebildet wurden, schwächten sich zu Hemmnissen ab. Der Krieg muss nicht mehr als Kampagne geplant werden, weil im Marsch- und Operationsgebiet der Truppen keine große Mengen Futter für die Pferde und für den Transport notwendige Tiere vorhanden sein müssen. Von vor Ort vorhandenen Ressourcen hängt die Kriegführung nicht mehr ab. Sie ist vielmehr abhängig von der industriellen Produktion und der Zufuhr von Personal und Gütern aus dem Hinterland. Ohne die Zuführung von fossilen Brenn- und Treibstoffen, die vor ihrer

16 Ausführlich zeigt Kaufmann die Bedeutung des Funks für die Offensivkonzeption der Wehrmacht auf (1996: 302). 
Verwendung industriell aufbereitet werden müssen, verlieren die Verbände ihre Beweglichkeit. $\mathrm{Zu}$ schlechtes Wetter, ungenügende Sichtverhältnisse für den Einsatz bestimmter Waffen gibt es weiterhin, doch verhindert der Winter oder Regen nicht mehr, dass Waffen abgefeuert werden können, wie dies bei Waffen wie dem Bogen oder den Steinschlossflinten der Fall war. Ein Krieg wird nun nicht mehr notwendigerweise von demjenigen verloren, der die größeren Verluste an physischen Kräfte erleidet. Nicht die Höhe der Verluste entscheidet die Frage Sieg oder Niederlage, sondern ob es gelingt, neue Kräfte dem Krieg zuzuführen.

- Das Kriegsgeschehen kann und muss sich in allen technisch erreichbaren Räume ausbreiten und sie dauerhaft in Beschlag nehmen. Aufgrund der Abhängigkeit von der ständigen Zufuhr von Ressourcen zielen militärische Operationen darauf $\mathrm{ab}$, die Versorgungslinien der gegnerischen Truppen zu unterbrechen. Um diese Gefahr abzuwenden, müssen die Kriegsparteien potentiell um alle Räume kämpfen können, die der Gegner seinerseits angreifen kann. Zwischen den Kriegsparteien entstehen deshalb permanent umkämpfte Räume. Diese umkämpften Räume hatten im 1. Weltkrieg am Boden noch eine halbwegs eindeutige Grenze, die vor allem von der Reichweite der gegnerischen Artillerie umrissen wurde. Nur vereinzelt griffen damals Flugzeuge und Luftschiffe auch jenseits dieser Grenze das rückwärtige Gebiet des Gegners an und warfen Bomben beispielsweise auf Bahnhöfe und Städte. Dies änderte sich ab den 30er Jahren des 20. Jahrhunderts, nachdem Flugzeuge entwickelt wurden, die ein erhebliches Zerstörungspotential weit über die Front hinweg in das Hinterland des Gegners transportieren konnten. Seitdem hängt es von der Herrschaft über den Luftraum sowie der Reichweite der eingesetzten Flugzeuge und später von Raketen ab, wie sehr der Krieg im Hinterland präsent wird.

- Die weitgehende Unsichtbarkeit der Gegner ist neben der immensen Ausdehnung des umkämpften Terrains verantwortlich für die Unübersichtlichkeit des Gefechtsfeldes. Auf dem Gefechtsfeld sind nur selten Menschen zu sehen und wenn doch, dann meist nur schemenhaft auf weite Entfernungen hin. Es wirkt deshalb auf den Betrachter als menschenleer. Für die Infanteristen, die mitunter allein oder mit wenigen anderen Soldaten das Gefechtsfeld beobachten, ist es »die einsamste Gegend, in der Menschen beisammen sind.« (Marshall 1947: 45)

Die Artilleriegeschütze, die Infanteriewaffen, zu denen auch das Maschinengewehr zählt, und die Angriffe aus der Luft, mit denen seit dem Ende des 1. Weltkrieges in zunehmenden Umfang gerechnet werden muss, können das Gefechtsfeld mit einer großen Zahl tödlicher Geschosse eindecken. Deshalb versuchen sowohl Verteidiger als auch Angreifer, möglichst wenig das gegnerische Feuer auf sich zu ziehen und sich möglichst lange vor der Waffenwirkung zu schützen. Aus 
einem Verhalten, das noch im 19. Jahrhundert als ehrenrührig, unsoldatisch galt, wurde eine Gefechtstugend: sich vom Gegner nicht sehen zu lassen. Das Suchen bzw. Herstellen von Deckung gehört heute zu den Ausbildungszielen von Soldaten. Das Ideal für die Gefechtsführung ist: die Lage erkennen, sich auf dem Gefechtsfeld zu bewegen, den Gegner zu bekämpfen und dabei für ihn stets unsichtbar zu bleiben.

- Im industriellen Krieg erzeugen die Waffen vornehmlich killing fields. Ein gemeinsames Merkmal dieser Waffen ist ihre hohe Feuergeschwindigkeit. Artilleriegeschütze, Maschinengewehre und Raketenwerfer richten sich aufgrund ihrer Kadenz, aber auch durch die Streuung der abgefeuerten Geschosse, letzteres gilt auch für Bomben, nicht gegen einzelne Menschen. Sie sind vor allem dazu geeignet, sichtbare wie unsichtbare Gegner in einem bestimmten Gebiet tödlich zu verletzen oder doch zumindest in Deckung zu zwingen und großflächige Zerstörungen anzurichten. Auch mit den automatischen Gewehren und Maschinenpistolen mit denen Infanteristen spätestens seit dem 2. Weltkrieg ausgerüstet werden, lässt sich ein Geschosshagel erzeugen, der das beschossene Areal in eine tödliche Zone verwandelt.

Dieses Merkmal des industrialisierten Krieges führt dazu, dass selbst nach kurzen Feuergefechten der betroffene Raum mit Einschüssen übersät ist. Je nach Dauer des Gefechts und der eingesetzten Waffen wird die gesamte Topographie des Raumes von den Destruktionskräften geprägt und verwandelt sich in eine zertrümmerte, zerschlagene und ausgebrannte Landschaft. Eine Unterscheidung zwischen militärischer und ziviler Infrastruktur findet dabei ebenso wenig statt wie zwischen Kombattant und Nichtkombattant. In den killing fields sind Gefechtsformen, wie Kämpfe über kurze Distanz, der gezielte Schuss auf einzelne Menschen oder auch auf Waffen, wie Panzer, eingebettet.

- Die Industrialisierung bedeutete eine Steigerung der Destruktionskräfte. Die von industriell gefertigten Waffen ausgehende Gewalt macht die Kriegführung nicht brutaler, gemeiner oder inhumaner. Die Schmerzen, die vorindustriell hergestellte Waffen hervorrufen, sind prinzipiell nicht geringer als die Schmerzen, die Projektile verursachen, die beispielsweise ein Granatwerfer verschießt. Die Industrialisierung der Destruktionskräfte vertiefte aber die seit Einführung der Schusswaffe geltende Tendenz, jeden einzelnen Waffenträger mit Mitteln auszustatten, in denen zerstörerische Energien gespeichert sind, die keine unmittelbare Verbindung zu seinen individuellen Fähig- und Fertigkeiten haben. Sie bedeutete vor allem eine zeitliche Verdichtung bei der Freisetzung zerstörerischer, tödlich wirkender Energie. Dies gilt bereits für jeden einzelnen Infanteristen und mehr noch für das gesamte Waffenarsenal eines Heeres. Über Jahrtausende hinweg benötigten Akteure für bestimmte Gewalttaten, wie das Verwüsten eines Landstrichs, das Brandschatzen und Plündern von Land und Städten sowie das Hinmetzeln 
ihrer Bevölkerung ungefähr die gleiche Zeit, weil sie neben dem Feuer vor allem auf ihre Muskelkraft angewiesen waren, um ihr Werk zu vollbringen. Heute hängt das Tempo, in dem solche Gewalttaten vollbracht werden, entscheidend von den eingesetzten Mitteln ab. Im Extremfall benötigt eine Atombombenexplosion nur noch wenige Sekundenbruchteile. Allgemein gilt, dass das Ausmaß der angerichteten Zerstörungen und die Zahl der Toten weniger denn je von der Zahl der unmittelbar eingesetzten Waffenträger bestimmt werden, sondern von den eingesetzten Mitteln.

- In den Destruktionsräumen bilden sich Ensemble sozialer Verhältnisse, deren Spezifikum die permanente Präsenz des Tötens ist. So viel Elend, Leid und Tod bereits der Kriegszustand in vorindustriell geführten Kriegen für die Menschen bereithielt, so groß die Gefahr war, zu verhungern und an einer Krankheit zugrunde zu gehen - die Todesgefahren im Rahmen eines Gefechtes bestanden meist nur für relativ kurze Zeiträume. Und so heftig die Affekte des Einzelnen waren, so traumatisch das hier Erlebte auf ihn wirkte, erst mit der Industrialisierung verdichten sich solche Situationen regelmäßig zu einem Dauerzustand. Für Soldaten bedeutet die Permanenz der Kampfhandlungen, dass sie Todes- und Tötungsbereitschaft in einem zuvor unbekannten Ausmaß in ihren Alltag integrieren müssen. Durch das extensiv gesteigerte Kampfgeschehen steigt die prinzipiell bestehende Wahrscheinlichkeit für die Akteure enorm an, dass sie im Verlauf der Kampfhandlungen mit ihren physischen wie psychischen Grenzen konfrontiert werden und folglich in der Gefahr stehen, vom Erlebten überwältigt zu werden. Die Akteure sind einem zerstörerischen physischen und psychischen Raubbau ausgesetzt, auf den sie sich vorbereiten können, aber an dem sie sich nicht gewöhnen können. Kampfeinsätze müssen deshalb in aller Regel durch Ruhephasen unterbrochen werden, um für eine Regeneration der physischen Verfassung zu sorgen, die von einem Mangel an Flüssigkeit, Nahrungsmittel und Schlaf angegriffen wurde. Auch für die psychische Regeneration sind Ruhephasen notwendig, allerdings ist eine Regeneration im Sinne einer Wiederherstellung in den vorherigen Zustand ausgeschlossen.

Für einen nachhaltigen Effekt des Kampfgeschehens auf die Psyche der Akteure spricht neben seiner zeitlichen Ausdehnung auch die gesteigerte Destruktionskraft der eingesetzten Waffen, die zu intensiven sinnlichen Eindrücken bei den Soldaten führen. Beim Abschuss und noch mehr beim Detonieren bzw. Einschlag der Projektile wird sehr viel Energie freigesetzt. Bereits ohne eine unmittelbare Verletzung hervorzurufen, strapazieren sie als Lärm, als Erschütterung des Raums, als Gestank, Hitze und Luftdruck intensiv die Sinne der Soldaten. Beispielsweise wird der Knall, der beim Abschuss eines Artilleriegeschosses entsteht, häufig zum Getöse 
im Ohr der Soldaten, die das Geschütz bedienen, weil er die Fähigkeit ihres Gehörsinns zur Aufnahme des Geräuschs übersteigt und droht es dauerhaft zu schädigen. Schon die von der eingesetzten Waffentechnik ausgehenden Sinneseindrücke tragen zur Unwirklichkeit der Kriegserlebnisse bei, was wiederum dazu führt, dass sie von den Subjekten schwerer zu etwas Erfahrenem gemacht und kommuniziert werden können.

\subsection{Folgen des industrialisierten Krieges}

Mit den Kriegserklärungen im August 1914, die den Beginn des 1. Weltkrieges markieren, wird bis heute die Erinnerung an jubelnde, mitunter fahnenschwenkende Menschen (überwiegend Männer) und an Frauen verbunden, die den aus den Kasernen ziehenden Soldaten Blumen schenkten. Die Kriegsbegeisterung erfasste tausende überwiegend junge Männer, die noch nicht beim Militär gewesen waren und die sich nun als Kriegsfreiwillige ${ }^{17}$ bei den Militärbehörden meldeten. Diese Reaktionen auf den Kriegsbeginn waren zum einen den spezifischen Verhältnissen in den (westeuropäischen) Vorkriegsgesellschaften geschuldet und waren auch nicht gleichmäßig in allen sozialen Schichten anzutreffen. Bedeutsamer erscheint aber in dem hier zu besprechenden Zusammenhang zu sein, dass die Begeisterung schnell wieder verebbte und sie seitdem fast ein Unikum der Geschichte geblieben ist. Am industrialisierten Kriegsgeschehen entzündet sich keine Begeisterung. ${ }^{18}$

Im Nachstehenden sollen einige Auswirkungen der Industrialisierung des Krieges näher untersucht werden. Die Untersuchung konzentriert sich dabei auf drei Aspekte. 1.) Die Industrialisierung des Krieges kann als Grund dafür angesehen werden, dass die Begeisterung schwand, denn sie

17 Durch weit übertriebene Zahlenangaben wurde in der Öffentlichkeit der Eindruck erweckt, alle jungen Männer hätten sich zum Kriegsdienst gemeldet. Wer nicht uniformiert war, sah sich mit der Erwartung konfrontiert, entweder demnächst einen Stellungsbefehl zu erhalten oder sich freiwillig zu melden. Siehe hierzu Ulrich (1992a: 114). Weitere Informationen insbesondere zu den englischen Kriegsfreiwilligen sind in Ziemann (2004a: 639f.) zu finden.

18 Dass der auf Bildern dokumentierte Jubel bei weitem nicht die einzige Reaktion auf den Kriegsbeginn war, zeigen Berichte, die von um sich greifender Panik in der Bevölkerung berichten. Alles was als anormal und fremd erschien, löste häufig Angst aus und zog Aggressionen auf sich. Auf Pkws, die scheinbar zu schnell fuhren, wurde im August 1914 geschossen. Bereits das Aussprechen eines Fremdwortes auf der Straße konnte dazu führen, dass man als Spion verdächtigt, verprügelt und verhaftet wurde. An vielen Orten kam es zu Hamsterkäufen, Sparguthaben wurden aufgelöst und Händler weigerten sich Papiergeld anzunehmen. Literatisch hat Kraus (1929: 69f.) diese Stimmung dokumentiert. Psychiater stuften die Begeisterung schnell als eine Massenpsychose ein und Plaut wertete sie »als eine psychische Krise« (1921: 10); siehe hierzu auch Ulrich (1992a: 112). 
führte dazu, dass nicht nur das Vorkriegsbild vieler Kriegsteilnehmer zerbrach, sondern sie bot auch wenig Anknüpfungspunkte für Sinndeutungen, in denen sich die Soldaten als (heroische) Subjekte wiederfanden. 2.) Seit dem 1. Weltkrieg zählen heute psychosomatische Reaktionen auf Kriegserlebnisse zu den unvermeidlichen Folgen von Kampfeinsätzen. 3.) Die Industrialisierung erschwerte den Angriff auf Defensivstellungen enorm. Jahrelange Stellungskämpfe um den gleichen Raum, vor allem an den Kriegsschauplätzen im Westen und in den Alpen, waren das Ergebnis. Der Frage, mit welchen taktischen Einsatzkonzeptionen die militärischen Führungen versuchten, die gegnerischen Stellungen zu durchbrechen, soll am Schluss dieses Abschnitts nachgegangen werden.

\subsubsection{Das industrialisierte Kriegsgeschehen}

»Nicht Aggression oder ein geheimer Todestrieb motivierten die Kriegsbegeisterten dazu, freudig in den Krieg zu ziehen, sondern der Wunsch, sich und ihren Kameraden die eigene Tapferkeit und Männlichkeit unter Beweis zu stellen.« (Rohkrämer 1990: 263) In einem zuvor unbekannten Ausmaß erfüllte vor dem 1. Weltkrieg die Ableistung des Kriegsdienstes die Funktion eines Initiationsritus, der trotz eines für Wunschträume und Illusionen zerstörerischen (Kasernen-)Alltages »eine kritische Beurteilung des Soldatendaseins fast unmöglich« machte (ebd.). Über Schicht- und Klassengrenzen hinweg wurde Männlichkeit und Soldatsein im Kaiserreich zusammengedacht. Diese Subjektkonstruktion machte es möglich, den Krieg als einen befreienden Akt zu begreifen bzw. als eine Bewährungsprobe zu sehen, nach der sich sehr viele Männer sehnten, die aufgrund ihrer militarisierten Sozialisation ein am Krieg orientiertes Selbst entwickelt hatten. ${ }^{19}$ Ihr Vor-Kriegsbild war überwiegend eine Mixtur aus Militärparade und Kriegserzählungen anno 1871, amalgamisiert mit dem romantischen Bild, das man sich vom Gefecht eines Ritters im Mittelalter machte.

Eine neue Erfahrung formulierte der Kriegsfreiwillige Toller nicht, als er feststellte, dass seine Vorgesetzten nicht wussten, was sie $»$ mit unserem Enthusiasmus« anfangen sollten und dass er und die anderen Soldaten »sinnlos gedrillt« (1933: 41) würden. Neu waren die Erlebnisse und Erfahrungen, die die Soldaten mit dem Kriegsgeschehen machen mussten.

Im Fokus des Kriegsgeschehens stand der Raum, der sich zwischen den gegnerischen Armeen befand, der, wie seine Bezeichnung Niemandsland verrät, von keiner Streitmacht beherrscht wurde, dafür aber mit diversen bodengestützten Waffen beschossen werden konnte, und sein Nahbereich, die Frontlinien, dessen äußerer Rand wiederum von der Reichweite

19 Über weitere, hier aber nicht berücksichtigte Aspekte der Selbstentwürfe >soldatischer Männer` vor dem 1. Weltkrieg, beleuchtet die Arbeit von Theweleit (1977). 
der gegnerischen Artillerie bestimmt wurde. Die Breite dieses Raumes variierte und umfasste gegen Ende des Krieges insgesamt allenfalls mehrere 1000 Meter. In dieser Zone starben die meisten Soldaten des 1. Weltkrieges. Ob und mit welcher Intensität die Soldaten Kontakt mit der Todeszone hatten, hing entscheidend davon ab, welchem Truppenteil sie zugeordnet waren, sowie von ihrer Stellung in der Militärhierarchie. Viele Soldaten, die den Unterstützungstruppen zugeordnet waren, ob nun als >Schipper oder Trainsoldat, standen meist am Rande dieses Fokus, mussten sich nicht in Schützengräben aufhalten, aber sehr wohl im Feuerbereich der Artillerie, und sie waren auch nicht vor Fliegerangriffen sicher. Je höher der Dienstgrad eines Soldaten war, desto eher konnte, ja musste er sogar Distanz zum unmittelbaren Kampfgeschehen halten. Während sich noch die unteren Offiziersränge ebenfalls in den vordersten Stellungen aufhalten mussten, rückten mit dem steigenden Rang die Offiziere von der Todeszone ab, weil sie nur auf diese Weise einen Überblick über die Lage erhalten und die ihnen unterstehenden Truppen kommandieren konnten. ${ }^{20}$ Nur punktuell konnte ein hochrangiger Offizier durch seine Anwesenheit im vordersten Graben die Lage besser beurteilen, aber dafür erhielt er in dieser Zeit schwerer Nachrichten von anderen Abschnitten, und für ihn war es schwieriger, Truppenteilen, die jenseits des Grabens ihre Stellung hatten, Befehle zu erteilen. Für hochrangige Offiziere bestand also kein sachlicher Grund, sich im gleichen Grad den Gefahren auszusetzen, wie dies den Soldaten im Mannschaftsdienstgrad zugemutet wurde. Die Position in der Militärhierarchie wirkte sich obendrein auf den Umfang und die Qualität der Verpflegung, der Besoldung, sowie der Unterkunft aus. Offiziere hatten grundsätzlich den Zugriff auf die besten und sichersten Quartiere, und bevor sie unter Verpflegungsmängel leiden mussten, hungerten die Mannschaften schon lange.

Bereits die Anschauung des Raumes verdeutlichte den Soldaten, die sich in der Todeszone aufhielten, in welcher Gefahr sie sich befanden. Vertraute Landschaftsformen waren einer von der Waffenwirkung zerschlagenen, mit Müll, Leichen(teilen) und zerstörtem Kriegsinventar angefüllten Ödnis gewichen. Ihr Geruchssinn drängte ihnen vor allem im Sommer ekelerregende Empfindungen auf, roch es doch nach Kot und vor allem nach Verwesung. Auch die Empfindungen, die durch den Gehörsinn ausgelöst wurden, konnten sehr quälend sein: Das Feuer der Geschütze bzw. die Einschläge der Granaten verursachten einen ohrenbetäubenden Lärm, der mitunter die Trommelfelle platzen ließ und »mehr mit den Augen, als mit dem Ohr« erfassbar (Latzko 1917: 61) war. Die Druckwellen konnten tödliche Lungenrisse verursachen. Andererseits konnte »insbesondere nachts beängstigende Stille [herrschen, d.A], die beim kleinsten

20 Zum Stand der Kommunikationstechnik im 1. Weltkrieg siehe Kaufmann (1996: 209f.). 
Geräusch aufschrecken ließ«. Hinzu kam »das Angstgeschrei der Pferde ${ }^{21}$ und am unerträglichsten die Hilferufe und das Stöhnen der Verwundeten, die, wenn überhaupt, oft erst nach langer Zeit geborgen werden konnten.« (Bröckling 1997: 203)

In der Todeszone gab es im Alltag der Soldaten Phasen langwieriger Vorbereitungen zur Verteidigung der Stellung bzw. des eigenen Angriffs auf die gegnerischen Gräben, Phasen, in denen sie angespannt auf gegnerische Offensiven bzw. auf das Signal zum Angriff warten mussten und schlussendlich die meist sehr kurzen Phasen größter Aktivität, wenn um die Gräben gekämpft wurde. Langeweile und höchste Anspannung konnten besonders beim lange währenden Beschuss zusammenfallen. Dass in den Erinnerungen ehemaliger Soldaten die Gefahren des Artilleriefeuers eine herausragende Bedeutung einnimmt, lässt sich mit Blick auf die Ursachen für Verletzungen und Todesfälle begründen. Mit zunehmender Dauer des Krieges waren sie »in der Mehrzahl aller Fälle eine Folge artilleristischen Beschusses [...]. 76 Prozent aller von Ende 1914 bis 1917 verwundeten französischen Soldaten wurden von Artilleriegeschossen getroffen. Dies ist ein Wert, der 1917 auch bei einer deutschen Armee gemessen wurde. Für die an der Westfront eingesetzten Truppen dürfte er somit repräsentativ sein.« (Ziemann 2004: 157) ${ }^{22}$ Aber auch aus einem anderen Grund traten in den Schilderungen der Fronterlebnisse andere Gefahren in den Hintergrund. Erfahrene Soldaten konnten riskante Situationen erkennen, Verhaltensregeln entwickeln, die beispielsweise einen gewissen Schutz vor den Auswirkungen von Giftgas versprachen. Die Hoffnung, durch eigenes Handeln die Situation zu entschärfen, half den Soldaten, ihre Angst vor Verletzungen und dem Verlust des eigenen Lebens zu verringern. Anders dagegen, wenn sie von der Artillerie beschossen wurden oder sich dem Maschinengewehrfeuer aussetzen mussten, dann lebten sie »in der Spannung des Ungewissen« (Remarque 1929: 76), die sie nicht durch eigene Handlungen verringern konnten. „Wenn ein Geschoss kommt, kann ich mich ducken, das ist alles; wohin es schlägt, kann ich weder genau wissen noch beeinflussen.« (Ebd.) Das Überleben hing vom Zufall ab. »Ebenso zufällig, wie ich getroffen werde, bleibe ich am Leben.« (Ebd.) Mit der Erinnerung an den Beschuss war unvermeidlich das quälende Gefühl der Hilflosigkeit gegenüber der tödlichen Gefahr verbunden. ${ }^{23}$ In

21 Pferde kamen im Frontbereich beim Transport von Nachschub und beim Stellungswechsel der Geschütze zum Einsatz.

$22 »$ Infanteriemunition verursachte dagegen nur rund 16 Prozent, Handgranaten 1-2 Prozent und Giftgasangriffe knapp 1,7 Prozent aller Verwundungen im deutschen Heer. Durch die blanke Waffe (Säbel, Dolch, Seitengewehr) wurden über den gesamten Krieg gesehen gerade einmal 0,1 Prozent aller Wunden beigefügt.« (Ebd.)

23 Eine gewisse Linderung dieses Gefühls versprachen Talismane und ähnliches mehr, mit denen viele Soldaten versuchten den Zufall zu ihren Gunsten quasi gewogen zu halten. 
dieser Situation sind die Individuen auf sich selber zurückgeworfen. Die Todesangst lässt alle anderen Empfindungen, selbst Hunger und Durst in den Hintergrund treten. Der soziale Horizont aller Handlungen schrumpft auf das eigene Überleben zusammen. Zugleich macht sich im Moment äußerster Hilflosigkeit auch eine gegenläufige Tendenz bemerkbar. Obwohl beispielsweise Infanteristen, die von Artilleriegeschützen beschossen werden, gegen den Beschuss nur Deckung suchen und sich nicht gegenseitig schützen können, suchen sie trotz gegenteiliger Anweisung die Nähe anderer Soldaten, weil das Gefühl der Hilflosigkeit nur schwer alleine auszuhalten ist. Die Todesangst trennt und verbindet die Soldaten. ${ }^{24}$

Die enthusiastische Bereitschaft, in den Krieg zu ziehen, die Vorstellung durch eigene Handlungen sich selber und anderen beweisen $\mathrm{zu}$ können, was für ein Mann in einem steckt, zerbrach aber nicht nur am Geschütz- und MG-Feuer. Zur Industrialisierung des Kriegsgeschehens gehörte, dass der Destruktionsprozess bürokratisch vorbereitet und zahlreiche Tätigkeiten der Soldaten sich analog zu Arbeitsprozessen in der Industrie vollzogen, wenn auch mit dem entscheidenden Unterschied, dass die Prozesse nur auf Zerstörung und Tod abzielten. In den Dienststellen mussten die Truppenbewegungen geplant, der Nachschub berechnet, Urlaubsscheine ausgegeben, über Versetzungen entschieden und Fortbildungen genehmigt werden, Dienstvorschriften mussten formuliert, verteilt und beachtet werden. Auch im Krieg galt für die Ausführung bürokratischer Vorgänge »die Herrschaft der formalistischen Unpersönlichkeit: sine ira et studio, ohne Hass und Leidenschaft, daher ohne >Liebe< und `Enthusiasmus`, unter dem Druck schlichter Pflichtbegriffe« (Weber 1922: 129) als ideal. Beim Einsatz der Geschütze, der Maschinengewehre, überhaupt aller Artefakte kam es nicht darauf an, ob die Soldaten begeistert waren, sondern darauf, dass die Maschinen von ihnen sachgerecht bedient wurden. Während Maschinengewehrschützen mitunter direkt die gegnerischen Soldaten anvisierten, galt bereits für die Bedienungsmannschaften weit reichender Geschütze des 1. Weltkrieges, dass bei ihnen eine große Distanz zwischen ihrem Handeln und dessen Wirkung eintreten konnte. Um das Geschütz auf das Ziel auszurichten, zu laden und abzufeuern mussten die Geschützmannschaften ihre Tätigkeit arbeitsteilig und auf einander bezogen koordinieren. Arbeitssoziologisch ausgedrückt bildeten sie eine gefügeartige Kooperation (Popitz/Bahrdt 1957: 66f.). Den Gegner sahen sie nie, und selbst die Geschützführer wurden nur telefonisch durch in den vordersten Gräben positionierten Artilleriebeobachter über die Wirkung der abgefeuerten Granaten unterrichtet. Mit den Folgen ihres Handelns, ihrer Gewaltanwendung waren diese Soldaten nicht unmittelbar konfrontiert. Deshalb waren sie zwar nicht ahnungslos, was die abgefeuerten

24 Da die »Angst, die zur >Tuchfühlung〈 drängt«, aber tödlich sein kann, müsse sie, so eine Ausbildungsschrift der Bundeswehr, »unnachsichtig >weggeübt< werden« (Elser 1985: 79). 
Geschosse bei ihrer Detonation bewirkten, - zumal sie selber mitunter Angriffsziele der gegnerischen Artillerie waren - aber aufgrund der Distanz zum Fokus der Todeszone konnten sie in ihrem Alltag Routinen entwickeln, die frei von Gewalttätigkeit und Krieg schienen.

Die Vorgesetzten zeichneten sich gegenüber ihren Untergebenen zunächst durch eine große Machtfülle aus, die durch ihre Befehle Gunst wie Missgunst ausdrücken und damit auch erheblich die Überlebenschancen beeinflussen konnten. Zugleich waren aber auch ihre Entscheidungen eingebettet in eine Militärorganisation, die auch ihnen als abstrakte Macht gegenüber trat. Abstrakt, weil für die meisten Soldaten die erteilten Befehle überwiegend auf Entscheidungsprozessen beruhten, die als fern von ihnen geronnene Ergebnisse >nach Unten durchsickerten` und deshalb undurchsichtig und unverständlich waren. Sie erlebten sich als ohnmächtige Objekte einer Macht, die nicht zwischen Material und Individuen unterschied, sondern sie als Menschenmaterial unterschiedslos nur nach Maßgabe ihrer Ersetzbarkeit einstufte (siehe Bröckling 1997: 205f.).

Am Grabenkrieg vermochten sich keine romantischen Vorstellungen zu entzünden. Nachdem Hunderttausende hier den >Heldentod ‘ fanden, war es auch schwierig, ihn als Ort für individuelle Bewährung zu sehen, der einen besonders auszeichnet. Einen Fluchtpunkt für solche Vorstellungen bot das Fliegerkorps. Mit der Luft-Kriegführung wurde im 1. Weltkrieg eine neue Raumdimension vom Kriegsgeschehen erfasst. Im Mittelpunkt der öffentlichen Wahrnehmung stand der Luftkampf zwischen den Jagdfliegern, die als ritterliche Zweikämpfe interpretiert wurden. Die Jagdflieger wurden zu den gefeierten Helden des 1. Weltkrieges, zu den aus dem »Massenleben« und »Massensterben ${ }^{25}$ herausragenden Subjekten. Diese Vorstellung wurde durch die Publikation von Büchern wie »Der rote Kampfflieger« gefördert, das auf persönlichen Aufzeichnungen von Manfred von Richthofen (1892-1918) beruhen soll. Es schildert den Krieg vorwiegend als abenteuerlichen Spaß und zeigt den Piloten als souveränen Akteur. Doch dieses obendrein auf den Luftkampf gegen gegnerische Jagdflieger konzentrierte Bild täuschte gleich in mehrfacher Hinsicht über die realen Verhältnisse bei den Luftstreitkräften. Zum einen war in den ersten Kriegsjahren das Einsatzspektrum der Flugzeuge und ihrer Besatzungen noch nicht ausdifferenziert, das heißt sie mussten zu Aufklärungs- und Beobachtungsflügen starten sowie Bomben aus ihren Flugzeugen werfen. Als auf deutscher Seite ab 1916 das Einsatzspektrum ausdifferenziert wurde, wurden die wenigsten Piloten als Jagdflieger eingesetzt. Überhaupt gehörten schon damals die meisten Soldaten bei den Luftstreitkräften nicht zum fliegenden Personal und damit zum kämpfenden Teil der Truppe. Die überwiegende Mehrheit der Soldaten hatte unterstützende Aufgaben und

25 Mit diesen Worten begründete Ernst Toller, weshalb er sich nach 13 Monaten als Infanterist freiwillig zum Fliegerkorps meldete (1933: 54). 
musste beispielsweise die Maschinen einsatzbereit halten. ${ }^{26}$ Die Bekämpfung gegnerischer Jagdflieger war zwar eine wichtige Aufgabe, aber die meisten Piloten starteten zu Beobachtungs- und Aufklärungsflügen. Besonders in den ersten Kriegsjahren war die Gefahr, vom Boden aus beschossen zu werden, solange gering, wie die Flugzeuge nicht im Tiefflug über die Front flogen, weil es noch keine effektiven Flugabwehrkanonen gegen hoch fliegende Maschinen gab (siehe Köhler 1968: 292f., 310f.). Eine weitaus größere Gefahr drohte ihnen dagegen von gegnerischen Flugzeugen. Entgegen der glorifizierenden Vorstellung vom ritterlichen Kampf zwischen gegnerischen Piloten von Jagdflugzeugen griffen diese häufig Flugzeuge an, die, wenn sie nicht sogar unbewaffnet, so doch aufgrund der Wendigkeit der Maschinen und der Bewaffnung unterlegen waren. War es schon an sich schwierig, die Flugzeuge in die Luft zu bringen und mussten die Piloten routinierte habitualisierte Handlungsweisen entwickeln, um das Flugzeug überhaupt in der Luft zu halten, so verlangte der Luftkampf bzw. der Luftkrieg die Beherrschung weiterer Flugtechniken, um zum Beispiel verschiedene Flugfiguren fliegen zu können. Wie man dem von Richthofen verfassten und während des Krieges als Geheimsache geltenden »Reglement für Kampfflieger« entnehmen kann, sollten die Piloten keine Luftakrobaten, sondern »Draufgänger« (1917: 135) sein, die sich zugleich unbedingt den Anweisungen ihres Staffelführer, Geschwaderkommandeurs unterordneten. Die Piloten hatten besonders beim Geschwaderflug Disziplin zu wahren, da nur so der Kommandeur eine Übersicht über das Geschehen gewinnen und die Formation zu einem geschlossenen Angriff auf gegnerische Verbände führen konnte. Auf diese Weise sollte der gegnerische Verband aufgesprengt und in Einzelkämpfe verwickelt werden. In Richthofens Darlegungen zum Einzelkampf wird deutlich, dass es nicht darum ging, die >Kräfte ২ zu messen, auch formuliert er keine Regeln, die geeignet wären, den Gegner zu schonen. Es galt die Gegner möglichst überraschend anzugreifen, damit sie nicht die Flucht ergreifen bzw. nicht ihrerseits das Feuer eröffnen konnten. Ein Luftkampf sollte kein Duell sein, und sollte er zu einem werden, war dies allenfalls die Folge eines fehlgeschlagenen Überraschungsangriffs. Draufgänger sollten die Piloten sein, weil sie den Mut haben mussten, »an den Gegner bis auf nächste Nähe heranzugehen« (ebd.: 138) und ihn zu beschießen. Dabei kam es nicht auf Fairplay, sondern auf die Fähigkeit an, den Gegner ohne Rücksicht auf die eigenen Gefühle zu töten. Auf einer Entfernung, aus der der Pilot nicht

26 Und schon damals setzte sowohl das Fliegen, wie die Einsatzbereitschaft der Flugzeuge umfangreiches (technisches) Fachwissen voraus, weshalb der Anteil der Offiziere gegenüber den Unteroffizieren und vor allem gegenüber den Mannschaften bei den Luftstreitkräften im Verhältnis zu den Bodentruppen überproportional hoch war. Gegen Ende des Krieges betrug die Gesamtstärke der Feldverbände der Luftstreitkräfte 6100 Offiziere und 55000 Unteroffiziere und Mannschaften mit 4800 Flugzeugen (Köhler 1968: 297). 
nur gut zielen, sondern auch gut sehen konnte, was er dem Gegner antat, musste er das Feuer eröffnen und durfte sich dabei weder von seiner eigenen Angst noch von Empathie für den Gegner behindern lassen. Einen anderen erfolgreichen deutschen Jagdflieger zitierend, lasse sich das Geheimnis des Abschießens in dem Satz zusammenfassen: ") Ich gehe bis auf $50 \mathrm{~m}$ an den Feind von hinten heran, ziele sauber, dann fällt der Gegner.« $(\text { Ebd. })^{27}$ Diese Nähe zum Gegner und seine Sichtbarkeit in und aus der Luft unterschieden im 1. Weltkrieg das Kriegsgeschehen erheblich von dem am Boden. Erst mit den in den folgenden Jahrzehnten entwickelten Flugzeugen und Waffen wuchs die Distanz der Piloten und der Crew zum Gegner und auch zur eigenen Gewaltausübung. Mit zunehmender Geschwindigkeit der Maschinen und der Ausstattung mit Bordwaffen, die Ziele auch aus großer Entfernung attackieren können, verschwanden die Menschen in den gegnerischen Flugzeugen aus dem Blickfeld, weil sie immer weniger unterscheidbar von den Maschinen wurden. Gleiches gilt auch für den Angriff auf Bodenziele. Am ehesten können von der Besatzung noch markante Bodenpunkte wie Fahrzeuge oder Gebäude ausgemacht werden, und selbst hiervon sehen sie mitunter nur noch deren Datenschatten.

$\mathrm{Ob}$ in der Luft oder am Boden, das Kriegsgeschehen und damit auch die Art und Weise, wie der Krieg erlebt wurde, wird seit der Industrialisierung entscheidend von den eingesetzten Maschinen bestimmt. Soldaten sitzen in Maschinen, arbeiten an ihnen, bedienen sie. Durch ihren Einsatz können sie sich im Raum mit ansonsten unerreichbarer Geschwindigkeit bewegen und sogar in ansonsten verschlossene Raumdimensionen vorstoßen. Und die Maschinen steigern ihre Fähigkeiten, zu zerstören und zu töten. Kriegsmaschinen wirken, auch wenn dies schwer zu quantifizieren ist, als ein Faszinosum auf die Soldaten, nicht zuletzt, weil ihnen durch die Bedienung der Maschinen Macht zufällt. Freilich, bevor sie von dieser Macht Gebrauch machen können, müssen sie die von den Konstrukteuren geschaffenen Merkmale berücksichtigen und entsprechend sachadäquat handeln, um die maschinellen Prozesse in Gang zu setzen und zu unterhalten. ${ }^{28}$ Bei der Anwendung von Maschinen lässt sich darüber hinaus auch

27 Die viel zitierte Ritterlichkeit der Jagdflieger des 1. Weltkrieges beschränkte sich also bei genauer Betrachtung auf gefangen genommene und getötete gegnerische Piloten.

28 Mit dem »Konstruktionskunststück (wird) eine neue Entität, ein neuer Prozess in die Welt gesetzt, der den Menschen definitiv und in unerhörtem Ausmaß der Fremdbestimmung durch das von ihm Kreierte aussetzt." (Popitz 1995: 32) Wie schon zahlreiche Berichte aus dem 1. Weltkrieg zeigen, bedeutet das allerdings nicht, dass sie die ihnen zufallende Macht nur so einsetzen, wie sich dies ihre Vorgesetzten vorstellen. Wenn beispielsweise mit Maschinengewehren »ständig aufs Geratewohl geschossen (wurde) - von Posten, die damit ihre Wut gegen den Krieg ausdrückten« (Ranke-Graves 1959: 161), dann galt dies als Munitionsverschwendung, die die Position der 
der gegenteilige Effekt beobachten. Was als ein Zuwachs von Handlungsmacht erlebt werden kann, schlägt beim Versagen der Technik in das Gefühl des Ausgeliefertseins um. Dies gilt erst recht, wenn sie selber der maschinellen Waffenwirkung ausgesetzt sind. Die Kräfte, die nun nicht vom Soldaten als Subjekt kontrolliert werden, dementieren seine Souveränität und drohen ihn zu überwältigen. Ohnmachtserfahrungen gehören deshalb zu den zentralen Momenten des Kriegserlebnisses von Soldaten im industrialisierten Kriegsgeschehen. Die Konfrontation mit maschineller Kriegstechnologie verstärkt den Eindruck, eingespannt zu sein in eine umfassende Maschinerie mit technischen wie sozialen Komponenten, >Rädchen und Handlungen nicht beeinflusst werden können.

Zwischen dem, was die einzelnen Soldaten an den Maschinen tun und den Folgen ihres Handelns besteht ein, mit Anders gesprochen, "prometheisches Gefälle«. Anders bezeichnet damit den Abstand zwischen den Fähigkeiten des Menschen und seiner Produktewelt, der sich durch ASynchronisiertheit auszeichne (Anders Bd. 1, 1956: 16). »Machen können wir zwar die Wasserstoffbombe; uns aber die Konsequenzen des Selbstgemachten auszumalen, reichen wir nicht hin. - Und auf gleiche Weise humpelt unser Fühlen unserem Tun nach: Zerbomben können wir zwar Hunderttausende; sie aber beweinen oder bereuen nicht.« (Ebd.: 17) Begünstigt wird die Diskrepanz zwischen dem eigenen Handeln und dem moralischen Empfinden durch die meist große Distanz zwischen dem Ort des Handelns und der Stelle, an dem die Folgen des Tun zu spüren sind, sowie auch die Einbettung der Handlungsvollzüge in einen komplexen, arbeitsteiligen Prozess. Das >prometheische Gefälle` macht sich aber >nicht nur defizitär auf der Ebene des moralischen Empfindens bemerkbar. Es bildet auch die Basis für eine spezifische Wahrnehmung des an den menschlichen Leib gebundenen Leistungsvermögens. Während Maschinen durch technische Innovationen permanent für weitere Leistungssteigerungen optimiert werden können (siehe auch Popitz 1995: 29), zeige sich der Leib gegenüber solchen Optimierungsversuchen als >stur`, weil »morphologisch konstant« (ebd.: 33). »Die >Sturheit〈 seines Leibes macht den Menschen zum Saboteur seiner eigenen Leistungen. [...] Gemessen an seinen Aufgaben, belehrt ein amerikanischer Luftwaffen-Instruktor seine Kadetten, sei der Mensch, wie die Natur ihn nun einmal hervorgebracht habe, eine »faulty construction«, eine Fehlkonstruktion.» (Anders Bd. 1, 1956: 31f.) Ob diese Aussage ernsthaft oder als Scherz gemeint war, sie stehe für die weit verbreitete Scham gegenüber den perfekter werdenden Produkten. Nicht der Mensch, sondern das von ihm Kreierte werde zum Maßstab aller Dinge. Nur aus dieser Perspektive könne der unkonstruierte

Stellung dem Gegner verriet und wird in der deutschen Militärliteratur als ein Verstoß gegen die Feuerdisziplin eingestuft. 
Leib als »Schlechtkonstruiertes« (ebd.: 32) erscheinen (siehe hierzu auch Fohler 2003: 157f.).

Die Defizitliste des Leibes ist lang und umfassend. Um dies kurz am Beispiel des Fliegens zu veranschaulichen: Der menschliche Leib verfügt nicht nur über keine Flügel, er ist obendrein ein Hindernis für technisch mögliche Leistungssteigerungen der Maschine Flugzeug. Bereits in den 50er Jahren des vergangenen Jahrhunderts hielten Flugzeugkonstruktionen den bei schneller Beschleunigung und Richtungswechsel auftretenden Kräften eher stand als die Leiber der Besatzungen, die aufgrund des auf ihnen lastenden Druckes erhebliche Probleme mit der Atmung und der Durchblutung ihres Körpers hatten.

Allgemein lässt sich formulieren, dass der Leib gemessen an Maschinen als zu wenig widerstands- und belastungsfähig gilt. ${ }^{29}$ Sein Sensorium kann eine Vielzahl technisch abtastbarer Umgebungsqualitäten, wie die Infrarotstrahlung, unzureichend oder wie im Falle radioaktiver Emissionen gar nicht erfassen. Seine visuellen Fähigkeiten sowie der Geruchssinn gelten ebenfalls als zu unempfindlich. Andererseits reagieren die Individuen bereits auf diese >eingeschränkten`Sinneseindrücke häufig allzu empfindlich. Die Individuen sehen sich nicht den an sie gestellten Anforderungen gewachsen, sind überfordert, weichen von den Planungen ab und verändern ihre Einstellungen. Ihre Fähigkeit, situativ zu handeln, also nicht nur zu funktionieren, wird dann zur Fehlerquelle. Es entsteht der Eindruck, dass ihre Verwendung im Zusammenhang mit den perfektionierten Maschinen »eigentlich unangemessen ist« (Anders Bd. 1, 1956: 327).

Schon Ende der 60er Jahren wurde die Prognose getroffen, dass der Einsatz von Menschen in Kampfhandlungen überflüssig werde. »Der Mensch«, so Thring, "wird in der Schlacht seinen Wert verlieren; für die Systemplanung werden Menschen vielmehr schwere Komplikationen mit sich bringen, da sie das System mit ihrem Volumen, ihrem Gewicht und ihrer Verwundbarkeit belasten.« (1969: 188) Bei der Entwicklung neuer Kriegstechnologie werde man auf Automaten setzen. Soldaten würden durch Roboter ersetzt, die

»keine Angstgefühle kennen und einen Selbsterhaltungstrieb nur in dem Ausmaß, in dem ihm sein Konstrukteur Reflexe dieser Art eingebaut hat, um die Maschine vor Schaden zu bewahren. Der Roboter kann viel rascher und genauer als ein Mensch eine vorher festgelegte Handlung seinen Anweisungen gemäß durchführen, wenn es die äußere Situation erfordert.« (Ebd.: 177)

Soldatische Subjektivität wird in dieser Prognose gleich in mehreren Dimensionen als defizitär für das Kriegsgeschehen der Gegenwart wie der

29 Dies kommt auch in der Differenzierung zwischen so genannten harten Zielen (Gebäude, Panzer) und weichen Zielen zum Ausdruck. Als das weichste, also das verletzlichste Ziel, gilt der menschliche Körper. 
Zukunft qualifiziert. Sie sei unzureichend, störend und belastend. Aber nicht nur, weil Roboter bald entschieden schneller Befehle ausführen könnten, sondern auch weil Maschinen grundsätzlich nur das tun, was man ihnen befiehlt. Menschen widersetzten sich nicht nur bewusst den erteilten Anweisungen, sondern auch, weil sie durch ihre Angst und ihre Orientierung, das Kriegsgeschehen (unverletzt) zu überleben, unbewusst an der Umsetzung der Befehle gehindert werden. Kurz: Soldatische Subjektivität sei ein Hindernis bei der weiteren Steigerung der Destruktionskräfte und damit ein Auslaufmodell, das durch artifizielle Intelligenz ersetzt werde.

\subsubsection{Persönlichkeitsveränderungen und psychosomatische Reaktionen auf das Kriegsgeschehen}

Schon gleich nach Beginn des 1. Weltkrieges wurden die Ärzte mit einem Phänomen konfrontiert, das sie in seinem Ausmaß und seiner Intensität überraschte (Ulrich 2004: 654). Viele Soldaten litten unter Weinkrämpfen sowie unter Erbrechen, und die Ärzte beobachteten bei ihnen »Zittern, Schwäche der Beine, Heulen und Lachen in wildem Durcheinander« (zitiert nach Riedesser/Verderber 2004: 23). Andere Soldaten »wurden im Trommelfeuer apathisch oder schliefen einfach ein.« (Ebd.) Auf physiologische oder auf neurologische Verletzungen konnten die Ärzte diese Symptome nicht zurückführen, aber an der Front konnten die Soldaten zumindest zeitweise nicht mehr eingesetzt werden. Dass viele Soldaten psychosomatisch auf das Kriegsgeschehen reagieren, ist kein singuläres Phänomen, das auf die besonderen Bedingungen des 1. Weltkrieges zurückgeführt werden kann. Es wurde vielmehr seitdem stets von Neuem bei Soldaten beobachtet, die zuvor dem unmittelbaren Kampfgeschehen ausgesetzt waren.

Zerstören, verletzen, töten, aber auch verletzt werden und den Tod anderer Menschen erleben, ergreift die Akteure affektiv und emotional. Im Krieg leiden die Akteure meist unter Durst und Hunger, sie sind häufig müde und erschöpft, geraten in Phasen der Wut und müssen vor allem mit ihrer Furcht zurecht kommen, die sie vor Verletzungen und dem eigenen Sterben, aber auch vor dem (weiteren) Verlust von sozialen Beziehungen haben. Welche affektiven und emotionalen Reaktionen die Akteure entwickeln und wie sie sie bewältigen, lässt sich schwer vorhersagen, weil bereits die Wahrnehmung der Situation von individuell variablen Faktoren abhängt. Wenn ein Akteur beispielsweise bei der Bewältigung der Situation auf geeignete Erfahrungen zurückgreifen kann, stellt sich für ihn die gleiche Situation anders dar, als wenn er von ihr überrascht wird. Aber auch die aktuelle physische wie psychische Verfassung des Individuums beeinflusst entscheidend seine Handlungsmöglichkeiten und damit, ob es der Situation hilflos oder handlungsmächtig gegenübersteht. Ob die Subjekte auf das Erlebte mit einem psychischen Trauma reagieren und welche 
Verlaufsform das Trauma hat, lässt sich aus dem gleichen Grund nicht mit einer ähnlichen Sicherheit vorhersagen, wie dies bei Verletzungen der Physis möglich ist. Psychische Traumata haben keinen überindividuell voraussagbaren Schädigungs- und Heilungsverlauf.

Die Ausübung und das Erleben von Gewalt und Tod beeinflusst die Persönlichkeit der Akteure. »Mythen, Religionen, später auch Literatur und Philosophie sind voll von Auseinandersetzung mit Leiden und Tod und dem Eindruck, der Prägewirkung, den diese bei den betroffenen Menschen hinterlässt.« (Fischer/Riedesser 1999: 29) Dass diese Prägewirkung wahrlich kein neues Phänomen ist, zeigt auch die instruktive Studie Shays, der es gelingt, die Wirkung von Kampfeinsätzen in Vietnam auf USSoldaten anhand Homers Ilias erhellend zu beleuchten. Die Geschichte der Figur des Achill dient Shay als Folie zum Verständnis der Genese und der Symptome eines bestimmten Typus von Kriegstrauma. Dieses Trauma verwandelt disziplinierte Krieger bzw. Soldaten, die ihre Affekte und Emotionen kontrollieren können, in Berserker, die in den Zustand äußerster Wut verfallen und deren Taten sich durch hemmungs- und schrankenlose Gewalttätigkeit auszeichnen. Es lassen sich allerdings auch Unterschiede zwischen der Sichtweise Homers auf Achills Taten und der der von Shay behandelten Vietnamveteranen ausmachen. Homer bezeichnet »Achills Wüten als >schändlichen Frevel«" (Shay 1998: 120), da er in seiner Wut gegen die herrschenden Normen verstößt, die für den Umgang mit Getöteten galten. Obendrein überwindet Achill seine Traumatisierung, findet also wieder aus dem Zustand des Berserkertums heraus. Bei Shays Vietnamveteranen hält dagegen die Prägewirkung des Traumas an, sie kehren mit einer veränderten, als pathologisch gewerteten, Persönlichkeitsstruktur aus dem Krieg zurück unter der sie, aber auch andere leiden (werden).

Die Gefahr, dass eine Persönlichkeit nachhaltig von den Kriegserlebnissen erschüttert wird, ist mit der Ex- und Intensivierung des Kriegsgeschehens gewachsen. Die Wahrscheinlichkeit wiederum, dass Persönlichkeitsveränderungen aufgrund von Kriegserlebnissen als pathologisch eingestuft werden, hängt entscheidend davon $a b$, ob die Soldaten in eine zivile soziale Welt zurückkehren müssen, in der andere Normen vorherrschen als beim Militär und im Krieg und ob der Habitus, den sich die Soldaten im Krieg angeeignet haben, in einem konflikthaften Verhältnis zu den Umgangs- und Verkehrsformen steht, die in der zivilen Gesellschaft gelten. Umso mehr und je länger die Soldaten im Zuge ihres Kriegseinsatzes quasi zu Angehörigen einer eigenständigen sozialen Welt werden, deren Normen und alltäglichen Handlungsroutinen im Widerspruch zu denen der zivilen Gesellschaft stehen, je größer die Kluft zwischen der Person, die ein Soldat vor seinem Kriegseinsatz war, und der Person, die sie aufgrund ihrer Erlebnisse und Erfahrungen wurde, umso schwerer wird sich diese Person den Verhältnissen in der zivilen Gesellschaft (wieder) 
anpassen können, umso größer die Wahrscheinlichkeit, dass diese Persönlichkeitsveränderungen als pathologisch eingestuft werden. Anders ausgedrückt: Besonders in solchen modernen Krieg führenden Gesellschaften werden zahlreiche kriegsbedingte Persönlichkeitsveränderungen als pathologisch eingestuft, die trotz des Krieges einen sozialen Alltag beibehalten, der vom Kampfgeschehen weitgehend unbeeindruckt bleibt und in dem militärische Normen und der vom Kriegseinsatz geprägte Habitus wenig Anerkennung erfahren.

Wie sehr es vom sozialen Umfeld abhängt, ob eine Persönlichkeitsveränderung als krankhaft eingestuft wird, zeigt sich besonders prägnant bei Soldaten, die zum Berserkertum neigen. ${ }^{30}$ Berserker zeichnen sich durch ein Verhalten und Handeln aus, das keine Zurückhaltung beim Ausagieren ihrer Aggression gegenüber den Objekten ihrer Wut, aber auch gegenüber sich selber und gegenüber Dritten mehr kennt. Sie schränken ihre sozialen Beziehungen zu den Angehörigen der eigenen Kriegspartei auf ein Minimum ein und fühlen sich von »aller menschlichen Verbundenheit abgeschnitten. « (Shay 1998: 130) Die Symptome traumatischer Reaktionen auf Kriegserlebnisse sind keine Verrücktheiten, sondern können als ein Versuch interpretiert werden, sich dem Erlebten anzupassen und es zu bewältigen. Dies gilt auch für die Ausbildung der Berserkerwut, die unter den Bedingungen des Dschungelkrieges in Vietnam zumindest manchmal sogar eine optimale mentale Anpassung an das Kriegsgeschehen bedeutete, weil sie eine extreme physiologische Einsatzbereitschaft erzeugte - eine reduzierte Schmerzempfindlichkeit, das Schlafbedürfnis verringerte und alle Sinneswahrnehmungen enorm sensibilisierte - und dadurch die Überlebensfähigkeit der Soldaten stark erhöhte. Wenngleich berserkerhaft agierende Soldaten sich nur eingeschränkt unter ein Kommando stellen lassen und deshalb lediglich für Kampfeinsätze geeignet sind, in denen ihre Gewalttätigkeit gefragt ist, kann im Krieg ein Verhalten und Handeln, das durch berserkerhafte Wut geprägt wird, als angemessen und sogar als heldenhaft eingestuft werden. ${ }^{31}$

30 Zur Ätiologie dieser Persönlichkeitsveränderung siehe Shay (1998: 120f.) und zusammenfassend Fischer/Riedesser (1999: 30).

31 Eine bedeutsame Differenz bei der Auslösung der Berserkerwut zwischen der Ilias und den Berichten der Vietnamveteranen sieht Shay darin, dass niemand in der Ilias die Krieger dazu drängte Rache am Gegner zu nehmen, während nach den Berichten der Veteranen das Rachenehmen zu den Motivierungstechniken einiger Vorgesetzter zählte (1998: 124). Auch in diesem Zusammenhang ist auf die Bedeutung unterschiedlicher Normenwelten hinzuweisen: Im antiken Griechenland wurde auch jenseits des Schlachtfeldes das Töten als Rache ausdrücklich gebilligt. Zumindest in den westlichen Industriestaaten wird heute >Blutrache` als Mord verurteilt (ebd.: 125). Deshalb konnten bei den Soldaten nach ihren Taten Schuldgefühle entstehen, die einem griechischen Krieger unbekannt waren. 
Dass viele Veteranen ihre im Krieg erworbenen Verhaltensmuster, die fortan ihre Persönlichkeit prägen, nicht oder nur schwer wieder ablegen und auch dann nicht moderieren können, wenn sie ihren sozialen Alltag nicht bewältigen, führt Shay darauf zurück, dass die Kriegsereignisse neben der psychischen Verfassung auch physiologische Prozesse verändert haben. Die Kriegsereignisse fügten, so Shay, den Individuen schwerste psychologische und psycho-physiologische Verletzungen zu, die zu »lebenslänglichen physiologischen und emotionalen Schäden« (1998: 146) führten. Die Soldaten, die mitunter überrascht waren, dass sie ihren Kampfeinsatz überlebt hatten, litten an ihren auch für sie feststellbaren unangemessenen Reaktionen in alltäglichen Situationen im Zivilleben (ebd.: 230f.), die sich beispielsweise in ihrem Unvermögen ausdrückte, ihre Erinnerungen an Kampfsituationen zu kontrollieren. Sie nehmen deshalb auch alltägliche Situationen in der Zivilgesellschaft als hoch bedrohlich wahr. »Die alltägliche Erfahrung der Beherrschung mentaler Prozesse fehlt demjenigen, der ein schweres Kampftrauma überlebt hat.« (Ebd.: 230) ${ }^{32}$ Dass ehemalige Kriegsteilnehmer auf ihre Verlust- und Entgrenzungserfahrungen fixiert bleiben, obwohl ihnen die gestörte, wenn nicht gar zerstörte normative und die emotionale Bindung an die zivile Welt auffällt, zeigt an, dass die Kriegserlebnisse ihr Handlungspotential als Subjekt eingeschränkt hat. Aber auch Soldaten, bei denen sich das Erlebte nicht in traumatischen Symptomen niederschlägt, haben im Zivilleben, also in der Familie, unter Freunden und am Arbeitsplatz mit den im Kampf verfestigten Haltungen - möglichst geringe Empathie $\mathrm{zu}$ zeigen, Intimitäten $\mathrm{zu}$ scheuen und die »Erotisierung der Gewalt« (Shatan 1983: 226) - häufig ein Handicap. In der Literatur wird dieses Handicap der in den Krieg ausgezogenen Soldaten meist unter der Thematik einer Heimkehr als Fremder angesprochen. $\mathrm{Ob}$ im Falle der Vietnam-Veteranen sie als Folge ihrer Schwierigkeiten sich zu reintegrieren eher zum Suizid neigen als gleichaltrige US-Bürger ist zwar umstritten (Shay 1998: 244), festzustehen scheint dagegen der Befund zu sein, dass sie mehr Gewalttaten begehen. Erhoben wurde dieser Befund im Rahmen einer Studie, die Ende der 80er Jahre vom US-Kongress Auftrag gegeben wurde. »Der Anteil der Veteranen, die berichteten, im Durchschnitt mehr als eine Gewalttat im Monat zu begehen, war beinahe fünfmal so hoch wie unter der entsprechenden Vergleichsgruppe von Zivilisten, die nicht in Vietnam waren.« (Ebd.: 146)

Dass Gewalttaten ehemaliger Soldaten signifikant die Zahl der Gewaltverbrechen in einer Nachkriegsgesellschaft noch oben schnellen lassen, ist aber kein verallgemeinerungsfähiger Befund. Für die deutschen Kriegsteilnehmer des 2. Weltkrieges liegen keine ähnlichen Untersuchun-

32 Dieses Phänomen wird in der Literatur auch als Wahrnehmungsdissonanz und genauer noch als flash back bezeichnet. Über Studien, die die Prozesse in den zentralnervösen Strukturen untersuchen, die diesem Phänomen zugrunde liegen, informiert Fischer/Riedesser (1999: 88f.). 
gen vor. Es wäre in diesem Fall im Übrigen auch schwierig, eine Vergleichsgruppe mit Nicht-Kriegsteilnehmern zu finden. Zugleich zeigt das Beispiel des Nationalsozialismus, dessen Kader und erste Anhänger sich aus ehemaligen Soldaten des 1. Weltkrieges rekrutierten, dass sich die Prägewirkung des Krieges auf die soldatischen Subjekte auch in einer politischen Bewegung ausdrücken kann.

Die Prägewirkung von Kampfhandlungen auf die Persönlichkeit der Soldaten und auf die Gesellschaft ist vermutlich noch für den Vietnamkrieg am besten untersucht worden. Es war, und man kann wohl auch sagen, es sind, nicht die langfristigen Folgen des Kampfeinsatzes auf die Soldaten, die die Aufmerksamkeit des öffentlichen Interesses an den psychosomatischen Reaktionen auf das Kriegsgeschehen auf sich ziehen. Die Aufmerksamkeit konzentriert sich vielmehr auf solche psychosomatischen Reaktionen, die während eines Krieges die Einsatzfähigkeit der Soldaten herabsetzen.

Psychosomatische Reaktionen auf Gefechtssituationen hat es auch für die Zeit vor dem 1. Weltkrieg gegeben. So berichten Zeitzeugen des 18. Jahrhunderts, dass Soldaten im Verlauf von Gefechten akute Schreck- und Panikreaktionen zeigten, die sie unter anderen als Kanonenfieber bezeichneten. ${ }^{33}$ Während die Fähigkeit, die eigene Furcht zu kontrollieren und den Gegner trotz aller Gefahren mit größter Entschlossenheit anzugreifen, als Tapferkeit honoriert wurde, galten Angst-, Schreck- und Panikreaktionen als momentane Schwächen, die meist eine Flucht auslösten bzw. eine Niederlage im Kampf besiegelten. Sie galten zugleich als eine vorübergehende Erscheinung, der man in Zukunft durch eine erhöhte Willensanstrengung, möglicherweise auch durch verschärfte Disziplinierung vorbeugen konnte. Deshalb waren sie vor dem 1. Weltkrieg kein Thema für die Medizin. Der "Sanitätsbericht über die deutschen Heere» im Deutsch-FranzösischenKrieg (1870-71) enthält, laut Karl Bonhoeffer (1868-1948) zwar ein Kapitel >Kriegspsychosen`, doch wurden damals nur 316 Soldaten »wegen nachweislicher Geistessstörung in Lazaretten aufgenommen « (Bonhoeffer 1922: 1). Bereits wenige Wochen nach Kriegsbeginn sollten 1914 tausende Soldaten mit den unterschiedlichsten physischen Ausfallserscheinungen (z.B. einzelner Gliedmaße, des Sprachvermögens und Gehörsinn) bzw. Störungen (Zittern, Erbrechen, ...) in die Lazarette eingeliefert werden. ${ }^{34}$

33 Ein Überblick über solche Zeitzeugenberichte ist bei Möbius zu finden (2001: 81f.).

34 Für die Zeit vor dem 1. Weltkrieg findet Gabriel einige Berichte, denen zu Folge Soldaten darüber klagten, dass ihre Gliedmaßen vorübergehend paralysiert waren (1988: 16), und noch häufiger Hinweise auf »nostalgia«. »Nostalgia is a cluster of symptoms marked by excessive physical fatigue, an inability to concentrate, an unwillingness to eat or drink leading at times to anorexia, a feeling of isolation und total frustration leading to a general inability to function in a military environment.« (Ebd.: 15) 
»Allein für Deutschland wird nach vorsichtigen Schätzungen von mindestens 200.000 Kriegsneurotikern ausgegangen.«(Ulrich: 2004)

Das militärische Interesse, die betroffenen Soldaten möglichst schnell wieder verwendungsfähig zu machen, schlug in Deutschland im 1. Weltkrieg auf die ätiologischen Annahmen sowie auf die Ausgestaltung der Therapie durch. In den ersten Kriegsmonaten erfuhren die >Kriegszitterer noch eine schonende Behandlung. Sie wurden vom Dienst befreit und sollten sich fern von der Front zum Beispiel bei Wasserkuren erholen. Begründet werden konnte eine solche Behandlung mit Hinweis auf die Neuropsychiatrie Hermann Opperheims (1858-1919), der psychologische Gründe für die Symptome verwarf. Die Symptome würden von den Erschütterungen der Granatenexplosionen verursacht, so die zentrale These, die auf molekularer Ebene das Gehirn schädigten. Diese im Kern mechanische Begründung der Symptome hatte nicht nur den Nachteil, dass auf molekularer Ebene kein Nachweis möglich war, sie konnte obendrein unter anderen auch nicht erklären, weshalb viele Soldaten ihre Symptome häufig erst mit zeitlichem Abstand zu ihrem Fronteinsatz ausbildeten. Doch diese Mängel sollten nicht dafür verantwortlich sein, dass diese Erklärungsansätze offiziell auf einer »Kriegstagung« im September 1916, an der die führenden Psychiater und Nervenärzte zusammenkamen, verworfen wurde. Der entscheidende Vorteil der fortan vorherrschenden Ätiologie war, dass sie, wie von den Militärs verlangt, einen schnellen Behandlungserfolg in Aussicht stellte. Es galt, die Soldaten möglichst schnell symptomfrei wieder als kriegsverwendungsfähig an die Front zu entlassen. Dem nicht genug bot sie obendrein den Vorteil, dass die Symptombildung weitgehend von den Kriegsereignissen abgelöst wurde und deshalb half, eventuelle Renten- bzw. Schadensansprüche abzuwehren, falls sich doch kein Therapieerfolg einstellen sollte.

Zentrales Element der nun vorherrschenden Ätiologie war die Auffassung, die Symptome würden im Grunde nicht vom Kriegsgeschehen verursacht. Das an der Front Erlebte spiele allenfalls eine untergeordnete Rolle bei der Ausbildung der Symptome. Verantwortlich für die psychosomatischen Reaktionen der betroffenen Soldaten sei ihre psychophysische Struktur. Wenn die Fronterlebnisse die Soldaten erzittern, verstummen oder gelähmt sein ließen, sei dies ein Ausdruck ihrer Willensschwäche gegenüber ihren Affekten und Emotionen. Entweder seien die Soldaten aufgrund ihrer psychophysischen Struktur für die Reaktionsbildung prädispositioniert oder aufgrund ihrer Herkunft aus einer bestimmten Region, als Angehörige einer sozialen Klasse oder sogar Rasse konstitutionell nicht in der Lage, den Belastungen an der Front standzuhalten. Die ganze Wucht dieser Argumentation sollte insbesondere die Mannschaften und Unteroffiziere treffen. Wenngleich auch Offiziere unter den gleichen Symptomen litten, so durften sie eher hoffen, vom Arzt eine Neurasthenie, eine nervöse Erschöpfung, bescheinigt zu bekommen. Sie hatten die größte soziale 
Chance, als »von Haus aus gesunde Menschen« (Gaupp 1922: 85) anerkannt zu werden, die in diesem Zustand durch »seelische Überanstrengung, übermäßige Verantwortung, Überspannung des Willens unter Nichtbeachtung aller Mahnungen der Müdigkeit und subjektiven Abspannung« (ebd.: 89) gerieten. ${ }^{35}$ Für alle anderen Betroffenen wurde ein Set unterschiedlicher Annahmen aufgeboten, die sie aber stets stigmatisierend und abfällig bewertete. Ihnen wurden angeborene, konstitutionelle Nervosität und Psychopathien (ebd.: 85) bescheinigt, deren Vorkommen zwischen Nationen, Rassen, Regionen oder Klassen unterschiedlich verteilt seien. ${ }^{36}$ So wurde den Kriegsfreiwilligen neben einer schwächlichen körperlichen Konstitution »seelische Unausgeglichenheit« attestiert (Bonhoeffer 1922: 26). Neben den »schwächlichen Naturen« (Binswanger 1922: 45), die sich unter anderen durch Alkoholkonsum weiter geschwächt hatten, waren es besonders die »Psychopathen«, die die Psychiater geradezu in Wut versetzten. Sie seien »psychisch-infektiöses Material«, das die Disziplin und den Kampfwillen der Geschwächten zersetzt hätte (Bonhoeffer 1922: 10). ${ }^{37}$

Diese abwertende Sichtweise auf die betroffenen Soldaten, deren Reaktionen auf das Kampfgeschehen als anormal eingestuft wurde, prägte den methodischen Ansatz der Behandlungen, die sich durch »ausgesuchte Brutalität« (Ulrich 2004: 655) auszeichneten. Schonende und zeitintensive Therapien wurden als Belohnungen für ihre Willensschwäche interpretiert. Die Behandlungen, die die Soldaten stattdessen erfahren sollten, wiesen manipulative Elemente auf, beinhalteten meist die Anwendung von gegen den Leib gerichteter Gewalt und hatten einen strafenden Charakter. Durch schmerzhafte Stromschläge, Hungerkuren, Dauerbäder, Scheinoperationen sowie »Gewaltexerzieren«, um nur einige Methoden anzuführen (siehe hierzu ausführlich Riedesser/Verderber 2004: 48f.), sollten den Soldaten ihre Symptome ausgetrieben und ihr Wille gestärkt werden, wieder an die Front zu gehen. Erklärtes Ziel der Behandlungsmethoden war, ihnen jeglichen `Krankheitsgewinn` für die Symptombildung zu nehmen, der bei den

35 Die gängige Praxis, Offizieren Neurasthenie, Ischias, Neuralgie zu diagnostizieren charakterisierte Ernst Simmel (1882-1947) als kameradschaftliche "Gefälligkeitsdiagnosen« unter Standesangehörigen (1918: 24). Sie blieben damit auch von den aggressiven Behandlungsmethoden verschont.

36 So meint Robert Gaupp (1870-1953): »Polen und Juden schienen mir leichter zu erkranken als Deutsche; Rheinländer häufiger als Pommern; Soldaten häufiger und auffälliger als Offiziere.« (1922: 70)

37 Ein besonders wüstes Konglomerat von Zuschreibungen ist bei Otto Binswanger (1852-1929) zu finden: Sie gehörten zu den Kriegshysterikern, die »in die Kriegssphäre überhaupt nicht hineinpassten, die ausgesprochenen Neuropathen und Neuroastheniker, die Psycho- oder Hysteropathen, die debilen und ausgeprägt Schwachsinnigen, die degenerativen Konstituierten einschließlich der asozial Entgleisten und der Kriminellen (neuro-resp. psychopathische Naturen).«(1922: 45) 
Soldaten auf den »pathogene[n] Einfluss der Selbsterhaltungswünsche» (Bonhoeffer 1922: 29) zurückgeführt wurde. ${ }^{38}$

Auch wenn die Ärzte es in ihrem nach dem Krieg verfassten Erfahrungsberichten nicht offen zugaben, blieben die Erfolge ihrer >Therapien weit hinter den Erwartungen zurück. Zwar bewegten Soldaten, deren Arme und Beine gelähmt waren, ihre Glieder wieder, nachdem sie mit Elektroschocks traktiert wurden, aber solche schnellen Erfolge waren meist nicht von Dauer, und auch langwierige und mit verschiedenen Methoden kombinierte Behandlungen führten häufig nicht zum Ziel. Die Soldaten waren anschließend meist lediglich als >garnisonsdienstfähigく entlassen. Auch die abschreckende Wirkung gegen "Simulanten und Aggravanten« (zitiert nach Riedesser/Verderber 2004: 71) blieb aus. »Die Zahl der >Kriegsneurotiker» schwoll trotz der vereinten Bemühungen von Neuropsychiatrie und militärischer Führung in einem für diese besorgniserregenden Maße an [...].« In den Heimatlazaretten gab es obendrein, wie ein Psychiater nach dem Krieg schrieb, ") für den Nachdruck und die Schärfe doch eine gewisse Grenze. Die Überschreitung derselben beschwor die Gefahr der Meuterei, der Revolution im Lazarettı.« (Ebd.) Die ausbleibenden Behandlungserfolge drückten sich noch am deutlichsten aus, wenn die Ärzte auf »sichere Simulanten, demente Psychopathen, Individuen mit bewusster Willenssperrung und bewusst Gesundheitstrotzige« (Nonne 1922: 112) zu sprechen kamen, also denjenigen, die ihrer Behandlung widerstanden. Ihre Wortwahl zeigt, dass sie diese Patienten als ihre Feinde betrachteten, mit denen man sie beschwert habe. Anstatt dass im Sinne einer

»Darwinschen Zuchtwahl« bei diesen »körperlich und geistig Minderwertigen, Nutzlosen und Schädlinge [...] bei dieser Gelegenheit [den Krieg, d.A.] eine gründliche Katharsis stattgefunden hätte, die zudem durch den Glorienschein des Heldentodes, die an der Volkskraft zehrenden Parasiten verklärt hätte«, habe man sie »konserviert« (ebd.).

Im Zuge psychiatrischer Behandlungen kam in Deutschland eine unbekannte Zahl von Soldaten um. Todesfälle wurde von den Ärzten im Zusammenhang mit der Verabreichung von Elektroschocks eingestanden (Riedesser/Verderber 2004: 63f.). Gleichzeitig muss man allerdings feststellen, dass es auch Ärzte gab, die mehr Verständnis für die Leiden ihrer

38 Dieses Argumentationsmuster wurde von Psychiatern bereits vor dem 1. Weltkrieg im Zusammenhang mit Arbeits- und Verkehrsunfällen entwickelt und im Krieg dann radikalisiert. Die Symptome der Unfallopfer seien von der Vorstellung ausgelöst worden, Schadensersatz für das Erlittene zu erhalten (siehe Fischer-Homberger 1975: 128f.). Diagnostisch bot diese Argumentation den Vorteil, dass zwischen einer Simulation der Symptome und eines tatsächlichen Kontrollverlusts beispielsweise über die Stimme, nicht unterschieden werden musste, weil im jeden Fall die »krankhaft verkehrte Willensrichtung« (Nonne 1922: 116) gebrochen werden musste. 
Patienten zeigten als die oben zitierten Psychiater. ${ }^{39}$ Da in Deutschland der Psychiatrie bei der Begutachtung von Soldaten, denen vorgeworfen wurde, Befehle bzw. den Dienst verweigert zu haben, eine wichtige Rolle zukam, schützte obendrein in vielen Fällen die Psychiatrisierung die Angeklagten vor hohen Haftstrafen bzw. einem Todesurteil. Die Gefahr, mit den gleichen Symptomen vor ein Militärgericht gestellt und zum Tode verurteilt zu werden, war deshalb in anderen Ländern größer als in Deutschland. ${ }^{40} \operatorname{Im} 2$. Weltkrieg sollte sich diese Praxis nicht wiederholen. Die Ätiologie und auch die Methodik der Behandlung der Neuropsychiater sollten vor allem im Heer wieder den Umgang mit psychosomatischen Reaktionen bestimmen, ihre nun verstärkt rassenhygienisch ausgerichteten Gutachten schützten die Soldaten weder vor einer Bestrafung noch vor Todesurteilen. Sofern Soldaten als dienstunfähig begutachtet wurden, stieg für sie nun die Gefahr, dass sie »Konzentrationslagern und Heil- und Pflegeanstalten übergeben (wurden). In beiden Einrichtungen konnten sie von der T4Aktion erfasst werden, so dass einige Kriegsneurotiker in Vernichtungsanstalten getötet wurden.«(Blaßneck 2000: 88) ${ }^{41}$

Auch in anderen Armeen gingen die Militärpsychiater im 1. Weltkrieg von ähnlichen ätiologischen Annahmen aus wie die deutschen Nervenärzte. So interpretierten die US-amerikanischen Militärärzte anfangs die psychosomatischen Reaktionen als Folge einer Hirnschädigung, um anschließend davon auszugehen, dass meistens im emotionalen Bereich die Gründe für die Ausbildung der Symptomatik liegen. Auch wenn sie auf Elektroschocks und Hypnose als Behandlungsmittel verzichteten und befanden, dass die meisten Symptome verschwanden, wenn die Soldaten im frontna-

39 Als Gruppe traten am Ende des Krieges vor allem die Psychoanalytiker öffentlich hervor, die mit einer anderen Ätiologie und anderen Behandlungsansätzen die Kriegsneurotiker behandelten und als Konkurrenten der Neuropsychiater auftraten; siehe hierzu Reichmayr (1983), Bröckling (1997: 221f.).

40 Trotz schlechter Forschungslage zur Militärjustiz in Deutschland für die Zeit des 1 . Weltkrieges, scheint dies die vergleichsweise geringe Zahl der verhängten Todesurteile in Deutschland anzudeuten. In der deutschen Armee wurden 150 Todesurteile ausgesprochen und 48 Soldaten wurden hingerichtet« (Riedesser/Verderber 2004: 175). Britische Kriegsgerichte verhängten »3000 Todesurteile - in der Regel wegen Desertion, Befehlsverweigerung oder Feigheit vor dem Feind. 346 dieser Todesurteile wurden vollstreckt« (Ulrich 1992b: 182) Nach dem Krieg setzte in England eine kritische Auseinandersetzung zum Verhältnis Shell-Shock, Wille und Todesstrafe ein, die dazu führte, dass im 2. Weltkrieg in den britischen Streitkräften kein einziger Soldat wegen $>$ Feigheit vor dem Feind hingerichtet wurde (ebd.: 183). Einen Überblick über die Rechtsprechung im 2. Weltkrieg bei den deutschen Streitkräften sowie den Alliierten ist bei Messerschmidt (2005: 170f.) zu finden.

41 Nachdem Karl-Heinz Roth in den 80er Jahren auf die Behandlung von 〉Kriegsneurotikern im Dritten Reich aufmerksam machte, wird das Thema heute in einer ganzen Reihe von Publikationen behandelt. Stellvertretend für andere sei hier auf Riedesser/Verderber 2004 (101f.), Blaßneck (2000), Bröckling (1997: 261f.) und Müller (2001) hingewiesen. 
hen Bereich einige Ruhetage und Essen erhielten, gingen sie von einer Prädisposition der Soldaten aus, von der abhing, ob ein Soldat psychisch zusammenbrach. Dieser Annahme Rechnung tragend, unterzogen die USStreitkräfte im 2. Weltkrieg alle einberufenen Wehrpflichtige psychologischen Tests und schlossen 18,5 Prozent der Wehrpflichtigen vom Kriegsdienst aus, weil ihre Testergebnisse prognostizierten, dass sie eher zu einem psychischen Zusammenbruch im Gefecht neigen würden als andere Soldaten (Gabriel 1988: 126f.). ${ }^{42}$ Die mit diesem Screening verbundene Erwartung, dass allenfalls wenige US-Soldaten unter psychosomatischen Symptomen leiden würden, bestätigte sich nicht:

»the rate at which soldiers in World War II were admitted to psychiatric hospitals was double the World War I rate, and separations from service for mental and emotional reasons increased almost seven times over the rate for World War I. Psychiatric casualties constituted the single largest category of disability discharges in World War II.« (Ebd.: 128)

504.000 Soldaten schieden dauerhaft für den Kriegseinsatz aus, und weitere 596.000 Soldaten waren für Wochen oder Monate nicht einsetzbar (ebd.: 27; siehe auch Roghmann/Ziegler: 176f.). Vor diesem Hintergrund vollzog sich in den US-Streitkräften ein Wandel in der Beurteilung der psychosomatischen Reaktionen der Soldaten. Da selbst kampferprobte Soldaten mit psychosomatischen Symptomen auf ihre Kampfeinsätze reagierten, war die Annahme, die Betroffenen seien schwach oder gar feige, nicht mehr zu halten, und

»the military began to recognize that psychiatric breakdown was too common a phenomenon to be regarded as abnormal. The diagnostic name for psychiatric collapse was changed from >psychoneurosis to >exhaustion`, a change indicating that there was nothing particularly shameful about collapsing under the stress of battle.«(Ebd.: 128)

Gegen die Einsicht, dass psychosomatische Reaktionen auf das Kriegsgeschehen alles andere als anormal sind, gab es große Widerstände zu überwinden. In Deutschland wurde noch 1961 eine Arbeit unter dem Titel »Die abnormen Erlebnisreaktionen im Kriege bei Truppe und Zivilbevölkerung« veröffentlicht, die anzeigt, wie sehr sich der Verfasser bemühte, psychosomatische Reaktionen bestimmten »Persönlichkeitsstrukturen« zuzuordnen. Der Mensch habe, wie Bonhoeffer 1947 schrieb, »eine >fast

42 Bei Watson werden andere Zahlen angegeben: Demnach wurden im 2. Weltkrieg und im Koreakrieg wegen psychischer Anfälligkeit und mangelnder Intelligenz jeweils ungefähr $12 \%$ der amerikanischen Soldaten »als für jede Frontverwendung ungeeignet befunden.« (1985: 166) Helmus/Glenn geben wiederum einen Anteil von 18 Prozent der Wehrpflichtigen im 2. Weltkrieg an, die aus »psychiatric causes« abgelehnt wurden (2005: 95). 
absolute Toleranz` gegenüber Erschöpfungseinflüssen«, und deshalb sei die »Bezeichnung combat exhaustion und operational fatigue [...] sachlich meist nicht gerechtfertigt« (Meyer 1961: 587). Als interessant wird eingestuft, dass Soldaten mit einer »unglücklichen Kindheit« und ähnliches mehr eher zu einer Neurose neigten als andere Soldaten. Es wird behauptet, dass es unter den Ärzten eine »Übereinstimmung gibt, dass diejenigen, die frühzeitig und unter geringem Druck zusammenbrechen, von jeher labile Persönlichkeiten waren, die oft schon in Friedenszeiten nervöse Störungen gezeigt hatten.« Es wird betont, dass in »36 von 100 Fällen, [...] die Kriegsneurose nur eine Verstärkung einer früheren Neurose« war, ohne sich die Frage zu stellen, welche Bedeutung in diesem Zusammenhang die 64 anderen »Fälle« haben könnten. Zum »hysterischen Mechanismus« würden »unterdurchschnittlich Intelligente«, »undifferenzierte und schwach Begabte« neigen, um anschließend auf italienische Mannschaftssoldaten, »Inder, Gurkas und Neger« sowie Frauen zu verweisen (ebd.: 589f.). $\mathrm{Zu}$ einer gewundenen Formulierung greift dagegen der Autor, nachdem er feststellt, "Anankasten« seien »nicht selten besonders mutig im Einsatz« gewesen. »Aber andere neurotische oder psychopathische Persönlichkeiten bewährten sich nicht ganz selten im Kriegseinsatz unerwartet gut« (ebd.). Völlig unerwähnt bleiben dagegen Untersuchungen, die keine Beziehung zwischen einer psychischen Prädisposition und der Ausbildung psychosomatischer Reaktionen herstellen konnten: »the fear and anxiety implicit in combat brought forth psychosomatic manifestations in so many men that these served less and less discriminate between men who were labeled psychiatric casualties und those who were not." (Stouffer 1949b: 455) Dies gilt erst recht für eine Studie aus dem Jahr 1946 auf die Gabriel verweist, die darlegt,

sthat the only people who do not succumb to the stress of war are those who are already mentally aberrant in a clinically defined sense. About 2 percent of soldiers exposed to combat over long periods of time do not break under stress. An examination of these sheroes` reveals that their most commonly held trait was that they were saggressive psychopathic personalities\& who were this way before they entered the battle zone.«(Ebd.: 31$)$

Es waren aber eben nicht nur die >schwachen` oder die >feigen`Soldaten, die unter den Belastungen ihres Kriegseinsatzes zusammenbrachen. $\mathrm{Ob}$ die Soldaten auf das Kriegsgeschehen mit unmittelbaren Angstreaktionen vor oder im Zuge eines Gefechts reagieren, die sich unter anderem in heftigen Herzklopfen, kalten Schweißausbrüchen, in Zucken und Zittern des Körpers oder auch im unwillkürlichen Harnlassen äußern (Stouffer 1949b: 201, ähnlich Meyer: 575), oder ob sich bei ihnen anhaltende Erschöpfungszustände, Magengeschwüre, sowie Schlafstörungen ausbildeten oder sie eine schwer revidierbare Persönlichkeitsstörung entwickelten, wie sie das Syndrom des Berserkers darstellte - in allen Fällen beeinflusste zwar 
ihre individuelle >Persönlichkeitsstruktur` die psychosomatische Reaktionsbildung, aber letztlich hängen ihre psychosomatischen Reaktionen von den konkreten Kriegserlebnissen, der Art und der Dauer des Einsatzes ab. Diese beunruhigende Erkenntnis bedeutet, dass für fast alle Soldaten die Gefahr besteht, im Zuge eines lange dauernden und intensiven Kampfeinsatzes mit schwerwiegenden und chronischen psychosomatischen Leiden auf das Kriegsgeschehen zu reagieren. »Thus, psychiatric casualties are as inevitable as gunshot and shrapnel wounds in warfare.« (Marlowe, zitiert nach Gabriel 1988: 30)

Dass der Mensch eine fast absolute Toleranz gegenüber Erschöpfungseinflüssen habe, wie dies Bonhoeffer behauptete, ist eine Auffassung, der heute selbst in Deutschland kaum noch jemand zustimmen mag. Als sinnliches, emotionales Wesen kann ein Mensch zwar seinen eigenen Körper wie ein Instrument verwenden, er muss weder unmittelbar seinem Bedürfnis nach Schlaf, Hunger und Durst nachgeben, und er muss nicht handeln, wie es ihm seine physiologischen Reaktionen snahe legen Mensch nicht nur einen Körper hat, sondern dieser zugleich auch sein Leib ist (siehe hierzu Abschnitt 5.4.), verwandelt er sich trotzdem nicht in eine Maschine für die das Geschehen äußerlich bleibt.

Die veränderte Sichtweise auf die Leiblichkeit der soldatischen Subjekte drückt sich prägnant im Begriff des Stresses aus, der erstmals von amerikanischen Psychiatern im Verlauf des 2. Weltkrieges verwendet wird. Das Kampfgeschehen wird von ihnen als eine Stresssituation beschrieben (siehe Stouffer 1949b: 76f.). Mit dem Begriff Stress wird anerkannt, dass die Soldaten nicht nur Subjekte mit einem Willen und einem Körper sind, sondern auch aus einem Leib bestehen. Stress, ursprünglich ein technischer Begriff aus der Werkstoffkunde, der für den Druck bzw. Zug steht, dem man dem untersuchten Stoff aussetzte, bezeichnet komplexe physiologische Prozesse, die durch zumeist äußere Faktoren ausgelöst werden (Stressoren). Stress steht in dem grundlegenden theoretischen Modell von Hans Selye (1907-1982) sowohl für ungewöhnliche Belastungen, denen ein Individuum ausgesetzt wird, als auch für die physiologischen Prozessen, mit denen der Leib auf diese Belastungen reagiert. Selye hat diese Prozesse als Adaptions- bzw. Anpassungssyndrom interpretiert, also als sinnvolle Prozesse, die dem Subjekt helfen, auf das Ereignis zu reagieren, um beispielsweise Gefahren abzuwenden. So löst Angst eine Reihe physiologischer Prozesse aus, die insgesamt die körperlichen Kräfte des Individuums mobilisieren, seine Wahrnehmungsfähigkeit erhöhen und gleichzeitig sein Schmerzempfinden sowie sein Gefühl für Hunger und Durst reduzieren und damit die Chancen des Subjekts erhöhen, sei es durch Flucht, sei es durch aggressives Handeln die Situation zu bewältigen. Nicht jeder Stress bzw. jede Stressreaktion ist folglich als pathologisch zu bezeichnen. Pathologisch wirkt sich Stress erst aus, wenn das Individuum zuviel bzw. dauerhaftem Stress ausgesetzt ist, der dann zu verschiedenen 
Krankheitssymptomen führen kann. Bis heute ist Selye's dreiteilige Phaseneinteilung des Stress' - angefangen von der Schockphase bzw. Alarmreaktion, der Widerstands- bzw. Einwirkungsphase und der anschließenden Erholungsphase grundlegend für das Verständnis des Verlaufs von Stressreaktion.

Mit der Verwendung des Begriffs Stress wird angezeigt, dass es Belastungsgrenzen für die Soldaten gibt, die von ihnen nicht willkürlich geändert werden können und die zur Einschränkung ihrer Einsatzfähigkeit führen. Als mögliche Stressoren führt bereits Stouffer im Abschnitt »Combat as a Situation of Stress« (1949b: 76f.) neben der Bedrohung für Leib und Leben zahlreiche Faktoren, wie schlechte Verpflegung, Schlafmangel, Mangel an sexueller und sozialer Zufriedenheit, Verlust von Kameraden, Wertekonflikte zwischen der militärischen Verpflichtung und der Verpflichtung, sich um familiäre Angelegenheiten zu kümmern, an. Gefechtsstress, so definieren die verschiedenen US-Teilstreitkräfte, »is the mental, emotional or physical tension, strain, or distress resulting from exposure to combat and combat-related conditions." (Department of the Army 2000: Preface) Auch hier gilt, dass Gefechtsstress nicht unmittelbar die Einsatzfähigkeit einschränkt, aber dass er im Zuge eines Gefechtes dazu führt, dass viele Soldaten unter ihm leiden und sich deshalb im Kampf falsch verhalten (misconduct behavior), ${ }^{43}$ sie zusammenbrechen und verschiedenste Symptome von combat stress reactions entwickeln oder gar unter einem posttraumatischen Stress-Syndrom (PTSD) ${ }^{44}$ leiden (siehe hierzu beispielsweise Helmus/Glenn 2005: XIII).

Vor dem Hintergrund der nach dem 2. Weltkrieg einsetzenden Bemühungen der US-Streitkräfte, die Anzahl der Soldaten zu verringern, die mit psychosomatischen Leiden auf den Kampfeinsatz reagieren und nicht mehr eingesetzt werden können, formuliert Watson die Befürchtung, Stress werde von Psychologen als ein manipulierbarer Faktor aufgefasst, der seiner legitimen moralischen Bedeutung entkleidet werde, weil aus dem Blick gerate, dass es sich um eine »legitime menschliche Reaktion auf furchterregende Situationen« (1985: 45) handelt. Die Durchsicht amerikanischer wie

43 Unter dieser Kategorie wird ein großes Spektrum von Handlungen zusammengefasst. Es reicht von Gehorsamsverweigerung, über den Angriff auf den Vorgesetzten bis hin zur Vergewaltigung und das Töten von Gefangenen. Siehe hierzu Field Manuel (FM) 22-51 »Leaders' Manuel for Combat Stress Control« (1994) der US-Armee, dass auch der Bundeswehr zur Orientierung dient (siehe Wothe 2001).

44 Die Symptome und Klassifikation von PTSD (Post Traumatic Stress Disorder) erfolgt in der Regel nach dem Diagnostisch Statistischen Manual der nordamerikanischen psychiatrischen Gesellschaft (DSM IV). In der Internationalen Klassifikation psychischer Störungen, Kapitel V, Forschungskriterien wird PTSD ähnlich beschrieben (ICD 10, F43.1). Siehe hierzu auch Fischer/Riedesser (1999: 42f.). 
auch der deutschen militärischen Dienstliteratur ${ }^{45}$ zeigt erst einmal ein etwas anderes Bild, da in den Schriften grundsätzlich anerkannt wird, dass es sich beim Gefechtsstress um normale Reaktionen auf extreme Belastungen handelt (siehe beispielsweise Zentrum für Innere Führung (ZIF) 1997: 15). Auch wird eingeräumt, dass die Belastungen zu schwerwiegenden psychischen und sozialen Störungen (führen), und auch langfristige Schäden wie PTSD verursachen können (ebd.: 27). Gleichzeitig signalisieren die Texte den Adressaten aber, dass sie den Gefechtsstress »in aller Regel in den Griff« (ebd.: 15) bekommen werden. Der Gefechtsstress wird bevorzugt als eine manipulierbare Größe dargestellt, die durch geeignete Maßnahmen erheblich reduziert werden kann. Diese Wahrnehmung des Stresses ist insofern konsequent, als es im Kern in diesen Schriften darum geht, die Leistungsfähigkeit der Soldaten trotz ihrer zwangsläufig auftretenden psychosomatischen Reaktionen zu erhalten bzw. zu erhöhen.

Zur Umsetzung dieses Ziel lassen sich vier verschiedene Maßnahmen unterscheiden: 1. Sollen durch psychologische Tests »stresssensitiv« reagierende Soldaten für bestimmte Einsatzbereiche ausgeschlossen werden. So werden bei der Bundeswehr die Soldaten des Kommandos Spezialkräfte (KSK) unter anderen ausdrücklich im Hinblick auf ihre Belastungsfähigkeit untersucht und als Bewerber gegebenenfalls ausgeschlossen (Kreim 2001a: 50). 2. In der Ausbildung wird gezielt versucht, die Belastungsgrenzen für die Soldaten zu erhöhen (siehe Helmus/Glenn 2005: 99f.). ${ }^{46} 3$. Fällt insbesondere den Offizieren und den Unteroffizieren die Aufgabe zu, Stresssymptome bei ihren Untergebenen zu erkennen, möglichst dafür zu sorgen, dass die betroffenen Soldaten entlastet werden und sich erholen können, sowie 4. falls solche im Truppenverband praktizierbaren Maßnahmen nicht greifen, soll therapeutische Unterstützung für die Soldaten angefordert werden.

Dass es Aufgabe der Truppen- und Unteroffiziere sei, Symptome von Stressreaktionen der Soldaten zu beobachten und Gegenmaßnahmen einzuleiten, wird in den vorliegenden Schriften der US-Streitkräfte mehr als in den Texten des Zentrums für Innere Führung betont. In Letzteren wird dagegen mehr die Verantwortung des einzelnen Soldaten hervorgehoben, bei sich selber auf Anzeichen zu reagieren und darauf insistiert, dass die empfohlenen Verhaltensregeln - zum Beispiel sich in »positivem Denken« zu

45 Neben dem bereits zitierten FM 6-22.5 (DoA 2000), das identisch ist mit den gleichnamigen Schriften des US-Marine-Corps (MCRP 6-11C) und der Navy (NTTP 1-15M), sei hier noch auf das Pamphlet 600-63-10 »Fit to Win Stress Management (1987) der US-Armee, hingewiesen. In mehreren Schriften des Zentrum für Innere Führung (ZIF) der Bundeswehr wird ausführlich auf das Thema Gefechtsstress eingegangen.

46 Darum erinnert die militärische Ausbildung in einigen Bereichen auch heute noch an den Drill. So soll durch häufiges Schießtraining die Trefferquote der Soldaten verbessert und ihre Bereitschaft erhöht werden von der Waffe Gebrauch zu machen (siehe Grossman 1995: 252f.). 
üben, eingehalten werden. ${ }^{47}$ Als eines der obersten Behandlungsprinzipi$\mathrm{en}^{48}$ gilt, dass schon innerhalb des Truppenverbandes, dem die Soldaten angehören, auf ihre Symptomatik eingegangen bzw. sie möglichst bald wieder ihm zugeführt werden sollen. Dies gilt vor allem für leichte Stressreaktionen. Während allerdings die von der Wehrmacht praktizierte »frontnahe Therapie« ganz im Zeichen des defizitären militärischen Personalbedarfs stand, wird sowohl bei der Bundeswehr als auch bei den USStreitkräften dieses Prinzip eher mit einer therapeutischen Absicht verfolgt. Indem die betroffenen Soldaten allenfalls kurzzeitig von ihrer Einsatzgruppe getrennt werden, sollen die interpersonalen Konflikte zwischen der empfundenen Verpflichtung, die Angehörigen der Gruppe nicht im Stich zu lassen und dem Wunsch, die Gefahrenzone zu verlassen, nicht geschürt werden und damit weiterer Stress vermieden werden. Es geht um die Minimierung des Risikos, dass die Soldaten schwerer wiegende combat stress reactions bzw. ein postraumatisches Belastungssyndrom erleiden (DoA 2000: 55). Die Beachtung dieses Behandlungsprinzips habe allerdings auch noch einen weiteren positiven Effekt für die Militärs. Denn wenn die Soldaten in der Nähe ihrer Einheiten behandelt werden, würden, so die Einschätzung der US-Streitkräfte 65 bis 85 Prozent

»of combat stress casualties treated in medical CSC [Combat Stress Control, d.A.] facilities return to duty within 1 to 3 days. About 15 to 20 percent more return to duty in 1 to 2 weeks. Only 5 to 10 percent are sent home, and these usually have other problems in addition to combat stress reactions. If evacuated, few combat stressed Service members will return to duty. In fact, many are likely to be permanently disabled.«(Ebd.: 54)

Die Bundeswehr zeigte sich Anfang der 90er Jahre erstaunt über das Ausmaß der Stressreaktionen, das ihre Soldaten bei Auslandseinsätzen entwickelten, obwohl sie, abgesehen von einigen Flugbesatzungen, nicht an Gefechten beteiligt waren. Nach Analyse nationaler und internationaler Modelle bzw. Vorgehensweisen mit Gefechtsstress bzw. ungewöhnlichen

47 Dieser Eindruck kann allerdings auch schlicht ein Befund sein, der auf die ausgewählte Literatur zurückgeht. Die Schriften des Zentrums für Innere Führung der Bundeswehr (ZIF) richten sich stärker an die einzelnen Soldaten und es sind keine Handbücher für Offiziere und Unteroffiziere. Andererseits sind die US-Streitkräfte stärker auf Kampfeinsätze ausgerichtet und sie müssen deshalb mit mehr psychosomatischen Reaktionen der Soldaten rechnen als die Bundeswehr, die bislang eher nur in Ausnahmefällen davon ausgeht, dass ihre Verbände Kampfeinsätze durchführen.

48 Die US-Streitkräfte gehen insgesamt von 6 grundlegenden Behandlungsprinzipien aus: Brevity, immediacy, centrality, expectancy, proximitiy und simplicity (siehe DoA 2000: 54f., sowie Riedesser/Verderber 2004: 207, Gabriel 1988: 140f.). Im Rahmen der deutschen »Kameradenhilfe« werden davon 4 Prinzipien hervorgehoben: Unverzüglichkeit, Frontnähe, Zuspruch und Einfachheit (ZIF 1996: 35). 
Stressbelastungen entschied sich die Bundeswehr, ein besonderes präventives Verfahren anzuwenden, um die Folgen des Stresses zu minimieren. Sie orientierte sich dabei an dem Critical Incident Stress Management (CISM) von Mitchell, das ursprünglich vor allem für Polizisten, Feuerwehrleute und andere Angehörige von Rettungsdiensten entwickelt wurde, die sich im Zuge eines Einsatzes außergewöhnlichen Situationen ausgesetzt sehen. Es wird als Konzept seit Anfang 1996 »mit allen aus dem Einsatz zurückkehrenden UN-Beobachtern und nach fast allen Dienstunfällen mit Todesfolge (Flugunfälle, Schießunfälle usw.) im In- und Ausland« (Willkomm 2001: 104) durchgeführt. Es handelt sich nicht um ein therapeutisches Verfahren im engeren Sinne, sondern um Experten bzw. zuvor entsprechend ausgebildeten Angehörigen der betroffenen Einheit geleitete und strukturierte Gruppengespräche, die den Teilnehmern die Gelegenheit geben sollen, ihre Emotionen zu bearbeiten, bestehende Spannungen und Schuldgefühle unter den Betroffenen abzubauen und ihnen Informationen $\mathrm{zu}$ vermitteln, wie sie am besten mit ihren eigenen Reaktionen umgehen können. Als sekundäre präventive Maßnahme habe CISM dazugeführt, dass »der Anteil derjenigen, die weiterer Nachsorge/Therapie bedürfen, deutlich niedriger (ca. 1 bis 2 Prozent aller Betroffenen) liegt, als vor deren Einführung« (ebd.), der bei ungefähr 8 bis 15 Prozent lag.

Auch wenn in der militärischen Dienstliteratur betont wird, dass es sich bei Stressreaktionen um normale Phänomene handelt, so wird zugleich an anderen Stellen der Eindruck geweckt, dass die Soldaten den Gefechtsstress erfolgreich bewältigen können, gar eine Immunisierung möglich sei, »worunter eine mindestens einmalige vorausgegangene erfolgreiche Problemlösung in gleicher (ähnlicher) Situation verstanden wird « (Kreim 2001b: 493) Hier wird freilich eine Wiederholbarkeit und Kalkulierbarkeit von Gefechten vorausgesetzt, die sich für die eingesetzten Soldaten, die sich jeweils in unwägbaren Situationen befinden und Angst vor dem Verlust ihres einmaligen Leben haben, nicht gegeben ist. Aus dem Blick gerät bei solchen Sätzen, dass mit zunehmender Intensität und Dauer von Kampfeinsätzen die Wahrscheinlichkeit, psychosomatisch auf den Gefechtsstress $\mathrm{zu}$ reagieren und unter einem posttraumatischen Belastungssyndrom zu leiden, erheblich steigt und die verletzende Wirkung des Erlebten, ebenso wenig wie das Risiko, physisch verletzt und getötet $\mathrm{zu}$ werden, ausgeschlossen werden kann. Als Akteure, deren Handeln für andere Menschen tödliche Folgen haben kann, müssen Soldaten auch mit irreversiblen aber nicht intendierten Folgen ihres Handelns zurechtkommen. $^{49}$

49 Wright, ein amerikanischer Journalist, der Marineinfanteristen bei ihren Feldzug im Irak im März und April 2003 begleitete, berichtet von einigen Vorfällen, die bei den Soldaten schwere Schuldgefühle auslöste. So habe zu ihm ein Unteroffizier gesagt, der zuvor irrtümlich einen Feuerbefehl auf ein Kind erteilte, dass deshalb schwer verletzt wurde: »Ich werde das mit nach 
Trotz aller Auswahlverfahren, der Trainings, die die Belastungsgrenzen verschieben, bleibt der Krieg für die Soldaten ein Geschehen mit einer unkalkulierbaren, traumatisierend wirkenden Ereignisdynamik. ${ }^{50}$ Sie sind nicht davor gefeit, während eines Kampfeinsatzes unter den psychosomatischen Reaktionen des Gefechtsstress zu leiden, zumal gerade während heftiger Gefechte die Möglichkeiten, für eine Entlastung der Soldaten zu sorgen, eher abnehmen. Gleichzeitig ist im Kampf selber, wie ein amerikanischer Militärpsychiater sagt, »no time to get stress casualties. You do what you're doing or you're dead.« (Marlove, zitiert nach Helmus/Glenn 2005: 86) ${ }^{51}$ Deshalb sind Symptome von Gefechtsstress und PTSD vor allem Probleme der Überlebenden.

Die Informationen, wie man sich vor Reaktionen des Gefechtsstresses wirkungsvoll schützen kann, hat für die Überlebenden eine weitere Folge: Wer als Überlebender unter den Reaktionen des Gefechtsstress leidet, sieht sich mit dem Makel des persönlichen Versagens konfrontiert. Dies gilt beispielsweise dann, wenn das Behandlungsprinzip expectancy bzw. Zuspruch nicht die erwünschte Wirkung entfaltet und die Soldaten nicht, wie ihnen suggeriert werden soll, nach kurzer Zeit wieder bei »ihren Kameraden sein werden« und auch das »Ablenken« vom Geschehen, das »Bagatellisieren« und »Aufmuntern« (siehe ZIF 1996: 35) nicht greifen. Wenngleich in anderen Passagen der militärischen Dienstliteratur Verständnis für die Symptome von Gefechtsstress geäußert wird, hier führt die Intention der Verfasser, die Soldaten weiter einsatzfähig zu halten, quasi zu einer Bagatellisierung des Kampfgeschehens, die unangemessen ist. Sicher ist, dass nach wie vor psychosomatische Reaktionen auf das Kampfgeschehen weniger vorzeigbar sind als physiologische geschlagene

Hause nehmen und damit leben müssen.« Dem schließt sich die Klage an, dass Infanteristen eher mit den Folgen ihres Handelns konfrontiert werden als Soldaten anderer Waffengattungen. »Ein Pilot geht nicht runter und sieht sich die Zivilisten an, die seine Bomben getroffen haben. Die Artilleristen sehen nicht, welche Wirkung das hat, was sie tun. Aber die Jungs am Boden sehen es. Das bringt mich innerlich um.« (2005: 219)

50 Auf die Bedeutung der Situation für die Entwicklung von PTSD machen unter anderen Fischer/Riedesser aufmerksam. Es gibt zwar eine »relativ breite interindividuelle Variation bei der Verarbeitung potentiell traumatischer Situationen« (1999: 142), aber diese Variationsmöglichkeiten nehmen gerade mit zunehmendem Einsatzstress stark ab. In Studien zu Vietnamveteranen konnte außerdem nachgewiesen werden, dass sich der »erbgenetische determinierte Varianzanteil [...] in engen Grenzen« bewegt (ebd.).

51 Die Bundeswehr rät Soldaten, die Reaktionen von Gefechtsstress bei ihren Kameraden beobachten, zu »rauen und robusten Maßnahmen [...], um eine Ansprechbarkeit zu erreichen oder eine panikartige Flucht zu verhindern.« (ZIF 1998: 20) Gemeint ist damit ein Handlungsspektrum das vom »kräftigen Anschreien über die Ohrfeige bis zum gewaltsamen Festhalten« (ebd.) reicht. Ob sie die Betroffenen tatsächlich ansprechbar machen, darf als unsicher gelten. Sicher dagegen ist, dass das Ohrfeigen etc. den Handelnden über sein Gefühl der Hilflosigkeit zumindest kurzzeitig hinweg zu helfen vermag. 
Wunden, dabei sind auch psychologischen Traumen vor allem eines - Verletzungen. ${ }^{52}$

\subsubsection{Taktische Angriffskonzeptionen im 1. Weltkrieg}

An der Westfront des 1. Weltkrieg stand im Mittelpunkt der taktischen Überlegungen aller Kriegsparteien die Frage, wie die Truppen das Niemandsland überwinden und die gegnerischen Stellungen durchbrechen können. Hunderttausende verloren ihr Leben, weil ihre Kommandeure nicht bereit waren zu akzeptieren, dass selbst in großer Zahl vorrückende Soldaten nicht die gegnerischen Stellungen erreichen konnten, wenn sie bereits im Niemandsland vom Feuer der Artillerie und der Maschinengewehre erfasst wurden. Vorrückende Infanteristen waren nicht nur schutzlos dem Geschosshagel ausgesetzt, sie konnten auch von ihren eigenen Waffen kaum Gebrauch machen, da sie möglichst schnell die gegnerischen Gräben erreichen sollten, um wenigstens dem gegnerischen Artilleriefeuer zu entgehen. Sie machten den Angriff, um Ludendorff zu paraphrasieren, »allein mit ihren Leibern« (1919: 460), und der Erfolg des Angriffs hing vom unwahrscheinlichen Zufall ab, dass ihre Leiber unverletzt die gegnerischen Linien erreichten.

Um wenigstens die Zahl der Verteidiger in den gegnerischen Stellungen zu verringern, gingen die Kriegsparteien ab 1915 dazu über, die anzugreifenden Frontabschnitte mit sehr vielen Artilleriegeschossen zu beschießen, bevor die Infanteristen aus den Gräben kletterten und angriffen. Aus dem gleichen Grund und weil sie Anfang 1915 über geringe Pulverund Granatenvorräte verfügten, verfiel die deutsche Armee auf die Idee, Giftgas freizusetzen, das die gegnerischen Soldaten in den Gräben und Unterständen ersticken sollte. Beim ersten Giftgasangriff bei Ypern im April 1915 gelang es den deutschen Truppen noch, die Gegner zu überraschen, aber nach vier Kilometer kam die Frontlinie wieder zum Stillstand (siehe Borgert 1979: 506f.). Selbst solche Erfolge gelangen später nur in Ausnahmefällen, da die Soldaten an der Westfront mit Gasmasken ausgerüstet wurden, die für sie zwar lästig und bei Bewegungen hinderlich waren, jedoch einen gewissen Schutz vor dem Giftgas boten. ${ }^{53}$ Auch die Bemühungen, die Verteidiger der gegnerischen Linien durch konventionelles Artilleriefeuer zu töten, führten nicht zum erwünschten Durchbruch,

52 Dies drückt sich auch in der öffentlichen Reputation aus, die die unter PTSD leidenden Kriegsveteranen erfahren. Obwohl sie als psychisch Verletzte gelten müssen, scheinen beispielsweise amerikanische Kriegsveteranen, die unter PTSD leiden, nicht mit dem amerikanischen Verwundetenabzeichen »Purple Heart« ausgezeichnet zu werden.

53 Anders sah die Situation an der Ostfront aus: Da die zaristischen Truppen nicht oder nur äußerst unzureichend mit Gasmasken ausgerüstet waren, wird davon ausgegangen, dass die Gasangriffe »in erheblichem Ausmaß zur Demoralisierung beigetragen haben.« (Müller 2004: 522) 
weil die umfangreichen Vorbereitungen für einen solchen Angriff selten verborgen blieben und die Verteidiger dazu übergingen, ihre Verteidigungsstruktur tief in den Raum zu staffeln. Insbesondere die deutschen Truppen hatten bis 1917 ein sehr erfolgreiches Verteidigungskonzept entwickelt, das später von den westlichen Alliierten zumindest in Teilen übernommen wurde. ${ }^{54}$ Es sah vor, dass die Angreifer nicht unbedingt am äußeren Rand des Grabensystems aufgehalten werden müssen. Es sollte keine Linie verteidigt werden, sondern Zonen, deren innere Struktur für den Gegner möglichst unsichtbar sein sollte. Durch die Staffelung der Verteidigungsstellungen in ein Vorfeld, »Großkampf-« und rückwärtige Kampfzone (siehe hierzu Oberste Heeresleitung (OHL) 1918a: 596) sollte der zu verteidigende Raum eine Tiefe haben, in der die Kampfkraft der angreifenden Truppenverbände aufgerieben werden sollte, um sie, falls sie nicht durch »Gegenstöße« der bereits im Kampfgebiet eingesetzten Verbände zurückgeworfen werden können, durch Gegenangreifen mit von außerhalb der Gefechtszone herangeführten Truppen zurückzuschlagen (siehe OHL 1918b: 618). Um dieses Ziel zu verwirklichen, wurde den Kommandeuren gestattet, flexibel auf die Angriffe zu reagieren. So wurden die äußeren Gräben nur mit relativ wenigen Soldaten besetzt und konnten zeitweilig aufgegeben werden, wenn der Gegner mit einem überlegenen Truppenverband angriff. Durch das eigene Artilleriefeuer sollten die angreifenden Truppen im Laufe des Gefechts geschwächt, ihre Beweglichkeit und ihr Angriffschwung durch Hindernisse auf dem Gefechtsfeld, wie Stacheldrahtbarrieren, gehemmt und durch zahlreiche, gut ausgebaute so genannte »Stützpunkte und Anklammerungspunkte« (ebd.: 598), die auch nicht aufgegeben werden sollten, wenn der sie umgebende Raum vom Gegner beherrscht wird, zermürbt werden und auf diese Weise allmählich ihre Kampfkraft verlieren. Die Rückeroberung des verloren gegangenen Raumes bestimmte die deutsche Dienstvorschrift zur »Abwehr im Stellungskrieg« nicht als das Hauptziel der »Gegenstöße« bzw. »-angriffe«. Zwar dürfe die »Entscheidung über dauernde Räumung oder über Verzicht auf Wiedereroberung eines Stellungsteils [...] nicht nur von örtlichen Erwägungen abhängig gemacht werden« (ebd.: 607), doch der »Zweck der Schlachtverteidigung besteht darin, den Angreifer sich abringen und verbluten zu lassen, die eigenen Kräfte aber zu schonen. Je mehr das gelingt, umso größer ist der Erfolg.« (Ebd.: 606; siehe hierzu Keegan 2001: 285f.; Lupfer 1981: 14f.)

Bereits unter dem Oberkommando von Falkenhayn (1861-1922) wurde zwar die Verteidigung des Geländes flexibler gehandhabt (siehe Borgert 1979: 513), aber erst unter Ludendorff wurde dezidiert bestimmt, dass die

54 Umstritten ist beispielsweise, ob und inwieweit es der englischen Armeeführung gelang, neben der räumlichen Gliederung des Grabensystems auch die Elemente der beweglichen Kampfführung zu adaptieren (siehe Storz 1999: 75 und Gudmundsson 1989: 157). 
Rückeroberung verloren gegangenen Terrains eine nachrangige Bedeutung hat. Auch wurden die Kommandeure ausdrücklich darauf hingewiesen, dass sie ungünstige Stellungen, die beispielsweise vom Gegner eingesehen werden können, räumen sollten (OHL 1918b: 618). Die Vorstellung, dass die Gegner durch ihre Angriffe »verbluten«, knüpfte im Übrigen an einen Gedanken an, der bereits den deutschen Planungen unter Falkenhayn zu Verdun zugrunde lag. Nun sollten sich die gegnerischen Kräfte aber nicht in einer großen, sondern in vielen Abwehrschlachten erschöpfen. ${ }^{55}$

Um die deutschen Frontlinien zu durchbrechen, versuchten zuerst die britischen Truppen in der Somme-Offensive (1916) und später die französischen Truppen in der Nivelle-Offensive (1916/7), ihre angreifenden Verbände durch permanentes Artilleriefeuer auf die gegnerischen Stellungen zu schützen. Insbesondere die britischen Kommandeure setzten zu Beginn ihrer Offensive an der Somme großes Vertrauen auf die vernichtende Wirkung der Artillerie. Sie erwarteten, dass ein großer Teil der deutschen Soldaten in den ersten Grabenlinien durch das Tage anhaltende Trommelfeuer verletzt oder tot waren und es die deutschen Kommandeure auch daran hindern würde, weitere Verstärkungen in die Gräben zu schicken. Die überlebenden gegnerischen Infanteristen sollten durch das fortgesetzte Artilleriefeuer daran gehindert werden, ihre Unterstände zu verlassen und mit ihren Waffen das Feuer zu eröffnen, wenn die britischen Soldaten ihre Gräben verließen. Die britischen Soldaten - beschwert mit über 27 Kilo Gepäck, das angefüllt war mit Verpflegung und Munition für mehrere Kampftage, die angesetzt waren, bis sie die deutsche Front durchbrochen hatten - sollten »langsam und überlegt« (Keegan 1991: 268) aus ihren Stellungen klettern, sich »im Abstand von zwei bis drei Metern nebeneinander und [in] Reihen zwischen fünfzig und hundert Metern hintereinander« (ebd.) auf die deutschen Stacheldrahtverhaue zugehen. Minutiös war vorab festgelegt worden, wann die Soldaten ihre Stellungen verließen und wann sie welche Punkte im Gelände zu erreichen hatten. Da zwischen den vorrückenden Infanterieverbänden und der Artillerie kein Sichtkontakt und auch keine Möglichkeiten bestanden, direkt miteinander zu kommunizieren, bildeten diese Vorgaben wiederum die Grundlage für die ebenso detaillierten Befehle an die Artillerie, denn wenn die Infanteristen einen bestimmten Punkt erreicht hatten, musste das Artilleriefeuer weiter nach

55 Es waren vor allem die Versuche verloren gegangenes Gelände zurückzuerobern, die bei den deutschen Verbänden zu zahlreichen Verletzten und Toten führten. Deshalb betrug die Zahl der Verletzten und Getöteten auf Seiten der deutschen Truppen am 1. Juli 1916 nur 10 Prozent der britischen Verluste (Keegan 2001: 412), stiegen aber in den folgenden Tagen und Wochen erheblich an. Zusammen mit den französischen Verlusten verzeichnete man auf Seiten der Alliierten nach 150 Tagen über 700.000 verletzte oder getötete Soldaten und auf Seiten der Deutschen fast 500.000 Männer. Nach Simkins Einschätzung war die deutsche Armee durch diese Verluste, die sie nicht ersetzen konnte, »schwer angeschlagen « (2004: 855). 
Vorne verlegt werden, damit es die Verteidiger daran hindern konnte, ihre Unterstände zu verlassen und das Feuer auf die Angreifer zu eröffnen. Die bürokratisch ausgearbeiteten Planungsvorgaben erwarteten von den Artilleristen und von den Infanteristen, dass sie die erteilten Handlungsanweisungen akkurat erfüllten, sie quasi mechanisch ihre Handlungen vollzogen. In den Planungen waren für die Akteure, deren Handlungsvollzüge miteinander verzahnt waren, keine Entscheidungs- und Handlungsspielräume vorgesehen, um auf unerwartete Hindernisse zu reagieren. All dies, zu dem noch der umfangreiche und von langer Hand vorbereitete Materialeinsatz in Gestalt von fast 3 Millionen Artilleriegeschossen kam, sowie das Vertrauen, das in die Destruktionskraft der Geschosse gesetzt wurde, verlieh der Somme-Offensive die Charakteristika eines industriellen Prozesses.

Am ersten Tag der Offensive (1. Juli 1916) zeigte es sich, dass keine der Erwartungen des britischen Oberkommandos an die Letalität der eigenen Artillerie gerechtfertigt war und die Einhaltung der bürokratischmechanischen Planungsvorgaben für die Infanteristen tödliche Folgen hatte. Trotz des mehrtägigen Geschosshagels waren die Unterstände, in denen sich die deutschen Soldaten aufhielten, weitgehend intakt geblieben, und sie konnten deshalb mit ihren Waffen die vorrückenden britischen Infanteristen unter Feuer nehmen. Obendrein fürchteten die britischen Artilleristen, die eigene Infanterie zu treffen, vergrößerten deshalb den räumlichen Abstand zwischen dem Sperrfeuer und der Infanterie und verlegten das Feuer schneller nach Vorne, als die britischen Soldaten vorrückten. »Das führte dazu, dass das Sperrfeuer sich oft vor den Angriffswellen her wälzte, jenseits der noch von starken feindlichen Truppen gehaltenen Stellungen; in einer solchen Situation hatten die Angriffswellen keinerlei Möglichkeit, das Sperrfeuer zurückrufen. Der von einigen Korps unternommene Versuch, das Sperrfeuer zurück- und dann wieder vorzuverlegen, [...] erschreckte die Infanterie zu sehr, dass sie vor dem eigenen Artilleriefeuer in Deckung ging« (Keegan 2001: 409). Ohne den Schutz des eigenen Artilleriefeuers wurden die britischen Infanteristen von den deutschen Gräben aus beschossen, und insbesondere die Maschinengewehrschützen richteten ein Gemetzel unter ihnen an. Viele britische Soldaten wurden verletzt oder starben, bevor sie die gegnerischen Linien erreichten. "Von den 100.000 Briten, die das Niemandsland betreten hatten, waren 20.000 nicht zurückgekehrt und weitere 40.000 verwundet zurückgebracht worden.« (Ebd.: 412) Auch nachdem in den folgenden Tagen, Wochen und Monaten es die britischen und französischen Kommandeure vermieden, ihre Infanterieverbände auf die oben beschriebene Weise dem gegnerischen Feuer auszusetzen, sie das Artilleriefeuer und die Truppenbewegungen besser koordinierten ${ }^{56}$ und erstmals auch

56 Aber auch beim im Rahmen der Nivelle-Offensive als entscheidend eingestuften Angriff der französischen Armee bei Chemin des Dames am 16.4.1917 gelang die Koordination des Artilleriefeuers mit der Truppenbe- 
Panzer einsetzten, gelang ihnen kein entscheidender Einbruch in die gegnerische Front.

Um einen entscheidenden Sieg gegen die westlichen Alliierten herbeizuführen, bevor sie durch amerikanische Truppenverbände gestärkt wurden, entschied sich die Oberste Heeresleitung (OHL) unter Ludendorff (1865-1937) und von Hindenburg (1847-1934), die, seit August 1916 mit umfassenden Vollmachten ausgestattet, einen entscheidenden Einfluss auf die deutschen Kriegsziele und die Kriegspolitik nach Innen und Außen hatten, für eine Offensive an der Westfront im Frühjahr 1918, in der alle noch zur Verfügung stehenden Ressourcen eingesetzt werden sollten. Vor dem Hintergrund der hohen Verluste an Soldaten entschied sich die OHL zu einer Neubewertung des Verhältnisses von Mensch und Maschine (siehe hierzu ausführlich Kaufmann 2002). »Bei der feindlichen Infanterie war bereits in weitem Umfange die Kraft des Menschen durch die Maschine erhöht; wir dagegen arbeiteten [sic!] noch zu sehr allein mit dem Menschen. Wir hatten allen Grund ihn ängstlich zu schonen.« (Ludendorff 1919: 214) Durch eine umfangreiche Aufrüstung der Infanterie mit schweren und vor allem leichten Maschinengewehren, die von den Soldaten auf dem Gefechtsfeld bewegt werden konnten, und durch die Ausstattung mit weiteren Infanteriewaffen, wie Granatwerfern und Flammenwerfern, sollte die Kampfkraft der Infanterie entscheidend verbessert werden. Zugleich entschied sich Ludendorff in seiner Funktion als Erster Generalquartiermeister dafür, die positiven Erfahrungen bei der Verteidigung der Stellungen auch für eine Angriffstaktik zu nutzen. Die taktischen Prinzipien, die der neuen Angriffstaktik für die Infanterie zugrunde lagen, waren, wie van Creveld schreibt, von dem britischen Einsatzkonzept soweit entfernt, wie man es sich nur vorstellen kann (1985: 174). Schrieben die britischen Kommandeure in den Befehlen ihren Untergebenen in aller Regel detailliert vor, wie sie einen erteilten Befehl auszuführen hatten, wodurch ihnen meist nur einen geringer Gestaltungsspielraum bei der Ausführung der Befehle blieb, - für diese Form der Befehlsausgabe wird in der deutschen Militärpublizistik der Begriff der Befehlstaktik verwendet - forderte die deutschen Einsatzbefehle von Truppen- und Unteroffizieren, dass sie selber Initiative bei der Ausgestaltung der ihnen erteilten Aufträge zeigten. So wurde von den Truppenoffizieren und ihren Untergebenen verlangt, dass sie entschieden, wann und wie sie bei der Verteidigung der Stellungen mit ihrem Verband »Gegenstöße« ausführten, um den Gegner zurückzuschlagen. Verlangt wurde von ihnen, dass sie jeweils angepasst an die Situation, ohne weitere Rückversicherung ihrer Vorgesetzten, zu denen sie auch keine Verbindung hatten, handelten. Wie schon für die Verteidigung sollte

wegung nicht. Obwohl die so genannte Feuerwalze nicht mehr jede Minute um 50 Meter vorrückte, wie an der Somme, sondern alle drei Minuten um jeweils 100 Meter, verschwand sie vielfach aus dem Blickfeld der Infanteristen (Keegan 2001: 456f.). 
nun auch für die Angriffstaktik auf Prinzipien der vor dem 1. Weltkrieg entwickelten Auftragstaktik zurückgegriffen werden.

Das Modell für die deutsche Angriffstaktik der Infanterie bildete das Verfahren der so genannten Stoßtruppen. Bei den Stoßtruppen handelte es sich um kleine Infanterieverbände, meist in Zugstärke, - das sind ungefähr 20 Soldaten - die möglichst unter Ausnutzung vorhandener Deckungen das Niemandsland durchquerten und die Aufgabe hatten, die gegnerischen Linien zu infiltrieren, um dort Gefangene zu nehmen oder eine als wichtig eingestufte Stellung zu erobern. Die deutschen Stoßtruppen gehörten zu einer ganzen Reihe ähnlicher Verbände, die von allen Kriegsparteien aufgebaut wurden. Sie gingen anfangs häufig von der Initiative einzelner Truppenoffiziere, aber auch einzelner Armeeführer aus, die Freiwillige für besondere Kampfeinsätze anwarben. Die einzelnen Verbände waren unterschiedlich bewaffnet. Sie entwickelten im Laufe der Zeit verschiedene Einsatztaktiken. Mit ihnen sammelten die Armeen Erfahrungen, wie infanteristische Truppen in das Niemandsland und in die gegnerischen Stellungen eindringen konnten, ohne sogleich einen großen und verlustreichen Angriff an einem Frontabschnitt unternehmen zu müssen. Neben der Erkundung und Eroberung gegnerischer Positionen fiel ihnen des Weiteren die Aufgabe zu, die Frontlinie zu >beunruhigen`. Damit wurde nicht nur das Ziel verfolgt, die gegnerischen Kräfte auch an ruhigen Frontabschnitten $\mathrm{zu}$ binden, also an Frontabschnitten, an denen keine Offensiven vorgetragen wurden. Durch Überfälle oder auch durch den Einsatz von Scharfschützen, »die jedes unvorsichtig über die Grabenböschung herausragende gegnerische Körperteil unter Feuer nahmen« (Ziemann 2004: 158), sollte auch verhindert werden, dass die eigenen Soldaten eine Politik des »leben und leben lassen« praktizierten (Gudmundsson 1989: 83; siehe auch Keegan 2001: 461f.). Die Scharfschützen und die Soldaten der Stoßtrupps waren »Spezialisten der Gewaltanwendung [...], die sich selber als Täter in einem emphatischen Sinne verstanden « (Ziemann 2004: ebd.), und die aufgrund der von ihnen betriebenen Eskalation der Gewalt im Frontabschnitt, den sie nach ihrem Einsatz verließen, bei den hier verbleibenden Infanteristen »auf massive Ablehnung« (ebd.) stießen.

Der Stoßtruppentaktik lag beim deutschen Heer ab 1916 ein standardisiertes Konzept zugrunde, das auch die Struktur und die Bewaffnung spezieller Kampfeinheiten, den Sturmbataillonen, regelte. Neben den Kampfeinsätzen bestand eine weitere Aufgabe dieser Verbände in der Ausbildung weiterer Soldaten in der Angriffstaktik. Die Bedeutung der deutschen Stoßtruppentaktik lag in dem ab 1917 unternommenen Versuch, sie bei der Struktur und Bewaffnung aller Heeresverbände zu berücksichtigen und grundsätzlich alle Infanteristen in dieser Taktik zu auszubilden. Damit sollte die Stoßtruppentaktik nicht mehr länger, wie dies bei den westlichen Alliierten der Fall war, eine Einsatzkonzeption nur für Spezialeinheiten sein (siehe Gudmundsson 1989: 145f.) und ein entscheidendes 
Element für die Frühjahrsoffensiven 1918 bilden. Durch punktuelle Stoßbewegungen sollten nun aber nicht mehr nur einzelne Stellungen erobert werden, sondern die gegnerischen Frontlinien durchbrochen werden. Dabei wurde davon ausgegangen, dass nur nach immer wieder neuen Angriffstößen der Stellungskrieg überwunden werden kann. Deshalb kodifizierte die Anfang 1918 von der OHL herausgegebene Vorschrift »Der Angriff im Stellungskriege«: »Der Durchbruchskampf ist ein Durchfressen durch die feindlichen Stellungssysteme meist unter starker offensiver Gegenwirkung des Feindes. Er muss schnell und tief vorgetragen werden.« (1918c: 642) Damit die angreifenden Infanterieverbände schnell und tief in die Stellungen einbrechen konnten, hatten sie keine Rücksicht auf ihre Flankensicherung zu nehmen und stark verteidigte Positionen des Gegners möglichst zu umgehen. Die Offensive sollte wie ein fortgesetzter Überfall wirken, damit der Gegner paralysiert wird, er nicht »zur Besinnung« (ebd.) kommt, und durch die mit großer Schnelligkeit vorgetragenen Angriffe sollten seine Gegenmaßnahmen »durchkreuzt werden.« (Ebd.)

Die Stoßtruppen verfügten über ein umfangreiches Waffenequipment, das wiederum ihre Einteilung in Gruppen und Züge strukturierte. Die Gruppen mit ihren besonderen Waffen (Infanteriegewehre, Maschinengewehr, Granatwerfer,...) wurden in der Ausbildung und auch vor einzelnen Einsätzen dazu angehalten, ihr Vorgehen arbeitsteilig zu koordinieren. Die Gruppen sollten sich auf diese Weise gegenseitig unterstützen, ohne dass hierfür im Einzelnen noch ein Befehl erteilt werden musste. Nicht die Masse der eingesetzten Soldaten wurde als entscheidend für den Verlauf des Gefechts erachtet, sondern die Kombination und Konzentration der artilleristischen und infanteristischen Feuerkraft auf ein bestimmtes Ziel (ebd.). Deshalb wird in zahlreichen Bestimmungen betont, dass »alles von schnellem und selbsttätigem Handeln aller Stellen im Rahmen des Ganzen« (ebd.) abhängt und dass dieses »Ganze« sorgfältig vorbereitet und beim Angriff ständig mit anderen Gruppen und Verbänden zusammengearbeitet werden muss. Im Prinzip sollte jeder Soldat über die Absichten seiner Vorgesetzten in einem zuvor unbekannten Ausmaß informiert werden, damit er selbsttätig den erteilten Auftrag ausführen kann (siehe Gudmundsson 1989: 51). »Jeder einzelne Mann muss erzogen sein, den Zusammenhang mit seinem Stoßtrupp-Gruppenführer dauernd zu wahren. Kein Führer darf auch nur einen Augenblick die Zusammenarbeit mit dem nächst höheren und benachbarten Verband sowie mit den anderen Waffen aus dem Auge lassen.« (OHL 1918c: 657)

Mit dem industrialisierten Kriegsgeschehen stiegen die physischen und psychischen Belastungen der soldatischen Subjekte durch die Ex- und Intensivierung des Tötens und der Gefahr des Getötetwerdens. Mit dem deutschen Stoßtruppverfahren wiederum wurde das Ziel verfolgt, eine weitere Folge der Industrialisierung - die Dominanz defensiver Stellungen gegenüber offensiven Operationen - zu brechen, indem die Entscheidungs- und 
Handlungsfähigkeit der soldatischen Subjekte genutzt werden sollte, um die Angriffsoperationen zu schleunigen und den lokalen und situativen Bedingungen anzupassen. ${ }^{57} \mathrm{Um}$ sich auf die Kampfeinsätze vorzubereiten, durften die Angehörigen der Stoßtruppenverbände nicht auf die Einhaltung eingedrillter Bewegungsabläufe und auf ein Handeln auf Kommando verpflichtet werden. Sofern die Truppen überhaupt gedrillt wurden, dienten solche Unterweisungen ausschließlich der Haltungsdisziplinierung. An die Stelle des Drills traten in der Ausbildung der Stoßtruppen sportliche Übungen wie Fußball und Handgranatenwerfen. Daneben wurde die Ausbildung von der Unterweisung in Gefechtspraktiken - wie das Niemandsland zu durchqueren ist, gegnerische Gräben erobert und die verschiedenen Gruppen mit ihren unterschiedlichen Bewaffnung kooperieren können bestimmt (siehe Gudmundsson 1989: 87).

Parallel zum Versuch, die an den Leibern gebundenen Kompetenzen der individuellen Subjekte zu nutzen, wurde in den Vorschriften der OHL von 1917/18 eine weitere Abkehr von einer Auffassung anvisiert, die vor 1914 vorherrschte. Wurde bislang immer wieder hervorgehoben, dass >Manneszucht` die durch Maschinen gesteigerte Destruktionskraft überwinden könne, ${ }^{58}$ so wurde nun durchgängig die Abhängigkeit des Erfolgs vom Einsatz der Artillerie und vor allem des Maschinengewehrs betont. Ohne die artilleristische Feuerkraft, die die gegnerische Artillerie ausschaltet, dessen Infanterie an Bewegungen hindert und seine Verbindungs- und Kommunikationslinien stört, galt jede Angriffsoperation als aussichtslos. Vom »Nachziehen der Artillerie und vom Munitionsnachschub« (OHL 1918c: 642), um beispielsweise die Maschinengewehre einsatzfähig zu halten, hing der Durchbruch der gegnerischen Stellungen ab. Das veränderte Verhältnis von Technik und Soldat kommt nicht zu letzt in der Wertschätzung gegenüber dem Maschinengewehr zum Ausdruck, mit dem die Infanteristen verstärkt ausgestattet wurden (ebd.: 656), das aber, wie Ludendorff nach dem Krieg beklagte, noch immer als »Nebenwaffe der Infanterie angesehen« (1919: 460) wurde. Tatsächlich sei aber das Maschinengewehr /selbst >Infanterist` und der bisherige Infanterist der >Gewehrträger`» (ebd.). Ohne die Maschine als »Hauptträger des Feuerkampfes der Infanterie« (ebd.: 461), war im industrialisierten Krieg keine Überlegenheit im Gefecht zu zielen.

57 Innerhalb der Generalität war die Entscheidung, das Stoßtruppverfahren als bevorzugte Angriffstaktik zu bestimmen, wie Ludendorff andeutet, umstritten, weil befürchtet wurde, dass durch die hohen Verluste der Ausbildungsstand und die »Manneszucht« zu sehr gesunken seien (1919: 307). Es fehlte im Frühjahr 1918 auch nicht an Klagen über >Unterführer`, die nicht gewohnt seien, selbstständig zu denken (siehe Storz 1999: 67).

58 Das hinderte Ludendorff allerdings nicht daran, in seinen Kriegserinnerungen »Nerven, Manneszucht und Unerschrockenheit« als die besten Waffen gegen Panzer zu erklären (1919: 462). 
Trotz großer Geländegewinne führte keine der deutschen Offensiven im Frühjahr $1918 \mathrm{zu}$ einem entscheidenden Einbruch in die von französischen, englischen und dann auch amerikanischen Truppen gehaltenen Stellungen. Für dieses Scheitern werden in der Literatur zahlreiche Gründe erörtert. So funktionierte die angestrebte Koordination zwischen Artillerieeinsatz und infanteristischen Truppenbewegungen meist nur bei den ersten Stoßangriffen, es gelang aber nicht, sie mit den zur Verfügung stehenden Kommunikationstechniken aufrechtzuerhalten, wenn die Truppen in die gegnerischen Stellungen eingedrungen waren (Kaufmann 1996: 252f.). Ebenso scheiterte das Nachziehen der Artillerie und der Nachschub an Munition, aber auch mit Verpflegung durch das in den jahrelangen Stellungskämpfen verwüstete Terrain, an der ungenügenden schlechten Ausstattung mit geeigneten Transportfahrzeugen (Storz 1999: 68f.). Auch wird darauf hingewiesen, dass die Zahl der zur Verfügung stehenden Stoßtruppen nicht ausreichte, um die Verluste zu kompensieren, die in den ersten Angriffsoperationen entstanden waren. Dies wog umso schwerer, da nur ein Teil der Infanterieverbände tatsächlich auf Stoßtruppangriffe hin strukturiert und ausgebildet werden konnte. Auch deshalb griffen die Infanteristen teilweise weiterhin in »zu dichten Kampfformen« an, wie Ludendorff im Juni 1918 monierte, um dies mit der Forderung zu verbinden, dass »unsere Verluste mit allen Mitteln« einzuschränken seien (OHL 1918c: 686). ${ }^{59}$ Letzteres weist auf die wohl entscheidende Ursache für das Scheitern der Offensiven hin: Die westlichen Alliierten verfügten nach dem Kriegseintritt der USA schlicht über die größeren Ressourcen an Personal und Kriegsgerät, um die entstandenen Verluste auszugleichen und den Angreifern immer neue Verbände entgegensetzen (Gudmundsson 1989: 178; Keegan 2001: 566f.). Obendrein waren ihre Truppen in einer weiteren Hinsicht entschieden besser ausgestattet als die deutschen Verbände: Die deutschen Kommandeure hatten große Schwierigkeiten, ihre Truppen zu immer neuen Angriffsoperationen anzutreiben, weil ihre Soldaten derart unter Entbehrungen litten, dass sie in den eroberten Unterständen nach Nahrung suchten und sich ausgiebig in erbeuteten Magazinen satt aßen (Keegan 2001: 561). Gegen diese vom Hunger moti-

59 Dabei ist in Rechnung zu stellen, dass es sich bei dem Stoßtruppverfahren grundsätzlich um eine hochriskante, weil verlustreiche Angriffstaktik handelte. Dies kündigt bereits die Sprache an, die die Vorschrift »Angriff im Stellungskriege « verwendete. So fordert die Vorschrift von den Soldaten »entschlossenes und rücksichtsloses Draufgehen«, spricht wiederholt von »energischen Führern« (OHL 1918c: 657) und empfahl, dass »der kühnste Entschluss allemal der beste« ist. Ob da noch der Hinweis verfing, dass durch »unüberlegtes Vorstürmen leicht Rückschläge« (ebd.: 658) entstehen, ist zu bezweifeln. Wie groß die Opferbereitschaft sein sollte, die von den Soldaten verlangt wurde, wird möglicherweise daran am deutlichsten, dass Verluste in den eigenen Reihen durch heute als friendly fire bezeichneten Waffeneinsatz als opportun eingeschätzt wurde (ebd.: 671). 
vierten Plünderungen halfen weder die im Vorfeld erlassenen Bestimmungen gegen »Drückeberger und Beutemacher«, die »durch Kommandos des eigenen Regiments aufgegriffen und sogleich nachgeführt werden« sollten (OHL 1918c: 657), und auch nicht der angeordnete verstärkte Einsatz von Militärpolizisten (ebd.: 665). ${ }^{60}$ Obwohl mit der neuen Angriffstaktik bereits bei der ersten großen Offensive (Michael-Offensive, März 1918) kein entscheidender Durchbruch erzielt werden konnte, setzte die OHL immer neue Angriffsoperationen an, deren Aussichten auf Erfolg immer geringer wurden. Mit diesen Offensiven betrieb die deutsche Generalität das, was man »im Geschäftsleben als Konkursverschleppung bezeichnen würde« (Storz 1999: 94). Die deutschen Streitkräfte waren >im Feld geschlagen und die militärische Führung konnte die militärische Zerschlagung des Heers nur vermeiden, weil sie im Herbst auf Waffenstillstandsverhandlungen drängte.

Wenngleich das Angriffsverfahren der Stoßtrupps notwendigerweise an eine spezifische Form der Befehlsgebung gebunden war und sich eine solche unmittelbare Verbindung zwischen Einsatzkonzept und Befehlsgebung nicht mehr einstellte, blieb auch nach dem 1. Weltkrieg die Auftragstaktik immer dann relevant, wenn eine >Amtsautorität (Mosen) die Handlungen der Soldaten strukturiert, also durch die Art und Weise, wie sie Befehle erteilt, Handlungsspielräume öffnet oder schließt. Die Reichswehr bzw. später die Wehrmacht nahm wichtige Grundsätze der Auftragstaktik »wörtlich oder sprachlich leicht verändert« (Millotat 2002: 18) in ihr Regelwerk auf. Durch diese Regelungen etablierte die Wehrmacht, folgt man van Creveld, ein entschieden besseres »Führungssystem, das auf der untersten Ebene Raum für Initiative und den unterstellten Kommandeuren Raum für vernünftige Zusammenarbeit lässt« (1989: 42) als einer ihrer Gegner - die US-Army. Van Creveld stützt sich bei diesem Urteil weitgehend auf Befragungen und Analysen, die ehemalige hochrangige Wehrmachtsoffiziere unter der Leitung von Franz Halder (1884-1972) im Rahmen der Historical Division des US-Heeres verfasst haben. So schrieb Halder in einem Gutachten zu einer »Neuausgabe der FM 100-5 [das Field Manual 100-5 ist die Heeresdienstvorschrift, d.A.], die Anfang

60 Ludendorff konnte in den Plünderungen nur ein »Zeichen mangelhafter Manneszucht « und geringer Autorität der Offiziere und Unteroffiziere erblicken (1919: 491). Für letzteres machte er den Verlust des alten »Friedensoffizierskorps « und die von den Politikern gemilderten Strafgesetze verantwortlich. Durch »strengen Arrest durch Anbinden« wäre die Disziplin zu wahren gewesen (ebd.: 492). Im Kern enthält diese Auffassung eine Variante der später ausformulierten Dolchstoßlegende (ebd.: 493). Die deutsche Zivilbevölkerung litt noch mehr als die Soldaten unter der schlechten Versorgungslage. Die Zahl der Verhungerten, vor allem Kinder, Frauen und Greise, ist nur schwer einzuschätzen. Die Enzyklopädie Erster Weltkrieg versieht deshalb die Zahl der Hungertode von 700.000 mit einem Fragezeichen (Overmans 2004: 665). 
der 50er Jahre überarbeitet wurde, [...] um Lehren aus dem Krieg einzubringen«: Die »deutsche Führung hat als hauptsächliche Ziele jeder Führungserziehung angesehen: 1. einen hohen Grad an Selbstständigkeit in allen Stufen der Führung, 2. die Auftragsdisziplin, das heißt die innere Verpflichtung, immer im Sinne des erteilten Auftrages zu handeln, 3. die Freiheit vom Schema, [...].« (Zitiert nach van Creveld 1989: 48f.) Die ihm vorgelegten US-Vorschriften beurteilte Halder demgegenüber unter anderen als zu schematisch und den Handlungsspielraum der Truppenführer zu sehr einengend (ebd.).

Vor allem mit den Arbeiten der Historical Division unter Halder ${ }^{61}$ setzte zumindest im angelsächsischen Raum eine gewisse Rezeption der Auftragstaktik außerhalb Deutschland ein. Zwar gliederten und bewaffneten auch die anderen Streitkräfte ihre Infanterie ähnlich wie die deutschen Verbände, doch die Gestaltung der Befehlsgebung blieb am Rahmen der Befehlstaktik bzw. der >close order tactics`(Gudmundsson). Die close order tactics bot den Kommandeuren nicht nur den Vorteil, den beispielsweise Gudmundsson anführt, dass man mit ihr erschöpfte Soldaten in eine geschlossene Formation eingliedern und in das Gefecht werfen könne (Gudmundsson 1989: 167), sondern sie passt vor allem zu einer Auffassung, die die Gefechtsoperationen als Teil eines technisch-industriellen Prozesses auffasst. Der Erfolg hängt nach dieser Auffassung von der Fähigkeit ab, industrielle Ressourcen zu mobilisieren und den Einsatz von Soldaten und Kriegsmittel langfristig zu planen. Für die Gefechtsoperationen selber werden Befehle erteilt, die den Entscheidungs- und Handlungsspielraum begrenzen und die eher kurzfristige Zielvorgaben machen. Diese Art der Befehlsgebung geht tendenziell von der Planbarkeit des Vorhabens aus, setzt darauf, dass die bereitgestellten Ressourcen der Gegner überwältigt werden. Wo sich herausstellt, dass die Destruktionskräfte nicht ausreichen, wird von den höheren Kommandostäben erwartet, dass sie möglichst schnell geeignete Befehle erteilen, um das Ziel doch noch zu erreichen. Der Vorteil einer solchen Befehlsgebung besteht in der besseren Koordination der Verbände auf der höheren Kommandoebene, die jedoch mit dem Nachteil verbunden ist, dass dadurch die Reaktionsgeschwindigkeit der Truppenkommandeure auf unerwartete Geschehnisse sinkt und durch den dadurch entstehenden Zeitverlust möglicherweise Chancen ungenutzt bleiben und auf Gefahren zu spät reagiert wird. Gerade bei dynamischen Prozessen zeigen sich diese Nachteile, weil dann die Gefahr groß ist, dass die erteilten Befehle auf einer inzwischen überholten Lagebeschreibung beruhen.

Die US-Army erweckt, so van Creveld in seiner Untersuchung zur Kampfkraft der US-Army und der Wehrmacht, fast den Anschein, als ob

61 Einen kurzen Überblick über die Aktivitäten der deutschen Offiziere in der Historical Division gibt Wette (2002: 225f.). Ausführlicher wird die Wirkungsgeschichte der Historical Division bei Wegner (1995) betrachtet. 
sie, "gestützt auf einen gigantischen Produktionsapparat und vielleicht mit einem Blick über die Schulter auf die Organisation eines Automobilkonzerns, es vorzog, den Krieg nicht so sehr als einen Kampf gegnerischer Heere zu betrachten, sondern als einen Kampf, dessen Ausgang vorwiegend von Maschinen entschieden würde. Daher konzentrierte sie sich nicht so sehr auf die Kampfkraft, sondern darauf, dem Feind mit größtmöglicher Feuerkraft entgegenzutreten. Es ging ihr auch nicht mehr um Rücksicht auf die Bedürfnisse der Soldaten, sondern um ein wissenschaftlich fundiertes Management und die optimale Verteilung und Entfaltung der Ressourcen.« (1989: 209) Die operativen Aspekte des Krieges seien deshalb gegenüber einer ausgewogenen Organisation, die auf Koordination und Kontrolle setzte, nachrangig gewesen. Bei der Wehrmacht stellt er eine diametrale Ausrichtung fest: »Doktrin, Ausbildung und Organisation des Heeres [waren] alle im engeren Sinne auf das Kämpfen ausgerichtet« (ebd.: 204). Folgt man van Creveld, kompensierte die Wehrmacht mit der Auftragstaktik einen Mangel. »In weit größeren Maße als ihre amerikanischen Kontrahenten waren [...] die deutschen Befehlshaber auf allen Ebenen dazu gezwungen, das Wesentliche auszuwählen und sich darauf zu beschränken und es ihren Untergebenen zu überlassen, Details auszuarbeiten « (1989: 205). Die Wehrmacht habe also schlicht nicht über das Personal verfügte, aber auch nicht über mechanische Datenverarbeitungsmethoden, um in übergeordneten bürokratischen Planungsstäben Operationen detailliert vorzubereiten und für die Truppenkommandeure entsprechend enge Vorgabe zu formulieren. Paradoxerweise habe der Mangel aber dazu geführt, die Kampfkraft der Verbände zu steigern.

Diese Ausführungen van Crevelds sind vor dem Hintergrund des verlorenen Vietnamkrieges und dem gescheiterten Versuch die amerikanischen Botschaftsangehörigen im Iran durch eine Militärintervention zu befreien, zu interpretieren (1979). Seine Studie war vom US-Militär in Auftrag gegeben worden, das - mit seinen eigenen Leistungen unzufrieden - nach Wegen suchte, die Kampfkraft zu erhöhen. Soviel stand schon vor der Studie fest: Der Einsatz überlegener Waffentechnologie garantierte keine militärische Dominanz, denn die Gegner, die dem US-Militär Niederlagen zugefügt hatten, waren weder waffentechnologisch überlegen noch verfügten sie auch nur annähernd über gleichwertige industrielle Ressourcen. Das Interesse an der deutschen Auftragstaktik, in dem manche »ausländischen Analytiker [...] ein Geheimrezept, ein Arkanum des Sieges mit Zügen einer Geheimwissenschaft« (Millotat 2002: 27) vermuten, signalisiert eine gewisse Erschütterung in das Vertrauen, dass bereits überlegene Feuerkraft militärische Auseinandersetzungen entscheidet und eine gewisse Skepsis in eine Befehlsform, die den soldatischen Subjekten einen möglichst geringen Entscheidungs- und Handlungsspielraum zubilligt. 


\section{Soldatische Subjektivität in avancierten Militärorganisationen}

\subsection{Wie die Sozialwissenschaften zur Optimierung soldatischer Subjekte verwendet werden}

Die soldatische Subjektivität wurde mit dem 2. Weltkrieg erstmals ein $\mathrm{Ob}$ jekt groß angelegter sozialwissenschaftlicher Studien. Noch vor Kriegseintritt der USA erhielten Psychologen, Psychiater und Soziologen den Auftrag, die Effizienz der ergriffenen Maßnahmen zum Aufbau der Streitkräfte $\mathrm{zu}$ evaluieren. Vor dem 2. Weltkrieg zeichnete sich lediglich in Bezug auf die Personalauswahl eine gewisse Öffnung gegenüber den sozialwissenschaftlichen Untersuchungen $\mathrm{ab}$, da es mit dem 1. Weltkrieg üblich wurde, dass die am besten geeigneten Soldaten für den Einsatz an Maschinen durch psychologische Eignungstests ausgewählt wurden. Die Ausbildungsmethoden, die Struktur der Verbände und die Einsatzprinzipien beruhten dagegen weiterhin vor allem auf in vorherigen Kriegen gewonnenen Erfahrungen und waren damit weitgehend historische Fundsache. Durch die in Auftrag gegebenen sozialwissenschaftlichen Studien versuchten die US-Streitkräfte, die Effizienz der ergriffenen Maßnahmen zu erhöhen. Diesem Beispiel sollten in den darauf folgenden Jahrzehnten auch andere Staaten folgen.

In einem ersten Schritt soll im Folgenden auf diese Entwicklung eingegangen werden. Anschließend stehen die Folgen der seit dem 2. Weltkrieg anhaltenden umfassenden Technisierung des Krieges auf die soldatische Subjektivität im Mittelpunkt der Analyse. Dabei wird unter anderem auf die Vorstellung eingegangen, Soldaten avancierte Streitkräfte seien als Cyborg zu begreifen und Soldaten würden durch Roboter ersetzt werden. Nachdem die Auf- und Umrüstungen der Streitkräfte betrachtet wurden, 
sollen diese Maßnahmen abschließend mit den gegenwärtig absehbaren Einsatzszenarios konfrontiert werden.

Bereits in der Mitte des 19. Jahrhunderts versuchte der französische Infanterieoffizier Ardant du Picq (1821-1870) zu erfahren, wie und aus welchen Gründen Soldaten auf dem Schlachtfeld handelten, in-dem er Fragebögen an Offiziere verteilte (siehe Keegan 1991: 78f.). Aber diese Befragung und weitere Versuche, Befragungen unter Soldaten durchzuführen, stießen auf erheblichen Widerstand. Die Erhebung du Picqs scheiterte, weil die Offiziere die Beantwortung der Fragen als zu langweilig empfanden (ebd.: 79). Eine zu Beginn des 1. Weltkrieges geplante Befragung von Frontsoldaten durch deutsche Psychologen, die eine »Psychographie des Kriegers« erstellen wollten, stieß dagegen auf den Widerstand der Militärzensur. Diese rieb sich an einigen Passagen des Frageschemas, die beispielsweise das Verhältnis zwischen Vorgesetzten und Untergebenen betrafen und sowohl danach fragten, ob die Vorgesetzten als Vorbilder fungierten als auch, ob sie sich aufgrund ihrer Position Vorteile verschafften (siehe Plaut 1921: 111f.). Eine derartige Beurteilung des Verhaltens der Offiziere durch ihre Untergebenen war in den Augen der Militärzensur suspekt, bedeutete sie doch, den Soldaten das Recht einzuräumen, die Entscheidungen ihrer Vorgesetzten zu missbilligen und damit ihre Autorität in Zweifel zu ziehen (siehe hierzu auch Bröckling 2003: 191).

In den USA wurde zwar noch im Mai 1941 das Instrument der Meinungsumfragen vom Secretary of War ausdrücklich untersagt, doch sollte dieses Verbot nicht mehr lange Bestand haben. Die Vorbehalte aus dem Kriegsministerium stießen in der politischen Administration unter Roosevelt nur auf wenig Rückhalt, standen sie doch den Befürwortern des Einsatzes von Methoden der empirischen Sozialforschung, die sich in der Wirtschaft bewährt hatten, eher aufgeschlossen gegenüber (vgl. Stouffer 1949a: 12f.). Noch vor Kriegsbeginn setzten die zuletzt Genannten die Gründung einer soziologischen Forschungsabteilung durch, der Research Branch, die dem War Department unterstand. Obwohl die Research Branch bereits am 1. Tag nach Pearl Harbor ihren ersten Soldaten interviewte, war die Abteilung noch 1942 nur mit wenig Personal ausgestattet und nahm eher schleppend ihre Arbeit auf. Im weiteren Kriegsverlauf erfuhr die Forschungsabteilung jedoch zunehmende Unterstützung durch das Militär, und am Ende des Krieges hatten die aus Militärs und Zivilisten zusammengesetzten Teams über 200 Einzelstudien durchgeführt und mehr als eine halbe Million Soldaten interviewt (Stouffer 1949a: 5). Dass ihre Tätigkeit von den US-Militärs als bedeutsam anerkannt wurde, ist auch auf das Selbstverständnis der beteiligten Sozialwissenschaftler zurückzuführen. Die Research Branch, so Stouffer, »existed to do a practical engineering job, not a scientific job. Its purpose was to provide the Army command quickly and accurately with facts about the attitudes of soldiers which, 
along with other facts und inferences, might be helpful in policy formation.« (1949a: 5)

Die Research Branch schuf mit ihren Studien den Grundstein für die Militärsoziologie und verfasste mit dem insgesamt 4 Büchern umfassenden Werk »The American Soldier« (Stouffer 1949), in dem ihre Ergebnisse zusammenfassend 1949 veröffentlicht wurden, das grundlegende Werk dieser neuen soziologischen Disziplin. Die Research Branch war primär an empirischer Sozialforschung interessiert. Ihre Arbeit war, wie insgesamt das, was sich später als Militärsoziologie im engeren Sinne etablieren sollte, auf organisatorische Optimierungen ausgerichtet, die von dem aktuellen militärischen Interessen vorgegeben wurden. Diese Ausrichtung brachte es mit sich, dass die meisten Fragestellungen der Erhebungen nach Kriegsende nur wenig Interesse auf sich zu ziehen vermochten. So wurde beispielsweise untersucht, welche Einstellungen die Soldaten zu den britischen Verbündeten haben, welche Magazine und Bücher die Soldaten in ihrer Freizeit lasen und welche Radiosendungen sie bevorzugt hörten, wie sie auf verschiedene ihnen gezeigte Filme reagierten, und gegen Kriegsende fragten die umfangreichsten Samples nach den Auffassungen der Soldaten zu ihrer anstehenden Demobilisierung. Fragen nach der Kampfmotivation und dem Gefechtsverhalten der Soldaten machten nur »eine vergleichsweise kleine Zahl von Erhebungen aus« (Bröckling 2003: 193). ${ }^{1}$ Gerade sie sollten sich aber langfristig als folgenreich erweisen, weil sich ihre Ergebnisse im Widerspruch zu zahlreichen gängigen Antworten auf die Fragen bewegten, weshalb Soldaten kämpfen und wie ihre Einsatzbereitschaft unter extremen Bedingungen erhalten werden kann. Nicht nur sie, aber auch die untersuchenden Soziologen stellten überrascht fest, wie Janowitz schreibt, dass sie vor den Untersuchungen »ideologische und politische Werte als Faktoren der Schlagkraft militärischer Verbände« überschätzten (Janowitz/Little 1965: 109). Unterschätzt wurde dagegen, welchen Einfluss der Zusammenhalt der Kampfgruppen auf das Handeln der einzelnen Soldaten und damit wiederum auf die Einsatzfähigkeit der einzelnen Truppenverbände hat. Die Ergebnisse waren derart frappant, dass sie nicht nur zahlreiche Nachfolgeuntersuchungen nach sich zogen und Soziologen veranlassten, «auch in anderen komplexen Organisationen wie Erziehungswesen, Industriebetrieb und Behörden« (ebd.) die Bedeutung informeller Gruppenbeziehungen $\mathrm{zu}$ untersuchen, sondern auch $\mathrm{zu}$ nachhaltig veränderten militärischen Ausbildungskonzepten und bei den US-Streitkräften zu einer Revision des Ersatzwesens führten.

Die Ergebnisse von »The American Soldier«, die unter anderen von den Beobachtungen Marshalls (1947) gestützt wurden, machen darauf aufmerksam, dass das Kampfverhalten der einzelnen Soldaten unter den Bedingungen des industrialisierten Gefechtsfeldes stark von ihren sozialen

1 Eine Übersicht über die durchgeführten Studien sind in Stouffer (1949b: 645f.) zu finden. 
Beziehungen zu den anderen Angehörigen ihres Truppenverbandes beeinflusst wird. Gewonnen wurden die Erkenntnisse und Beobachtungen überwiegend anhand der Verhältnisse bei den Bodentruppen, insbesondere bei infanteristischen Kampfverbänden. Diese eigneten sich nach Auffassung der Autoren besonders gut, weil sich bei ihnen »the stresses and countermotives« (Stouffer 1949b: 59) am deutlichsten zeigten. Das Buch Marshalls »Soldaten im Feuer« veranschaulicht sehr gut, wie sehr sich durch die Industrialisierung der Kriegführung die Handlungsbedingungen der Infanteristen verändert hatten. Gerade weil die Soldaten nun nicht mehr in geschlossenen Gefechtsformationen kämpfen, hat der einzelne Infanterist mit Ankunft in der Gefechtszone »das Gefühl, ganz plötzlich einsam und verlassen dazustehen in der Stunde seiner größten Gefahr. Er kann die Gefahr fühlen, aber sie nicht fassen, er kann nicht dagegen kämpfen. Aus der Mischung von Nichtverstehen und Angst entsteht ein Gefühl der Hilflosigkeit, die seinerseits die Angst wieder steigert.« (Ebd.: 46) Das Nichtverstehen wird als die Folge einer Ausbildung geschildert, die sich immer noch an der Praxis geschlossener Formationen orientierte. Marshall beobachtete auch, dass die hochrangigen Vorgesetzten auf dem Gefechtsfeld überwiegend weder visuell noch akustisch präsent sein können und deshalb die Gefahr besteht, dass die Kampfeinheiten warten, nichts tun, wenn sie mit dem >Unerwarteten $<$ im Gefecht konfrontiert werden. Dieses Untätigsein wiederum habe auf die Truppe eine demoralisierende Wirkung, die langfristig die Kampfkraft der Einheit schädige (ebd.: 49f.).

Die Beobachtungen Marshalls sowie die Befragungen durch die Research Branch zeigten nach Auffassung der Autoren an, dass die Führungsprobleme von Bodentruppen durch ein autoritäres, repressives Führungsmodell nicht gelöst und dadurch ebenso wenig die Kampfmotivation der einzelnen Soldaten wie die Kampfkraft der Verbände insgesamt positiv stimuliert werden kann. Auch dem Glauben der Soldaten an die Ziele des Krieges, ihrer Haltung gegenüber dem Gegner, ihrem Patriotismus oder ähnlichen Loyalitätsgefühlen maßen sie keinen entscheidenden Einfluss auf die individuelle Kampfmoral zu. Dieser Befund galt nicht nur für amerikanische Soldaten. Vor allem eine Studie zu deutschen Kriegsgefangenen (Shils/Janowitz 1948) stützte die Auffassung, dass die Kampfkraft von Soldaten in einem industrialisierten Krieg von anderen Faktoren abhängig ist. Auf die Frage, weshalb die deutschen Soldaten ihren aussichtslosen Kampf am Ende des Krieges fortsetzten, fanden Shils/Janowitz die Antwort, dass der Einfluss der nationalsozialistischen Überzeugungen auf die Motivation der Soldaten nur sehr gering gewesen sei (1948: 281).

»The Nazi army was an effective armed force, not because of ideological indoctrination, but because its non-commissioned and commissioned officers were competent leaders who were able, due to their technical ability and demonstrated concern for their men, to develop cohesive social relations. «(Janowitz 1964: 43) 
Insbesondere von den Beziehungen zwischen den Vorgesetzten und ihren Untergebenen sowie unter den Angehörigen kleiner Kampfeinheiten, die als Teilverbände ${ }^{2}$ von Kompanien auf dem industrialisierten Gefechtsfeld zu den Trägern des Gefechts geworden waren, hänge es ab, wie die einzelnen Soldaten mit den Belastungen eines Kampfeinsatzes umgehen und wie lange sie mit den anderen Angehörigen einer Kampfeinheit den Zumutungen trotzen. Diese informellen Beziehungsformen weisen typische Merkmale auf, die man zuvor bevorzugt für Familien, Nachbarschaften und Dorfgemeinschaften herausgearbeitet hatte und die deshalb auch als Primärgruppen bezeichnet wurden (siehe Cooley 1909: 23f.). Es war für die Soziologen verblüffend festzustellen, in welchem Ausmaß die Leistungsfähigkeit einer ausdifferenzierten und von formalen Strukturen geprägten Organisation, also einer modernen Organisation, von Gruppenbildungen abhing, die sie eher mit traditionellen Institutionen bzw. vormodernen Sozialformen in Verbindung brachten.

Die Primärgruppen basieren auf informellen, durch den täglichen Umgang miteinander entstandenen und stark von Emotionen geprägten direkten persönlichen Beziehungen zwischen den Angehörigen der Kampfeinheiten. Die Zugehörigkeit zu einer bestimmten Primärgruppe fällt nur bedingt mit der Zuordnung zu einer bestimmten formalen Einheit zusammen. Entscheidend sind die Chancen, dass sich zwischen den Soldaten persönliche und intime Beziehungen entwickeln können, die allerdings wiederum erheblich von der Zuordnung zu einer Kampfeinheit mit bestimmt werden. Das Bedürfnis der einzelnen Soldaten, einer informellen Gruppe anzugehören, hängt eng mit der als übermächtig erlebten Formalorganisation zusammen. Für die Soldaten bietet sich dadurch der Vorteil, dass sie mit ihrem Zusammenschluss nicht mehr alleine der Macht der Organisation gegenüberstehen, untereinander Wissen über die vorgefundenen Verhältnisse austauschen und gemeinsam erkannte >Lücken` der Kontrollmacht ausnutzen können, indem sie sich beispielsweise über die Schwächen und Stärken ihrer Vorgesetzten informieren. Durch gegenseiti-

2 Die Größe dieser kleinen Kampfgruppen ist nicht genau zu bestimmen, da die Gliederung der Verbände zwischen den nationalen Streitkräften und noch mehr zwischen den einzelnen Teilstreitkräften variiert. Beim deutschen Heer gilt als die die kleinste infanteristische Einheit der Trupp, der einem Unteroffizier untersteht. Betrachtungen zur Kohäsion der Einheiten setzen aber meist auf der Ebene der Gruppe ein, die wiederum aus 2 Trupps gebildet wird. Gruppen können bis zu 12 Soldaten umfassen. Zwischen 2 und 5 Gruppen bilden wiederum die nächste übergeordnete Einheit, den Zug, dessen Kommandeur in der Regel ein Leutnant oder Oberleutnant ist. Mehrere Züge werden in einer Kompanie zusammengefasst, deren Gesamtstärke meist mit circa 120 Soldaten angegeben wird. Eine ähnliche Struktur weist das amerikanische Heer auf. Die Kampfeinheit platoon entspricht ungefähr der Verbandsbezeichnung Zug und die untergeordnete Einheit squad ist mit der Gruppe vergleichbar. Die kleinste Einheit wird vom US-Heer prägnant als fireteam bezeichnet und ihm gehören meist 4 bis 5 Soldaten an. 
ge Unterstützung bilden Primärgruppen eine gewisse Macht aus, die zumindest etwas die Überlegenheit der Organisationsmacht kompensiert. Dieser Aspekt bedingt auch, dass die Normen von Primärgruppen nicht mit dem offiziellen Wertekanon des Militärs übereinstimmen müssen und möglicherweise als »deviante [...] Wertmaßstäbe und Verhaltensnormen« (Geser 1981: 160) eingestuft werden. Doch bedeutsamer als solche Abweichungen vom kodifizierten Regelkanon des Militärs wurde von den Autoren der Research Branch und anderen Sozialwissenschaftlern der Beitrag der Primärgruppe zur individuellen Kampfmotivation eingestuft, weil entscheidend von der Integration in einer Primärgruppen abhängt, wie die einzelnen Soldaten mit ihrer Angst während des Gefechts umgehen. Primärgruppen üben zum einen auf ihre Angehörigen einen enormen Konformitätsdruck aus. Zum anderen, so bilanziert Bröckling die Ergebnisse der Research Branch, profitierte der Einzelne »von seiner Konformität mit den Gruppenregeln, weil diese Anpassungsleistung ihm den psychosozialen Rückhalt sicherte, den er brauchte, um die Belastungen des Fronteinsatzes auszuhalten. Das Gefühl, auf dem Schlachtfeld einer anonymen Vernichtungsmaschinerie ohnmächtig ausgeliefert zu sein und jeden Augenblick getötet werden zu können, warf den Soldaten in einer existenziellen Weise auf sich selber zurück. Die Gewissheit, Teil einer Gruppe zu sein und sich auf die Kameraden verlassen zu können, vermochte diese Atomisierungserfahrung zwar nicht auszuschalten, aber doch ein Stück weit zu kompensieren.« (2003: 197) Während des Kampfeinsatzes verengt sich der soziale Horizont der Soldaten auf die Primärgruppe, der sie im optimalen Fall angehören. Die Motivation, den Kampf auch nach großen Entbehrungen und unter Todesgefahren fortzusetzen, speist sich deshalb nur zu einem geringen Teil aus politischen Überzeugungen, die keinen unmittelbaren Bezug zu ihrer Primärgruppe haben. Die Soldaten, so lässt sich der Befund knapp zusammenfassen, kämpfen nicht für >home and country<, sondern für ihre buddies. ${ }^{3}$

Offiziere und auch Unteroffiziere gehören normalerweise, und dies bezieht sich vor allem auf den Dienstalltag in der Kaserne, keiner Primärgruppe von Soldaten im Mannschaftsdienstgrad an. Je größer die Rangdifferenz, desto größer ist in der Regel auch die soziale Distanz zwischen den Soldaten und umso geringer sind die Chancen, dass sich zwischen Vorgesetzten und Untergebenen intime soziale Beziehungen entwickeln. Im Verlauf längerer Kampfeinsätze, in denen die Truppenoffiziere mit ihren Untergebenen weitgehend den gleichen tödlichen Bedingungen ausgesetzt sind, schwinden jedoch die Möglichkeiten, an der Distanz qua Status festzuhalten und nehmen die Chancen zu, dass auch

3 Einen ähnlichen Schluss legten die Untersuchungen im »The American Soldier« zur Bedeutung religiöser Bindungen nahe: »Angst lehrt zwar beten, aber mehr als Beten hilft die Gruppensolidarität mit ihr fertig zu werden.« (Bröckling 2003: 199) 
zwischen ihnen affektive und solidarische Bindungen entstehen (Stouffer 1949b: 119). Diese Bindungen zwischen Vorgesetzten und Untergebenen müssen aber einen anderen Charakter haben, wenn ein formaler Vorgesetzter weiterhin auch die »impersonal, coercive institutional authority« (ebd.: 118) repräsentieren soll und Befehle qua seiner Position in der formalen Hierarchie durchsetzen will. Ein Offizier, der von seinen Untergebenen persönlich respektiert wird und den sie loyal unterstützen, mobilisiere, so die Autoren in »The American Soldier«, »the full support of a willing followership« (ebd.); ihm stünden zwei Machtressourcen zur Verfügung: seine Sanktionsmöglichkeiten aufgrund seiner Position in der militärischen Organisation und der Konformitätsdruck, den die informellen Gruppen auf ihre Angehörigen ausüben können. Um eine solche Gefolgschaftsbindung aufzubauen und damit auch in kritischen Situationen die Kampfmotivation aufrechtzuerhalten, müsse der (Unter-)Offizier das Vertrauen der Soldaten gewinnen. In den Interviews gaben die Soldaten zu Protokoll, dass sie von ihren Vorgesetzten erwarteten, in gefahrvollen Situationen Führungsstärke und Mut zu zeigen. Sie hätten sich ihren Untergebenen durch vorbildhaftes Handeln als Identifikationsfigur anzubieten und das hieß nicht zuletzt, sich selber gefahrvollen Situationen auszusetzen. Die Autoren der Studie kamen zu dem Urteil, dass die Vorgesetzten in der Lage sein sollten, an den Beziehungen der Untergebenen zu ihren Vätern und anderen Respektspersonen anzuknüpfen, was sich beispielsweise in der Erwartung ausdrückte, dass sie sich erfolgreich um das Wohlergehen und die Sicherheit ihrer Untergebenen kümmern (ebd.: 124f.). Auch Marshall setzte dieses Kriterium an die erste Stelle seiner Liste idealer Qualitäten, über die ein Offizier verfügen muss, damit es ihm am besten gelingt, seine Untergebenen »mit Erfolg durch den Schock eines Gefechts zu führen.«(Ebd.: 177) Deutlicher als bei den Forschern der Research Branch zeigt sich bei Marshall, wie die Offiziere selber einer bestimmten Rollennorm der Primärgruppen entsprechen müssen, um von ihnen als formeller wie informeller Anführer voll akzeptiert zu werden. Die Offiziere der Kompanien, die »die größten Erfolge erzielten«, hätten sich zwar »peinlich gewissenhaft [...] um ihre Leute« (ebd.: 176) gekümmert, aber nicht wie »)Kindermädchen«« (ebd.). Sie hätten ihre Untergebenen weder als Jugendliche behandelt, noch hätten sie ihnen gegenüber »Schulmeistermethoden« (ebd.) angewandt. Die Soldaten erwarteten stattdessen von ihren Vorgesetzten, als Männer anerkannt und behandelt zu werden. Diese Erwartungshaltung der Soldaten weist die Primärgruppen als Männerbünde aus, deren spezifische Normen neben ihren devianten Ausprägungen auch die Möglichkeit beinhalten können, dass sich institutionelle und Primärgruppennormen verschränken und gegenseitig verstärken (siehe Bröckling 2003: 198). Die Soldaten teilten nicht nur die institutionelle Norm des Militärs, dass Männlichkeit im Soldatsein seine Bewährung findet, sondern sie erwarteten von ihren Vorgesetzten, dass sie obendrein dieser Norm in einem besonders hohen 
Maße entsprachen. Den Soldaten »imponiert Männlichkeit, nicht frauenhaftes Getue. Sie schätzen einen Kommandanten umso mehr, wenn er wie ein Soldat aussieht und auftritt; jedoch wird die gute Erscheinung ihm doppelt zum Verhängnis, wenn er kein wahrer Mann ist.« (Marshall 1947: 177) Die Bewährungsprobe für >wahre` Männlichkeit und das Soldatsein der Offiziere in den Augen ihrer Untergebenen war ihr Handeln im Gefecht und ihre Fähigkeit, mit der andrängenden Angst umzugehen.

In welchem Ausmaß die Kampfbereitschaft der Soldaten während eines Fronteinsatzes von ihrer Einbindung in informelle Gruppen abhängt, war immer wieder Gegenstand von Debatten. So wurde noch in den 90er Jahren des vergangenen Jahrhunderts aus militärhistorischer Sicht gegen Shils und Janowitzs Feststellung - die Kohäsion der Verbände und die Kampfmoral der Wehrmachtssoldaten werde von ihrer Integration in Primärgruppen bestimmt und demgegenüber habe ihre politische Einstellung eine geringe Bedeutung gespielt (1948: 314f.) - Einwände erhoben. Der israelische Militärhistoriker Bartov widerspricht dieser Einschätzung, auf die sich auch Crevelds Vergleich der US-Streitkräfte mit der Wehrmacht (1989) bezieht, und macht stattdessen hierfür »hauptsächlich ideologische Gründe« (1995: 59) verantwortlich. Als Grund führt Bartov die sehr schweren Verluste der Verbände an, die dazu geführt hätten, dass die Primärgruppen »mehr oder weniger verschwanden« (ebd.: 57). Tatsächlich kann Bartov zeigen, dass im Verlauf des Krieges aufgrund der Verluste die Primärgruppen-Bindungen sowohl zwischen den Soldaten wie ihren Vorgesetzten schwächer geworden sein müssen. Allerdings verliert durch diesen Hinweis auf abgeschwächte Bindungen die Argumentation von Shils und Janowitz keineswegs an Aussagekraft. Zum einen verweist auch Bartov auf die Bemühungen der Wehrmacht, den Personalersatz möglichst geschlossen von ihren Ausbildungseinheiten an die Front zu schicken, damit zwischen den Soldaten und ihren Vorgesetzten eine gewisse Vertrautheit besteht (1995: 63f.). Auch weist er auf die hohen Verluste und die Klagen über die geringe Kampfkraft der Einheiten hin, wenn schlecht ausgebildeter Ersatz und Überlebende aus verschiedenen Verbänden gemeinsam unter dem Kommando eines ihnen unbekannten Offiziers ins Gefecht geschickt wurden (ebd.: 65, 78f.). ${ }^{4}$ Zum anderen bestreiten Shils

4 Die Untersuchung von Rass, in der die Sozialstruktur einer Infanteriedivision untersucht wird, die seit dem Angriff auf die Sowjetunion bis zum Kriegsende überwiegend an der Ostfront eingesetzt wurde, legt nahe, die Schwächung des Primärgruppenzusammenhalts als temporäre Phänomene zu begreifen, die auftraten, wenn anstelle der getöteten oder verwundeten Soldaten für die Überlebenden unbekannte und auch noch unerfahrene Soldaten traten (2003: 198, 201). Bei der von ihm untersuchten Infanteriedivision kam es zweimal, im Winter 1941/42 und zu Beginn des Jahres 1945, zur Krise des sozialen Gefüges. Der Wehrmacht sei es aber nach 1942 überwiegend gelungen, durch die Rückführung von Verwundeten zu ihren alten Truppenteilen neue soziale Kleingruppen zu bilden, die aus »brutalisierten Veteranen« (ebd.: 204) und aus 
und Janowitz gar nicht, dass es neben der Primärgruppen-Bindung noch weitere Faktoren gab, die die Kampfkraft der Soldaten beeinflusste. So weisen sie ausdrücklich darauf hin, was im übrigen auch Bartov nicht entgeht, dass insbesondere der stärkere Widerstand gegen die vorrückenden sowjetischen Streitkräfte auf eine erfolgreiche NS-Propaganda, aber noch mehr auf die Angst zurückzuführen sei, die »the projection onto the Russians of the guilt feelings generated by the ruthless brutality of the Germans in Russia during the occupation period « (Shils/Janowitz 1948: 301) ausgelöst habe. Ebenso wenig bleibt die Wirkung der Unteroffiziere und jungen Offizieren (ebd.: 286f.), die von der nationalsozialistischen Ideologie durchdrungen waren, sowie der Einfluss des Führerglaubens (ebd.: 304f.) auf die Kampfmoral der Verbände von Wehrmacht und SS unerwähnt. Nicht, dass die Soldaten der Wehrmacht und der SS von der nationalsozialistischen Ideologie und der Praxis des Vernichtungskrieges geprägt waren, stand für die Autoren in Frage, sehr wohl aber die Vorstellung, dass die Kampfkraft der Soldaten von einer »>ideological possession«" (ebd.: 314) herrühre, und sie verbanden ihre Skepsis mit der Warnung, die Möglichkeiten von Propaganda und Indoktrinationen zu überschätzen. An einer genaueren Gewichtung des Beitrags ideologischer Motive zur Kampfleistung der Wehrmachtsoldaten zeigten sie, aber auch die Militärsoziologie im Allgemeinen, kein Interesse, zumal es sich mit der Kapitulation der deutschen Streitkräfte um eine historische Frage handelte. ${ }^{5}$

Die Sozialwissenschaftler nach dem Krieg beschäftigten sich weiter mit der Erforschung der informellen Beziehungen und Bindungen zwischen den einzelnen Soldaten und der Frage, wie durch sie die Leistungsfähigkeit der militärischen Organisation gesteigert werden kann. In zahlreichen Folgeuntersuchungen versuchten sie dabei, nicht nur durch Befragungen die Einstellungen zu erheben, sondern wendeten auch Praktiken der teilnehmenden Beobachtung der Soldaten im Kampfeinsatz an (Janowitz/Little 1965: 131f.). So stellte Little fest, dass der Gruppenzusammenhalt der US-Soldaten während des Koreakrieges (1950-1953) weniger von den informellen Gruppen innerhalb der Gruppen und Züge abhing, sondern mehr von den dyadischen buddy relations, weil die Stellungskämpfe und der ständige Personalwechsel »die Entstehung weiterrei-

jüngeren Soldaten bestanden, die er aufgrund ihrer Sozialisation im nationalsozialistischen Erziehungssystem als »ideologisch hoch motivierter Personalersatz« (ebd.) einstuft.

5 Kühne betont in diesem Zusammenhang, dass die soziale Kohäsion unter den Soldaten im Falle der Wehrmacht, selber von einem Mythos der Kameradschaft geprägt gewesen sei, dem der Nationalsozialismus seinen Stempel aufgedrückt habe. Deshalb hätten die Soldaten nicht einfach nur für ihre Kameraden gekämpft, sondern um einen Mythos zu aktualisieren und ihrem Leben Sinn zu geben (1999: 542). Dass die Wehrmacht am Ende des Krieges keine dominierende Kampfkraft hatte - ein gegenteiliger Eindruck wird mitunter in der Publizistik hervorgerufen - darauf weist Kunz hin (2005: 197f.). 
chender zwischenmenschlicher Beziehungen« (Janowitz/Little 1965: 133) zwischen den Soldaten erschwerten. Andere Untersuchungen betonten wieder mehr die Bedeutung von Einstellungen und Haltungen der Soldaten für ihre Einsatzmotivation. Als einflussreich erwies sich die Interpretation Moskos', der in den 60er Jahren aufgrund teilnehmender Beobachtung von US-Kampfgruppen im Vietnamkrieg zu dem Ergebnis kam, dass die Kampfmotivation aus dem Zusammenwirken »von individuellen Eigeninteressen [die letztlich in der Selbsterhaltung kulminiert, d.A.], Primärgruppenprozessen und den gemeinsamen Überzeugungen der Soldaten« (1968: 200) resultiere. Diese gemeinsamen Überzeugungen werden von den Soldaten nicht unbedingt manifest und in der Form reflektierter Aussagen formuliert, vielmehr handele es sich überwiegend um gemeinsam geteilte »latente Wertbindungen« (ebd.: 218), die sich beispielsweise in der Überzeugung ausdrücke, dass der >American way of life sischen Gegners überlegen sei (ebd.: 216). Gemeinsam geteilte Werte erleichtern zum einen die Bildung von informellen Gruppen. Zum anderen können sie aber auch als ein eigenständiger Beitrag zur Einsatzmotivation aufgefasst werden, weil sie dazu beitragen, dass die Soldaten in Krisensituationen beständiger von der Richtigkeit ihres Handelns überzeugt bleiben.

Die sozialwissenschaftlichen Studien der Research Branch beschäftigten sich auch mit den Fragen, was Vorgesetzte tun können, um ihre Untergebenen $\mathrm{zu}$ motivieren und welche administrativen Rahmenbedingungen die Kohäsionskräfte fördern. Dass sie dabei ihre Kritik an der Führungspraxis der Mehrheit der (Unter-)Offiziere der US-Streitkräfte im 2. Weltkrieg indirekt formulierten, indem sie in ihrer Darstellung vor allem herausarbeiteten, was gute Truppenoffiziere auszeichnete, dürfte die Akzeptanz ihrer Überlegungen erhöht haben. Sie wiesen darüber hinaus auf institutionelle Defizite hin, die die Bildung von Primärgruppen erschwerten. Besonders intensiv widmete sich diese Kritik dem Personalersatzwesen, das nicht die Bedeutung der Existenz von Primärgruppen für die Kohäsion der Verbände berücksichtigte. So war es in den US-Streitkräften üblich, dass die Soldaten nach ihrer Ausbildung einzeln, je nach Bedarf, auf verschiedene bereits bestehende Einheiten verteilt oder aus verschiedenen Ausbildungseinheiten neue Verbände zusammengestellt wurden. Für die einzelnen Soldaten, die als Ersatz einer bereits bestehender Einheit zugeteilt wurden, stellte sich deshalb das Problem, dass sie als Individuum einer Primärgruppe gegenüberstanden, die aus Überlebenden vorangegangener Kampfhandlungen bestand, und die sie allenfalls nach längerer Zeit als Teil ihrer Gruppe akzeptierte, worunter währenddessen die Kampfkraft der gesamten Einheit litt (siehe Stouffer 1949b: 242f.). ${ }^{6}$ Nach dem 2.

6 Wie groß der Unmut über das Personalersatzwesen war, zeigt Marshalls Bemerkung: Die für »die Personalpolitik verantwortlichen Herren (neigen) dazu, mit Menschen umzugehen, als ob es sich um Schmiermittel oder Kartoffel- 
Weltkrieg wurde aufgrund dieser Kritik die bis dahin übliche Versetzungspraxis von den Ausbildungs- zu den Kampfeinheiten teilweise verändert (siehe Janowitz/Little 1965: 118f.).

Diese Ergebnisse der empirischen Sozialforschung zum US-Militär sollten nach dem 2. Weltkrieg auch von den anderen westlichen Armeen berücksichtigt werden und die von den formellen Organisationen geschaffenen Rahmenbedingungen beeinflussen. Ihre Erkenntnisse $\mathrm{zu}$ den Primärgruppen gehören heute beispielsweise zu den Essentials der Ausbildung von Truppenoffizieren in den westlichen Streitkräften. Sie werden dazu angehalten, Prozesse informeller Gruppenbildung zu beachten, ihre Konformität mit den institutionellen Normen zu fördern und einzelne Soldaten, die nicht mit den Vorgesetzten kooperieren, dem Konformitätsdruck der Primärgruppe auszusetzen, sowie die informellen Anführer der Gruppen zu ihren Verbündeten zu machen (beispielhaft führt Braun (1985: 70f.) aus, wie auf diese Weise Vorgesetzte Einfluss auf die informellen Gruppen nehmen können). Bei der Bundeswehr wird ihre Fähigkeit, das Vertrauen der Untergebenen zu gewinnen, als eine entscheidende Qualität eines Truppenoffiziers eingestuft, um eine vertikale Kohäsion der Verbände, also eine Gefolgschaftsbindung zwischen Vorgesetzten und Untergebene aufzubauen. Als Vorgesetzte sind sie deshalb »institutionell verpflichtet, persönliche und soziale Belange des Soldaten nicht nur zu berücksichtigen, sondern auch mitzugestalten« (Biehl/Hagen/Mackewitsch 2000: 368). ${ }^{7}$ Auch der horizontalen Kohäsion wird bei der Bundeswehr in hohem Maße Bedeutung zugemessen (siehe hierzu beispielsweise Hoffmann 2003: 58f.). Festzustellen ist aber auch, dass bei der Bundeswehr die horizontale Kohäsion mit dem Begriff der Kameradschaft in eins gesetzt wird. Dadurch wird von Seiten der formalen Organisation die informelle Gruppe (und im Grunde alle Beziehungen zwischen Soldaten) normativ derart aufgeladen, dass sie - trotz des expliziten Bezugs auf sie - im Widerspruch zu den Arbeiten der Research Branch und Shils/Janowitz geraten. Die Soldaten sehen sich mit dem Anspruch konfrontiert, dass Kameradschaft gleichzeitig eine selbstverständliche wie eine gesetzliche Verpflichtung für alle Soldaten sein soll. »Jeder hat dem anderen - vor allem auch in Not und Gefahr - beizustehen. Dabei umschließt Kameradschaft nicht nur Angehörige der gleichen Dienstgruppe, sondern >alle Soldaten`, also Vorgesetzte und Untergebene.« (Biehl/Hagen/Mackewitsch 2000: 369) Hier wird mehr ein Soll-Zustand als ein Ist-Zustand benannt, wie auch der Verweis auf den Paragraphen 12 des Soldatengesetzes anzeigt, der bestimmt, dass der $\mathrm{Zu}$ -

säcke handelte. [...] Soldaten schob man herum wie Holzpflöcke, ohne anderen Grund, als eine besondere Zuteilungsnummer.«(1947: 168f.)

7 Sie verweisen in diesem Zusammenhang auf den $\S 10,3$ des Soldatengesetzes, der bestimmt, dass Vorgesetzte für ihre Untergebenen zu sorgen haben (siehe Gesetz über die Rechtstellung der Soldaten, in der Fassung vom 30.5.05. Online: http://bundesrecht.juris.de/bundesrecht/sg/gesamt.pdf; Zugriff: 12.10.07). 
sammenhalt der Bundeswehr »wesentlich auf Kameradschaft» beruhe. Ausgeblendet wird an dieser Stelle, dass eine informelle Gruppe eben nicht alle Angehörigen der Streitkräfte umfasst und ihre kohäsive Wirkung wesentlich darauf beruht, dass die Gruppenangehörigen exklusive Beziehungen und Bindungen zueinander haben, von denen andere Soldaten ausgeschlossen bleiben. Ausgeblendet wird auch der Aspekt, dass sich die Solidaritätsbindungen untereinander gegen die Anforderungen der formellen Organisation richten können. Das Ineinssetzen der Kohäsionswirkung von informellen Gruppen und von Kameradschaft klingt wie ein Nachhall einer Gemeinschaftsideologie, die durch den Nationalsozialismus desavouiert worden war.

Auch in jüngster Vergangenheit wurden administrative Entscheidungen, die die Einsatzmotivation der Soldaten bei Auslandseinsätzen ${ }^{8}$ erhöhen sollten, von neueren US-Studien beeinflusst. So wurde als ein weiterer Einflussfaktor auf die Einsatzmotivation der Soldaten ihre Beziehung zu ihren Familien herausgearbeitet, und sowohl die US-Streitkräfte als auch die Bundeswehr versuchen, negative Einflüsse auf die Motivation der Soldaten zu minimieren, indem sie unter anderem dafür sorgen, dass der Kontakt zwischen den Soldaten, die im Ausland eingesetzt werden, und ihren Familien nicht aufgrund schlechter Kommunikationsmöglichkeiten abreißt (siehe Biehl/Hagen/Mackewitsch 2000: 363f.).

Mit den Arbeiten der Research Branch begann eine Soziologie militärischer Institutionen und Praktiken Gestalt anzunehmen, die sich für das Handeln von Soldaten als soziale Subjekte interessierte, wenngleich ihr die Subjektivität überwiegend als manipulierbarer Faktor ins Blickfeld geriet, der sich aus zahlreichen Partialgrößen zusammensetzt, die es im Zusammenspiel mit Faktoren wie Organisationsstruktur zu optimieren galt. Die Form des Erkenntnisgewinns der sich nach dem 2. Weltkrieg entwickelnden Disziplin der Militärsoziologie unterscheidet sich in verschiedener Hinsicht von den zuvor unternommenen Bemühungen, soldatisches Handeln möglichst effizient in militärische Kampfkraft umzuwandeln. Sie beruhte nicht auf einer Übernahme von erfolgreichen Organisationsmodellen anderer Armeen, rekurrierte auch nicht auf Erfahrungen subalterner Offiziere, die diese quasi als Tradition an nachfolgende Generationen von Truppenoffizieren weitergaben. ${ }^{9}$ Die sozialwissenschaftliche empirische

8 Während in der älteren militärsoziologischen Literatur bevorzugt von Kampfmoral gesprochen wird, spricht die aktuellere Literatur eher von Einsatzmotivation, da Soldaten im Ausland auch dann großen Belastungen ausgesetzt sind, wenn ihnen keine Kampfaufträge erteilt werden (siehe Biehl/Hagen/ Mackewitsch 2000: 352).

9 Prinzipiell schlossen zwar Bemühungen, die auf solchen Methoden rekurrierten, nicht aus, dass eine Militärorganisation auf neue Herausforderungen adäquat reagieren kann, wie das Beispiel des deutschen Militärs und seine Reaktionen auf das industrialisierte Gefechtsfeld zeigen. So ist der weitgehende Verzicht auf den Drill und das Spielen von Fußball und ähnliche mehr bei den 
Untersuchung, die Überprüfbarkeit und Verallgemeinerungsfähigkeit ihrer Ergebnisse beansprucht, bedeutet »eine gesteigerte Selbstreflexivität der militärischen Menschenführung.» (Bröckling 2003: 205). Bei allem Misstrauen, das den mit der Forschung beauftragten Sozialwissenschaftlern wohl immer wieder entgegenschlägt, ${ }^{10}$ fällt es einer Top-down Organisation, wie dem Militär, doch leichter, auf ihre Erkenntnisse zu rekurrieren als beispielsweise auf die arbiträren Erfahrungen einzelner subalterner Offiziere.

Auch andere Sozialwissenschaften werden seit dem 2. Weltkrieg verstärkt von den Streitkräften herangezogen, um die Leistungsfähigkeit der Soldaten zu optimieren. Die Psychologie kann dabei freilich schon auf eine längere Geschichte zurückschauen. So lassen sich für Deutschland bereits für den Zeitraum vor dem 1. Weltkrieg Vorschläge finden, wie man die »junge Wissenschaft der experimentellen Psychologie im militärischen Bereich nutzbringend zur Anwendung« (Petri 2001: 51) bringen kann. Während des 1. Weltkrieges wurden vor allem Kraftfahrer sowie Flieger und Flugbeobachter psychologischen Eignungstests unterzogen, vereinzelt auch Funker, Richtkanoniere und Schallmesser. Daneben wurde »mithilfe psychologischer Verfahren die Leistungsfähigkeit Verwundeter getestet und Forschungen an Hirnverletzten und Amputierten« sowie »experimentalpsychologische Untersuchungen, etwa des Gleichgewichtssinns beim Fliegen« (ebd.: 52) durchgeführt.

Auch andere Streitkräfte verwendeten psychologische Tests vor allem zur Personalauswahl. Sie griffen dabei jedoch auf unterschiedliche Testmethoden zurück. So spielten in den USA psychologische Intelligenztests bei der Auswahl des Personals eine erhebliche Rolle. Da die US-Streitkräfte bis zum Kriegseintritt 1917 aus relativ wenigen Berufssoldaten bestanden, die nun durch Millionen Rekruten verstärkt werden sollten, über deren militärischen Fähigkeiten nichts bekannt war, sollten Intelligenztests über die Eignung der Soldaten entscheiden. Unter anderen sollten überdurchschnittlich begabte Rekruten für die höheren Laufbahnen gefunden, >gering Begabte` sollten dagegen zum Ausheben der Schützengräben herangezogen werden. Auch sollten die Soldaten in den Einheiten einen in etwa gleich hohen Intelligenzquotienten aufweisen (siehe Riedesser/Verderber 1985: 83f.). Vermutlich wurden in den USA zwischen 1917

deutschen Stoßtruppen im 1. Weltkrieg nicht nur als körperliches Training zu interpretieren, das die körperliche Leistungsfähigkeit der Soldaten steigerte (Gudmundsson 1989: 87), sondern auch als ein Maßnahme, die die Beziehungen und Bindungen zwischen den Soldaten intensivierte und damit die Kohäsion der Einheiten erhöhte.

10 Der Kern dieses Misstrauens bildet die Befürchtung des Militärs, die Sozialforscher könnten Schwachstellen aufdecken, sensible Strukturen beleuchten, etc. und durch ihr Interesse an der Veröffentlichung ihrer Ergebnisse dem Gegner bekannt machen und ihm dadurch Vorteile verschaffen (siehe König 1968: 9f., sowie Geppert 1998: 19). 
und 1918 über 1,75 Millionen Soldaten Intelligenztests unterzogen (siehe auch Seifert 1996: 75f.). Gegen Ende des Krieges sollte das US-Militär den Wert der Massentestungen allerdings als gering einstufen, und darum nahm in den Folgejahren das Interesse an der Psychologie stark ab. ${ }^{11}$ Erst ab 1939 wurde die Militärpsychologie bei den US-Streitkräften wieder ausgebaut, und abermals wurden etwa 12 Millionen Rekruten auf ihre Fähigkeit hin, »eine militärische Ausbildung erfolgreich abzuschließen« (Riedesser/Verderber 1985: 85) und auf spezielle Fähigkeiten für Mechaniker, Piloten, etc. getestet.

In Deutschland wurden nach dem 1. Weltkrieg bei der Reichswehr zunächst weiterhin vor allem Kraftfahrer und Funker (Petri 2001: 52) psychologisch auf ihre Befähigung hin geprüft. Seit Beginn der 20er Jahre wurde an Methoden gearbeitet, mit deren Hilfe alle Mannschaftssoldaten, die für spezielle Tätigkeiten vorgesehen waren - vor allem an Maschinen auf ihre Eignung untersucht werden sollten. Obendrein entschloss sich die militärische Leitung, dass sich auch angehende Offiziere psychologischen Eignungstests unterziehen müssen, um die Offiziersauswahl zu verbessern. Den Hintergrund für die Entscheidung, die Ansprüche an das Führungspersonal zu erhöhen, bildeten die Bestimmungen des Versailler Vertrages, die vorsahen, dass die Reichswehr höchstens über 100.000 Soldaten verfügen darf, weshalb die Reichswehr über weniger Offiziersstellen verfügte als ihr an Offiziersanwärtern zur Verfügung standen. Um das allmählich immer umfassender werdende Prüfwesen mit psychologischen Test durchführen zu können, schuf die Reichswehr 1925 die ersten öffentlich-rechtlichen Planstellen für Psychologen in Deutschland, und sie war ab Ende der 20er Jahre zu ihrem größten Arbeitgeber geworden (Geuter 1988: 268). Untersucht wurde beispielsweise die Reaktions- und Konzentrationsfähigkeit der Offiziersanwärter und auf visuelle und auditive Reize in Stresssituationen, ihr Vermögen, verschiedene visuelle bzw. auditive Reize, und wenn zum Beispiel die Soldaten als Gasspürer eingesetzt werden sollten, auch Gerüche von einander zu unterscheiden bzw. zu bestimmen. Luftwaffensoldaten, die als fliegendes Personal eingesetzt werden sollten, wurden obendrein noch im Hinblick auf ihre Drehempfindlichkeit und ihren Gleichgewichtssinn untersucht. Zum anderen wurden >charakterologische

11 Bei Behörden und in der Wirtschaft sollte dagegen das Interesse parallel zunehmen und psychologische Tests bei Bewerbungen Einzug halten. Die Testdaten, die im Zuge der Rekrutierung erhoben wurden, sollten nach dem Krieg ausgewertet werden. »Man hielt [...] die Testergebnisse für den Ausdruck grundlegender Fähigkeiten und vernachlässigte die Einflüsse des sozialen und kulturellen Umfelds, wie z.B. Erziehung und Bildung, auf die Intelligenzwerte, und kam zu Ergebnissen, die für manche gesellschaftliche Gruppe fatale Auswirkungen hatten« (Riedesser/Verderber 1985: 84f.). So wurde mit Hinweis auf das schlechtere Abschneiden von Afroamerikanern bei den Tests ihre Rassendiskriminierung als das gerechte Ergebnis angeborener Fähigkeiten legitimiert (ebd.: 85). 
Methoden entwickelt, die vor allem zentraler Bestandteil der Offiziersanwärterprüfungen waren. Ihr Kennzeichen war, dass es weniger auf die quantitativ messbaren Ergebnisse, die die Prüflinge an den Apparaten erzielten, ankam, sondern auf ihr Verhalten, das von den Psychologen in "'symptomatologische< Beschreibungsbegriffe wie Frische, Aktivität und Durchsetzungsfähigkeit; Erreglichkeit; Selbstgefühl, Ichbezogenheit, Gelassenheit, Schwerfälligkeit« (Petri 2001: 56) gefasst wurde. So erwarteten Luftwaffenpsychologen von Piloten, dass sie Charaktermerkmale wie »Aktivität, Schwung und Stoßkraft« aufwiesen, während man von Bombenschützen »eher ein ruhiges und gelassenes Temperament und eine nüchternrationale Einstellung« (Geuter 1988: 198f.) verlangte.

Nahmen zwischen 1928 und 1933 die Zahl der Prüfungen vor allem deshalb zu, weil das Prüfwesen in der Reichswehr immer weiter ausgebaut wurde, so dokumentiert ihr enormer Anstieg ab 1933 die beschlossenen Aufrüstungsmaßnahmen unter dem nationalsozialistischen Regime (siehe Zahlen bei Geuter 1988: 257f. und Simoneit 1939: 17). Insbesondere mit der Einführung der Wehrpflicht und dem offiziellen Aufbau der Luftwaffe (ab 1935) nahm die Zahl der Untersuchungen sprunghaft zu. Allein beim Heer wurden zwischen 1928 und 1942 über 580.000 Spezialistenuntersuchungen, neben Funkern und Kraftfahrern unter anderen für Entfernungsmesser (Flak) und Artilleriebeobachter (Flik 1942: 58), durchgeführt.

Ab 1942 wurde beim Heer und der Luftwaffe auf den psychologischen Teil der Offiziersanwärterprüfung und wohl auch weitgehend auf die experimentalpsychologischen Prüfungen bei den Spezialistenprüfungen verzichtet bzw. kam ihnen keine große Bedeutung mehr zu. Aufwendige Eignungstests, wie sie insbesondere die Offiziersanwärterprüfung vorsah, aber auch Spezialistenprüfungen, um die am besten geeigneten Soldaten aus dem vorhandenen Angebot auszuwählen, verloren aufgrund der Personalnot, die mit den hohen Verlusten im Zuge des Krieges gegen die Sowjetunion einsetzte, ihren Sinn. ${ }^{12}$

Spätestens seit dem 2. Weltkrieg greifen alle Streitkräfte auf verschiedene psychologische Testmethoden zurück, angefangen von den experimentellpsychologischen bis hin zu den Intelligenztests, um zu entscheiden, für welche Tätigkeit die Soldaten geeignet sind. Die Art, aber auch der

12 Die Marinepsychologen setzten noch bis 1945 ihre Arbeit fort, weil sie wohl weniger aufwendige Verfahren praktizierten und sich mehr darauf konzentrierten, das zur Verfügung stehende Personal im Hinblick auf ihre Befähigung für die einzelnen Spezialistentätigkeiten zu sortieren (siehe Mitze 1985: 231f.). In der neueren Literatur herrscht Einigkeit darüber, dass insbesondere die Darstellung des wissenschaftlichen Leiters zwischen 1931 und 1942, Simoneit, der für die Auflösung der Heeres- und Luftwaffenpsychologie Animositäten in Teilen der politischen und militärischen Führung verantwortlich macht, unzutreffend ist. Die Vorbehalte haben den Entscheidungsträgern allenfalls die Auflösung erleichtert, sie waren aber nicht ausschlaggebend (siehe Renthe-Fink (1985) und Geuter (1988: 427f.) 
Umfang der Untersuchungen hängt stark von den Aufgaben ab, für die sie vorgesehen sind. Die umfassende Technisierung des Militärdienstes und des Kriegseinsatzes verlangt, dass die Soldaten nicht nur im Hinblick auf ihre Kenntnisse untersucht werden, sondern ob sie obendrein auch die physischen, beispielsweise die perzeptuellen und motorischen Fähigkeiten aufweisen, um die Maschinen zu bedienen. Je komplexer und kostspieliger die Maschinen sind, die die Soldaten bedienen sollen, desto intensiver sind in aller Regel die Untersuchungen, denen sich die Soldaten unterziehen müssen. Grundsätzlich lässt sich deshalb auch sagen, dass die umfangreichsten Ansprüche an das fliegende Personal gestellt werden.

Aus der Tätigkeit der Soldaten an Maschinen bildete sich bereits während des 2. Weltkrieges neben der Auswahl des Personals ein weiterer Arbeitsschwerpunkt der Psychologen heraus. Durch ihre umfangreichen Tests mit den Soldaten verfügten sie über eine große Datenmenge, die Aufschluss über die physischen Eigenschaften und sensorischen Fähigkeiten einer statistischen Durchschnittsperson gaben. Diese Eigenschaften und Fähigkeiten zu berücksichtigen, wurde bei der Entwicklung neuer Waffen und Kommunikationseinrichtungen immer wichtiger, weil die Maschinen von den Soldaten ansonsten nicht optimal bedient werden konnten. So untersuchten Psychologen die Frage, weshalb die Bordschützen des 1944 eingeführten B-29-Bombers über die Qualität der Waffenoptik klagten (siehe Watson 1985: 69f.). Als ein immer wieder von neuem zu lösendes Problem stellte sich heraus, wie die Soldaten Informationen, die sie für ihre Tätigkeit an der Maschine benötigen, erfassen können. Allgemeiner formuliert: Wie die Schnittstelle zwischen der Maschine/Technik und dem sie bedienenden Menschen ausgestaltet sein muss, damit das Gerät optimal eingesetzt werden kann. Im 2. Weltkrieg kamen die Forschungsergebnisse der Psychologen zu spät, um noch die Waffenentwicklung zu beeinflussen. Seit dem 2. Weltkrieg fließen unter einer Vielzahl von Labels - zu denen unter anderen das human engineering und die Ergonomie gehören - beim Design neuer Geschütz-, Raketenabschussinstrumente, Cockpitdisplays, die Forschungsergebnisse der Psychologen ein und spielen eine erhebliche Rolle bei der Ausgestaltung der >Arbeitsplätze` von Soldaten.

Erst nach dem 2. Weltkrieg zogen auch Soldaten im Mannschaftsrang, die für den infanteristischen Kampfeinsatz vorgesehen waren, das Interesse von Psychologen auf sich. Ausgelöst wurde ihr Interesse durch die Untersuchung Marshalls zur Feuerleistung von Infanteristen. Er kam aufgrund von Befragungen von Soldaten, die die Kampfeinsätze überlebt hatten, zu dem Ergebnis, dass während eines Kampfes im »Durchschnitt nicht mehr als 15 Prozent der Mannschaften auf die feindlichen Stellungen oder einzelne Feinde gefeuert hatten« (1947: 56). Wenn man davon ausgehe, dass alle Verwundeten und Getöteten ebenfalls einen Betrag zum Kampfgeschehen geleistet haben, könne allenfalls jeder vierte Soldat als »aktiver 
Kämpfer« bezeichnet werden (ebd.). ${ }^{13}$ Marshall stellte zwar bei den USInfanteristen des Koreakrieges einen deutlich höheren Prozentsatz von aktiven Kombattanten von annähernd 50 Prozent fest (siehe Watson 1985: 51), aber nichtsdestotrotz wurde seitdem versucht, die Merkmale zu bestimmen, die einen Soldaten eher für einen fighter bzw. non fighter disponieren. Die Studien aus den 50er und 60er Jahren, auf die sich Watson bezieht, kamen zu dem Schluss, dass man die meisten Merkmale bereits vor dem Fronteinsatz feststellen kann und obendrein bereits vor dem Militärdienst ausgebildet sind. Die Persönlichkeit eines fighter zeichne sich demnach durch eine deutlicher ausgeprägte Maskulinität, durch eine größere Furchtlosigkeit etc. aus. Diese Merkmale wurden mit bestimmten Sozialisationserfahrungen der Individuen in Zusammenhang gebracht. So führe ein früher Tod des Vaters häufig zu einer geringer ausgeprägten maskulinen Rolle und diejenigen Soldaten, die in der Geschwisterfolge Erstgeborene sind, würden eher zu größerer Ängstlichkeit als Zweitgeborene neigen, weil sie meist einsamer aufwachsen. Dass den non fighters ein geringerer Intelligenzquotient bescheinigt wurde, hängt vermutlich mit ihrer ebenfalls festgestellten schlechteren Schulbildung zusammen (siehe Watson 1985: 54f.). Die US-Streitkräfte konnten ab den 50er Jahren durch »entsprechende Änderungen in den Auswahl- und Ausbildungsmethoden [...] ein günstigeres Verhältnis zwischen Kämpfern und Nichtkämpfern in den Einsatzverbänden erreichen« (ebd.: 51). Die Ausbilder, so Grossman, förderten während der Ausbildung von Rekruten soziale Verhältnisse, die die Rekruten ein Rollenverständnis ausbilden ließen, das die Anwendung von Gewalt begünstigen (1995: 313f.). Durch umfangreiche und realitätsnahe Schießtrainings und eine Verstärkung von gewaltfördernden Normen, sei es gelungen, dass die meisten angehenden Soldaten ihre Tötungshemmung ablegen, die Grossman als einen anthropologisch angelegten Widerstand gegen die Tötung von Artgenossen bezeichnet, der aber zugleich unter anderen durch kulturelle und soziale Faktoren beeinflussbar sei (ebd.: 39). Im Vietnamkrieg hätten 90 bis 95 Prozent der US-Soldaten ihre Waffen eingesetzt (ebd.: 189).

Obwohl seit der 2. Hälfte des 20. Jahrhunderts Soldaten in aller Regel nicht Tage und Wochen lang über weite Strecken marschieren müssen, obwohl sie sich bei weitem besser vor Hitze und Kälte schützen können, als dies in den vorangegangenen Jahrzehnten und Jahrhunderten möglich war, bedeutet ein Kriegseinsatz für sie große physische Belastungen. Die Soldaten leiden unter Schlafmangel, weil die Kampftätigkeit aufgrund der

13 Nach Auffassung von Grossman sind no-fighter kein Phänomen, dass es erst seit dem 2. Weltkrieg gibt, es wurde hier >lediglich erstmals wissenschaftlich untersucht. Bereits im US-Bürgerkrieg hätten viele Soldaten auf beiden Seiten nicht ihre Waffen abgefeuert. Er verweist dabei unter anderen auf über 10.000 geladene Gewehre, die auf dem Schlachtfeld von Gettysburg (1863) gefunden wurden (1995: 21f.). 
technischen Ausrüstung nicht auf den Tag beschränkt ist und von den Verbänden ein möglichst permanenter Kampfeinsatz erwartet wird, um den Gegner zu überraschen und ihm die Möglichkeit zu nehmen, sich zu sammeln. Hinzu kommen die affektiven und emotionalen Anspannungen, also die Angst, im Kampf verletzt oder getötet zu werden bzw. aufgrund dieser Angst, die erteilten Befehle nicht ausführen zu können, zu versagen. Selbst im 21. Jahrhundert klagen US-Soldaten während ihrer Kampfeinsätze über Hunger und Durst (siehe beispielsweise Exum 2004: 149f.). Um trotz alledem handlungsfähig zu bleiben, nehmen Soldaten aus Eigenantrieb, meist mit Duldung und Unterstützung ihrer Vorgesetzten, zahlreiche Stimulanzien ein. In Europa hat besonders der Alkoholkonsum eine lange Tradition unter den Soldaten. So schreibt Keegan, beispielsweise für eine Schlacht im Mittelalter (Azincourt 1415), dass »viele Soldaten beider Heere alles andere als nüchtern ins Handgemenge [gingen], wenn sie nicht überhaupt betrunken kämpften« (1991: 131). Vor allem wegen der sedierenden Wirkung des Alkohols, die Schmerzen, Angst, aber auch Hunger und Durst in den Hintergrund treten lässt, sowie seiner euphorisierenden euphorisierend Wirkung, die die Akteure zu enthemmtem aggressivem Handeln befähigt, wird im Krieg von den Akteuren Alkohol konsumiert. Spätestens seit Beginn des 19. Jahrhunderts ist der Konsum von Nikotin und Koffein unter Soldaten weit verbreitet.

Zum Alkoholkonsum hatten militärische Führungen immer ein ambivalentes Verhältnis. Wenngleich es in zahlreichen Armeen üblich war, vor Kampfeinsätzen den Soldaten eine Sonderzuteilung Alkohol zu gewähren, so wurde sehr wohl gesehen, dass alkoholisierte Soldaten schwerer unter dem Kommando ihrer Vorgesetzten zu halten waren und mit zunehmender Alkoholisierung ihre Koordinationsfähigkeit verloren, so dass beispielsweise ihre Fähigkeit, Ziele treffsicher unter Feuer zu nehmen, sank. Obendrein sahen schon Psychiater im 1. Weltkrieg im Alkohol- und Tabakmissbrauch eine mögliche Ursache für die Ausbildung einer Kriegsneurose (siehe Gaupp 1922: 68).

So kritisch diese Drogen von den Psychiatern beurteilt wurden - seit dem 2. Weltkrieg wenden sie andere psychogene Substanzen bei der Behandlung von Kriegsteilnehmern an, die mit psychosomatischen Leiden auf ihre Erlebnisse reagieren. Nach Gabriel wurden damals US-Soldaten Barbiturate und andere Beruhigungsmittel verabreicht, nachdem ihnen die Ärzte einen battle shock diagnostiziert hatten. Dabei kam es anfangs zu zahlreichen Fehldiagnosen und Überdosierungen, die für die Betroffenen mitunter tödliche Folgen hatten. Später, im Koreakrieg, verfügten die Ärzte über mehr Erfahrung im Umgang mit diesen Psychopharmaka, aber erst mit der so genannten psychopharmakologischen Revolution, die Anfang der 50er Jahre einsetzte, verbreiterte sich die Palette der psychogenen Medikamente erheblich. Seitdem gehören sie zur Standardbehandlung von Soldaten, die unter Symptomen von Kampfstress oder PTSD leiden (Gab- 
riel 1988: 155f.). Aufgrund der Behandlungserfolge mit Psychopharmaka in den 50er und 60er Jahren wurden fast alle anderen auf den Leib der Patienten gerichteten Behandlungsmethoden aufgegeben, und es gab Vorhersagen, die für die 80er und 90er Jahre eine erhöhte Heilbarkeit psychiatrischer Erkrankungen und die allgemeine Akzeptanz der Einnahme von Drogen zur gezielten Veränderung der Persönlichkeit erwarteten (Helmer-Gordon 1964: 12f.). Noch Anfang der 80er Jahre lassen sich Zukunftsentwürfe für die Jahrtausendwende finden, in denen davon ausgegangen wird, dass »Müdigkeit und Gefechtsstress [...] durch spezielle, >sichere` Drogen bekämpft (werden), die aber die Leistung nicht beeinträchtigen.« (Lopez 1983: 1554). Tatsächlich sind derartige Drogen bis heute nicht gefunden worden, denn alle Psychopharmaka haben jeweils gravierende und aus Sicht der Militärs leistungsabsenkende Wirkungen auf die Fähigkeiten der Soldaten. Sowohl die unmittelbaren Nebenwirkungen als auch die Langzeitfolgen des Konsums von Psychopharmaka verhindern, dass Soldaten, wie dies Gabriel für eine nicht näher bestimmte Zukunft vorhersagt, zu »chemical automatons« (1988: 173) geworden sind.

Eine gewisse Ausnahme bildet die Verabreichung von Amphetaminen. Im Verlauf des 2. Weltkrieges verabreichten Militärärzte der Wehrmacht wiederholt Piloten, aber auch Soldaten des Heeres, das Aufputschmittel Pervitin, das Methylamphetamin enthielt (siehe Baader 1990). Auch britischen Piloten wurden damals Amphetamine verabreicht, um ihre Einsatzdauer zu verlängern. In dem Handbuch »Performance Maintenance During Continuous Flight Operations« - herausgegeben vom Naval Strike and Air Warfare Center für die Ärzte der Luftwaffe - wird ebenfalls darauf hingewiesen, dass die Piloten der US-Luftwaffe und der US-Marine im Vietnamkrieg Amphetamine verwendeten. Außerdem hätten britische Piloten im Falklandkrieg (1982) Sedativa eingenommen, und seit dem 2. Golfkrieg (1991) nehmen Piloten der US-Luftwaffe sowohl Aufputsch- wie auch Beruhigungsmittel, um ihre Einsatzfähigkeit zu erhöhen (Naval Strike/Air Warfare Center 2000: Foreword). Mit den Aufputschmitteln soll die während langer Einsätze entstehende Müdigkeit der Piloten reduziert werden, die auftritt, weil die Einsätze von den Piloten zwar ein Höchstmaß an Konzentration verlangen, aber zugleich über weite Strecken auch sehr langweilig sind (ebd.: 7). Auf die Praxis der Einnahme von so genannten Gound No-Go-Tabletten unter US-Piloten wurde eine breitere Öffentlichkeit im Zuge einer Prozesseröffnung gegen zwei Piloten aufmerksam, die im Jahr 2002 in Afghanistan durch den Abwurf einer Bombe vier kanadische Soldaten getötet und acht weitere verletzt hatten. Ihre Rechtsanwälte rechtfertigten das Handeln ihre Mandanten mit dem Hinweis auf die Einnahme von Amphetamin (Dexedrin): Ihre Urteilsfähigkeit sei dadurch herab- und ihre Aggressivität heraufgesetzt gewesen. Die Einnahme erfolge zwar freiwillig, aber eine Verweigerung könne ein Startverbot zu Folge haben, 
da sich die Einsätze, inklusive der Vor- und Nachbereitungen oft über 24 Stunden hinziehen (siehe Buse 2003 und Hürter 2002).

In seiner Wirkungsweise vergleicht das Handbuch die verabreichten Amphetamine mit Koffein, das allerdings aufgrund seiner konzentriert in Tabletten zu verabreichenden Form von dem fliegenden Personal praktischer angewendet werden kann (Naval Strike/Air Warfare Center 2000: 8). Die Gefahr der Abhängigkeit von den Medikamenten für die Piloten wird zwar angedeutet, aber für gering erachtet. Gleiches gilt für die Möglichkeit, dass die erwünschten Effekte nicht mehr kontrolliert werden können und die Piloten unter Schlaflosigkeit, Euphorie, Magersucht und Konzentrationsmangel (channelized attention) leiden (ebd.: 15). Unerwähnt bleibt, dass Amphetamine ihre Konsumenten dazu verleiten können, sich selbst zu überschätzen, und dass sie depressive oder sogar psychotisch-paranoide Zustände auslösen können (siehe Schmidbauer/Scheidt 2004: 358).

Während die Verabreichung von Amphetaminen und Sedativa bei Piloten unter ärztlicher Aufsicht erfolgt bzw. sie medizinisch intensiv überwacht wird, gilt das bei anderen Soldaten allenfalls eingeschränkt. Vermutlich ein Grund, weshalb in anderen Teilstreitkräften der USA die Einnahme von Aufputschmitteln grundsätzlich verboten ist. Trotzdem berichtet der amerikanische Journalist Evan Wright, der Marineinfanteristen während der Angriffsoperationen im Irak (Frühjahr 2003) begleitete, dass viele Soldaten nicht nur wasserlösliches Kaffeepulver direkt trocken aus der Verpackung löffelten, sondern dass sie sich selber mit großen Mengen von aufputschenden Medikamenten versorgt hatten, die sie während des Einsatzes und besonders vor erwarteten Gefechten freigebig zu sich nahmen (2005: 71; 293). Er berichtet obendrein von Marineinfanteristen, die psychotische Zustände hatten und in den ersten Tagen der Besetzung Bagdads unter anderem »imaginäre Fedajin anschrien«. Der Divisionsarzt vermutete, dass es sich überwiegend um temporäre Psychosen handele, ausgelöst durch »übermäßigen Konsum von Aufputschmitteln« (ebd.: 415). ${ }^{14}$ Dennoch: Auch Amphetamine führen nicht zur Erfüllung von Gabriels Zukunftsprognose, dass "soldiers will become no more than one more death-inflicting combat machine - like tanks, missiles, and guns - to be used by commanders in much the same way. [...] Amid the death, pain, and horror, the chemical soldier will simply fight on." (Gabriel 1988: 173)

Auch eine noch so gute Auswahl des Personals, seine optimale Vorbereitung auf den Einsatz und auch eine gute Motivation schließen nicht aus, dass Soldaten die ihnen gestellten Aufgaben nicht erfüllen können. Dass bedeutet: »Even a brave and patriotic man can be broken by the agonies of

14 Es handelt sich dabei vor allem um ephedrinhaltige Präparate. Ausdrücklich erwähnt Wright Ripped Fuel, dass zumindest damals als so genanntes Nahrungsergänzungsmittel von Bodybuildern geschätzt wurde, weil es die Fettverbrennung im Körper erhöht. Ephedrin ähnelt dem körpereigenen Adrenalin und ist chemisch mit der Gruppe der Amphetamine verwandt. 
combat.« (Ginzberg Bd. 2, 1959: 275) Wie das interdisziplinär angelegte Projekt Conversation of Human Resources aufzeigt, das von Eisenhower (1890-1969) in seiner Funktion als Präsident der Columbia Universität Ende der 40er Jahre initiiert wurde, kann jeder zum Militärdienst Herangezogene sich dem Kriegsgeschehen mental oder emotional als nicht gewachsen erweisen. Die Zahl ineffektiver Soldaten, so auch der Titel des dreibändigen Werks in dem die Ergebnisse des Projekts 1959 (Ginzberg) veröffentlicht wurden, könne aber verringert werden und sie müsse nicht derart hoch sein wie bei den US-Streitkräften im 2. Weltkrieg. Dieses Ziel ließe sich ohne eine psychiatrische Selektion, wie dies im 2. Weltkrieg geschah, erreichen, verlange aber eine sorgfältige Personalplanung, eine adäquate Ausbildung und Training der Soldaten. ${ }^{15}$ Ausdrücklich wendet sich die Studie gegen eine Diffamierung der Soldaten, die dem Kriegsgeschehen nicht standgehalten haben und psychisch zusammengebrochen sind. Jeder Mann habe seine Schwäche, also auch seine Stärken. Dieser Auffassung lassen die Autoren die pathetisch wirkenden Worte folgen: »Even if he breaks down, he is likely to recover if he is aided by a loving family, a sympathetic government, and there is a place for him in an expanding economy.« (Ebd.: 275)

Der Bundesrechnungshof der Vereinigten Staaten schätzte 2004 aufgrund seiner Recherchen, dass über 15 Prozent aller in Afghanistan und dem Irak eingesetzten Soldaten, inklusive der Reservisten und der Nationalgardisten, unter PTSD leiden werden (United States Government Accountability Office (GAO) 2004a: 1). Da im Verlauf der vergangenen 5 Jahre die US-Streitkräfte weit über 1.500.000 Männer und Frauen in beide Kriegsgebiete eingesetzt haben, würde dies bedeuten, dass mehr als 225.000 Soldaten und Soldatinnen mit diesen psychischen Leiden zurechtkommen müssen.

\subsection{Technisierung des Kriegsgeschehens}

Der Schwerpunkt der Rüstungsanstrengungen liegt auch nach dem 2 . Weltkrieg nicht in der Optimierung der soldatischen Subjektivität. Wie effizient eine Waffe eingesetzt werden kann, hängt zwar, wie die sozialwissenschaftlichen Studien zeigen konnten, von den sie bedienenden Soldaten $\mathrm{ab}$, aber zu ihren Erkenntnissen gehörte auch, dass sich das Leistungsvermögen der Soldaten nicht unendlich steigern lässt.

$15 »$ While selection can be used to reject severely handicapped individuals who are likely to fail, it cannot do more than this. Selection is a useful and even necessary facet of a comprehensive personnel program, but training and assignment must be relied upon to fit the individual into an organization so that he can perform effectively.« (Ginzberg Bd. 3, 1959: 198) 
Die finanziellen Aufwendungen in den Militärbudgets zeugen davon, welche enormen Summen für die Entwicklung, Anschaffung und Bereitstellung der jeweils neusten Rüstungstechnologien ausgegeben wurden, um die Schlagkraft der Streitkräfte zu erhöhen. Schlaglichtartig sei zur Veranschaulichung der umfassenden Technisierung des Militärs auf ein paar wichtige Veränderungen hingewiesen: Unter den Vorzeichen des Kalten Krieges wurden alle Landstreitkräfte motorisiert, das heißt, seit dem 2. Weltkrieg werden Kampfverbände durch Fahrzeuge bis ins das Gefechtsfeld gebracht und die Kampfverbände sind in aller Regel mit (gepanzerten) Waffenträgern ausgestattet. Für Pferde war nun beim Militär auch als Transportmittel kein Bedarf mehr, nachdem die Kavallerie als Waffengattung bereits mit der Niederlage der französischen Truppen im 2. Weltkrieg (1940) vom Gefechtsfeld verschwunden war. Es wurden neue Technologien bei den Streitkräften eingeführt. So wurden in vielen Bereichen propellergetriebene durch strahlengetriebene Flugzeuge ersetzt, weil diese wesentlich höhere Geschwindigkeiten erreichen können. Um Soldaten und Nachschub ins Einsatzgebiet zu transportieren als auch für Kampfeinsätze wurden die Streitkräfte mit verschiedenen Hubschraubertypen ausgerüstet. Für eine andere Technologie wurden neue Einsatzgebiete entwickelt. Mit Raketen, die bislang hauptsächlich quasi als Artilleriegeschosse verwendet wurden, lassen sich nun auch Panzer und Flugzeuge angreifen. Es wurden immer kleinere Raketen entwickelt, die deshalb heute auch von Flugzeugen abgeschossen werden, und die auch nach dem Abschuss steuerbar bleiben bzw. selbstständig ein Ziel verfolgen können. Obendrein wurden sie zu Waffenträgern von konventionellen wie um atomaren Gefechtsköpfen, letzteres über interkontinentale Strecken. Auf- und ausgebaut wurden eine Vielzahl von Informationserfassungs- und Kommunikationstechnologien, wie Radar, Funk und der Datenverkehr per Telefonleitung (das Internet war ursprünglich eine militärische Einrichtung), die unverzichtbar geworden sind, um den Einsatz der Streitkräfte koordinieren zu können.

Der Einzug von immer mehr Technik und neuen Technologien bei den Kampfverbänden erhöhte die Zahl der Soldaten, deren Aufgabe nicht darin besteht, zu kämpfen, deren Tätigkeit aber unverzichtbar ist, damit andere Soldaten von den Waffen Gebrauch machen können. Wie rasant sich diese Veränderung im 20. Jahrhundert vollzog, zeigt eine Studie, die »spezialisierte Funktionen« von Unteroffizieren und Mannschaftssoldaten beim US-Heer vom Bürgerkrieg (1861-1865) über den 1. Weltkrieg bis hin ins Jahr 1954 vergleicht. Demnach hatten im Bürgerkrieg 93,2 Prozent dieser Soldaten unmittelbar kampfbezogene Funktionen, wurden also als Kombattanten ins Gefecht geschickt. Bereits im 1. Weltkrieg sank ihr Anteil auf 34,1 Prozent, um allmählich immer weiter auf 28,8 Prozent zu sinken. Über 2/3 der Soldaten, genauer 71,2 Prozent waren 1954 für nichtkämpferische Funktionen vorgesehen. Der Anteil der Soldaten in der Rubrik »Techniker, Wissenschaftler« und »Verwaltungs- und Büroberufe« stieg 
von 3,7 bzw. 8 Prozent im 1. Weltkrieg auf 14,5 und 17,5 Prozent. Leicht sank dagegen der Anteil der Soldaten, die als »Reparatur-, Instandsetzungsmechaniker und sonstige Fachkräfte« gezählt wurden, - vermutlich, weil ihre Tätigkeit in einigen Fällen nun in die Rubrik »Techniker« fiel umfasste 1954 aber 20,3 Prozent der Soldaten. Für angelernte und ungelernte Hilfsdienste wurden 1954 18,8 Prozent der Soldaten herangezogen. Die Zahl der für einen Kampfeinsatz vorgesehenen Soldaten sank also mit der Industrialisierung des Krieges drastisch und dieser Trend hat seitdem angehalten. Auch machte sich ein weiterer Trend bemerkbar: Die Tätigkeiten spezialisierten sich und die Funktionen differenzierten sich aus. Ablesen lässt sich diese Tendenz am sinkenden Anteil der Soldaten, die für ungelernte Hilfsdienste herangezogen wurden, zugunsten der Techniker, Wissenschaftler, Instandsetzungsmechaniker und ähnliches mehr (alle Angaben nach Janowitz/Little 1965: 43). ${ }^{16}$ Der Trend zur Spezialisierung drückt sich obendrein in den Dienstgraden aus, die Soldaten haben. Befanden sich beim US-Heer 1948 circa 45,5 Prozent der Soldaten in den beiden niedrigsten Diensträngen (Rekrut und Gefreiter), sank ihr Anteil im Jahr 1962 auf 25,8 Prozent. Noch deutlicher fiel diese Entwicklung bei der Luftwaffe aus, die einen höheren Technisierungsgrad als das Heer aufweist. Deshalb hatten bereits 1948 lediglich 39 Prozent der Soldaten und 1962 sogar weniger als 21 Prozent die beiden niedrigsten Dienstränge (Zahlen nach Schössler 1980: 128). Ähnliche Verhältnisse zeigen Angaben zur Verteilung von Offizieren, Unteroffizieren und Mannschaften bei der Bundeswehr für das Jahr 1973 aus. Beim Heer hatten 69 Prozent der Soldaten Mannschaftsränge, während es bei der Luftwaffe nur 55 Prozent waren. Da die Zahl der Offiziere in der Luftwaffe nur leicht höher war, lässt sich diese Differenz vor allem auf den Umfang des Unteroffizierskorps mit 32 Prozent zurückführen (ebd.: 131).

Die Ausdifferenzierung und Spezialisierung der Aufgaben betrifft sowohl die Soldaten, die unmittelbar in Kampfeinsätzen wirken sollen, als auch die Soldaten, deren Aufgabe darin besteht, jene darin zu unterstützen, da das Zusammenwirken der Soldaten im Kampf eine zeitintensive Ausbildung und wiederholte Übungen verlangt. Die Bedienung einer Handfeuerwaffe, beispielsweise eines automatischen Gewehrs, kann zwar innerhalb der Grundausbildungsphase erlernt werden, der kombinierte Einsatz verschiedener Waffen und infanteristische Einsatztaktiken aber schon nicht mehr. Deshalb verfügen Soldaten, die nicht für kampfbezogene Aufgaben vorgesehen sind, auch über keine Ausbildung für Kampfeinsätze.

16 Die Kategorie Hilfsdienste durch angelernte und ungelernte Kräfte ist in der Studie sehr unbestimmt definiert. Ein sehr großer Anteil dieser Soldaten wurde und wird vermutlich im Bereich Logistik eingesetzt. Auffallend viele Soldaten, 20,2 Prozent, wurden im 1. Weltkrieg der Rubrik »ungelernte Hilfskräfte (insbesondere Bedienungspersonal)« (Janowitz/Little 1965: 43) zugeordnet. Ihr Anteil betrug 1954 immerhin noch 8,4 Prozent. 
An dem Verhältnis zwischen kampfbezogenen und unterstützenden Funktionen der Soldaten hat sich seit den 50er Jahren grundsätzlich wenig geändert. Allerdings hat das seit den 90er Jahren betriebene Outsourcing, das besonders weit bei den amerikanischen und britischen Truppen vorangeschritten ist, möglicherweise dazu geführt, dass der Anteil der Soldaten, die unmittelbar kampfbezogene Aufgaben haben, wieder etwas gestiegen ist, da im Rahmen des Outsourcings vor allem die unterstützenden Tätigkeiten - im Bereich Logistik, von der Lieferung von Versorgungsgütern bis hin zur Anlieferung von Waffen, die Instandsetzung von Fahrzeugen und Waffen und ähnlichem mehr - von Privatfirmen übernommen werden. ${ }^{17}$

Eine weitere Folge der Industrialisierung und der Technisierung des Kriegsgeschehens drückt sich in der Klage von Offizieren über die Bürokratisierung ihres Dienstes aus. So schreibt Leistenschneider: »Im Oktober 1977 maßen die Vorschriften, Befehle, Erlasse und Weisungen, die eine selbstständige Kompanie der Bundeswehr bei der Erfüllung ihres Auftrages $\mathrm{zu}$ berücksichtigen hatte, nebeneinander aufgereiht 27,44 laufende Meter.« (Leistenschneider 2002: 5) Durch diese `Bibliothekı sei der Handlungsspielraum des Kompaniechefs, in diesem Falle einer selbstständigen Nachschubeinheit, stark eingeschränkt gewesen und für die Auftragstaktik bliebe kaum Raum. Vermutlich kann man über die Zweckmäßigkeit des einen oder anderen Meters dieser Regelungen streiten, zugleich kann man aber auch eine solche Kritik an bürokratischen Regeln als ein Indiz für den Verdacht werten, dass viele Bundeswehroffiziere in ihrem Berufsbild auf einen Kampftruppenoffizier fixiert sind, der den modernen Krieg als Industrie- und Logistikkrieg immer noch nicht verarbeitet hat (siehe Ulrich 1999: 16). Denn aus dem Blickfeld einer solchen Kritik gerät, dass auch Kompaniechefs einer komplexen Organisation angehören, die einen umfassenden Regelungsbedarf hat, um den Anforderungen des industrialisierten Kriegsgeschehens zu genügen. Nicht die Bewältigung der Kontingenz eines Militäreinsatzes durch eigene Entscheidungen und Handlungen stehen dabei im Mittelpunkt, sondern die Einhaltung von Routinen. Anders ausgedrückt: im tagtäglichen Dienst müssen auch Kompaniechefs Routineaufgaben erfüllen, bei denen sie sich nicht als gestaltendes Subjekt einer Situation erleben.

17 Auch das Bundesministerium für Verteidigung versucht insbesondere durch die Gründung eines privatwirtschaftlich organisierten Unternehmens das militärische Personal von »Nicht-Kernaufgaben« zu entlasten, indem so genannte Servicetätigkeiten von Privatunternehmen übernommen werden (vgl. Gesellschaft für Entwicklung, Beschaffung und Betrieb m.b.H.2007: 22). Durch die Kooperation der Bundeswehr mit Privatunternehmen sollen vor allem Kosten gespart und die Effektivität der Leistungen erhöht werden. In den Bereichen Logistik/Fuhrpark und Bekleidung ist bislang diese Kooperation am Weistesten gediehen. Zur Diskussion und Stand der Umsetzung siehe Richter (2007) und Gesellschaft für Entwicklung, Beschaffung und Betrieb m.b.H. (2007). 
Für die rangniedrigeren Soldaten bedeutet die Technisierung ihres Dienstes, dass zahlreiche Handlungen von keiner Amtsautorität strukturiert, sondern von der Funktionsweise der Technik bestimmt werden, die sie zu bedienen haben. Auf diese Entwicklung reagierten erstmals in den 60er Jahren verschiedene Autoren mit der These der Zivilisierung des Militärs. Gemeint ist damit in erster Linie eine Annäherung des militärischen Dienstes an zivile Arbeitsverhältnisse und Berufsbilder. Diese Annäherung, so die Diagnose, veränderte die Umgangsformen zwischen Vorgesetzten und Untergebenen. Verursacht werde diese Veränderung durch den Verlust von Sachautorität der Vorgesetzten, da diese nicht über das technische Fachwissen verfügen können, das ihre Untergebenen in den verschiedensten Spezialausbildungen erwerben. Ohne das notwendige Fachwissen reduzieren sich aber ihre Möglichkeiten, als Amtsautoritäten in die Arbeitsprozesse ihrer Untergebenen kompetent einzugreifen, und sie müssen bei ihren Entscheidungen deren Sachkenntnisse berücksichtigen. Die Vorgesetzten reglementieren deshalb nicht die Tätigkeiten ihrer Untergebenen in allen Details, sondern beschränken sich mehr auf die Ergebniskontrolle (siehe Mosen 1967: 47; und auch Janowitz/Little 1965: 62f.). Aufgrund dieses Vorgesetzten-Untergebenen-Verhältnisses verliert die Haltungsdisziplin, auf die noch in der ersten Ausbildungsphase der Soldaten viel Wert gelegt wird, im Dienstalltag an Gewicht, und die Umgangsformen zwischen den Soldaten gleichen sich in vielen Bereichen den gängigen Praktiken in der zivilen Arbeitswelt an, in der schon früher eine Abkehr vom >Prinzip Befehl und Gehorsam` erfolgte. Das Auseinandertreten von Sach- und Amtsautorität ist ein weiterer Grund dafür, die Qualität eines Vorgesetzten daran zu bestimmen, inwieweit es ihm gelingt, die von Seiten der Organisation gestellten Aufgaben zu bewältigen und gleichzeitig die (Arbeits-)Zufriedenheit seiner Untergebenen im Auge zu behalten.

Gegenüber weitergehenderen Erwartungen an die Zivilisierung des Militärs, wie sie beispielsweise Mosen formuliert, wenn er von »Trends zur Egalisierung und Demokratisierung in modernen Armeen« (1967: 53) spricht, zeigte sich bereits Janowitz skeptisch. Er geht von einem dauerhaften Spannungsverhältnis zwischen einem »modernen industriellen Führungsstil« (Janowitz/Litttle 1965: 64) und den Praktiken, die sich beim hierarchisch strukturierten Militär durchsetzen, aus. Die militärische Organisation weise besondere Merkmale auf, die dazu führen, dass der Führungsstil komplizierter als in der zivilen Arbeitswelt bleibe und sich dieser auch nicht vollständig annähert (ebd.: 66). Gemeint sind zum einen die von Soldaten geforderte Bereitschaft, im Kampf Leib und Leben zu riskieren, die von keiner zivilen Organisation erhoben wird, und zum anderen der Kontrollbedarf des Militärs, damit nur aufgrund von Befehlen Gebrauch von Waffen gemacht wird. So sehr sich deshalb das Prinzip >Befehl und Gehorsam` im Dienstalltag abschwächen mag, seine Gültigkeit wird nicht gänzlich aufgehoben, und Vorgesetzte können beispielsweise zur Bewälti- 
gung von Krisensituationen während eines Kampfeinsatzes ihre Amtsautorität herausstreichen. In ihren Berufsbildern müssen zwar vor allem hochrangige Offiziere die Vorstellung integrieren, dass sie als militärische Manager wirken, die das Maß und die jeweils erforderliche Gewaltausübung organisieren, und rangniedrige Offiziere, Unteroffiziere und Mannschaften kommen ohne ein Selbstverständnis als Techniker nicht aus. Aber ebenso wie ein Teil des Idealbilds eines Offiziers die Vorstellung bleibt, als strategischer Befehlshaber zu wirken, bleibt für alle Soldaten die mit einem Kriegseinsatz verbundene Gefahr konstitutiv für ihr Selbstverständnis und damit der Rückgriff auf »the heroic traditions of fighting men« (Janowitz 1960: 35). Der konkrete Umgang zwischen Vorgesetzten und Untergebenen, sowie das jeweils vorherrschende professionelle Selbstverständnis der Soldaten variiert zwischen den einzelnen Teilstreitkräften ${ }^{18}$ und auch zwischen den einzelnen Verbänden.

Für die Bundeswehr kann man feststellen, dass die mit ihrer Orientierung auf Auslandseinsätze zu Beginn der 90er Jahre einsetzende Neuausrichtung der Streitkräfte ein verändertes Berufsbild nach sich zog. Im Zentrum dieser Veränderungen steht eine Neubewertung der konventionellen Kriegführung und damit des Kampfes. Hatten sich nach dem bis Ende der 80er Jahre gültigen Credo die Bundeswehr-Soldaten auf den Kampf nur vorzubereiten, um ihn nicht führen zu müssen, so sollten sie nun den konventionellen Krieg üben, um ihn besser führen zu können. $\mathrm{Zu}$ den Konsequenzen dieser Veränderung gehört, dass das zuvor bestehende Verhältnis zwischen zivilem und militärischem Habitus unter Druck geraten ist und sich das professionelle Selbstverständnis der Soldaten verändert und auch, wie Äußerungen des amtierenden Heeresinspektors Hans-Otto Budde bei seiner Amtsübernahme 2004, zeigen, verändern soll. Er betont, dass der `Staatsbürger in Uniform`, der mit seiner Familie in unserer Nachbarschaft wohnte und um siebzehn Uhr dreißig nach Hause kam, ausgedient habe. "Wir brauchen den archaischen Kämpfer und den, der den HighTech-Krieg führen kann.« (Winkel 2004).

Aus dem vermehrten Einsatz von Technik bzw. verbesserten Technologien ergibt sich nicht eine weitere denkbare Zivilisierung des Krieges, dieses Mal im Sinne einer Normierung von Kampfhandlungen durch quasipolizeiliche oder humanitäre Regeln. Wie bereits im Zusammenhang mit der Industrialisierung des Kriegsgeschehens erörtert (siehe Abschnitt 7.2.), führt der Einsatz von Technik dazu, dass den Soldaten vor allem erst ein-

18 In der Bundesrepublik wird traditionell zwischen dem Heer, der Luftwaffe und der Marine unterschieden. Heute werden noch der Zentrale Sanitätsdienst und die Streitkräftebasis als weitere Untergliederungen genannt. In der Streitkräftebasis werden eine Reihe von Unterstützungs- und Dienstleistungen für die anderen Gliederungen zusammengefasst. Der militärischen Nachrichtendienst (MAD), die Militärpolizei (Feldjäger), diverse Transporteinheiten, etc. gehören ebenso dazu, wie die Big Band und das Militärgeschichtliche Forschungsamt (siehe http://www.streitkraeftebasis.de; Zugriff: 12.10.07). 
mal ein größeres Destruktionspotential zur Verfügung steht. Überwiegend handelt es sich dabei um Distanzwaffen. Gerade für die Soldaten, die die destruktivsten Waffen auslösen, gilt, - zu denken ist dabei an Soldaten, die Raketen starten, an Artilleristen und fliegendes Personal - dass sie eine große Distanz zu dem Ort haben, an dem die von ihnen ausgelösten Waffen ihre Wirkung entfalten. Mit der Distanz steigt auch die Wahrscheinlichkeit, dass für sie die Folgen ihres Handelns abstrakt bleiben. Die Leiden, die durch ihren Waffeneinsatz verursacht werden, müssen sie nicht sehen, und jene lösen deshalb nicht unbedingt Emotionen aus, die Einfluss auf ihre zukünftigen Handlungen haben. Eine verbesserte Waffentechnik kann zwar dazu führen, dass militärische Ziele präziser getroffen werden und die Gefahren für Zivilisten mindern, durch großflächige Bombardements getötet zu werden, aber ihr Einsatz hängt von Effektivitätskriterien $\mathrm{ab}$, und diese müssen sich nicht an einer Einhegung des Kriegsgeschehens orientieren. Es hängt letztlich vom politischen Willen und nicht von der Technik ab, ob es zur Einhegung des Krieges im Sinne einer ethischen Normierung des Kampfverhaltens kommt (siehe hierzu Heins/Warburg 2004: 70f.).

Um (Waffen-)Technik effektiv im Gefecht einsetzen zu können, müssen die Soldaten an ihr ausgebildet werden. In der Ausbildung werden den Soldaten nicht nur notwendige Kenntnisse über die Funktionsweise der Geräte und Maschinen vermittelt, sie müssen auch Handlungsroutinen erlernen, und dazu gehört, dass sie ihren Körper an den Umgang mit der Technik gewöhnen. Um die Artefakte möglichst effektiv zu handhaben, müssen die Soldaten ihre sensorischen Fähigkeiten und ihre motorischen Bewegungsabläufe an die von den Konstrukteuren geschaffenen Parameter anpassen. Übungen und anhaltendes Training dienen diesem Ziel. Am sichtbarsten zeigen sich die Folgen des Trainings an der Muskulatur der Soldaten, wenn der Umgang mit den Artefakten große physische Belastungen mit sich bringt. Die Soldaten müssen sich aber auch bestimmte Haltungen ihrer Körper beim Umgang mit den Artefakten angewöhnen und fähig sein, mit den Begleiterscheinungen, die bei ihrer Verwendung auftreten, umzugehen. Um beispielsweise eine Handfeuerwaffe effektiv einzusetzen, kann es notwendig sein, dass ein Soldat die Waffe so in die Hand nimmt, dass er durch das Visier das Ziel sehen kann. Sein Körper muss obendrein auf die akustischen, optischen und mechanischen Effekte (Mündungsknall und -feuer, Rückschlag), die bei der Auslösung des Schusses entstehen, konditioniert sein, um die Waffe nach dem ersten Schuss weiterhin kontrolliert verwenden zu können. Nur wenn es dem Soldaten gelingt, seine Motorik und Sensorik den Erfordernissen der Waffennutzung anzupassen bzw. sich auf sie einzustellen, nur wenn er versteht, seinen Körper wie ein Instrument einzusetzen und dieser gleichsam zum Teil der Waffe wird, kann der Soldat die Waffe optimal als ein von ihm kontrolliertes Instrument verwenden. Die Waffe lässt sich freilich nur im Rahmen eines 
situativ beschränkten Kontextes quasi als ein Körperteil des Soldaten bezeichnen. Sie wird zu keinem Zeitpunkt Teil seines Leibes; sie bleibt materiell von ihm getrennt. Dies zeigt sich nicht zuletzt an einer Eigenschaft der Waffe: Im Gegensatz zum Körper, der vom Subjekt nicht ausgetauscht werden kann, kann der Soldat die Waffe loslassen, sie ablegen und sei es auch nur, um sie gegen eine andere Waffe auszutauschen. Die Differenz zwischen Leib und Technik gilt auch für andere Artefakte, mit denen Soldaten für das Gefecht ausgerüstet werden.

Eine Konsequenz aus diesem Verhältnis von Artefakt und Subjekt ist, dass die Technik nur dann optimal von den Soldaten genutzt werden kann, wenn die Konstrukteure neben den Fähigkeiten auch die Grenzen des Leibes berücksichtigen, die durch kein noch so umfassendes Training überwunden werden können. Das ist grundsätzlich nichts Neues, musste doch bereits ein Schmied bei der Herstellung des Griffes einer Waffe die Physiognomie der Hand beachten, dafür sorgen, dass die Waffe für denjenigen, der mit ihr kämpfen soll, nicht zu schwer war und ähnliches mehr. Als neu kann jedoch die mit dem 20. Jahrhundert einsetzende intensive wissenschaftliche Auslotung der leiblichen Fähigkeiten und Grenzen durch die Physiologie, Psychologie und andere Disziplinen bewertet werden. Neu ist zugleich, in welchem Ausmaß Menschen Geräte, Apparate und Maschinen nutzen, in welchem Ausmaß technische Artefakte in ihrem Alltag präsent sind. Und nicht zuletzt für Soldaten gilt, dass sie sich im Zuge ihres Einsatzes vermehrt in Räumen aufhalten müssen, die selber ein Teil einer Maschine sind, um diese Maschine zu steuern, Instrumente abzulesen, Einstellungen vorzunehmen oder Apparate zu bedienen. In einigen dieser Räume können die Soldaten nur leben, wenn die sie umgebende Technik spezifische Lebensbedingungen erzeugt, weil die Umwelt außerhalb dieser Räume, beispielsweise im Falle eines 10.000 Meter über den Meeresspiegel fliegenden Flugzeuges, für sie zu kalt ist und zu wenig Sauerstoff enthält. Der Einsatz von Technik sorgt in diesem Fall für die Aufrechterhaltung von lebensnotwendigen Bedingungen. Damit dies gelingt, müssen die Ingenieure in die Konstruktion dieser Artefakte umfangreiche Erkenntnisse über den menschlichen Leib einfließen lassen. Auch um die Steuerung der Maschinen zu verbessern, die sensorischen Fähigkeiten der Soldaten bei der Erfassung von Informationen möglichst optimal zu nutzen etc. muss Technik auf die Eigenschaften des menschlichen Leibes zugeschnitten, muss versucht werden, die Probleme, die sich aus der materiellen Differenz von Organischem und Technologischem ergeben, zu minimieren. Diese Bemühungen zielen aber nicht nur darauf ab, die leibgebundenen Fähigkeiten des Leibes zu nutzen und auszuschöpfen. Sie werden auch mit der Vorstellung verbunden, dass die quasi auf den Leib hin konstruierte Technik den Leib selber verändert, er quasi technologisch >aufgerüstet` wird. Dies gilt besonders für solche Technologien, die unmittelbaren Kontakt mit dem Leib haben und die, nach Auffassung einiger 
Autoren, ein Hybridwesen aus organischen und technologischen Bestandteilen entstehen lassen, das spätestens seit den 90er Jahren als Cyborg bezeichnet wird (siehe Spreen 2004). Hier deutet sich zumindest eine Veränderung des Verhältnisses von Technologie und Leib ab, auf die im Folgenden näher eingegangen werden soll. Von dieser Entwicklung lassen sich technologische Innovationen unterscheiden, die nicht die Kompatibilität technischer Systeme mit dem Leib erhöhen sollen, sondern deren Ziel die Übertragung von bislang leibgebundenen Fähigkeiten auf technische Systeme ist. Da hiermit möglicherweise ebenfalls ein verändertes Verhältnis von soldatischer Subjektivität und Technik verbunden ist, werden die nachstehenden Ausführungen auch auf dieses Thema eingehen, vor allem im Hinblick auf die Stellung, die der Einsatz von Robotern in der Kriegführung hat bzw. voraussichtlich haben wird. Anschließend soll auf die Bemühungen zur so genannten Transformation der Streitkräfte eingegangen werden, die von den US-Streitkräften ausgehend unter anderen auch die Bundeswehr sich zu Eigen gemacht hat. Erklärtes Ziel der unter dem Label Transformation zusammengefassten Maßnahmen ist der Umbau der Streitkräfte hin auf die Kriege des 21. Jahrhunderts. Die Darstellung wird sich vor allem auf die Network Centric Warfare (NCW) oder wie eine ähnliche Konzeption bei der Bundeswehr heißt, auf die Vernetzte Operationsführung (NetOpFü) konzentrieren und den Veränderungen bei der Infanterie, die im Rahmen der aktuell diskutierten Konzepte eine Aufwertung erfahren hat, besondere Aufmerksamkeit widmen.

\subsubsection{Cyborgs}

Ein paar Jahre, nachdem Anders in den 50er Jahren feststellte, dass vor dem Hintergrund des wachsenden Leistungsvermögens und des Entwicklungspotentials technischer Artefakte der nichtkonstruierte Mensch als "Schlechtkonstruiertes" umgedeutet werde und der Leib der Raketenbauer sich so gut wie gar nicht von dem des Schimpansen unterscheide (Bd. 1, 1956: 32f.), entwickelten der unter anderem im Bereich Neurophysiologie tätige Forscher Clynes zusammen mit dem Psychiater Kline im Auftrag der NASA das Konzept des Cyborgs. Sie schlugen vor, sich nicht allein darauf zu konzentrieren, Räume zu schaffen, die den Raumfahrern ein Leben im Weltall ermöglichen, sondern diese sollten selber künstlich, das heißt durch Implantierung von Technik, den Bedingungen des Alls angepasst werden. Die technischen Implantate sollten in das biologische System vollständig integriert und durch ein neues sich selbst regulierendes Gesamtsystem, einen cybernetic organism, kurz einen cyborg, geschaffen werden. Die auf diese Weise entstandenen Wesen sollten besser in der Lage sein, unter den Bedingungen jenseits der irdischen Atmosphäre zu leben als Menschen, die durch die Evolution auf der Erde entstanden sind (siehe Clynes/Kline 1960; sowie Spreen 2004: 338f.). Das Konzept wurde von 
der NASA nicht aufgegriffen, - in den 60er Jahren sollte der erste Mensch auf dem Mond ein US-Amerikaner sein, kein Cyborg - und fand auch keinen Eingang in die (natur-)wissenschaftliche Terminologie, die andere Begriffe wie Biotelemetrik, Mensch-Maschine-System, Teleoperator und im englischen Sprachraum bionic den Vorzug gaben (Gray 2001: 35). Der Begriff wurde jedoch in der Science-Fiction-Literatur aufgegriffen, um in den 80er Jahren dann in der sozialwissenschaftlichen Literatur, zuerst in der Auseinandersetzung mit dieser Literatur, aber dann auch als diagnostischer Begriff für die Gegenwart verwendet zu werden (Haraway 1985; Gray 1996: 195f.).

Trotz der Abstinenz zum Begriff Cyborg lassen sich aber vor allem im Rahmen von Forschungsvorhaben mit militärischer Ausrichtung bereits für die 60er und 70er Jahre Beispiele finden, die sich konzeptuell als Umsetzungsprogramme einer Cyborgisierung des soldatischen Leibes interpretieren lassen. So berichtet Watson für die 70er Jahre von einem Vorhaben, das darauf abzielte, die Gehirne von Piloten mit den Waffen und der Flugsteuerung zu verbinden. Sobald der Pilot seinen Helm aufsetzt, sollten sich winzige Nadeln durch seine Kopfhaut bohren. Auf diese Weise sollte zwischen dem Gehirn und dem Bord-Computer des Flugzeuges eine Verbindung hergestellt werden und der Computer sollte die Gedanken des Piloten erkennen und ausführen können, so dass dieser nur an einen Ausführungsbefehl, wie den Abschuss einer Rakete, denken müsse. In den 60er Jahren habe die US-Marine an einem mechanischen Anzug gearbeitet, der wie ein Außenskelett wirken und die Muskelkraft des Soldaten um das 25 fache steigern sollte (ebd.: 103). Wenn auch diese Vorhaben nicht auf eine dauerhafte Implantierung von Technik in die Leiber der Soldaten abzielten, so lassen sie sich doch als Umsetzungsversuche einer angestrebten Symbiose von Mensch und Maschine lesen, - konkret wurde darunter eine direkte Interaktion zwischen Computer/Technik und Gehirn verstanden die Anfang der 60er Jahre einer Studie der Rand Corporation zufolge mit hoher Wahrscheinlichkeit um das Jahr 2020 vollzogen sein wird (Gordon/Helmer 1964: 38). Die Ergebnisse dieser Forschungsbemühungen aus den 60er und 70er Jahre haben jedoch vor allem eines klar gemacht: Die unmittelbare Verbindung von Gehirn, aber auch von Muskulatur mit Technik ist weit schwieriger, als man sich dies in den 60er Jahren vorgestellt hatte. Bis heute ist eine Flugzeugsteuerung durch einen »Gehirnstromcomputer« unmöglich, weil beispielsweise die Kenntnisse über die Funktionsweise des menschlichen Gehirns zu gering sind. An der Stärkung der Muskelkraft durch die Aufrüstung des Leibes mit Technik wurde und wird bis heute gearbeitet. Aus den 90er Jahren liegen Berichte über ein Projekt vor, das darauf abzielte, den Körper von Infanteristen mit einem Körperpanzer zu umhüllen, der den Insassen von den Umweltbedingungen auf dem Gefechtsfeld abschotten und ihm zugleich große Kräfte verleihen sollte (Helms 1996: 142f.). Dieses Projekt ist vor einigen Jahren eingestellt 
worden. Die Vorstellung, die Muskelkraft von Infanteristen zu potenzieren, taucht gegenwärtig in Verbindung mit dem Rüstungs-Programm »Future Combat Systems« auf. Im Rahmen eines Teilprojektes, das die Uniform der Infanteristen betrifft, wird unter anderen angestrebt, dass diese quasi eine Muskulatur bilden kann. Nicht durch eine mechanische Konstruktion, sondern durch Nanotechnologie soll nun dieses Ziel erreicht werden. Eine schnelle Realisierung wird dieses Mal nicht erwartet, denn erst in einigen Jahren soll die Technologie zur Verfügung stehen - nicht vor 2020. ${ }^{19}$ Aber auch diese Terminierung muss nicht bedeuten, dass es bis dahin erreicht wird, zumal nach Auffassung des derzeitigen Leiters der Abteilung Technologieanalysen und -vorschau am Frauenhofer Institut, Kretschmer, völlig »neuartige auf Nanotechnologie basierende Waffensysteme oder Wirkprinzipien [...] nicht in Sicht« sind (Grüne/Kretschmer 2005: 15).

Auch zahlreiche Versuche, insbesondere die visuellen Sinne der Soldaten eng mit technischen Ressourcen $\mathrm{zu}$ verbinden, sind in den vergangenen Jahrzehnten in ihrer Mehrzahl gescheitert. Eine gewisse Ausnahme bildet die Ausstattung der Kampfverbände mit Nachtsichtgeräten. Nachdem anfangs nur die Besatzungen von Flugzeugen und Hubschraubern mit solchen Geräten ausgestattet wurden, gehört inzwischen das Nachtsichtgerät zum Equipment von Infanteristen im Kampfeinsatz. Mit diesen Geräten können die Soldaten, ob im Dämmerlicht oder im Dunkeln, entscheidend besser sehen und mitunter machen sie überhaupt erst eine Bilderkennung möglich. ${ }^{20}$ Auf bislang kaum zu überwindende Schwierigkeiten sind dagegen bislang die Bemühungen gestoßen, die Soldaten mit so genannten Datenbrillen auszurüsten. Die Brillen sollen zu einer Bilderkennung fähig sein, die ihre Anwender mit den jeweils adäquaten Informationen zu dem aufgefassten Bild versorgen. Neben dem auch vom Auge erfassbaren Bild sollen die Anwender also noch zusätzlich Daten sehen, die sie befähigen sollen, ihre Tätigkeit effizienter zu gestalten. Bislang funktionieren solche Vorrichtungen lediglich bei Piloten von Flugzeugen und Hubschraubern und im Rahmen von Simulationen. Bei allen anderen Tätigkeiten kommen die bestehenden Hürden, die mit dieser Technologie

19 Wie Nanotechnologie militärisch genutzt werden soll, wird ausführlich in Kretschmer (2006) dargelegt. Für die Nutzung der Nanotechnologie hat die US-Armee 2002 eine eigenständige Forschungsabteilung am MIT gegründet, das Institute for Soldier Nanotechnologies (http://web.mit.edu/isn/index.html; Zugriff: 10.10.07).

20 Technisch lässt sich zwischen Restlichtverstärkern, die das vorhandene Licht elektronisch verstärken und Geräten unterscheiden, die das für das menschliche Auge unsichtbare Infrarotlicht empfangen können und für das menschliche Auge sichtbar machen. Dazu wird entweder aktiv die Umgebung durch eine Infrarotlampe ausgeleuchtet oder das Gerät nutzt passiv das von Wärmequellen ausgehende Licht, um ein Bild zu erzeugen. Häufig sind beide Arten der Bilderkennung in einem Gerät kombiniert. 
verbunden sind, zum Tragen. Ein Grund ist, dass die Brillen sehr viel Strom verbrauchen, und deshalb selbst schwere Batterien nach kurzer Zeit entladen sind. Auch lässt sich die Performanz der Bilderkennung jenseits eines Cockpits, in dem sich die Besatzungen nur wenig und dadurch in einem reduzierten Raum bewegen können, kaum aufrechterhalten. Die Anwendung von Datenbrillen scheitert vor allem »beim Zusammenspiel der künstlichen mit den menschlichen Sinnen. So klagten Boing-Mitarbeiter, die mit halb durchsichtigen Brillen an dicken Kabelbäumen im Flugzeugrumpf hantieren sollten, über Schwindelgefühle. Es zeigte sich, dass die hoch modernen mobilen Computer gegenüber dem menschlichen Wahrnehmungsapparat um den Bruchteil einer hundertstel Sekunde zu langsam waren.« (Asendorpf 2002: 29) Der Versuch, dem Auge ausschließlich nur technisch aufbereitete Bilder zur Verfügung zu stellen, führt wiederum zu einem Schwindelgefühl, denn »nun stimmt der Sehsinn nicht mehr mit den Informationen des Gleichgewichtssinns überein.« (Ebd.)

Man muss feststellen, dass die äußere Aufrüstung des soldatischen Leibes in weit geringerem Umfang sich vollzogen hat, als dies in den vergangenen Jahrzehnten immer wieder erwartet wurde. Im Bezug auf die Implantierung von Technik in den Leib lässt sich diese Feststellung sogar noch deutlicher formulieren. Die Implantierung von Technik, die nach der ersten und engeren Definition aus dem Menschen einen Cyborg macht, hat bislang in keinem Fall zu einer Leistungssteigerung geführt. Es gibt zwar heute Technologien, die unter die Haut gehen, »wobei es sich um >HighTech ' handelt, die gezielt zu diesem Zweck konstruiert worden ist « (Spreen 2004: 342), und diese Menschen können qua Definition als Cyborgs aufgefasst werden, doch ein neue evolutionäre Stufe markieren diese Implantierungen nicht. Die Implantierungen passen die Leiber nicht an eine ansonsten lebensgefährliche Umwelt an, auch verfügen die Subjekte anschließend nicht über zuvor unbekannte Fähigkeiten und über ein außerordentliches Leistungsvermögen, die ihnen leiblich neue Ebenen der Welt erschließen. Bei den implantierten Technologien handelt es sich um Prothesen, wie im Falle des Innenohrimplantats (Cochleaimplant), oder um Steuerungsgeräte, die Organe, hormonelle Prozesse etc. im Leib stimulieren. Beides soll jeweils spezifische Defizite des Leibes, beispielsweise aufgrund einer Erkrankung, kompensieren.

Nicht unerwähnt soll hier eine Konsequenz für die einzelnen Subjekte bleiben: Durch das >Auch-Technologie-Sein « resultiert eine »Anbindung an außerkörperlichen Institutionen qua Leib-Sein. Wie andere Technologien auch, müssen Körpertechnologien gewartet, repariert, novelliert und eventuell extern mit Energie versorgt werden.« (Spreen 2004: 342) Durch ihren Bio-Technik-Körper sind menschliche Cyborgs auf leiblicher Ebene systematisch auf verschiedene Organisationen und Institutionen und bestimmte technische Standards angewiesen. Diese Konsequenz erweitert aber nur das bereits zuvor bestehende Verhältnis von Mensch und Technik. 
Denn schon zuvor waren die menschlichen Individuen als »konstitutiv heimatlos(e)« Wesen (Plessner 1928: 310) darauf angewiesen, in Verhältnissen >natürlicher Künstlichkeit` zu leben. Es ist die Technik und die Kultur, die die sozialen Räume >natürlicher Künstlichkeit`schaffen (ebd.: 311).

So bedeutsam die Innovationen bei den Implantaten, die man mit Spreen auch als Cyborgtechnologien bezeichnen kann, so gravierend die Fortschritte bei der äußeren >Aufrüstung ‘ des soldatischen Leibes sind, das bisherige Scheitern vieler Projekte, die auf eine weitaus engere leibliche Mensch-Maschinen-Symbiose abzielten und eine unmittelbare Leistungssteigerung des Leibes durch den Einsatz von Technik anstrebten, ist letztlich auf folgende Gründe zurückzuführen: Die Differenzen zwischen Organischem und Technologischem wurden und werden grob unterschätzt. Die vorhandenen Kenntnisse über die komplexen Wirkungszusammenhänge biologischer Prozesses sind für die angestrebte technische Aufrüstung des Leibes meist unzureichend, und dies führt eher zu gering veranschlagten Anforderungen an die Technik, um die >Schnittstellenprobleme $<\mathrm{zu}$ überwinden. Obendrein werden häufig die Entwicklungspotentiale vorhandener Technologien überschätzt.

Dessen ungeachtet ist mit Blick auf Forschungsvorhaben, die beispielsweise im Zusammenhang mit den weitgreifenden Zielen der zukünftigen infanteristischen Ausrüstung des US-Verteidigungsministeriums stehen, festzuhalten, dass die Soldaten weiterhin mit neuen quasileiblichen Fähigkeiten ausgestattet werden sollen. Die zahlreichen gescheiterten Projekte sind offenkundig angesichts der noch so geringen Möglichkeit, dass das jeweilige Projekt doch zu einer eklatanten Kampfkraftsteigerung der einzelnen Soldaten beitragen kann, keine schwerwiegendes Argument. Es besteht jedoch kein sozialwissenschaftlicher Grund, aus den Vorhaben oder den euphorischen Verlautbarungen von Projektleitern, die letztlich dem Ziel dienen, die Finanzierung ihrer Arbeit sicherzustellen, den zwingenden Schluss zu ziehen, dass diese Ziele auch in einem Zeitraum von mehr als 10 Jahren realisierbar sind.

\subsubsection{Von Robotern, unbemannten Vehikeln und Agenten}

Bis vor einigen Jahren sollten Maschinen grundsätzlich nur zwischen zwei Zuständen oszillieren - zwischen Leerlauf und berechneten Verlauf. Eine "Art Selbstlauf in dem Sinne, dass die Bewegung selbst aufgenommen wird und die Bewegungsrichtung selbst bestimmt wird, war nicht vorgesehen; ja, diese Eigenläufigkeit galt eher als Fehler und Versagen der Technik.« (Rammert/Schulz-Schaeffer 2002: 14) Mit dieser Entwicklung scheint die Vorstellung, dass Menschen Artefakte herstellen können, die als lebendige Wesen aufgefasst werden und womöglich sogar menschenähnlich handeln, zumindest etwas näher ihrer Realisierung gerückt zu sein. 
Bereits die Zeitgenossen des 18. Jahrhunderts zeigten sich von Maschinen fasziniert, die zumindest dem Beobachter den Eindruck vermittelten, sie würden sich selbstständig bewegen. Auf dieser Fiktion - denn tatsächlich wiederholten sie stets die gleiche Bewegungsfolge und ihnen fehlte die Fähigkeit, auf Reize aus ihrer Umwelt zu reagieren - beruhte der Eindruck, diese Maschinen wären lebendig. Ein Beispiel für eine solche Maschine ist die mechanische Ente von Jacques de Vaucanson (1709-1782). Bis in das 20. Jahrhundert hinein wurden solche Maschinen überwiegend als Automaten bezeichnet. Heute wird allgemein die Bezeichnung Roboter bevorzugt. Sie wiederum lässt sich auf das tschechische Wort robota zurückführen, das aber auch in vielen slawischen Sprachen zu finden ist, und das für Fronarbeit bzw. Zwangsdienst steht. Robota steht obendrein für schwere, körperlich belastende Arbeiten, da solche Tätigkeiten die zur Fronarbeit Verpflichteten zumeist verrichten mussten. Beide Bedeutungsdimensionen - ein rigides Herrschaftsverhältnis und schwere Arbeiten verrichten - sind dem Begriff eingeschrieben. ${ }^{21}$ Technisch betrachtet sind Roboter, folgt man der Definition von Christaller,

»sensumotorische Maschinen zur Erweiterung der menschlichen Handlungsfähigkeit. Sie bestehen aus mechatronischen Komponenten, Sensoren und rechnerbasierten Kontroll- und Steuerungsfunktionen. Die Komplexität eines Roboters unterscheidet sich deutlich von anderen Maschinen durch die größere Anzahl von Freiheitsgraden bei den Bewegungsmöglichkeiten und die Vielfalt und den Umfang seiner Verhaltensformen.«(2001: 5)

Von den Freiheitsgraden und der Komplexität der Umwelt, in der sich die Maschine bewegen soll, hängt es ab, ob und inwieweit sie zur Selbststeuerung fähig ist.

Eine der ersten Maschinen, die ein paar der oben genannten technischen Eigenschaften von Robotern aufwies und die damit nach Shaker und Wise am Beginn der Evolution von militärischen Robotersystemen steht (1988: 13f.), war ein Flugzeug, das nach ihrem Konstrukteur Kettering Bug genannt wurde. Es handelte sich um eine fliegende Bombe, die über zwei Sensoren gesteuert wurde (Höhenmesser und Gyroskop). Im März 1918 wurde im Auftrag der US-Streitkräfte erstmals erfolgreich ein Kette-

21 Den Begriff Roboter hat Karel Capek (1890-1938) mit seinem Theaterstück R.U.R. (Rossums Universal Robots, 1920 erschienen) geprägt. Im Mittelpunkt der Handlung steht, wie auch in vielen später verfassten Werken des Genres, dass sich die Roboter durch eine ihnen neu verliehene Fähigkeit auf eine nicht vorhergesehene Weise grundlegend verändern. Nachdem sie mit der Fähigkeit ausgestattet wurden, Emotionen zu empfinden, ertragen sie nicht länger die erniedrigende Behandlung durch die Menschen, sie lehnen sich gegen ihre Erbauer auf und vernichten die Menschheit. Zur Etymologie des Wortes Roboter siehe auch Duden `Etymologie`, hrsg. von Drosdowsi (1989). 
ring Bug gestartet (ebd.: 22). Nach dem Start hatten die Konstrukteure keine Kontrolle über das Flugzeug. Es nahm aufgrund der vor dem Start vorgenommenen Einstellungen (Flughöhe und -richtung) seinen Flug auf. »Once the estimated distance for the target was reached, the engine was stopped, and a mechanical device removed the bolts holding the wings in place. The fuselage und explosive would then drop on the target.« (Ebd.) Eine Schwachstelle dieses Konzeptes bestand darin, dass im Grund nur zwei Einstellungen vorgenommen werden konnten, die es obendrein nur erlaubten, ein großflächiges Ziel zu attackieren. Trotzdem beeindruckten die 4 von 14 durchgeführten erfolgreichen Versuche das US-Militär. Es finanzierte auch nach Kriegsende Arbeiten zur Entwicklung unbemannter Flugzeuge (ebd.: 24). Eine weitere Schwachstelle war, dass man nach dem Start vollständig die Kontrolle über die Maschine verlor. Dieser Schwäche konnte nur entgegengewirkt werden, wenn die Maschine mit einem Operator verbunden blieb, zumal es zu dieser Zeit nicht möglich war, viele Sensoren für Regelungs- und Steuerungsprozesse per Computer miteinander zu verknüpfen. Die Funk- bzw. Kabelverbindungen boten ferner den Vorteil, dass ein Operator vor allem aufgrund seiner visuellen Beobachtungen der Maschine - beispielsweise der Differenz zwischen ihrem Ziel und ihrer Position - zumindest hoffen konnte, dem Fahrzeug oder Flugzeug geeignete Steuerungsbefehle zu übermitteln, damit die Maschine präziser ihr Ziel erreichte.

$\mathrm{Ob}$ Maschinen, die durch ein Kabel oder Funk ferngesteuert werden, als Roboter bezeichnet werden dürfen, ist umstritten. Folgt man jedoch dem Definitionsvorschlag von Christaller, ist die Verwendung des Begriffs Roboters nicht abhängig von der Möglichkeit eines Operators, auf die Funktionen und Funktionsweisen der Maschine Einfluss zu nehmen, sondern wie umfassend die Maschine von den Steuerungskommandos eines Operators abhängig ist bzw. wie groß ihr Anteil der Selbststeuerung bleibt. Solche Fragen lassen sich nur mit Blick auf die jeweilige Maschine beantworten. Bei einigen Maschinen, die Shaker und Wise im Rahmen ihrer Evolution von militärischen Robotersystemen besprechen, lässt sich feststellen, dass die Maschinen ohne die Fernsteuerung nicht funktionierten und die vorhandenen Regelungsprozesse zur Selbststeuerung allenfalls ihren Leerlauf aufrechterhielten. ${ }^{22}$ Solche Maschinen sind der Definition Christallers nach heute kaum noch als Roboter zu bezeichnen. Aufgrund der Betonung der größeren Anzahl von Freiheitsgraden im Verhältnis zu anderen Maschinen bei den Bewegungsmöglichkeiten und der Vielfalt und dem Umfang der >Verhaltensformen` können aber auch Maschinen, die nach ihrem Start nicht von einem Operator beeinflussbar sind, umstandslos

22 Dies gilt zum Beispiel für den von der Wehrmacht während des 2. Weltkrieges eingesetzten Kleinstpanzer Goliath, der durch Funk oder Kabel gesteuert wurde (Shaker/Wise 1988 16f.). Er trug eine Sprengladung und sollte unter anderen in befestigten Stellungen des Gegners detonieren. 
als Roboter eingestuft werden. So würde heute kaum noch jemand im Hinblick auf den Kettering Bug von einem Roboter sprechen, dessen Flug vor dem Start nur durch ein paar Parameter beeinflusst werden konnte. Erst wenn eine solche Maschine über die Fähigkeit verfügt, unabhängig von einem Operator unter mehreren Zieloptionen auszuwählen, würde man von einem Roboter sprechen. Im Rahmen der von Shaker und Wise ausgemachten Evolution militärischer Robotersysteme war zwar die Idee wichtig, Roboter herzustellen, tatsächlich entwickelt wurden aber überwiegend auf Operatoren angewiesene Maschinen - unbemannte Vehikel. Einige dieser Maschinen weisen jedoch tatsächlich - vor allem in jüngster Zeit - unbestritten auch Eigenschaften auf, die sie nach der oben ausgeführten Definition zu Robotern machen.

Sowohl vor dem 2. Weltkrieg als auch während des Krieges finanzierten verschiedene Streitkräfte Projekte, deren Ziel die Entwicklung unbemannter Waffensysteme war. Um die Ausgaben für diese Projekte zu begründen, wurden bereits damals Argumente verwendet, die bis heute aktuell geblieben sind (siehe u.a. Lange 2003: 12f.).

- Ein immer wieder genanntes Argument ist die Aussicht, dass die Herstellungskosten unbemannter ungleich geringer seien als die bemannter Vehikel. Dies leuchtet heute insbesondere beim Bau von modernen Flugzeugen ein, da sie keine teuren Lebenserhaltungssysteme für das Bordpersonal enthalten müssen. Als kostengünstig herstellbare Waffen konnte und kann ihre Zerstörung am Ende ihres Einsatzes stehen, weil sie quasi wie eine Granate oder Bombe auf ihr Ziel einschlagen und detonieren sollen.

- Ob sie der Aufklärung dienen oder ob sie als Waffe oder Waffenträger konzipiert wurden bzw. werden, als billiges und damit leicht ersetzbares Vehikel sollen Roboter zum zweiten Einsatzformen ermöglichen, die mit bemannten Fahrzeugen eher vermieden werden. Gemeint sind Einsätze, die mit einem sehr hohen Risiko für eine Besatzung verbunden wären, höchstwahrscheinlich zu ihrem Tod führen würden. $\mathrm{Zu}$ denken ist hierbei beispielsweise an den Einsatz von Drohnen, die in den gegnerischen Luftraum eindringen sollen. Durch die Aktivitäten des Gegners, die wahrscheinlich zum Verlust der Maschine führt, lassen sich, so die Hoffnung, die gegnerischen Luftabwehrstellungen feststellen. Dieses Argument weist auf ein weiteres Motiv für den Einsatz von unbemannten Vehikeln hin: die Schonung der Personalressourcen. Das Interesse, möglichst wenig Soldaten einzusetzen und im Verlauf eines Einsatzes zu verlieren, kann seinerseits in verschiedenen Argumentationsfiguren auftreten. Noch unter den Vorzeichen des Kalten Krieges verfasst, forderte in den 80er Jahren das Konzept AirLand Battle 2000 (das beanspruchte, die Ausrichtung der US- und der NATO-Landstreitkräfte in den kommenden 20 Jahre, zu prägen) unter anderem eine »umfangreiche Verwendung von Robotern« (U.S. Army: 
D30), weil der »wehrfähige Anteil der Bevölkerung« (D28) abnehme. Zwar gelte dies auch für die Sowjetunion, aber nicht für die aufstrebenden Dritte Welt-Staaten, die von der UdSSR mit modernen Waffen versorgt würden (ebd.). Seit Beginn der 90er Jahre wird zwar kein Krieg erwartet, der eine umfassende Mobilisierung der eigenen Bevölkerung in den westlichen Industriestaaten erfordert, doch spätestens seit der gescheiterten UN-Intervention in Somalia (1992-1994) gilt die Bevölkerung als unwillig, hohe Verluste bei Auslandseinsätzen hinzunehmen (siehe Mann 2000: 47f.). Durch den Einsatz von Robotern und unbemannten Vehikeln sollen folglich die politischen Opportunitätskosten eines Militäreinsatzes möglichst gering gehalten werden.

- Verluste in den eigenen Reihen können nur dann vermieden werden, wenn sich ein weiteres Argument der Befürworter solcher Projekte als stichhaltig erweist: Sie verweisen darauf, dass unbemannte Vehikel als High-End-Rüstungsgüter zu betrachten sind und die Auftraggeber deshalb einen Vorteil gegenüber Gegnern erringen, die nicht über Gleichwertiges verfügen. Die Vorteile des >prometheischen Gefälles` (Anders), so die Hoffnung, stehen demnach nur den avanciertesten Militärmächten zur Verfügung. Durch die Entwicklung immer leistungsfähigerer unbemannter Vehikel und Roboter gelte es diesen Vorteil zu erhalten bzw. auszubauen.

Die allermeisten vor und während des 2. Weltkrieges in Auftrag gegebenen Projekte sollten nicht die Erwartungen ihrer Auftraggeber erfüllen. So konnten die britischen Luftstreitkräfte lediglich funkgesteuerte Flugzeuge bei der Ausbildung von Flak-Kanonieren einsetzen, die Luftziele hinter sich herzogen (Shaker/Wise 1988: 25). Eher den Erwartungen der Auftraggeber entsprach ein deutsches Rüstungsprojekt, das an das oben dargestellte Prinzip des Kettering Bugs anschloss. Neben einer verbesserten Eigensteuerung, es verfügte über eine Kreiselkurssteuerung und einen Sensor für die zurückgelegte Strecke, konnte diese fliegende Bombe durch die Entwicklung einer neuartigen Antriebsform großflächige Ziele weit hinter den eigenen Frontlinien angreifen. Bekannt wurde diese Waffe unter der Bezeichnung V 1. Mehrere tausend Drohnen flogen vor allem London und Antwerpen an und sollten dort für Angst und Schrecken sorgen. Mehrere tausend Menschen starben bei diesen Angriffen. Heute gilt diese Waffe als Vorläufer der Marschflugkörper (Cruise Missiles), die ihr Ziel im Tiefflug anfliegen und deshalb vom gegnerischen Radar schwer zu entdecken sind.

Nach dem 2. Weltkrieg machte die Entwicklung von unbemannten Vehikeln für die Bewegung durch die Luft und im Wasser deutliche Fortschritte, und es kamen einige Maschinen bei den Streitkräften zum Einsatz. Die bei Shaker und Wise dokumentierten Landfahrzeuge der 80er 
Jahren verließen dagegen nie die Entwicklungslabors (1988: 47f.). Diese Differenz zwischen unbemannten Luft- und Wasservehikeln auf der einen Seite und Landfahrzeugen auf der anderen Seite verweist auf die Komplexität des Raumes, in dem sich unbemannte Landfahrzeuge bewegen sollen. Sie müssen sich in einem Raum bewegen, der von ihnen verschiedene Bewegungsarten bzw. eine komplexe Apparatur verlangt, damit die Bodenbeschaffenheiten nicht zu unüberwindbaren Hindernissen werden. Sie müssen zusätzlich fähig sein, sehr genau ihre Position zu lokalisieren, $\mathrm{Ob}-$ jekte im Raum als Hindernisse zu erkennen und einen Weg zu finden. In der Luft und im Wasser müssen die Maschinen zwar auch ihre Position bestimmen können, aber die Zahl der Hindernisse bzw. Störungen sind eng limitiert und vorhersehbar (Wind bzw. Wasserströmung, ihre Intensität, sowie Luft- oder Wasserdruck). Trotz aller Fortschritte seit den 80er Jahren bereitet beispielsweise bis heute Robotern die visuelle Interpretation ihrer Umwelt erhebliche Probleme (siehe Brooks 2002: 86f.). Die Folge lässt sich an Roboterentwicklungen für den zivilen Gebrauch gut nachvollziehen, die ohne einen Operator auskommen: Diese Roboter haben jeweils eine bestimmte Aufgabe zu bewältigen. Überwiegend sollen sie den Rasen mähen oder in einer Wohnung Staub saugen. Sie sind nicht fähig, ihre Umwelt aufgrund visueller Daten zu interpretieren und sie benötigen diese Fähigkeit auch gar nicht, weil sie sich nur innerhalb eines spezifischen und relativ kleinen Raums bewegen müssen.

Sich in unterschiedlichen Räumen mit verschiedenartigen Anforderungen fortzubewegen, gelingt unbemannten Bodenfahrzeugen bis heute nur, wenn ihre Steuerung durch einen Operator per Kabel oder Funk erfolgt. Bei diesen Maschinen kann es sich auch um Roboter handeln, wenn sie trotz dieser Steuerung, beispielsweise auch über Freiheitsgrade bei der Fortbewegung verfügen. Brooks nennt solche Maschinen Telepräsenzroboter (ebd.: 146). Brooks rechtfertigt die Bezeichnung Roboter damit, dass der Operator zwar das Ziel der Bewegungen angeben muss, die Feinsteuerung dagegen, die Ausführung der Bewegungen, wie z.B. die Kraft des Motors auf die einzelnen Ketten bzw. Räder verteilt wird, bleiben der Maschine überlassen (ebd.: 150).

Solche unbemannten Fahrzeuge werden inzwischen von USInfanterieverbänden in Afghanistan und im Irak eingesetzt. Einige dieser Fahrzeuge sind relativ klein und leicht. Sie können deshalb von Infanteristen mit sich geführt werden. ${ }^{23}$ Sie dienen vor allem der Aufklärung: Ein

23 »Before sending in soldiers, send the PackBot Scout« ist ein Werbeslogan mit dem die iRobot Corporation für den iRobot PackBot Scout wirbt. Es handelt sich um einen $18 \mathrm{~kg}$ schweren und nur $20 \mathrm{~cm}$ hohen Telepräsensroboter, der laut Konzern bereits in Afghanistan und im Irak zum Einsatz gekommen ist und deshalb als battle-tested bezeichnet wird. Der Konzern wurde unter anderen von Brooks mitgegründet und er nimmt derzeit die Position des leitenden technischen Managers ein. Auf den Internetseiten des Konzern (http://www. irobot.com) werden auch weitere Roboter für militärische Aufgaben vorge- 
Operator kann, ohne sich selber im Fahrzeug zu befinden, durch eine eingebaute Kamera die Situation vor Ort beobachten und möglicherweise erkennen, ob sich Gegner verstecken. Sie sollen in urbanem Gelände eingesetzt werden, dass heißt auf Straßen fahren können, einige dieser Fahrzeuge soll man aber z.B. auch durch das Fenster eines Hauses werfen können, damit das Haus erkundet wird, bevor es von den Infanteristen gestürmt wird. Häufig wird auch als weitere Einsatzform erwähnt, dass sie in der Lage sein sollen, Höhlen zu erkunden, was dem Umstand zuzuschreiben ist, dass US-Infanteristen bei solchen Operationen in Afghanistan (2002) große Schwierigkeiten hatten (siehe Exum 2004: 141f.). Neben solchen Aufklärungsmissionen sollen die Fahrzeuge, sofern sie mit einer entsprechenden Spezialelektronik ausgestattet sind, feststellen, ob auf dem Weg des Infanterieverbandes ein Sprengsatz versteckt wurde, und diese zünden können.

Neben den bereits genannten unbemannten Vehikeln verfügen die USStreitkräfte heute vor allem über verschieden große Drohnen, die sich in ihrer Einsatzdauer und -reichweite stark unterscheiden. Auch die Drohnen müssen meist recht umfassend von einer Kontrollstation aus gesteuert werden. Eine Ausnahme davon bildet die sehr hochfliegende Aufklärungsdrohne RQ-4 Global Hawk, die über eine große Reichweite verfügt (fast $22.000 \mathrm{~km}$ ). Sie führt ihre Lagekontrolle, Navigation und inneren Steuerungsprozesse selbstständig durch, und ein Operator gibt beispielsweise lediglich die Flugrichtung vor. Wie die Global Hawk dienen die meisten unbemannten fliegenden Vehikel der Aufklärung, allerdings kann die Drohne Predator (A/B) auch mit verschiedenen Raketen bestückt werden und wurde in den vergangenen Jahren bei mehreren Angriffsoperationen eingesetzt (siehe Department of the Army 2006).

Die US-Streitkräfte verfügen derzeit sicher über das umfangreichste Equipment an unbemannten Vehikeln, und an ihrem Beispiel orientieren sich auch andere Streitkräfte. Spätestens in ein paar Jahren werden alle avancierten Streitkräfte über eine gewisse Zahl an Fahrzeugen verfügen, in denen keine Soldaten sitzen. Ohne hier weitere Details zu den einzelnen Projekte auszubreiten, zeichnet sich folgendes Bild ab: Es wird eine große Zahl unbemannter Vehikel entwickelt. Überwiegend handelt es sich um Drohnen, also um unbemannte Flugzeuge. Die meisten Vehikel dienen der Aufklärung. Einige Vehikel werden aber auch mit Waffen ausgestattet sein. Auch wenn das Beispiel Locaas zeigt, dass sich Maschinen entwickeln lassen, die in der Lage sind, selbstständig Ziele zu suchen und anzugreifen, bleiben die meisten Vehikel, die längere Einsatzzeiten und komplexere Aufgaben haben, auf die Steuerfähigkeiten eines Operators angewiesen.

stellt. Zum Packbot Scout siehe http://www.irobot.com/sp.cfm?pageid=140; Zugriff: 8.9.07. 
Die unterschiedlichen Gliederungen der Streitkräfte werden über jeweils ihren Interessen angepasste unbemannte Vehikel verfügen. Die Informationen, die eine Langstreckendrohne wie der Global Hawk erfasst, sollen das Lagebild ergänzen, das sich ein Oberkommando über eine Region verschaffen will und komplettiert die Informationen, die durch Daten von Satelliten zur Verfügung stehen. Sie dienen der taktischen und strategischen Planung von Einsätzen durch ein Oberkommando. Auch die vor Ort eingesetzten Verbände werden über ihre eigenen unbemannten Vehikel verfügen, bis hin zu einzelnen Verbänden der Bodentruppen. Bei den Infanterieverbänden wird der Einsatz von unbemannten Vehikeln besonders spürbar ihren Einsatz verändern. Neben unbemannten Bodenfahrzeugen, die beispielsweise ihren Weg durch ein urbanes Gebiet besser absichern sollen, werden sie auch mit flugfähigen Drohnen ausgestattet werden. So soll die Drohne der US-Streitkräfte Raven (RQ-11) von den Kampfverbänden und nicht von Unterstützungstruppen gestartet und gesteuert werden. Um die Drohne zu starten, reicht es aus, dass ein Soldat das circa 2 Kilogramm schwere Fluggerät mit der Hand in die Luft schleudert. Die batteriebetriebene Drohne soll die nähere Umgebung des Verbandes aufklären und soll bis zu 90 Minuten in der Luft bleiben können. ${ }^{24}$

Auch jenseits der Gefechtsfelder wird an dem Einsatz von unbemannten Fahrzeugen gearbeitet. Bekannt geworden ist in diesem Zusammenhang ein Projekt der DARPA ${ }^{25}$ das darauf abzielt, die Zahl der Lastwagenfahrer für Transportaufgaben zu reduzieren, indem ein Konvoi, bestehend aus mehreren Fahrzeugen, nur von wenigen Soldaten gesteuert werden muss. $^{26}$

Die zum Teil einsatzfähigen Maschinen markieren eine beachtliche Weiterentwicklung gegenüber den vorangegangenen Jahrzehnten, in denen ihre Herstellung zwar projektiert, aber überwiegend Science Fiktion blieb. Es gilt aber zu beachten, dass die unbemannten Fahrzeuge und die Roboter

24 Von dieser Drohne sollen ungefähr 3300 Stück beschafft werden (siehe http://www.designation-systems.net/dusrm/app2/q-11.html; Zugriff 12.10.07. Siehe auch Department of the Army (2006). Unter anderen mit Hinweis auf die Effizienz dieses Rüstungsprojekt stoppte das Pentagon im Februar 2004 die Einführung eines bemannten Hubschraubers (RAH-66 Comanche) für dessen Entwicklung im Laufe von über 20 Jahren bereits an die 7 Milliarden US-Dollar ausgegeben wurden (http://www.cnn.com/2004/US/02/23/helicop ter.cancel.ap/index.html; Zugriff 12.10.07).

25 Die Defense Advanced Research Projects Agency ist eine Behörde des USVerteidigungsministeriums, die Hightech-Projekte für das Militär durchführt.

26 Ausführliche Informationen sind auf der Internetseite http://www.darpa.mil/ grandchallenge/index.asp zu finden (Zugriff: 12.10.07). Aufgabe in den Jahren 2004 und 2005 war es, ein Fahrzeug an den Start zu schicken, dass insgesamt eine Strecke von $240 \mathrm{~km}$ in einer Wüste überwinden sollte, ohne dass dem Fahrzeug nach dem Start noch Steuerbefehle übermittelt werden. 2004 scheiterten alle Fahrzeuge nach wenigen Kilometer, aber im darauf folgenden Jahr erreichten 5 von 22 Fahrzeugen das Ziel. 
weiterhin erhebliche Schwachstellen aufweisen. Vor allem für alle kleineren unbemannten Vehikel gilt, dass sie überwiegend mit Elektromotoren ausgestattet sind. Gerade in Kriegszeiten fällt es aber Kampftruppen schwer, in ihren Einsatzgebieten Energiequellen zu finden, um die Akkumulatoren aufzuladen oder bei längeren Einsatzzeiten genügend Batterien bereit zu halten. ${ }^{27}$ Ein möglicherweiser schwerer wiegender Schwachpunkt stellt die meist funkgestützte Fernsteuerung vieler Maschinen dar. Technisch weit unterlegene Gegner sind zwar kaum in der Lage, die Fernsteuerung zu stören, sicher ist aber, dass jeder, der dazu in der Lage ist, über ein höchst wirkungsvolles Mittel gegen diese Maschinen verfügt. So hat die Unterbrechung der Datenverbindung zwischen Drohne und Kontrollstation, wenn auch unterschiedliche, aber doch immer jeweils gravierende Folgen. Wenn die Aufklärungsdrohne Global Hawk den Kontakt zur Kontrollstation verliert, fliegt sie selbstständig zum vorgesehenen Stützpunkt zurück. Der Predator A würde dagegen abstürzen (Lange 2003: 16).

Roboter, aber zumindest auch einige ferngesteuerte unbemannte Maschinen verfügen über Eigenschaften, die sie in der Sprache der Kognitionswissenschaften zu Agenten machen, da sie aufgrund ihrer Programmierung in der Lage sind, über ihre Sensoren in die eigenen Steuerungsprozesse einzugreifen und auf ihre Umwelt einzuwirken. Auch im Rahmen handlungstheoretischer Überlegungen lassen sich viele dieser Maschinen als Agenten einstufen (siehe Rammert/Schulz-Schaeffer 2002: 15, 36), denn durch ihren Einsatz muss möglicherweise ein Militärverband keine eigenen Soldaten in einer Gefahrenzone einsetzen. ${ }^{28}$ Die Maschinen beobachten und erkunden stellvertretend für einen tatsächlich nicht präsenten Soldaten einen bestimmten Raum, sie entschärfen bzw. zünden Sprengfallen, ohne dass ein Soldat verletzt oder getötet wird. Durch ihren Einsatz soll zugleich das Risiko für den Gegner steigen, erkannt und damit zum Angriffsziel zu werden, ohne dass er seinerseits mit den ihm zu Verfügung

27 Immer wieder lassen sich Berichte finden, dass US-Bodentruppen im Zuge ihres Einmarsches und Besetzung des Irak (2003) technische Geräte, die Strom benötigen, nicht einsetzen konnten, weil ihnen die Batterien ausgegangen waren (siehe beispielsweise Wright 2005: 293)

28 Obwohl die fliegenden und weitgehend sich selbst steuernden >Granaten vom Typ Locaas eindeutig als Agenten im Sinne der Kognitionswissenschaften einzustufen sind, ist fraglich, ob sie auch in handlungstheoretischer Hinsicht als beauftragte Stellvertreter bezeichnet werden können. Im Kontext eines konventionellen militärischen Selbstverständnisses wird die Frage eher $\mathrm{zu}$ verneinen sein, weil diese Artefakten nicht anstelle von Menschen eingesetzt werden. Demgegenüber kann man aber darauf hinweisen, dass unter dem Vorzeichen der Niederlage im 2. Weltkrieg das japanische und das deutsche Militär Soldaten in Flugzeugen und Boote auf Missionen schickten, in denen sie ihre Maschinen wie Bomben einsetzen sollten. Weiter lässt sich anmerken, dass im Rahmen asymmetrisch geführter Auseinandersetzungen so genannte Selbstmordattentäter ihren Leib als Trägersystem für Sprengsätze verwenden (siehe hierzu auch Heins/Warburg 2004: 20f., 34f.). 
stehenden Waffen diesen Angriff abwehren oder die ihn angreifenden Soldaten attackieren kann. Ein paar unbemannte Vehikel dienen auch als Waffenplattformen, das heißt sie transportieren Waffen in das Operationsgebiet, und von ihnen aus werden diese Waffen gestartet, z.B. in Gestalt einer oder mehrerer Rakete(n), wie dies heute bereits beim Predator der Fall ist. Durch den Einsatz von Maschinen kann für bestimmte Gefechtssituationen auf den Einsatz von Soldaten verzichtet werden. Sie werden substituiert. Doch als Substitution ist dieser Prozess der Technisierung nur ungenügend beschrieben, denn einen Raum zu erkunden und auf der Basis dieser Informationen in ihn hineinwirken zu können, obwohl man nicht leiblich in diesem Raum präsent ist, bedeutet zugleich eine Steigerung der Handlungsmacht desjenigen, der über solche Mittel verfügt. Diese Steigerung ist besonders signifikant, wenn nur eine Kriegspartei entsprechende technische Mittel einsetzen kann. Die Verfügbarkeit beispielsweise von Telepräsenzrobotern erlaubt es einer Kriegspartei, Einsätze durchzuführen, die zuvor als hoch riskant galten, ohne nun tatsächlich eigene Soldaten zu gefährden. Ein mögliches Szenario wäre, einen gegnerischen Infanterieverband durch Artillerie anzugreifen, der zuvor durch einen Telepräsenzroboter entdeckt wurde, und innerhalb dessen Waffenreichweite sich lediglich der Roboter aufhält. Die gesteigerte Handlungsmacht fällt der Streitmacht in toto zu, und sie ist zugleich spürbar für den einzelnen Soldaten, z.B. für einen Infanteristen, der selber eine derartige Maschine steuert, aber selbst beim Einsatz von Waffen nicht sein Leben riskiert. Wenn beide Kriegsparteien über unbemannte Vehikel bzw. Telepräsenzroboter einsetzen können, ist es denkbar, dass ein Teil der Gefechte zwischen diesen Maschinen ausgetragen wird. In einem solchen Gefecht sterben keine Kombattanten; der Tod von Nicht-Kombattanten bleibt jedoch nicht ausgeschlossen. Das Operationsziel eines solchen Gefechts wäre aber weniger die Zerstörung der gegnerischen Fahrzeuge, sondern das Aufspüren derjenigen, die diese Maschinen steuern bzw. kontrollieren, um sie handlungsunfähig zu machen, was meistens darauf hinauslaufen wird, sie zu töten. Der absehbare Bedeutungszuwachs von unbemannten Vehikeln wird von den Soldaten neue Qualifikationen im Umgang mit der Technik und den Friktionen verlangen, die sich aus ihrer Anwendung und den Aktivitäten des Gegners ergeben, der beispielsweise versuchen wird, diese Maschinen zu stören und seinerseits versuchen wird, durch die Steuerungssignale die Position des Gegners festzustellen. ${ }^{29}$

Die Fähigkeiten militärischer unbemannter Vehikel werden in den kommenden Jahrzehnten steigen. Sie werden autonomer über innere Steuerungsprozesse verfügen können und auch ihre Möglichkeiten, unabhängig

29 Zum Teil wird man Qualifizierungs- wie Dequalifizierungsprozesse feststellen können. Denn die Drohnen werden nicht unbedingt von ausgebildeten Piloten gesteuert und gleichzeitig müssen Infanteristen lernen, wie Bodenfahrzeuge und Drohnen bedient werden. 
von einem Operator auf ihre Umwelt einzuwirken, - dies schließt die Fähigkeit ein, Menschen zu töten - werden wachsen. Eine menschliche Fähigkeit wird ihnen aber verwehrt bleiben: Die Fähigkeit, über ihre Funktion autonom zu entscheiden, also z.B. eine ganz andere Funktion zu erfüllen als die von ihren Anwendern programmierte. Ganz abgesehen von den technischen Schwierigkeiten, ein solches Entwicklungsziel zu verwirklichen, ist auch kein militärisches Interesse erkennbar, dass eine Maschine über die Fähigkeit verfügt, über ihre Tätigkeit reflexiv >nachzudenken sich Sinngebungsprozessen zu unterziehen. Die Folge einer solchen Fähigkeit kann nur im Verlust an Steuerbarkeit bestehen - also im Verlust einer Qualität, die an solchen Maschinen heute sehr geschätzt wird. Ebenso wenig, wie es erwünscht sein wird, dass ein Roboter Emotionen empfinden kann, die sein Handeln beeinflussen, weil dies dazu führen könnte, dass eine Maschine ihre Funktion verweigert, ist erkennbar, welcher militärischen Vorteil im Einsatz einer Maschine bestehen kann, die in der Lage wäre, darüber zu reflektieren, ob sich ihr Einsatz lohnt, ob sie es riskieren soll, dass sie zerstört wird bzw. sich selber zerstört. Dass Maschinen aufgrund technischer Fehlfunktionen als Agenten versagen, wird sich auch in Zukunft nicht ändern, dass sie ihre Funktion verweigern, sich gar gegen ihre Auftraggeber wenden, sollte nicht nur aus dem Blickwinkel des Militärs ein Science Fiktion Thema bleiben.

\subsubsection{Zur Transformation der Streitkräfte und der Bedeutung der Network Centric Warfare}

Anfangs unter dem Titel »Revolution in Military Affairs« (RMA), derzeit eher unter der Bezeichnung Transformation rüsten die USA, aber auch mit ihnen verbündete Staaten, so zum Beispiel die Bundesrepublik Deutschland, ihre Streitkräfte um. Erklärtes Ziel der >Transformation< ist die Anpassung des Militärs an die Kriegsszenarios des 21. Jahrhunderts. Mit der Transformation werden aber nicht nur Konsequenzen aus der militärpolitischen Situation gezogen, die seit dem Ende des Kalten Krieges besteht. Bis vor wenigen Jahren wurde stärker als heute betont, dass die Umrüstung der Streitkräfte zugleich zu einem enormen Zuwachs an Kampfkraft führen soll, der weit über das hinausgeht, was im Zuge der >normalen` waffentechnologischen Entwicklung erwartet werden kann. Durch die Transformation sollten Streitkräfte entstehen, deren qualitativ hochwertige Ausrüstung von keinem Gegner durch eine quantitative Aufrüstung ausgeglichen werden kann. Zielvorstellung war, dass alle militärischen Organisationen, die diesen Prozess nicht durchlaufen haben, keine Möglichkeit haben sollten, im Kampf gegen die transformierten Verbände zu bestehen. Sie sollte den US-Streitkräften und den wenigen Verbündeten, die sich diese Aufrüstungen ebenfalls leisten können, eine uneinholbare militärische Überlegenheit verschaffen. Auch wenn in den Debattenbeiträgen derzeit eher von 
einer >Transformation` im Sinne einer Umrüstung gesprochen wird, um das Militär neuen Krisen- und Kriegskonstellationen anzupassen, ist die Vorstellung, dass im Zuge der Umrüstung eine enorme militärische Überlegenheit erzeugt wird, erhalten geblieben.

In den USA hat der Transformationsprozess des Militärs längst begonnen. Als größte Militärmacht der Welt prägt die Entwicklung bei den USStreitkräften obendrein auch die Um- und Aufrüstungsprozesse der mit den USA verbündeten Staaten. ${ }^{30}$ Im Mittelpunkt der Transformation steht kein Waffensystem. Sicher, für Raketen und Granaten, die über eine noch weitere Distanz und mit größerer Präzision ihr Ziel treffen sollen, für den Bau von Flugzeugen, die vom gegnerischen Radar nicht entdeckt werden können (Stealth-Fähigkeit) und später vielleicht auch einmal optisch nur schwer zu entdecken sind, sowie für die Entwicklung unbemannter Vehikel wird in den Rüstungshaushalten sehr viel Geld bereit gestellt. Noch mehr Geld steht für den Ausbau der Transportkapazitäten zu Luft und zu Wasser zur Verfügung und für die Entwicklung von Fahrzeugen, die in Transportflugzeuge verladbar sind. Grundsätzlich sollen zukünftig alle Waffen leichter und trotzdem wirkungsvoller werden. Und für die Anschaffung neuer Kampfschiffe, inklusive Flugzeugträgern, geben die USA, aber auch ihre europäischen Verbündeten England und Frankreich, weitere Milliarden aus. Trotz der horrenden Ausgaben für diese Waffen und Rüstungsvorhaben hängt ihre Wirksamkeit in den Kriegen des 21. Jahrhunderts - so die Einschätzung des Vereinigten Generalstabs der USA (Joint Chiefs of Staff, JCoS), dem die Oberkommandierenden aller US-Teilstreitkräfte angehören - von der Erhebung von Informationen und den Kommunikationsprozessen innerhalb der Streitkräfte ab. Als zentrales Element zur Steuerung zukünftiger Informationsprozesse gilt das Konzept des Network Centric Warfare (NCW), das parallel von dem US-Verteidigungsministerium, genauer vom »Command and Control Research Program (CCRP)«, das dem »Office of the Assistant Secretary of Defense (NII)« angegliedert ist, lanciert wurde (siehe Alberts/Garstka/Stein 2000). Gerade

30 Der Anteil der Militärausgaben der USA am Bruttoinlandsprodukt ist niedriger als beispielsweise für Staaten wie Nord-Korea, Israel oder den meisten arabischen Staaten. In absoluten Zahlen weist aber das Budget des Verteidigungsministeriums der USA den weltweit höchsten Betrag aus. Für das Jahr 2006 sind über 512 Milliarden Dollar vorgesehen. Allein 70 Milliarden Dollar soll der >Global War on Terror kosten. Weitere 71 Milliarden Dollar werden in die Forschung, die Entwicklung und die Einführung neuer Militärtechnologien investiert (siehe http://www.whitehouse.gov/omb/budget/fy200 7/defense.html; Zugriff 12.10.07). Zum Vergleich: Der gesamte Bundeshaushalt 2006 sieht Ausgaben von ungefähr 262 Milliarden Euro vor. Der Etat des Verteidigungsministeriums (Einzelplan 14), der nicht alle, aber doch den größten Teil der Militärausgaben erfasst, weist 2006 fast 28 Milliarden Euro aus (http://www.Bundesfinanzministerium.de/bundeshaushalt2006/html/ep14 /ep14epabs.html; Zugriff: 12.10.07). Der Etat soll in den kommenden Jahren erhöht werden. 
zur Bekämpfung künftiger Gegner, die zu asymmetrischen Kampfmethoden greifen bzw. neue "asymmetric threats« entwickeln, wird die Bedeutung der NCW hervorgehoben (JCoS: 6f.).

Die NCW soll auf allen Ebenen der Kriegführung, von der Logistik bis hin zum Gefecht, wirksam sein. ${ }^{31}$ Sie basiert zum einen auf einer umfassenden Digitalisierung aller Informationen, die über den Gegner, das Kampfgebiet, aber auch über die eigenen Truppen vorliegen. Diese Informationen sollen dynamisch sein, dass heißt den Soldaten sollen nicht nur statische Daten zur Verfügung gestellt werden, die sie zum Beispiel über die räumliche Struktur des Kampfgebiets informieren, sondern möglichst zeitnah zum Geschehen sollen alle Veränderungen erfasst werden und dies möglichst detailliert. Um das Spektrum der zu erfassenden Informationen zu illustrieren: Erfasst werden sollen neben den Bewegungen großer Truppenverbände möglichst auch die Bewegung eines jeden Kombattanten; der Munitionsverbrauch der eigenen Verbände soll ebenso bekannt sein wie der Zustand eines Soldaten, der im Verlauf eines Gefechts verwundet wird. Zum anderen sollen diese Daten in ein Computersystem eingespeist werden, auf das alle am Geschehen beteiligten Akteure, gleichgültig in welcher Entfernung sie sich zum Ort des Geschehens befinden, zugreifen können.

Die netzwerkzentrierte Kriegführung, aber auch ihr bundesdeutsches Pendant >Vernetzte Operationsführung s stellt hohe technische Anforderungen. Informationen aus höchst unterschiedlichen Quellen - die Palette reicht von Satelliten über Drohnen, die aus kurzer Distanz einen Raum erkunden sollen, bis hin zu Sensoren, die am Körper der Soldaten angebracht werden sollen - müssen innerhalb eines Computersystems kompatibel sein und über ebenfalls sehr unterschiedliche Kommunikationsgeräte verfügbar sein. ${ }^{32}$ Nicht minder gravierend sind die Anforderungen an die historisch gewachsenen Organisationsstrukturen der Streitkräfte. Die NCW stellt die Gliederung der Streitkräfte in unterschiedliche Organisationseinheiten (Heer, Luftwaffe, Marine) in Frage, weil sie von den Verbänden dieser Teilstreitkräfte eine auf das Gefechtsfeld hin bezogene intensive Kommunikationsvernetzung und ein Zusammenwirken verlangt. Eine konsequente Umsetzung der NCW hat obendrein erhebliche Folgen für die Binnenstrukturen dieser Teilstreitkräfte, vor allem im Hinblick ihrer hierarchischen Strukturierung.

31 Umfassender als dies hier geschehen kann, wird die NCW von Kaufmann (2005) soziologisch analysiert. Die nachstehenden Erläuterungen zur NCW konzentrieren sich auf Aspekte, die das Gefecht von Infanteristen betreffen.

32 Um diese Anforderungen zu bewältigen, haben allein die US-Streitkräfte für den Zeitraum 2002-2012 und im Bereich »Command, Control, Communications, Computer, Intelligence, Surveillance and Reconnaissance (C4ISR) 70 Milliarden Dollar für Forschung und Entwicklung vorgesehen (Schwiebert 2004: 37). 
Im Rahmen der NCW wird von den am Gefecht beteiligten Verbänden, genauer gesagt den Kommandeuren der Kampfeinheiten und je nach konzeptioneller Ausgestaltung auch von den einzelnen Soldaten, erwartet, dass sie direkt miteinander kommunizieren können und insbesondere auf aktuelle Aufklärungsdaten zugreifen können. Die kommunikative Vernetzung der am Kampfgeschehen Beteiligten soll ihnen eine umfassende Beurteilung der Lage ermöglichen und sie zugleich befähigen, ihr Handeln zu koordinieren, ohne dass sie hierzu auf die Entscheidungsprozesse übergeordneter Kommandostrukturen angewiesen sind. Damit wird die Bedeutung der Koordinationsleistung der Stäbe relativiert, die vor allem Ende des 19. Jahrhunderts mit der Gefechtsführung nach Kommandoeinheiten an Bedeutung gewonnen hatten (siehe hierzu Abschnitt 7.1.). Solange die Streitkräfte nicht auf die NCW ausgerichtet sind, laufen bei diesen Kommandostäben die Berichte der einzelnen Einheiten zusammen, die die Facetten einer Lagebeurteilung bilden, auf deren Grundlage hin wiederum Befehle an die einzelnen Einheiten erteilt werden. Die NCW unterminiert diese Kommandostrukturen obendrein, weil sie nicht ihrem Modus der $\mathrm{Zu}$ ständigkeiten folgt: Die Kommandostrukturen hatten mit den ihnen unterstellten Kräften innerhalb eines eindeutig umrissenen Raumsegments und innerhalb einer bestimmten Dimension (Boden, Luft, Wasser) das Gefecht $\mathrm{zu}$ führen. Immer erst auf einer jeweils übergeordneten Ebene erfolgte die Koordination der verschiedenen Kommandoeinheiten und auch der Teilstreitkräfte. Nicht die Zugehörigkeit zu einem bestimmten Verband und die räumliche Position zum Geschehen legt bei der NCW fest, welche Soldaten bei den Kommunikations- und Entscheidungsprozessen beteiligt sind, sondern die Möglichkeit, einen Beitrag zum Gefecht zu leisten, also den Gegner zu attackieren. Vom formalen militärischen Rang und der Position in der Befehlskette hängt die Ausgestaltung dieser Prozesse nicht $\mathrm{ab}$, sondern von einer Fähigkeit, die in der NCW-Literatur als Selbstsynchronisation bezeichnet wird (siehe Alberts/Garstka/Stein 2000). Jeder Soldat müsse dazu in der Lage sein, eigene taktisch-operative Einschätzungen zu entwickeln und diese mit denen der anderen Akteure abzustimmen. Zwar sollen die beteiligten Soldaten darüber nicht die Absichten der oberen Führung aus den Augen verlieren, aber die ihnen zugewiesene Handlungskompetenz geht über das hinaus, was herkömmliche Führungsverfahren von rangniedrigen Soldaten erwarten. Sie sollen nicht nur quasi im Notfall Situationen mitgestalten können, die entstehen, wenn in der Befehlslage Lücken durch unerwartete Ereignisse auftreten. Sie sollen vielmehr durch ihre Kommunikation untereinander erst diese Befehlslage selber erzeugen und damit die Grundlage für ihr weiteres Vorgehen schaffen. Mit anderen Worten: Von ihnen wird ein kreativ-strukturierendes Handeln erwartet.

Konzeptionell bricht die NCW deshalb deutlich mit militärischen Führungsverfahren, die an der Befehlstaktik ausgerichtet sind. Im Bezug auf 
die Auftragstaktik lässt sich zumindest ein Spannungsverhältnis konstatieren. Der Einsatz neuer Informations- und Kommunikationstechnologien verbindet nicht nur »die altbekannten Stärken der Auftragstaktik mit modernsten Mitteln der Informationstechnologie synergetisch«, wie es auf einer Internetseite der Bundesluftwaffe heißt (Bundesministerium für Verteidigung 2006a). Die NCW-Doktrin ermächtigt die Untergebenen, darüber zu entscheiden, wie sie einen von den höheren Kommandoebenen erteilten >Auftrag a ausführen und welche Einheit diesen Auftrag ausführt. Ohne die höheren Kommandoebenen zu kontaktieren, sollen die Einheiten quasi selber aus dem Geschehen heraus sich mit Aufträgen versorgen (siehe hierzu Schäfer 2004: 45f.). »Dies erfordert von jedem Einzelnen ein deutlich gesteigertes Verantwortungsbewusstsein und Eigeninitiative.« (Ebd.)

Dass auf solche Weise betont wird, die NCW könne nur dann gelingen, wenn die Soldaten verantwortungsbewusst, sprich im Sinne der Organisationsziele, handeln, ist ein Hinweis auf eine weitere Wirkung der NCW auf die Organisationsstrukturen (siehe hierzu Alberts/Garstka/Stein 2000: 157). Sie schwächt solche Elemente der Organisation, die die Handlungen der Soldaten rigide strukturieren und geeignet sind, ihre Handlungen $\mathrm{zu}$ reglementieren und zu kontrollieren. Fragiler werden diese Strukturen noch aus einem weiteren Grund, der sich zwar nicht zwingend aus der NCW ergibt, der jedoch dazu dient, die in ihr angelegten Chancen auszuschöpfen, um die Kampfkraft zu erhöhen: Im Zuge der Transformationsbemühungen erfahren große Verbände, wie die Division, - der mitunter mehr als 15.000 Soldaten angehören - und die bislang optimal als ganze Einheit eingesetzt wurden, einen Bedeutungsverlust. An ihre Stelle treten kleinere Verbände, - meist werden sie als Brigaden bezeichnet - die je nach Einsatzprofil formiert und unterschiedlichen Kommandostrukturen unterstellt werden können sowie mit anderen Verbänden kombinierbar sein sollen. ${ }^{33}$ Die Flexibilisierung und die so genannte modulare Verwendung der Verbände schwächen abermals tradierte Organisationsstrukturen »wie formale Kommunikationshierarchien, klar geregelte Zuständigkeiten, festgelegte Dienstwege, Buch- und Aktenführung « (Kaufmann 2005: 249), die bislang dazu dienten, Befehle zu erteilen und ihre Ausführung zu überwachen. An die Stelle dieser Organisationsstrukturen tritt »die kommunikative Dichte« der Akteure (ebd.). Permanenz und Transparenz der Kommunikationsprozesse, die Möglichkeit, sich jederzeit über die Handlungen der anderen Akteure zu informieren, sind ihre tragenden Prinzipien. Die Beobachtbarkeit der Anderen stimuliert zugleich die Akteure, sich selber zu kontrollieren. Inwieweit all dies zu einer erhöhten Effektivität der Kommandostrukturen führt, hängt allerdings entscheidend davon ab, ob die Akteure Vorstellun-

33 Die US-Streitkräfte wollen ihre Kampfverbände an einem Brigademodell ausrichten, den Units of Action (UOA), das lediglich 2245 Soldaten und 369 Fahrzeuge umfassen soll (siehe Schreer 2004: 10). Auch bei der Bundeswehr hat die Brigade als Verbandstypus an Bedeutung gewonnen. 
gen miteinander teilen, die sie überhaupt erst befähigen, gemeinsam eine Lagebeurteilung zu entwickeln. Die angestrebte Effektivitätssteigerung hängt also nicht zuletzt davon ab, ob die Ausbildung der Soldaten einen Habitus fördert, der adäquat zu den Prinzipien der NCW ist. Als ein Verstoß gegen diese Prinzipien wird ein Verhalten von Untergebenen aufgefasst, wenn sie die durch die NCW geschaffenen flexibleren Strukturen nicht dazu nutzen, um sich selber mit Aufträgen zu versorgen und sich stattdessen der >Verantwortung « entziehen. Auch die Kommandierenden können die Effektivität in Frage stellen, wenn sie dazu neigen, die technischen Kommunikationsmöglichkeiten zu nutzen, um auf Entscheidungsprozesse durch alle Ebenen hindurch zuzugreifen. Das zentrale Stichwort in diesem Zusammenhang lautet Mikromanagement. Ein solches Verhalten der Befehlshaber kann dazu führen, dass sie sich mit taktischen Fragen der Operationsführung beschäftigen, darüber den strategischen Überblick verlieren und obendrein ihre Untergebenen daran hindern, selber taktischoperative Entscheidungen zu treffen. Im Einzelfall, so ist auf der oben erwähnten Internetseite der Bundesluftwaffe nachzulesen, könne aber das Durchgreifen der »höchsten Ebene« auf der unmittelbaren operativen Ebene sinnvoll sein. Immer wenn hier Entscheidungen getroffen werden, die auch eine strategische Komponente aufweisen, sei ein Durchgreifen durch die Kommandoebenen sinnvoll. Beispielhaft wird der Befehl an einen Scharfschützen genannt, der einen gegnerischen politischen Führer »durch gezieltes Feuer außer Gefecht« setzen soll. Da politische Anführer aber eher selten an Gefechten beteiligt sind, verschleiert hier das »außer Gefecht setzen«, dass der Scharfschütze den Befehl von anderen politisch Verantwortlichen erhält, zu töten.

Zur Erklärung der Wirkungsweise der NCW wird häufig das Entscheidungsmodell von Colonel John Boyd (1927-1997) herangezogen. Boyd, der im Korea-Krieg als Jagdflieger Kampfeinsätze flog, versucht mit seinem Entscheidungsmodell zu erklären, worin die Leistungen eines erfolgreichen Kommandeurs, also beispielsweise eines Flugzeugführers, bestehen. Um wiederholt im Kampf den Gegner zu besiegen, müsse jeder Kommandeur, aber auch jedes Entscheidungsgremium, immer wieder einen Entscheidungszyklus durchlaufen, der aus vier Phasen besteht: Beobachten, Orientieren, Entscheiden und Handeln (observe, orient, decide, act; OODA-Loop). ${ }^{34}$ Die NCW soll die Durchlaufgeschwindigkeit des Zyklus und zugleich die Effizienz der Entscheidungsprozesse erhöhen. Im Bezug auf das Beobachten wird mit der NCW angestrebt, dem Kommandeur ein umfassendes Lagebild zu übermitteln, das möglichst zeitnah die aktuelle Situation abbildet. Durch den Einsatz zahlreicher und miteinander

34 Von Boyd existiert kein Text, in dem er sein Entscheidungsmodell umfassend vorstellt, umso zahlreicher sind dafür die Interpretationen seines Modells. Stellvertretend für andere Schriften sei hier auf Bazin hingewiesen, der den OODA-Loop für den Kommandeur einer Infanteriekompanie veranschaulicht. 
vernetzter Aufklärungssysteme soll sich für den Kommandeur der >Nebel des Krieges` (Clausewitz) weitgehend lichten, und auch bei dynamischen Prozessen sollen unerwartete Ereignisse möglichst früh von ihm erkannt werden können. Durch die umfassende Aufklärung sollen sich die Kommandeure leichter über die Situation orientieren können. Die Vernetzung der Kommunikationswege wiederum soll die Entscheidungsprozesse beschleunigen, und nach dem Abschluss der Handlung soll dem Kommandeur bzw. dem Entscheidungsgremium möglichst schnell, am besten in >real time` also in so genannter Echtzeit, Daten über den Effekt der Handlung zur Verfügung stehen, damit ein neuer Zyklus durchlaufen werden kann.

Die Möglichkeit, auf umfassende und aktuelle Daten zur Lage zuzugreifen und die dichte Kommunikation im Netzwerk sollen konventionellen Streitkräften helfen, gegen ihre Gegner eine Taktik anzuwenden, die bislang hauptsächlich nur asymmetrisch Kämpfenden zur Verfügung steht. Sie sollen dazu fähig sein, nicht mehr nur in kompakten und großen Verbänden den Gegner zu attackieren, sondern selber in kleinen Verbänden als ১Schwarm` operieren können. Als Schwarm zu operieren bedeutet für die Verbände, den Gegner aus unterschiedlichen Richtungen zu attackieren und dabei selber schwer lokalisierbar zu sein. Die Verbände sollen im Verlauf eines Gefechts so genannte Duellsituationen vermeiden, indem sie sich beispielsweise beim Anrücken überlegener Verbände zurückziehen. Durch diese Annäherung an die Kampfweise der Guerilla werden die Streitkräfte, die auf der Basis der NCW-Doktrin operieren, aber nicht zu Guerilla-Verbänden, da sie weiterhin von einer zentralen Kommandoebene koordiniert werden und weil sie den Einsatz von komplexen Waffensysteme anfordern können. Durch die Feuerkraft von Artilleriegeschossen, Bomben und Raketen, in Kombination mit der Beschleunigung des OODA-Loops soll es möglich sein, auf einen »)überwältigenden Kräfteeinsatz` (overwhelming force)« zu verzichten (Schreer 2004: 12). Die Verbände sollen punktuell eine »)überwältigende Feuerkraft` (overwhelming power)« (ebd.) entwickeln, die nicht unbedingt darauf abzielen muss, die gegnerischen Kampfverbände zu zerschlagen. Primäres Ziel dieser Feuerkraft ist der gegnerische OODA-Loop, der unterbunden oder doch zumindest nachhaltig gestört werden soll, indem beispielsweise die gegnerischen Kommandostellen angegriffen werden. "Netzwerkzentrisch wird nicht die überlegene Masse, sondern die überlegene Koordination und Geschwindigkeit entscheidend: >shock and awe zepte.« (Kaufmann 2005: 254)

Bei der Infanterie bündeln sich die unterschiedlichen Anforderungen der NCW an die Streitkräfte und die Soldaten. Ließen sich im Rahmen bisheriger operativer Konzepte die Ergebnisse der Aufklärung, die Entscheidungsprozesse und das Handeln der Soldaten, ihre Bewegungen und auch der Einsatz von Waffen als von einander getrennte Ebenen behandeln, die 
sich überwiegend seriell aufeinander bezogen, sollen innerhalb der NCW diese Prozesse, die im Rahmen der NCW als Entitäten bezeichnet werden, durch Informationstechnologie miteinander vernetzt werden (Alberts/Garstka/Stein 2000: 94f.).

\section{Grafik 1: Infantrist und NCW}

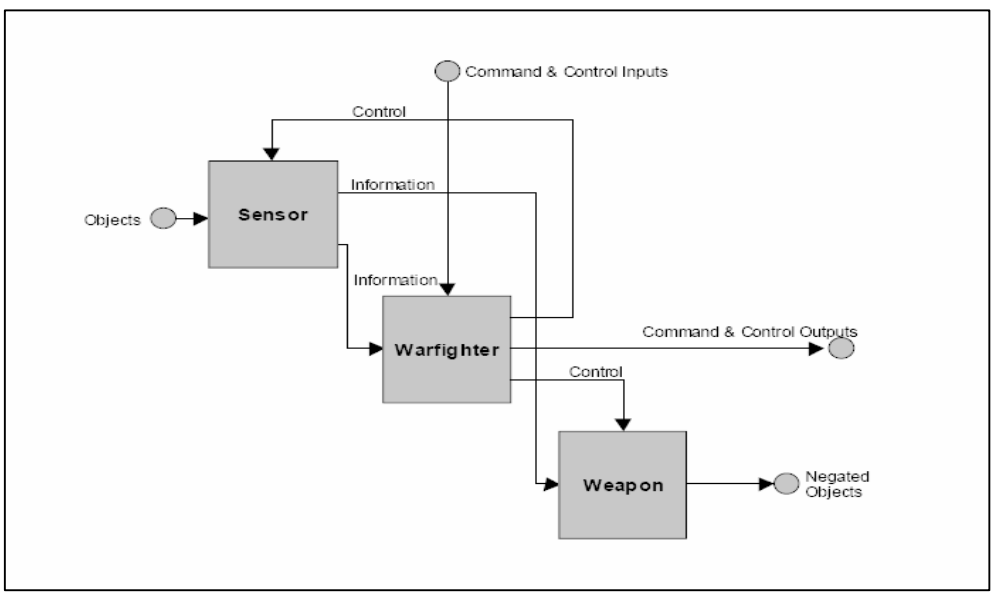

Aus: Alberts/Garstka/Stein 2000: 95

Bei Infanteristen, oder allgemeiner Soldaten, die unmittelbar während eines Gefechtes ihre Waffen einsetzen, fallen die Entitäten schon mit der Auflösung der geschlossenen Formationen insofern zusammen, da sie mit ihren >Sensoren` (den Augen, den Ohren usw.) ihre Umgebung erkunden müssen und die sinnlichen Eindrücke ihre Entscheidungen und ihre Handlungen beeinflussen. Aber Beobachtungen, die zum Beispiel von einem Aufklärungsflugzeug gemacht werden, und Befehle, die von Vorgesetzten getroffen werden, die einer anderen Hierarchieebene angehören, mussten bislang erst seriell >verarbeitet` werden, bevor sie den Soldaten erreichen. Die seriellen Verfahren beanspruchen Zeit, und die Möglichkeit, diese Zeit nach der Vernetzung einzusparen, soll den OODA-Loop beschleunigen. Obendrein können die Führungsebenen, wenn überhaupt, nur mit großer zeitlicher Verzögerung, z.B. wenn ein schriftlicher Bericht vorliegt, und damit äußerst eingeschränkt auf die Informationen zugreifen, über die die unmittelbar auf dem Gefechtsfeld Handelnden durch ihre Wahrnehmungen verfügen. Durch die Ausstattung der Infanteristen mit digitalen Kameras, Laserzielentfernungsmessern etc. und durch Sensoren, die am Leib der Soldaten Messdaten erheben, soll sich dies grundlegend ändern. Diese Daten sollen aber nicht nur den Führungsebenen zur Verfügung stehen, auf sie sollen, zumindest den US-Planungen zufolge, auch andere bei der Operation beteiligte Soldaten zugreifen können. Ein Soldat soll folglich nicht 
nur das sehen und hören können, was er mit den eigenen Augen und Ohren erfassen kann, sondern auch das, was alle anderen Soldaten wahrnehmen können. Durch die Vernetzung werde, so die Erwartung, die `Sensorreichweite der einzelnen Soldaten größer. Mit der NCW sollen die technischen Voraussetzungen geschaffen werden, damit quasi die bislang separierten Fähigkeiten und Wahrnehmungen der einzelnen Soldaten zu einer kollektiv agierenden Entität verschmelzen können.

\section{Grafik 2: platform-centric shooters}

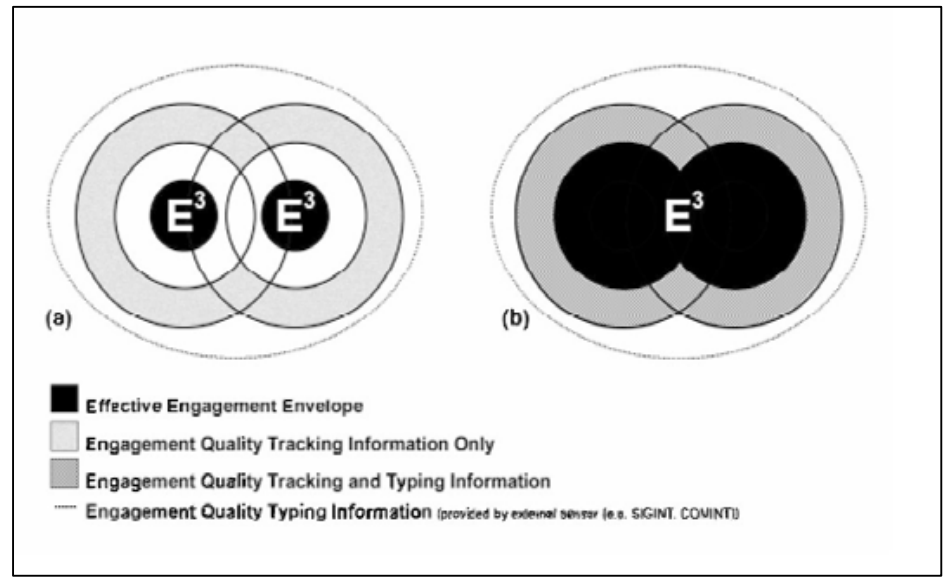

(a) soll die Situation für zwei "platform-centric shooters" darstellen, die ohne NCW miteinander kooperieren; (b) mit NCW. Aus:

Alberts/Garstka/Stein 2000: 102)

Durch den Informationsverbund wiederum könnten die Soldaten ihre Handlungen schneller aufeinander abstimmen und schneller als Kollektiv auf Veränderungen der Situation reagieren. Die NCW erhöht zwar nicht die Reichweite ihrer mitgeführten Waffen, sie erlaubt es ihnen aber, den Einsatz weiterreichender Distanzwaffen anzufordern und zu koordinieren. Die Aufgabe der Infanteristen besteht in diesem Fall nicht so sehr darin, den Gegner selber zu bekämpfen, - da sie dabei möglicherweise in seine Waffenreichweite kommen würden - sondern darin, ihn aufzuspüren und ihn zu markieren, damit er von den Distanzwaffen getroffen wird. Eine $\mathrm{NCW}$, die bis hinunter auf der Ebene des Infanteristen praktiziert wird, verspricht überdies, ihnen auch das Gefühl der Vereinzelung und Einsamkeit zu nehmen, das mit dem industrialisierten Schlachtfeld aufgekommen ist. Sie bleiben zumindest konzeptionell oder technisch immer mit ihrer Gruppe, ihrem Verband verbunden, wenn auch nicht so sehr face-to-face, eher face-to-screen. 
Bislang handelt es sich bei dem oben Dargestellten um konzeptionelle Überlegungen, nicht um bereits realisierte Projekte. Auch die horrenden Ausgaben der amtierenden US-Administration im Bereich Forschung und Entwicklung haben in den vergangenen Jahren nicht dazu geführt, dass die dazu erforderlichen Technologien bereit stehen. Dies gilt sowohl für die Kommunikations- und Informationstechnologien, als auch für die Waffenprogramme. So wird in einem Bericht des Bundesrechnungshofes 2004 festgestellt, dass das US-Verteidigungsministerium nicht weiß, wie es die erforderliche Interoperabilität der Computersysteme und -netzwerke umsetzen soll (GAO 2004b: 3). Und einem anderen Bericht zufolge kommt das Programm >Future Combat Systems` der US-Army, mit dem das Heer seine Ausrüstung (Panzer; unbemannte Vehikel, Kommunikationstechnologien, Munition und die Ausrüstung der Infanteristen) der netzwerkzentierten Kriegführung anpassen will, kaum voran. Obwohl innerhalb von zwei Jahren 4,6 Milliarden Dollar investiert wurden, sei nur eine von 50 benötigten Technologien als ausgereift einzustufen (siehe GAO 2005: 2f.). Deshalb verfügt die Infanterie bis heute nicht über die Ausrüstung, um die Visionen der NCW zu realisieren. Noch 2003 wurde erwartet, dass mit dem bereits in den 90er Jahren aufgelegte >Land Warrior〈 Programm erstmals eine serienreife Ausrüstung erstellt werden kann, mit denen die Infanteristen unter anderem selber Sensordaten erheben können, die sie in ein Kommunikationsnetzwerk einspeisen und auf das sie selber zugreifen können. Für das Jahr 2006 war bereits die 2.0 Version vorgesehen (Siebrand 2003: 35). Entgegen diesen Erwartungen hat >Land Warrior noch den Status eines Forschungsprogramms, das nun als Bestandteil der 〉Future Combat Systems` betrachtet wird. Das Kommunikationsnetzwerk reicht zurzeit maximal bis zum Zugführer (platoon leader). Von einem Taschencomputer, dem >Commander's Digital Assistant`, der einige Funktionen der NCW erfüllt, sollen 2005 einige hundert Exemplare an Infanterieverbände verteilt worden sein. Anhand von digitalen Landkarten sollen auf diese Weise die Offiziere, angefangen vom Bataillonskommandeur bis hin zum Zugführer, sich über die aktuelle Situation informieren können, und sie sollen mit dem eingebauten datenfähigen Funkgerät die Möglichkeit haben, selber Informationen in das Kommunikationsnetz einzustellen. $^{35}$ Erst ab 2010/12 sollen Ausrüstungskomponenten zur Verfügung stehen, - nun als Bestandteil eines Programms namens >Future Force Warrior - die eine netzwerkzentrierte Kriegführung auf der Ebene des infanteristischen Kampfes erlauben würden. ${ }^{36}$

35 Über die Kommunikationsschwierigkeiten der US-Army im Verlauf der Eroberung des Irak (2003) informiert Schwiebert (2004). Zum >Commander's Digital Assistant< siehe: http://www.defense-update.com/products/c/cda.htm (Zugriff: 9.9.07).

36 Einen Überblick über die derzeitige Konzeption des >Future Force Warriors gibt das U.S. Army Soldier Systems Center, einem Forschungs- und Entwick- 
Auch bei den europäischen Verbündeten der USA, die ebenfalls eine NCW anstreben, sind ihre Auswirkungen auf die Infanterie sehr eingeschränkt. Die Bundeswehr hat sich mit dem >Infanterist der Zukunftく (IdZ) zwar vorgenommen, Grundlagen für eine >Vernetzte Operationsführung bei der Infanterie zu schaffen, doch sie hat sich darauf beschränkt, ein so genanntes Basismodell zu entwickeln, von dem 2004 die ersten Exemplare an die Truppe ausgeliefert wurden. Dieses Basismodell soll ab 2008 erweitert werden, und es ist geplant, lediglich um die 1.100 Komplettausrüstungen des IdZ anzuschaffen. Es ist also nicht beabsichtigt, alle Infanteristen der Kampftruppen mit dieser Ausrüstung auszustatten, sondern lediglich einige Spezialverbände. Die anderen Soldaten sollen einzelne Komponenten dieser Ausrüstung erhalten. Im Vergleich zu den US-Programmen handelt es sich insgesamt um ein wesentlich weniger ambitioniertes Vorhaben, das zwar einige Parameter der NCW erfüllen soll, aber beispielsweise darauf verzichtet, jeden einzelnen Soldaten in das Informations- und Kommunikationsnetzwerk zu integrieren. Dies zeigt sich auch daran, dass nur der Kommandeur einer Gruppe von 10 Soldaten durch Funk in ein übergeordnetes Kommunikations- und Informationsnetz eingebunden werden soll. Die anderen Soldaten der Gruppe bleiben von der Kommunikation mit übergeordnete Kommandostellen ausgeschlossen und auf den Austausch untereinander angewiesen. Da obendrein derzeit verschiedene Kommunikationssysteme zwischen dem Verteidigungsministerium und den übergeordneten Führungsstellen sowie den sich im Einsatzgebiet befindlichen Einheiten bestehen, die nicht oder nur äußerst eingeschränkt interoperabel sind (siehe Lange 2004: 23f.), genügt all dies den Erfordernissen einer oben beschriebenen NCW nur rudimentär. ${ }^{37}$

Obwohl eine NCW nicht im vollen Umfang praktiziert werden kann, weil die notwendigen Kommunikationsmittel fehlen, deuten einige Berichte aus Kriegen der jüngeren Vergangenheit an, dass sich das Führungsverhalten von Kommandeuren bereits durch die immer umfassendere Digitalisierung von Informationen und ihre Einspeisung in Computernetzen verändert hat. Da sie große Schwierigkeit haben auf diese Informationen zuzugreifen, wenn sie sich mit ihren Untergebenen auf dem Gefechtsfeld befinden, entscheiden sich zumindest einige Kommandeure dafür, aus dem rückwärtigen Raum ihre Befehle zu erteilen. Die Vorgesetzten führten, so eine Klage eines israelischen Leutnants im Libanonkrieg 2006, nicht mehr ihre Untergebenen ins Gefecht und teilten deshalb nicht mehr

lungszentrum der US-Army in Natick, Massachusetts (siehe http://nsc.natick. army.mil/media/print/FFW_Trifold.pdf; Zugriff 9.9.07). Siehe auch die Internetseite des Konzerns General Dynamics zum Future Force Warrior Programm. Eine Planungsübersicht ist unter http://www.gdc4s.com/documents/w arriorsystems_0307.pdf zu finden (Zugriff: 9.9.07).

37 Über die derzeitige Ausrüstungskomponenten des IdZ's informiert die Bundeswehr auf ihrer Internetseite http://tinyurl.com/ypbmca (Zugriff. 12.10.07). 
mit ihnen das gleiche Risiko verletzt oder getötet zu werden. Weit weg vom Kampf, verfolgten sein Bataillon- und sein Brigadekommandeur an ihren Computermonitoren das Geschehen (siehe Keller, A. 2006). Die Feststellung, dass seine Vorgesetzten am Monitor sitzend das Geschehen verfolgen und von hier aus Befehle erteilen, erhöhte wahrscheinlich nicht die Kampfmotivation des Soldaten.

Von der Schwierigkeit für die Kommandeure während eines Gefechts Informationen in das Computernetz zu speisen und auszuwerten, zeugt auch ein Bericht über Experimente, die die Bundeswehr 2006 auf Kompanieebene mit ihrem Konzept der >Vernetzten Operationsführung « unternommen hat. Durch diese Form der Operationsführung lasse sich zwar der Einsatzwert einer Kompanie erhöhen, so ein vorsichtig formuliertes Fazit, aber es bestehe auch ein »unmittelbares Spannungsfeld zwischen der Führung des Waffensystems bzw. der Teileinheit im Gefecht sowie der Eingabe am Informationssystem« (Hübner 2007: 24). Die Vorteile der Vernetzung machen sich vor allem bei der Vorbereitung eines Gefechts bemerkbar und verringern sich im Verlauf eines Kampfes, da nun die gewonnenen Informationen von den Kommandeuren immer weniger vor Ort digital erfasst und ausgewertet werden können.

Jenseits des infanteristischen Kampfes sieht die bisherige Bilanz der NCW etwas besser aus, da sich durch sie die Entscheidungsprozesse inbesondere bei der US Air Force beschleunigen ließen und die Luftwaffe ihre Operationen enger mit denen der Bodentruppen koordinieren konnte (Schreer 2004: 12, siehe auch Eder/Hofbauer 2003: 580f.). Auch die Entscheidung der US-Administration den Irak mit wesentlich weniger Bodentruppen als noch im 2. Golfkrieg (1991) anzugreifen, ${ }^{38}$ wird im allgemeinen auf konzeptionelle Überlegungen der NCW zurückgeführt (Kaufmann 2005: 254). Trotzdem: die NCW bleibt, auch in den kommenden Jahren vor allem eines: eine Vision. Eine Vision, die sich aber bereits heute auf die Vorstellungen von soldatischer Subjektivität auswirkt. $\mathrm{Ob}$ und inwieweit in der Ausbildung der Soldaten die Erfordernisse der NCW berücksichtigt werden, darüber lässt sich zwar anhand der ausgewerteten Publikationen keine Aussage treffen, aber es lässt sich feststellen, dass zahlreiche Publikationen konzeptionell auf die NCW hinweisen oder zu-

38 Über die Schwächen der NCW im Krieg gegen die irakischen Streitkräften (2003) informieren unter anderen Schwiebert (2004) sowie Reisner (2006). In den letzten Jahrzehnten sind für Flugzeugbesatzungen die Gestaltungsmöglichkeit ihres Einsatzes eher gesunken, weil die Kampfflugzeugen der avancierten Militärmächte hauptsächlich zur Bekämpfung von Bodenzielen eingesetzt werden bzw. die Bodentruppen bei ihren Operationen zu unterstützen haben. Die Kommandeure der Bodenverbände fordern diese Unterstützung an und nach wie vor spielen Befehlszentralen, von denen aus die Flugzeuge aus kontrolliert werden, eine wichtige Rolle. Die umfangreichen Aufklärungsinformationen, die inzwischen häufig beanspruchen die aktuelle Situation abzubilden, schaffen die Grundlage für immer detailiertere Anweisungen. 
mindest doch erkennbar vom »network-centric thinking « (Alberts/Garstka/ Stein 2000: 88) beeinflusst sind. Ein Beispiel für Letzteres ist ein von der US-Army veröffentlichter Videofilm, der wie folgt beschrieben wird: »Every soldier is a sensor. The individual Soldier is the most capable, sophisticated collector of intelligence in today's Army. In order to fully harness this capability, the Army must ensure that `Every Soldier is a Sensor.« (http://www.army.mil/professionalvideo/movies/sensor.html; Zugriff 10.10.07)

Die von der NCW angestrebte Effektivitätssteigerung der Soldaten orientiert sich stark an den Rationalisierungsprozessen der New Economy. Mobiler, kleiner, flexibler und effektiver sollen die Streitkräfte werden. Veranschaulicht werden diese Zielvorstellungen mit Bezügen auf Unternehmenskonzepte wie >lean production « und >just in time ২. Während in der Produktion und im Handel versucht wird durch Einsatz von Informationstechnologien den Gewinn zu steigern, soll beim Militär die Schlagkraft erhöht werden. ${ }^{39}$ Nicht nur der Begriff des Netzwerkes steht in den Publikationen hoch im Kurs, sondern auch originäre ökonomische Begrifflichkeiten, die herangezogen werden, um die angestrebten Veränderungen zu erläutern (siehe beispielsweise Bundesministerium für Verteidigung 2006b: 99).

Grafik 3: Vernetzte Operationsführung

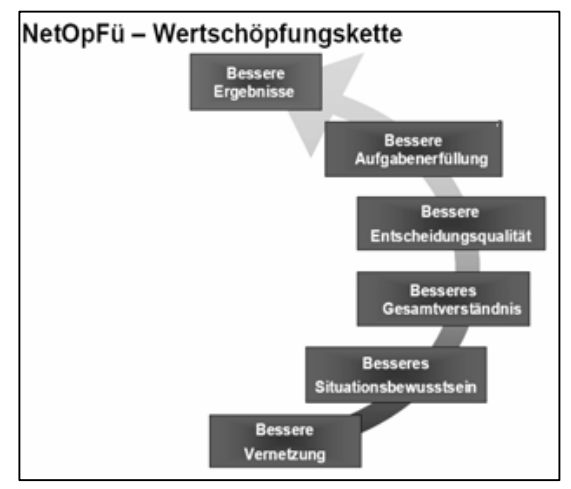

Aus: Luftwaffenamt: 14

Kooperations- und Kommunikationsfähigkeit sowie die Gabe, sich schnell auf verändernde Situationen einzustellen, werden als zentrale Tugenden

39 Als ein Vorbild der >Network Centric Philosophy< (Schwiebert) wurde ausdrücklich der Einzelhandelskonzern Wal-Mart erwähnt (Cebrowski/Garstka 1998: 28). Der Konzern minimierte unter anderen seine Lagerhaltung, indem er die Daten verkaufter Waren von den Kassen direkt an die Lieferanten übermittelte (Schwiebert 2004: 36; Cebrowski/Garstka 1998). Zu Wal-Mart siehe auch Lichtenstein (2006). 
von Soldaten eingestuft, die für eine Kriegführung nach Maßgaben der NCW besonders geeignet sein sollen. Diese Anforderungsprofile an (künftige) Soldaten stimmen weitgehend mit denen überein, die in der zivilen Arbeitswelt en vogue sind und in der (Industrie-)Soziologie unter dem Stichwort Subjektivierung diskutiert werden.

Die ökonomische Betrachtung jedes einzelnen Soldaten, seiner Ausrüstung und Bewaffnung drückt sich auch darin aus, dass sie als zu optimierende Systeme aufgefasst werden. Die Streitkräfte in toto werden ebenfalls als ein Verbund von Systemen erachtet. So findet man in verschiedenen Dokumenten der US-Army die Formulierung: »Soldiers systems will be treated as an integrated System of Systems (SoS).« (siehe beispielsweise www.army.mil/fcs/whitepaper/FCSWhitePaper(v19_29Sep 05).doc; Zugriff: 10.10.07) Diese Integration geht einher mit gesteigerten Anforderungen an das $>$ System Soldat .

Die NCW sieht in der soldatischen Subjektivität eine Effektivitätsressource, die durch den Einsatz neuer Technologien und organisatorischer Veränderungen des Militärs mobilisiert werden soll, um die Schlagkraft des Militärs auf allen Ebenen - als Sensor, als Entscheider und als Anwender von >Wirksystemen`, sprich Waffen - zu erhöhen. Ob aber die soldatischen Subjekte die Vorstellungen der NCW zu professionellem soldatischem Handeln übernehmen,

- ob sie also in der Lage sein werden, sich flexibel auf immer neue Situationen einzustellen,

- ob sie im angestrebten Ausmaß mit Soldaten aus unterschiedlichen Teilstreitkräften und Rängen kooperieren und kommunizieren und eigenverantwortlich initiativ handeln können,

- ob die Hierarchieebenen den notwendigen Freiraum dafür gewähren,

- ob sie sich durch technische Innovationen, durch eine (angestrebte) NCW-adäquate Ausbildung und durch einige organisatorische Veränderungen in dem erwünschten Maße für diese Form der Kriegführung mobilisieren lassen, sind Fragen, die offen sind.

Soviel ist aber sicher: Die NCW beansprucht, ähnlich wie die deutsche Auftragstaktik vor dem 1. Weltkrieg, die überkommenen Methoden der Kriegführung zu ändern, um sie neuen Bedingungen anzupassen. Die Soldaten soll(t)en kreativ die offen gelassenen Handlungssituationen für eine effektivere Kriegführung nutzen. Während allerdings die Befürworter der Auftragstaktik auf die sich vollziehende Industrialisierung des Schlachtfeldes reagierten, müssen im Falle der netzwerkzentrierten Kriegführung die neuen Technologien erst noch bei den Streitkräften implantiert werden, damit sich das Gefechtsfeld ändert. 


\subsection{Paradoxien gegenwärtiger Einsatzszenarios}

Soldaten haben ihre gesamte Person, Leib und Leben einzubringen, um die ihnen erteilten Befehle auszuführen. Diese institutionelle Erwartung an das Handeln der Soldaten gilt besonders im Kriegseinsatz. Auch in Friedenszeiten können den Soldaten extreme Belastungen auferlegt werden und sie können sich in lebensgefährlichen Situationen befinden, wenn sie Deiche vor andrängenden Wassermassen sichern oder Schiffbrüchige retten sollen. So wichtig aber solche Einsätze für das Selbstverständnis der Soldaten sein mögen und sie auch ein Bestandteil der Selbstdarstellung des Militärs sein können, die Militärorganisation sowie die Ausrüstung der Soldaten sind nicht an der Abwehr von Naturgewalten ausgerichtet, sondern auf die Fähigkeit selber Gewalt gegenüber anderen Menschen auszuüben.

Bis Ende der 80er Jahre des vergangenen Jahrhunderts waren die Streitkräfte der westlichen Industriestaaten vor allem auf die Austragung von Staatenkriegen ausgerichtet. Im Zentrum verschiedener Kriegsszenarios stand dabei die militärische Zuspitzung des Kalten Krieges, die zu Kämpfen zwischen den Truppen der NATO und des Warschauer Paktes führt. Mit dem Ende des Ost-West-Konfliktes bestimmt die klassische >Landesverteidigung zum Schutz des staatlichen Territoriums nicht mehr die Einsatzszenarios der westlichen Militärs. Der Staatenkrieg ist damit jedoch nicht aus dem Repertoire ihrer Einsatzszenarios verschwunden. An die Stelle der großen Konfrontation mit einem anderen Staatenbund ist vielmehr die Intervention gegen oder in mitunter weit von den eigenen Landesgrenzen entfernten Staaten getreten.

\subsubsection{Tableau der Einsatzszenarios}

Zwischen den Verbündeten herrscht weitgehender Konsens in der Beschreibung möglicher Gegner. So werden in den Verteidigungspolitischen Richtlinien der Bundesrepublik und in den Darlegungen der US-Administration zu ihrer Nationalen Sicherheitsstrategie gegen den >internationalen Terrorismus $\iota$, die Proliferation von Massenvernichtungswaffen sowie weiterreichender Trägermittel als Bedrohungen benannt. Weiter wird betont, dass sich Bedrohungen aus regionalen Krisen und Konflikte ergeben können (siehe Bundesministerium für Verteidigung 2006b: 21f.; White House 2002: 5f.). Die konventionellen Streitkräfte anderer Staaten können in allen genannten Bedrohungsszenarios ein möglicher zu bekämpfender Gegner sein und der größte Teil der Rüstungsausgaben der USA und ihrer Verbündeten dienen dem Zweck, ihre Fähigkeiten zu verbessern, Staatenkriege in vom eigenen Territorium weit entfernten Gebieten zu führen. Als mögliche Gegner in konventionellen Kriegen rechnen die US-Streitkräfte konkret mit dem iranischen und dem nordkoreanischen Militär. Im Falle 
einer militärischen Bedrohung Taiwans durch die Volksrepublik China gelten militärische Auseinandersetzungen mit den chinesischen Streitkräften als denkbar (siehe Schreer 2004: 22; zu China siehe Department of Defense 2006: 29f.). Auch wenn die Verbündeten der USA meist weniger deutlich andere Staaten als potentielle Kriegsgegner benennen als die amtierende US-Administration, so schließen auch ihre Einsatzszenarios einen Krieg gegen andere Staaten grundsätzlich nicht aus.

Die Streitkräfte anderer Staaten bilden allerdings nur eine Gruppe potentieller Gegner. Bei weitem zahlreicher sind solche Akteure, die nicht zu den bewaffneten Kräften eines Staates gezählt werden können, also substaatlich sind. Viele dieser substaatlichen Akteure werden derzeit als terroristisch eingestuft. Sie können aus sehr unterschiedlichen Gründen zu Kombattanten werden. Mit der Bekämpfung von Gruppen, die verdächtigt werden, Anschläge auf Einrichtungen und Staatsangehörige der Industriestaaten im Ausland vorzubereiten, durchgeführt zu haben oder für solche Anschläge in Europa oder Nordamerika verantwortlich zu sein, werden Einsätze des Militärs ebenso begründet, wie mit der Bekämpfung von Gruppen, die eine von den Industriestaaten anerkannte politische Ordnung bekämpfen oder gefährden. Spätestens im Zuge der Konfrontation mit regulären Streitkräften wenden diese Gruppen überwiegend Methoden der Kleinkriegführung an.

Substaatliche Akteure sind keine neuen militärischen Gegner für reguläre Streitkräfte, vor allem nicht für die Truppen ehemaliger Kolonialmächte und den USA. Neu ist, dass heute der Kampf gegen Gegner, die Methoden der Kleinkriegführung anwenden, als gleichrangig mit dem Krieg gegen regulär kämpfende Truppen gilt. Letztere stellen dem Verständnis der amtierenden US-Administration nach die traditionellen Herausforderungen, die die »well-established forms« der militärischen Konkurrenz bilden (White House 2006: 44). Anders dagegen die irregulären Herausforderungen: Sie entstehen wenn "state and non-state actors employing methods such as terrorism and insurgency to counter our traditional military advantages, or engaging in criminal activity such as piracy and drug trafficking that threaten regional security.« (Ebd.) Mit dem erhöhten Stellenwert, den der Krieg vor allem gegen substaatliche Akteure heute einnimmt, reagieren die USA, aber auch die politischen und militärischen Führungen anderer Staaten konzeptionell auf die Realitäten der Militäreinsätze der westlichen Industriestaaten. ${ }^{40}$ Seit dem Ende der

40 Der konzeptionelle Wandel soll in den USA rüstungspolitische Folgen haben. So empfiehlt das US-Verteidigungsministerium dem Kongress unter anderen den Umfang der »Special Operations Forces« (SOF) erheblich zu erhöhen, um verstärkt in »denied areas « operieren zu können (siehe Department of Defense 2006: 5, 44f.). Neben solchen rüstungspolitischen Maßnahmen sieht das Ministerium einen wachsenden Bedarf an Kampfkommandeure mit »politicalmilitary analysis, critical language skills and cultural adeptness « (ebd.: 78). Angestrebt wird ein »level of understanding and cultural intelligence about 
Kampfhandlungen gegen die irakische Armee im Frühjahr 2003 kämpfen die Streitkräfte der USA und ihrer Verbündeten in Afghanistan und dem Irak ausschließlich gegen substaatliche Akteure.

Vor allem der Kampf gegen substaatliche Akteure hat zu einer großen Varianz möglicher Einsatzszenarios geführt, die Interventionstruppen heute beherrschen sollen. Dabei ist zu beachten, dass die einzelnen Staaten die Bedeutung der einzelnen Szenarios unterschiedlich gewichten. Dies gilt unter anderen für die Frage, welches Gewicht sie Einsätzen zumessen in deren Zentrum keine intensiven Kampfhandlungen stehen. In den vergangenen Jahren haben sowohl die US-Army als auch die amtierende USAdministration wiederholt die Auffassung vertreten, dass solche Einsätze schädlich für die Moral und Kampfbereitschaft der Truppe seien (siehe Moskos 2001). Um die Truppen für hochintensive Kampfeinsätze einsatzbereit zu halten, müssten die Truppen verbündeter Staaten solche Einsätze übernehmen (siehe Schreer 2004: 23). Das aktuelle Papier zur Nationalen Sicherheitsstrategie erklärt zwar inzwischen die Stabilisation und den Wiederaufbau für eine wichtige Phase bei Interventionen in »regional conflicts« (White House 2006: 15), doch wird, wie die Ausführungen des Verteidigungsministeriums zeigen, weiterhin dabei vor allem an die Kapazitäten verbündeter Staaten gedacht (88f.). Einer dieser Bündnispartner, die Bundeswehr, bereitet einen Teil seiner Verbände, die so genannten Stabilisierungskräfte, auf solche Einsätze vor (siehe Bundesministerium für Verteidigung 2006b: 87).

Für die US-Streitkräfte gilt obendrein, dass sie nach Ansicht der amtierenden US-Administration offensive Präventivoperationen durchführen sollen, wenn sie beispielsweise zu dem Schluss kommt, das staatliche oder substaatliche Akteure Massenvernichtungswaffen gegen die USA entwickeln. Solche Operationen werden zumindest öffentlich nicht für die Bundeswehr diskutiert.

Versucht man die in der Diskussion stehenden möglichen Einsatzszenarios anhand ihrer als wahrscheinlich angenommene Dauer aufzulisten, stehen im Allgemeinen an erster Stelle Operationen, die die eigenen und die Staatsbürger verbündeter Staaten vor der Gewalt der Kriegsparteien schützen sollen. $\mathrm{Zu}$ denken ist dabei zum einen an Evakuierungen aus Kriegsgebieten, zum anderen aber auch an Kommandounternehmen, mit denen die Staatsbürger aus der Gewalt gegnerischer Kombattanten befreit werden sollen. ${ }^{41}$ Mit Staatenkriege die sich über Monate, gar Jahre hinziehen, rechnen die Militärs dagegen nicht. Allenfalls wird damit gerechnet, dass sich die Kampfhandlungen mit gegnerischen und regulär kämpfenden Truppen über Wochen hinziehen könnten. Solche Einsätze würden damit

the Middle East and Asia comparable to that developed about the Soviet Union during the Cold War."

41 Für solche Einsätze sieht das Heer den Einsatz von Verbänden der Division Spezielle Operationen vor (siehe Glatz 2003: 28). 
in das Mittelfeld der Liste angenommenen Einsatzszenarios fallen. Am Ende einer solchen Liste stehen Operationen, die langwierige politische Prozesse absichern sollen - die Stabilisierungseinsätze. Mit ihnen sollen zugleich zuvor erfolgreich geführte Staatenkriege abgeschlossen werden.

Alle genannten Einsatzszenarios können Phasen hoher Kampfintensität aufweisen. Dies gilt auch für die Stabilisierungseinsätze. Die Stabilisierungskräfte der Bundeswehr sind, wie es in der Grundkonzeption der Bundeswehr aus dem Jahr 2004 heißt, für

»multinationale, streitkräftegemeinsame, militärische Operationen niedriger und mittlerer Intensität und längerer Dauer im breiten Spektrum friedensstabilisierender Maßnahmen vorgesehen. Sie müssen in der Lage sein, sich gegen einen teilweise militärisch organisierten Gegner sowie asymmetrisch kämpfende Kräfte bei möglichst geringen eigenen Verlusten durchsetzen zu können. [...] Einsätze zur Konfliktverhütung und Krisenbewältigung können den gleichzeitigen oder zeitlich eng nachgestaffelten Einsatz von Eingreifkräften [zu denken wäre dabei an Verbände der Division Spezielle Operationen, d.A.] und Stabilisierungskräften bedeuten. Zwischen ihnen besteht ein operatives Wechselspiel.« (Bundesministerium für Verteidigung 2004: 26)

In Hinblick auf die Intensität der Gefechte weist der amtierende Inspekteur des Heeres Budde darauf hin, dass das »was aus strategischer und politischer Sicht als Teil einer Stabilisierungsoperation angesehen wird [...] für die taktischen Führer vor Ort Kampf in höchster Intensität« (Budde 2005: 111) sein kann. Bereits der Einsatz in einem mittleren Intensitätsspektrum könne für die Truppe »sehr heftig sein« (ebd.) und er nennt dazu beispielhaft die Straßenkämpfe in Falludscha. Er spielt dabei vermutlich auf Operationen der US-Streitkräfte im November 2004 an, die zur Eroberung der irakischen Großstadt führten. Um sich eine Vorstellung von diesen Kämpfen zu machen: Obwohl vor den Kämpfen ein großer Teil der Bevölkerung aus der Stadt floh, wurden vermutlich 1250 Zivilisten verwundet und starben 600 im Verlauf der Gefechte zwischen den Aufständische und den USTruppen (Luyken 2005: 13). Über die Hälfte der 39.000 Gebäude der Stadt waren anschließend schwer beschädigt, »10.000 davon so sehr, dass sie nicht wiederaufgebaut werden können.« (Ebd.: 14) Die US-Streitkräfte gehen von 1.200 getöteten Aufständischen aus (ebd.) und hatten im Verhältnis zur Dauer der Kampfhandlungen mit 71 toten und über 600 verwundeten Soldaten höhere Verluste als während des Feldzuges des Irak im Frühjahr 2003 (Lange 2005a: 3; Luyken 2005: 14).

Mag der Einsatz der US-Truppen in Falludscha geeignet sein, die mögliche Intensität von Gefechten zu charakterisieren, zu denen Interventionstruppen fähig sein sollen, in einer anderen Hinsicht müssen diese Operationen als eher untypisch für den Kampf gegen Gegner gelten, die Methoden der Kleinkriegführung anwenden. Großräumig angelegte Kampfhandlungen, die darauf abzielen, die militärische Kontrolle über 
eine Großstadt zu erlangen, gelten nicht als alltägliches Einsatzszenario. Es ist vielmehr erwartet, dass die Soldaten gezwungen sind, in sehr eng benachbarten Räumen auf unterschiedliche Einsatzlagen reagieren und entsprechend anders geartete Operationen durchzuführen zu müssen. Wenn in benachbarten Räumen parallel oder doch zumindest zeitlich eng aufeinander folgend verschiedenartige Formen von Einsätze durchgeführt werden, spricht die Bundeswehr von Three-Block-Operationen (siehe Budde 2005: 107). Damit wird eine Begrifflichkeit aufgegriffen, die vom in der 2. Hälfte der 90er Jahre amtierenden Generalstabschef des US-Marine-Corps, General Charles Krulak, geprägt wurde. In einer Rede vor der amerikanischen Journalistenvereinigung >National Press Club führte Krulak in Washington 1997 aus, dass die Soldaten

»in one moment in time [...] will be feeding and clothing displaced refugees providing humanitarian assistance. In the next moment, they will be holding two warring tribes apart - conducting peace-keeping operations. Finally, they will be fighting a highly lethal mid-intensity battle. All on the same day, all within three city blocks.« (Zitiert nach Cocksedge 2005: 267).

Krulak nannte dieses Szenario einen »three block war«. Mit dieser Bezeichnung wollte er auch den bevorzugten Einsatzort der Soldaten umreißen: den urbanen Raum. Die Annahme, dass Städte und ihre urbanes Umfeld ein immer wichtiger werdendes Kampfgebiet für Interventionstruppen werden, stützt sich auf demographische Forschungserkenntnisse, die beispielsweise von den Vereinten Nationen publiziert werden. So weisen die Vereinten Nationen unter anderen darauf hin, dass in den entwickelten Regionen bereits im Jahr 2003 knapp 75 Prozent in urbanen Räumen lebten und noch vor dem Jahr 2010 mehr Menschen in städtischen Gebieten leben werden als auf dem Land (United Nations D.o.E.a.S.A. 2003: 4f.).

So verschiedenartig die einzelnen Interventionen sich auch gestalten mögen, zusammenfassend lässt sich feststellen, dass im Mittelpunkt der konzeptionellen Überlegungen zu möglichen Einsatzszenarios Kampfhandlungen stehen. Soldaten können zwar den Befehl erhalten, Brücken zu bauen, Lebensmittel an Zivilisten zu verteilen und zwischen verschiedenen Konfliktparteien moderierend einzugreifen, aber in ihrem Selbstverständnis bleiben sie auf das Äußerste hin - dem Kampf - fokussiert. Dies gilt auch für die Bundeswehr, die nicht so explizit wie beispielsweise die USStreitkräfte auf die Durchführung intensiver Kampfhandlungen ausgerichtet sind. So führte der Heeresinspektor Budde aus: "Wir Soldaten sind eben keine bewaffneten Sozialhelfer und sind auch kein bewaffnetes THW! Das verlangt, die Ausbildung konsequent auf die heute und in $\mathrm{Zu}-$ kunft wahrscheinlichen Einsatzerfordernisse auszurichten, und das verlangt, hart und konsequent auszubilden. Es gilt, das militärische Handwerk zu beherrschen, unter allen Bedingungen. Das erfordert physische und psychische Robustheit, und das erfordert nach wie vor die Befähigung zum 
Kampf. Denn die Fähigkeit zum Kampf ist die Klammer, die das Heer wenn Sie so wollen - auch zusammenhält, ist die Voraussetzung zur Durchsetzung von Aufträgen in jedem Intensitätsspektrum - und darüber hinaus auch Teil der persönlichen »Risikovorsorge« unserer Soldaten.« (2005: 113f.)

Das Tableau der Einsatzszenarios hält zahlreiche Paradoxien bereit. Eine solche Paradoxie ergibt sich aus der Vorstellung zukünftige Kriege mit sehr wenigen Soldaten zu führen, während gleichzeitig ausgesprochen personalintensive Militärinterventionen als wahrscheinlich gelten. Wenn die Truppen Regionen und Städten kontrollieren sollen, um solche Verhältnisse zu verhindern, wie sie 2003 nach dem Sieg über die irakische Staatsmacht entstanden, einen Waffenstillstand zwischen regionale Kontrahenten überwachen und einen Prozess der Staatenbildung (nationbuilding) absichern sollen, dann werden sehr viele infanteristische Verbände benötigt. Auf einer ähnlichen Ebene bewegt sich der Widerspruch zwischen der Vorstellung, dass die Truppen hochmobil und deshalb auch luftverladbar sein sollen und der Erwartung, dass sie mit sicheren Fahrzeugen ausgestattet sind. Die Verbände sind aber vor allem deshalb mobiler geworden, weil man meinte, auf stark gepanzerte Fahrzeuge verzichten zu können, da die zu erwarteten Gegner ihrerseits entweder nicht über solche Fahrzeuge verfügen oder im Kriegsgebiet schnell die Luftherrschaft errungen werden kann. Sofern also ein Gegner doch einmal über Panzer und Artillerie verfügt, wären diese leicht auszumachende Ziele und könnten aus großer Distanz bzw. aus der Luft attackiert werden. Un- oder nur leichtgepanzerte Fahrzeuge sind allerdings, dies zeigen die Erfahrungen der Kriege in Afghanistan und im Irak auch gute Ziele für Gegner, die snur» mit panzerbrechenden Raketen und mit Bomben angreifen (Schreer 2004: 19). Die Bundeswehr versucht diesen Zielkonflikt zu lösen, indem sie einen Schützenpanzer (Projektname Puma) entwickeln lässt, der mit ebenfalls noch zu bauenden Transportflugzeuge (Airbus A400 M) ins Kriegsgebiete geflogen werden kann, aber vor Ort mit zusätzlichen Panzerungen ausgestattet werden muss, um tatsächlich Schutz vor Panzerabwehrraketen zu bieten. Ob dies aber als eine sinnvolle Vorstellung gelten kann, »scheint«, so formuliert Lange vorsichtig, »einer näheren Untersuchung wert zu sein.« (Lange 2005b: 19)

In den nachfolgenden Ausführungen wird auf solche Widersprüche nicht weiter eingegangen. Sie konzentrieren sich stattdessen auf Paradoxien, die die soldatischen Subjekte betreffen. Wie sich vor allem an der Wirkung von Auslandseinsätzen auf das Selbstverständnis von Soldatinnen und Soldaten der Bundeswehr im Zuge ihres Einsatzes zeigen wird, ergeben sich zum einen Paradoxien quasi als unintendierte Nebenfolgen der gefahrvollen Auslandseinsätze. Zum anderen stellen die Einsatzszenarios die Einsatzkräfte vor verschiedene, disparate, wenn nicht gar paradoxe Verhaltensanforderungen. Dies gilt mit besonderer Härte für die Soldaten, 
die den Kampfverbänden von Bodentruppen zugeordnet sind und die einen three block war führen sollen.

\subsubsection{Zu den Auswirkungen von Auslandseinsätzen auf das Verhältnis von nichtmilitärischer Gesellschaft und Militär}

Soldaten, die in weit entfernten Regionen intervenieren sollen, werden auf eine militärische Lebenswelt verwiesen, die sich in Abgrenzung von der sie umgebenden Zivilgesellschaft bildet. Sie kommen meist in Regionen, deren Klima sie als belastend erleben und in denen es ungewohnte Krankheiten gibt. Sie sehen häufig ein vom Kriegsgeschehen gezeichnetes Land, in dem sie sich kaum jenseits dienstlicher Belange bewegen können, weil sie damit das Risiko stark erhöhen, ihr Leben zu verlieren. In den Einsatzgebieten gibt es zahlreiche Bedrohungen, die von kriegerischen Hinterlassenschaften wie Minen, über feindselig eingestellte Bevölkerungsgruppen, bis hin zu der Gefahr, Opfer von Anschlägen zu werden, reichen. Viel stärker als in den Herkunftsgesellschaften sind sie deshalb gezwungen für die Dauer ihres Auslandseinsatzes auch ihre Freizeit permanent mit den Angehörigen ihres Verbandes zu verbringen. Die meisten Angehörigen von Interventionstruppen leben in Lagern und Soldaten, die Kommunikations-, Wartungsarbeiten etc. innerhalb der Lager zu verrichten haben, verlassen es mitunter nur bei der An- und Abfahrt. Mit der sie umgebenden zivilen Gesellschaft haben diese Soldaten kaum Kontakt.

Wie sehr Auslandseinsätze nicht nur eine geographische Entfernung von der vom Entsendeland, sondern auch von der Herkunftsgesellschaft bedeuten, zeigt eine Befragung von Bundeswehr-Soldaten und -Soldatinnen. Sie wurden in der 2. Hälfte der 90er Jahre während und nach ihrem Einsatz in Bosnien-Herzegowina vor allem in Hinblick auf ihr Selbst- und Berufsverständnis interviewt (Seiffert 2005). Die Autorin beobachtet bei den Soldaten und Soldatinnen, dass ihre Einsatzteilnahme zu einem »Umdenkungs- und Anpassungsprozess des soldatischen Selbstverständnisses an die Anforderungen des militärischen Einsatzalltages (176f.) führt. Mit ihrer »Integration in die Einsatzwelt« (ebd.: 198) nehme merklich ihre Orientierung an militärischen Wert- und Normorientierung zu (ebd.: 176). Im Verlauf ihres Einsatzes und im Zuge wiederholter Verwendung zu weiteren Auslandseinsätzen verschiebe sich das »soldatische Selbstverständnis vom Staatsbürger in Uniform zu einem Soldatentypus, der in einem internationalen Umfeld multifunktional einsetzbar ist und sich als Einsatzprofi versteht.« (Ebd.: 179) Die Soldatinnen und Soldaten orientierten sich an einer »kollektiven sozialen Praxis«, die sich an einer »möglichst effiziente(n) und funktionale(n) Auftragsdurchführung« ausrichte (ebd.: 200f.). Dies führe zu einer stärkeren Gewichtung der formalen Praxis von Befehl und Gehorsam, mit der die Subjekte die in den Einsätzen gestiegene »Ver- 
antwortlichkeit für eignes Handeln« sowie den Zwang, rasch und zügig Entscheidungen zu treffen (ebd.) milderten. Militärische Werte seien »immer weniger an und in einem gesamtgesellschaftlichen Bezugssystem verortet« (ebd.: 230) und in der Konsequenz sei zu befürchten, »dass die Entwicklung militärischer und ziviler Sinn- und Wertewelten weiter auseinanderdriftet« (ebd.: 231). Für die Soldaten und Soldatinnen bedeute diese Entwicklung soziale Anpassungsschwierigkeiten, wenn sie in eine nicht vom Krieg und Militär geprägte Gesellschaft zurückkehrten (ebd.: 179). Allgemeiner formuliert, desintegrative Prozesse von Militär und Gesellschaft seien vorprogrammiert. Eine Folge wäre die Bildung von abgeschotteten Milieus - ein Weg, der »für eine Teilgruppe von Soldaten, mit einem militärisch-handwerklichen Verständnis von Disziplin [...] längst gebahnt« sei (ebd.: 298).

Durch die Anpassung des soldatischen Selbstverständnisses wird die Einsatzfähigkeit der Soldaten aber nicht nur gestärkt, sondern paradoxerweise auch untergraben. »Ein Disziplinverständnis« so Seiffert, »das sich strikt an der militärischen Praxis von Befehl und Gehorsam orientiert, ist angesichts der komplexen Anforderungen an Verhaltens- und Handlungsweisen in den Kriseneinsätzen der Bundeswehr geradezu kontraproduktiv.« (Ebd.: 230)

Die Fügsamkeit und Bereitschaft zur Unterordnung der Soldaten steigt nicht nur, weil sie die Komplexität von Situationen senken wollen, indem sie sich den Entscheidungslasten entziehen. Sie wird auch in hohem Maße von ihnen gefordert, um ihr Gewaltpotential zu kontrollieren. Besonders für Truppenverbände, die einen zuvor ausgehandelten Waffenstillstand absichern sollen, für Soldaten, denen kein eindeutig erkennbarer militärischer Gegner gegenübersteht und die stattdessen mit einer Vielzahl unterschiedlicher Konflikte konfrontiert sind, die nicht eskalieren sollen, werden umfangreiche und detaillierte Handlungsanweisungen von Seiten der politischen und militärischen Führung erlassen. Von den Mitgliedsstaaten der NATO werden diese Anweisungen als rules of engagement bezeichnet. In ihnen werden die Umstände festgelegt, die Bedingungen sowie der Grad und die Art und Weise formuliert unter denen die Soldaten Gewalt anwenden dürfen. Diese Regelungen werden meist vor dem Einsatz zwischen beteiligten Staaten und den Konfliktparteien ausgehandelt. Die einzelnen Soldaten werden zumindest in Grundzügen über die Einsatzregeln unterrichtet. Darüber hinaus erhalten die militärischen Befehlshaber oft noch zahlreiche minutiöse Anweisungen, die der Geheimhaltung unterliegen. Die rules of engagement halten Vorgesetzte, wie Susanne Gaschke von einem Lehrgang für ein Kontingent von Bundeswehr-Soldaten berichtet, das nach Afghanistan entsandt wurde, dazu an, ihren Untergegebenen stringente Handlungsanweisungen zu geben. Befehle, die den Untergebenen Interpretationsspielraum über die Art und Weise ihre Gewaltausübung gewähren, sollen vermieden werden. Ein Hauptmann, dem eine unklare 
Befehlserteilung an einen Scharfschützen vorgeworfen wird, weisen die Ausbilder darauf hin, dass er sich, »wenn alles schief geht« unverzüglich bei der Staatsanwaltschaft in Potsdam melden müsse (Gaschke 2004: 3). Ziel dieser Form der Befehlserteilung ist die Vermeidung von ungeplanten politischen Konsequenzen aufgrund von Gewaltanwendungen, die zuvor nicht mit den Bündnispartnern und den Konfliktparteien abgesprochen waren.

Vor allem von Seiten hochrangiger Offiziere des deutschen Heeres haben die rules of engagement und der mit ihnen verbundene Zwang, ihre Entscheidungen mit verschiedenen Regierungen abzustimmen zu der Klage geführt, dass die Auftragstaktik mit den Auslandseinsätzen an Bedeutung verloren habe (siehe Leistenschneider 2002: 149). Die Auftragstaktik verliere obendrein an Relevanz, weil sich an den meisten Einsätze mehrere nationale Streitkräfte beteiligen, die überwiegend die Befehlstaktik anwenden. Auch Millotat kommt zu dem Ergebnis, dass Auftragstaktik als Führungsprinzip durch die rules of engagement eingeschränkt sein kann (2002: 25). ${ }^{42}$ Als Führungsprinzip sei sie aber noch bei » ungeklärter Rechtslage und bei Entscheidungen und Handlungen, d.A.] unter Zeitdruck ins Ungewisse hinein« (ebd.: 26) relevant. Im Rahmen dieser Interpretation der Auftragstaktik fällt damit der soldatischen Subjektivität also die Aufgabe zu, kompensatorisch Befehlslücken auszufüllen. Nicht zuletzt vor dem Hintergrund der Diskussionen um die Network Centric Warfare wird damit den soldatischen Subjekten überraschend wenig Entscheidungs- und Handlungsspielraum eingeräumt. ${ }^{43}$

Die rules of engagement lösen vor allem bei den rangniedrigen Offizieren, die in der Militärhierarchie zwischen den Unteroffizieren und Mannschaften sowie den Stabsoffizieren stehen, Unzufriedenheit aus. Verantwortlich ist hierfür ihre Position in der Hierarchie: Da ihnen die Aufgabe zufällt, an ihren Untergebenen Befehle zu erteilen, die, wie Seiffert schreibt, von einer verregelten und bürokratisierten »Einsatzwelt« geprägt

42 Die Auftragstaktik wird in den derzeit gültigen Heeres-Dienstvorschriften als Führungsprinzip bezeichnet und der Begriff der Konzeption wurde auf die »Innere Führung« eingeschränkt (Millotat 2002: 21). Die »Innere Führung« definiert die Soldaten als »Staatsbürger in Uniform«, die keinem Befehl >blind ' gehorchen, sondern aus Einsicht und Überzeugung folgen sollen. Kritisch wird die Geschichte der »Inneren Führung« von Bröckling betrachtet (1997: 295f.). Seiffert bewertet sie für die Vergangenheit positiver, sieht sie aber aktuell in der Krise (2005: 303f.).

43 Untergebenen auf der Basis der Befehlstaktik Anweisungen zu erteilen, bereitet den meisten Offizieren der Bundeswehr keine Schwierigkeiten: In einer Untersuchung aus dem Jahr 2003 zum Führungsverhalten von 177 Offizieren mit dem Dienstrang Hauptmann/Kapitänleutnant wurde festgestellt, dass drei Viertel der Befragten ihren Untergebenen keinen Gestaltungsspielraum bei der Ausführung von Befehlen gewähren. Lediglich 10 Prozent definierten für sich ein Verfahren, dass der Auftragstaktik gleichkommt (siehe Keller 2006: 152f.). 
sind, seien sie in besonderem Maße gezwungen »zwischen einer formalisierten Praxis und den komplexen Anforderungen der Aufträge« (Seiffert 2005: 197) zu vermitteln. Ihre Mitgestaltungsansprüche gerieten dabei gegenüber den äußeren Handlungsbedingungen in ein Missverhältnis. Für die niedrigeren Dienstgrade stellt sich die Situation während der Auslandseinsätze anders dar. Ihnen biete die Teilnahme an Auslandseinsätzen häufig einen erweiterten Handlungsspielraum und größere Herausforderungen als der Kasernendienst (ebd.).

Einige und obendrein als hochwahrscheinlich geltende Einsatzszenarios verlangen heute von den Soldaten Verhaltens- und Handlungsweisen, die bis vor wenigen Jahren ausschließlich zivilen Berufen zugeordnet wurden. So schreibt Kümmel, dass die Soldaten »neben rein militärischen nun auch über kulturelle und diplomatische Kompetenzen verfügen müssen, um ihrer neuen Rolle im Spannungsfeld zwischen hochgerüsteten Krieger und global street worker gerecht zu werden.« (2005a: 44) Seiffert erwartet sogar von den Soldaten, dass sie über »soziale Empathie- und Konfliktfähigkeit, interkulturelle Kompetenz sowie Rollendistanz und politische Urteilskraft« (ebd.: 303) verfügen müssen. Um jederzeit als Soldat handlungsfähig zu bleiben und gleichzeitig den neuen Erfordernissen der Einsatzszenarios gerecht zu werden, müsse der Soldat, so Haltiner, "polyvalent, fast ein Supermann« (2003: 175) sein. Er »ist ebenso Schutzmann wie Helfer, ist mit dem internationalen Recht vertraut, weiß zu vermitteln und sich als Diplomat zu betätigen, ist Samariter und Paramediziner und ist schließlich fähig zur Empathie und in hohem Maße frustrationstolerant« (ebd.). Das Militär müsse insgesamt, so Charles Moskos (2000), zu einer postmodernen Organisation werden, damit es seinen Aufgaben gerecht werden kann. Postmodern meint hier vor allem eine wachsende Durchlässigkeit der militärischen und zivilen Sphären der Gesellschaft, die vor allem auf Seiten des Militärs nachzuvollziehen sei. Im Grunde habe sich das Militär für Prinzipien der zivilen Gesellschaft zu öffnen, um in Zukunft Ordnungsaufgaben übernehmen zu können.

In diesen umfassenden und offenkundig schwer einlösbaren Anforderungsprofilen an den Soldatenberuf drückt sich eine mit Beginn der 90er Jahre beschleunigte Funktionsausweitung des Militärs aus, die häufig auch als eine Verpolizeilichung bezeichnet wird (siehe Haltiner 2003: 159f.). Obwohl seit den Kriegen in Afghanistan und dem Irak wieder von Remilitarisierung gesprochen wird und die klassischen Kampffunktionen des Militärs wieder bedeutsamer geworden sind (Kümmel 2005a: 53, 62), ist diese Funktionsausweitung nicht zurückgenommen worden.

Dies liegt, bezogen auf die Streitkräfte der westlichen Industriestaaten, weniger an den seit Jahren größer werdenden Kontingenten, die Staaten unter dem Kommando der UN für so genannte Blauhelmmissionen zur 
Verfügung stellen. ${ }^{44}$ Die Funktionsausweitung bleibt erhalten, weil die Militärinterventionen nicht zur dauerhaften Militärpräsenz in den betroffenen Regionen führen sollen. Wenn die Intervention doch zu einer langanhaltenden Präsens von Truppen führt, zeigt dies vor allem ein Scheitern an. Eine Ausweitung der territorialen Herrschaft wird, soweit erkennbar, nicht angestrebt. Nicht Kolonien, sondern stabile politische Regime sollen entstehen, die zumindest keine mit der Politik der Industriestaaten unvereinbaren Absichten verfolgen. Um dieses Ziel umzusetzen, müssen in diesen Ländern Akteure gefunden werden, die in der Lage sind, entsprechende politische Regime aufzubauen. Damit solche Akteure gefunden werden können und als Verbündete im Verlauf der Intervention erhalten bleiben, dürfen die eingesetzten Soldaten nur zurückhaltend von dem ihnen zur Verfügung stehenden Gewaltpotential Gebrauch machen. Etwas anders formuliert: Die Soldaten sind nicht immer mit eindeutig auszumachende Gegnern konfrontiert, die sie bekämpfen können. Sie haben es auch mit Akteuren zu tun, die sich als Störer des politischen Prozesses bezeichnen lassen. Die Einstellungen und Verhaltensweisen der Störer sollen die Soldaten durch wohldosierte Gewaltandrohungen und -praktiken kontrollieren und modifizieren, um ihre Bereitschaft zu erhöhen, sich an dem angestrebten Prozess, der beispielsweise unter der Bezeichnung nation-buildung firmiert, zu beteiligen (siehe Heins/Warburg 2004: 96).

$\mathrm{Zu}$ den Folgen der Funktionsausweitung gehört auch, dass sich die Bewertungsmaßstäbe an das Verhalten der Soldaten verändern. Verhaltensweisen, die früher im Allgemeinen eher als >unschönes Benehmen erachtet wurden, können nun als völlig inakzeptabel gelten. Sie werden nicht mehr als im Grunde harmlose Begleiterscheinungen eines Männerbundes angesehen, der »informell in größerem Maße Ausschweifungen im Verhalten duldet als die gemischte zivile Gesellschaft« (Janowitz/Little 1965: 75), sondern als Irrungen, die den gesamten Einsatz gefährden können (siehe Debatte im Oktober 2006 zum Vorwurf der Totenschändung durch Bundeswehr-Soldaten in Afghanistan).

44 Die größten Truppenkontingente stellen seit Jahren Staaten wie Bangladesh, Pakistan, Indien, Ghana, Äthiopien und Uruguay. Vor allem ärmere Staaten, die große Heeresverbände unterhalten, lassen sich auf diese Weise ihre Soldaten von der UN bezahlen. Finanziert werden die Truppenkontingente unter dem Kommando der UN wiederum von den größten Beitragszahlern der UN. Die USA stellen ausschließlich Militärbeobachter und Polizisten für UNMissionen ab. Auch die anderen westlichen Industriestaaten beteiligen sich neben kleinen Truppenverbänden an diesen Missionen meist mit Militärbeobachtern und Polizisten. Eine Ausnahme bildet hiervon seit September 2006 die Beteiligung an der UNIFIL-Mission im Libanon. Insgesamt standen Ende September 2008 über 83.000 Männer und Frauen unter dem Kommando der UN (siehe http://www.un.org/Depts/dpko/dpko/; Zugriff: 18.10.07). Zur Beurteilung des Verhältnisses der >developing countries`zu Peacekeeping-Operationen unter UN-Kommando siehe Cunliffe (2007). 
Da die Funktionsausweitung trotz der Remilitarisierung erhalten bleibt, bleibt auch das Spannungsfeld, in dem die Soldaten handeln müssen, erhalten. Die paradoxen Anforderungen, die an die Soldaten gestellt werden, nehmen sogar an Schärfe zu. Die Beteiligung an Gefechten wird die Fähigkeiten der Soldaten für interkulturelle Handlungskompetenzen, etc. nicht fördern. Im Gegenteil ist zu vermuten: Bereits der Aufenthalt in einem Gebiet in dem sie sich aus 360 Grad von der sie umgebenden Zivilgesellschaft bedroht fühlen, wird solche Fähigkeiten schwächen.

In diesem Zusammenhang ist auch an einer phänomenologischen Grundeigenschaft der Gewalt zu erinnern: Gewalt zerstört und schafft Ordnungen. Sie reduziert Komplexitäten, weil sie dort wo vormals Ambivalenz herrschte, Eindeutigkeit befördert. Konzeptionen, die das unterschätzen, drohen an denjenigen zu scheitern, die die Gewalt exekutieren sollen: Wer beschossen wird, will zu allererst nicht verstehen, warum dies geschieht, sondern er wird dafür sorgen wollen, dass der Andere damit sofort aufhört.

Die Paradoxie tritt vielleicht noch deutlicher hervor, wenn man berücksichtigt, dass an die Soldaten und Soldatinnen nicht nur schwer einzulösende Anforderungsprofile herangetragen werden. Von ihnen wird verlangt, dass sie sich unterschiedliche Normenkanons zu Eigen machen, die sich jeweils für spezifische Berufsrollen entwickelt haben. Die Funktionsausweitung des Militärs wird quasi mit einer Entdifferenzierung des Soldatenberufs beantwortet. Damit werden die Soldaten und Soldatinnen aber dazu angehalten, Normen zu befolgen, die im Widerspruch zueinander stehen können. Dabei ist nicht das Problem, dass von den Soldaten und Soldatinnen erwartet wird, dass sie mehrere Berufsrollen ausüben. Mit Popitz lässt sich festhalten, dass jedes Individuum mehreren sozialen Einheiten angehört und damit Träger mehrerer sozialer Rollen ist (siehe Popitz 1961: 67). Problematisch ist die Erwartung, dass sie innerhalb des gleichen Berufs ihr Handeln an Normen ausrichten, die sie zum einen dazu befähigen, Menschen zu verletzen und zu töten und die zum anderen ihr Handeln darauf orientieren, Menschen zu helfen und zu unterstützen. Die Paradoxie wird im Einsatzszenario des three block besonders eklatant: An der einen Straßenecke sollen sie Zivilisten helfen und an der nächsten Straßenecke müssen sie womöglich auf Zivilisten schießen.

Der Bedeutungszuwachs des Militärs als Instrument der Außenpolitik hat sich in der Bundesrepublik ohne eine durchgreifende soziale oder innere Militarisierung der Gesellschaft vollzogen. Eine soziale Militarisierung, hier als Prozess definiert, der die Zivilbevölkerung auf gegenwärtige oder geplante Kriege psychisch vorbereitet und mobilisiert und der sich beispielsweise in einer gestiegenen Wertschätzung für traditionelle militärische Werte niederschlagen müsste, ist auch in anderen westlichen Industriestaaten nicht zu beobachten (siehe hierzu Heins/Warburg 2004: 121f.). Das Verhältnis nichtmilitärischer Gesellschaft und Militär gestaltet 
sich durch die verstärkte Inanspruchnahme der Streitkräfte für außenpolitische Ziele nicht einfacher. Dies gilt auch für die Bundesrepublik. Denn den Krieg als Gesellschaftszustand erleben und erfahren nur die Soldaten, die ins Ausland geschickt werden. Für die meisten Angehörigen der nichtmilitärischen Gesellschaft bleibt der Krieg ein entferntes, durch die Medien mitgeteiltes Geschehen. Schon heute lassen sich Absonderungstendenzen von Militär und Gesellschaft konstatieren. Wie weit diese Tendenzen gehen können, lässt sich jedoch kaum prognostizieren.

Als ein wichtiger Konnex für das Verhältnis von nichtmilitärischer Gesellschaft und Militär gilt die Art und Weise, wie das Militär sein Personal rekrutiert. In den politischen Diskussionen der Bundesrepublik spielt in diesem Zusammenhang die Wehrpflicht eine zentrale Rolle. Obwohl in zahlreichen anderen europäischen Staaten seit Anfang der 90er Jahre die Wehrpflicht abgeschafft oder zumindest ausgesetzt wurde (einen Überblick gibt Werkner 2005: 102f.) und in den USA die Streitkräfte bereits seit 1975 ausschließlich Freiwillige rekrutierten, sind in Deutschland weiterhin alle Männer ab ihrem 18. Lebensjahr wehrpflichtig. Legitimiert werden die damit verbundenen Einschränkungen der bürgerlichen Rechte der Wehrpflichtigen ausdrücklich mit dem Hinweis, dass die Wehrpflicht die Bundeswehr mit der Gesellschaft verklammere (siehe Koalitionsvertrag der CDU/CSU/SPD: 133, Bundesministerium für Verteidigung 2006b: 76). Diese Form der Verklammerung hat aber trotz des Fortbestands der Wehrpflicht auch in der Bundesrepublik an Bedeutung verloren. Ein Blick auf die Personalplanungen der Bundeswehr aus dem Jahr 2005 zeigt an, dass der Anteil der Geburtsjahrgänge, die als Wehrpflichtige zum Dienst bei den Streitkräften herangezogen werden, in den vergangenen Jahren gesunken ist und weiter sinken wird (Tobiassen 2005: 21). Die Tauglichkeitskriterien sind derart heraufgesetzt worden, dass voraussichtlich knapp 36 Prozent der Männer des Jahrganges 1990 aus der Wehrpflicht entlassen werden, weil sie als untauglich gelten. Weiter lässt sich anhand der Verweigerungsquote der letzten Jahre prognostizieren, dass über 30 Prozent des Jahrgangs den Kriegsdienst verweigern wird. Weniger als 13 Prozent dieses Jahrgangs beabsichtigt die Bundeswehr als Wehrdienstleistende einzuberufen (siehe Tobiassen 2005: 2f., 24). Der Staat fordert also heute von jungen Männern nicht mehr mit der gleichen Unbedingtheit, wie noch in den 80er Jahren, dass sie zumindest zeitweilig Soldat werden. Keinen Militärdienst abgeleistet zu haben, gilt nicht mehr als ein Makel in der Biographie.

An Auslandseinsätzen müssen Wehrpflichtige nicht teilnehmen. Ihre Verwendung im Ausland hängt davon ab, ob sie freiwillig eine besondere Erklärung abgeben und bereit sind ihre Dienstzeit zu verlängern. ${ }^{45} \mathrm{Die}$ Bundeswehr im Auslandseinsatz ist folglich eine Armee aus Freiwilligen.

45 Siehe Wehrpflichtgesetz $\S 6 \mathrm{a}$, in der Fassung vom 30.5.2005 (Online: http:// bundesrecht.juris.de/wehrpflg/index.html; Zugriff: 12.10.07). 
Die Institution der Wehrpflicht wird deshalb Absonderungsprozessen der Soldaten von der nichtmilitärischen Gesellschaft aufgrund ihrer Teilnahme an Militärinterventionen im Ausland kaum entgegenwirken können. Es ist in diesem Zusammenhang aber auch darauf hinzuweisen, dass die Bereitschaft, freiwillig zumindest zeitweilig den Beruf des Soldaten zu ergreifen, nicht bereits einen Hinweis auf eine militarisierte Zivilgesellschaft enthält. Auch wenn »das Militär eine hohe Anziehungskraft für junge Männer mit nationalen, rechten oder tendenziell rechtsextremistischen politischen Orientierungen« (Apelt 2006: 30) besitzt, die wenigen Untersuchungen zum beruflichen Selbstverständnis oder den berufsbestimmenden Motiven von Soldaten betonen vor allem, »dass die Entscheidung für den Soldatenberuf immer stärker den allgemein gültigen Mechanismen der Berufswahl folgt« (Leonhard/Biehl 2005: 259). Es ist neben der Bezahlung vor allem die hohe Arbeitsplatzsicherheit, die den Befragten als besonders attraktiv am Soldatenberuf erscheint (ebd.: 260; siehe hierzu auch Seiffert 2005: 128f.). Den Beruf des Soldaten aus ökonomischen Gründen als attraktiv einzuschätzen und ihn gar als einen Job anzusehen, wird aber in der Fachliteratur als unprofessionelle Haltung eingestuft (siehe Leonard/Biehl 2005: 263). Nicht zu unrecht, ist doch die Jobmentalität unangemessen, "weil sie mit den dramatischen Nebenfolgen des kriegerischen Handelns ebenso wenig fertig wird wie mit Kontrahenten, die keineswegs nach dem Jobprinzip handeln.« (Heins/Warburg 2004: 65)

Eine gegenüber der Wehrpflicht wachsende Bedeutung für das Verhältnis von nichtmilitärischer Gesellschaft und dem Militär hat die Öffnung der Streitkräfte für Frauen. Mit dem 1. Weltkrieg endete eine Periode, in der das Militär relativ >frauenfrei< war (siehe Kapitel 4.3.). Insbesondere im 1. und 2. Weltkrieg wurden viele Frauen zu Angehörigen des Militärs, zu Soldatinnen, die meist den Kampf unterstützende Tätigkeiten verrichteten. Jenseits von Kriegseinsätzen und damit Zeiten größter Personalnot blieb der Einsatz von Frauen innerhalb westlicher Streitkräfte weitgehend auf Tätigkeiten innerhalb des Sanitätsdienstes, von Militärkapellen, Büroarbeiten, etc. und damit auf Tätigkeiten beschränkt, die nicht die Vorstellung irritieren konnten, dass es sich bei soldatischen Subjekte ausschließlich um (männliche) Männer handelt. Denn Attribute wie >Tapferkeit`, Zähigkeit, >Körperkraft`, die Fähigkeit eine Emotion, wie die Angst, disziplinieren zu können, die Fähigkeit über Leben und Tod anderer Menschen zu entscheiden, werden mit diesen Tätigkeiten nicht verbunden.

Seit den 90er Jahren lässt sich aber, so Kümmel, »bemerkenswerte Schritte zu weiteren Zugangsmöglichkeiten für Frauen [...] verzeichnen.« (Kümmel 2005b: 118) Sie spielten eine aktivere und sichtbarere Rolle in den Streitkräften und ihr Anteil am Personalbestand habe deutlich zugenommen (ebd.). Aber nur bei ein paar Streitkräften (Slowenien, Lettland und den USA) ist die Öffnung für Frauen soweit vorangeschritten, dass sie 
mehr als 15 Prozent der Soldaten stellen. ${ }^{46}$ Soldatinnen können deshalb nicht als normal integrierte Angehörige des Militärs bezeichnet werden. Sie bleiben als Vertreter einer Minderheit unter kritischer Beobachtung, sind visibler als Männer, und vor allem ihre Fehlleistungen werden aufmerksam registriert (Kümmel 2005b: 125). Nach wie vor haben Frauen meist keinen Zugang zu Einheiten mit Kampffunktionen. Letzteres trifft auch für die US-Streitkräfte zu, die in absoluten Zahlen den größten Frauenanteil haben. Selbst dort, wo es keine formellen Beschränkungen für Frauen gibt, wie dies bei der Bundeswehr seit 2001 der Fall ist, sind vor allem infanteristische Kampfverbände aufgrund physiologischer Eignungstests, die sich an den Dispositionen des männlichen Leibes orientieren, weiterhin als eher verschlossen einzustufen. ${ }^{47}$ Soldatinnen, denen es doch gelingt, in solche Verbände vorzudringen, müssen damit rechnen, nicht als Frauen anerkannt zu werden, sondern als `männlich Infizierte` (vgl. Seifert 1996: 176f.).

Im Rahmen gegenwärtiger Einsatzszenarios ist aber die Bedeutung gerade dieser infanteristischen Verbände angestiegen. Dies gilt sowohl für hoch intensive Kampfeinsätze als auch für die von der Bundeswehr als Stabilisierungsoperationen bezeichneten Szenarios. Nicht Flugzeuge und nicht Panzer erobern und durchsuchen Häuser, besetzen Städte, sondern Infanteristen. Sie tragen auch das größte Risiko im Verlauf von Kämpfen verletzt oder getötet zu werden. ${ }^{48}$ Es ist deshalb davon auszugehen, dass, trotz der Öffnung der Streitkräfte für Frauen, dieses Kampfgeschehen von einer Aura der Männlichkeit umgeben bleibt. Dies ist umso relevanter je mehr das Soldatische vom Leitbild des (infanteristischen) Kämpfers geprägt wird. Obwohl es also Frauen in den Streitkräften gibt, die man als Soldatinnen bezeichnet, blieben sie in einer spezifischen Weise vom Kern

46 Siehe Kümmel (2005b: 119f.). Nach Angaben des »Committee on Women in the NATO Forces« war 2006 der Frauenanteil in den ungarischen Streitkräften auf über 17 Prozent gestiegen, für Lettland und Slowenien lagen keine Angaben vor. Bei den US-Streitkräften war dagegen der Anteil der Frauen auf knapp 10,5 Prozent gesunken (siehe http://www.nato.int/issues/women_n ato/perc_fem_soldiers_2001_2006.pdf; Zugriff 12.10.07.

47 Die Leistungsfähigkeit des Leibes setzt sich aus unterschiedlichen Komponenten wie Ausdauer und Beweglichkeit zusammen. Besonders im Hinblick eines Parameters, dem der Körperkraft, sind Frauen gegenüber Männern mit etwa 30 Prozent der absoluten Maximalkraft im Nachteil, da ihre Muskulatur im Durchschnitt einen geringeren Anteil am Körper ausmacht (siehe Krainz 2003).

48 Anders dagegen sind die Gefahren zu bewerten, die die Soldaten und Soldatinnen auf den Weg in oder von einem Lager und insgesamt während ihres Auslandsaufenthalts ausgesetzt sind, Opfer eines Bombenanschlag oder eines Granatenangriffs zu werden. Diese Risiken hängen nicht davon ab, ob der Soldat oder die Soldatin einem spezifischen Kampfverband oder einer Unterstützungseinheit angehört, sondern in welchem Ausmaß die gegnerischen Akteure die Truppen mit Methoden des Kleinkrieges angreifen. 
des Soldatischen ausgeschlossen, das in der Figur des Kämpfers oder gar Kriegers angesprochen wird. Das soldatische Subjekt bliebe damit männlich konnotiert und das Militär nicht geschlechtsneutral. ${ }^{49}$

Würden die gegenwärtigen Einsatzszenarios das Soldatische ausschließlich auf den Kämpfer reduzieren, begünstigte dies eine Tendenz, die auf eine Aufspaltung der Vorstellungsgehalte für Männlichkeit und Weiblichkeit an der Trennlinie zivil und militärisch hinausliefe. Tatsächlich stehen aber solche Denkmuster im Widerspruch zur Funktionsausweitung des Militärs. Einem Infanterist mag es vielleicht durch dichotome Zuordnung von zivil-weiblich und militärisch-männlich leichter gelingen, ein Selbstbild zu entwickeln, das ihm hilft, mit Emotionen wie Angst und Wut umzugehen, die ihn im Kampfeinsatz bedrängen. Eine derart konstruierte Deutung von Männlichkeit ist jedoch ungeeignet den Anforderungsprofilen eines Soldaten gerecht zu werden, der als peace-keeper eingesetzt wird. Sie müssen beruflichen Anforderungsprofilen aus der zivilen Arbeitswelt genügen. Sie müssen obendrein ihr Handeln an Werten und Normen ausrichten, die im Rahmen klischeehafter Vorstellungen von Männlichkeit und Weiblichkeit, mit weiblichen Tugenden assoziiert werden. Um dies zu verdeutlichen: Sozialarbeiter ist nicht nur ein ziviler Beruf par excellence, er wird auch überwiegend von Frauen ausgeübt. Soldaten, die ihrer Aufgabe als peace-keeper entsprechend handeln, verhalten sich aus einem traditionellen Blickwinkel betrachtet und erst recht aus der Sicht eines >archaischen Kämpfers` (Budde) wie Frauen. Nicht von ihrer Körperkraft, ihrer Fähigkeit zu gezieltem aggressiven Handeln, der Bereitschaft zu töten und getötet zu werden, hängt ihre Qualifikation ab. Betont werden in der Literatur vielmehr Sprach- und soziokulturelle Kompetenzen, sowie Einfühlungsvermögen in die Position des Gegenübers, um im Interventionsgebiet die Eskalationsgefahr von Konflikten zu mindern. Die Öffnung der Streitkräfte für Frauen wird auch mit dem Hinweis vorangetrieben, dass sie eher zu alltagsdiplomatischen Gebarensformen fähig sind als Männer (siehe Heins/Warburg 2004: 113).

In welchem Ausmaß sich die nichtmilitärische Gesellschaft und das Militär von einander absondern, wie sehr innerhalb der >Streitkräfte im Einsatz` militärische Normen an Gewicht gewinnen und auch die Frage, wie nachhaltig das Selbstverständnis der Soldaten vom Auslandseinsatz beeinflusst wird, hängt von einer Reihe von Faktoren ab: vom Verlauf der Militärinterventionen, der Intensität der Kampfhandlungen und nicht zu letzt von der Haltung der nichtmilitärischen (Herkunfts-)Gesellschaft zu den Militäreinsätzen. Hier eine Prognose zu geben, ist unmöglich. Möglich ist allerdings festzustellen, dass es keine Debatte zur »revitalisierte[n] und neumodellierte[n] Subjektorientierung in der Konstruktion des Soldaten als

49 Wie sehr, trotz Öffnung der Streitkräfte und sogar einer Wehrpflicht für Frauen, das soldatische Subjekt als männlich gedacht wird, zeigt die Studie von Klein (2001) zu Militär und Geschlecht in der israelischen Gesellschaft. 
Staatsbürger in Uniform« gibt, wie sie Seiffert (2005: 304) für zwingend geboten hält, um soziale und zivile Desintegrationsprozesse von Militär und Gesellschaft zu verhindern.

Als unwahrscheinlich kann man die Erwartung bezeichnen, dass die Streitkräfte viele Soldaten und Soldatinnen rekrutieren können, die als Allrounder den Anforderungen aller Einsatzszenarios und damit den paradoxen Verhaltensanforderungen gerecht werden können. Der >archaische Kämpfer`, der sozial empathische peace-keeper und der technisch versierte Soldaten wird kaum in einer Person zur Verfügung stehen. Aus organisationssoziologischer Sicht ist die Annahme plausibler, dass das Militär versuchen wird, den Paradoxien mit funktionalen Differenzierungen, die mit Professionalisierungen der unterschiedlichen Tätigkeiten einhergehen, zu begegnen.

Diese funktionalen Differenzierungen können unterschiedliche Formen annehmen, die sich zum Teil gegenseitig ergänzen.

- Die funktionale Differenzierung innerhalb einer Armee

Um das Tableau der Einsatzszenarios abzudecken werden innerhalb der nationalen Streitkräfte die Einheiten auf jeweils einen bestimmten Typus von Einsatzszenarios ausgerüstet und ausgebildet. Dieses Modell wird derzeit von der Bundeswehr verfolgt, indem sie die zur Verfügung stehenden Kräfte in Eingreif- und Stabilisierungsverbände gliedert. Als funktionale Differenzierung lassen sich auch die Bemühungen bezeichnen, die darauf abzielen Organisationseinheiten modular aufzubauen. Je nach spezifischer Aufgabe sollen die Verbände aufgabenbezogen und erst vor den Einsätzen zusammengestellt werden (siehe Haltiner 2003: 181).

- Funktionale Differenzierung zwischen verschiedenen Streitkräften Eine solche Differenzierung wird von den US-Streitkräften favorisiert, wenn sie ihre Verbände an intensiven Kampfhandlungen orientieren und versuchen den Verbündeten die Aufgabe zuzuteilen, nach einem militärischen Sieg die Region zu stabilisieren und Prozesse wie nationbuilding voranzutreiben. Faktisch lässt sich eine solche Arbeitsteilung zwischen den verschiedenen nationalen Streitkräften im Bezug auf die Truppenkontingente beobachten, die der UN unterstellt werden. In den vergangenen Jahren haben sich die führenden Industriestaaten kaum noch an den klassisch zu nennenden Blauhelmeinsätzen mit großen Truppenkontingenten beteiligt. Wenn die Interventionstruppen versuchen, im Interventionsgebiet Streitkräfte aus der einheimischen (männlichen) Bevölkerung zu rekrutieren, auszubilden, auszustatten und sie zu militärischen oder zumindest polizeiähnlichen Einsätzen heranziehen, liegt ebenfalls eine solche Differenzierung vor.

- Outsorcing

Wenn das Militär auf »zivile Befähigungen und temporär militarisierbare Experten« (Haltiner 2003: ebd.) zugreift, führt dies zu einer 
Mischform der zuerst genannten Differenzierungstypen. Sowohl innerhalb als auch außerhalb der Streitkräfte sind Zivilisten, die bei Privatfirmen angestellt sind, für das Militär im Kriegseinsatz tätig. Überwiegend werden diese zwei Formen der Differenzierung als ein Prozess der Privatisierung militärischer Leistungen beschrieben, der immer mehr an Bedeutung gewinnt. Private Military Firms arbeiten mit den Streitkräften in höchst unterschiedlichen Tätigkeitsbereichen. Ihre Beschäftigten warten Computernetzwerke, rüsten als Zivilisten zum Beispiel Kampfflugzeuge mit Waffen aus, sind mit ihrem sozialen Know-how als Berater und Ausbilder tätig, bewachen Gefängnisse, verhören Gefangene und führen mitunter auch Kampfeinsätze durch. Das Personal, der so genannten Private Military Firms stellt im Irak nach den US-Streitkräften das größte Truppenkontingent (Singer 2006: 387).

- Verstärkte Zusammenarbeit des Militärs mit zivilen Organisationen Vor allem im Rahmen von so genannten Peace-keeping-Einsätze und Stabilisierungsoperationen wird zunehmend davon ausgegangen, dass eine Zusammenarbeit mit zivilen Organisationen einen wichtigen Beitrag leisten kann, um die Verbände vor Angriffen zu schützen (siehe u.a.: Irlenkaeuser 2006). Gleichgültig, ob es sich um nichtmilitärische, aber staatliche oder um nichtstaatliche Organisationen (NGOs) handelt, durch die Zusammenarbeit sollen die Lebensbedingungen der einheimischen Bevölkerung in den Einsatzräumen der Truppenverbände verbessert und damit das Risiko gemindert werden, dass die Soldaten angegriffen werden. Zugleich dient die Zusammenarbeit mit Zivilisten der Gewinnung von Informationen für ein verbessertes Lagebild, kurz: der Aufklärung. Von Seiten des Militärs wird diese Zusammenarbeit aus militärisch-operativen Gesichtspunkten angestrebt und vorangetrieben, um nicht zuletzt auch die Handlungskompetenzen von NGOs und $\mathrm{Zu}$ gänge $\mathrm{zu}$ den einheimischen Strukturen im Einsatzgebiet nutzen zu können. Die Bundeswehr hat im Mai 2006 ein Zentrum für ZivilMilitärische-Zusammenarbeit (Cimic-Zentrum) gegründet, in dem einmal 500 Spezialisten zusammengefasst sein sollen, und die alle Verbände bei ihren Auslandseinsätzen bei der angestrebten intensiveren zivilmilitärischen Zusammenarbeit unterstützen sollen. ${ }^{50}$

Wenn zivile Organisationen in ein militärisch-operatives Konzept einbettet werden, wird der Kontrast zwischen ihnen und dem Militär geringer. Es ist deshalb nicht überraschend zu hören, dass vor allem NGOs skeptisch auf die Bemühungen des Militärs reagieren, mit ihnen zusammenzuarbeiten. Sie befürchten, dass ihr humanitäres Mandat, das auf Unparteilichkeit be- 
ruht, durch eine Zusammenarbeit mit dem Militär gefährdet wird (siehe Verband Entwicklungspolitik 2007: 3). ${ }^{51}$

Das Bedürfnis nach Abgrenzung des Zivilen vom Militärischen besteht aber nicht nur auf Seiten ziviler Organisationen, wie die Äußerung des Heeresinspektor Budde zeigt, dass das Militär keine Organisation bewaffneter Sozialarbeiter sei und den Kampfeinsatz als das Spezifikum des Soldaten betont (2005: 113f.). An dieser Stelle wird auch deutlich, dass durch die verschiedenen Formen der Differenzierungen die Paradoxien nicht aufgelöst werden, sondern allenfalls auf anderen Ebenen weiter prozessieren.

Und am virulentesten werden die Paradoxien im Krieg spürbar und sich folgenreich nicht nur auf die soldatischen Subjekte einwirken.

51 Dieser Skepsis widerspricht nicht, dass »auf der Arbeitsebene die Kooperation zwischen den Soldaten und den NGOs zumeist reibungsloser funktioniert als die zivil-militärische Zusammenarbeit auf den Leitungsebenen der jeweiligen Organisationen.« (Irlenkaeuser 2006: 311) 


\section{Soldatische Subjekte im modernen Krieg}

Das Militär und der Krieg sind soziale Phänomene und Bestandteile moderner Gesellschaften. Dennoch spielen das Militär - und noch mehr der Krieg - in den allermeisten Entwürfen von Gesellschaft keine oder nur eine randständige Rolle. Beide, Militär und Krieg, stehen im Ruf, soziale Atavismen zu sein, die keiner weiteren soziologischen Betrachtung wert sind. Wurde das Desinteresse vor dem 1. Weltkrieg noch hoffnungsvoll und explizit mit dem weiteren Fortschreiten der Moderne begründet, so erwartet heute kaum jemand mehr, dass der Krieg in den nächsten Jahrzehnten auf dem 〉Müllhaufen der Geschichte landen wird.

Aufgrund dieses Desinteresses bleiben die Gefahren, die von der kriegerischen Gewalt ausgehen und die noch jede Gesellschaft strukturell prägten und zu zerstören vermochten, außerhalb der Theoriebildung. Verkannt wird auf diese Weise, in welchem Ausmaß das weltweite Kriegsgeschehen von dem geprägt wird, was man Moderne nennt. Vertan werden damit auch Chancen, durch ein besseres Verständnis des Phänomens, den Krieg zu bannen.

Ein Element des Krieges, die Subjektivität der Soldaten im Krieg, bildet den Mittelpunkt dieser Untersuchung. Die biologische Konstitution, die ein Ergebnis der phylogentischen Entwicklung des Menschen ist, befähigt den homo sapiens zu einem besonderen Verhältnis zu seiner Umwelt und zu sich selber, die Plessner als exzentrische Positionalität bezeichnet hat. Die exzentrische Positionalität ist systematisch konstitutiv für das menschliche Individuum und damit grundlegend für seine Subjektivität. Das menschliche Subjekt hat einen Körper und ist zugleich ein Leib. Ein Leib zu sein und einen Körper zu haben, bilden die anthropologische Wurzel für die Künstlichkeit der Subjektivität. Der Körper ist eine soziale Konstruktion, die aber immer mit dem (natürlichen) Leib verschränkt bleibt. Im Gegensatz zum interpretierbaren Körper ist der Leib nicht als unendlich 
variabel zu bezeichnen. An der Leiblichkeit findet die Konstruierbarkeit der soldatischen Subjektivität ihre Grenze.

Für das soldatische Subjekt bedeutet das, sich zwischen zwei Polen zu bewegen. Den einen Pol bilden Praktiken der Formbarkeit, die einen tätigen Held kreieren sollen, einen Heros - am anderen Pol steht das Subjekt, das mit seiner Leiblichkeit hadert. Es geht um das konkrete Subjekt, das sich im Spannungsfeld zwischen Vorstellungen und Praktiken der Formbarkeit und seiner Konstitution bewegt; das Opfer des Kriegsgeschehens ist, aber zugleich auch selber die destructio des Krieges vorantreibt, an das Größen- und Opferwahn, Omnipotenzphantasien und Todesangst nicht als Fremdes herangetragen werden müssen. Eindeutigere Festlegungen im Sinne einer anthropologischen Konstitutionierung des Subjekts, aber ebenso auch im Sinne einer vollständigen Formbarkeit der Subjektivität durch die Sozialität, in das es hineingeboren wird, sind aus dieser Perspektive nicht möglich. Oder noch einmal ganz anders: Der Leib ist nicht hintergehbar, er ist aber auch nicht das letzte Argument.

Die Einbindung bzw. Berücksichtigung von Handlungskompetenzen der Soldaten bildet eine wichtige Innovationsressource der Kriegsführung. So sehr man mit Bezug auf Plessner und andere von einer Subjektivität eo ipso sprechen kann, konkret entwickelt sich die Subjektivität nur im Rahmen spezifischer historischer Kontexte. Auf die Subjektivität der Soldaten wurde im Verlauf der Geschichte, so lässt sich bilanzieren, sehr unterschiedlich rekurriert und das heißt zumal im Krieg, dass die Soldaten ihren Körper/Leib auf unterschiedliche Weise einbringen und gefährden mussten. Die Soldaten taten aber nicht nur, was ihnen befohlen wurde, sondern sie handelten und reagierten auf jeweils spezifische Weise auf die an sie gestellten Forderungen.

Es wurde in der Arbeit gezeigt, wie unterschiedlich in verschiedenen Kriegführungskonzeptionen die Subjektivität der Kämpfenden nutzbar gemacht werden sollte bzw. soll und wie tatsächlich auf sie zugegriffen wurde. Ebenso wurde gezeigt, welche Effekte das Handeln der Soldaten als Subjekte seinerseits auf das Kriegsgeschehen hatte und hat. Es wurde dargelegt, in welchem Ausmaß vor allem heute die Fähigkeit der Soldaten geschätzt wird, mit ihrer Kreativität Handlungssituationen für eine effektivere Kriegführung zu nutzen. Im 20. Jahrhundert trugen umfangreiche soziologische, psychologische und medizinisch-psychiatrische Forschungen dazu bei, die soldatische Subjektivität zu optimieren. Es wurde im Verlauf der vergangenen Jahrzehnte ein umfangreiches Reservoir an wissenschaftlich abgesicherten Erkenntnissen erarbeitet, das dem Ziel dient, die individuelle Kampfleistung bzw. die des Verbandes zu erhöhen. Zwar lassen sich die Effekte im Einzelnen kaum quantifizieren, aber die Personalauswahl, die Ausbildung der Soldaten, ihre Ausrüstung, inklusive der Bewaffnung und die Art, wie sie von ihren Vorgesetzten behandelt werden, wurde 
durch alle diese Kenntnisse zumindest in den avancierten Militärorganisationen erheblich beeinflusst.

$\mathrm{Zu}$ den Erkenntnissen gehört, dass das erreichbare Optimum immer unterhalb der gewünschten und von den Soldaten geforderten Leistungsfähigkeit bleiben wird. Bereits die angestrebte optimale Vorbereitung der Soldaten auf den Kriegseinsatz droht immer an der Unplanbarkeit des Krieges zu scheitern. Die Ausbildung und das Training der Soldaten müssen geplant werden, aber der Krieg »cannot be adequately planned for. All contingencies can not be foreseen. Many plans will have to be modified or scrapped.« (Ginzberg Bd. 1, 1959: 196) Allen sozialwissenschaftlichen und psychologischen Anstrengungen zum Trotz, hat dieser Satz nichts an seiner Gültigkeit verloren. Mehr noch, die soldatische Subjektivität ist bis heute eine unberechenbare Qualität geblieben. Die Haltung militärischer Organisationen gegenüber der am Individuum gebundenen Subjektivität ist darum ambivalent und durch Misstrauen gekennzeichnet.

Die Subjektivität der Soldaten bildet deshalb nicht nur eine Innovationsressource für die Kriegführung. Sie ist eine Quelle von Friktionen für die Kriegführung. Sie bildet zugleich auch eine Grenze für eine greedy institution (Coser), die von ihren Angehörigen verlangt, Leib und Leben einzusetzen. Die an den Leib gebundenen Begabungen befähigen die Subjekte zu Leistungen, die bis heute von keiner Maschine erreicht werden, aber ihre Leistungsgrenzen sind ebenfalls durch ihre Leiblichkeit definiert. "Man, not his machines, sets the ultimate limits on battle performance." (Gabriel 1988: 23) Durch den Leib nehmen die Soldaten sich selber und die umgebende Welt fühlend wahr. Affekte und Emotionen ermöglichen es ihnen, die Welt zu erschließen. Deshalb bleibt den Soldaten aber auch das im Krieg Erlebte, Erlittene und Erfahrene nicht äußerlich und sie können nachhaltig vom Geschehen emotional ergriffen werden. Ihre Reaktionen auf das Kriegsgeschehen bilden eine Schwachstelle für eine Kriegführung, die von einer instrumentellen Einsetzbarkeit von Gewalt ausgeht. Als soziale, als empfindungsfähige sowie auf Empfindungen angewiesene Wesen können sie nicht folgenlos, das heißt ohne Schaden zu nehmen, wiederholt oder gar ständig Situationen ausgesetzt werden, in denen sie Angst um ihr Leben und um das der ihnen umgebenden Menschen haben müssen. Wenn Gewöhnung als die Einverleibung von Strukturen bezeichnet werden kann (Waldenfels 2000: 166), muss darauf hingewiesen werden, dass es unmöglich ist, sich an die Bedingungen eines sozialen Raumes zu gewöhnen, der von Tod und Todesgefahren, von Leid und Schmerzen geprägt ist.

Die eingehende Erörterung der psychischen Leiden der Soldaten dient wesentlich dazu, die Grenzen der Formbarkeit des Subjekts aufzuzeigen. Nicht, dass sich die Soldaten weigern im Krieg eingesetzt zu werden, ist in diesem Zusammenhang das Interessante, sondern dass sie nicht mehr >verwendungsfähig` sind, selbst wenn sie es wollen. Weder durch äußere Zwänge noch von den Soldaten selber lässt sich verhindern, dass sie vom 
Gesehenen, Gehörten, Empfundenen ergriffen werden, dass sie beschädigt werden in ihrem Empfindungs-, Denk- und Handlungsvermögen.

Aber auch schon vor einer solchen möglicherweise irreversibel Schädigung ist die Leiblichkeit konstitutionell für die Handlungsfähigkeit der Soldaten im Kriegseinsatz. Die konstitutionelle Bedeutung des Leibes ist zwar grundsätzlich für alle menschlichen Individuen gegeben, aber bei Soldaten fällt sie besonders auf, weil sie in Extremsituationen, also Situationen, in denen sie häufig an ihrer physischen Belastungsgrenzen stehen, handeln sollen. In den Extremsituationen wirken auf ihre Person womöglich widerstreitende Affekte und Emotionen wie Angst und Wut ein. Sie dürfen darüber nicht verzweifeln und ihre Orientierung verlieren. Sie sollen auch nicht weinen und nicht lachen, sondern den erteilten Befehlen entsprechend handeln, auch wenn dies zu ihrem Tod führen mag. Wie sehr ihr Handeln von Empfindungen, Schmerz oder Affekten wie Angst und Ekel, sowie von Emotionen wie Freude und Wut beeinflusst wird, hängt entscheidend vom jeweiligen situativen Kontext ab. Gleiches gilt für die physischen Bedürfnisse, die sich in Hunger, Durst und Müdigkeit ausdrücken. Zum situativen Kontext gehört, ob und inwieweit das Individuum auf diese Situation vorbereitet wurde, ob die Situation für das Individuum noch als Subjekt beantwortbar erscheint. Die Soldaten gegen den Ansturm ihrer Gefühle zu wappnen, ist deshalb bis heute ein gültiges Ausbildungsziel geblieben. Dieses Ziel wird heute nicht mehr durch den Drill des 18. Jahrhundert erreicht. So geht es im Kampftraining neben dem Erlernen der jeweiligen Techniken darum, die Belastungsgrenzen der Soldaten durch Körpertraining zu verschieben. Zugleich werden sie aber durch das Körpertraining auch an ihre Belastungsgrenzen herangeführt und von ihnen wird verlangt, dass sie in der Nähe dieser Grenze Erfahrung mit dem Umgang ihrer Affekte und Emotionen machen, um sie in einer Kampfsituation zu kontrollieren. Außerdem sollen im Zuge der Ausbildung Handlungsroutinen etabliert werden, in der Hoffnung, dass sie auf diese während des Kampfeinsatzes zugreifen.

Inwieweit diese Praktiken bei den einzelnen Soldaten tatsächlich greifen, lässt sich nicht oder nur ungenügend vorhersagen. Zumal es nicht allein von den Formierungspraktiken abhängt, wie die Soldaten auf ihren jeweiligen Kriegseinsatz reagieren. Entscheidend ist auch, was für eine prätraumatische Persönlichkeit die Soldaten vor ihrem Einsatz hatten. Da diese Eingangsbedingung von Individuum zu Individuum variiert, reagieren die Soldaten nicht gleichförmig auf die gleichen Erlebnisse.

Die Auswirkungen eines Kriegseinsatzes auf die Soldaten betreffen nicht nur ihre unmittelbare Einsatzfähigkeit auf den Gefechtsfeldern. Ein noch so ferner Krieg kommt mit den Soldaten auch in eine zivil gebliebene, aber Krieg führende Gesellschaft zurück. Die vielfältigen Formen psychischer Beschwerden, unter denen die Soldaten nach ihren Einsätzen leiden, haben Konsequenzen für ihre nächsten Angehörigen und ihr sozia- 
les Umfeld. Nachhaltig können die durch den Krieg veränderten Persönlichkeiten der Veteranen die Einstellungen zur Bedeutung von Gewalt für Konfliktlösungen beeinflussen. Ebenso lassen sich Folgen für das Geschlechterverhältnis und das Männlichkeitsideal prognostizieren, wenn diese auch nicht vor einem Krieg detailliert abschätzbar sind. All dies gehört zu den meist unbeachtet bleibenden Kosten, die aus einem Kriegseinsatz für die Individuen und die Gesellschaft resultieren.

Soldaten sollen als fungible Objekte eines instrumentellen Kalküls wirken und gleichzeitig mit ihren Entscheidungs- und Handlungskompetenzen die Effektivität der Kriegführung steigern. Welche Kompetenzen von den Soldaten verlangt werden, kann zwischen den Streitkräften und noch mehr zwischen den spezifischen Verwendungsbereichen variieren. Dies gilt auch für die Anforderung, kreativ zu handeln. Sie wird kaum zum Beispiel von einem Soldaten verlangt, der auf einem Schiff seinen Dienst verrichtet und dort eine Bordkanone bedient. Auch für Piloten und die Besatzungen von Bombern und ähnlichen Fluggeräten lässt sich feststellen, dass der Spielraum bei der Ausgestaltung ihrer Einsätze für die einzelnen Besatzungsmitgliedern ingesamt eher gesunken ist, weil die Befehlszentralen aufgrund der ihnen vorliegenden Aufklärungsdaten detaillierte Vorgaben machen können. In diesen Einsatzbereichen kommt es vor allem auf den Vollzug von Routinehandlungen - unter großem Stress - an und weniger um die Bewältigung und Chancenauswertung handlungsoffener Situationen. Mit solchen Situationen sind besonders die Soldaten im Verlauf von Kampfhandlungen am Boden konfrontiert. Hier gilt heute die Fähigkeit zu kreativem Handeln als die Voraussetzung für dynamische und flexible Handlungsprozesse in kontingenten und komplexen Situationen. Konzeptionen wie die NCW erwarten im Grunde von jedem Infanteristen, unabhängig von seiner Position in der Militärhierachie, einen kreativen Umgang mit der Handlungssituation. Seine an den Leib gebundene Fähigkeit, Situationen wahrzunehmen, zu erkunden und situativ adäquat $\mathrm{zu}$ handeln, seine Fähigkeit, Situationen kreativ neu zu gestalten - und das bedeutet Pläne ändern zu können - wollen gerade avancierte Führungskonzeptionen nutzen. Deshalb wird der Fähigkeit jedes Soldaten in unwägbaren Situationen, Unwägbares zu tun, selbst in Streitkräften, wie denen der USA, die traditionell eher rigide den Soldaten vorschreiben, was sie tun sollen, eine bisher unbekannte Wertschätzung entgegengebracht.

Trotz dieser konzeptionell-positiven Einstufung des kreativen Vermögen der Soldaten, ist aber auf Seiten der militärischen Führungen ein ambivalentes Verhältnis zu einem derartigen Handeln ihrer Untergebenen zu verzeichnen. Denn so vorteilhaft es für eine Kriegspartei ist, wenn ihre Soldaten auf unvorhergesehene Situationen eigenmächtig und doch befehlskonform handelnd reagieren, so sehr besteht nach wie vor die Gefahr, dass solche Eigenmächtigkeiten das Vorhaben der Befehlshaber durchkreuzen können. Darum gilt nicht nur in der zivilen Wirtschaft die 
»Objektivierung subjektgesteuerten Handelns« und das heißt die »)Spaltung < des Subjekts in seine objektivierbaren und nicht objektivierbaren Anteile« (Böhle 2002: 114), wodurch letzteres ausgegrenzt werden soll, als große Herausforderung und bildet den Grund für die Aufrechterhaltung rigider Gehorsamsforderungen und Disziplinarpraktiken (Bröckling 2003: 189). Die Folge ist ein Spannungsfeld, das zum einen aus dem Handeln soldatischer Subjekte und zum anderen aus den Bemühungen der militärischen Organisation erwächst, die Subjektivität ihrer Angehörigen im Kriegseinsatz zu kontrollieren. Gerade gegenwärtige Führungskonzepte bemühen sich um eine Nutzung des subjektiven Leistungsvermögens der Soldaten und hadern mit dem Problem, wie sichergestellt werden kann, dass soldatische Subjektivität nicht eigensinnig die Befehlslage durchbricht.

Die Möglichkeit durch den Einsatz von Technik die Unwägbarkeiten der soldatischen Subjektivität zu bannen, bildet einen Ansporn für die Technisierung der Streitkräfte. Ein weiterer Grund ist in der aus militärischer Sicht defizitären Beschaffenheit des Leibes der Soldaten zu sehen. Der Leib gilt gemessen an Maschinen als zu verletzlich und seine Leistungsdaten als sehr unbefriedigend. Die Orientierung an maschinellen Leistungsdaten, die sich im Gegensatz zum Leib der Soldaten ständig verbessern lassen, lässt den Leib als schlechtkonstruiertes erscheinen. Die `Empfindsamkeit, die ja gleichzeitig für die besondere und technisch nicht simulierbare Qualität der Soldaten steht, verkehrt sich in diesem Zusammenhang in eine Schwachstelle. Maschinen haben den Vorzug, keine Empfindungen zu haben. Sie empfinden keine Angst. Sie lassen sich nicht erschrecken. Sie sind quasi `blind ‘ für die Leiden am und im Krieg.

Tatsächlich hat die Technisierung aber bislang nicht zu einem Bedeutungsverlust soldatischer Subjektivität geführt. Stattdessen läßt sich sogar feststellen, dass sich einige große Waffensysteme in einer Krise befinden. Dies gilt vor allem für den Kampfpanzer und die unterschiedlichsten Artilleriesysteme. Von ihrer Destruktionskraft hängt derzeit der Verlauf keines Krieges ab, den die avancierten Militärmächte führen. Auch der Einsatz neuer Technologien, wie zum Beispiel von unbemannten Vehikeln, schmälert nicht das Gewicht der soldatischen Subjektivität in der Kriegführung. Diese Technologien wirken vor allem als Agenten. Da sie weiterhin bestenfalls ungenügend selbstständig >handeln` können, können Soldaten allenfalls in einigen Einsatzbereichen durch Artefakte substituiert werden. $\mathrm{Zu}$ diesen Einsatzbereichen gehören vor allem Operationen im bzw. aus dem Luftraum heraus. So erfolgt inzwischen ein Teil der Aufklärung aus der Luft durch Drohnen, die aber zum größten Teil auf eine Fernsteuerung angewiesen sind.

Infolgedessen bleibt auch zukünftig die Kriegführung avancierter Militärmächte auf Soldaten angewiesen. Nicht die Ersetzbarkeit soldatischer Subjekte durch technische Artefakte ist zu prognostizieren, sondern allen- 
falls ihre weitere technische Aufrüstung und damit verbunden, ein $\mathrm{Zu}$ wachs ihrer Handlungsmacht. Soldaten bleiben insbesondere als Entscheidungsträger, als Akteur vor Ort, unverzichtbar. Die grundsätzliche Paradoxie, die ihren Einsatz im Krieg kennzeichnet, bleibt damit bestehen: Ihre an den Leib gebundenen Begabungen befähigen sie zu Leistungen, die von keiner Maschine erreicht werden, aber sie bleiben eben aufgrund ihrer Leiblichkeit verletzbar und können nachhaltig vom Erlebten emotional ergriffen werden.

Mit dem Ende der Blockkonfrontation wurden die Streitkräfte der westlichen Industriestaaten zunehmend zu neuartigen Aufgaben herangezogen. Soldaten sollen nicht mehr ausschließlich einen Gegner unter Einsatz von Gewaltmitteln bekämpfen, sie sollen auch für ein Ende von Gewalttätigkeiten sorgen, ohne dabei selber die Situation eskalieren zu lassen. Sie sollen mitunter keine Gegner bekämpfen, sondern zur Beruhigung zwischen den verschiedenen an einem Konflikt beteiligten Akteuren beitragen. Diese Entwicklung wird in der Literatur als Funktionsausweitung charakterisiert und gelegentlich wird auch davon gesprochen, dass sich das Militär in eine >postmoderne` Organisation verwandeln würde.

Mit dieser Überlegung ist zumindest implizit die Erwartung verbunden, dass sich die Differenz zwischen dem Militär und zivilen Organisationen nivillieren würde. Neben der Funktionsausweitung könnte für eine solche Erwartung vor allem die Übernahme von Organisationskonzepten aus der Privatwirtschaft sprechen, die die Produktivität und Effektivität der Unternehmen erhöhen sollen. Mit konzeptionellen Überlegungen, die mit so unterschiedlichen Stichwörtern wie >outsorcing`, >lean production` und >just in time` verbunden sind, sollen hier wie dort Personal eingespart, Bürokratien abgebaut, Führungsstrukturen ausgedünnt, Entscheidungsprozesse beschleunigt, letztlich die Effektivität des eingesetzten Personals stark erhöht werden. Damit diese Konzepte greifen können, müssen die Militärorganisationen auch jenseits der Gefechtsfelder Subjektivierungskonzepte anwenden, wie sie für die Privatwirtschaft diskutiert werden. Eine Folge ist, dass das Militär und die Privatwirtschaft auf dem Arbeitsmarkt Personal versucht anzuwerben, das über die gleiche Fähigkeiten verfügt.

Aber im Unterschied zu den Tätigkeiten in Fabriken und Büros müssen die Soldaten weiterhin im Verlauf von Militäroperationen ihr Leib und Leben riskieren. Am existenziellen Drama der Angst, der Schmerzen und des Todes ändert sich für die Soldaten auch nichts durch die Zuweisung weiterer Aufgabenfelder. Muss nicht an diesem Faktum die Durchlässigkeit des Militärs für zivile Normen und Werte ihre Grenze finden? Auch avancierte Streitkräfte benötigen ein >Milieu des Tötens` (Reemtsma) und des Getötetwerden. Dadurch wird sich auch zukünftig das Militär von anderen modernen Institutionen und Organisationen substanziell unterscheiden. 
Vieles spricht dafür, dass sich ein >postmodernes` Militär, deren Angehörige sowohl in klassische Kriegseinsätze geschickt als auch mit polizeiähnlichen Operationen beauftragt werden, auf schwerwiegende Paradoxien einstellen muss. Denn für die Soldaten bedeutet die Funktionsausweitung, dass sie nun über zuvor nicht oder nur in geringem Umfang abverlangte soziale Kompetenzen verfügen müssen. Da die Soldaten gleichzeitig weiterhin dazu in der Lage sein sollen, Gegner militärisch zu bekämpfen, sehen sie sich durch die zusätzlichen Funktionen mit paradoxen Verhaltensanforderungen konfrontiert. Die Verwendung unterschiedlicher Berufsbezeichnungen als Tätigkeitsmerkmale, die die Soldaten und Soldatinnen erfüllen sollen, markieren diese Paradoxien. Zuvor unbekannte Friktionen können die Folge der paradoxen Verhaltensanforderungen sein.

Mögliche Antworten auf die Paradoxien sind funktionale Differenzierungen innerhalb der Militärorganisation, die verstärkte Kooperation mit zivilen Organisationen und arbeitsteilige Strukturierungen bei Militärinterventionen. Die Paradoxien werden damit freilich nicht aufgehoben. Letztlich können die Soldaten den paradoxen Verhaltensanforderungen nicht gerecht werden. 


\section{Literatur}

Adorno, Theodor W. (1959): Zum gegenwärtigen Stand der deutschen Soziologie. In: Derselbe (1979): Soziologische Schriften I. Frankfurt. Suhrkamp. 500-531.

Adorno, Theodor W. (1966): Negative Dialektik. Frankfurt. Suhrkamp. (1975)

Adorno, Theodor W. (1967): Einleitung zu Emile Durkheim, >Soziologie und Philosophie`. In: Derselbe (1979): Soziologische Schriften I. Frankfurt. Suhrkamp. 245-279.

Adorno, Theodor W. (1969): Einleitung zum >Positivismusstreit in der deutschen Soziologie«. In: Derselbe (1979): Soziologische Schriften I. Frankfurt. Suhrkamp. 280-353.

Adorno, Theodor W. (1987): minima moralia. Frankfurt. Suhrkamp.

Alberts, David S./Garstka, John J./Stein, Frederick P. (2000): Network Centric Warfare. Developing and leveraging information superiority. Washington. CCRP publication series. Online: http://www.dodccrp.org /files/Alberts_NCW.pdf; Zugriff: 16.12.07.

Albrecht, Christoph V. (1998): Geopolitik und Geschichtsphilosophie 1748-1798. Berlin. Akademie Verlag.

Alexander, Caroline (2004): Die Bounty. Die wahre Geschichte der Meuterei auf der Bounty. Berlin. Berlin Verlag.

Alpers, Hans-Joachim (2004): Krieg unter Segeln. Erftstadt. Area-Verlag. Althoff, Gerd (2003): »Besiegte finden selten oder nie Gnade«, und wie man aus dieser Not eine Tugend macht. In: Martus, Steffen/Münkler, Marina/Röcke, Werner (Hg.): Schlachtfelder. Codierung von Gewalt im medialen Wandel. Berlin. Akademie Verlag. 131-145.

Anders, Günther (1956): Die Antiquiertheit des Menschen. Über die Seele im Zeitalter der zweiten industriellen Revolution. 2 Bände. München. Beck. (1987) 
Apelt, Maja (2006): Militärische Sozialisation. In: Gareis, Sven B./Klein, Paul (Hg.) (2006): Handbuch Militär und Sozialwissenschaften. Wiesbaden. VS Verlag für Sozialwissenschaften. 26-39.

Arendt, Hannah (1970): Macht und Gewalt. München. Piper.

Aristoteles (1963a): Psychologie. In: Derselbe (1963): Hauptwerke. Stuttgart. Kroener. 150-208.

Aristoteles (1963b): Nikomachische Ethik. In: Derselbe (1963): Hauptwerke. Stuttgart. Kroener. 209-284.

Asendorpf, Dirk (2002): Handbuch im Kopf. In: Die Zeit. 29.05.2002, Nr. 23. Hamburg. 29.

Baader, Gerhard (1990): Menschenversuche in der deutschen Wehrmacht Pervitin als Beispiel. In: Tschimer, Martina/Göbel, Heinz-Werner (Hg.) (1990): Wissenschaft im Krieg - Krieg in der Wissenschaft. Ein Symposium an der Philipp-Universität Marburg. Marburg. Eigenverlag. 258-266.

Bartlett, Robert (1996): Die Geburt Europas aus dem Geist der Gewalt. Eroberung, Kolonisierung und kultureller Wandel von 950 bis 1350 . München. Kindler.

Bartov, Omer (1995): Hitlers Wehrmacht. Hamburg. Rowohlt.

Bauman, Zygmunt (1995): Moderne und Ambivalenz. Frankfurt. Fischer.

Baumann, Reinhard (1977): Das Söldnerwesen im 16. Jahrhundert im bayerischen und süddeutschen Beispiel. München. Wölfle.

Baumann, Reinhard (1994): Landsknechte. München. Beck.

Bazin, Aaron A. (2005): Boyd's O-O-D-A-Loop and the Infantry Company Commander. In: Infantry Magazine. January-February 2005. Fort Benning. 17-19. Online: http://d-n-i.net/fcs/pdf/bazin_ooda.pdf; Zugriff: 11.10.07.

Bei der Wieden, Brage (1996): Niederdeutsche Söldner vor dem Dreißigjährigen Krieg. In: Kroener, Bernhard R./Pröve, Ralf (Hg.) (1996): Militär und Gesellschaft in der frühen Neuzeit. Paderborn; München; u.a. Schöningh. 85-108.

Biehl, Heiko/Hagen, Ulrich vom/Mackewitsch, Reinhard (2000): Die Motivation von Soldaten im Auslandseinsatz. Ein Problemaufriss in forschungspraktischer Perspektive. In: Kümmel, Gerhard/Prüfert, Andreas (Hg.) (2000): Military sociology. The richness of a discipline. Baden-Baden. Nomos. 345-378.

Binswanger, Otto (1922): Die Kriegshysterie. In: Bonhoeffer, Karl (Hg.) (1922/1934): Handbuch der Ärztlichen Erfahrung im Weltkriege 1914/1918. Bd. IV. Geistes- und Nervenkrankheiten. Leipzig. Barth. 45-67.

Blaßneck, Klaus (2000): Militärpsychiatrie im Nationalsozialismus. Kriegsneurotiker im Zweiten Weltkrieg. Würzburg. Dr. Wiss-Verlag. 
Böhle, Fritz (2002): Vom Objekt zum gespaltenen Subjekt. In: Moldaschl, Manfred/Voß, Günter (Hg.) (2002): Subjektivierung von Arbeit. Band 2. München. Hampp. 101-134.

Böndel, Dirk (Hg.) (1987): Admiral Nelsons Epoche: die Entwicklung der Segelschaffahrt von 1770 bis 1815 . Herford. Mittler.

Bonhoeffer, Karl (1922): Psychosen und Neurosen. In: Derselbe (Hg.) (1922/1934): Handbuch der Ärztlichen Erfahrung im Weltkriege 1914/1918. Bd. IV. Geistes- und Nervenkrankheiten. Leipzig. Barth. 144.

Borgert, Heinz-Ludger (1979): Grundzüge der Landkriegsführung von Schlieffen bis Guderian. In: Militärgeschichtliches Forschungsamt (Hg.) (1983): Deutsche Militärgeschichte in sechs Bänden 1648-1939. Bd. 6., Abschnitt IX. Herrsching. Pawlak. 427-584.

Borst, Arno (1959): Das Rittertum im Hochmittelalter. In: Borst, Arno (Hg.) (1976): Das Rittertum im Mittelalter. Darmstadt. Wiss.Buchges. 212-246.

Bräker, Ulrich (1789): Lebensgeschichte und Natürliche Ebentheuer des Armen Mannes im Tockenburg. In: Ders. (2000): Sämtliche Schriften. Band 4. Herausgegeben und bearbeitet von Hollinger-Wiesmann, Claudia, u.a. München. Beck. 357-557.

Braun, Michael (1985): Rationale Akteure und institutionelle Regelungen in Militärorganisationen. In: SOWI-Berichte Nr. 39. München 1985. 1164

Bredekamp, Horst (2003): Thomas Hobbes. Der Leviathan. Berlin. Akademie Verlag.

Brieler, Ulrich (1998): Die Unerbittlichkeit der Historizität. Köln u.a. Böhlau.

Bröckling, Ulrich (1997): Disziplin. München. Fink.

Bröckling, Ulrich (2003): Schlachtfeldforschung. Die Soziologie im Krieg.

In: Martus, Steffen/Münkler, Marina/Röcke, Werner (Hg.) (2003): Schlachtfelder. Codierung von Gewalt im medialen Wandel. Berlin. Akademie Verlag. 189-206.

Bröckling, Ulrich/Krasmann, Susanne/Lemke, Thomas (2000): Gouvernmentalität der Gegenwart. Studien zur Ökonomisierung des Sozialen. Frankfurt. Suhrkamp.

Brooks, Rodney (2002): Menschmaschinen. Frankfurt. Fischer. (2005)

Budde, Hans-Otto (2005): Aktuelle Aspekte zur Transformation des Deutschen Heeres. In: Clausewitz-Gesellschaft e.V. (Hg.) (2005): Die Jahrbücher der Clausewitz-Gesellschaft e.V. Band 1. Jahrbuch 2005. Hamburg. 105-123. Online: http://clausewitz-gesellschaft.de/uploads/media /Jahrbuch_2005.Inhalt_01.pdf; Zugriff: 11.10.07.

Bundesministerium für Verteidigung (2003): Verteidigungspolitische Richtlinien für den Geschäftsbereich des Bundesministerium der Ver- 
teidigung. 21. Mai 2003. Presse- und Informationsstab. Arbeitsbereich Öffentlichkeitsarbeit. Berlin.

Bundesministerium für Verteidigung (2004): Grundzüge der Konzeption der Bundeswehr. 10. August 2004. Presse- und Informationsstab. Arbeitsbereich Öffentlichkeitsarbeit. Berlin.

Bundesministerium für Verteidigung (2006a): Häufig gestellte Fragen zur Vernetzten Operationsführung«. Online: http://www.luftwaffe.de/por tal/a/luftwaffe/team/auftrag/transformation. Zugriff: 11.10.07.

Bundesministerium für Verteidigung (2006b): Weißbuch 2006 zur Sicherheitspolitik Deutschlands und der Zukunft der Bundeswehr. Berlin. Online: http://www.bmvg.de/portal/a/bmvg/sicherheitspolitik/grund lagen/weissbuch2006. Zugriff: 10.10.07.

Burkhard, Johannes (1992): Der Dreißigjährige Krieg. Frankfurt. Suhrkamp.

Burschel, Peter (1993): Söldner in Nordwestdeutschland des 16. und 17. Jahrhunderts. Göttingen. Vandenhoeck und Ruprecht.

Buse, Uwe (2003): Kampfpiloten auf Speed. In: Der Spiegel. Heft 10/2003. 1. März 2003. 66-72.

Capek, Karel (1920): R.U.R. (Rossums Univeral Robots). New York. Penguin (2004).

Cebrowski, Arthur K./Garstka, John J. (1998): »Network-Centric Warfare: Its Origin and Future«, Proceedings, Vol. 124, Januar 1998, 28-35. Online: http://tinyurl.com/33nmm8; Zugriff: 20.11.06.

Chojnacki, Sven (2007): Auf der Suche nach des Pudels Kern: Alte und neue Typologien in der Kriegsforschung. In: Beyrau, Dietrich/Hochgewschwender, Michael/Langewiesche, Dieter (Hg.) (2007): Formen des Krieges. Von der Antike bis zur Gegenwart. Schöningh. Paderborn. 479-502.

Christaller, Thomas (2001): Robotik. Perspektiven für menschliches Handeln in der zukünftigen Gesellschaft. Berlin etc. Springer.

Clausewitz, Carl v. (1832): Vom Kriege. Hamburg. Dümmler. (1991)

Clynes, Manfred/Kline, Nathan S. (1960): Cyborgs in Space. In: Mentor, Steven/Figueroa-Sarriera, Heidi J./Gray, Chris Hables (Hg.) (1995): The Cyborg Handbook. New York u.a. Routledge. 29-34.

Cocksedge, Simon (2005): The three-block war and future conflict. Some implications for the rifle platoon. In: Defence Army (Hg.) (2005): Australian Army Journal. Volume III, Number 1. Duntroon, New South Wales. 267-272. Online: http://tinyurl.com/26fgvb; Zugriff: 11.10.07.

Comte, Auguste (1974): Die Soziologie. Hrsg. von Friedrich Blaschke. Stuttgart. Kröner.

Cooley, Charles Horton (1909): Social organization. A Study of the Larger Mind. New Brunswick NJ. Transaction Publishers. (1983)

Creveld, Martin van (1985): Command in war. Cambridge (Mass.). Harvard University Press. 
Creveld, Martin van (1989): Kampfkraft. Militärische Organisation und militärische Leistung 1939-1945. Freiburg i.Br. Rombach.

Creveld, Martin van (1998): Die Zukunft des Krieges. München. Gerling.

Cunliffe, Philip (2007): Poor man's ethics? Peacekeeping and the contradictions of ethical ideology. In: Chandler, David/Heins, Volker (Hg.) (2007): Rethinking Ethical Foreign Policy: Pitfalls, Possibilities and Paradoxes. London and New York. Routledge. 70-89.

Daase, Christopher (1999): Kleine Kriege - Große Wirkung. BadenBaden. Nomos.

Damasio, Antionio R. (1997): Descartes’ Irrtum. München. dtv.

Daniel Hohrath (1999): Spätbarocke Kriegspraxis und aufgeklärte Kriegswissenschaften. Neue Forschungen und Perspektiven zu Krieg und Militär im »Zeitalter der Aufklärung«. In: Daniel Hohrath/Klaus Gerteis (Hg.): Die Kriegskunst im Lichte der Vernunft: Militär und Aufklärung im 18. Jahrhundert. Teil 2 (= Aufklärung, Jg. 12, Heft 1). Hamburg 1999. S. 5-47.

Delbrück, Hans (1920): Geschichte der Kriegskunst. 4 Bände. Berlin. Gruyter. (2000)

Department of Defense (2006): Quadrennial Defense Review Report. 6. Februar 2006. Washington. Online: http://www.defenselink.mil/qdr/re port/Report20060203.pdf; Zugriff: 11.10.07.

Department of the Army (1994): Leaders' Manuel for Combat Stress Control. FM 22-51. Washington D.C.

Department of the Army (2000): Combat Stress. FM 6-22.5. Washington D.C.

Department of the Army (2006): Army Unmanned Aircraft System Operations. FMI 3-04.155. Washington D.C. Online: http://www.fas.org/irp/ doddir/army/fmi3-04-155.pdf; Zugriff: 11.10.07.

Descartes, René (1637): Discours de la Méthode; Bericht über die Methode. Stuttgart. Reclam (2001)

Dinges, Martin (1998): Formenwandel der Gewalt in der Neuzeit. In: Sieferle, Rolf Peter/Breuninger, Helga (Hg.) (1998): Kulturen der Gewalt. Frankfurt, New York. Campus. 171-194.

Dornes, Martin (2000): Die emotionale Welt des Kindes. Frankfurt. Fischer.

Dreyer, J.F. (1810): Leben und Taten eines preußischen RegimentsTambours. Osnabrück. Biblio-Verlag. (1975)

Drosdowsi, Günther (Hg.) (1989): Duden `Etymologieく. Mannheim, Wien, Zürich. Dudenverlag.

Duby, Georges (1984): Krieger und Bauern. Die Entwicklung der mittelalterlichen Wirtschaft und Gesellschaft bis um 1200. Frankfurt. Suhrkamp.

Duerr, Hans Peter (1988-2002): Der Mythos vom Zivilisationsprozess. Bisher 5 Bände. Frankfurt. Suhrkamp. 
Dülffer, Jost (1994): Kriegserwartung und Kriegsbild in Deutschland vor 1914. In: Michalka, Wolfgang (Hg.) (1994): Der erste Weltkrieg. München. Piper. 778-798.

Durkheim, Emilie (1924): Soziologie und Philosophie. Frankfurt. Suhrkamp. (1976)

Eder, Philipp/Hofbauer, Bruno Günter (2003): Operative Führung der Alliierten im Krieg gegen den Irak 2003. In: Österreichische militärische Zeitschrift. Jg. 41, Ausgabe 5/2003. Wien. 571-582.

Eibl-Eibesfeldt, Irenäus (1997a): Krieg und Frieden aus der Sicht der Verhaltensforschung. München. Piper.

Eibl-Eibesfeldt, Irenäus (1997b): Die Biologie des menschlichen Verhaltens. München. Piper.

Eichberg, Henning (1989): Festung, Zentralmacht und Sozialgeometrie. Köln, u.a. Böhlau.

Elias, Norbert (1981): Über den Prozess der Zivilisation. 2 Bände. Frankfurt. Suhrkamp.

Elser, G. (Bearbeiter) (1985): Kriegsnah ausbilden. Hilfen für den Gefechtsdienst aller Truppen. Heeresamt der Bundeswehr, Abteilung II, 1. Köln.

Engels, Friedrich (1877): Taktik der Infanterie aus den materiellen Ursachen abgeleitet. (Materialien zum >Anti-Dühring`) In: MEW Bd. 20 Berlin. Dietz (1990). 597-603

Engels, Friedrich (1894): Herrn Eugen Dührings Umwälzung der Wissenschaft. (`Anti-Dühring〈). In: MEW Bd. 20. Berlin. Dietz. (1990). 5303.

Exerzier-Reglement für die Infanterie vom 29.5.1906. Neuabdruck mit Einfügung der bis August 1909 ergangenen Änderungen (Deckblatt 178). Berlin. Mittler. (Ex.-Regl. 1906)

Exum, Andrew (2004): This man's army. A Soldier's Story form the Front Lines of the War on Terrorism. New York. Gotham Book's.

Feldt, Lutz (2004): Führung von Streitkräften im Frieden. In: Soldat und Technik. 2-2004 (Februar). Bonn. Report-Verlag. 44-48.

Ferro, Marc (1988): Der große Krieg 1914 - 1918. Frankfurt. Suhrkamp

Fetscher, Iring (1984): Einleitung. In: Hobbes, Thomas (1651): Leviathan. Hrsg. und eingeleitet von Iring Fetscher. Frankfurt. Suhrkamp. IXLXVI (1984)

Fischer, Gottfried/Riedesser, Peter (1999): Lehrbuch der Psychotraumatologie. München, Basel. Reinhardt.

Fischer-Homberger, Esther (1975): Die traumatische Neurose. Vom somatischen zum sozialen Leiden. Bern, Stuttgart, Wien. Huber.

Flik, Gotthilf (1942): Historisches und Organisatorisches über Spezialistenuntersuchungen. In: Fritscher, Werner (Hg.) (1990): Wehrpsychologie in Dokumenten. München. Verlag für Wehrwissenschaften. 57-64.

Fohler, Susanne (2003): Techniktheorien. München. Fink. 
Förster, Stig (1995): Der deutsche Generalstab und die Illusion des kurzen Krieges, 1871-1914. Metakritik eines Mythos. In: Militärgeschichtliche Mitteilungen. Hrsg. v. Militärgeschichtlichen Forschungsamt. Jg. 54. (1995), Heft 1. München. Oldenbourg. 61-95.

Foucault, Michel (1976): Überwachen und Strafen. Frankfurt. Suhrkamp.

Foucault, Michel (1996): Der Mensch ist ein Erfahrungstier. Frankfurt. Suhrkamp

Fried M./Harris M./Murphy R. (Hg.) (1971): Der Krieg. Zur Anthropologie der Aggression und des bewaffneten Konflikts. Frankfurt. Fischer.

Friedeburg, Ludwig von/Brandt, Gerhard (1966): Aufgaben der Militärpublizistik in der modernen Gesellschaft. Frankfurt. EVA.

Friedrich II. (1748): Generalprincipien des Krieges in Anwendung auf die Taktik und auf die Disziplin der preußischen Truppen. In: Merkens, Heinrich (Hg.) (1875): Ausgewählte Kriegswissenschaftliche Schriften Friedrich's des Grossen. Jena. Herman Costenoble. 1-195. Reprint: Braunschweig. Archiv. (1997)

Fromm, Erich (1977): Anatomie der menschlichen Destruktivität. Frankfurt. Rowohlt.

Gabriel, Richard A. (1988): The Painful Field. The psychiatric dimension of modern war. New York. Greenwood Press.

Gantzel, Klaus Jürgen (2002): Neue Kriege? Neue Kämpfer. Universität Hamburg, IPW, Forschungsstelle Kriege, Rüstung, Entwicklung. Arbeitspapier 2/2002.

Gaschke, Susanne (2004): Am Hindukusch in Stullenstadt. In: Die Zeit. 2.09.2004, Nr. 37. Hamburg. 3.

Gaupp, Robert (1922): Schreckneurosen und Neurasthenie. In: Bonhoeffer, Karl (Hg.) (1922/1934): Handbuch der Ärztlichen Erfahrung im Weltkriege 1914/1918. Bd. IV. Geistes- und Nervenkrankheiten. Leipzig. Barth. 67-101.

Geppert, Heinrich (1998): Die Militärsoziologie aus der Sicht des Bedarfsträgers. SOWI-Papier 108. Strausberg.

Gesellschaft für Entwicklung, Beschaffung und Betrieb m.b.H. (2007): Teamarbeiter. Jahresbroschüre 2006. Online: http://www.gebb.de/Do wnloads/070730_gebb_07_Final.pdf; Zugriff: 11.10.07.

Geser, Hans (1981): Organisationsprobleme des Militärs. Soziologische Aspekte der Organisationsformen in der Armee und in der Wirtschaft. In: Wachtler, Günther (Hg.) (1983): Militär, Krieg, Gesellschaft. Frankfurt, New York. Campus. 139-164.

Geuter, Ulfried (1988): Die Professionalisierung der deutschen Psychologie im Nationalsozialismus. Frankfurt. Suhrkamp.

Giddens, Anthony (1995): Die Konstitution der Gesellschaft. Grundzüge einer Theorie der Strukturierung. Frankfurt, New York. Campus.

Ginzberg, Eli u.a.(1959): The Ineffective Soldier. Lessons for Management and the Nation. 3 Bände. New York. Columbia University Press. 
Gitermann, Valentin (1987): Geschichte Russlands. 3. Band. Frankfurt. Athenäum.

Glatz, Rainer (2003): Die Division Spezielle Operationen. Spezialisierte und Spezialkräfte des Heeres. In: Soldat und Technik. 10-2003 (Oktober). Bonn. Report-Verlag. 27-33.

Gneisenau, Neithardt von (1808): Die Freiheit der Rücken. In: Bundesministerium der Verteidigung (1987): Gneisenau. Ausgewählte Briefe und Schriften. Beiheft 2/87 zur Information der Truppe. Bonn. 97-98.

Goethe, Johann Wolfgang von (1808): Der Faust, eine Tragödie. In: Goethe, Johann Wolfgang von (1996): Goethes Faust. Gesamtausgabe. Frankfurt. Insel. 133-516.

Gordon, Theodore J./Helmer, Olaf (1964): Report on a Longe Range Forecasting Study. P 2982. Rand Corporation. Online: http://www.rand.org /pubs/papers/2005/P2982.pdf; Zugriff: 11.10.07

Gray, Chris Hables (1996): Postmodern War. The New Politics of Conflict. New York. Guiford Press.

Gray, Chris Hables (2002): Cyborg Citizen. Politik in posthumanen Gesellschaften. Wien. Turia + Kant.

Greiner, Christian (1982): >Operational History (German) Section` und $>$ Naval Historical Team`. Deutsches militärstrategisches Denken im Dienst der amerikanischen Streitkräfte von 1946 bis 1950. In. Messerschmidt, Manfred (Hg.) (1982): Militärgeschichte. Probleme - Thesen - Wege. Stuttgart. Deutsche Verlags-Anstalt. 409-435.

Grimm, Jacob/Grimm, Wilhelm (1960): Deutsches Wörterbuch. 32 Bände. Auf CD-ROM: Der Digitale Grimm. 2 CD-ROMs. Frankfurt. Zweitausendeins. (2004)

Grimmelshausen, Hans Jakob Christoffel von (1669): Simplicius Simplicissimus. München. dtv. (1975)

Grossman, Dave (1995): On killing. The psychological cost of learning to kill in war and society. Boston. Little, Brown und Company

Grüne, Matthias/Kretschmer, Thomas (2005): Nanotechnologie. Die Zukunft hat begonnen. In: Strategie \& Technik. 1-2005 (Januar). Bonn. Report-Verlag. 14-15.

Gudmundsson, Bruce I. (1989): Stormtroop tactics. Innovation in the Germany Army, 1914-1918. New York. Praeger Publishers.

Hagemann, Karen (2002): »Mannlicher Muth und Teutsche Ehre«. Nation, Militär und Geschlechter zur Zeit der Antinapoleonischen Kriege Preußens. Paderborn. Schöningh.

Hagemann, Karen/Pröve, Ralf (Hg.) (1998): Landsknechte, Soldatenfrauen und Nationalkrieger. Frankfurt, New York. Campus.

Haltiner, Karl W. (2003): Erfordern neue Militäraufgaben neue Militärstrukturen? Organisationssoziologische Betrachtungen zur Verpolizeilichung des Militärs. In: Collmer, Sabine (Hg.) (2003): Krieg, Konflikt und Gesellschaft. Hamburg. Kovac. 159-186. 
Haraway, Donna (1985): Ein Manifest für Cyborgs. Feminismus im Streit mit den Technowissenschaften. In: Dieselbe (1995): Die Neuerfindung der Natur. Primaten, Cyborgs und Frauen. Frankfurt, New York. Campus. 33-72.

Heins, Volker/Warburg, Jens (2004): Kampf der Zivilisten. Militär und Gesellschaft im Wandel. Bielefeld. transcript.

Heiseler, Johannes Henrich v. (1966): Militär und Technik. In: Picht, Georg (Hg.) (1966): Studien zur politischen und gesellschaftlichen Situation der Bundeswehr. Zweite Folge. Witten/Berlin. Eckart-Verlag. 66-158.

Helms, Hans G. (1996): Computer aus der Alchemistenküche. In Behrens, Hermann/Anderson, Arne (Hg.), 1996: Wirtschaftsgeschichte und Umwelt. Marburg. BdWI-Verlag. 142-204.

Helmus, Todd C./Glenn, Russel (2005): Steeling the mind. Combat stress reactions and their implications for urban warfare. RAND. Online: http:/www.rand.org/pubs/monographs/MG191/index.html; Zugriff: 11.10.07.

Herder, Johann Gottfried (1774): Auch eine Philosophie der Geschichte zur Bildung der Menschheit. Stuttgart. Reclam. (1997)

Herder, Johann Gottfried (1791): Ideen zur Philosophie der Geschichte der Menschheit. Gesammelte Werke Bd. 6. Frankfurt. Dt. Klassiker Verlag. (1989)

Heyne, Moritz (1906): Deutsches Wörterbuch. Leipzig. Hirzel.

Hirschfeld, Gerhard/Krumeich, Gerd/Renz, Irina (Hg.) (2004): Enzyklopädie. Erster Weltkrieg. Paderborn. Schöningh.

Hobbes, Thomas (1651): Leviathan. Hrsg. und eingeleitet von Iring Fetscher. Frankfurt. Suhrkamp. (1984)

Hobsbawm, Eric (1995): Das Zeitalter der Extreme. München. Hanser.

Hoffmann, Erwin (2003): Die Sozialisation wehrpflichtiger Soldaten. Berlin. Logos.

Hohrath, Daniel: Der Bürger im Krieg der Fürsten. In: Kroener, Bernhard R./Pröve, Ralf (Hg.) (1996): Krieg und Frieden. Militär und Gesellschaft in der frühen Neuzeit. Paderborn; München; u.a. Schöningh. 305-329.

Hondrich, Karl Otto (1992): Lehrmeister Krieg. Hamburg. Rowohlt.

Honneth, Axel (1985): Kritik der Macht. Frankfurt. Suhrkamp.

Honneth, Axel/Joas, Hans (1980): Soziales Handeln und menschliche Natur. Frankfurt, New York. Campus.

Horkheimer, Max/Adorno, Theodor W. (1947): Dialektik der Aufklärung. Frankfurt. Fischer. (1969)

Horstmann, Theodor (Hg.) (1997): Generallieutenant Johann Nicolaus von Luckner und seine Husaren im Siebenjährigen Kriege. Osnabrück. Biblio-Verlag. 
Howarth, David (1979): Die Kriegsschiffe. Amsterdam. Time-Life International (Nederland).

Huntington, Samuel P. (1957): The Soldier and the State. The Theory of Civil-Military-Relations. Cambridge/Ma. Belknap Press.

Hübner, Heico (2007): Vernetzte Operationsführung. Führungsverfahren und -organisation Erste Erfahrungen aus der $>$ NetOpFü-Experimentserieı. In: Strategie und Technik. 4-2007 (April). Bonn. Report-Verlag. 20-24.

Hüppauf, Bernd (2003): Das Schlachtfeld als Raum im Kopf. In: Martus, Steffen/Münkler, Marina/Röcke, Werner (Hg.) (2003): Schlachtfelder. Codierung von Gewalt im medialen Wandel. Berlin. Akademie Verlag. 207-233.

Hürter, Tobias (2002): Der Kick im Cockpit; US-Kampfpiloten halten sich während ihrer Einsätze mit Amphetaminen wach. In: Süddeutsche Zeitung vom 13.August 2002.

Irlenkaeuser, Jan C. (2006): CIMIC als militärische Herausforderung. In: Gareis, Sven B./Klein, Paul (Hg.) (2006): Handbuch Militär und Sozialwissenschaften. Wiesbaden. VS Verlag für Sozialwissenschaften. 303-313.

Jähns, Max (1891): Geschichte der Kriegswissenschaften, vornehmlich in Deutschland. Band 3. Das 18. Jahrhundert seit dem Auftreten Friedrich des Großen. München, Leipzig. R. Oldenbourg. Reprint 1966. New York. Johnson Reprint Corporation

Janowitz, Morris/Little, Roger W. (1965): Militär und Gesellschaft. Boppard. Harald Boldt.

Jean, François/Rufin, Jean-Christophe (Hg.) (1999): Ökonomie der Bürgerkriege. Hamburg. Hamburger Edition

Joas, Hans (1996): Die Kreativität des Handelns. Frankfurt. Suhrkamp.

Joas, Hans (2000): Kriege und Werte. Weilerswist. Velbrück.

Johrendt, Johann (1976): Milites und Militia im 11. Jahrhundert in Deutschland. In: Borst, Arno (Hg.) (1976): Das Rittertum im Mittelalter. Darmstadt. Wiss. Buchges. 419-436.

Joint Chiefs of Staff (2000): Joint Vision 2020. Online: http://www.dtic. mil/jointvision/jvpub2.htm; Zugriff 11.10.07.

Jürgens-Kirchhoff, Annegret (2007): Der Beitrag der Schlachtenmalerei zur Konstruktion von Kriegstypen. In.: Beyrau, Dietrich/Hochgewschwender, Michael/Langewiesche, Dieter (Hg.) (2007): Formen des Krieges. Von der Antike bis zur Gegenwart. Schöningh. Paderborn. 443-458.

Jütte, Robert (2000): Arme, Bettler, Beutelschneider. Weimar. Böhlaus Nachf.

Kahl, Martin/Teusch, Ulrich (2004): Sind die `neuen` Kriege wirklich neu? In: Leviathan. Zeitschrift für Sozialwissenschaft. Jahrgang 32, Heft 3. Sept. 2004. Wiesbaden. VS Verlag. 382-401. 
Kaldor, Mary (2000): Neue und alte Kriege. Organisierte Gewalt im Zeitalter der Globalisierung. Frankfurt. Suhrkamp.

Kant, Immanuel (1784a): Ideen zu einer allgemeinen Geschichte in weltbürgerlicher Absicht. In: Derselbe (1977): Werkausgabe. v. Weischedel, Wilhelm (Hg.). Bd. XI. Frankfurt. Suhrkamp. 31-50.

Kant, Immanuel (1784b): Beantwortung der Frage: Was ist Aufklärung. In: Derselbe (1977): Werkausgabe. v. Weischedel, Wilhelm (Hg.). Bd. XI. Frankfurt. Suhrkamp. 51-62.

Kant, Immanuel (1785/86): Grundlegung zur Metaphysik der Sitten. In: Derselbe (1974): Werkausgabe. v. Weischedel, Wilhelm (Hg.). Bd. VII. Frankfurt. Suhrkamp. 11-102.

Kant, Immanuel (1788): Kritik der praktischen Vernunft. In: Derselbe (1974): Werkausgabe. v. Weischedel, Wilhelm (Hg.). Bd. VII. Frankfurt. Suhrkamp. 107-302.

Kaufmann, Stefan (1996): Kommunikationstechnik und Kriegführung 1815-1945. München. Fink.

Kaufmann, Stefan (2002): Kriegführung im Zeitalter technischer Systeme - Zur Maschinisierung militärischer Operationen im Ersten Weltkrieg. In: Militärgeschichtliches Forschungsamt (Hg.): Militärgeschichtliches Zeitschrift. 61 (2002). München. Oldenbourg. 337-368.

Kaufmann, Stefan (2005): Network Centric Warfare. Den Krieg netzwerktechnisch denken. In: Gethmann, Daniel/Stauff, Markus (Hg.) (2005): Politiken der Medien. Zürich, Berlin. Diaphanes. 245-264

Keegan, John (1991): Das Antlitz der Schlacht. Frankfurt, New York. Campus.

Keegan, John (1995): Die Kultur des Krieges. Berlin. Rowohlt.

Keegan, John (2001): Der Erste Weltkrieg. Eine europäische Tragödie. Hamburg, Rowohlt.

Keen, Maurice (1999): Das Rittertum. München, Zürich. Artemis.

Keller, Jörg (2006): Mythos Auftragstaktik. In: Hagen, Ulrich vom (2006): Militär in Demokratien. Zum Verhältnis von zivilen und militärischen Prinzipien. Wiesbaden. VS Verlag für Sozialwissenschaften. 141-164.

Keller, Adam (2006): The Other Israel. Newsletter of the struggle for Israeli-Palestinian Peace. Ausgabe September-October 2006, No 127128. Herausgegeben von Adam Keller. Holon. 26-27.

Kernic, Franz (2003): Kritik der militärischen Gewalt. Eine gesellschaftstheoretische Analyse zum Verhältnis von Politik, Staat und organisierter kollektiver Gewaltanwendung. Frankfurt, u.a. Lang.

Kleemann, Frank/Matuschek, Ingo/Voß, G. Günter (2002): Subjektivierung von Arbeit - Ein Überblick zum Stand der soziologischen Debatte. In: Moldaschl, Manfred/Voß, Günter (Hg.) (2002): Subjektivierung von Arbeit. Band 2. München. Hampp. 53-100.

Kleemeier, Ulrike (2002): Grundfragen einer philosophischen Theorie des Krieges. Berlin. Akademie Verlag. 
Klein, Uta (2001): Militär und Geschlecht in Israel. Frankfurt. Campus.

Kleinschmidt, Harald (1989): Tyrocinium militare. Militärische Körperhaltungen und -bewegungen im Wandel zwischen dem 14. und dem 18. Jahrhundert. Stuttgart. Autorenverlag.

Kleinschmidt, Harald (1999): Mechanismus und Biologismus im Militärwesen des 17. und 18. Jahrhunderts. Bewegungen - Ordnungen Wahrnehmung. In: Aufklärung. Interdisziplinäre Halbjahresschrift zur Erforschung des 18. Jahrhunderts und seiner Wirkungsgeschichte. Jahrgang 11, Heft 2, 1996. Hamburg. Meiner. 51-73.

Knöbl, Wolfgang (2004): Krieg, »Neue Kriege« und Terror: Sozialwissenschaftliche Analysen und »Deutungen« der aktuellen weltpolitischen Lage. In: Soeffner, Hans-Georg u.a. (Hg.): Soziologische Revue. Jahrgang 27, Heft 2/2004. München. Oldenbourg. 186-200.

Knöbl, Wolfgang/Schmidt, Gunnar (Hg.) (2000): Die Gegenwart des Krieges. Frankfurt. Fischer.

Koalitionsvertrag CDU/CSU/SPD: Gemeinsam für Deutschland - mit Mut und Menschlichkeit. 11.11.2005. Online: http://tinyurl.com/yshwug; Zugriff: 11.10.07.

Köhler, Karl (1968): Organisationsgeschichte der Luftwaffe von den Anfängen bis 1918. In: Militärgeschichtliches Forschungsamt (Hg.) (1983): Deutsche Militärgeschichte in sechs Bänden 1648-1939. Bd. 3, Abschnitt V. Herrsching. Pawlak. 283-311.

König, René (1968): Vorwort. Einige Bemerkungen zu den speziellen Problemen der Begründung einer Militärsoziologie. In: Derselbe (Hg.) 1968: Beiträge zur Militärsoziologie. Zeitschrift für Sozialforschung. Sonderheft 12. Köln/Opladen. Westdeutscher Verlag. 7-12.

König, René (1974): Soziologie. Frankfurt. Fischer.

Krainz, Eva E. (2003): Die körperliche Leistungsfähigkeit weiblicher Soldaten. In: Truppendienst. Folge 272. Ausgabe 5/2003. Zeitschrift für Führung und Ausbildung im Österreichischen Bundesheer. Wien. 468473.

Kraus, Karl (1926): Die letzten Tage der Menschheit. Frankfurt. Suhrkamp (1986).

Krause, Rainer (1990): Psychodynamik der Emotionsstörungen. In: Scherer, Klaus R. (1990): Psychologie der Emotion. Göttingen. Hogrefe. 630-705.

Kreim, Günther R. (2001a): Eignungsfeststellung für Kommandosoldaten der Bundeswehr. In: Puzicha, Klaus J./Hansen, Dieter/Weber, Wolfgang W. (Hg.) (2001): Psychologie für Einsatz und Notfall. Bonn. Bernard \& Graefe. 48-55.

Kreim, Günther R. (2001b): Stressmanagement beim Kommando Spezialkräfte. In: Puzicha, Klaus J./Hansen, Dieter/Weber, Wolfgang W. (Hg.) (2001): Psychologie für Einsatz und Notfall. Bonn. Bernard \& Graefe. 492-504. 
Kretschmer, Thomas (Hg.) (2006): Grundlagen und militärische Anwendung der Nanotechnologie. Frankfurt. Report Verlag.

Krippendorff, Ekkehart (1985): Staat und Krieg. Die historische Logik politischer Unvernunft. Frankfurt. Suhrkamp.

Krippendorff, Ekkehart (1986): Internationale Politik. Frankfurt, New York. Campus.

Kroener Bernhard R. (1998): Die Armeen Frankreichs und Preußens am Vorabend der Schlacht von Jena und Auerstedt. In: Opitz, Eckardt (Hg.) (1998): Gerhard von Scharnhorst. Vom Wesen und Wirken der preußischen Heeresreform. Bremen. Ed.Temmen. 12-30.

Kroener, Bernhard R.: »Das Schwungrad an der Staatsmaschine« ? In: Derselbe/Pröve, Ralf (Hg.) (1996): Militär und Gesellschaft in der frühen Neuzeit. Paderborn; München, u.a. Schöningh. 1-23.

Krumeich, Gerd: Militärgeschichte für eine zivile Gesellschaft. In: Cornelißen, Christoph (Hg.) (2000): Geschichtswissenschaften. Eine Einführung. Frankfurt. Fischer. 178-193.

Kühlich, Frank (1995): Die deutschen Soldaten im Krieg von 1870/81. Frankfurt. Lang.

Kühne, Thomas (1999): Gruppenkohäsion und Kameradschaftsmythos in der Wehrmacht. In: Müller, Rolf-Dieter (Hg.) (1999): Die Wehrmacht. Mythos und Realität. München. Oldenbourg. 534-549.

Kümmel, Gerhard (2005a): Auftrag und Aufgaben des Militärs im Wandel. In: Leonhard, Nina/Werkner, Ines-Jacqueline (Hg.) (2005): Militärsoziologie - Eine Einführung. Wiesbaden. VS Verlag für Sozialwissenschaften. 24-49.

Kümmel, Gerhard (2005b): Frauen im Militär. In: Leonhard, Nina/Werkner, Ines-Jacqueline (Hg.) (2005): Militärsoziologie - Eine Einführung. Wiesbaden. VS Verlag für Sozialwissenschaften. 114-134.

Kümmel, Gerhard/Prüfert, Andreas (Hg.) (2000): Military sociology. The richness of a discipline. Baden-Baden. Nomos.

Kunisch, Johannes (1973): Der kleine Krieg. Wiesbaden. Steiner.

Kunisch, Johannes (1992): Fürst, Gesellschaft, Krieg. Studien zur bellizistischen Disposition des absoluten Fürstenstaates. Köln. Böhlau.

Kunz, Andreas (2005): Wehrmacht und Niederlage. Die bewaffnete Macht in der Endphase der nationalsozialistischen Herrschaft 1944 bis 1945. München. Oldenbourg.

La Mettrie, Julien Offray de (1747): Der Mensch eine Maschine. Stuttgart. Reclam (2001)

Lange, Sascha (2003): Flugroboter statt bemannter Militärflugzeuge? SWP-Studie S29, Juli 2003. Herausgegeben von der Stiftung Wissenschaft und Politik. Deutsches Institut für Internationale Politik und Sicherheit. Berlin.

Lange, Sascha (2004): Netzwerk-basierte Operationsführung (NBO). SWP-Studie S22, Mai 2004. Herausgegeben von der Stiftung Wissen- 
schaft und Politik. Deutsches Institut für Internationale Politik und Sicherheit. Berlin.

Lange, Sascha (2005a): Falludscha und die Transformation der Streitkräfte. Häuserkampf in Städten als dominante Kernfähigkeit der Zukunft. Diskussionspapier Januar 2005. Herausgegeben von der Stiftung Wissenschaft und Politik. Deutsches Institut für Internationale Politik und Sicherheit. Berlin.

Lange, Sascha (2005b): Neue Bundeswehr auf altem Sockel. Wege aus dem Dilemma. SWP-Studie S2. Januar 2005. Herausgegeben von der Stiftung Wissenschaft und Politik. Deutsches Institut für Internationale Politik und Sicherheit. Berlin.

Latour, Bruno (1998): Über technische Vermittlung. Philosophie, Soziologie, Genealogie. In: Rammert, Werner (Hg.) (1998): Technik und Sozialtheorie. Frankfurt, New York. Campus. 29-81.

Latzko, Andreas (1917): Menschen im Krieg. Zürich. Rascher \& Cie.

Lehnart, Ulrich (1993): Die Schlacht von Worringen. Butzbach. Griedel. AFRA-Verl.

Leistenschneider, Stephan (2002): Auftragstaktik im preußisch-deutschen Heer 1871-1914. Hamburg. Mittler.

Leonhard, Nina/Biehl, Heiko (2005): Soldat: Beruf oder Berufung? In: Leonhard, Nina/Werkner, Ines-Jacqueline (Hg.) (2005): Militärsoziologie - Eine Einführung. Wiesbaden. VS Verlag für Sozialwissenschaften. 243-267.

Leonhard, Nina/Werkner, Ines-Jacqueline (Hg.) (2005): Militärsoziologie - Eine Einführung. Wiesbaden. VS Verlag für Sozialwissenschaften.

Lichtenstein, Nelson (2006): Wal-Mart: A field guide to America's largest company and the world's largest Employer. New York. New Press.

Lindemann, Gesa (2005): Die Verkörperung des Sozialen. Theoriekonstruktion und empirische Forschungsperspektiven. In: Schroer, Markus (Hg.) (2005): Soziologie des Körpers. Frankfurt. Suhrkamp. 114-138.

Lindner, Thomas (1993): Die Peripetie des Siebenjährigen Krieges. Der Herbstfeldzug 1706 in Sachsen und der Winterfeldzug 1760/61 in Hessen. Berlin. Duncker und Humblot.

Lopez, Ramon (1983): Die Kontroverse um AirLand Battle 2000. In: Internationale Wehr-Revue. Jahrgang 16 (1983), Heft 11. Genf. Interavia. 1551-1556.

Luckmann, Thomas (1992): Theorie des sozialen Handelns. Berlin, New York. Gruyter.

Ludendorff, Erich (1919): Meine Kriegserinnerungen 1914-1918. Berlin. Mittler und Sohn.

Luftwaffenamt (Hg.) (2005): Vernetzte Operationsführung. (NetOpFü) Eine Einführung. Version 1.0. Februar 2005. Zentrum für Weiterentwicklung der Luftwaffe.Dezernat Konzeptionelle Zielvorstellungen. Köln-Wahn. 
Luh, Jürgen (2004): Kriegskunst in Europa 1650-1800. Köln. Böhlau.

Luhmann, Niklas (1984): Soziale Systeme. Grundriss einer allgemeinen Theorie. Frankfurt. Suhrkamp.

Lupfer, Timothy T. (1981): The Dynamics of Doctrine: The Changes in German Tactical Doctrine During the First World War. Leavenworth Papers No. 4, Combat Studies Institute. U.S. Army Command and General Staff College. Leavenworth (Kan.).

Luyken, Reiner (2005): Die Falludscha Falle. In: Die Zeit. 28.07.2005, Nr. 31. Hamburg. 13-16.

Machiavelli, Niccoló (1513): Der Fürst. In: Derselbe (1990): Politische Schriften. Herausgegeben und eingeleitet von Herfried Münkler. Frankfurt. Fischer. 51-123.

Machiavelli, Niccoló (1513/1519): Discorsi. In: Derselbe (1990): Politische Schriften. Herausgegeben und eingeleitet von Herfried Münkler. Frankfurt. Fischer. 127-269.

Mann, Michael (1990): Geschichte der Macht. Bd. 1. Von den Anfängen bis zur Griechischen Antike. Frankfurt, New York. Campus.

Mann, Michael (1991): Geschichte der Macht. Bd. 2. Vom Römischen Reich bis zum Vorabend der Industrialisierung. Frankfurt, New York. Campus.

Mann, Michael (1998): Geschichte der Macht. Bd. 3, Teil I. Die Entstehung von Klassen und Nationalstaaten. Frankfurt, New York. Campus.

Mann, Michael (2000): Krieg und Gesellschaftstheorie. In: Knöbl, Wolfgang/Schmidt, Gunnar (Hg.) (2000): Die Gegenwart des Krieges. Frankfurt. Fischer. 25-51.

Marlowe, David H. (1978): Cohesion, anticipated breakdown, and endurance in battle: considerations for service and high intensity combat, Washington, D.C. Walter Reed Army Institute of Research.

Marshall, Samuel L.A. (1947): Soldaten im Feuer. Frauenfeld. Huber. (1959)

Marx, Karl (1852): Der 18. Brumaire des Louis Bonaparte. MEW 8 (1961). Berlin. Dietz. 111-207.

Marx, Karl (1858): Einleitung zu den Grundrissen der Kritik der politischen Ökonomie. In:. MEW 42 (1983). Berlin. Dietz. 19-45.

Marx, Karl (1859): Zur Kritik der politischen Ökonomie. MEW 13 (1961). Berlin. Dietz.

Marx, Karl (1867): Das Kapital. Band 1. MEW 23 (1962). Berlin. Dietz.

McNeill, William H. (1984): Krieg und Macht: Militär, Wirtschaft und Gesellschaft vom Altertum bis heute. München. Beck.

Mentzos, Stavros (1993): Der Krieg und seine psychosoziale Funktionen. Frankfurt. Fischer.

Merta, Klaus-Peter: Kurzer Überblick über die Entwicklungsgeschichte des Auszeichnungswesens. Online http://tinyurl.com/2nnpgo; Zugriff: 11.10.07. 
Mertens, Wolfgang/Waldvogel, Bruno (Hg.) (2000): Handbuch psychoanalytischer Grundbegriffe. Stuttgart. Kohlhammer.

Messerschmidt, Manfred (1975/76): Die preußische Armee. In: Militärgeschichtliches Forschungsamt (Hg.) (1983): Deutsche Militärgeschichte in sechs Bänden 1648-1939. Bd. 2., Abschnitt IV, Zweiter Teil. Herrsching. Pawlak.

Messerschmidt, Manfred (2005): Die Wehrmachtsjustiz 1933-1945. Paderborn. Schöningh.

Meyer, Joachim Ernst (1961): Die abnormen Erlebnisreaktionen im Kriege bei Truppe und Zivilbevölkerung. In: Gruhle, H.W. u.a. (Hg.) (1961): Psychiatrie der Gegenwart. Forschung und Praxis. Bd. III. Soziale und angewandte Psychiatrie. Berlin. Springer. 574-619.

Meyer-Drawe, Käte (1996): Menschen im Spiegel ihrer Maschinen. München. Fink.

Millotat, Christian (2002): Auftragstaktik, das oberste Führungsprinzip im Heer der Bundeswehr. Ihr Entwicklung und Darstellung in deutschen Führungsgrundlagen. In: Führungsakademie der Bundeswehr (Hg.) (2002): Beiträge zur Weiterentwicklung der Lehre. 1/2002. Hamburg.

Mitze, Wilhelm (1985): Zur Geschichte der Deutschen Marinepsychologie. In: Hofstätter, Peter R. (Vorr.) (1985): Deutsche Wehrmachtspsychologie 1914-1945. München. Verlag für Wehrwissenschaft. 185-286.

Möbius, Sascha (2001): Psychologische Aspekte friederizianischer Taktik im Siebenjährigen Krieg. Unveröffentlicht.

Möbius, Sascha (2004): Die Kommunikation zwischen preußischen Soldaten und Offizieren im Siebenjährigen Krieg zwischen Gewalt und Konsens. In: Militärgeschichtliche Zeitschrift. Hrsg. v. Militärgeschichtlichen Forschungsamt. Jg. 63 (2004), Heft 2. München. Oldenbourg. 325-353.

Möbius, Sascha (2004b): Die Entwicklung der Infanterietaktik des hessischen Heeres vor dem Hintergrund der Erfahrungen des amerikanischen Unabhängigkeitskrieges. Online: http://wiki.genealogy.net/index .php/Milit\%C3\%A4r/Reglement/Kampfweise/Hessen; Zugriff 1.11.07.

Moldaschl, Manfred/Voß, Günter (Hg.) (2002): Subjektivierung von Arbeit. Band 2. München. Hampp.

Mommsen, Wolfgang J. (1974): Max Weber. Gesellschaft, Politik und Geschichte. Frankfurt. Suhrkamp.

Mosen, Wido (1967): Eine Militärsoziologie. Technische Entwicklung und Autoritätsprobleme in modernen Armeen. Neuwied, Berlin. Luchterhand.

Moskos, Charles C. (1968): Eigeninteresse, Primärgruppen und Ideologie. Eine Untersuchung der Kampfmotivation amerikanischer Truppen in Vietnam. In: König, René (Hg.) 1968: Beiträge zur Militärsoziologie. Zeitschrift für Sozialforschung. Sonderheft 12. Köln/Opladen. Westdeutscher Verlag. 199-220. 
Moskos, Charles C. (2000): Towards a Postmodern Military. The United States as a Paradigm. In: Moskos. Charles C./Williams, John Allen/Segal, David R. (Hg.) (2000): The Postmodern Military, Armed Forces After the Cold War. New York. Oxford University Press. 14-31.

Moskos, Charles C. (2001): Peacekeeping verbessert die Kampfbereitschaft. In: Allgemeine Schweizerische Militärzeitschrift. Herausgegeben von der Schweizerischen Offiziersgesellschaft. Ausgabe Januar 2002. Online: http://www.asmz.ch/hefte/artikel.php?artikel=176; Zugriff: 10.11.07.

Müller, Roland (2001): Wege zum Ruhm. Militärpsychiatrie im Zweiten Weltkrieg. - das Beispiel Marburg. Köln. PapyRossa-Verlag.

Müller, Rolf-Dieter (2004): Gaskrieg. In: Hirschfeld, Gerhard/Krumeich, Gerd/Renz, Irina (Hg.) (2004): Enzyklopädie. Erster Weltkrieg. Paderborn. Schöningh. 519-522.

Münkler, Herfried (1990): Einleitung. In: Machiavelli, Niccoló (1990): Politische Schriften. Herausgegeben und eingeleitet von Herfried Münkler. Frankfurt. Fischer. 15-47.

Münkler, Herfried (1992): Gewalt und Ordnung. Frankfurt. Fischer.

Münkler, Herfried (2002): Die neuen Kriege. Hamburg. Rowohlt.

Naval Strike Air Warfare Center (2000): Performance Maintenance During Continuous Flight Operations. Online: http://tinyurl.com/2dsney; Zugriff: 11.10.07.

Neckel, Sighard (2006): Kultursoziologie der Gefühle. In. Schützeichel, Rainer (Hg.) (2006): Emotionen und Sozialtheorie. Frankfurt, New York. Campus. 124-139.

Nerlich, Michael (1997): Abenteuer oder das verlorene Selbstverständnis der Moderne. München. Gerling-Akademie.

Nonne, Max (1922): Therapeutische Erfahrungen an den Kriegsneurosen in den Jahren 1914 bis 1918. In: Bonhoeffer, Karl (Hg.) (1922/1934): Handbuch der Ärztlichen Erfahrung im Weltkriege 1914/1918. Bd. IV. Geistes- und Nervenkrankheiten. Leipzig. Barth. 102-153.

Nowosadtko, Jutta 2002: Gewalt und Ordnung. Einführung in die Militärgeschichte. Tübingen. Edition diskord.

Nowosadtko, Jutta: Ordnungselement oder Störfaktor. Zur Rolle der stehenden Heere innerhalb der frühneuzeitlichen Gesellschaft. In: Pröve, Ralf (Hg.) (1997): Klio in Uniform. Köln, u.a. Böhlau. 5-34.

Oberste Heeresleitung (Hg.) (1918a): Allgemeines über Stellungsbau. In: Ludendorff, Erich (Hg.) (1921): Urkunden der Obersten Heeresleitung über ihre Tätigkeit 1916/18. Berlin. Mittler und Sohn. 594-604.

Oberste Heeresleitung (Hg.) (1918b): Die Abwehr im Stellungskriege. In: Ludendorff, Erich (Hg.) (1921): Urkunden der Obersten Heeresleitung über ihre Tätigkeit 1916/18. Berlin. Mittler und Sohn. 604-640. 
Oberste Heeresleitung (Hg.) (1918c): Der Angriff im Stellungskriege. In: Ludendorff, Erich (Hg.) (1921): Urkunden der Obersten Heeresleitung über ihre Tätigkeit 1916/18. Berlin. Mittler und Sohn. 641-686.

Osborne, Thomas (2001): Techniken und Subjekte, von der >Governmentality Studies` zu den 〉Studies of Governmentality<. In: Demokratie. Arbeit. Selbst. Analysen liberal-demokratischer Gesellschaften im Anschluss an Michel Foucault, Mitteilungen des Instituts für Wissenschaft und Kunst, 56 (2001), Nr. 2/3. 12-16.

Overmans, Rüdiger (2004): Kriegsverluste. In: Hirschfeld, Gerhard/Krumeich, Gerd/Renz, Irina (Hg.) (2004): Enzyklopädie. Erster Weltkrieg. Paderborn. Schöningh. 663-666.

Papke, Sven (1979): Von der Miliz zum Stehenden Heer. Wehrwesen im Absolutismus. In: Militärgeschichtliches Forschungsamt (Hg.) (1983): Deutsche Militärgeschichte in sechs Bänden 1648-1939. Bd. 1, Abschnitt I. Herrsching. Pawlak.

Parker, Geoffrey (1990): Die militärische Revolution. Frankfurt, New York. Campus.

Paul, Gerhard (2004): Bilder des Krieges. Krieg der Bilder. Paderborn. Schöningh

Petri, Stefan J. (2001): Experten des Charakters. Veränderung der Methodologie psychologischer Eignungsuntersuchungen in der deutschen Wehrpsychologie 1914-1945. In: Die Psychologie in praktischen Kontexten. Workshop 11. Mai 2001. Online: http://www.bbaw.de/bbaw/

Forschung/Forschungsprojekte/psychologie/bilder/ws1.pdf; Zugriff: 12.10.07. 49-58.

Plaut, Paul (1921): Zur Psychographie des Krieges. In: Lipmann, O., Stern, W., (Hg.) (1921): Psychologie des Kriegers, Beihefte zur Zeitschrift angewandte Psychologie, Heft 21, Leipzig. Johann Ambrosius Barth. $1-123$.

Plessner, Helmuth (1928): Die Stufen des Organischen der Mensch. Berlin, New York. Gruyter. (1975)

Plessner, Helmuth (1941): Lachen und Weinen. Eine Untersuchung der Grenzen menschlichen Verhaltens. In: Plessner, Helmuth (2003): Ausdruck und menschliche Natur. Gesammelte Schriften. Bd. VII. Frankfurt. Suhrkamp. 201-387.

Plessner, Helmuth (1961): Die Frage nach der Conditio humana. In Plessner, Helmuth (1983): Conditio humana. Gesammelte Schriften. Bd. VIII. Frankfurt. Suhrkamp. 136-217.

Popitz, Heinrich (1961): Soziale Normen. In: Derselbe (2006): Soziale Normen. Frankfurt. Suhrkamp. 61-75.

Popitz, Heinrich (1992): Phänomene der Macht. Tübingen. Mohr.

Popitz, Heinrich (1995): Der Aufbruch zur Artifiziellen Gesellschaft. Tübingen. Mohr.

Popitz, Heinrich (2000): Wege der Kreativität. Tübingen. Mohr. 
Popitz, Heinrich/Bahrdt, Hans Paul/u.a. (1976): Technik und Industriearbeit. Tübingen. Mohr.

Popplow, Marcus (1996): Verfügten mittelalterliche Autoren über einen Maschinenbegriff? In: Lindgren, Uta (1996): Europäische Technik im Mittelalter. Berlin. Gebr. Mann. 537-538.

Pröve, Ralf: Vom Schmuddelkind zur anerkannten Subdisziplin? Die »neue Militärgeschichte« der Frühen Neuzeit. Perspektiven, Entwicklungen, Probleme. [GWU 51 (2000), 597-612].

Rammert, Werner/Schulz-Schaeffer, Ingo (2002): Technik und Handeln. Wenn soziales Handeln sich auf menschliches Verhalten und technische Abläufe verteilt. In: Dieselben (Hg.) (2002): Können Maschinen handeln? Soziologische Beiträge zum Verhältnis Mensch und Technik. Frankfurt, New York. Campus. 7-64.

Ranke-Graves, Robert von (1959): Strich drunter. Hamburg. Rowohlt (1990)

Rass, Christoph (2003): Menschenmaterial. Deutsche Soldaten an der Ostfront. Innenansichten einer Infanteriedivision 1939-1945. Paderborn. Schöningh.

Reemtsma, Jan Philipp (1996): Trauma und Moral. Einige Überlegungen zum Krieg als Zustand einer kriegführenden Gesellschaft und zum pazifistischen Affekt In: Reemtsma, Jan Philipp (1998): Mord am Stand. Allianzen von Zivilisation und Barbarei. Aufsätze und Reden. Hamburg. Hamburger Edition. 347-368

Regling, Volkmar (1979): Grundzüge der Landkriegführung zur Zeit des Absolutismus und im 19. Jahrhundert. In: Militärgeschichtliches Forschungsamt (Hg.) (1983): Deutsche Militärgeschichte in sechs Bänden 1648-1939. Bd. 6, Abschnitt IX. Herrsching. Pawlak. 11-425.

Reichmayr, Johannes (1983): Psychoanalyse im Krieg. Zur Geschichte einer Illusion. In: Passet, Peter/Modena, Emilio (Hg.) (1983): Krieg und Frieden aus psychoanalytischer Sicht. München. Piper. 36-58.

Reisner, Markus (2006): Vorstoß nach Bagdad. Die eingeschränkten Möglichkeiten der Hochtechnologie. In: Truppendienst. Zeitschrift für Führung und Ausbildung im Österreichischen Bundesheer. Wien. Folge 290. Ausgabe 2/2006. Online: http://www.bundesheer.gv.at/truppen dienst/ausgaben/artikel.php?id=439; Zugriff: 12.10 .07

Remarque, Erich Maria (1929): Im Westen nichts Neues. Frankfurt, Berlin. Ullstein. (1968)

Renn, Ludwig (1979): Krieger, Landsknecht und Soldat. Unter Mitarbeit von Helmut Schnitter Berlin, Weimar. Aufbau.

Renthe-Fink, Leonhard von (1985): Von der Heerespsychotechnik zur Wehrmachtspsychologie. In: Hofstätter, Peter R. (Vorr.) (1985): Deutsche Wehrmachtspsychologie 1914-1945. München. Verlag für Wehrwissenschaft. 3-184. 
Richter, Gernot (Hg.) (2007): Die ökonomische Modernisierung der Bundeswehr. Wiesbaden. VS Verlag für Sozialwissenschaften.

Richthofen, Manfred (1917): Der rote Kampfflieger. In: Derselbe (1990): Der rote Kampfflieger. Die persönlichen Aufzeichnungen des roten Barons, mit dem >Reglement für Kampfflieger`. Einführung von Manfred Wörner. Hamburg. Germa Press.

Rick, Martin (1999): Vom >Parteygänger` zum Partisan. Die Konzeption des kleinen Krieges in Preußen 1740 - 1813. Frankfurt, u.a. Lang.

Riedesser, Peter/Verderber, Axel (1985): Aufrüstung der Seelen. Militärspsychiatrie und Militärpsychologie in Deutschland und Amerika. Freiburg. Dreisam.

Riedesser, Peter/Verderber, Axel (2004): >Maschinengewehre hinter der Front . Zur Geschichte der deutschen Militärpsychiatrie. Frankfurt. Mabuse-Verlag.

Ritter, Gerhard (1956): Der Schlieffenplan. Kritik eines Mythos. München. Oldenbourg.

Rogg, Matthias (1996): »Zerhauen und zerschnitte, nach adelichen Sitten«: Herkunft, Entwicklung und Funktion soldatischer Tracht des 16. Jahrhunderts im Spiegel zeitgenössischer Kunst. In: Kroener, Bernhard R./Pröve, Ralf (Hg.) (1996): Militär und Gesellschaft in der frühen Neuzeit. Paderborn; München; u.a. Schöningh. 109-136.

Rogg, Matthias (1998): Wol auff mit mir, du schoenes weyb. Anmerkungen zur Konstruktion von Männlichkeit im Soldatenbild des 16. Jahrhunderts. In: Hagemann, Karen/Pröve, Ralf (Hg.), (1998): Landsknechte, Soldatenfrauen und Nationalkrieger. Frankfurt, New York. Campus. 51-73.

Rogg, Matthias (2002): Landsknechte und Reisläufer. Bilder vom Soldaten; ein Stand in der Kunst des 16. Jahrhunderts. Paderborn. Schöningh.

Roghmann, Klaus/Ziegler, Rolf (1977): Militärsoziologie. In: König, René (Hg.) (1977): Handbuch der empirischen Sozialforschung. Organisation, Militär. Band 9. Stuttgart. Enke. 142-227.

Rohkrämer, Michael (1990): Der Militarismus der `kleinen Leuteく. München. Oldenbourg.

Roth, Karl-Heinz (1987): Die Modernisierung der Folter in den beiden Weltkriegen. Der Konflikt der Psychotherapeuten und Schulpsychiater um die deutschen >Kriegsneurotiker` 1915-1945. In: Hamburger Stiftung für Sozialgeschichte (Hg.): 1999. Zeitschrift für Sozialgeschichte des 20. und 21. Jahrhunderts. Heft 3, Juli 1987. Hamburg. Mittelweg 36. 8-75.

Rüstow, Wilhelm (1864): Geschichte der Infanterie. 2. Band. Vom Anfang des 17. bis zur Mitte des 19. Jahrhunderts. Nordhausen. Reprint. Wiesbaden. LTR-Verlag (1981)

Sarasin, Philipp (2001): Reizbare Maschinen. Frankfurt. Suhrkamp. 
Schäfer, Sebastian (2004): Von der Vernetzung zur Vernetzen Operationsführung. In: Europäischer Sicherheit. Heft 12/2004. Jahrgang 53. Bonn. Verlagsgruppe Koehler-Mittler. 42-48.

Scharnhorst, Gerhard von (1795-1801): Private und dienstliche Schriften. Stabschef und Reformer. Bd. 2. Hg. von Johannes Kunisch. Köln. Böhlau. (2003)

Schivelbusch, Wolfgang (2001): Die Kultur der Niederlage. Berlin. Alexander Fest.

Schlunk, Andreas/Giersch, Robert (2003): Die Ritter. Theiss. Stuttgart.

Schmidbauer, Wolfgang/Scheidt, Jürgen vom (2004): Handbuch der Rauschdrogen. Frankfurt. Fischer.

Schmidt, Peer (2003): Der Guerillero. In: Langewiesche, Dieter/Osterhammel, Jürgen (Hg.): Geschichte und Gesellschaft. Der Krieger. 29. Jahrgang. Heft 2. 2003. Göttingen. Vandenhoeck \& Ruprecht. 161-190.

Schmidtchen, Volker (1982): Militärische Techniken zwischen Tradition und Innovation am Beispiel des Antwerks. Ein Beitrag zur Geschichte des mittelalterlichen Kriegswesens. In: Keil, Gundolf (Hg.): »Gelêrter der arzenîe, ouch apotêker«: Beitr. zur Wiss.-Geschichte; Festschrift zum 70. Geburtstag von Willem F. Daems. Würzburger medizinhistorische Forschungen. Bd. 24. Pattensen. Wellm. 91-196

Schmidtchen, Volker (1990): Kriegswesen im Mittelalter. Technik, Taktik, Theorie. Weinheim. VCH.

Schnädelbach, Herbert (2000): Descartes und das Projekt der Aufklärung. In: Niebel, Wilhelm Friedrich/Horn, Angelica/Schnädelbach, Herbert (Hg.) (2000): Descartes im Diskurs der Neuzeit. Frankfurt. Suhrkamp. 186-206.

Schnitter, Helmut/Schmidt, Thomas (1987): Absolutismus und Heer. Berlin. Militärverlag der DDR.

Schössler, Dietmar (1980): Militärsoziologie. Königsstein/Ts. Athenäum.

Schreer, Benjamin (2004): Die U.S.-Army nach dem Irakkrieg. Lehren und Versäumnisse. SWP-Studie S37, September 2004. Herausgegeben von der Stiftung Wissenschaft und Politik. Deutsches Institut für Internationale Politik und Sicherheit. Berlin.

Schreiber, Wolfgang (Hg.) (2004): Das Kriegsgeschehen 2003. Wiesbaden. VS Verlag für Sozialwissenschaften.

Schroer, Markus (2001): Das Individuum der Gesellschaft. Frankfurt. Suhrkamp.

Schulz, Hans/Otto Basler (1942): Deutsches Fremdwörterbuch. Berlin. Gruyter.

Schulz, Lothar (Red.) (2003): Infanterist der Zukunft. Wehrtechnischer Report 2/2003. Bonn, Frankfurt. Report Verlag.

Schumpeter, Joseph (1919): Zur Soziologie der Imperialismen. In: Ders., 1953: Aufsätze zur Soziologie. Mohr. Tübingen. 72-146. 
Schüßler, Gerhard (2002): Aktuelle Konzeption des Unbewußten - Empirische Ergebnisse der Neurobiologie, Kognitionswissenschaften, Sozialpsychologie und Emotionsforschung. In: Zeitschrift für psychosomatische Medizin und Psychotherapie, Heft 48/1. Vandenhoeck \& Ruprecht. 192-214.

Schwiebert, Rainer (2004): Iraqi Freedom. Hat NCW die Feuertaufe bestanden? In: Soldat und Technik. 2-2004 (Februar). Bonn. ReportVerlag. 36-42.

Seifert, Ruth (1996): Militär, Kultur, Identität. Bremen. Edition Temmen.

Seiffert, Anja (2005): Soldat der Zukunft. Wirkungen und Folgen von Auslandseinsätzen auf das soldatische Selbstverständnis. Berlin. Verlag Dr. Köster.

Selzer, Stefan (2001): Deutsche Söldner im Italien des Trecento. Tübingen. Niemeyer.

Shaker, Steven M./Wise, Alan R. (1988): War Without Men. Robots on the Future Battlefield. Volume II of the Future Warfare Series. Washington, etc. Pergamon-Brassey's.

Shapin, Steven (1998): Die wissenschaftliche Revolution. Frankfurt. Fischer.

Shatan, Chaim F. (1983): Militarisierte Trauer und Rachezeremoniell. In: Passett, Peter/Modena, Emilio (Hg.) (1987): Krieg und Frieden aus psychoanalytischer Sicht. München, Zürich. Piper. 220- 249.

Shay, Jonathan (1998): Achill in Vietnam. Kampftrauma und Persönlichkeitsverlust. Hamburg. Hamburger Edition.

Shils, Edward A./Janowitz, Morris (1948): Cohesion und Disintegration in the Wehrmacht in World War. In: Public opinion Quarterly 12. 280315.

Siebrand, Michael (2003): Überlegungen anderer Staaten zum `System Soldat . In: Schulz, Lothar (Red.) (2003): Infanterist der Zukunft. Wehrtechnischer Report 2/2003. Bonn, Frankfurt. Report Verlag. 3140.

Sieferle, Rolf Peter (1989): Die Krise der menschlichen Natur. Zur Geschichte eines Konzepts. Frankfurt. Suhrkamp.

Sikora, Michael (1996): Disziplin und Desertion. Berlin. Duncker und Humblot.

Sikora, Michael (1998): Desertion und nationale Mobilmachung. Militärische Verweigerung 1792-1813. In: Bröckling, Ulrich/Sikora, Michael (Hg.) (1998): Armeen und ihre Deserteure. Göttingen. Vandenhoeck und Ruprecht. 112-140.

Sikora, Michael (1999): Scharnhorst und die militärische Revolution. In: Kunisch, Johannes/Münkler, Herfried (Hg.) (1999): Die Wiedergeburt des Krieges aus dem Geist der Revolution. Studien zum bellizistischen Diskurs des ausgehenden 18. und beginnenden 19. Jahrhunderts. Berlin. Duncker und Humblot. 
Sikora, Michael (2003): Söldner - historische Annäherung an einen Kriegertypus. In: Geschichte und Gesellschaft, Zeitschrift für Historische Sozialwissenschaft. Der Krieger. Jahrgang 29 (2003), Heft 2. 210-238.

Simkins, Peter (2004): Somme. In: Hirschfeld, Gerhard/Krumeich, Gerd/Renz, Irina (Hg.) (2004): Enzyklopädie. Erster Weltkrieg. Paderborn. Schöningh. 851-855.

Simmel, Ernst (1918): Zur Psychoanalyse der Kriegsneurose. In: Hermanns, Ludger M./Schultz-Venrath, Ulrich (Hg.) (1993): Ernst Simmel. Psychoanalyse und ihre Anwendung. Ausgewählte Schriften. Frankfurt. Fischer. 21-35.

Simmel, Georg (1917): Grundfragen der Soziologie. In: Ders. (1999): Der Krieg und die geistigen Entscheidungen (u.a.). Hg.: Fitzi, Gregor/Rammstedt, Otthein. Frankfurt. Suhrkamp. 59-150.

Simmel, Georg (1917b): Der Krieg und die geistigen Entscheidungen. In: Derselbe (1999): Der Krieg und die geistigen Entscheidungen. Herausgegeben von Fitzi, Gregor/Rammstedt, Otthein. Frankfurt. Suhrkamp. $59-150$.

Simmel, Georg (1958): Soziologie. Untersuchungen über die Formen der Vergesellschaftung. Berlin. Duncker und Humblot.

Simoneit, Max (1939): Zum Werden der deutschen Wehrmachtspsychologie - Ein geschichtlicher Rückblick. In: Fritscher, Werner (Hg.) (1990): Wehrpsychologie in Dokumenten. München. Verlag für Wehrwissenschaften.1-56.

Singer, Peter W. (2006): Die Kriegs-AGs. Über den Aufstieg der privaten Militärfirmen. Frankfurt. Zweitausendeins.

Sombart, Werner (1916): Die vorkapitalistische Wirtschaft. 2 Bände. Reprint 1987. München. dtv.

Specht, Rainer (1966): Descartes in Selbstzeugnissen und Bilddokumenten. Reinbek. Rowohlt.

Spreen, Dierk (2004): Menschliche Cyborgs und reflexive Moderne. In: Bröckling, Ulrich/Kaufmann, Stefan (Hg.) (2004): Vernunft - Entwicklung - Leben. Schlüsselbegriffe der Moderne. München. Fink. 317-346.

Stollberg-Rilinger, Barbara (1986): Der Staat als Maschine. Berlin. Duncker und Humblot.

Storz, Dieter (1992): Kriegsbild und Rüstung vor 1914. Europäische Landstreitkräfte vor dem 1. Weltkrieg. Herford. Mittler.

Storz, Dieter (1999): >Aber was hätte anders geschehen sollen?^ Die deutschen Offensiven an der Westfront 1918. In: Duppler, Jörg/Groß, Gerhard P. (1999): Kriegsende 1918. Ereignis. Wirkung, Nachwirkung. München. Odenbourg. 51-96.

Storz, Dieter (2003): Modernes Infanteriegewehr und taktische Reform in Deutschland in der Mitte des 19. Jahrhunderts. In: Epkenhans, Mi- 
chael/Groß, Gerhard P. (Hg.) (2003): Das Militär auf der Aufbruch in die Moderne 1860- 1890. München. Oldenbourg. 209-230.

Stouffer, Samuel A./u.a. (1949a): The American Soldier: Adjustment During Army Life. Volume I Princeton. Princeton University Press.

Stouffer, Samuel A./u.a. (1949b): The American Soldier: Combat and its Aftermath. Vol. II. Princeton. Princeton University Press.

Theweleit, Klaus (1977): Männerphantasien. 2 Bände. Frankfurt. Roter Stern.

Thring, M.W. (1969): Krieg der Roboter. In: Calder, Nigel (Hg.) (1969): Eskalation der neuen Waffen. München. Desch. 175-196.

Thukydides (1991): Die Geschichte des Peloponnesischen Krieges. München. dtv.

Tobiassen, Peter (2005): »Jeder Zweite muss nicht mehr dienen.« Wehrgerechtigkeit 2005. Eine umfassende Auswertung aktueller statistischer Angaben des Bundesministeriums der Verteidigung. 11.10.2005. Online: http://www.zentralstelle-kdv.de/z.php?ID=2; Zugriff: 12.10.07.

Toller, Ernst (1933): Eine Jugend in Deutschland. Hamburg. Rowohlt. (1963)

Tomasello, Michael (2002): Die kulturelle Entwicklung des menschlichen Denkens. Zur Evolution der Kognition. Frankfurt. Suhrkamp.

Treiber, Hubert (1973): Wie man Soldaten macht. Düsseldorf. Bertelsmann.

Trotha, Trutz von (Hg.) (1997): Soziologie der Gewalt. Opladen, Wiesbaden. Westdeutscher Verlag.

Tuchman, Barbara (1988): Der erste Salut. Frankfurt. Fischer.

U.S. Army (1982): U.S. Training and Doctrine Command. AirLand Battle 2000. Fort Monroe: U.S. Army Training and Doctrine Command. In: Die Grünen im Bundestag (1984): Angriff als Verteidigung. Bonn. D27-D30.

Ulrich Bernd (1992b): Nerven und Krieg - Skizze einer Beziehung. In: Loewenstein, Bedrich (Hg.) (1992): Geschichte und Psychologie. Annäherungsversuche. Pfaffenweiler. Centaurus.

Ulrich, Bernd (1992a): Die Desillusionierung der Kriegsfreiwilligen. In: Wette, Wolfram (Hg.) (1992): Der Krieg des kleinen Mannes. München. Piper. 110-126.

Ulrich, Bernd (1999): Der deutsche Offizier stirbt ... In: Breymayer, Ursula (Hg.): Willensmenschen. Frankfurt. Fischer. 11-20.

Ulrich, Bernd (2004): Kriegsneurosen. In: Hirschfeld, Gerhard/Krumeich, Gerd/Renz, Irina (Hg.) (2004): Enzyklopädie. Erster Weltkrieg. Paderborn. Schöningh. 654-656.

United Nations Department of Economic and Social Affairs, Population Division (Hg.) (2003): World UrbanizationProspects. The 2003 Revision: Data Tables and Highlights. Online: http://www.un.org/esa/popu lation/publications/wup2003/WUP2003Report.pdf; Zugriff: 12.10.07. 
United States Government Accountability Office (2004a): VA and Defense Health Care. More Information needed to determine if VA can meet an increase in demand for Post-Traumatic Stress Disorder Services. Report to the Ranking Democratic Member, Committee on Veterans' Affairs, House of Representatives. September 2004. GAO-04-1069. Online: http://www.gao.gov/new.items/d041069.pdf; Zugriff: 9.10.07.

United States Government Accountability Office (2004b): Defense Acquisitions. The Global Information Grid and challenges facing its Implementation. July 2004. Report to Subcommittee on Terrorism, Unconventional Threats, and Capabilities, Committee on Armed Services, House of Representatives. GAO-04-858. Online: http://www.gao.gov/ new.items/d04858.pdf; Zugriff: 12.10.07.

United States Government Accountability Office (2005): Defense Acquisitions. Future Combat Systems Challenges and Prospects for Success. Testimony before the Subcommittee on Airland, Committee on Armed Services, U.S. Senate. Statement of Paul L. Francis, Director Acquisition and Sourcing Management. March 2005. GAO-05-442T. Online: http:/www.gao.gov/new.items/d05442t.pdf; Zugriff: 12.10.07.

Verband für Entwicklungspolitik deutscher Nichtregierungsorganisationen e.V. (2007): Perspektiven für Frieden, Wiederaufbau und Entwicklung in Afghanistan. VENRO-Positionspapier 2. Oktober 2007. Bonn. Online: http://www.venro.org/publikationen/archiv/VENRO-Positionspap ier\%20Afghanistan.pdf. Zugriff: 12.10.07.

Verbruggen, J.F. (1998): The Art of Warfare in Western Europe. Woddbridge. Boydell.

Vormbusch, Uwe (2006): Management by Foucault? Betriebliches Controlling und Subjektivierung. Unveröffentlichtes Manuskript.

Wachtler, Günther (Hg.) (1983): Militär, Krieg, Gesellschaft. Frankfurt, New York. Campus.

Waldenfels, Bernhard (2000): Das leibliche Selbst. Vorlesungen zur Phänomenologie des Selbst. Frankfurt. Suhrkamp.

Wallach, Jehuda L. (1970): Das Dogma der Vernichtungsschlacht. Die Lehren von Clausewitz und Schlieffen und ihre Wirkung in 2 Weltkriegen. München. dtv.

Walter, Dierk (2003): Preußische Heeresreformen. Paderborn. Schöningh.

Walter, Dierk (2004): Im Niemandsland. Cold Harbor, 31.Mai bis 3.Juni 1864. In: Förster, Stig/Pöhlmann, Markus/Walter, Dierk (Hg.) (2004): Schlachten der Weltgeschichte. Von Salamis bis Sinai. München. dtv. 200-215.

Warburg, Jens (1999): Maschinen der Vernichtung. Das industrialisierte Schlachtfeld. In: Neckel, Sighard/Schwab-Trapp, Michael (Hg.) (1999): Ordnungen der Gewalt. Beiträge zu einer politischen Soziologie der Gewalt und des Krieges. Opladen. Leske und Budrich. 97-117. 
Warburg, Jens (2001): Der industrialisierte Tod. Kriege des 20. Jahrhunderts. In: Armanski, Gerhard/Warburg, Jens (Hg.) (2001): Der gemeine Unfrieden der Kultur. Europäische Gewaltgeschichten. Würzburg. Königshausen \& Neumann. 185-223.

Watson, Peter (1985): Psycho-Krieg. Möglichkeiten, Macht und Missbrauch der Militärpsychologie. Frankfurt. Fischer.

Weber, Max (1913): Über einige Kategorien der verstehenden Soziologie. In: Derselbe, hrsg. v. Winckelmann, Johannes (1973): Soziologie Universalgeschichtliche Analysen - Politik. Stuttgart. Kröner. 97-150.

Weber, Max (1922): Wirtschaft und Gesellschaft. Tübingen. Mohr. (1980) Wegner, Bernd (1995): Erschriebene Siege. Franz Halder, die >Historical Division des deutschen Generalstabes. In: Hansen, Ernst Willi/Schreiber, Gerhard/Wegner, Bernd (Hg.) (1995): Politischer Wandel, organisierte Gewalt und nationale Sicherheit. Beiträge zur neueren Geschichte Deutschlands und Frankreichs. München. Oldenbourg. 287-302.

Wehler, Hans-Ulrich (1987/1995): Deutsche Gesellschafts-Geschichte. Band 1 und 3. München. Beck.

Werkner, Ines-Jacqueline (2005): Wehrsysteme. In: Leonhard, Nina/ Werkner, Ines-Jacqueline (Hg.) (2005): Militärsoziologie - Eine Einführung. Wiesbaden. VS Verlag. 91-113.

Wette, Wolfram (2002): Die Wehrmacht. Feindbilder. Vernichtungskrieg, Legenden. Frankfurt. Fischer.

Whipple, A.B.C. (1979): Krieg unter Segeln. Amsterdam. Time-Life International (Nederland).

White House (Hg.) (2002): The National Security Strategy of the United States of America September 2002. Washington. Online: http://www.w hitehouse.gov/nsc/nss.pdf; Zugriff: 12.10.07.

White House (Hg.) (2006): The National Security Strategy of the United States of America March 2006. Washington. Online: http://www.white house.gov/nsc/nss/2006/nss2006.pdf; Zugriff 17.11.06.

Willkomm, Bernd (2001): Critical Incident Stress Management (CISM). In: Puzicha, Klaus J./Hansen, Dieter/Weber, Wolfgang W. (Hg.) (2001): Psychologie für Einsatz und Notfall. Bonn. Bernard \& Graefe. 99-105.

Winkel, Wolfgang (2004): Bundeswehr braucht archaische Kämpfer. In: Welt am Sonntag. Ausgabe vom 29.2.04. Online: http://www.wams.de/ data/2004/02/29/244658.html; Zugriff: 12.10.07.

Wohlfeil, Rainer (1964): Vom Stehenden Heer des Absolutismus zur Allgemeinen Wehrpflicht (1789-1815). In: Militärgeschichtliches Forschungsamt (Hg.) (1983): Deutsche Militärgeschichte in sechs Bänden 1648-1939. Bd. 1., Abschnitt II. Herrsching. Pawlak. 
Wohlfeil, Rainer (1966): Ritter - Söldnerführer - Offizier. In: Borst, Arno (Hg.) (1976): Das Rittertum im Mittelalter. Darmstadt. Wiss. Buchges. 315-348.

Wortmann, Rolf (1998): Das Bild vom Krieg vor 1914. In: Spilker, Rolf/ Ulrich, Bernd (Hg.) (1998): Der Tod als Maschinist, Der industrialisierte Krieg 1914-1918. Ausstellungskatalog des Museums Industriekultur Osnabrück. Bramsche. Rasch Verlag. 22-31.

Wothe, Klaus (2001): Belastungsfaktoren im Einsatz. In: Puzicha, Klaus J./Hansen, Dieter/Weber, Wolfgang W. (Hg.) (2001): Psychologie für Einsatz und Notfall. Bonn. Bernard \& Graefe. 58-64.

Wright, Evan (2005): Generation Kill. Das neue Gesicht des amerikanischen Krieges. Frankfurt. Zweitausendeins.

Zentrum für Innere Führung der Bundeswehr (Hg.) (1996): Umgang mit Verwundung und Tod im Einsatz. Arbeitspapier 2/1996, 4. überarbeitete Fassung, April 2000. Koblenz.

Zentrum für Innere Führung der Bundeswehr (Hg.) (1997): Stressmanagement - oder: »Wie bleibe ich stark?«. Arbeitspapier 1/1997, 2. überarbeitete Fassung, April 2000. Koblenz.

Zentrum für Innere Führung der Bundeswehr (Hg.) (1998): Psychologische Selbst- und Kameradenhilfe. Arbeitspapier 3/1998, 2. überarbeitete Fassung, April 2000. Koblenz.

Ziemann, Benjamin (2004): Soldaten. In: Hirschfeld, Gerhard/Krumeich, Gerd/Renz, Irina (Hg.) (2004): Enzyklopädie. Erster Weltkrieg. Paderborn. Schöningh. 153-168.

Ziemann, Benjamin (2004a): Kriegsfreiwillige. In: Hirschfeld, Gerhard/Krumeich, Gerd/Renz, Irina (Hg.) (2004): Enzyklopädie. Erster Weltkrieg. Paderborn. Schöningh. 639-640.

Zima, Peter V. (2000): Theorie des Subjekts. Tübingen, Basel. Francke.

Zur Lippe, Rudolf (1984): Autonomie als Selbstzerstörung. Frankfurt. Syndikat. 


\section{Dank}

Für die Geduld meinen Ausführungen zuzuhören und auf sie mit Anregungen, Ermutigungen und Kritiken zu reagieren, schulde ich zahlreichen Menschen Dank. Besonders sind hier Gerhard Armanski, Ulrich Bröckling, Rudi Friedrich, Rüdiger Fries, Volker Heins, Stefan Kaufmann, Johannes Süßmann, Sascha Möbius, Dorith Seuring und Uwe Vormbusch zu nennen. Dem Soziologischen Kollogium in Gießen im Allgemeinen und im Besonderen Anke Barzantny, Jörn Lamla, Andreas Langenohl, Carmen Ludwig, Georgia Rakelmann und natürlich Sieghard Neckel habe ich für ihre Kritik und die Möglichkeit zu danken, dass ich ihnen mein Vorhaben wiederholt vorstellen konnte.

Diese Arbeit gäbe es nicht ohne die Unterstützung von Angela Dunker. 


\section{Sozialtheorie}

Andrea D. Bührmann, Werner Schneider

Vom Diskurs zum Dispositiv

Eine Einführung in die

Dispositivanalyse

Juni 2008, ca. 140 Seiten,

kart., ca. 13,80 €,

ISBN: 978-3-89942-818-6

\section{Max Miller}

\section{Sozialtheorie}

Eine Kritik aktueller

Theorieparadigmen.

Gesammelte Aufsätze

Mai 2008, ca. 300 Seiten,

kart., ca. $27,80 €$,

ISBN: 978-3-89942-703-5

Kay Junge, Daniel Suber,

Gerold Gerber (Hg.)

Erleben, Erleiden, Erfahren

Die Konstitution sozialen Sinns jenseits instrumenteller

Vernunft

Mai 2008, ca. 300 Seiten,

kart., ca. $27,80 €$,

ISBN: 978-3-89942-829-2

Manfred Füllsack (Hg.)

Verwerfungen

moderner Arbeit

Zum Formwandel

des Produktiven

April 2008, ca. 180 Seiten,

kart., ca. $22,80 €$,

ISBN: 978-3-89942-874-2

René John

\section{Die Modernität}

der Gemeinschaft

Soziologische Beobachtungen

zur Oderflut 1997

April 2008, ca. 300 Seiten,

kart., ca. $29,80 €$,

ISBN: 978-3-89942-886-5
Patricia Purtschert,

Katrin Meyer,

Yves Winter (Hg.)

Gouvernementalität

und Sicherheit

Zeitdiagnostische Beiträge

im Anschluss an Foucault

April 2008, ca. 250 Seiten,

kart., ca. $25,80 €$,

ISBN: 978-3-89942-631-1

Janine Böckelmann,

Frank Meier,

Claas Morgenroth (Hg.)

Politik der Gemeinschaft

Zur Konstitution des Subjekts

in der politischen Philosophie der Gegenwart

April 2008, ca. 250 Seiten, kart., ca. $29,80 €$,

ISBN: 978-3-89942-787-5

Jörg Döring,

Tristan Thielmann (Hg.)

Spatial Turn

Das Raumparadigma

in den Kultur- und

Sozialwissenschaften

März 2008, 350 Seiten,

kart., ca. $29,80 €$,

ISBN: 978-3-89942-683-o

Daniel Hechler,

Axel Philipps (Hg.)

Widerstand denken

Michel Foucault und

die Grenzen der Macht

März 2008, ca. 250 Seiten,

kart., ca. $25,80 €$,

ISBN: 978-3-89942-830-8

Jens Warburg

Das Militär und

seine Subjekte

Zur Soziologie des Krieges

Februar 2008, 376 Seiten,

kart., 32,80 €,

ISBN: 978-3-89942-852-o

Leseproben und weitere Informationen finden Sie unter: www.transcript-verlag.de 


\section{Sozialtheorie}

Ekaterina Svetlova

Sinnstiftung in der Ökonomik

Wirtschaftliches Handeln aus

sozialphilosophischer Sicht

Februar 2008, ca. 180 Seiten,

kart., ca. $20,80 €$,

ISBN: 978-3-89942-869-8

\section{Franz Kasper Krönig}

Die Ökonomisierung

der Gesellschaft

Systemtheoretische

Perspektiven

2007, 164 Seiten,

kart., $20,80 €$,

ISBN: 978-3-89942-841-4

Andreas Pott

\section{Orte des Tourismus}

Eine raum- und

gesellschaftstheoretische

Untersuchung

2007, 328 Seiten,

kart., $28,80 €$

ISBN: 978-3-89942-763-9

\section{Tanja Bogusz}

\section{Institution und Utopie}

Ost-West-Transformationen

an der Berliner Volksbühne

2007, 354 Seiten,

kart., $32,80 €$,

ISBN: 978-3-89942-782-0

Johannes Angermüller Nach dem Strukturalismus

Theoriediskurs und intellektuelles Feld in Frankreich

2007, 290 Seiten,

kart., $28,80 €$

ISBN: $978-3-89942-810-0$
Anette Dietrich

Weiße Weiblichkeiten

Konstruktionen von "Rasse» und Geschlecht im deutschen Kolonialismus

2007, 430 Seiten,

kart., $29,80 €$,

ISBN: 978-3-89942-807-o

Daniel Suber

Die soziologische Kritik der philosophischen Vernunft Zum Verhältnis von Soziologie und Philosophie um 1900 2007, 524 Seiten, kart., $39,80 €$,

ISBN: 978-3-89942-727-1

Susanne Krasmann, Jürgen Martschukat (Hg.) Rationalitäten der Gewalt Staatliche Neuordnungen vom 19. bis zum 21. Jahrhundert 2007, 294 Seiten,

kart., $26,80 €$,

ISBN: 978-3-89942-680-9

Markus Holzinger

Kontingenz in der

Gegenwartsgesellschaft

Dimensionen eines Leitbegriffs moderner Sozialtheorie

2007, 370 Seiten,

kart., $29,80 €$,

ISBN: $978-3-89942-543-7$

Jochen Dreher,

Peter Stegmaier (Hg.)

Zur Unüberwindbarkeit

kultureller Differenz

Grundlagentheoretische

Reflexionen

2007, 302 Seiten,

kart., $28,80 €$,

ISBN: $978-3-89942-477-5$

Leseproben und weitere Informationen finden Sie unter: www.transcript-verlag.de 


\section{Sozialtheorie}

Sandra Petermann

Rituale machen Räume

Zum kollektiven Gedenken der Schlacht von Verdun und der Landung

in der Normandie

2007, 364 Seiten,

kart., zahlr. Abb., 33,80 €,

ISBN: 978-3-89942-750-9

Benjamin Jörissen

Beobachtungen der Realität

Die Frage nach der Wirklichkeit im Zeitalter der Neuen Medien 2007, 282 Seiten,

kart., $27,80 €$,

ISBN: 978-3-89942-586-4

Susanne Krasmann,

Michael Volkmer (Hg.)

Michel Foucaults »Geschichte der Gouvernementalität« in den Sozialwissenschaften

Internationale Beiträge

2007, 314 Seiten,

kart., $28,80 €$,

ISBN: 978-3-89942-488-1

Hans-Joachim Lincke

Doing Time

Die zeitliche Ästhetik

von Essen, Trinken und

Lebensstilen

2007, 296 Seiten,

kart., $28,80 €$,

ISBN: 978-3-89942-685-4

Nina Oelkers

Aktivierung von

Elternverantwortung

Zur Aufgabenwahrnehmung

in Jugendämtern nach dem

neuen Kindschaftsrecht

2007, 466 Seiten,

kart., $34,80 €$,

ISBN: 978-3-89942-632-8
Thomas Jung

Die Seinsgebundenheit

des Denkens

Karl Mannheim und

die Grundlegung

einer Denksoziologie

2007, 324 Seiten,

kart., $29,80 €$,

ISBN: 978-3-89942-636-6

Ingrid Jungwirth

Zum Identitätsdiskurs

in den Sozialwissenschaften

Eine postkolonial

und queer informierte

Kritik an George H. Mead,

Erik H. Erikson

und Erving Goffman

2007, 410 Seiten,

kart., $33,80 €$,

ISBN: 978-3-89942-571-0

Christine Matter

"New World Horizon"

Religion, Moderne und

amerikanische Individualität

2007, 26o Seiten,

kart., $25,80 €$,

ISBN: 978-3-89942-625-O

Petra Jacoby

Kollektivierung

der Phantasie?

Künstlergruppen in der DDR

zwischen Vereinnahmung und

Erfindungsgabe

2007, 276 Seiten,

kart., $27,80 €$,

ISBN: 978-3-89942-627-4

Leseproben und weitere Informationen finden Sie unter: www.transcript-verlag.de 
